\title{
IMPORTANCE OF
}

\author{
RELATING WITH GOD
}

\author{
FOR
}

\section{SPIRITUAL WELL-BEING}

\author{
John Wayne Fisher \\ BSc(Hons), MSc, DipT(Sec), DipEd(Prim), MEd, PhD, EdD \\ This dissertation is submitted \\ in total fulfilment of the requirements \\ for the degree of \\ Doctor of Philosophy \\ Faculty of Education \& Arts \\ Federation University Australia \\ PO Box 663 \\ University Drive, Mount Helen \\ Ballarat, Victoria 3353, Australia
}

Submitted July 2014 


\section{ABSTRACT}

\section{The importance of relating with God for Spiritual Well-Being}

Twenty years of research in spiritual health/well-being culminate in this thesis. My $\mathrm{PhD}$ (1998), University of Melbourne, presented a Four Domains Model of Spiritual Health/Well-Being. This formed the theoretical base for several spiritual well-being questionnaires, presented in my EdD (2009), University of Ballarat. The main instrument, Spiritual Health And Life-Orientation Measure (SHALOM), proposed a novel method of assessing quality of relationships which are posited as reflecting spiritual well-being. These relationships are of each person with themselves, others, the environment and/or with a Transcendent Other (God). Instead of just investigating lived experiences, SHALOM asks for two responses to each item. Each respondent's lived experience is compared with their stated ideals. Studies presented herein show that this double-response method, comparing ideal with actual, provides a statistically stronger measure of quality of relationships than lived experiences alone, thus spiritual well-being.

Eighteen publications included in this thesis relate to studies of spiritual wellbeing in educational, healthcare and general community settings. A total of 52 studies, using SHALOM with 41686 people from 27 countries, have shown that, of the four sets of relationships measured by SHALOM, relating with God explains greatest variance in spiritual well-being, so is therefore most important.

An international study with people involved with, as well as some opposed to, spirituality and religious education led to a generic form of SHALOM, in which the theistic words were replaced by 'Transcendent', with 19 alternatives provided from which to select preferred Transcendent, or none. This project revealed that relating with God, as Transcendent, provides greatest support for a person's relating with self and others, in contrast to help provided by non-theistic and non-religious Transcendents and not believing in Transcendents.

This research implies that researchers need to investigate relationship with God in any study of spiritual well-being, whether or not it fits their personal worldview. 


\section{DECLARATION OF AUTHORSHIP}

Except where explicit reference is made in the text of the thesis, this thesis contains no material published elsewhere or extracted in whole or in part from a thesis by which I have qualified for or been awarded another degree of diploma. No other person's work has been relied upon or used without due acknowledgement in the main text and bibliography of the thesis.

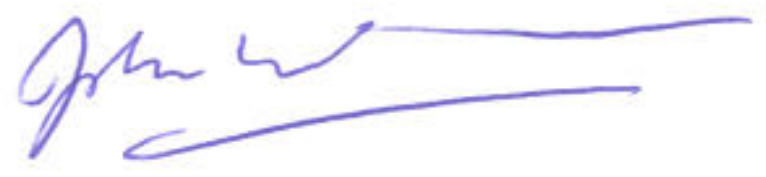

John W Fisher

Dated $8^{\text {th }}$ July, 2014 


\section{ACKNOWLEDGEMENTS}

I am most thankful for the many people who have supported my research over the last twenty years, beginning with successive supervisors for my first $\mathrm{PhD}$, at the University of Melbourne, Murray Seiffert, Sandy Yule, Sue Wright, and David Clarke.

Since 1995, Leslie J. Francis, currently at University of Warwick, has mentored me, providing great support, encouragement and constant challenge to take the extra step on my research journey.

Lawrence Angus and Genée Marks not only supervised my EdD at the Unversity of Ballarat but they willingly continued with this PhD. Many thanks for your friendly, capable and timely assistance, especially Lawrie's insightful comments on drafts of work. Various ways in which John McDonald has facilitated my research over the last fifteen years have been invaluable. My appreciation is expressed to the university research staff, especially Sue Read, Brad Mitchell and Rob Watson, for your friendly, willing help. I also appreciate the moderate, yet valuable, financial assistance provided by the Faculty and Research Services, which enabled me to participate in several international conferences during my candidature. Rapson Gomez helped validate SHALOM with initial Confirmatory Factor Analyses and Item Response Theory analyses for which I am most thankful.

To my colleagues at the Australian Catholic University, Marian de Souza, Michael

Buchanan and Brendan Hyde, who have been great sounding boards and assisted with publications, my grateful thanks.

To fellow conferees at spirituality conferences since 1995, Ron Best (Roehampton), Jack Priestley, Clive and Jane Erricker, Cathy Ota, Ruth Wills, Jacqueline Watson, Tony Eaude (UK), Sturla Sagberg (Norway), Peter Ng (Hong Kong), John Hochheimer (USA) and Galyna Schevchencko (Ukraine) thank you for your willingness to share ideas.

To Wong Ping Ho (Centre for Religious \& Spirituality Education, Hong Kong), thanks for your friendship and collegial research over the last fifteen years.

To members of ISREV, and colleagues in Australian and New Zealand Palliative Care Associations, especially David Brumley, thank you for contributing to my thinking about research relating to patients' quality of life.

For the invaluable assistance provided by librarians at Ballarat Health Services and library services at University of Ballarat/Federation University Australia and University of Melbourne, you enabled vital access to relevant publications that underpinned this research.

To many researchers, especially David O. Moberg, Craig Ellison, Harold Koenig, Ken Pargament and Arndt Büssing, you laid a foundation on which I could build. To hundreds of researchers, who have sought SHALOM for use in projects and shared results, you have encouraged continuation of my research in the knowledge that it is being beneficial to others. To the thousands of people, who so kindly participated in my research projects, my sincere thanks, because without your input, this thesis would not have eventuated. To my co-authors, I express thanks for your collaboration. To the editors and reviewers who approved my publications, my sincere thanks.

To fellow research students, family and friends, who have exhibited great grace in enduring my incessant chatter about my research, my grateful thanks.

To Marlie, my wonderful, longsuffering wife of 44 years, words cannot adequately express my love and gratitude for the sacrifices, financial and health-wise, you have made in supporting me through five higher degrees by research.

To my dear Heavenly Father, precious Saviour and Lord Jesus Christ, blessed Holy Spirit, Triune God, you are my constant companion, my source of meaning, hope and inspiration, for life everlasting. 
ABSTRACT

DECLARATION OF AUTHORSHIP

ACKNOWLEDGEMENTS

TABLE OF CONTENTS

Chapter 1 Introduction 1

1.1 Brief overview of project 1

$\begin{array}{ll}1.2 \text { Research questions } & 2\end{array}$

1.3 Contribution to literature by the project 2

1.4 Research approach and methods 4

$\begin{array}{ll}1.5 \text { Ethical issues } & 7\end{array}$

$\begin{array}{ll}1.6 \text { Thesis overview } & 7\end{array}$

$\begin{array}{ll}1.7 \text { A quick way to read this work } & 14\end{array}$

Chapter 2 From the Beginning to Spiritual Well-Being 15

$\begin{array}{ll}2.1 \text { In the beginning } & 15\end{array}$

$\begin{array}{ll}2.2 \text { Nature of spirit } & 16\end{array}$

$\begin{array}{ll}2.3 \text { Spirit, soul and mind } & 17\end{array}$

2.4 Spirituality 20

2.5 Spiritual well-being 23

2.6 Spirituality/well-being Measures 26

Chapter 3 Spiritual Well-being among University Students 30

3.0 Introduction $\quad 30$

3.1 Pre-service teachers' spiritual well-being across time and faiths $\quad 30$

3.2 Comparing pre-service teachers' spiritual well-being in Hong Kong and Australia 42

3.3 Spiritual well-being among Divinity and Religious education students in Turkey $\quad 55$

$\begin{array}{ll}\text { 3.4 Summary of Chapter } 3 & 70\end{array}$

Chapter 4 Spiritual Well-being and School Education 71

4.0 Introduction $\quad 71$

4.1 Connectedness: At the heart of resiliency and spiritual well-being 71

4.2 Publications relating to spirituality in Australian education 85

4.3 Spirituality and Religious Education in the National Curriculum 106 
4.4 Importance of relating with God for school students' spiritual well-being 107

4.5 New models of schooling: Community-based Christian schools in Australia 129

4.6 Summary of Chapter $4 \quad 142$

Chapter 5 Spiritual Well-Being in Healthcare Settings 143

5.0 Introduction 143

5.1 Nurses' and carers' spiritual well-being in the workplace 143

5.2 Palliative care doctors need help with spiritual well-being 158

5.3 Spiritual well-being of staff and family members in dementia care $\quad 170$

5.4 Summary of Chapter 5

Chapter 6 Relating with God and spiritual Well-Being in Community

Settings 183

6.0 Introduction $\quad 183$

6.1 Quality of life in the workplace: Spirituality, meaning and purpose 183

6.2 Relating with God, happiness, personality and age 195

$\begin{array}{ll}\text { 6.3 Summary of Chapter } 6 & 208\end{array}$

$\begin{array}{ll}\text { Chapter } 7 \text { Synthesis of Studies } & 209\end{array}$

$\begin{array}{ll}7.0 \text { Introduction } & 209\end{array}$

7.1 Development and application of SHALOM 209

7.2 Importance of relating with God for spiritual well-being 231

7.3 Assessing spiritual well-being among Australian youth 241

$\begin{array}{ll}\text { 7.4 Summary of Chapter } 7 & 254\end{array}$

Chapter 8 God, other Transcendents and Spiritual Well-Being 255

8.0 Introduction 255

8.1 You can't beat relating with God for spiritual well-being - with a generic

SHALOM 255

8.2 Comparing the influence of God and other Transcendents on spiritual wellbeing 265

$\begin{array}{ll}\text { Chapter } 9 \text { Conclusion } & 279\end{array}$

REFERENCES 282

APPENDICES

A. Attribution of papers to author \& Final Project Report 292

B. Composition of Spirituality/Well-Being Measures 296

C. Information letter for SHALOM 330 



\section{Chapter 1 Introduction}

\subsection{Brief overview of project}

\section{Background/motivation}

My original motivation to inquire into the nature of spirituality and its relationship to health, especially in education, came from the 1994 Australian curriculum documents at national and state level (Australian Education Council, 1994; Board of Studies, Victoria, 1994), which led to my first $\mathrm{PhD}$ (Fisher, 1998). The model of spiritual health/well-being I developed in $\mathrm{PhD}$ posits four domains in which the quality of relationships reflects the underlying spiritual health/well-being of an individual. These relationships are with self, others, environment and/or with God. By June 2014 an updated summary of this model had been downloaded 6355 times since its publication in January 2011 (Fisher, 2011).

Using this model, in the following decade I progressively developed several spiritual well-being questionnaires, which I applied to primary and secondary school students and teachers, university students and staff, and members of the wider community, including in healthcare settings. These projects comprised my EdD (Fisher, 2009). Key research instruments produced as outcomes of that study were my Spiritual Health And Life-Orientation Measure (SHALOM) (Fisher, 2010) used with youth and adults, and Feeling Good, Living Life (Fisher, 2004), used with children, to enable assessment of quality of relationships in the four stated domains of spiritual well-being. With only 20 and 16 items respectively, these instruments cannot be considered exhaustive measures. However, they are very much like spiritual thermometers, being suitable indicators of spiritual health/well-being.

Before commencing this study I had 41 peer-reviewed publications related to spiritual well-being and had presented 40 related papers and workshops to Religious Education teachers, chaplains, educators, psychologists and health professionals at different levels through a number of conferences (Australian College of Educators, Children's Spirituality - London, International Conferences on Children's Spirituality, International Seminars on Religious Education and Values, Christian Schools Australia, Spirituality Leadership and Management, Asia-Pacific conference on Children's Spirituality, World Religions Congress, Palliative Care Australia \&Victoria conferences, Australian \& New Zealand Society of Palliative Medicine, Australian College of Psychological Medicine, Research Conferences at the University of Ballarat and University of Melbourne).

I found that audiences generally did not question that relationships with self, 
others and environment have a genuine place in discussions of spiritual health/well-being. It was always the God-factor which provoked discussion. Initially, I faced some opposition to my research among state school staff in the interviews I undertook for my first $\mathrm{PhD}$, and I experienced further difficulty in gaining ethics approval from some university and healthcare settings and principals, when developing the surveys for my EdD. This difficulty stemmed from these people challenging me directly on the inclusion of 'God' words in my questionnaires.

\section{Rationale for this research}

A kaleidoscope of contemporary opinions on spirituality see it ranging from being a subset of religion, through being equated with religion, or having similarities yet differences from religion, or being the over-arching umbrella that embraces religion, through to being regarded as humanistic spiritualities devoid of religion. Naturalists even believe there is no such thing as spirituality. (More detail about these distinctions, including references can be found in Chapter 2). This broad spectrum of viewpoints illustrates how people's worldviews and beliefs can influence their understanding of spirituality.

The most contentious issue in discussions over spiritual well-being relates to the question of a Transcendent Other (e.g., God) having influence over humans. Worldviews and opinions are many, but empirical studies are few. Research needs to focus clearly on this point.

\subsection{Research questions}

The paramount question that is crying out to be answered is:

'How important is relating with God (or Transcendent) for spiritual well-being?' This was selected as the principal research question, in keeping with the title of this research project. Close scrutiny of existing studies and an international web survey provided empirical evidence to answer this question in this $\mathrm{PhD}$ by publication.

A second question addressed in this thesis is, 'How does relating with God and other Transcendents influence other domains of spiritual well-being?'

\subsection{Contribution to literature by the project}

Soon after commencement of my candidature in September 2011, I undertook a survey of 22 databases (via Ballarat Health Services, University of Ballarat and University of 
Melbourne) which revealed over one million publications with the keyword 'spiritual*' somewhere in the abstract or text. This number was reduced to 329,000 when the word 'God' was added to the search of full-text material. Only 21,000 publications had both words in the abstract. The number was further shortened to 504 when the terms 'spiritual well-being' and 'God' were searched for in full-text papers. Only 104 papers contained these two expressions in their abstracts. Of these, four were mine. Another eighteen of my papers, which have been peer-reviewed and published, with one, accepted for publication, are included in this $\mathrm{PhD}$ by publication. This project will therefore have a significant influence on clarifying the importance of relating with God for spiritual well-being. The rationale for using words in abstracts to judge relevance of papers was based on the assumption that authors include the most important aspects of their work there.

Of the 100 publications, other than mine, that featured 'God' and 'spiritual wellbeing' in their abstracts, the four domains of spiritual well-being featured prominently (Oneha, 2001; Niuatoa, 2007). A few studies neglected the environmental domain, thus providing three-domains models (Mahlungulu, 2004; Jo, 2005; McFadden, 2006).

Consensus was shown in that having wholesome images of God (Bauman, 1995; Wong-McDonald, 2004) and a sense of forgiveness from God (Neto et al., 2006; Gibson et al., 2006) relate positively with spiritual well-being. Relating with God, an indicator of spiritual well-being, correlated with positive health outcomes for patients with stress and depression (Maton, 1989); cancer (Wilson, 1999; Tatsumura et al., 2003; Bontempo, 2004); bulimia nervosa (Tramontana, 2009); alcohol dependency (States, 2002); and at end-of-life care (Gibson et al., 2006). A few of these studies quoted correlation coefficients to indicate strength of relationship between participating factors. However, very few of them reported multiple regression analyses to indicate relative contribution to variance made by the factors under consideration.

This brief review of literature reinforces the notion that spirituality is relationallybased. Considerable breadth of argument has been reported about a connection between relating with God and relationship with others (Ribeiro, 1989; Vela, 1997; Warren, 1998; Gray, 2001; Sinott, 2001; Smith, 2004; Joules, 2007; Guy, 2009). However, demographic differences among groups have yielded varying responses on levels of spiritual wellbeing. This was particularly evident by ethnicity (Miller et al., 1998; Dericquebourg, 2007; Tanyi \& Werner, 2007) and religious influences (Benzein et al., 1998; Nielsen, 2001; Mack, 2003).

Therefore, how important relating with God is for spiritual well-being is still an open question. Empirical evidence extracted from more than 30 studies using SHALOM, 
will show the importance of relating with God/Transcendent Other for spiritual wellbeing.

Note: Federation University Australia Guidelines for the award of $\mathrm{PhD}$ Incorporating Published Papers Regulation 5.1 Section 2 stipulates that 'a maximum of $66 \%$ of papers selected for inclusion in the thesis may be drawn from papers published prior to candidature'. The normal requirement will be that up to six peer-reviewed journal articles, book chapters, or ranked conference papers need to be submitted. Other papers under review or prepared for publication can also be submitted as long as their status is clearly identified.

Of the eighteen papers presented here, I was sole author of twelve; three in which I was first author are evenly shared with each other co-author; three in which I was major author have details shown in Appendix A.

\subsection{Research approach and methods}

Many research projects on spirituality are based on qualitative, naturalistic or phenomenological inquiry. Such methods are useful in terms of attempting to tie down or make sense of such an intangible construct/entity as spirituality. I used principles of grounded theory to interpret the responses of 98 educators to a series of semi-structured questions, assisted by an open-ended survey of 23 experts, to develop my model of spiritual health/well-being (Fisher, 1998). This model describes the tangible impact of spirituality on health and well-being. Building on that study, sound psychological and statistical principles and procedures were employed in the construction of my spiritual well-being questionnaires (Fisher, 2009). Mixed methods were used in papers in this thesis, but the prevailing approach is quantitative - correlational statistical design.

With the increasing interest in spirituality and well-being, especially over the last 30 years, numerous quantitative surveys have been developed to investigate this area (Hill \& Hood, 1999; MacDonald et al., 1999; Koenig et al., 2001; Vivat, 2008). This is an accepted and sound research method to be employed in this area (Moberg, 2002, 2005; Cotton et al. 2010; Koening, 2011; Park et al., 2011). Of around 200 available measures used to assess spirituality, recent evidence has been presented to show that my Spiritual Well-Being Questionnaire (SWBQ) - SHALOM is considered among the best (Moodley, 2008) or most promising (Meezenbroek et al., 2010). The survey design, content, style of responses and statistical analysis employed in my SWBQ-SHALOM are consistent with 
standard quantitative research methodology. National and international studies have shown the suitability of SHALOM for research in SWB in a variety of settings and languages (See Chapter 7.1). A summary of this research has spawned considerable interest, being downloaded 5648 times from the time of its publication in December 2010 to June 2014 (Fisher, 2010).

This PhD mainly employs a correlational statistical design to interrogate data from over 20 studies in which I have been involved in Australia, Canada, Hong Kong, Iran, Turkey and UK, in universities, schools, healthcare settings and the wider community. For example, factors (such as age, gender, religious affiliation, type of organisation, personality, happiness, and a variety of 'helps' for nurturing SWB) are investigated with respect to their connection of relating with God for spiritual well-being.

The foundation for the research presented here is the use of reliable, wellvalidated statistical instruments employed in quantitative studies. The key measure is SHALOM, a 20-item instrument, which has been subjected to rigorous validation that demonstrates its suitability as a balanced measure of spiritual well-being, as described in my four domains model. Exploratory and confirmatory factor analyses were performed on four groups comprising nearly 4500 participants in secondary schools (both students and teachers), university students and staff, nurses, church-attenders and general populace. Gomez \& Fisher (2003) reported good reliability for the SWBQ-SHALOM (Cronbach's alpha, composite reliability and variance extracted), and validity (construct, concurrent, discriminant, predictive and factorial independence from personality). SHALOM withstood a barrage of extended statistical interrogation performed on it: There was general support for the psychometric properties of this SWBQ from an Item Response Theory (IRT) perspective (Gomez \& Fisher, 2005a). SHALOM is one of only two SWBQs that have reported IRT analysis on them (Hall et al., 2007). Multi-group confirmatory factor analysis showed the statistical fit results supported the invariance of the measurement model, and of both the measurement and structural models. The results also showed little gender differences. Together, these findings support gender equivalencies for this SWBQ, i.e., SHALOM (Gomez \& Fisher, 2005b).

SHALOM has been used in a variety of multi-cultural settings. Confirmatory factor analyses have supported the four domains factor structure of SHALOM in Portuguese (Gouveia et al., 2008) and German (Rowold, 2011). Exploratory factor analyses support this structure in Afrikaans, Xhosa \& Sesotho (Van Rooyen, 2007; Vogt, 2007; Moodley, 2008), Farsi (Iran) (Dehshiri, 2011), Chinese (Mok, 2013; Fisher \& Wong, 2013), and Turkish (Fisher \& Coskun, 2013). SHALOM is also undergoing testing 
in Spanish, Filipino, Hebrew, Hindi and Czech, with planned studies in Russian, Hindi, Indonesian, Italian, French, Norwegian, Hungarian, Korean and Urdu (Pakistan).

Other instruments used in projects reported here include my Quality Of Life Influences Survey (QOLIS) (Fisher, 2006), which was also grounded on my four domains model of spiritual health/well-being, together with work on resilience (Resnick et al., 1993). In QOLIS, the influence of approximately 20 'people' from family, school, church and community, on relationships with Self, Others, Nature and God, is assessed using a 4point Likert scale. Other 'helps' for the four domains are also investigated with university students and adults. For Personal SWB, these 'helps' include self-improvement, time-out/ relaxing and being happy. For Communal SWB, 'helps' address family, friends and helping others. For Environmental SWB, walks, nature, sport and music are investigated. For Transcendental SWB, 'help' is addressed from prayer/meditation, church/religious activities, scripture and pastor/priest. Each is scored on a 5-point Likert scale to show the 'extent to which each build up SWB.' The validated Eysenck Personality Questionnaire Revised (Francis et al., 1994), and Oxford Happiness Inventory (Argyle \& Hills, 2000) were also used.

SPSS was used to perform appropriate statistical procedures on data collected via surveys. The most common procedures employed are descriptive statistics such as mean (SD), correlations, t-tests, ANOVA, together with exploratory factor analyses and multiple regression analyses, using whole groups and split samples. AMOS was used for confirmatory factor analyses on data from several studies.

\section{Limitations of this research}

1. As a researcher using quantitative techniques, and a qualified pastor and evangelical Christian, I try very hard to be objective and check that my worldview impacts as little as possible on procedures and interpretation of data. There will, however, be some chapters in this work that provide Christian exemplars related to aspects of spiritual well-being in practice. I rely on other people to provide sound views on other religions and world-views (e.g., as in the paper with Islamic university students). My world-view will show in some of the comments made herein. These will hopefully stimulate people with alternative worldviews to debate my interpretations and compare them with their own.

2. The ideal for quantitative research is to have randomly selected participants provide input on controlled variables, within tight time-space constraints. Sociological research rarely achieves such grandiose ideals. Although the studies reported herein used 
convenience samples, every effort was made to select participants from as broad a base as possible. However, it cannot be said for certain that the results are indeed representative of the populations from which they were drawn.

3. The references used in this work were based on publications in English, because I only have access to these through my university sources, and my language skills are limited. I have communicated with doctoral students using SHALOM, by translating their Chinese, French, Indonesian, Iranian, Portuguese and Spanish emails using Google Translate, which is sufficient to understand the gist of their messages, but I look forward to seeing the outcomes of their, and others, ongoing research in spiritual well-being translated fully into English in the not-too-distant future. I feel certain that their studies will enrich the field.

\subsection{Ethical issues}

All quantitative studies reported here were granted ethics approval by the Human Research Ethics Committees (HREC) at Ballart Health Service/ St John of God Healthcare, (for medical research projects) and the University of Ballarat (for others involving education and community participants). Collaborative studies with colleagues overseas (Hong Kong, Turkey, UK) were granted appropriate ethics approval by their universities. The final investigation in this project, entitled 'Background, beliefs and spiritual well-being', was granted ethics approval by the University of Ballarat (precursor to Federation University Australia) HREC on 2 April 2012.

\subsection{Thesis overview}

\section{Chapter 1. Introduction}

This chapter comprises Background to the project (set in relevant literature); Research Questions; PhD by Publication requirements; Methodology; and Overview of thesis.

\section{Chapter 2 From the Beginning to Spiritual Well-Being}

This chapter outlines potential interactions of humanity with God from the dawn of time through to attaining spiritual well-being. It briefly mentions alternative theories of origin, which connect to questions of ultimate reality, origin of human beings and our spiritual well-being. The nature of spirit and its relationship with soul and mind is then canvassed, followed by an account of historical developments in 'spirituality'. The Four Domains Model of Spiritual Health/Well-Being is presented with discussion of measures of spiritual well-being, which have shown a decline in the number of instruments assessing human relationship with God in recent years. 
In a tentative step toward interdisciplinary explorations of spirituality, Waaijman (2007) offered theoretical analyses of the way spirituality is studied in twelve academic disciplines. The next four chapters of this thesis present empirical studies which touch on six of these disciplines, namely education, management, medicine, psychology, religious studies and theology.

\section{Chapter 3 Spiritual Well-Being among University Students}

\subsection{Introduction}

Three papers are included in this section to provide insight into factors associated with spiritual well-being among an international cohort of university students. Each of the papers is described briefly below.

\subsection{Pre-service teachers' spiritual well-being across time and faiths}

Data collected from pre-service teachers in public, secular and religious universities, and from Christian universities in Australia and Northern Ireland, show the respondents were not overly optimistic about the level of help provided by schools to nurture their students' relationship with God. This finding has implications for religious education in schools, within discussions of the holistic development and well-being of students.

\subsection{Comparing pre-service teachers' spiritual well-being in Hong Kong and}

\section{Australia}

A Chinese version of SHALOM developed in this study was shown to be a sound measure of spiritual well-being. Pre-service teachers at Hong Kong Institute of Education reported lower levels of Personal and Communal SWB, but higher levels of Environmental and Transcendental SWB, than a group of similar pre-service teachers in the University of Ballarat, Victoria, Australia.

\subsection{Spiritual well-being among Divinity and Religious Education students in Turkey}

The Spiritual Health And Life-Orientation Measure was used to assess four domains of spiritual well-being among Divinity and Religious Education students in Turkey. According to this research, relating with God significantly influenced aspects of the spiritual well-being of respondents but the most highly rated nominated helps, particularly prayer and scripture, did not feature as key influences among these students for their spiritual well-being. Universities in Turkey provided small yet significant support in developing the four domains of spiritual wellbeing for these Divinity and Education students.

\subsection{Summary of Chapter 3}




\section{Chapter 4 Spiritual Well-Being and School Education}

\subsection{Introduction}

This chapter comprises five publications related to practice, pedagogy and principles in the realm of spiritual well-being and school education.

\subsection{Connectedness: At the heart of resiliency and spiritual well-being}

Studies of resiliency often stand alongside those of health deficits, the intention being to point to positive ways in which the well-being of young people can be addressed, often in and through education. The underlying theme of 'connectedness' or building relationships, which is gaining in importance in resiliency discussions, also undergirds research in spiritual well-being. This study revealed that how well students connect, especially with themselves and God, influences their spiritual well-being and resilience.

\subsection{Publications relating to spirituality in Australian education}

This chapter begins with a brief overview of 'spiritual' in Australian curriculum documents. Following classic and contemporary definitions of spirituality, general comments are gleaned from publications on spirituality in Australia, and spirituality in education in particular. Curriculum concerns and views on spirituality related to values education and school leadership are then canvassed. Empirical research studies on spirituality reveal the variety and extent of work done in this area in Australia from early childhood to community education. Concluding comments challenge educators with regard to the impact of their worldviews on providing holistic, spiritually-inclusive education in Australia.

\subsection{Spirituality and Religious Education in the National Curriculum}

Duncan Reid's paper (2011) provided a springboard from which to launch into discussions about making space for Religious Education in the (Australian) National Curriculum. Some brief comments are presented in this paper to expand thinking in the area of religious education with particular reference to spirituality.

\subsection{Importance of relating with God for school students' spiritual well-being}

Students reported on the extent to which different entities helped them develop relationships in four domains of SWB. Levels of perceived help in relating with God (from mothers, friends, themselves, teachers, RE teachers and God) varied significantly between schools, in line with students' self-reports of their relationship with God (i.e., Christian Community schools provide more help than Catholic, then independent and government schools). 


\subsection{New models of schooling: Community-based Christian schools in Australia}

Although their schools were relatively new, there were approximately 150 years of educational experience amongst eight principals who provided in-depth responses to fifteen questions about aspects of leadership in their distinctive Christian schools in Australia. In Honouring Christ as Head, working according to biblical precepts and being inspired by God's living presence, the Holy Spirit, leaders of Christian schools have an eternal source of wisdom, strength, love and grace to conquer whatever challenges come their way. This paper helps explain why students in Christian schools claim greater help from God for their spiritual well-being.

\subsection{Summary of Chapter 4}

\section{Chapter 5 Spiritual Well-Being in Healthcare Settings}

\subsection{Introduction}

Based on over ten years' experience in nurse education and palliative care research, this chapter contains reflections on three studies in spiritual well-being performed during this time.

\subsection{Nurses' and carers' spiritual well-being in the workplace}

The major finding of this study is the influence that nurses' and carers' personal experience has on the level of help they think clients receive from the services offered in their workplace. Those who are more fulfilled in relationships, with themselves, others, the environment and/or God, believe that clients receive greater help for spiritual wellbeing in these four areas from the services provided in their workplace.

\subsection{Palliative care doctors need help with spiritual well-being}

Spirituality is widely recognized as a key component of holistic care for palliative care patients. Palliative care doctors do not have adequate time, experience or training to provide all aspects of spiritual care, especially the relationship with God. Patients need holistic care provided by comprehensive, well-balanced teams. In brief, this paper demonstrates that palliative care doctors need help personally and in providing spiritual care for patients.

\subsection{Spiritual well-being of staff and family members in dementia care}

The spiritual well-being of providers and patients influences holistic care in nursing. Staff and family members in a dementia care unit based their judgements on dementia patients' needs for spiritual well-being on different rationale. However, they agreed on the 
priorities to be set in nurturing residents' spiritual well-being, especially those pertaining to their relationship with God.

\subsection{Summary of Chapter 5.}

\section{Chapter 6 Relating with God and Spiritual Well-Being in Community Settings 6.0 Introduction}

This chapter contains two papers of a more general nature than the specific education and healthcare papers presented in preceding chapters.

\subsection{Quality of life in the workplace: Spirituality, meaning and purpose}

This paper reports on research which aimed to investigate relationships between meaning and purpose in life and workplace expectations in an Australian regional university. Overall, participants classified as administrators, professionals, service workers or labourers reported that they feel good about themselves and their relationships with others and the environment. The relationship with a god-type figure was of lesser importance for the spiritual well-being of the majority of participants, who do not expect the workplace to provide a major role in their spiritual well-being.

\subsection{Relating with God, happiness, personality and age}

Studies with university students from Australia and Northern Ireland, and with people attending churches in Ballarat, as well as secondary school students in Victoria, provide empirical evidence to show that relating with God influences happiness (an aspect of subjective well-being), for certain people, in addition to their personality and age.

\subsection{Summary of Chapter 6}

\section{Chapter 7 Synthesis of Studies}

\subsection{Introduction}

The four preceding chapters focus on aspects of spiritual well-being in specified settings. This chapter comprises a review of international studies that have employed SHALOM, together with critiques of methods used in assessing spiritual well-being, with particular emphasis on the importance of relating with God.

\subsection{Development and application of SHALOM}

My Four Domains Model of Spiritual Health and Well-Being was used as the theoretical base for the development of several spiritual well-being questionnaires, with progressive fine-tuning leading to the Spiritual Health And Life-Orientation Measure (SHALOM). 
SHALOM has undergone rigorous statistical testing in several languages. This instrument has been used with school and university students, teachers, nurses, medical doctors, church-attendees, in industry and business settings, with abused women, troubled youth and alcoholics. SHALOM provides a unique way of assessing spiritual well-being as it compares each person's ideals with their lived experiences, providing a measure of spiritual harmony or dissonance in each of four domains of spiritual well-being.

When assessing the relative importance of the four domains of SWB, it would be convenient to just compare the mean values of each contributing factor. However, this is not a statistically valid procedure. It was not until November of 2011 that the appropriate statistical procedures came to my mind for taking this study to a deeper level, as described in the papers below.

\subsection{Importance of relating with God for spiritual well-being}

Spiritual well-being is reflected in the quality of relationships in up to four areas, namely with self, others, environment and/or God. People are generally content to accept self, others and environment as legitimate contributors to SWB, but the God-factor is controversial. Nearly all measures of spirituality/well-being only ask for a single response, to indicate level of lived experience. However, respondents' ideals are also sought by SHALOM, which provides a balanced selection of items across four domains of SWB.

Analysis of 52 studies (with nearly 42,000 people) reported here provides reasonable support for the notion that relationship with God has greatest importance for SWB. However, potential objections and limitations to just using lived experience are discussed. A better method of assessing quality of relationships, by comparing each person's ideals with their lived experiences, shows that relating with God is most important for spiritual well-being, among people with a variety of worldviews.

Following the high degree of interest shown in this paper when it was presented in Prague, my mind was challenged with the thought about different instruments providing different scores for SWB and how to interpret this in some objective manner. Further effort clarified this:

\subsection{Assessing spiritual well-being among Australian youth}


How do we set standards in assessing spiritual well-being? Most measures only provide scores on arbitrary scales. Therefore, if the questions differ, the scores are likely to as well. This paper reports on a second scale developed alongside of SHALOM among 460 Australian secondary school students, with diverse cultural and religious backgrounds, from State, Catholic, Christian Community and Independent schools.

My four domains model of spiritual health/well-being was the theoretical base from which twelve items were developed to reflect quality of relationships with self, others, environment and God/the Divine. Principal Components Analyses (PCA) were employed on the resultant exploratory questionnaire. The instrument with the five topscoring items in each domain, known as SHALOM, has been used extensively. The second-highest scored sets of five items were extracted and found to form statistically valid factors, to comprise a new instrument called SWBQ2.

As would be expected, the mean values for the factor scores varied between SHALOM and SWBQ2 overall, as well as by school type. However, regression analyses of the lived experience scores showed that relating with God provided the greatest explanation of variance in spiritual well-being on both measures.

The double-response method introduced for SHALOM was also used with SWBQ2 to compare each person's lived experience with their ideals, as this method is better for assessing quality of relationships which reflect spiritual well-being, than using lived experiences alone. There was negligible difference in dissonance scores on the four factors in both measures, that is, in comparing the difference between ideals and lived experiences. This method showed consistency in the quality of relationships reflecting SWB, which contrasted with differences shown using only lived experience, as mentioned above. Relating with God was again most influential on SWB.

These findings have implications for methods used in assessing SWB as well as outcomes.

\subsection{Summary of Chapter 7}

\section{Chapter 8 God, other Transcendents and Spiritual Well-Being}

\subsection{Introduction}

\subsection{You can't beat relating with God for spiritual well-being - with a generic SHALOM}

Following some challenges with respect to adequately representing the Transcendental domain for non-theistic as well as theistic respondents, I undertook a web-based survey with targeted populations (starting with 600 people, most of whom were interested in 
spirituality, some of whom were opposed to it). If people believe in someThing or someOne supernatural, this study was designed to investigate what words they use to describe this Transcendent entity, whether it be angels, a presence, deity, the divine, God, heaven, higher power, mystery, otherness, something there, Tao, etc. The chosen terms were analysed to see if opening up the Transcendental factor provides an equally valid, more generic version of SHALOM.

\subsection{Comparing the influence of God and other Transcendents on spiritual well-being}

The second research question posed in this thesis is answered by comparing the influence of God and other Transcendents on the other three domains of spiritual well-being in turn, using the generic form of SHALOM. Several statistical procedures were employed in this task. All indicated that God is the most influential Transcendent in terms of helping people relate with themselves and other people. In contrast, general support was provided from most Transcendents for relationship with the environment. More work is needed to clarify the exact nature of this relationship.

\section{Chapter 9 Conclusion}

The concluding discussion summarises the major findings of the body of my published work, articulates the degree to which the body of published work answers the research questions. It draws overall conclusions, and links the research with the established body of knowledge, and clearly describes how the published body of work makes an original contribution to knowledge in the field.

\subsection{A quick way to read this work}

A quick overview of this work can be gleaned by reading Chapter 2, followed by the summary pages positioned in front of the published papers in Chapters 3 to 8 . Then conclude with Chapter 9. Each of the 18 papers presented can be read in detail as desired. 


\section{Chapter 2 From the beginning to spiritual well-being}

This chapter outlines positions ascribed by alternate worldviews to the place of God with regards to questions or origin, spirit, spirituality and spiritual well-being.

\subsection{In the beginning}

'In the beginning, God created the heavens and the earth' are the opening words of the most published book, The Bible (Genesis 1:1). These words form the foundation of a Judaeo-Christian worldview that places God as the First Cause of everything we know and experience. This belief is said to derive from supernatural revelation from God to humankind. The beginning of the universe is connected to questions of ultimate reality. Cosmologists cannot agree on the origin of the universe (Chown, 2012). However, according to Lennox, science has shown that the hypothesis of Creation is testable. The universe is mathematically extremely well organised, which provides an overwhelming indication of its 'design' by a 'mind that was responsible for both the universe and for our minds' (Lennox, 2009, p.207). Lennox claims, 'what lies behind the universe is much more than a rational principle; it is God, the Creator, Himself' (ibid.), not just an abstraction or impersonal force. This dissertation investigates the importance of relating with this God (or other Transcendents) for spiritual well-being.

Belief in God is at one end of a spectrum of worldviews held by people. In fact it was a, or the, dominant worldview in Western civilisation until the 1800s. Slightly before this time, Rene Descartes (in 1637) penned the phrase, 'Cogito ergo sum (I think, therefore I am) (Encyclopedia Brittanica, 2013), which was built on by Rationalists, who hold reason, not revelation, as the chief source and test of knowledge. Another rival of Rationalism is Empiricism, which holds that knowledge comes from, and must be tested by, sense experience. Many atheists believe that empirical science is the true path to understanding. The reason for saying many, rather than all, is that variations exist among people who claim each worldview. (For a useful exposition of many worldviews, please see Sire, 2009). The very idea of 'empiricism' itself was not derived from scientific experimentation, so, it can therefore be considered a faith statement - considering something that is not visible as true. Ideas are not visible. Empiricism is an idea; therefore it requires faith to believe, but just not in God (Geisler \& Turek, 2004).

The answer to the existential question, 'Where did we come from?' has a major influence on one's quality of life and spiritual well-being. Believing in God and His Creation requires faith, as does belief in whatever permutation of the Big Bang Theory is 
presumed responsible for providing matter and energy from nothing to constitute our physical universe in four dimensions of space-time. Although Genesis starts, 'In the beginning,' this does not mean that nothing existed before Creation. Jesus claimed that God the Father loved Him before the foundation of the world (John 17:24), and that they shared glory before the world came into existence (John 17:5) (Schaeffer, 1972, p.17). Two extreme worldviews posit 'man' [sic] being made in the image of God through Creation (Genesis 1:27), as opposed to inanimate matter yielding elemental life forms which subsequently evolved into human beings, without apparent causation. Both views are statements of faith. Neither of these worldviews on the origin of 'man' can be validated scientifically; not that science can be held as the arbiter of truth.

As valuable as science is, it is a limited way of knowing, or attempting to explain, what happened, how and possibly where and when. It does not recognise revelation as a valid source of knowledge. Science can never answer the question, 'Why?' However, this question is critically important for spiritual well-being because it relates to meaning and purpose in life. According to theistic worldviews, God made man for a purpose - to commune with Him. Conversely, no matter how one tries to anthropomorphise it, Mother Nature, Father Time and Lady Luck could not have made life, nor given it purpose.

\subsection{Nature of spirit}

Some Empiricists claim that spirit does not exist because it cannot be gauged/measured directly by human senses or the machines we have made. The same could be said of beauty and love, even mind, conscience and intelligence, but Empiricists are likely to believe in them, and deal with these matters as if they are real. Moberg clearly attests,

just because many scientists' opinions overstep the limitations of science by rejecting spirituality and the Bible as possible aspects of reality, is no reason for denying them. The fact of the existence of a spiritual dimension or of an intelligent Creator is outside the sphere of scientific examination per se. What is obvious in everyday experience need not be overlooked just because it cannot be measured. (2010, p.106).

The first obvious recorded mention of 'spirit' in the Bible was attributed to Moses writing some time before $1100 \mathrm{BC}$ (Morris, 1984). Moses may have recorded the stories handed down orally by generations of Jews, or some even suggest there could have been a written record made by Adam, following his conversations with his Creator in the Garden of Eden. But, evidence for this is disputed (Jewish Encyclopedia, 2002). Whatever the 
source, Moses was inspired by God to write the book of Genesis, as all scripture is inspired by God (2 Timothy 3:16). Genesis 2:7 states, 'The Lord God formed man from the dust of the ground and breathed into his nostrils the breath or spirit of life, and man became a living being'.

According to Moberg (2010), the Hebrew word ruah, referred to 378 times in the Old Testament, and the Greek word pneuma, referenced 146 times in the New Testament, describe human beings as spirit. The word 'breath' is derived from spiritus, Latin for 'that which gives life or vitality' (ibid.). It is interesting to note that scriptural references posit this expression (life is in the breath) only applying to humans and not the other organisms that appeared on Earth before them. Human spirit is eternal, like angelic and demonic spirits, as well as God Himself, whereas the spirit of animals ceases to exist when animals die (Eccl. 3:21) (Morris, 1984, p.74). This statement challenges re-incarnation into or from lower forms of life associated with some worldviews that are distinct from the Judaeo-Christian. With spirit, humans were given moral consciousness, capacity for abstract thinking, appreciation of beauty and emotions, and the capacity to worship and love God (ibid.).

Alternative views on nature of spirit include: New Physics, which is spawning some fascinating ideas, such as 'The Spiritual Genome' in which it is postulated, 'the DNA of all living creatures (including plants) is connected in the quantum substratum, and that it is this networked intelligence which constitutes the essential oneness from which springs all the diversity of life we see around us' (Bartholomew, 2014). Simply put, this DNA-based supercomputer is supposedly 'the ultimate source of life' (ibid.). Bartholomew, who is heavily influenced by Hinduism, at least asks the reader to 'take a leap of faith', regarding his proposition. In similar vein, many ideas and philosophies, some having a form of god, are espoused in relation to 'spiritual evolution', without offering any alternative source of spirit, apart from God (Wikipedia, 6/5/14).

\subsection{Spirit, soul and mind}

Many believe humans are spirit, have a soul, and live in a body (Hagin, undated; Moberg, 2011). The supposed tri-partite nature of man is illustrated in the Bible quotation, 'And the God of peace Himself sanctify you completely, and your whole [being]; the spirit and the soul and the body be kept blameless in the presence of our Lord Jesus Christ' (1 Thess. 5:23). However, spirit and soul are often conflated, with both being claimed as the essence of life, or the immaterial part of 'man', which survives death (Oxford and Webster Dictionaries). For example, according to Moberg, 'Spirit and its overlapping 
concept of soul refer primarily to the whole person...that can be interpreted as consisting of body, mind, and spirit or soul (2011). Some even conflate spirit with mind (Helminiak, 1996; Newberg et al., 2001; Seybold, 2005). It appears that the spirit can impact the mind, or at least the brain, as 'different aspects of spirituality may be mapped in different neural regions' (Urgesi et al., 2010). Pandya's review of brain, mind and soul concludes, 'The mind and soul remain fascinating enigmas. Whilst we have made some progress in our understanding of these two hazy constituents of life, much is yet poorly understood' (2011). Going one step further, 'A growing body of empirical evidence suggests that human consciousness...is not confined to specific points in space, such as brains and bodies [and that] nonlocal consciousness and spirituality are seen as a complementary dyad' (Dossey, 2014).

Although it is difficult for some people to distinguish between spirit and soul, one Christian model proposes that soul (the seat of human personality) comprises conscious mind (thinking and reasoning), unconscious mind (will and emotions) together with beliefs, attitudes, feelings and memories (Copeland, undated). Hebrews 4:12 states that spirit and soul can be separated or divided as they are separate entities (Word of God ...dividing... soul and spirit) (Hagin, undated). Although these scriptures identify separate aspects of our human being we are integrated wholes, made complete in Christ (Colossians 2:10), from a Christian perspective.

What does the spirit influence first - the heart (spirit) or the head (mind)? Berryman (1990) provided a thought-provoking view to help answer this question:

When people have a tangible spiritual experience, words often fail them, as they just sense 'the larger presence to our being and knowing' (e.g., John Wesley's heart strangely warmed (Graves, undated) which 'causes us to draw in our breath' (Berryman, 1990). The experience causes a silent inspiration, followed by the response, a 'sigh of ecstasy ('AHH!')...which helps us uncover the deepest integration of self' (ibid. p.531). Following this sigh, 'a sense of discovery ('AHA!') introduces us to the possibility of reflection on the experience' (ibid.). This could lead to a narrative or 'master story'. The accompanying sense of knowing, which comes from inspiration, is etched at the very core (French 'coeur'), or heart of our being. Such a connection with God can lead to 'cosmic laughter' ('HAHA!') which 'marks awareness of a paradox, which stimulates the imagination to recover what is no longer present to it in experience' (ibid.). Berryman's narrative posits mental understanding as the rear guard, or interpreter of the event, rather than the instigator. As such, the language used to describe outcomes of 
spiritual, with subsequent mental, experiences, should be moderated in recognition that human beings are integrated wholes, not compartmentalised or fragmented parts. Mind is the last place to recognise and interpret the impact of spirit on humans. As we are holistic beings, spirit and soul (thus mind) interact with each other and the body. Eastern philosophies take this holistic notion of human beings further by considering relationship with their environment (Chan et al., 2001).

There appears to be a heightening in the battle for hearts (spirits) and minds of the populace, between two extremes. The battle lines are not clearly divided by religion and science. Rather, it is discussion of contrasting views of theism and atheism (naturalism), which has been the subject of many books over the last two centuries (e.g., Dawkins, 2006; McGrath, 2007; Hawking \& Mlodinow, 2010; Lennox, 2011). Theism goes beyond science to explain how perceived order is possible in the universe. Theism states that the universe is not self-generating, causing its own effect (Lennox, 2009, pp.63-4); it was made by a pre-existent, personal God, not some impersonal force that condensed itself into matter. Naturalists have their theories and laws, which by themselves cannot bring anything into existence. People believe what they want to believe, and this has consequences for their actions (York, 2012). Many people try to sit on the fence between theism and atheism, but that position becomes rather untenable. The New Atheists, such as Dawkins and Hitchens, not only want to deny that God exists, they want to eradicate any mention of, or allegiance to, Him (Lennox, 2009). So, they should really be called anti-theists.

One psychologist proposes that transcendence, going beyond the rational, is an ego experience rather than a metaphysical statement (Mirman, 2012). Countering this position, Hanfstingl (2013) argues that ego-transcendence is a kind of spiritual experience that contrasts with mystical experience, which itself involves spiritual transcendence and perception of divinity. Others are more subtly attempting to 'bracket out God' from psychology of spirituality by seeking removal of 'God and other non-falsifiable metaphysical entities or constructs from 'truly scientific study' (Helminiak, 2008). As has been previously mentioned, science is not the arbiter of truth. That notwithstanding, psychologists find ways of studying intelligence and personality, which are reflections of underlying states of humanity, not directly observable entities. In like manner, spirituality can be studied by its outcomes or effects on people. Some researchers are investigating a theistic approach to psychology to complement the more traditional secular approaches normally undertaken, in recognition that 'theists make up the vast majority of psychology's clientele', at least in the USA (Slife et al., 2012). In summary, then, science 
explains to a limited extent. To think not constitutes 'scientism' or absolute faith in science. Science cannot explain why anything happens, but, God explains why science explains. 'God is not an alternative to science as an explanation....He is the ground of all explanation ... whether scientific, or not' (Lennox, 2009, p.48).

New Physics seems to be presenting a challenge to God, although not front-on. Shelton proposes, 'Quantum Skills are premised on the assumption that the quantum realm of energy is primary or causal and the material world is secondary' (2010, p.165). These quantum skills supposedly provide humans with the ability to see intentionally, to think paradoxically, to feel vitally alive, to know intuitively, to act responsibly, to trust life's processes, and to be in relationship. However, no source of these skills is stated. Further detail in Shelton's paper concurs with recent thoughts by positive psychologist, Seligman, who effectively suggested that we make ourselves like god by use of our minds (2014). Some Transhumanists have a similar goal of transforming humans, but by use of technology and genetic manipulation, to attain immortality (Wikipedia, 12/05/14). However, Christians already have the promise of immortality. John 3:16 (NIV) states, 'For God so loved the world that He gave His one and only Son, that whoever believes in Him, shall not perish but have eternal life' [italics added for emphasis].

The battle for hearts and heads continues.

\subsection{Spirituality}

Considerable debate about the nature of spirituality has taken place for centuries. However, writers have had difficulty defining the concept (Goodloe \& Arreola, 1992; Diaz, 1993; Seaward, 2001; Moberg, 2010). A conciliatory approach claims that agnostics and atheists can express a form of spirituality without God (Mohr, 2006). In contrast to this and the above views of New Physics, positive psychology and Transhumanism, Waaijman contends, 'spirituality appears as a complex whole, constructed out of elements which are complementarily interrelated. Spirituality is a relational process which constitutes an original whole in which God and man [who was made by God in His image] are reciprocally related' (2006, p.14). However, not all people agree with Waaijman that God is essentially involved in spirituality. Views have changed over time.

According to Principe (1983), historically speaking, spirituality was based on the Latin concept of 'spiritualitas', which was not found in literature earlier than the fifth Century (C5th). Early comments on the Apostle Paul's writings posit the spiritual nature of a person being ordered, led and influenced by the Spirit of God. For Paul, being 
spiritual meant following the ways of Christ rather than the ways of man. Paul's ideas on spirituality held sway within Christian belief until around C12th, when there was a change in its meaning from a moral sense to an entitative-psychological sense, in which people began to despise the body. By C17th the word spiritualité (French) had been taken over by the Catholic Church and used as ecclesiastical property in the religious sense of a 'devout life', in contrast to physical property of the monarch, which was regarded as temporalitas (of this world, secular). In France, during the latter C18th and C19th, as the word 'spirituality' was used pejoratively, it fell into disuse until the early C20th, when it became frequently used once again, being linked to the soul in opposition to the body, in a bi-partite view of man. In English, a religious or devotional sense of 'spirituality' continued until the early C20th, when the term was appropriated by Hinduism to illustrate the superiority of Indian religion over Western 'materialism'. Thus, from a Western perspective, the original usage of the term spirituality was steeped in religion.

With increasing secularisation of the West, significant changes since the 1960s have seen 'spirituality acquire more distinct meanings... [being seen as] separate from religion' (Turner et al., 1995). With attendant 'increasing individualism in American religious culture...new spiritual practices are evolving' (Zinnbauer et al., 1999). A diversity of different forms of spirituality that are arising is not often encountered in an explicitly religious domain, but rather in a secular context (Heelas \& Woodhead, 2005).

The next three paragraphs are extracted from one of my published papers not included in this thesis (Fisher, 2011).

A variety of opinion currently prevails on the nature of any relationship between spirituality and religion. Some people equate 'spirituality' with 'religious activity', or use these words interchangeably (Piedmont, 2001; Gorsuch \& Walker, 2006), whereas others believe this stance is not valid (Banks et al., 1984; Scott, 2006). Some people discuss commonalities between spirituality and religion, as well as differences (Hill et al., 2000). Although spirituality and religiosity are often used interchangeably, they are distinct, yet overlapping, constructs. Three polarising views are held by some behavioural scientists, differentiating spirituality and religion (Zinnbauer et al., 1999). Some social scientists argue that spirituality is subsumed by religion (Hill et al., 2000), whereas others see religion as one dimension of spirituality (Nolan \& Crawford, 1997). The view that 'religiosity can but does not necessarily include spirituality' (Gough et al., 2010) is countered by one that claims, 'Outstanding spiritual leaders developed most religions' (Hay et al., 2006). Rather simplistically speaking, Horsburgh (1997) maintains that 
religion focuses on ideology and rules of faith and belief systems, whereas spirituality focuses on experience and relationships which go beyond religion (Lukoff et al., 1992). This simplistic view is rejected by many (Martsolf \& Mickley, 1998; Benson, 2004; Hay et al., 2006). In a recent study 'using a large sample of American adults, analyses demonstrate that subjective spirituality and tradition-oriented religiousness are empirically highly independent' (Saucier et al., 2006), suggesting divergence between the two constructs. A close inspection of the instruments used in that study is warranted to see how much confidence can be placed in the findings. In contrast to this view of divergence, Schneiders (2003) contends, 'some see religion and spirituality as two dimensions of a single enterprise... often in tension but are essential to each other and constitute, together, a single reality.....as partners in the search for God.'

'A relationship [of people] to the sacred or transcendent' [my italics] is included in many definitions of spirituality (Synott, 2001; Hyman \& Handal, 2006). Taking this broader view, Seaward asserts that spirituality involves 'connection to a divine source whatever we call it' (2001). But, spirituality does not have to include 'God-talk' according to Jose and Taylor (1986). A number of authors have followed this latter, humanistic line of thinking by attempting to define secular spirituality as a spirituality without any need for a religious/God component (Harvey, 1996; Newby, 1996). Understandably, many Christian writers raise arguments against removing religion and God from discussions of spirituality (Smith, 2000; Wright, 2000).

Abraham Maslow, claimed by many to be the father of humanistic psychology, and John Dewey, a founder of the philosophical school of Pragmatism, both consider spirituality to be part of a person's being, and therefore prior to and different from religiosity (Fahlberg \& Fahlberg, 1991). Many supporters of the notion of evolutionary psychology fail to distinguish between 'spiritual awareness as a natural phenomenon [i.e., innate] and religion as a belief system', which is enculturated through family, education and community (Brown, 1978).

A wide range of descriptions and classifications of spirituality can be found in relevant literature. From his review of literature, Spilka (1993) proposed three categories of spirituality oriented towards (i) God, (ii) the world, or (iii) people. Marty (1997) reduced this classification even further by naming two prominent orientations of spiritual wellness as (i) theocentric (God-centred), and (ii) nontheocentric. According to Cohen et al. (2012), Larson and colleagues (1998) identified 10 general domains of religion and spirituality. Zinnbauer, Pargament and Scott (1999) conducted content analysis of 40 definitions of spirituality and 31 of religiousness, which yielded 9 content categories. Hill 
and Hood (1999) reviewed 125 measures of religion and spirituality which they placed in 17 different categories. Moberg (2010) reported that eight of these measures included 'spiritual' in their titles, and others would now be considered as measures of spirituality. Koenig et al. (2001) proposed five types of spirituality , (i) humanistic, with no reference to any higher power, (ii) unmoored, with focus on energy, connection, nature; moored spirituality, (iii) Eastern, or Western, (iv) evangelical or (v) conservative). From a casual survey of literature, Moberg (2011) listed more than 20 'subcategories and types of spirituality, each reflecting a specialized range of perspectives'.

Therefore, it is not surprising to note that nearly every paper on spirituality/ spiritual well-being states there is no agreed definition of these terms. Although that is so, and spirituality/spiritual well-being cannot be observed directly, most are agreed that they involve relationships. Many have mentioned a number of commonalities or potential areas of focus for these relationships, which, when present, illustrate or reflect healthy spirituality or spiritual well-being (Hyland, Wheeler, Kamble \& Masters, 2010).

\subsection{Spiritual well-being}

The term 'spiritual well-being' appears to have first been mentioned at the 1971 White House Conference on Aging (Moberg, 2010). Subsequent establishment of the National Interfaith Coalition on Aging (NICA) led to its 'working definition', namely that, 'Spiritual well-being is the affirmation of life in relationship with God, self, community and environment that nurtures and celebrates wholeness' (NICA, 1975). Many subsequent descriptions of SWB have consistently referred to these four notions. For example, in highlighting the centrality of relationships in these four areas, Waaijman states, 'Spirituality unfolds itself as the unity of the divine-human, interhuman, human-cosmic, and intrahuman relationships' (2007). However, not all researchers address all four areas. For example, Rovers and Kocum's (2010) definition of spirituality as 'Faith, hope and love' excluded mention of nature/environment, thus denying, or at least diminishing, spiritual reality for many indigenous peoples and most people with Eastern philosophies or environmental sensitivities.

Although 'spiritual well-being' was only proposed as a concept 40 years ago, the influence of spirit on health has been discussed from at least Hippocrates' time, around 400BC (Adams, 1939), as well as in Chinese medicine. In a similar vein, psychology, as a study of mind and behaviour, dates back to Ancient Greece, but psychology, as an independent scientific discipline only originated in the 1870s. A German, Johann Christian Reil, is reported to be the first person to use the term Psychiatry, derived from 
psych- and -iatry, to mean 'medical treatment of the soul', in 1808 (Wikipedia, 12/5/14). Therefore, close relationships between spiritual and mental aspects of health have been known for a considerable time. An American psychiatrist, Harold Koenig, has made comments to the effect that the concept of spiritual well-being has contaminated current research into relationships between mental and physical health $(2008,2012)$. Such comments should be ameliorated in light of the historical connections between psychology, psychiatry and spirituality mentioned. A focus on holistic well-being could be said to comprise spiritual-psycho-social-biophysical aspects of people as integrated wholes, not fragmented parts. I have deliberately re-ordered the components to challenge thinking about the relative importance of each factor of health, in contrast to the standard view which places the biophysical before the psycho-social, with spiritual being considered in last place, if at all (e.g., Sulmasy, 2002).

My conception of spiritual health posits that it is ' $\mathrm{a}$, if not the, fundamental dimension of people's overall health and well-being, permeating and integrating all the other dimensions of health (i.e., physical, mental, emotional, social and vocational). Spiritual health is a dynamic state of being, shown by the extent to which people live in harmony within relationships in up to four domains of spiritual well-being' (from Fisher, 1998, p.181), namely with themselves in the Personal domain, with other people in the Communal domain, with nature in the Environmental domain, and/or with something or some-One beyond the human and natural world, in the Transcendental domain.

This working definition laid the foundation for the development of the Four Domains Model of Spiritual Health/Well-Being. In this model, nearly all descriptors that refer to self and to others are clearly stated, whereas the words 'environment' and 'nature' are used interchangeably. The fourth area, relationship with a Transcendent (commonly called God) is the one in which researchers use a diversity of terms depending on their worldview. My model delves beneath the surface of labels to interrogate the structure of four domains shown in literature to be key to the composition of spiritual health/wellbeing. This model can be represented pictorially as (Figure 1).

The more I read, the more I find this model captures the views expressed by authors on spirituality and well-being. For example, my claim that the Inspirational component of each domain, which can be considered as small $\mathrm{t}$ transcendent essence and motivation that can be experienced by people, is filtered by worldview, concurs with a statement by Sire:

A worldview is a commitment, a fundamental orientation of the heart, that can be expressed as a story or in a set of presuppositions that we hold about the basic 
constitution of reality, and that provides the foundation on which we live and move and have our being (2009, p.20).

Waaijman expresses a similar sentiment in a quote from philosopher Theo be Boer: one of the four pillars of scholarly research is inspiration: what animates and orientates human thought? Imagination, reasoning, and experience are not enough. A truth-loving mind is not content with the so called 'reality' or 'horizons' or 'categories'. The ultimate question is: what is this really? To what is this leading? What gives direction to these perceptions, constructions and argumentations? (2007, p. 105).

Figure 1 Four Domains Model of Spiritual Health \& Well-being

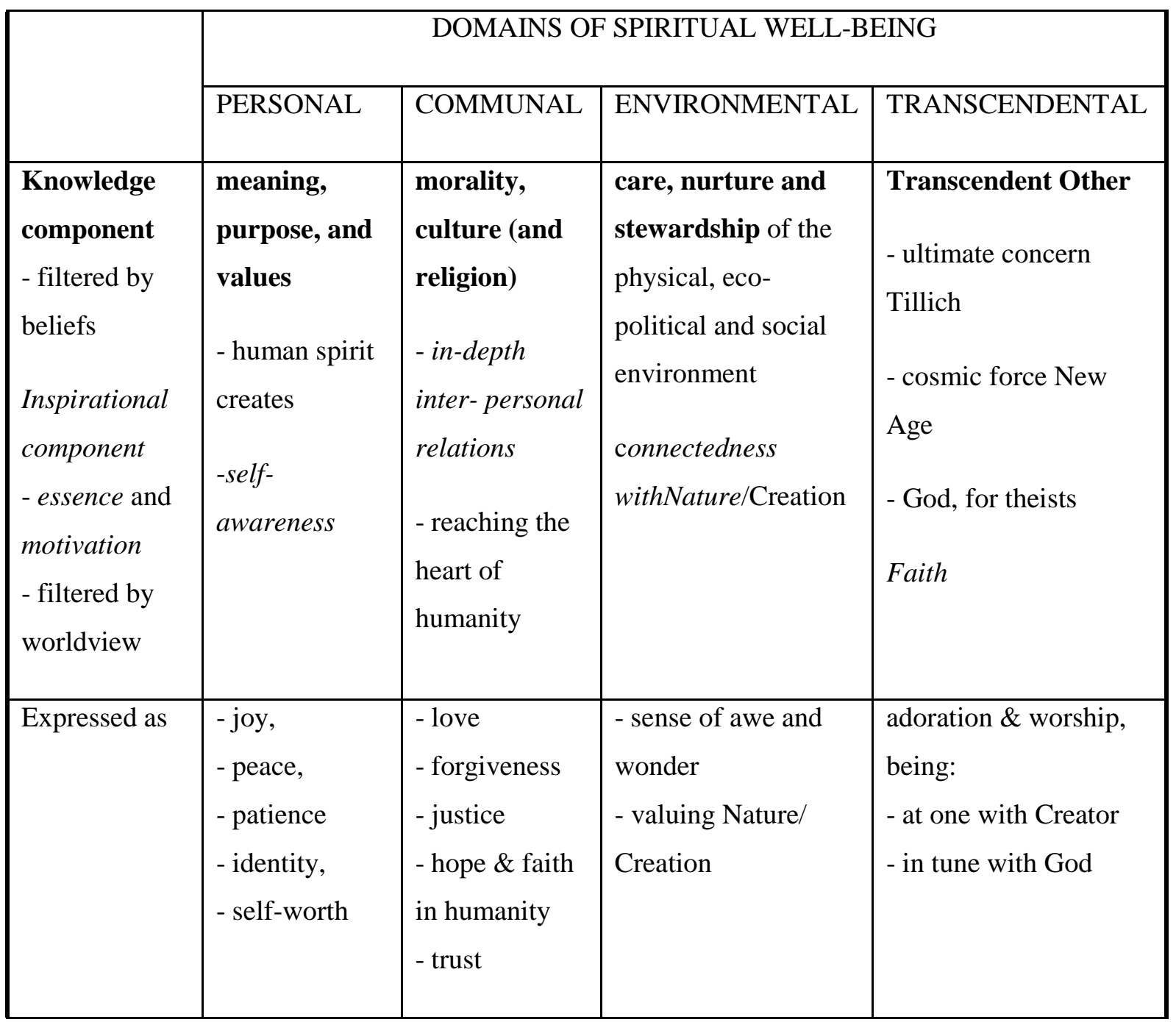

I have not found any expression of a worldview that does not fit my model. Put more positively, my model appears to encompass the vast majority of, if not all, worldviews.

The two components of each of the four domains in Figure 1 work synergistically, relating to, while building up, each other. Neither knowledge, as cognitive construct, nor 
inspiration, as essence and motivation, can be seen or measured directly. However, expressions of their effect can be measured. This four domains model provided the solid theoretical framework upon which my Spiritual Health And Life-Orientation Measure (SHALOM) was built (Fisher, 1998). A selection of 48 items was made from the model depicted in Figure 1. Exploratory Factor Analyses were used to select the best five items for each of the four domains. The resultant items in the four domains of SWB in SHALOM relate to developing:

Personal

sense of identity

self-awareness

joy in life

inner peace

meaning in life

\section{Environmental}

connection with nature

awe at a breathtaking view

oneness with nature

harmony with the environment

sense of 'magic' in the environment

\section{Communal}

love of other people

forgiveness toward others

trust between individuals

respect for others

kindness toward other people

Transcendental

personal relationship with the

Divine/God

worship of the Creator

oneness with God

peace with God

prayer life

Some studies, other than those using SHALOM, have also employed my model as the basis for their research in spirituality (Francis \& Robbins, 2005; 2012; Hughes, 2007).

\subsection{Spirituality/well-being Measures}

Publications abound with authors' personal beliefs about the relevance of God to spiritual well-being (see above), but very little hard evidence has been systematically supplied to support the plethora of divergent views. From a Western historical perspective, the term 'spirituality' was embedded in the confines of religion up to the start of the $20^{\text {th }}$ Century, but now applies to broad contemporary views within and without religion. Compendiums of religiosity measures have been compiled by Hill and Hood (1999) and Koenig et al. (2001; 2011). However, only instruments that focussed on spirituality have been included in this thesis. Those with a focus on religion were excluded because the thrust of this research is on the importance of relating with God for spiritual well-being, not religious 
well-being. As most instruments which clearly focus on religion would be expected to show some concern about relating with God, this would skew the results of this study.

Authors' views on what they consider important for spirituality/well-being are reflected in their choice of items included in any instrument or measure that they develop (Moberg, 2002). Three types of spirituality measures are found in literature:

- Those that focus on spiritual health, wellbeing or wellness (SH/WB)

- Those with specific mention of spirituality, and

- Related/partial spirituality measures (reflecting key aspects of the four domains model of SH/WB. These measures do not often employ a 'spirituality' label).

It is not possible for measures with only one, or even up to four, items to comprehensively cover four domains of spiritual health and well-being. In line with comments by Sloan et al. (2002), I decided that this multifaceted construct would best be measured with multidimensional, multi-item instruments. In my previous work, 169 multi-dimensional measures were described (Fisher, 2009, chapter 3). Further datamining using 'spiritual*' with 'measure' and 'assess*' has revealed another 88 instruments that fit similar criteria. There are probably more measures available in literature worldwide, but these are the only ones that were readily accessible to me.

A total of 257 spirituality/well-being measures are reported in Appendix B. These have been roughly divided into three groups in order to ascertain if any change in emphasis is present in the spirituality instruments developed over time. By the end of the $20^{\text {th }}$ century, 79 pertinent measures had been reported. In the first five years of the $21^{\text {st }}$ century, increasing interest in spirituality saw a further 90 instruments developed. Literature searches from 2006 to 2013 revealed another 86 newly-reported spirituality measures.

The percentage of instruments with three or more items per domain is shown in Table 2, for the three types of spirituality/well-being measures described above. Particular emphasis will be given here to the Transcendental domain, with cursory comments on religious items. Items in the instruments that referred to beliefs were categorised as either 'religious' or 'other'. Spirituality is taken to be reflected in respondents' quality of relationships, so an assessment of their lived experience is required, not just their beliefs. For example, belief in God is a religious attitude, that may or may not result in any form of relationship with God, as even the devil 'believes' in God. 
Some interesting trends were noted over time:

Personal SWB - Bregman claimed, 'The individual in his/her freedom and quest for meaning is now the whole focus of the concept of 'spirituality' [my italics] (2012).

However, focus on the Personal domain of spiritual well-being for the range of instruments has dropped slightly over time, but it is still greater than for the other three domains of Communal, Environmental and Transcendental spiritual well-being.

Communal SWB - A similar percentage of Communal and Transcendental spiritual wellbeing factors are present over time in the spirituality/well-being measures.

Table 2. Percentage composition of instruments in four domains of spirituality/well-

\section{being}

\begin{tabular}{|c|c|c|c|c|c|c|c|}
\hline Instrument type & year & No. & Per swb & Com swb & Env swb & Tra swb & Relig. \\
\hline & $<2000$ & 15 & 100 & 67 & 13 & 73 & 27 \\
\hline Spiritual Health/ & $2000-5$ & 8 & 100 & 63 & 75 & 75 & 17 \\
\hline \multirow[t]{3}{*}{ Well-being } & $2006+$ & 16 & 94 & 63 & 25 & 50 & 31 \\
\hline & total & 39 & 97 & 64 & 28 & 64 & 26 \\
\hline & $<2000$ & 32 & 88 & 66 & 25 & 72 & 47 \\
\hline \multirow[t]{3}{*}{ Spirituality } & $2000-5$ & 55 & 76 & 49 & 11 & 55 & 49 \\
\hline & $2006+$ & 47 & 79 & 53 & 21 & 47 & 43 \\
\hline & total & 133 & 80 & 55 & 18 & 56 & 46 \\
\hline Related/ & $<2000$ & 32 & 91 & 56 & 13 & 19 & 22 \\
\hline \multirow[t]{4}{*}{ Partial swb } & $2000-5$ & 27 & 78 & 44 & 19 & 22 & 30 \\
\hline & $2006+$ & 23 & 78 & 26 & 9 & 39 & 35 \\
\hline & total & 82 & 83 & 44 & 13 & 26 & 27 \\
\hline & $<2000$ & 79 & 91 & 62 & 19 & 51 & 33 \\
\hline \multirow[t]{3}{*}{ ALL } & $2000-5$ & 90 & 91 & 49 & 21 & 47 & 39 \\
\hline & $2006+$ & 86 & 81 & 49 & 17 & 45 & 37 \\
\hline & TOTAL & $255^{*}$ & 88 & 53 & 18 & 47 & 37 \\
\hline
\end{tabular}

NB $* 2$ undated, Per $=$ Personal, Com $=$ Communal, Env $=$ Environmental,

$$
\text { Tra }=\text { Transcendental spiritual well-being } \quad \text { Relig }=\text { religious items }
$$

Environmental SWB - apart from instruments based on my model, reported in 2000-05, only one in five instruments address environmental issues for spiritual well-being. 
Transcendental SWB - SH/WB measures developed since 2006 show a marked decline in percentage of instruments assessing relationship with a Transcendent (e.g., God); a drop from three quarters to half. This reducing trend had been noticed by Chiu et al. (2004). A more even decline of similar magnitude has taken place in spirituality measures from 2000 to the present time. Counter to this downward trend, related /partial measures of spirituality revealed an increase in assessment of relationships with a Transcendent over the last 40 years. However, even now, less than half of these instruments contain assessments of relationship with a Transcendent.

These trends in spirituality/well-being are of particular interest as they highlight the variations among researchers who are developing new scales. Are they building on their own worldviews or are they focussing on the perceived needs or lived experiences of people being studied by means of these instruments? The marked divergence of worldviews and noticeable variations in measures of spirituality/well-being identified here lays the foundation for the primary research question in this study, 'How important is relating with God (or Transcendent) for spiritual well-being?' Alternative worldviews are generally closely held truth claims, beliefs or opinions. No empirical studies have been identified that reported evidence comparing the importance of relating with God, with that of the other three sets of relationships, for spiritual well-being. However, what follows in this thesis does that. 


\section{Chapter 3 Spiritual well-being among university students}

\subsection{Introduction}

The work reported in this chapter stems from my research in spiritual well-being among school teachers and students reported previously (Fisher, 1998, 2009). This chapter comprises a trilogy of papers that tap into a broad spectrum of university students in Australia, Hong Kong, Northern Ireland and Turkey. Although some of the raw data have been used in a previous thesis, the analyses in the papers included here have not been presented for any previous award.

\subsection{Pre-service teachers' spiritual well-being across time and faiths}

\section{Background}

Given the emphasis of this thesis, I considered it appropriate to revisit some earlier research to elicit relevant information related to the importance of relating with God for spiritual well-being among pre-service teachers. Their perceptions of the level of help provided by schools for nurturing their students' spiritual well-being will also be addressed. My SHALOM questionnaire was used in this study. I was mainly responsible for this project. I designed the project and collected the data in Australia. Philip Barnes collected responses from students in Northern Ireland. I analysed all the data and wrote the report, with comments being made on the draft paper by Philip Barnes and Geneé Marks.

\section{Key points extracted from the paper}

- Variations were noted in the spiritual well-being of the pre-service teachers over time, between cohorts within selected universities. Variation was noted within universities and between universities, which is not surprising, due not least to variations in religious affiliations of students.

- Variations in spiritual well-being were observed across 'faiths.' Transcendental spiritual well-being (relation with God) was rated higher among pre-service teachers from Northern Ireland and Australian Christian universities in comparison with those from Australian Catholic University. Even lower ratings 
were reported for Transcendental SWB among the pre-service teachers in the secular, Australian public university.

- The pre-service teachers' level of lived experience accounted for the greatest variance in their perceptions of help provided by schools for their students' relationship with God. This perception of help from schools was scored highest among Northern Ireland pre-service teachers, with lower values being reported by Australian Catholic and secular university students. The Australian Christian university pre-service teachers rated perceived help for school students' relationship with God lowest. They also displayed the greatest dissonance between their personal ideals and lived experience in the area of relating with God.

\section{Implications}

As the lived experience of pre-service teachers influences their perceptions of help provided by schools in nurturing their students' spiritual well-being, spiritual formation programs were needed to help the pre-service teachers reflect on issues of spiritual wellbeing both personally and professionally. This was noted and acted on by staff in one Christian university following findings from this project.

Students in the secular university should fit well with secular State schools in Australia in the area of not relating with God highly for spiritual well-being. As Australian state schools do not have Religious Education classes at secondary level and as secular humanism is the dominant worldview presented in state schools, relating with God is not an area that is addressed often, or at all, in these schools.

Compulsory religious education in schools in Northern Ireland has a positive influence on the pre-service teachers' perceptions of help provided by schools for their students' relationship with God for spiritual well-being. A longitudinal study in Australian schools could help determine if the recent increase in school chaplaincy in Australia has any effect in the Transcendental, or any of the other three domains of, spiritual well-being.

\section{Paper:}

This paper was published as: Fisher, J.W., Barnes, L.P. \& Marks, G. (2009) Pre-service teachers' spiritual well-being across time and faiths: Implications for religious education. Religious Education Journal of Australia, 25(2):10-16. 


\title{
Pre-service teachers' spiritual well-being across time and faiths: implications for religious education.
}

\author{
John W. Fisher ${ }^{1}$, L. Philip Barnes ${ }^{2}$, Genée Marks ${ }^{1}$ \\ ${ }^{1}$ School of Education, University of Ballarat $\quad{ }^{2}$ King's College, London
}

\begin{abstract}
Spiritual well-being (SWB) is reflected in the quality of relationships people have in up to four areas, namely with themselves, with others, with the environment, and/or with God. A recent study has shown that the lived experiences of teachers have major influence on their perceptions of help provided to nurture students' SWB in schools.

Fisher's (1999) 20-item Spiritual Health And Life-Orientation Measure (SHALOM) elicited pre-service teachers' ideals for SWB, and their lived experiences in each of the four domains, as well as the level of help these pre-service teachers believe is provided to school students in these areas of their lives. Data were collected from 1361 pre-service teachers in public, secular and religious universities, and Christian universities in Australia and Northern Ireland in 2000 and 2007-8.

Significant variations were found in levels of SWB by gender and university type and between pre-service teachers from one year to another. The pre-service teachers in these studies were not overly optimistic about the level of help provided to nurture school students' relationship with God. This finding has implications for religious education in schools, within discussions of the holistic development and well-being of students.
\end{abstract}

\section{Key words}

Four domains of spiritual well-being SHALOM spiritual dissonance

\section{Contact}

Dr John W Fisher, School of Education, University of Ballarat

e-mail: j.fisher@ballarat.edu.au

\section{Introduction}

Although the theme of spiritual development and the related notion of spiritual well-being (SWB) are not new themes in post-war education, they have certainly come to prominence in the last few decades. In Britain, the Education Reform Act of 1988 required schools to promote "the spiritual, moral, social and cultural development of all pupils” (Her Majesty's Stationery Office, 1988, Chapter 40, p.1). In Australia, policy makers followed suit in 1994 by including the spiritual development of students for the first time in official Australian curriculum statements (Australian Education Council, 1994; Board Of Studies (Victoria), 1994). The Melbourne Declaration on Educational Goals for Young Australians (Ministerial Council on Education, Employment, Training and Youth Affairs (MCEETYA), 5 December, 2008) reinforced the place of the spiritual in education, wherein the goal of schools is seen as embracing the spiritual along with the 
"intellectual, physical, social,..., moral and aesthetic development and wellbeing of young Australians" (MCEETYA, 2008, p.4).

Spiritual development naturally embraces spiritual well-being, for why would educators want to develop the spirituality of students if it was not perceived as something positive that contributes to individual well-being? Of course spiritual well-being can include religion but is not restricted to it (Hill et al., 2000). There are four domains of SWB that are variously mentioned in literature and are clearly contained within Fisher's model of spiritual health and well-being (Fisher, 1998). In this model, spiritual health is seen as a, if not THE, fundamental dimension of health permeating and integrating all other dimensions of health (i.e., the physical, mental, emotional, social and vocational). Spiritual health is not static, but is a dynamic state of being shown by the quality of relationships in up to four domains of spiritual well-being, namely of people relating with themselves, with others, with the environment, and/or with God.

Spirituality is a rather elusive concept (Chiu et al., 2004), but tying it to health in the grounded manner above has enabled the development of quantitative instruments to assess or measure various aspects of SWB. The strength of the Spiritual Health And LifeOrientation Measure (SHALOM) (Fisher, 1999) is that it provides more than one view from respondents. SHALOM seeks each respondent's 'ideals' for SWB with which her/his 'lived experience' can be compared to indicate the quality of relationships in each of the four domains of SWB discussed here. In other words, each person becomes the standard against which s/he is measured for SWB.

SHALOM can also be used to elicit each respondent's views on the degree of help provided for themselves or others in developing these aspects of life. A recent study has shown that the lived experiences of teachers have major influence on their perceptions of help provided in schools to nurture students' SWB (Fisher, 2008).

\author{
Aim \\ This project used SHALOM to investigate SWB among pre-service teachers in \\ selected public, secular and religious universities as well as in private Christian \\ universities to: \\ - note any variation over time in four domains of SWB, \\ - compare levels of SWB in pre-service teachers in different types of university, and \\ - use the findings about relationship with God (Transcendental SWB) to inform \\ discussions on religious education in schools.
}

\title{
Method
}

Convenience samples of pre-service teachers formed the cohort for these studies, based on their accessibility by the authors of this paper. An Australian, secular, public university (hereafter called 'secular') was surveyed in 2000, 2007 and 2008. Two campuses of the Australian Catholic University (ACU-1, ACU-2) were surveyed in 2000 and 2008. ACU is a publicly-funded university with multiple campuses and a religious base. A university with a religious base in Northern Ireland was surveyed in 2000 and two recently-developed Australian, private, Christian universities were studied in 2007. 
Following ethics' approvals from each of the above mentioned universities, preservice teachers were invited to share their views on SWB in education. The plain language statement was provided to the pre-service teachers at the end of a lecture in their institution. Opportunity was provided for questions. The pre-service teachers who decided to participate took approximately ten minutes to complete a two-page questionnaire comprising Fisher's 20-item Spiritual Health And Life-Orientation Measure (SHALOM) and demographic data of gender, age, marital status together with year of course, area of teaching specialisation, religious affiliation, frequency of participation with a religious group and prayer, factors which build up SWB, and the importance of religion and spirituality in life. Data were collected from a total of 1361 pre-service teachers in 2000 and 2007-8.

The pre-service teachers were asked to give three responses to each of 20 items in SHALOM to indicate 1) their 'ideals' for SWB, 2) how each item reflected their 'lived experiences' (how they feel) most of the time, and 3) their perceptions of the level of 'help' provided for school students in developing each of these aspects of life. SHALOM comprises five items in each of the four domains. The Personal domain of SWB relates to developing 'a sense of identity', 'self-awareness', 'joy in life', 'inner peace' and 'meaning in life'. Communal SWB relates to developing 'a love of other people', 'forgiveness toward others', 'trust between individuals', ' respect for others' and 'kindness toward other people'. Environmental SWB relates to developing 'connection with nature', 'awe at a breathtaking view', 'oneness with nature', harmony in the environment' and a 'sense of "magic" in the environment'. Transcendental SWB relates to developing 'personal relation with the Divine/God', 'worship of the Creator', 'oneness with God', peace with God' and 'prayer life'.

Responses were given on a 5-point Likert scale from 1 = 'very low' to 5 = 'very high' for each of the 'ideal', 'lived experience' (or 'feel') and 'help' categories for each of the 20 items. All statistics were performed using SPSS for Windows 15.0.

\section{Results}

\section{Composition of universities}

Of the 1361 respondents, there was a large majority of females (77.7\%) who were slightly younger (average 22.3 years of age) than the males (average 23.7 years of age). As this paper focuses on religious education, the distribution of the respondents by university type and religious affiliation is recorded in Table 1.

It can be seen from Table 1 that the majority of the pre-service teachers in the Australian secular university expressed no religious affiliation, whereas those in the ACU campuses were mainly Catholic. The Christian universities comprised a high percentage of evangelical Protestants and the religious Northern Ireland university had a fairly even mix of Catholic and Protestant pre-service teachers.

\section{Within universities over time}

Independent t-tests revealed significant differences between female pre-service teachers in the secular university in 2000 compared with 2007. The ideals for SWB were lower in 
each of the four domains for those in 2007 compared with those in $2000\left(\mathrm{t}_{\text {per }}(449)=2.99\right.$, $\left.\mathrm{p}=.003 ; \mathrm{t}_{\text {com }}(449)=4.12, \mathrm{p}<.001 ; \mathrm{t}_{\text {env }}(449)=4.64, \mathrm{p}<.001 ; \mathrm{t}_{\text {tra }}(449)=3.58, \mathrm{p}<.001\right)$.

Table 1. Distribution of pre-service teachers by institution and religious affiliation

\begin{tabular}{|c|c|c|c|c|c|c|}
\hline \multirow[b]{2}{*}{ University type } & & \multicolumn{5}{|c|}{ Religious affiliation(\% shown) } \\
\hline & $\mathrm{n}$ & Catholic & Anglican & $\begin{array}{c}\text { other } \\
\text { Protestant }\end{array}$ & $\begin{array}{l}\text { other } \\
\text { religion }\end{array}$ & none \\
\hline Australian secular & 636 & 21.2 & 5.3 & 13.8 & 1.1 & 58.5 \\
\hline ACU-1 & 245 & 61.2 & 2.9 & 13.9 & 1.2 & 20.8 \\
\hline ACU-2 & 227 & 70.9 & 2.6 & 7.0 & 1.3 & 18.1 \\
\hline Christian & 119 & 5.0 & 1.7 & 89.1 & 0 & 4.2 \\
\hline $\begin{array}{l}\text { Northern Ireland } \\
\text { religious }\end{array}$ & 130 & 47.7 & 5.4 & 40.8 & 0 & 6.1 \\
\hline
\end{tabular}

Previous studies have shown that people's ideals have major influence on their lived experiences for SWB, as measured by SHALOM (Fisher 2006, 2007). Therefore, it was not surprising to find that female pre-service teachers at the secular university in 2007 reported that their lived experiences (how they feel most of the time) in relating with self, others and environment were lower, in line with their lower ideals. Matched pairs ttest results for both groups combined reflected this trend in each group: $t_{\text {per }}(449)=2.16$, $\mathrm{p}=.032 ; \mathrm{t}_{\text {com }}(449)=3.49, \mathrm{p}=.001 ; \mathrm{t}_{\text {env }}(449)=4.46, \mathrm{p}<.001 ; \mathrm{t}_{\text {tra }}(449)=1.49, \mathrm{p}=.14 \mathrm{~ns}$. Independent t-tests showed that the females' levels of 'lived experience' in 2007 were similar to that of males $\left(\mathrm{t}_{\mathrm{per}}(230)=1.87, \mathrm{p}=.065 \mathrm{~ns} ; \mathrm{t}_{\text {com }}(230)=1.90, \mathrm{p}=.061 \mathrm{~ns}\right.$; $\left.\mathrm{t}_{\text {env }}(230)=.75, \mathrm{p}=.46 \mathrm{~ns} ; \mathrm{t}_{\text {tra }}(230)=.09, \mathrm{p}=.93 \mathrm{~ns}\right)$. The males had reported similar responses between 2000 and 2007 (see results below).

Table 2 shows mean values of reported levels in four domains of SWB among pre-service teachers, by gender, in the secular university in 2000, 2007 and 2008.

The perception of the level of help provided for school students to develop these aspects of life was also rated lower by female pre-service teachers in 2007 compared with those in 2000 (see mean values in Table 2) (independent t-tests: $\mathrm{t}_{\mathrm{per}}(447)=6.33, \mathrm{p}<.001$; $\left.\mathrm{t}_{\text {com }}(447)=6.58, \mathrm{p}<.001 ; \mathrm{t}_{\text {env }}(447)=5.74, \mathrm{p}<.001 ; \mathrm{t}_{\text {tra }}(447)=3.75, \mathrm{p}<.001\right)$. [Similar lower levels of help were also expected by male pre-service teachers in the secular university in 2007 compared with those in 2000.]

With lower levels for relationships with self and others, the female pre-service teachers in 2007 could be considered as testing as less tender-hearted than their counterparts in 2000 . To see if this was a societal trend, the study was extended in 2008 to the secular university cohort as well as ACU and Australian Christian universities. In 2008 , the secular university females tested higher than in 2007, to a similar level to those in 2000 (see Table 2). However, their perceptions of levels of help for students in schools 
remained at lower levels than in 2000. A similar decline was reported among practising school teachers over the same period of time (Fisher, 2007).

Table 2. Levels of SWB among pre-service teachers in a secular university

\begin{tabular}{|c|c|c|c|c|c|c|c|c|c|c|c|c|c|}
\hline \multirow{2}{*}{$\begin{array}{l}\text { gender } \\
\text { year } \\
\text { F }\end{array}$} & \multirow[b]{2}{*}{$\mathrm{n}$} & \multicolumn{3}{|c|}{$\begin{array}{c}\text { Personal } \\
\text { SWB }\end{array}$} & \multicolumn{3}{|c|}{ Commmunal SWB } & \multicolumn{3}{|c|}{$\begin{array}{c}\text { Environmental } \\
\text { SWB }\end{array}$} & \multicolumn{3}{|c|}{$\begin{array}{c}\text { Transcendental } \\
\text { SWB }\end{array}$} \\
\hline & & ideal & feel & help & ideal & feel & help & ideal & feel & help & ideal & feel & help \\
\hline 2000 & 270 & 4.39 & 4.22 & 4.25 & 4.52 & 4.42 & 4.44 & 3.53 & 3.42 & 3.36 & 3.03 & 2.64 & 2.72 \\
\hline 2007 & 181 & 4.20 & 4.09 & 3.79 & 4.29 & 4.23 & 4.02 & 3.16 & 3.07 & 2.89 & 2.64 & 2.48 & 2.37 \\
\hline 2008 & 37 & 4.25 & 4.06 & 3.61 & 4.49 & 4.38 & 3.94 & 3.38 & 3.11 & 2.75 & 2.96 & 2.70 & 2.43 \\
\hline \multicolumn{14}{|l|}{$\mathrm{M}$} \\
\hline 2000 & 85 & 4.00 & 3.92 & 3.97 & 4.23 & 4.16 & 4.17 & 3.34 & 3.27 & 3.24 & 2.87 & 2.50 & 2.70 \\
\hline 2007 & 51 & 3.97 & 3.86 & 3.62 & 4.13 & 4.02 & 3.85 & 3.23 & 3.17 & 2.92 & 2.55 & 2.47 & 2.41 \\
\hline
\end{tabular}

Female pre-service teachers in ACU tested lower in 2008 than in 2000 on relating with the environment (independent t-test $\mathrm{t}_{\mathrm{env}}(381)=2.78, \mathrm{p}<.01$ ) and on their perceived level of help for school students' Personal, Communal and Environmental SWB $\left(\mathrm{t}_{\text {per }}(381)=5.25, \mathrm{p}<.001 ; \mathrm{t}_{\text {com }}(381)=3.50, \mathrm{p}<.001 ; \mathrm{t}_{\text {env }}(381)=3.36, \mathrm{p}<.001\right)$.

Independent t-tests revealed no significant difference among male pre-service teachers in the secular university between 2000 and 2007 ( $\mathrm{t}_{\mathrm{per}}(134)=.49, \mathrm{p}=.63 \mathrm{~ns}$; $\left.\mathrm{t}_{\text {com }}(134)=1.18, \mathrm{p}=.49 \mathrm{~ns} ; \mathrm{t}_{\text {env }}(134)=.70, \mathrm{p}=.49 \mathrm{~ns} ; \mathrm{t}_{\text {tra }}(134)=.19, \mathrm{p}=.85 \mathrm{~ns}\right)$. In 2008, males in one of the ACU campuses tested lower on lived experiences of SWB $\left(\mathrm{t}_{\mathrm{per}}(44)=1.84\right.$, $\left.\mathrm{p}=.073 ; \mathrm{t}_{\text {com }}(44)=2.16, \mathrm{p}<.05 ; \mathrm{t}_{\text {env }}(44)=3.07, \mathrm{p}<.01 ; \mathrm{t}_{\text {tra }}(44)=2.80, \mathrm{p}<.01\right)$ whereas males in the second ACU campus tested higher on lived experience of relating with God, compared with those in $2000\left(\mathrm{t}_{\text {tra }}(31)=-2.45, \mathrm{p}<.05\right)$.

In summary, these results indicate that variations in SWB exist between different cohorts of pre-service teachers in the same university, from year to year.

\section{Between universities -across 'faiths'}

ANOVA results revealed significant differences between pre-service teachers in different universities for Communal, Environmental and Transcendental SWB in 2000 and 2007-8. In 2000, the 'lived experiences' reported by those in the Northern Ireland university were lower than their Australian counterparts for Communal and Environmental SWB, but higher for Transcendental SWB, measured using SHALOM. Similar results to the Northern Ireland university were reported by pre-service teachers in the Australian Christian university, compared with their counterparts in other Australian universities in 2007-8. The greatest variations between universities were shown on the God-factor (Transcendental SWB) with pre-service teachers in the secular university relating with 
God least, those in religious universities higher and those in Christian (evangelical) universities highest (Table 3).

Table 3. ANOVA results for lived experiences of SWB among pre-service teachers

\begin{tabular}{|c|c|c|c|c|c|c|c|c|c|}
\hline 2000 & PER & $\mathrm{COM}$ & ENV & Tra & $2007-8$ & PER & $\mathrm{COM}$ & ENV & TRA \\
\hline university & & & & & university & & & & \\
\hline secular & 4.15 & 4.36 & 3.39 & 2.60 & secular & 4.14 & 4.20 & 3.10 & 2.53 \\
\hline ACU-1 & 4.14 & 4.37 & 3.59 & 3.35 & ACU-1 & 4.20 & 4.34 & 3.23 & 3.00 \\
\hline ACU-2 & 4.14 & 4.38 & 3.68 & 3.25 & ACU-2 & 4.05 & 4.24 & 3.49 & 3.43 \\
\hline N Ireland & 4.00 & 4.11 & 3.25 & 3.70 & Christian & 3.89 & 4.08 & 2.90 & 3.94 \\
\hline $\mathrm{F}(3,748)$ & 1.97 & 7.52 & 8.89 & 42.9 & $\mathrm{~F}(3,605)$ & 1.58 & 3.14 & 10.4 & 66.6 \\
\hline $\mathrm{p}$ & $.12 \mathrm{~ns}$ & $<.001$ & $<.001$ & $<.001$ & $\mathrm{p}$ & $.19 \mathrm{~ns}$ & $<.05$ & $<.001$ & $<.001$ \\
\hline
\end{tabular}

NB PER= Personal SWB, COM=Communal SWB, ENV=Environmental SWB, TRA=Transcendental SWB

There were also marked differences, with the pre-service teachers in the Northern Ireland scoring higher $(\mathrm{F}(3,748=36.7, \mathrm{p}<.001)$ and those in Australian Christian universities scoring lower $(\mathrm{F}(3,605)=37.9, \mathrm{p}<.001)$ on their perceptions of 'help' for school students' relating with God, compared with their counterparts in the Australian public, secular and Catholic universities. Further study is needed to determine the consistency of differences in SWB between pre-service teachers in the Australian universities and their comparison with counterparts overseas, using SHALOM.

\section{Comparing 'ideal' with 'lived experience' - 'spiritual dissonance'}

The data were grouped together for each type of university over the timeframe of 2000 to 2008. On average, the pre-service teachers rated their 'lived experience' at a lower level than their 'ideals' (matched pairs t-test values ranged from 2.02 to 10.2, most with $\mathrm{p}<.001)$. Spiritual dissonance has been posited as being shown by a difference of greater than 1.0 between the mean values for the 'ideal' and 'lived experience' scores for the five items in each domain of SWB (Fisher, 2006).

Spiritual dissonance was higher for Christian pre-service teachers in four domains of SWB. The greatest spiritual dissonance was shown on the God-factor (Transcendental SWB) for pre-service teachers in all the universities, even the secular university (see Table 4).

\section{Focus on the God-factor (Transcendental SWB)}

Linear regression analyses revealed that pre-service teachers' 'lived experience' of Transcendental SWB accounts for the greatest variance on the perceived 'help' for school students relating with God (see Table 5). 
Table 4. Percentage of spiritual dissonance among pre-service teachers

\begin{tabular}{lcccc}
\hline University & $\begin{array}{c}\text { Personal } \\
\text { SWB }\end{array}$ & $\begin{array}{c}\text { Communal } \\
\text { SWB }\end{array}$ & $\begin{array}{c}\text { Environmental } \\
\text { SWB }\end{array}$ & $\begin{array}{c}\text { Transcendental } \\
\text { SWB }\end{array}$ \\
\hline secular & 3.9 & 3.1 & 3.9 & 10.8 \\
ACU & 6.8 & 4.2 & 5.3 & 9.5 \\
N. Ireland & 10.5 & 4.5 & 6.0 & 14.2 \\
Christian & 16.8 & 14.3 & 9.2 & 21.0 \\
\hline
\end{tabular}

Table 5. Summary of linear regression analyses on 'help' for Transcendental SWB

\begin{tabular}{lllll}
\hline \multicolumn{1}{c}{ University } & \multicolumn{1}{c}{ secular } & N. Ireland & ACU & Christian \\
\hline $\mathrm{F}$ & $(6,275)=46.0$ & $(5,124)=23.6$ & $(6,201)=22.3$ & $(6,112)=8.8$ \\
$\mathrm{p}$ & $<.001$ & $<.001$ & $<.001$ & $<.001$ \\
$\Delta \mathrm{R}^{2}$ & .50 & .49 & .40 & .32 \\
$\beta$-values for lived & .79 & .70 & 65 & .33 \\
experience TRA SWB & & & & \\
\hline
\end{tabular}

\section{Discussion}

The higher level of 'help' for school students relating with God, expected by the Northern Ireland pre-service teachers (mean=3.61), illustrates the difference in emphasis in their schools in 2000. These schools were influenced by the National Curriculum used in England and Wales, with religious studies in the core curriculum. This situation contrasted with Australia, which only has religious education on a voluntary basis in state primary schools and not part of formal curriculum in state secondary schools. Therefore it was not surprising to find that pre-service teachers in the secular university had low perceptions of 'help' being provided for school students to relate with God (mean=2.58). Those in the Catholic university perceived that moderate levels of help were provided for this purpose for students in their schools (mean=3.32). These findings reflected the preservice teachers' own 'lived experiences' of relating with $\operatorname{God}\left(\operatorname{mean}_{\mathrm{Nl}}=3.70\right.$, mean $_{\mathrm{sec}}=2.57$, mean $_{\mathrm{ACU}}=3.28$ ).

These results indicate that the pre-service teachers in the secular university are likely to fit in well with the secular nature of state schools and that the pre-service teachers in the Catholic university have similar expectations to practising teachers in Catholic schools (mean values of 'help' for school students relating with God for state school teachers $=1.79$, for Catholic school teachers $=3.57$, as measured by SHALOM, personal communication with J Fisher, $15^{\text {th }}$ March, 2009). It was surprising to note the level of 'help' for school students relating with God, that was expected by pre-service teachers in Christian universities (mean=2.87). This was significantly lower than their 
own 'lived experience' with God (mean $=3.94, \mathrm{t}(119)=11.0, \mathrm{p}<.001)$. Further work is needed to find out if the pre-service teachers in these Christian universities were expressing views about state schools rather than Christian schools, as their views are more in line with practising state school teachers not those in Christian schools.

Pre-service teachers in the Christian universities actually showed highest dissonance together with perceived lower levels of help for school students in four domains of SWB, not just on the God-factor. These results prompted action from one of the Christian universities, with staff implementing a spiritual formation program with the requirement of an extra hour per week mentoring for pre-service teachers to reflect on these issues as they relate personally and in practice in education (Fisher, 2009). The evidence of spiritual dissonance on the God-factor among one in five Christian preservice teachers is a matter of concern. It is to be hoped that the spiritual formation mentoring program initiated will have positive benefit in helping these pre-service teachers to set more realistic ideals and/or live closer to their ideals, for their own SWB as well as for that of their future students

Findings from these studies provide challenges to teacher educators and curriculum developers if religious education is seen to have a goal of helping school students relate with God. If this goal is to be achieved, then pre-service and indeed practising teachers need to have a good relationship with God if they are intent on helping students do the same, as part of RE.

Results here show that pre-service teachers in the secular university had low perceptions of students being helped to relate with God in state schools in Australia. This begs the question as to how much the role of voluntary Christian religious education impacts the culture in Australian state primary schools. It will also be interesting to follow the effect of the initiative taken by the Australian Federal Government which has provided funds for the appointment of chaplains, who have the task of enhancing the spiritual development of students, in primary and secondary schools (Department of Education, Science \& Training, March 2007).

Forming caring relationships between people and God lies at the core of Transcendental SWB (commonly called the God-factor). Hyper-enthusiastic teachers whose practice denies their words, and others who attempt to apply pressure on students to conform to patterns of ritualistic behaviour (Dixon, 2001), might have some influence on the externals but not students' hearts. People cannot be bulldozed nor dragged into the kingdom of God. Such methods definitely have no rightful place in schools. In this vein, Wolf (2004) also encourages school counsellors to 'Teach, but Don't Preach' (p.363) when dealing with students' spiritual concerns. This principle should also hold for religious education in schools.

It is made clear in school policies (e.g., those relating to chaplaincy programs) that schools are not open to proselytisation, that is, attempts to coerce students into a particular belief. According to Hill (2004, p.87), schools should turn out "liberated choosers", students who are provided with adequate knowledge and opportunity for discussion to inform their decisions. This principle should apply to each of the four domains of SWB as part of holistic education.

Here is a reminder that the Melbourne Declaration on Educational Goals for Young Australians (MCEETYA, 5 December, 2008) reinforces the place of the spiritual 
in the goal of schools as being for the "intellectual, physical, social, spiritual, moral and aesthetic development and wellbeing of young Australians" (MCEETYA, 2008, p.4). How this relates to religious education compared with other aspects of the curriculum needs to be canvassed carefully in religious schools. The Transcendental aspect of SWB evokes a diversity of views, but it needs to be addressed for the holistic development and well-being of students in all schools.

\section{Conclusion}

Results presented here show that significant differences exist in pre-service teachers' levels of SWB from one year to another, by gender and university type. The pre-service teachers in these studies were not overly optimistic about the level of help provided for school students to relate with God. This research has provided some evidence of views among pre-service teachers that can inform debate and preparation of these teachers-intraining, with implications for the future of religious education in schools, as part of the holistic development and well-being of everyone concerned.

\section{Notes on contributors}

Over the last 46 years, Dr John W Fisher has taught, researched and published extensively in the areas of science, education, religious studies, psychology and spiritual well-being ( $\mathrm{PhD}$ [1998] University of Melbourne, EdD [2009] University of Ballarat). John is on the editorial boards of two spirituality and one religious education journal/s.

Dr L. Philip Barnes is Reader in Religious and Theological Education at King's College London. He has published widely in the areas of religious education, philosophy of education, religious studies and theology. He has recently contributed a short critical study of religious education, entitled Religious Education: Taking religious difference seriously (2009), to the Impact series on educational policy, and is published by the Philosophy of Education Society of Great Britain.

Dr Genée Marks is broadly experienced in primary, secondary and special education. While her primary work is in disability studies, where she co-researches with people with intellectual disability, her research and areas of interest focus on social justice, equity and human rights generally. She has carried out research into spirituality and transformational leadership in policing, and is interested in the links between spirituality and pastoral care in schooling.

\section{References}

Australian Education Council (AEC) (1994). A statement on studies of health and physical education for Australian schools. Melbourne: Curriculum Corporation.

Board of Studies (1994). Curriculum \& Standards Framework - Draft for Consultation 15 June, 1994. Carlton, Victoria: BOS.

Chiu,L., Emblen, J.D., Van Hofwegen, Sawatzky, R. \& Meyerhoff, H. (2004). An integrative review of the concept of spirituality in the health sciences. Western Journal of Nursing Research, 26(4), 405-428. 
Department of Education, Science and Training (DEST) (2007). National School Chaplaincy Programme. Canberra: Australian Government. Retrieved 16 March, 2007, from: http://www.dest.gov.au/sectors/school_education/ policy_initiatives reviews/key_issues/school_chaplaincy_programme/

Dixon, C. (2001) Nurturing the spirit or quenching it through coercion? An exploration of the tensions in nurturing children. Journal of Christian Education, 44(1), 15-28.

Fisher, J.W. (1998). Spiritual health: Its nature and place in the school curriculum. $\mathrm{PhD}$ thesis, University of Melbourne (http://eprints.unimelb.edu.au/archive/00002994/)

Fisher, J.W. (1999). Developing a Spiritual Health And Life-Orientation Measure for secondary school students. In J. Ryan, V Wittwer \& P. Baird (Eds), Research with a regional/rural focus: Proceedings of the University of Ballarat inaugural annual research conference, 15 October, 1999 (pp. 57-63). Ballarat: University of Ballarat, Research and Graduate Studies Office.

Fisher, J.W. (2006). Using secondary students' views about influences on their spiritual well-being to inform pastoral care. International Journal of Children's Spirituality, 11(3), 347-356.

Fisher, J.W. (2007). It's time to wake up and stem the decline in spiritual well-being in Victorian schools. International Journal of Children's Spirituality, 12(2), 165-177.

Fisher, J.W. (2008). Impacting teachers' and students' spiritual well-being. Journal of Beliefs \& Values, 29(3), 253-261.

Fisher, J.W. (2009). Investigating Australian education students' views about spiritual well-being and comparing them with teachers in schools. International Journal of Children's Spirituality, 14(2), 151-167.

Hill, B.V. (2004). Exploring religion in school: A national priority. Adelaide, SA: Open Book Publishers.

Hill, P.C., Pargament, K.I., Hood, R.W., McCullough, J.P., Swyers, D.B., Larson, D.B. \& Zinnbauer, B.J. (2000). Conceptualizing religion and spirituality: Points of commonality, points of departure. Journal for the Theory of Social Behavior, 30(1), 51-77.

Ministerial Council on Education, Employment, Training and Youth Affairs (MCEETYA) (2008). Melbourne Declaration on educational goals for young Australians. 5 December. Melbourne: MCEETYA.

Office For Standards in Education (1994). Spiritual, Moral, Social and Cultural Development - An OFSTED Discussion Paper. London: OFSTED.

Wolf, J.T. (2004). Teach, but don't preach: Practical guidelines for addressing spiritual concerns of students. Professional School Counselling, 7(5), 363-366. 


\subsection{Comparing pre-service teachers' spiritual well-being in Hong Kong and}

\section{Australia}

\section{Background}

Following discussions with Dr Wong Ping Ho at several International Conferences on Children's Spirituality, I eventually visited the Hong Kong Institute of Education in 2009 and became involved in the Centre for Religious and Spirituality Education there as an Honorary Senior Research Fellow. I presented papers and contributed as a researcher and supervisor of graduate student projects from 2010. This paper is one product of that research. I worked with Chinese colleagues to check the accuracy of the back-translation of my SHALOM instrument. A modified list of activities and people designed to help enhance university students' spiritual well-being from that employed in my previous studies with university students was investigated here. Ping Ho collected the data. I analysed the data and wrote the report, with comments being made by Wong Ping Ho. Attribution of authorship is shared evenly on this paper.

\section{Key points extracted from the paper}

- This is the first reported use of a Chinese translation of my spiritual well-being questionnaire called SHALOM. Sound psychometric data are provided in this study.

- In comparison with pre-service teachers in Hong Kong, those from the University of Ballarat reported higher levels of lived experience in relating with themselves (Personal SWB) and other people (Communal SWB). In contrast, the Hong Kong students reported higher lived experience in relating with the environment (Environmental SWB) and with God (Transcendental SWB).

- Similar sources of help were found to enhance the spiritual well-being of preservice teachers in Hong Kong and Ballarat. For example, positive affect 'being happy' helps Personal and Communal SWB. Significant help for Personal SWB is also reported from 'self-improvement', whereas 'helping others' enhances Communal SWB. 'Nature' explains greatest variance in Environmental SWB, with 'prayer' playing a major role in helping enhance Transcendental SWB. 


\section{Implications}

SHALOM appears to be a suitable instrument for future use in studies of spiritual wellbeing among Chinese people.

The fact that there are more similarities than differences between the Hong Kong and Ballarat cohorts emphasises the general applicability of SHALOM for assessing spiritual well-being cross-culturally.

Since low levels of relationship with God were reported by the secular pre-service teachers in Ballarat, there is little likelihood that these pre-service teachers will influence school students positively in relating with God. Their secular views might, however, make it more difficult for school students who are religious to feel free to express their views to these teachers in their classrooms.

The stronger relationship with God reported by the Hong Kong pre-service teachers may appear surprising in an Eastern country (now governed by Communists). However, the influence of the remaining Anglican and Catholic churches in Hong Kong holds sway over many of these pre-service teachers, many of whom aspire to teach in religious schools in Hong Kong.

\section{Paper:}

This paper was published as: Fisher, J.W. \& Wong, P.H. (2013) Comparing helps for spiritual well-being among pre-service teachers in Hong Kong and Australia. Religious Education Journal of Australia, 29(1): 34-40.

\section{Comparing levels of spiritual well-being and support among pre-service teachers in Hong Kong and Australia.}

Dr John W Fisher

Honorary Senior Research Fellow, School of Education \& Arts, University of Ballarat, Victoria, Australia

Email: j.fisher@ballarat.edu.au (corresponding author)

Associate Professor Ping Ho Wong

Director, Centre for Religious \& Spirituality Education, Hong Kong Institute of Education, Hong Kong

Email: phwong@ied.edu.hk 


\begin{abstract}
A Chinese version of the Spiritual Health And Life-Orientation Measure (SHALOM) developed in this study was shown to be a sound measure of spiritual well-being (SWB) in which 573 pre-service teachers from Hong Kong reported slightly lower levels of relating with themselves and other people, in Personal and Communal SWB, but higher levels of Environmental and Transcendental SWB compared with a group of 557 similar pre-service teachers at the University of Ballarat, Australia.

Using regression analyses, investigation of the relationships between levels of spiritual well-being and helps revealed very similar results in explaining variance for each of the four domains, as well as overall spiritual well-being, for these two groups. Prayer, nature and being happy contributed most to explanation of variance in spiritual well-being in both groups; helping others, friends, self-improvement, music, walks and other religious activities contributed variously as well. Common principles undergirded support provided for both groups of pre-service teachers' spiritual well-being. It was just a matter of degree as to how much they applied. SHALOM revealed more similarities than differences in spiritual well-being in these two groups of pre-service teachers, even though they were separated culturally and linguistically. These results do, however, raise questions about the efficacy of these pre-service teachers to adequately address school students' spiritual well-being.
\end{abstract}

Key words: spiritual well-being; SHALOM; pre-service teachers

\title{
Introduction
}

Many recent studies of spirituality among higher education students do not specifically mention teacher education. They do, however, point to increasing interest and involvement of tertiary students and staff investigating spiritual aspects for a balanced foundation of life (Palmer, 1998; Nash, 1999; Kazanjian \& Laurence, 2000; Hindman, 2002; Bradley \& Kauanui, 2003; Alexander, 2005; Chickering et al., 2006; Astin et al., 2011). For school and university students, understanding "the moral and spiritual ideals of eastern and western philosophers ... may offer valuable life lessons" in helping "society realise some fundamental links all humanity share in their worldviews on spirituality, morality and learning" (Baker, 2008, p.63). This view concurs with that previously expressed by de Souza (2001), Astin (2004), Buchanan \& Hyde (2008) about the complementarity of cognitive, affective and spiritual dimensions of learning. However, in contrast to 20 years ago, Astin (1998) asserts that university students are now less likely to develop a meaningful philosophy of life, thus nurturing a spiritual interior, because they have traded it for a focus on a material exterior. This is not surprising because modern-day universities are limiting liberal arts education, including focus on morals and character development, as they have shifted to become economically-driven bureaucracies seeking 'truth' through scientific endeavours, where "educating students...for a life of service and civic engagement became, at best, a secondary emphasis" (Murphy, 2005, p.25).

Back in 1967, lecturers in Colleges of Education in the UK wrestled with the implications of the 1944 Education Act, especially as it related to "the relevance of religion and the essential character of the Christian understanding of it, [and] the 
unpreparedness of [teacher education] students" (Dale, 1967, p.8). The title of Dale's paper shows that he had embraced religion as the 'spiritual dynamic for teacher education.' This view of equating spirituality with religion has prevailed for two millennia in Christian traditions (Poe, 2005). However, contemporary views of spirituality range from its equivalence with religion (Kuh \& Gonyea, 2006), through an understanding that there are similarities but also differences between the two constructs (Bainbridge, 2000, Johnson et al., 2004; Gilley, 2005), to views that spirituality can be expressed through religion (Emmons, 2006) or without it (Newby, 1996; Estanek, 2006). This diversity of views on spirituality provides challenges for people who are responsible for including it, as part of holistic education of students, at school and university level (Capeheart-Meningall, 2005; Schreiner, 2009). Nash passionately believes, "that the opportunity for professional educators (and their students as well) to confront the spiritual dimension of their lives in a formal classroom setting is an idea whose time has finally come in teacher education programs" (2001, p.18).

Spirituality per se is metaphysical. However, that which exists at the core of a person being human can outwork its effect on the physical person. In this paper, spiritual well-being is taken to be a reflection of the underlying state of spiritual health of each person, which is revealed by the extent to which people live in harmony within relationships in up to four domains, namely with self, with others, with the environment, and/or with a Transcendent Other (Fisher, 2011).

Challenges also exist when it comes to assessing spirituality and well-being. Literature searches have revealed nearly 200 spirituality and well-being measures, more than a quarter of which have been employed in studies with tertiary students (Fisher, 2009). There are only four reported instruments, that have been progressively developed, which provide a balance across the four domains of spiritual well-being mentioned above (ibid.). The most frequently used of these is the spiritual well-being questionnaire (SWBQ) called the Spiritual Health And Life-Orientation Measure (SHALOM), which has been reported in studies with pre-service teachers, other university students and staff (Fisher, 2010). In a recent survey of available instruments, this SWBQ/SHALOM was described as the most promising (Meezenbroek et al., 2012). Therefore, the authors decided to build on this base by using SHALOM for the study reported here.

The questions that underpinned this project were "How do levels of spiritual wellbeing compare between pre-service teachers in secular universities in Hong Kong and Australia?" and "What supports/helps in their development?"

\section{Method}

The participants in this study were convenience samples from the organisations to which the authors belong. Ethics approvals were sought and gained from the Hong Kong Institute of Education (HK) and the University of Ballarat, Victoria, Australia (UB). Preservice teachers in each organisation were invited to respond to a written survey, which took about fifteen minutes to complete at the end of lectures.

The survey elicited demographic and descriptive data from participants, including age, gender, year and type of course, educational setting, religious affiliation, frequency of prayer, importance of religion and spirituality. Participants were also asked to indicate how much nominated factors helped to build up their spiritual well-being. Items were 
scored on a 5-point Likert scale ( $1=$ very low to $5=$ very high). SHALOM (2010) was used to investigate the quality of relationships that these pre-service teachers reported with themselves (Personal SWB), with other people (Communal SWB), with the environment (Environmental SWB) and with God (Transcendental SWB). SHALOM comprises 20 items, with five in each of four domains of spiritual well-being, scored on the same 5-point Likert scale as above. Domain scores were calculated by taking the mean value of responses on each 5-item set. All calculations in this study were performed using SPSS for Windows Version 19.

\section{Results}

Participants

\section{Demographic data}

The similarly sized groups $(\mathrm{HK}, \mathrm{n}=573$, UB, $\mathrm{n}=557)$ contained identical distribution by gender (77\% female, $23 \%$ male) and similar percentages of first year students in each group (47\% in HK, 45\% in UB). However, a sizable post-graduate cohort in Hong Kong made that group older (Pearson $\mathrm{Chi}^{2}(3,1127)=51.3, \mathrm{p}<.001$, Cramer's V=.21). There were fewer future secondary than primary school teachers in each group, as well as Kindergarten pre-service teachers in the Hong Kong cohort only (Pearson $\mathrm{Chi}^{2}(2$, $1128)=151, \mathrm{p}<.001$, Cramer's $\mathrm{V}=.36$ ). There were similar distributions in major subject areas with key differences being provision of Chinese in Hong Kong and more respondents studying Health \& Physical Education in the University of Ballarat. Overall, these two groups were quite evenly matched.

\section{Religious group affiliation, activities and prayer}

As these were secular universities, similar low numbers claimed religious affiliation in the two groups $(\mathrm{HK}=38 \%, \mathrm{UB}=41 \%)$, with more Christian/Protestants in the HK group (32\% compared with $18 \%$ in UB) and a higher percentage of Catholics in the UB group (21\% compared with $3 \%$ in $\mathrm{HK}$ ), with similarly low percentage of other religions (mainly Buddhism with some Taoism; $1.9 \%$ in HK, $1.3 \%$ in UB) (Pearson $\mathrm{Chi}^{2}(3,1127)=95$, $\mathrm{p}<.001$, Cramer's $\mathrm{V}=.28)$. HK pre-service teachers participated in religious activities more often than those in UB (Pearson $\mathrm{Chi}^{2}(3,1127)=118, \mathrm{p}<.001$, Cramer's V=.31). In line with this difference in religious activity, pre-service teachers in $\mathrm{HK}$ also reported higher frequency of praying (Pearson $\mathrm{Chi}^{2}(5,845)=94.5, \mathrm{p}<.001$, Cramer's $\mathrm{V}=.33$ ).

\section{Importance of spirituality and religion}

Spirituality was of greater importance than religion for pre-service teachers in both HK and UB. This finding is in-line with recent research from USA, which has shown that students' religious engagement declines during college, but they also actively engage in a spiritual quest (Astin et al., 2011). Spirituality and religion were both rated of greater importance by the HK cohort, in comparison with $\mathrm{UB}\left(\mathrm{t}_{\text {spir }}=11.6, \mathrm{p}<.001 ; \mathrm{t}_{\text {relig }}=7.3\right.$, $\mathrm{p}<.001)$. 


\section{SHALOM Instrument}

This is the first report of a Chinese version of SHALOM. Following translation into Chinese, it was back-translated into English, then checked against the original English version. The 20 items of the SHALOM scale were subjected to principal components analysis (PCA) using SPSS Version 19. Prior to performing PCA, the suitability of data for factor analyses was assessed. Inspection of the correlation matrices revealed that all coefficients were above .3 for each item in both groups. The Kaiser-Meyer-Olkin (KMO) value was .92 for the HK cohort and .90 for the UB group, which exceeded the recommended value of .6 (Kaiser, 1974), and Bartlett's tests of Sphericity (1954) reached statistical significance, supporting the factorability of the correlation matrices.

Principal components analyses revealed the presence of three components with eigen values exceeding 1, explaining $37.7 \%, 16.5 \%$ and $8.8 \%$ of variance respectively in the HK group and $31.4 \%, 20 \%$ and $9.3 \%$ of variance in the UB group. As teaching is a people-oriented profession, it was not surprising to find that the Personal and Communal SWB items coalesced to form the major factor, revealing close links between relationships with self and others in both cohorts. However, PCA of the 5-item sets, showed that they loaded satisfactorily onto single factors, with KMO values ranging from .79 to .91 .

Table 1. Levels of lived experience in four domains of spiritual well-being among preservice teachers

\begin{tabular}{l|llll}
\hline & \multicolumn{4}{|c}{ Four domains of spiritual well-being } \\
\hline uni & Personal & Communal & Environmental & Transcendental \\
\hline HK (573) & $3.95(.64)$ & $4.05(.60)$ & $3.46(.71)$ & $2.95(1.11)$ \\
UB (557) & $4.09(.67)$ & $4.28(.60)$ & $3.26(.83)$ & $2.56(1.12)$ \\
\hline t (all p<.001) & -3.59 & -6.44 & 4.36 & 5.88 \\
Cohen's d & .21 & .38 & .26 & .36 \\
\hline
\end{tabular}

Levels of spiritual well-being

The domain scores revealed that the UB pre-service teachers reported higher levels of lived experience for both Personal and Communal SWB, whereas the HK cohort reported higher lived experiences for Environmental and Transcendental SWB (see Table $1)$.

Although t-tests revealed significant differences on the four domains $(\mathrm{p}<.001)$, Cohen's d showed that effect size was only small (.2) to less than medium (.5) (Cohen, 1988). 


\section{Variations by gender}

The UB females outscored their male counterparts on Personal SWB ( $\mathrm{F}=4.15, \mathrm{M}=3.87$, $\mathrm{t}(635)=4.44, \mathrm{p}<.001)$ and Communal SWB $(\mathrm{F}=4.35, \mathrm{M}=4.09, \mathrm{t}(635)=4.64, \mathrm{p}<.001)$, whereas females in HK reported similar levels of SWB to their male colleagues. Both these groups vary markedly from a cohort of American college students in whom the women 'experience a strong spiritual relational component to their religious faiths' (Buchko, 2004), which corresponds to a gender variation in Transcendental SWB.

\section{Course specialisation}

In the HK group, students who aspire to be RE teachers scored higher on Transcendental SWB as would be expected, because the focus of Religious Education involves relationship with God.

\section{Religious activities}

All except the Communal SWB were significantly improved by participation in religious activities among the HK group. However, only Transcendental SWB increased with more religious activities at $\mathrm{UB}$.

\section{Frequency of prayer}

As for religious activities, Communal SWB was the only one of the four domains not to benefit from prayer in HK. However, at UB, each of the four domains of SWB were significantly lower among those who never pray or only pray when they need to.

\section{Levels of support/help to build up spiritual well-being}

A study with Christian college students in the USA found that peer relationships had greatest influence on their spiritual formation, of the variables investigated (Ma, 2003). Ma suggested that future studies should also include sport, counselling, church involvement and family support. In the studies reported here, high levels of support for building SWB were claimed from four help factors, with HK having a slight edge over UB on being happy and timeout (work-life balance). Being happy provided more help than friends for the spiritual well-being of both groups. Time-out was more important than friends for the HK group, but of less importance for those at UB. Friends, however, were more influential than family and other factors listed by Ma (see Table 2).

Moderate to high levels of support/help for SWB were reported from selfimprovement, helping others, music, walks, nature and sport, with the HK group scoring markedly higher than UB on nature, self-improvement and walks. Low levels of support/help for SWB were indicated from meditation, religious activities and counselling, with HK scoring higher than UB, in keeping with greater religious affiliation and activity reported by these students. Drawing and handicraft, which were only assessed for the HK group, were rated low in help by them. Even lower levels of support for SWB were indicated from religious helps of scripture and pastor, with HK again scoring significantly higher than UB. Tai Chi and ancestor worship were rated lowest by the HK pre-service teachers, indicating some departure from traditional Eastern beliefs. 


\section{Discussion}

The two groups of pre-service teachers in Hong Kong and University of Ballarat were of similar size. The main differences were the post-graduate cohort, hence older sample, together with some Kindergarten pre-service teachers in the Hong Kong group.

An investigation of four domains of spiritual well-being, using SHALOM, revealed that the UB students reported values that were statistically higher for Personal and Communal SWB, although all scores were rated high by both groups, and Cohen's $\mathrm{d}$ scores indicated only small effect size. It would be valuable to further investigate these groups to see if differences in personality, such as extraversion, could account for this variation in reported levels of SWB (Fisher, 2002). As these are self-reported scores, comparison of third party observations of these pre-service teachers would also be worthwhile, to see how well the self-reports matched other people's views of their SWB.

Table 2. Independent t-tests of sources of support/helps for building SWB

\begin{tabular}{l|ll|ll|l}
\hline helps & HK & UB & $\mathrm{t}$ & sig & Cohen's d \\
\hline happy & $4.44(.74)$ & $4.28(1.02)$ & -3.06 & .002 & .18 \\
timeout & $4.24(.85)$ & $3.86(1.15)$ & -6.30 & $<.001$ & .38 \\
friends & $4.11(.83)$ & $4.14(1.07)$ & .53 & $.60 \mathrm{~ns}$ & .03 \\
family & $3.95(1.04)$ & $4.11(.83)$ & 2.85 & .004 & .17 \\
\hline self-improvement & $3.89(.91)$ & $3.48(1.11)$ & -6.80 & $<.001$ & .40 \\
help others & $3.81(.94)$ & $3.68(1.07)$ & -2.21 & .027 & .13 \\
music & $3.94(.95)$ & $3.64(1.21)$ & -4.60 & $<.001$ & .28 \\
walks & $3.68(.98)$ & $3.30(1.20)$ & -5.78 & $<.001$ & .35 \\
nature & $3.84(1.03)$ & $3.06(1.24)$ & -11.3 & $<.001$ & .68 \\
sport & $3.52(1.10)$ & $3.20(1.39)$ & -4.22 & $<.001$ & .26 \\
\hline meditation & $3.41(1.05)$ & $2.34(1.30)$ & -15.1 & $<.001$ & .91 \\
prayer & $3.01(1.41)$ & $2.16(1.46)$ & -9.94 & $<.001$ & .59 \\
religious activity & $2.67(1.31)$ & $1.93(1.34)$ & -9.34 & $<.001$ & .56 \\
counselling & $3.16(1.13)$ & $1.87(1.15)$ & -18.9 & $<.001$ & 1.13 \\
drawing & $2.96(1.18)$ & & & & \\
handicraft & $2.72(1.19)$ & & & & .63 \\
\hline scripture & $2.49(1.30)$ & $1.69(1.25)$ & -10.4 & $<.001$ & .63 \\
pastor & $2.34(1.19)$ & $1.58(1.11)$ & -11.0 & $<.001$ & .66 \\
Tai Chi & $2.26(1.14)$ & & & & \\
worship ancestor & $2.15(1.07)$ & & & & \\
\hline & & & & & \\
\hline
\end{tabular}


In keeping with their report of greater participation in religious activities, the Hong Kong pre-service teachers slightly outscored their UB counterparts on the lived experience of relating with God (Transcendental SWB). The Hong Kong cohort also scored higher than the University of Ballarat cohort on Environmental SWB, at moderately high levels. There appears to be a clear cause for the variations in Transcendental SWB, but further study would be warranted to ascertain underlying causes for differences in the Environmental domain. For example, is there a cultural variation worthy of attention?

Despite the reported differences on levels of lived experience in four domains of SWB, the Hong Kong pre-service teachers reported levels of support for building up SWB that were consistently higher on fourteen of the factors investigated here.

Participants' responses were based on how they perceived the nominated factors helped to build SWB in general. However, closer inspection of influences on individual domains of SWB revealed very similar patterns in both groups. These analyses were performed using linear multiple regression analyses of factors, which correlated greater than .23 with the SWB domain score in question. This correlation value, which is slightly lower than the 3 value indicative of moderate correlation (Cohen, 1988, p.79), was chosen to yield six initial factors for entry into each of the regression analyses:

Helps for developing SWB

The positive affect, being happy (Diener et al., 1999), appeared to be a prominent influence on both Personal and Communal SWB in both groups of pre-service teachers. Self-improvement also contributed positively in explaining variance on Personal SWB, whereas helping others helped explain variance in Communal SWB for both groups. The sole, strong influence on the Environmental domain of SWB was attributed to nature in both groups. The marked influence of prayer, with lesser help from scripture and religious activities contributed to explanation of variance in Transcendental SWB for both groups, to a similar extent. These religious influences appropriately helped to build up relationship with God, for some of the pre-service teachers.

Spiritual well-being

Similar patterns of help were seen in the two groups for development of spiritual wellbeing, in four domains studied here. However, these four domains cohere into a single higher order factor, called spiritual well-being (KMO \& \% variances were .69 \& 59.2\% for HK, .65 \&55\% for UB) (Fisher, 2012). So, linear, multiple regression analyses were performed on SWB, revealing that, of the nominated 20 helps, prayer and nature explained greatest variance, for both groups of pre-service teachers. Being happy was another common contributor to explanation of variance in SWB. Additional variance in SWB was explained by three factors in the HK group and two in the UB group (see Table $3)$.

It may seem strange that perceived helps with high mean values did not contribute significantly to variance in domains of SWB. This might be expected, as the domains of SWB may also have high scores. However, if most people rate a domain of SWB highly, while showing wide-ranging values on help scores, there is little correlation between the 
two. For example, these pre-service teachers obviously think that friends contribute meaningfully to their spiritual well-being, presumably in relating with other people, for Communal SWB.

Correlations show the strength of relationship between variables. In this case, mean values for help from friends were both high $(\mathrm{HK}=4.11, \mathrm{UB}=4.14)$ and Communal SWB scores were also high $(\mathrm{HK}=4.05, \mathrm{UB}=4.28)$. But, correlations between these two variables were not as strong as might be expected $(\mathrm{HK}=.27, \mathrm{UB}=.25)$. In keeping with these low correlation values, regression analyses revealed that friends did not feature as significant contributors to explaining variance in Communal SWB. Friends may contribute to some other aspect of well-being, such as social or emotional well-being, but they were not shown to be significant for spiritual well-being in this study.

Table 3. Regression analyses of helps for Spiritual Well-Being ( $\beta$-values shown)

\begin{tabular}{|c|c|c|}
\hline & \multicolumn{2}{|c|}{ uni } \\
\hline Helps & HK & UB \\
\hline $\mathrm{R}$ & .35 & .41 \\
\hline $\mathrm{F}$ & $49.9 * * *$ & $72.2^{* * *}$ \\
\hline Prayer & $.34 * * *$ & $.30 * * *$ \\
\hline Nature & $.19 * * *$ & $.26 * * *$ \\
\hline being happy & $.10 * *$ & $.17 * * *$ \\
\hline religious activities & $.13^{* *}$ & \\
\hline self-improvement & $.12 * *$ & \\
\hline Walks & $.10^{* *}$ & \\
\hline Scripture & & $.18 * * *$ \\
\hline Helping others & & $.09 *$ \\
\hline
\end{tabular}

The $\mathrm{R}^{2}$ values indicate how much of the variance in the dependent variables is explained by the models presented. It is clear that other factors, as yet undetermined, must influence the development of spiritual well-being, as only 15 to $57 \%$ of variance has been accounted for in the four domains and SWB overall in this study. Further investigation is needed to seek out these factors.

\section{Conclusion}

Four domains of spiritual well-being were investigated among pre-service teachers from Hong Kong and the University of Ballarat, Australia, using the Spiritual Health And LifeOrientation Measure. The Australians reported slightly higher levels of lived experience in relating with themselves (Personal SWB) and other people (Communal SWB), whereas 
those from Hong Kong showed higher levels of lived experience in relating with the environment (Environmental SWB) and with God (Transcendental SWB). The Hong Kong pre-service teachers also claimed greater support from several nominated helps for building up their spiritual well-being in general. Although statistical differences were observed in the raw scores for levels of SWB, as well as helps for building SWB, the scores were of the same order of magnitude, with mainly the religious helps showing noticeable differences.

Investigation of the relationships between levels of SWB and helps, using regression analyses, revealed very similar results in explaining variance for each of four domains of SWB and overall spiritual well-being for these two groups. Even though these pre-service teachers do not study religion in their secular institutions, prayer played the major role in explaining variance in their spiritual well-being. Nature and being happy also contributed to explanation of variance in SWB in both groups; scripture, religious activities, self-improvement, walks and helping others contributed variously as well.

Common principles undergirded support provided for both groups of pre-service teachers' SWB. It was just a matter of degree as to how much they applied. SHALOM revealed more similarities than differences in spiritual well-being in these two groups of pre-service teachers, even though they were separated culturally and linguistically. These pre-service teachers reported good relationships with themselves, other people and the environment, but only low levels of relationship with God. This is not surprising as they were at secular institutions. However, these findings have implications for the impact that these pre-service teachers are likely to have on the spiritual well-being of students in schools. Previous research has shown that teachers' lived experience has greatest impact on their perceptions of help provided by schools for students' spiritual well-being (Fisher, 2008). In other words, how they live is what they give in terms of help for students' spiritual well-being.

\section{Acknowledgements}

The Hong Kong part of the research reported here was supported by an Internal Research Grant from the Hong Kong Institute of Education. The assistance of Dr Rainbow Ho and Dr Jacob Lung was also appreciated in Hong Kong.

\section{Notes on Contributors:}

Dr John Fisher has expertise in teaching and research in science, education, sociology, psychology, religious studies and health education. John is currently completing his third doctorate in spiritual health and well-being.

Dr Wong Ping Ho is an Associate Professor of the Department of International Education and Lifelong Learning, in Hong Kong Institute of Education, and also serves as Director of the Institute's Centre for Religious and Spirituality Education.

\section{References}

Alexander, P.H. (2005). Professor as leader of students' faith development. $\mathrm{PhD}$ dissertation, Regent University, Virginia, USA. 
Astin, A.W. (1998). The changing American college student: Thirty-year trends, 19661996. The Review of Higher Education, 21(2), 115-135.

Astin, A.W. (2004). Why spirituality deserves a place in liberal education. Liberal Education, 90(2), 34-41.

Astin, A.W., Astin, H.S. \& Lindholm, J.A. (2011). Cultivating the spirit: How college can enhance students' inner lives. San Francisco: Jossey-Bass.

Bainbridge, R.M. (2000). The spiritual and the intending teacher. International Journal of Children's Spirituality, 5(2), 163-175.

Baker, A. (2008). A new educational philosophy; Building bridges in young minds. Teacher, (Dec.), 62-3.

Bartlett, M.S. (1954). A note on the multiplying factors for various chi square approximations. Journal of the Royal Statistical Society, 16 (Series B), 296-8

Bradley, J. \& Kauanui, S.K. (2003). Comparing spirituality on three southern California college campuses. Journal of Organizational Change Management, 16(4), 448-462.

Buchanan, M. \& Hyde, B. (2008). Learning beyond the surface: Engaging the cognitive, affective and spiritual dimensions within the curriculum. International Journal of Children's Spirituality, 13(4), 309-20.

Buchko, K. (2004). Religious beliefs and practices of college women as compared to college men. Journal of College Student Development, 45, 89-98.

Capeheart-Meningall, J. (2005). Role of spirituality and spiritual development in student life outside the classroom. New Directions for Teaching and Learning, 104, 31-6.

Chickering, A.W., Dalton, J.C. \& Stamm, L. (2006). Encouraging authenticity and spirituality in higher education. San Francisco: Jossey-Bass.

Cohen, J.W. (1988). Statistical power analysis for the behavioural sciences $\left(2^{\text {nd }} \mathrm{edn}\right)$. Hillsdale, NJ: Lawrence Erlbaum Associates.

Dale, A. (1967). A spiritual dynamic for teacher education. Learning for Living, 7(1), 812.

de Souza, M. (2001). Addressing the spiritual dimension in education: Teaching affectively to promote cognition. Journal of Religious Education, 49(3), 31-41.

Diener, E., Suh, E.M., Lucas, R.E. \& Smith, H.L. (1999). Subjective well-being. Three decades of progress. Psychological Bulletin, 125, 276-302.

Emmons, R.A. (2006). Spirituality: Recent progress. In M. Csikszentmihalyi (ed.). Lifeworth living: Contributions to positive psychology, (pp. 62-81). Cary, NC, USA: Oxford University Press. 
Estanek, S.M. (2006). Redefining spirituality: A new discourse. College Student Journal, 40(2), 270-281.

Fisher, J.W. (2008) Impacting teachers' and students' spiritual well-being. Journal of Beliefs \& Values, 29(3), 253-261.

Fisher, J.W. (2009) Reaching the heart: Assessing and nurturing spiritual well-being via education. EdD dissertation, University of Ballarat, Victoria, Australia. Availableat $\underline{\text { http://archimedes.ballarat.edu.au:8080/vital/access/HandleResolver/ 1959.17/13481 }}$

Fisher, J. (2010) Development and application of a spiritual well-being questionnaire called SHALOM. Religions, 1, 105-121.

Fisher, J. (2011) The Four Domains Model: Connecting spirituality, health and wellbeing. Religions, 2, 17-28.

Fisher, J.W. (2012). The importance of relating with God for spiritual well-being. In M. Weiss \& M. Fowler (Eds.), Spirituality: New reflections on theory, praxis \& pedagogy (pp.147-161). Oxford, UK: InterDisciplinary Press.

Fisher, J.W., Francis, L.J. \& Johnson, P. (2002). The personal and social correlates of spiritual well-being among primary school teachers. Pastoral Psychology, 51(1), 3-11.

Gilley, D. V. (2005). Whose spirituality? Cautionary notes about the role of spirituality in higher education. New Directions for Teaching and Learning, 104, 93-9.

Hindman, D.M. (2002). From splintered lives to whole persons: Facilitating spiritual development in college students. Religious Education, 97(2), 165-182.

Johnson, T.J., Kristeller, J. \& Sheets, V.L. (2004). Religiousness and spirituality in college students: Separate dimensions with unique and common correlates.Proceedings of the Institute on College Student Values: Soul searching: Trendsand patterns in college student spirituality. Florida State University, Tallahassee, Florida. https://characterclearinghouse.fsu.edu/files/pdf/2004InstituteProceedings/Institute_2004 Johnson_Kristeller_Sheets.pdf

Kaiser, H. (1974). An index of factorial simplicity. Psychometrika, 39, 31-6.

Kazanjian, V.H. \& Laurence, P.L. (Eds.). (2000). Education as transformation: Religious pluralism, spirituality, and a new vision for higher education in America. New York: Peter Lang.

Kuh, G.D. \& Gonyea, R.M. (2006). Spirituality, liberal learning, and college student engagement. Liberal Education, 92(1), 40-7.

Ma, S. (2003). The Christian college experience and the development of spiritualityamong students. Christian Higher Education, 2(4), 321-339.

Meezenbroek, E.deJ., Garssen, B., van den Berg, M. van Dierendonck, D., et al. (2012). Measuring spirituality as a universal human experience: A review of spirituality questionnaires. Journal of Religion \& Health, 51(2), 336-354. 
Murphy, C. (2005). The academy, spirituality, and the search for truth. New Directions for Teaching and Learning, 104, 23-9.

Nash, R.J. (1999). Faith, hype, and clarity: Teaching about religion in American schools and colleges. New York: Teachers College Press.

Nash, R.J. (2001). Constructing a spirituality of teaching: A personal perspective.Religion and Education, 28(1), 1-20.

Newby, M. (1996). Towards a secular concept of spiritual maturity. In R. Best (Ed.). Education, Spirituality and the Whole Child, (pp.93-107). London: Cassell.

Palmer, P. (1998). The courage to teach. San Francisco: Jossey-Bass.

Poe, H.L. (2005). Issues related to spirituality and the search for truth in sectarian institutions of higher education. New Directions for Teaching and Learning, 104, 59-66.

Schreiner, P. (2009). Holistic education and teacher training. In Me. De Souza et al.(Eds.). International handbook of education for Spirituality, Care and Wellbeing, International handbooks of religion and education 3 (pp. 753-770). Dordrecht: Springer.

\subsection{Spiritual well-being among Divinity and Religious Education students in Turkey}

\section{Background}

One of the first requests I received from researchers to use my SHALOM spiritual wellbeing questionnaire came from a university staff member in Turkey (Dr Kamil Coskun). I worked with him through the translation, back-translation and checking of the Turkish version of SHALOM as has happened since with other languages. Similar questions related to help for the development of university students' SWB were used as in the other two papers in this chapter. Kamil collected the data. I analysed the data and wrote the paper, with comments being added by the co-author, Dr Kamil Coskun. Each author is attributed equal share in this paper.

\section{Key points extracted from this paper}

- In keeping with previous studies using SHALOM, the university students' stated ideals for SWB were found to underpin their lived experiences in four domains of SWB. 
- Only slight differences were found by gender, with females scoring higher than males on ideals, as well as on lived experiences for Personal and Environmental SWB.

- Relating with God significantly influenced other aspects of the students' SWB, namely Personal and Environmental SWB.

- Highly religious students tended to over-state the influence of religiosity (e.g., prayer and scripture) on their SWB.

- Universities provided small, yet significant, support for these students' SWB.

- There were many similarities, but also significant differences, between the reported SWB of the Religious Education and Divinity students in Turkey.

- Contrary to previous studies, religion and spirituality were rated very highly in importance to life by the sample of RE and Divinity students, with religion being rated of higher importance than spirituality.

- A controversial finding was indicated that being Islamic was associated with significant negative effect on men's spirituality.

\section{Implications}

SHALOM generally contains two columns for assessing respondents' (i) stated ideals and (ii) lived experiences for SWB. Adding a third column to the SHALOM instrument was useful in helping universities to note the level of help that students reported being provided by the universities for the students' spiritual well-being. University staff should also monitor their own SWB and its effect on students.

As SHALOM provides a sound base for assessing and monitoring the SWB of university students in Turkey, a similar study within the wider Turkish community would be useful in order to see if the comparative importance of religion and spirituality holds in influencing one's SWB, as it does with these university students.

\section{Paper:}

This paper was published as: Fisher, J.W. \& Coskun, M.K. (2013) Investigating spiritual well-being among Divinity and Religious Education students in Turkey. Religious Education Journal of Australia, 29(2):21-28. 


\title{
Investigating spiritual well-being among Islamic Divinity and Religious Education students in Turkey.
}

Corresponding author: Dr John W Fisher,

School of Education \& Arts, University of Ballarat, PO Box 663, Ballarat 3353, Vic

Australia

Email: j.fisher@ballarat.edu.au

Co-author: Dr Mehmet Kamil Coşkun,

Faculty of Education, Mus Alparslan University, Turkey

Email: mk.coskun@alparslan.edu.tr

\begin{abstract}
In light of increased emphasis on universities being called to facilitate spiritual growth among students, the Spiritual Health And Life-Orientation Measure was used to assess four domains of spiritual well-being among 122 Divinity and 137 Religious Education students in Turkey. Students provided three responses to 20 items reflecting spiritual well-being, indicating their ideals for spiritual well-being, lived experience and how much university helped in each area. Another 16 potential factors were explored to help students develop their spiritual well-being, ranging from self-improvement to scripture. High scores on ideals for spiritual well-being, reported by both groups of students, underpin the lived experiences of Religious Education \& Divinity students in each of four domains of spiritual well-being. Relating with God significantly influenced aspects of spiritual well-being but it appears that the highly religious students overstate the influence of religious activities, such as prayer and scripture, on their spiritual well-being. Universities provide small yet significant support in developing the four domains of spiritual well-being for these students. Overall, this study has shown many similarities, yet some significant variations in spiritual well-being between these Divinity and Religious Education students in Turkey. This project provides a sound base from which future studies can be launched to review, enhance and monitor university students' spiritual well-being and to determine the influence of these students' spiritual well-being on the clients they will serve after graduating and gaining employment.
\end{abstract}

Keywords: spirituality; assessment; higher education

\section{Notes on contributors}

Dr John W. Fisher is Hon. Senior Research Fellow in the School of Education \& Arts, University of Ballarat, Australia. John has twenty years' experience of research in spiritual health and well-being, incorporating health, psychological and religious aspects. He earned his PhD, University of Melbourne in 1998, his EdD, University of Ballarat in 2009 , and is completing another $\mathrm{PhD}$, University of Ballarat. 
Dr Mehmet Kamil Coşkun is Assistant Professor in the Faculty of Education, Department of Religious Culture \& Moral Knowledge Education at Mus Alparslan University, Turkey. Kamil gained his PhD, University of Ankara in 2005, with a dissertation entitled 'Secondary school students' understanding of the Qur'an.'

\section{Introduction}

There has been an emerging emphasis on universities, especially in America, to embrace spirituality of students and staff to bring emotions and spirit to their teaching, together with the intellect (Palmer, 1998), with calls to open dialogue on spirituality and religion in academia (Nash, 1999) and ideas for tertiary institutions to amplify their programs to encourage increased authenticity and spiritual growth (Chickering, Dalton and Stamm (2006). Astin, Astin and Lindholm (2011) have reported longitudinal research that showed a lessening in religiosity, but increase in spirituality among students in their time at American universities. Closer scrutiny of the place of spirituality in education has been called for in other countries (de Souza et al. (eds), 2009).

A person's spirituality lies at the heart of who they are as a human being (McCarroll, O'Connor \& Meakes, 2005). In an attempt to integrate divergent views which abound, Palmer described spirituality as 'the ancient and abiding human quest for connectedness with something larger and more trustworthy than our egos - with our own souls, with one another, with the worlds of history and nature, with the invisible winds of the spirit, with the mystery of being alive' $(1999$, p.6). As such, it is not surprising to note that spirituality has been shown to relate with health. In fact, it has been proposed that spiritual health is a, if not the, fundamental dimension of health that permeates and integrates all other dimensions, such as physical, mental, social and emotional health, as well as vocational health (Fisher, 1998, 2011). Spiritual health is a state of being, which is revealed in practice as spiritual well-being (SWB).

Several theoretical frameworks posit spirituality and spiritual well-being comprising four domains, which themselves are reflected in the quality of relationships that people have with themselves (Personal SWB), with others (Communal SWB), with the environment (Environmental SWB), and/or with a Transcendent Other (Transcendental SWB) (NICA, 1975; Hay \& Nye, 1998; Fisher, 1998). The Spiritual Health And Life-Orientation Measure (SHALOM) is a quantitative instrument designed to assess these four domains of spiritual well-being (Fisher, 2010). It has undergone extensive psychometric testing (Gomez \& Fisher, 2003) and has been sought for use in over 200 studies in 20 different languages (Fisher, 2010).

As each person embraces each of these four domains of SWB to varying extents, SHALOM provides domain scores for each of them, rather than taking an overall score for SWB. In fact, SHALOM goes one step further in that it elicits each person's ideals in each domain and compares these with each person's lived experience, so they become the standard against which their level of spiritual harmony or dissonance in assessed. The Islamic religion embraces three of these four dimensions to organize and adjust relationships that all human beings have. These are between God, humans and the 
Universe (environment) (e.g., Surah 2 verse 177 and Surah 88 verses 17-20, from the holy book Qur'an).

Previous studies have not only elicited scores for these four domains of SWB, they have also sought feedback from respondents on factors that they perceive help develop their own spiritual well-being (Fisher, Barnes \& Marks, 2009; Fisher \& Wong, 2013). This study reports on an investigation of spiritual well-being among Divinity and Religious Education students in universities in Turkey. The research questions thus became:

1. Is there any significant difference between SWB levels of Divinity and Religious Education students in each of four domains of SWB?

2. What kind of variables effect or support SWB levels of Divinity and Religious Education students in each domain? Are there any differences?

3. Is there any significant difference in levels of help that Divinity and Religious Education students receive from their institutions?

\section{Method}

\section{Participants}

Mainly senior students were randomly selected from Divinity and Religious Education faculties in five universities, situated in the East, West, North, South and centre of Turkey. Surveys were completed by 259 university students, comprised of 122 Divinity students and 137 Religious Education students, 187 of whom were female and 72 male; 26 were in first year, 5 in second year, 121 in third year and 107 in fourth year. The sample size is small considering students were recruited from five universities. Further investigation is warranted with larger numbers of students to see how representative this sample is of the whole.

\section{Instruments}

Spiritual well-being was assessed using SHALOM, a 20-item questionnaire that sought three responses for each item. The responses indicated the importance of each item for each respondent's 'ideals' and 'lived experience' for spiritual well-being, as well as the 'level of help' they believe they obtain from the university in each area, scored on a 6point Likert scale, from $0=$ not at all, to $5=$ very high. There were five items in each of four domains of spiritual well-being: those reflecting Personal SWB were sense of identity, self-awareness, joy in life, inner peace, meaning in life; for Communal SWB, they were love of other people, forgiveness toward others, trust between individuals, respect for others, kindness towards other people; for Environmental SWB, they were connection with nature, awe at a breathtaking view, oneness with nature, harmony with the environment, sense of 'magic' in the environment; for Transcendental SWB, they were personal relationship with the Divine/God, worship of the Creator, oneness with 
God, peace with God, prayer life. Domain scores were calculated by taking the mean value of responses to the five items in each domain.

A number of factors which help university students develop their spiritual well-being have been investigated in other studies (Fisher, Barnes \& Marks, 2009; Fisher \& Wong, 2013). Sixteen of these factors were selected to seek respondents' views. These factors were self-improvement, timeout, being happy, family, helping others, friends, walks, nature, music, meditation, sport, prayer, counseling, pastor, religious activity and scripture. Each of these factors was scored on a 5-point Likert scale from $1=$ very low to $5=$ very high, in terms of importance.

Demographic details were also sought regarding gender, course, year of study, how often students attend religious group or place, where they want to work after graduation, where they get religious knowledge, and their perception of family's economical status.

\section{Procedure}

Following approvals from the five universities, the heads of departments of Divinity and Religious Education conducted the surveys with the selected students. These surveys took place between 10 March and10 June 2011.

\section{Analyses}

SPSS for Windows version 19 was used to record frequencies and distribution of data in factors, cross-tabulations, calculation of means, independent and matched pairs t-tests, factor analyses and regression analyses, as appropriate.

\section{Results}

\section{Factor analysis of SHALOM}

The 20 items of the SHALOM scale were subjected to principal components analysis (PCA) using SPSS for Windows Version 19. Prior to performing PCA, the suitability of data for factor analysis was assessed. Inspection of the correlation matrix revealed many coefficients of 0.3 and above. The Kaiser-Meyer-Olkin value was 0.92 , exceeding the recommended minimum of 0.6 (Kaiser, 1974) and Bartlett's Test of Sphericity (Bartlett, 1954) reached statistical significance, supporting the factorisability of the correlation matrix.

PCA revealed the presence of four components with eigenvalues exceeding 1.0, explaining $43.0 \%, 8.3 \%, 6.0 \%$ and $5.7 \%$ of the variance respectively. The fourcomponent solution explained a total of $63 \%$ of the variance. These results support the four factor solution of SHALOM as has been shown in previous studies (Fisher 2010). 


\section{Research question 1. Spiritual well-being scores}

Variations by course

The Religious Education students reported significantly higher levels of lived experience than Divinity students for Personal, Communal and Transcendental SWB and almost reached significance for Environmental SWB as well. However Divinity students claimed they received greater help from university in relating with God, which is not reflected in their ideals, nor lived experience, of relating with God (see Table 1).

Matched pairs t-tests were used to compare the mean scores on two different categories for the same group of students. This technique revealed that the Divinity and Religious Education students' ideals for spiritual well-being were higher than their lived experience, in keeping with other studies (Fisher, Barnes \& Marks, 2009; Fisher \& Wong, 2013).

Lived experience was rated significantly higher than help from university on the four domains of SWB, for both groups.

Table 1. Levels of spiritual well-being among Turkish Divinity \& Religious Education students

\begin{tabular}{llllllllllll}
\hline \multirow{2}{*}{$\begin{array}{l}\text { Domain } \\
\text { of SWB }\end{array}$} & \multicolumn{3}{c}{ a. ideal } & \multicolumn{4}{c}{ category of SWB } \\
& Group & mean & SD & $\mathrm{t}^{\text {sig }}$ & mean & SD & $\mathrm{t}^{\text {sig }}$ & \multicolumn{3}{c}{ c. help from uni } \\
& Per & Div & 4.56 & .63 & $-.83^{\text {ns }}$ & 4.03 & .79 & $-2.01^{*}$ & 2.67 & 1.19 & $.90^{\text {ns }}$ \\
& RE & 4.62 & .55 & & 4.22 & .77 & & 2.54 & 1.19 & \\
\hline Com & Div & 4.44 & .61 & $-2.74^{* *}$ & 4.05 & .72 & $-3.09^{* *}$ & 2.74 & 1.19 & $1.37^{\text {ns }}$ \\
& RE & 4.63 & .49 & & 4.31 & .62 & & 2.55 & 1.07 & \\
\hline Env & Div & 4.18 & .77 & $-.87^{\text {ns }}$ & 3.88 & .76 & $-1.94^{\text {ns }}$ & 2.29 & 1.23 & $.46^{\text {ns }}$ \\
& RE & 4.26 & .76 & & 4.07 & .81 & & 2.22 & 1.18 & \\
\hline Tra & Div & 4.74 & .52 & $-1.31^{\text {ns }}$ & 4.22 & .77 & $-2.19^{*}$ & 2.93 & 1.25 & $2.40^{*}$ \\
& RE & 4.83 & .51 & & 4.43 & .75 & & 2.56 & 1.25 & \\
\hline
\end{tabular}

$* \mathrm{p}<.05 ; * * \mathrm{p}<.01 \quad$ Per $=$ Personal, Com $=$ Communal, Env $=$ Environmental, Tra $=$ Transcendental domains of SWB

It was interesting to note that none of the respondents selected the zero score option for any of the 20 items on ideals and lived experience for spiritual well-being. This was the first time that this choice had been made available using SHALOM. This is also the first report of students' perceived help from university being assessed using a third column in SHALOM.

Other variables, such as gender and background

Minor variations were observed by gender. Independent t-tests showed that the female students held higher ideals than the males in each of four domains of SWB $\left(t_{\text {per }}(259)=-\right.$ 
$\left.\left.3.99, \mathrm{p}<.001, \mathrm{t}_{\text {com }}(259)=-2.49, \mathrm{p}<.05, \mathrm{t}_{\text {env }}(259)=-2.64, \mathrm{p}<.05, \mathrm{t}_{\text {tra }}(259)=-3.21, \mathrm{p}<.01\right)\right)$. However, their lived experience was only slightly higher than the males in two of the domains of $\operatorname{SWB}\left(\mathrm{t}_{\mathrm{env}}(259)=-1.99, \mathrm{p}<.05, \mathrm{t}_{\mathrm{per}}(259)=-2.20, \mathrm{p}<.05\right)$.

Other demographic variables yielded no significant results on studies of SWB. These were year level, how often students attend religious groups or places, where they want to work after graduation, who provides their religious education and family's perceived economic status. These findings are not surprising as these two groups of students came from similar cultural and religious backgrounds. For example, $90 \%$ of them came from religious high schools that provide both science and basic religious knowledge.

\section{Research question 2. Helps for spiritual well-being}

The rank order of helps reported by the Divinity and Religious Education students is very similar, with the greatest help reported from religious influence of prayer and scripture (see Table 2). Family, helping others, being happy, friends and self-improvement were all scored highly, with mean values above 4.0 on scales from 1 to 5 .

Table 2. Levels of help for SWB among Turkish Divinity \& Religious Education students

\begin{tabular}{lll|lll}
\hline \multirow{2}{*}{ help } & \multicolumn{2}{c|}{ Group } & help & \multicolumn{2}{c}{ Group } \\
\cline { 2 - 3 } & Div & RE & & Div & RE \\
\hline prayer & 4.73 & 4.84 & counseling & 3.91 & 3.91 \\
scripture & 4.72 & 4.82 & religious activity & 3.80 & 4.15 \\
\hline family & 4.61 & 4.56 & time out & 3.74 & 3.69 \\
help others & 4.60 & 4.65 & pastor & 3.43 & 3.53 \\
\cline { 5 - 7 } be happy & 4.42 & 4.45 & walks & 3.11 & 3.23 \\
friends & 4.09 & 4.25 & music & 3.11 & 2.92 \\
self-improvement & 4.09 & 4.07 & sport & 2.56 & 2.45 \\
\hline nature & 3.97 & 3.97 & meditation & 1.82 & 1.72 \\
\hline
\end{tabular}

NB mean values are reported on a scale from 1-5.

Nature, counseling and religious activity, time out and pastor also appear to provide important help for these students' SWB. Walks and music are personal pursuits that are reported to have moderate influence on their SWB, with sport influencing some. The very low score for meditation is not surprising, because Muslims do not practice it. They find it unnecessary, as praying five times a day is sufficient religious practice. In Islam, praying means getting close to God with Muslims accepting mosques as God's home (Al-Shareef, 2001).

\section{Research questions 2 \&3. Analysis of helps for SWB among Divinity \& RE students}

Despite the high levels of importance attributed by students to many of the above factors, most of them did not correlate highly $(r>.50)$ with lived experience in the four domains of 
SWB. Only nature correlated highly $(\mathrm{r}=.56)$ with lived experience of Environmental SWB.

\section{Personal SWB}

'In hierarchical regression, independent variables are entered into the equation (in steps or blocks) in the order specified by the researcher on theoretical grounds. Each independent variable is assessed in terms of what it adds to the prediction of the dependent variable, after the previous variables have been controlled for' (Pallant, 2007, p.147). Hierarchical multiple regression was used here to assess contributions made to Personal SWB by gender and the helps listed above (at Step 1), perceived help from university (at Step 2), by other domains of lived experience (at Step 3) and ideals for Personal SWB (at Step 4).

Among Divinity students. Based on an inspection of correlation values, family, nature and religious activities were entered at Step1, explaining $22 \%$ of the variance in the lived experience of Personal SWB. The total variance explained by the final model was $59.2 \%$, $\mathrm{F}(8,113)=20.5, \mathrm{p}<.001$, with three control measures being statistically significant, namely relation with God (beta $=.35, \mathrm{p}<.001)$, ideals for Personal SWB (beta $=.22$, $\mathrm{p}<.01$ ) and help from university (beta $=.14, \mathrm{p}<.05$ ). Although relation with others showed a beta value of .18 , it just missed significance, with $\mathrm{p}=.054$.

Among RE students. Based on an inspection of independent t-tests and correlation values, gender, self-improvement and religious activities were entered at Step1, explaining 21\% of the variance in the lived experience of Personal SWB. The total variance explained by the final model was $78.7 \%, \mathrm{~F}(8,128)=59.1$, $\mathrm{p}<.001$, with five control measures being statistically significant, namely relation with God (beta $=.48, \mathrm{p}<.001)$, relation with others (beta $=.41, \mathrm{p}<.001)$, help from university (beta $=.12, \mathrm{p}<.01)$, ideals for Personal SWB (beta $=.12, \mathrm{p}<.05)$ and religious activities (beta $=-.12, \mathrm{p}<.05)$.

\section{Communal SWB}

Hierarchical multiple regression was used to assess contributions made to Communal SWB by the helps listed above (at Step 1), perceived help from university (at Step 2), by other domains of lived experience (at Step 3) and ideals for Communal SWB (at Step 4).

Among Divinity students. Based on an inspection of correlation values, family and helping others were entered at Step1, explaining $21 \%$ of the variance in the lived experience of Communal SWB. The total variance explained by the final model was $63.0 \%, \mathrm{~F}(7,114)=$ $27.8, \mathrm{p}<.001$, with five control measures being statistically significant, namely relation with environment (beta $=.36, \mathrm{p}<.001)$, relationship with self (beta $=.22, \mathrm{p}<.01$ ), ideals for Communal SWB (beta $=.22, \mathrm{p}<.01)$, help others (beta $=.15, \mathrm{p}<.05)$ and help from university (beta $=.13, \mathrm{p}<.05)$.

Among RE students. Based on an inspection of correlation values, help others and religious activities were entered at Step1, explaining $26 \%$ of the variance in the lived experience of Communal SWB. The total variance explained by the final model was 
$72.8 \%, \mathrm{~F}(7,129)=49.3, \mathrm{p}<.001$, with five control measures being statistically significant, namely relation with self (beta $=.47, \mathrm{p}<.001$ ), relation with environment (beta $=.21$, $\mathrm{p}<.01$ ), ideals for Communal SWB (beta $=.20, \mathrm{p}<.01$ ), religious activities (beta $=.14$, $\mathrm{p}<.05)$ and help others (beta $=.13, \mathrm{p}<.05)$.

\section{Environmental SWB}

Hierarchical multiple regression was used to assess contributions made to Environmental SWB by the helps listed above (at Step 1), perceived help from university (at Step 2), by other domains of lived experience (at Step 3) and ideals for Environmental SWB (at Step 4).

Among Divinity students. Based on an inspection of correlation values, family, nature and meditation were entered at Step1, explaining $40 \%$ of the variance in the lived experience of Environmental SWB. The total variance explained by the final model was $74.8 \%$, $\mathrm{F}(8,113)=41.9, \mathrm{p}<.001$, with four control measures being statistically significant, namely ideals for Environmental SWB (beta $=.36, \mathrm{p}<.001)$, relationship with others (beta $=.32$, $\mathrm{p}<.001$ ), nature (beta $=.23, \mathrm{p}<.001)$ and relationship with self (beta $=.15, \mathrm{p}<.05)$.

Although relation with God showed a beta value of .12 , it missed significance as $\mathrm{p}=.071$.

Among RE students. Based on an inspection of correlation values, self-improvement, nature and religious activities were entered at Step1, explaining $35 \%$ of the variance in the lived experience of Environmental SWB. The total variance explained by the final model was $77.7 \%, \mathrm{~F}(8,128)=55.9, \mathrm{p}<.001$, with six control measures being statistically significant, namely ideals for Environmental SWB (beta $=.44, \mathrm{p}<.001)$, relationship with others (beta $=.24, \mathrm{p}<.01)$, nature (beta $=.21, \mathrm{p}<.001)$, relationship with God (beta $=.21$, $\mathrm{p}<.01$ ), help from university (beta $=.12, \mathrm{p}<.01$ ) and religious activities (beta $=-.14$, $\mathrm{p}<.01)$.

\section{Transcendental SWB}

Hierarchical multiple regression was used to assess contributions made to Transcendental SWB by gender and the helps listed above (at Step 1), perceived help university (at Step 2), by other domains of lived experience (at Step 3) and ideals for Transcendental SWB (at Step 4).

Among Divinity students. Based on an inspection of correlation values, family and helping others were entered at Step1, explaining $26 \%$ of the variance in the lived experience of Transcendental SWB. The total variance explained by the final model was $56.2 \%$, $\mathrm{F}(5,116)=29.7, \mathrm{p}<.001$, with three control measures being statistically significant, namely relationship with self (beta $=.45, \mathrm{p}<.001$ ), ideals for Transcendental SWB (beta $=$ $.22, \mathrm{p}<.01)$ and help from university (beta $=.19, \mathrm{p}<.01$ ).

Among RE students. Based on an inspection of independent t-tests and correlation values, self-improvement and religious activities were entered at Step1, explaining $18 \%$ of the variance in the lived experience of Transcendental SWB. The total variance explained by 
the final model was $68.8 \%, \mathrm{~F}(8,128)=35.3$, $\mathrm{p}<.001$, with three control measures being statistically significant, namely relationship with self (beta $=.69, \mathrm{p}<.001$ ), ideals for Transcendental SWB (beta $=.14, \mathrm{p}<.01)$ and help from university (beta $=.12, \mathrm{p}<.05)$. It may seem strange that prayer and scripture did not feature as significant contributors to variance in Transcendental SWB, but variance was not shown because $95 \%$ of the students scored 'high' or 'very high' on these two items.

\section{Comparing importance of religion with spirituality}

Other studies have shown spirituality to be of greater importance than religion to university students in Western (Fisher, Barnes \& Marks 2009) and Easter cultures (Fisher $\&$ Wong, 2013). However here, among Islamic students in Turkey, the reverse is true for females $(\mathrm{t}(259)=2.77, \mathrm{p}<.05)$ and Religious Education students $(\mathrm{t}(259)=3.25, \mathrm{p}<.01)$. Importance of both religion and spirituality were rated very highly by these students (with values from 4.66 to 4.81 on a scale with maximum score of 5). These results also challenge the tentative finding proffered by Bryant (2007) that 'being Islamic has a significant negative effect on men's spirituality.'

\section{Discussion}

It was not surprising to find religion being rated of higher importance than spirituality among Divinity and Religious Education students investigated here as it relates directly to their courses of study. These universities are, however, in Turkey, a country that is 'straddling secular and Islamic, modern and traditional, [that] wants to be Western yet tends to look eastwards' (Hasan, 2012). The findings run counter to other studies with less religious university students (Fisher, Barnes \& Marks, 2009; Fisher \& Wong, 2013). It would be valuable to study a wider sample of the Turkish population to see if they held similar views to the students studied here.

\section{Personal SWB}

Relation with God showed greatest influence on how well both groups of university students related with themselves. This was to be expected as the Religious Education students' personal values are guided by their Islamic faith. Divinity students' focus on theology also points to relationship with God influencing personal development. For the Divinity students, their personal ideals provided additional help for developing their Personal SWB, as does university, even though rated fairly low by students.

Key differences between the two groups were revealed in that Religious Education students' relationship with other people had a large influence on their Personal SWB. This finding fits well with the Religious Education students' focus on moral values, which tie together with culture and religion, according to Tillich (1967, p.6), who claimed, 'Morality, culture and religion interpenetrate one another. They constitute the unity of the spirit, wherein the elements are distinguishable but not separable.' 
At Step 1 in the hierarchical, multiple regression analysis, religious activity accounted for variance in Personal SWB for Divinity students, but this was overshadowed at Steps 2 and 3 by help from university and Communal, Environmental and Transcendental SWB. On the other hand, religious activity showed a persistent effect by accounting for a small yet significant amount of variance on Personal SWB for the Religious Education students from Step 1 through to Step 4. Tis was in accord with their report of greater help from religious activities compared with the Divinity students $(\mathrm{t}(257)=-2,5, \mathrm{p}<.05$ ) (see Table 2).

\section{Communal SWB}

University was seen to provide help for Divinity students' Communal SWB but not for Religious Education students, whose relationship with self had greater influence on the Communal SWB compared with Divinity students. This was in keeping with the high levels of correlation of relationships with themselves and other people discussed above.

It was somewhat surprising to note that relationship with the environment influenced Communal SWB for both groups, but relationship with God did not. It would be expected that, among highly religious students, relating with God should influence relationship with others, as well as self, as was shown above. However, religious activity made a small contribution to Religious Education students' Communal SWB. In keeping with the lack of God's influence on Divinity students' Communal SWB, religious activity was also found lacking in this regard.

\section{Environmental SWB}

Divinity and Religious Education students' ideals provided greatest support for their relationship with environment. It is easy to see how nature itself provided additional support for both groups of students' Environmental SWB, but not so easy to see why relationship with other people did likewise. This finding is, however, consistent with the influence of Environmental SWB shown on Communal SWB above.

Variations were again noted between the two groups. Personal SWB related to Divinity students' Environmental SWB, but no significant influence was forthcoming either from university or God. The reverse was found for the Religious Education students.

\section{Transcendental SWB}

Similar results were found between the Divinity and Religious Education students. Greatest help came from their relation with self, with additional support being provided by their ideals for relating with God. The help that would be expected from these universities for Divinity and Religious Education students to relate with God was also found to be present. 


\section{Follow up studies}

Results presented here are self-reports. It would be advisable for the university staff to enquire further of their students about the nature of help they find useful in supporting their spiritual well-being. Objective assessments of the quality of relationships in the four areas could also ascertain the congruence between students' stated and lived realities. For example, how do they express meaning, purpose and peace in life? How well do they show compassion, trust and forgiveness toward others? How and how well do they connect with the environment and with God?

Other research has shown a relationship between professionals' lived experience of SWB and the level of help they provide to clients (Fisher 2009). This project provides a sound base from which to follow up these university students in one to two years' time to see how well their stated ideals and lived experience of SWB translate into helping students in schools (for the Religious Education students) and community members in religious settings (for the Divinity students). It would be useful to compare these results with those from other cultures. They would also help assess the effectiveness of the universities' holistic education.

\section{Conclusion}

Consideration of research question 1 showed gender to have a slight influence among Religious Education students, but other demographic variables yielded no significant explanation of variance on any of the four domains of SWB investigated here.

High ideals and lived experiences were reported for spiritual well-being by these Islamic Divinity and Religious Education students in Turkey. Ideals were shown to underpin the lived experiences of both groups of students in each of four domains of spiritual wellbeing. The Religious Education students outscored their Divinity counterparts on the lived experience of all but Environmental SWB.

In answer to research question 2, the most highly rated nominated helps (particularly prayer and scripture) did not help explain variance in the SWB of these Divinity and Religious Education students, because nearly all of them were clustered on 'high' and 'very high' scores. It appears that these highly religious students tend to overstate the influence of prayer and scripture on their spiritual well-being. However, relating with God significantly accounted for variance on Personal SWB for both groups of students, as well as Environmental SWB for Religious Education, but not Divinity students. In contrast, relating with God appeared to have no significant influence on either group for Communal SWB. Whereas religious activities provided consistently small influence on the Personal, Communal and Environmental SWB of the Religious Education students, but not their relation with God, no lasting significant influence was found from religious activities on any of the four domains of SWB among the Divinity students.

Investigating research question 3 showed that the universities provided small yet significant support in developing all but Environmental SWB for these Divinity students. 
Universities also provided support for Religious Education students' Personal, Environmental and Transcendental SWB. This did not hold true for Communal SWB, as Personal SWB overshadowed the universities' influence in this area.

Overall, this study has shown many similarities, yet some significant variations in spiritual well-being, between these Islamic Divinity and Religious Education students in Turkey. Further studies are warranted to determine the influence of these students' SWB on the clients they will serve after graduating and gaining employment (Fisher, 2009)

As well as assessing ideals and lived experiences for spiritual well-being with SHALOM, a third response was used in this study to provide a snapshot of perceived help provided for spiritual well-being among Divinity and Religious Education students by universities in Turkey. A longitudinal study using SHALOM, comparing students on entry and exit to courses, as well as in transition through their programs of study, would help universities to gauge if, how, and how well, they value-add to the spiritual development of their students. The long-term influence of universities could also be compared with effects on students' lives outside of university, for their spiritual well-being. This study has shown that Divinity and Religious Education students ascribe assistance to the development of aspects of their spiritual well-being by their universities. Further enquiry is needed to uncover the exact nature of help so ascribed and at what stage in students' progress (e.g., a particular course, time, or religious event?) compared with significant life events (e.g., relationship formation or breakdown, marriage, birth or death in the family).

It is especially important for Divinity and Religious Education students to have enhanced spiritual well-being, because previous studies have indicated that lived experience of a teacher, or carer, impacts on the quality of spiritual care provided to clients (Kennedy \& Duncan, 2006; Fisher 2008, 2009). With this in mind, staff in universities would also do well to investigate their own spiritual well-being (using SHALOM) and its impact on that of their students, because as they nurture their students' spiritual well-being, they are likely to enhance their own (Palmer, 1998).

\section{References}

Al-Shareef, M.K. (2001). Spending the night in a mosque. Arab News, 30 July. http://www.arabnews.com/print/214196

Astin, A.W., Astin, H.S. and Lindholm, J.A. (2011). Cultivating the spirit: How college can enhance students' inner lives. San Francisco: Jossey-Bass.

Bartlett, M.S. (1954). A note on the multiplying factors for various chi-square approximations. Journal of the Royal Statistical Society, 16, Series B. 296-8.

Bryant, A.N. (2007). Gender differences in spiritual development during the college years. Sex Roles, 56, 835-846.

Chickering, A.W., Dalton, J.C. and Stamm, L. (2006). Encouraging authenticity and spirituality in higher education. San Francisco: Jossey-Bass. 
De Souza, M., Francis, L.J., O’Higgins-Norman, J. and Scott, D.G. (2009). International handbook of education for spirituality, care and well-being. Dordrecht, The Netherlands: Springer.

Fisher, J.W. (1998). Spiritual health: Its nature and place in the school curriculum. PhD thesis, University of Melbourne. http://eprints.unimelb.edu.au/archive/00002994/

Fisher, J.W. (2008). Impacting teachers' and students' spiritual well-being. Journal of Beliefs \& Values, 29(3), 253-261.

Fisher, J.W. (2009). Investigating Australian Education students' views about spiritual well-being as compared with teachers in schools. International Journal of Children's Spirituality, 14(2), 151-167.

Fisher, J. (2010). Development and application of a spiritual well-being questionnaire called SHALOM. Religions, 1, 105-121.

Fisher, J. (2011). The four domains model: Connecting spirituality, health and well-being. Religions, 2, 17-28.

Fisher, J.W., Barnes, L.P. and Marks, G. (2009). Pre-service teachers' spiritual well-being across time and faiths: Implications for religious education. Religious Education Journal of Australia, 25(2), 10-16.

Fisher, J.W. and Wong, P.H. (2013). Comparing levels of spiritual well-being and support among pre-service teachers in Hong Kong and Australia. Religious Education Journal of Australia, 29(1), 34-40.

Gomez, R. and Fisher, J.W. (2003). Domains of spiritual well-being and development and validation of the Spiritual Well-Being Questionnaire. Personality \& Individual Differences, 35, 1975-1991.

Hasan, M. (2012). The Turkish paradox. http://www.aljazeera.com/indepth/opinion/2012/07/201272011283765829.html

Hay, D. and Nye, R. (1998). The spirit of the child. London: Fount.

Kaiser, H. (1974). An index of factorial simplicity. Psychometrika, 39:31-36.

Kennedy, A. and Duncan, J. (2006) New Zealand children's spirituality in Catholic schools: Teachers' perspectives. International Journal of Children's Spirituality, 11(2), 281-292.

McCarroll, P., O'Connor, TStJ. and Meakes, E. (2005). Assessing plurality in spirituality definitions. In A. Meier et al. (Eds.). Spirituality and health: Multidisciplinary explorations (pp.43-61). Waterloo, ON, Can.: Wilfrid Laurier University Press.

Nash, R. (1999). Faith, hype and clarity: Teaching about religion in American schools and colleges. New York: Teachers College Press. 
National Interfaith Coalition on Aging (NICA) (1975). Spiritual well-being: A definition. Athens, Georgia: NICA.

Okon, T.R. (2005). Spiritual, religious, and existential aspects of palliative care. Journal of Palliative Medicine, 8, 392-413.

Palmer, P. (1998). The courage to teach. San Francisco: Jossey-Bass.

Palmer, P. (1999). Evoking the spirit in public education. Educational Leadership, 6(4), 6-11.

Seccareccia, D and Brown J.B. (2009). Impact of spirituality on palliative care physicians: Personally and professionally. Journal of Palliative Medicine, 12, 805-809.

Tillich, P. (1967). Systematic Theology, Volume III: Life and the spiritual history and the Kingdom of God. Chicago: University of Chicago Press.

\subsection{Summary of Chapter 3}

SHALOM has proven to be a sound instrument for assessing spiritual well-being across a range of university students in varying linguistic and cultural settings.

Personal ideals in each of four domains of spiritual well-being were shown to markedly influence lived experiences therein.

Lived experiences also influence perceptions of help provided by respondents for the spiritual well-being of people in their care.

The notion of assessing activities and people that help or nurture spiritual wellbeing has proven to be useful in identifying similarities and differences between university students over time and by variations in setting and religious beliefs. 


\section{Chapter 4 Spiritual Well-Being and School Education}

\subsection{Introduction}

The previous chapter addressed the implications of spiritual well-being for pre-service teachers and other university students. This chapter presents five papers which consider theoretical and practical issues related to the promotion of spiritual well-being in education in Australian schools.

\subsection{Connectedness: At the heart of resiliency and spiritual well-being}

\section{Background}

This invited book chapter comprises a combination of a keynote address and collegial paper, both of which were presented at the $10^{\text {th }}$ International Conference on Children's Spirituality, 19-23 July, 2010, at the Hong Kong Institute of Education. As such, this publication contains work prepared and presented solely by myself.

\section{Key points extracted from this paper}

- Connectedness is a key feature of both resilience and spiritual well-being which can be addressed in educational settings.

- In order to accommodate cultural variations while facilitating comparisons between groups, it is necessary to have a flexible, yet consistent approach to research in spirituality and resilience. This is best achieved by comparing each person with themselves to obtain factor scores, rather than using norms for comparison between groups, or even individuals.

- Comparing each person's lived experience with their ideals in relation to four specific aspects of their lives yielded measures of spiritual dissonance posited as a value greater than 1.0 (>1 S.D.) on scales from 1 to 5. People who reflected dissonance in two or more of the four domains of spiritual well-being assessed using the research instrument were described as being 'dissonants'. Spiritual dissonance, especially in Personal and Communal SWB, tends to relate to psychological depression.

- The Quality Of Life Influences Survey (QOLIS) was used to gauge the strength of support students receive from family, friends, school and church to help students relate with Self, Others, Nature and God.

- The students sampled reported that God provided the greatest support for helping them relate with God.

\section{Implications}

The identification of dissonants among student groups should assist school staff to provide appropriate pastoral care to enhance the students' relationships in order to develop their spiritual (and psychological) well-being. 
The importance of relating with God can be discussed in Religious Education classes in non-government Australian schools. With decreasing religious affiliation in Australia (and other Western nations), and with no Religious Education in secular state secondary schools (which cater for two-thirds of all students in Australian schools), it seems likely that relating with God will wane for many students. However, continuing Commonwealth funding for chaplains in all Australian schools, together with the increasing presence of Islamic and evangelical/fundamental Christian churches in Australia, might counteract this trend over time.

\title{
Paper:
}

This paper was published as: Fisher, J.W. (2012) Connectedness: At the heart of resiliency and spiritual well-being. In C.A. Stark \& D.C. Bonner (Eds) Spirituality: Belief Systems, Societal Impact and Roles in Coping (pp. 265-276) New York: Nova Science Publishers, Inc.

\section{Connectedness: At the heart of resiliency and spiritual well-being}

\begin{abstract}
Studies in resiliency often stand alongside those of health deficits, pointing to positive ways in which the well-being of young people can be addressed, (often) in and through education. The underlying theme of 'connectedness' or building relationships, which is gaining in importance in resiliency discussions, also undergirds research in spiritual well-being.
\end{abstract}

This paper reports how spiritual dissonance was identified among 1372 students aged 9 - 19 years, in non-government schools, in Victoria, Australia, using quantitative spiritual well-being questionnaires called SHALOM and Feeling Good, Living Life. The Quality Of Life Influences Survey was also used to gauge the strength of relationships (i.e., connectedness) of each student with family, friends, school and/or church. These are areas which have been shown to provide support for resiliency, especially among American youth.

The students classified as spiritual 'dissonants' reported lower levels of support from parents, school teachers and principals, female friends and God, together with themselves, in building relationships with self, others, environment and/or God. Spiritual well-being is reflected in the quality of relationships in these four domains. The dissonants also showed higher levels of psychoticism and lower levels of happiness, the inverse of depression.

How well students connect, especially with themselves and God, influences their spiritual well-being and resilience.

Author: Dr John W Fisher

Affiliation: Hon. Senior Research Fellow, School of Education and Arts, University of Ballarat 
Contact: j.fisher@ballarat.edu.au

Introduction

Current emphases within health and well-being focus on positive ways in which people can overcome adversity, whether physical, mental, emotional, social or environmental in origin. 'The importance of strengthening resiliency [especially in youth] cannot be emphasized enough' (Bell, 2001, p.375). Recent studies present resilience as a 'self-righting force within everyone that drives him/her to pursue self-actualization, altruism, wisdom, and harmony with a spiritual source of strength' (Richardson \& Waite, 2002, p.656).

The connection of spirituality with resilience can also be seen in a recent report from work celebrating the $20^{\text {th }}$ anniversary of the United Nations Convention on Rights of the Child (BICE, 2009). In Item ten of this report, the spiritual dimension is specifically targeted as part of the integral development of the child. Items eleven and twelve assert the role of resilience in empowering children to fight for their rights as well as providing elements by which resilience can be developed (namely solidarity in family and caring communities, supported by quality education).

Both the concepts, of spirituality and resilience, are multidimensional and not easy to define. Simply put, resilience is seen as the ability of a person to rebound after a traumatic situation. In more detail, resilience can be described as 'the process of, capacity for, or outcomes of successful adaptation despite challenging or threatening circumstances' (Masten et al., 1990). Spirituality can be described as that which lies at the heart, i.e., at the core, or as the French would say, 'coeur,' of a person being human (Fisher, 2009). Spirituality has also been described as a search for the sacred (Koenig et al., 2001). This latter description implies the notion of religion and God.

\section{Fine tuning resilience}

Richardson (2002) reported three waves of development of the concept of resilience. The first of these posited resilience as personal traits acting as protective factors to overcome risks. At the individual level they are shown as intelligence; an easygoing, confident nature; having high self-esteem; being talented; and having a religious faith. Family, community and school are also recognised as key sources of support as protective factors (Resnick, 1993). The second wave described resilience as a process for accessing the innate qualities which lead to positive outcomes. The qualities may not simply be latent potential awaiting opportunities to be expressed. Martin (2002) implies that these qualities can be learned, invoking the notion of development of resilience. The third, postmodern wave of resilience, views it as a force for growth through adversity and disruptions, with the goal of reaching fulfillment. Is this force the human spirit?

A model of resilience (Aronson, 2000) illustrates a transformational process from adversity to success, where: 
- adversities faced by individuals come in a variety of forms, from racial and ethnic identity issues, to isolation or hostile environments, limited education, conflict at and between home and school, and neglect or abuse.

- effects of adversity are evidenced as fear, anxiety, resentment, internalization, shame, early maturity and self-protection.

- enabling conditions to help overcome adversity include having a strong family; good support systems; good teachers; caring adults; higher intelligence; positive role models and clearly identified turning points in life.

- coping strategies to enhance the enabling conditions are perseverance, resistance, friendly competition, religious faith and spirituality.

- achievement, or success, is shown by graduation from high school or university; having a fulfilling career; a sense of autonomy; often associated with an escape from the oppressive environs that initiated the adversity.

\section{Connecting resilience and spirituality}

Victor Frankl has credibility with regards resilience, having withstood considerable maltreatment in concentration camps during World War II. Frankl contends that 'finding meaning and purpose is the crux of spirituality' and 'such thinking leads to resiliency' (1969, p.xi). The alternative is living in an 'existential vacuum' which is evidenced by boredom, apathy, burnout, mental illness, all of which illustrate a lack of resiliency. Is this an apt description of a twenty-first century syndrome? In support of Frankl's contention, Neimeyer (2001) believes that finding and defining meaning in life during trauma is not just a coping strategy, but a pathway to positive transformation. This is another way of expressing the view that spirituality leads to resilience. According to Eckersley et al. (2006) 'spirituality represents the broadest and deepest form of connectedness. It is the only form of meaning that transcends people's personal circumstances, social situation and the material world and so has a powerful capacity to sustain them through adversity.'

In the Adolescent Resilience Model, Haase (2004) describes resilience as being composed of a sense of confidence, self-esteem and self-transcendence. These characteristics are illustrated by meaning and purpose in life, having connectedness with others, nature and God.

In detailing ways in which religion and spirituality may promote resilience, Crawford et al. (2006) highlighted the relational nature of each: (i) through attachment relationships which illustrate family cohesion, prosocial peer interaction and mentoring and relationships with the divine; (ii) social support from communities through provision of food or visits to needy; counseling, prayers and rituals; (iii) having guidelines for conduct and moral values, with emphases on integrity, compassion, forgiveness, empathy, altruism, kindness and love; (iv) personal growth and development and transformational opportunities, which provide meaning and philosophy of life; regulate affect; reinforce 
family values; reframe trauma; with prayer/meditation, worship through liturgy and music, and experiences of conversion and transformation.

\section{Relational base of spiritual well-being}

The four sets of relationships, namely with self, others, nature and God, were posited as the key components in a definition of spiritual well-being (National Interfaith Coalition on Aging, 1975). Empirical support for this construct of spiritual well-being was provided by Rebecca Nye in her development of the concept of 'relational consciousness' in the four areas, in a study of spirituality with primary school pupils in the UK (Hay \& Nye, 1998). At the same time, the four domains model of spiritual health and well-being was developed from interviews with 98 secondary school educators and surveys with 23 experts in Australia (Fisher, 1998).

Fisher (ibid.) described spiritual health as a, if not the, fundamental dimension of health permeating and integrating all other dimensions of health (i.e., the physical, mental, emotional, social and vocational). With increasing publications linking these aspects of health, spirituality can be seen as the foundation as well as the glue which holds the whole person together. Spiritual health is also a dynamic state of being, shown by the quality of relationships in up to four domains of spiritual well-being (SWB):

- Self-awareness is the driving force, the inspiration (or heart) of the Personal domain of SWB, in which a person seeks not only meaning and purpose (as described by Frankl as the crux of spirituality) but also values in life. Personal SWB relates to the question, 'Who am I?' When harmony is attained between the head and the heart in this domain, then joy, inner peace, patience and a sense of identity and self-worth are shown as the result. A very small percentage of people think that relating with oneself is all that is necessary for spiritual well-being.

- The vast majority of people, however, see a need for in-depth inter-personal relationships, which are developed within a framework of morality, culture (and religion, for those for whom it is important) in the Communal domain of SWB. The outworking of this domain is shown in forgiveness toward others, justice, love, hope, faith and trust. The Communal domain of SWB builds on, but also builds up, the Personal domain of SWB.

- The third domain of SWB is embraced by people who go beyond the care, nurture and stewardship of the environment to a sense of connectedness with nature. This relationship is of paramount importance for indigenous peoples, many eastern philosophies and a growing number of westerners. This Environmental domain of SWB builds on but also builds up the Communal, thus Personal SWB.

- For those people, who, by faith, believe in either an impersonal higher power, cosmic force or ultimate concern, or a personal Transcendent Other, or God, this Transcendental domain of SWB embraces the other three and provides depth of understanding and wellbeing.

Different people embrace each of these four sets of relationships to varying extents depending on their worldview, based on personal and cultural beliefs and 
experience. It is also in this relational context that resilience and spirituality can be seen as connected.

\section{Influence of culture}

A few studies will be reported here to illustrate the way that researchers' own views colour or filter their research activities.

In the Chinese Resilience Measure for Children \& Adolescents in Hong Kong (Lee et al., 2010) four items were found to be predictive of positive child development. According to Chinese cultural beliefs about adversity, children's resilience beliefs are thought to be predictive of positive child development (as described in Chan et al., 2006). It is proposed that the predictive relationship is stronger with increasing adversity, although the adversity did not appear to be very great in this study. The personal-family interaction featured strongly in this study but there was no reference to religion or faith, even though this was mentioned as a relevant component in the literature review of the paper. Research is flavoured by the beliefs and/or interests of the researchers. In this case eastern philosophy has dominated despite the residual influence that the Catholic, Anglican and other churches have in the Hong Kong community.

In Yasui's study of adolescents in the USA (2009), among American Indians, spirituality correlated with racial awareness, ethnic exploration and family centredness. Among African-Americans spirituality related to cultural socialization but among European-Americans there was no correlation of spirituality with ethnic-racial socialization. These results reveal obvious differences in spirituality and socialization based on cultural identity.

In order to accommodate cultural variations while facilitating comparisons between groups, it is necessary to have a flexible, yet consistent approach to research in spirituality and resilience. Most measures of spirituality simply ask for a single response, describing each person's lived experience in a pertinent area, e.g., as in existential or religious well-being in Ellison's Spiritual Well-Being Survey (Ellison, 1983). Some arbitrary standard is then employed to rate the individual's response as high or low. In order to overcome the limitations of such approaches, a unique method has been employed in spiritual well-being measures developed by Fisher (SHALOM, 1999; Feeling Good, Living Life, 2004). These measures ask for two responses to each question, thus allowing each person's lived experience to be compared with their ideals. Each person is thus their own standard against which they are measured.

Most people think that relationships with themselves and other people are likely to enhance their spiritual well-being (i.e., ideals), so, if their lived experience is low, spiritual dissonance is present in the Personal and/or Communal domain of SWB. If, on the other hand, a person does not believe that a relationship with the environment or a god would ideally enhance spiritual well-being, and if their lived experience is rated low in either or both of these areas, there is no disharmony or spiritual dissonance in the Environmental and/or Transcendental domains of SWB. The degree of spiritual harmony or dissonance can be compared between groups without necessarily comparing the actual 
level of lived experience. Personal beliefs and cultural variations are thus accommodated using the one instrument.

Resnick et al. (1993) reported that relationships with family, school and church were protective factors for young people 'at risk.' This work informed the development of the Quality Of Life Influences Survey (QOLIS) (Fisher, 2006). In QOLIS, students were asked to indicate how well each nominated member of family, school, church and community helped them relate with Self, Others, Nature and God. In effect, QOLIS is a four-by-four matrix which relates spiritual well-being with resilience. Flexibility is built into QOLIS in that cultural variations can be accommodated, e.g., under family, as well as mother/father, self, siblings and grand-parents, aunt/uncle and/or ancestors can be added as appropriate. Students are asked to cross out the name of any people that are not relevant.

Method

\section{Setting}

There are four types of schools in Australia, with $67 \%$ of all students attending secular state schools, in which primary schools in most Australian states can provide voluntary Christian Religious Education for one lesson a week. Reference to religion might occur infrequently in some classes, but there is no formal provision for religious studies in Australian secondary state schools; $20 \%$ of Australian students attend Catholic schools, which have regular religious education (RE) classes and masses; the remaining $13 \%$ attend independent schools, most of which have religious bases, religion classes and chaplains. A special subset, $40 \%$ of the independent schools (5\% of the total student population), comprises low fee, other Christian schools, most of which have been established following the provision of funds from the Australian federal, followed by state, governments since 1973.

It has become increasingly difficult to gain support from staff for research in spiritual well-being in Australian state schools, as some principals and teachers automatically assume that spirituality equates with religion, which they believe does not fit with the secular humanistic philosophy prevalent in state schools (Fisher, 2007). A number express the view that religion should be excluded from schools because of assumed separation of Church and State. There is no such legal separation in Australia, as exists in the USA (Wallace, 2005). Secular, in this instance means freedom of religion, not freedom from it. The above not withstanding, the research reported here was undertaken with only students from Catholic, independent and other Christian schools, in Victoria.

\section{Sample and measures}

Ethics approvals were gained from the University of Ballarat, which required consent from principals, parents and students.

Three hundred and seventy-two primary school students (aged 10-12) completed Feeling Good, Living Life (FGLL), a 16-item instrument developed with a purposive 
sample of 1080 primary school students (aged 5-12) in the four school types in Victoria and Western Australia (Fisher, 2004). Responses were gathered on a 5-point Likert scale (YES, yes, ?, no, NO) for four items on each of four factors of spiritual well-being, indicating relationships with self, others, nature and God..

One thousand and two secondary school students (aged 12-18) completed the 20item Spiritual Health And Life-Orientation Measure (SHALOM), which was developed with a convenience sample of 850 secondary school students (aged 12-18) in state, Catholic, independent and other Christian schools in Victoria (Fisher, 1999). These schools were selected to include a range of ethnicities and religions. Each of the four factors in SHALOM is given a score by taking the mean value of responses to five items using a 5-point Likert scale (from 1=very low to 5=very high).

As well as the relevant spiritual well-being questionnaire, the primary and secondary school students also responded to the Quality Of Life Influences Survey (QOLIS), which asked for four responses (on a 4-point Likert scale, from $0=$ never to $3=$ always) indicating the extent to which 22 'people' (in family, school, church and wider community) influenced students' relationships with Self, Others, Nature and God (Fisher, 2006). The surveys were done in class under the supervision of a teacher.

Additional instruments were used to gain a greater understanding of participants. The abbreviated form of the Junior Eysenck Personality Questionnaire - Revised (JEPQR-A) (Francis, 1996) used Yes/No responses on 48 items to gain insight into students' levels of extraversion, neuroticism and psychoticism, with an attendant 'Lie' scale, which indicated social-desirability of responses. The importance of religion and spirituality were also assessed on 5-point Likert scales, (from 1=very low to 5=very high) among secondary school students, as was the Oxford Happiness Inventory (OHI) (Argyle \& Hills, 2000), comprising 29 items with four alternative responses.

\section{Study limits}

Due to sampling procedures, the results presented here are not necessarily representative of the types of school surveyed.

Results

Levels of spiritual well-being by dissonance

As mentioned previously, SHALOM and FGLL elicited two responses from each student, regarding their ideal and lived experiences on items which reflected their spiritual well-being in four domains. Each item was scored on a scale from 1 to 5 . A difference in score of 0.6-0.8 between 'ideal' and 'lived experience' categories of SWB yielded statistically significant results for small groups of students and teachers (Fisher, 2008a). It was therefore proposed that a slightly larger difference in the mean value, of greater than 1.0 (which is more than one standard deviation) between the ideal and lived experiences, indicates spiritual dissonance in any of the four domains (Fisher, 2006). Research has revealed that if people show spiritual dissonance in only one of the four domains, the other three can compensate for it. However, dissonance in two or more domains results in 
marked spiritual angst among people, who are therefore called 'spiritual dissonants' (Fisher, 2008b; Fisher \& Brumley, 2008).

Results in Table 1 show that $3.3 \%$ of primary school students and $13.4 \%$ of secondary school students in this study can be described as spiritual dissonants.

Table 1 Levels of spiritual well-being by dissonance

\begin{tabular}{l|ccc|ccc}
\hline & \multicolumn{3}{|c|}{ primary } & \multicolumn{3}{c}{ secondary } \\
\hline n & 360 & 12 & 880 & 118 \\
\hline SWB (means) & non-diss & dissonant & $\mathrm{t}^{\text {sig }}$ & non-diss & dissonant & $\mathrm{t}^{\text {sig }}$ \\
\hline Personal & 4.16 & 2.92 & $7.29 * * *$ & 3.87 & 3.38 & $7.01 * * *$ \\
Communal & 4.66 & 4.27 & $2.89 * *$ & 4.05 & 3.66 & $5.81^{* * *}$ \\
Environmental & 3.20 & 2.88 & $.198^{\mathrm{ns}}$ & 3.09 & 2.62 & $5.33^{* * *}$ \\
Transcendental & 4.15 & 3.33 & $2.85^{* *}$ & 3.15 & 2.42 & $7.48^{* * *}$ \\
\hline
\end{tabular}

Independent t-tests show significant differences between the dissonants and nondissonants at each school level, except on Environmental SWB at primary school level. A visual inspection reveals a considerable difference here, but it is not statistically significant due to the low number of dissonants at primary level.

Results from QOLIS, compared by dissonance

The extent of support from 22 'people' to help students relate with Self, Others,

Table 2 QOLIS (Self \& Others) by dissonance

\begin{tabular}{l|ccc|ccc}
\hline \multirow{2}{*}{$\begin{array}{l}\text { help from } \\
\text { 'people' }\end{array}$} & \multicolumn{3}{|c|}{ to relate with Self } & \multicolumn{3}{c}{ to relate with Others } \\
\cline { 2 - 7 } & non-diss & dissonant & $\mathrm{t}^{\mathrm{sig}}$ & non-diss & dissonant & $\mathrm{t}^{\mathrm{sig}}$ \\
\hline mother & 2.47 & 2.35 & $1.90^{*}$ & 2.27 & 2.27 & $1.07^{\mathrm{ns}}$ \\
father & 2.27 & 2.12 & $2.06^{*}$ & 2.13 & 1.95 & $2.18^{*}$ \\
female friend & 2.47 & 2.42 & $.68^{\mathrm{ns}}$ & 2.35 & 2.32 & $.39^{\mathrm{ns}}$ \\
teacher & 2.00 & 1.76 & $2.90^{* *}$ & 2.02 & 1.82 & $2.19 *$ \\
principal & 1.51 & 1.15 & $3.61 * *$ & 1.61 & 1.33 & $2.60^{* *}$ \\
self & 2.18 & 1.90 & $3.83 * * *$ & 2.39 & 2.17 & $3.38^{* *}$ \\
God & 2.28 & 1.93 & $3.07 * *$ & 2.29 & 1.89 & $3.30^{* * *}$ \\
\hline NB scale $0-3 . * \mathrm{p}<.05, * * \mathrm{p}<.01, * * * \mathrm{p}<.001$ & & & & &
\end{tabular}


Nature and God was gathered using QOLIS. Only findings for those 'people' who showed high levels of support and/or marked variations between dissonants and nondissonants are reported here. (See Tables $2 \& 3$.)

\section{Relations with Self}

The results from QOLIS revealed that the highest level of support for the development of relationships with Self came from mothers and female friends, with fathers not far behind. But, this finding held true for both dissonants and non-dissonants (with t-tests showing no or very little difference between the two groups). Teachers, and especially principals, were not seen by students to provide as much support in helping them relate well with themselves. This lack of support was more evident among dissonants than non-dissonants, not only from school staff but also from students themselves and God.

\section{Relation with Others}

The students indicated that the greatest support for them relating with Other people came from themselves and female friends, with lesser support from parents. As for relating with Self, no or very little difference was shown between dissonants and nondissonants on help from parents and female friends. School staff and God provided similar levels of help for students to relate with Self and Others. However, God, themselves and principals were again seen as providing less support for dissonants to relate, this time with other people. Even though they report helping themselves relate well with Others most of the time, dissonants still do this less well than non-dissonants.

Table 3 QOLIS (Nature \& God) by dissonance

\begin{tabular}{l|rrr|rrr}
\hline \multirow{2}{*}{$\begin{array}{l}\text { help from } \\
\text { 'people' }\end{array}$} & \multicolumn{3}{|c|}{ to relate with Nature } & \multicolumn{3}{c}{ to relate with God } \\
\cline { 2 - 7 } & non-diss & dissonant & $\mathrm{t}^{\text {sig }}$ & non-diss & dissonant & $\mathrm{t}^{\mathrm{sig}}$ \\
\hline mother & 1.91 & 1.61 & $3.27 * *$ & 1.66 & 1.21 & $4.33^{* * *}$ \\
father & 1.80 & 1.49 & $3.22^{* *}$ & 1.43 & 1.03 & $3.81^{* * *}$ \\
female friend & 1.73 & 1.65 & $.81^{\mathrm{ns}}$ & 1.29 & .97 & $3.03^{* *}$ \\
teacher & 1.73 & 1.58 & $1.52^{\mathrm{ns}}$ & 1.88 & 1.73 & $1.46^{\mathrm{ns}}$ \\
principal & 1.37 & 1.02 & $3.49^{* *}$ & 1.66 & 1.45 & $1.82^{\mathrm{ns}}$ \\
self & 2.00 & 1.61 & $4.18^{* * *}$ & 1.64 & 1.12 & $5.63^{* * *}$ \\
God & 2.18 & 1.81 & $3.05^{* *}$ & 2.40 & 1.98 & $3.33^{* *}$ \\
\hline
\end{tabular}




\section{Relation with Nature}

Most levels of support are relatively low in this area, with only God and self seen as providing help most of the time for non-dissonants. Significant differences are shown by dissonance not only for self, God, and principals but also parents on this occasion. Female friends are still rated consistently by dissonants and non-dissonants alike.

\section{Relation with God}

God provides the greatest support here for both dissonants and non-dissonants. Not only is there marked difference between the two groups by support from God, but also themselves, parents and female friends as well. Only the school staff provide similar, but low, levels of support for both groups of students in their relationship with God.

\section{Other variations by dissonance}

Key influences on dissonants' relation with Self, Others, Nature and God were shown to be how well they helped themselves and the level of perceived help from God.

Coupled with lower personal help, dissonants showed higher levels of psychoticism than did non-dissonants (3.71 compared with 2.86, $\mathrm{t}(1368)=3.72, \mathrm{p}<.001$ ). Dissonants also reported lower levels of happiness at secondary school level (41.06 compared with $47.13, \mathrm{t}(996)=4.53, \mathrm{p}<.001)$.

In accord with the less help from God, dissonants rated religion as less important compared with non-dissonants (2.71 compared with 3.04, $\mathrm{t}(980)=2.97, \mathrm{p}<.01$ ), but there was no significant difference in importance of spirituality between the two groups (3.08 compared with $3.29, \mathrm{t}(979)=1.84, \mathrm{p}=.066 \mathrm{~ns})$.

\section{Discussion}

\section{Sources of support for spiritual well-being}

A good level of support from parents and female friends was reported by the young people in their relations with Self and Others irrespective of dissonance. These personal and interpersonal relationships were obviously well supported by people with whom they had close emotional ties. However, less support was provided by parents and female friends in helping students relate with Nature and even less for relation with God. In these areas, significant differences were also noted with dissonants reporting lower support than non-dissonants. Further study could determine if less support was given to students because the parents and female friends had poorer relationships themselves with Nature and God, thus not have ability to provide assistance needed.

In schools, the teachers were seen as providing more help than principals for students in each of the four relationships. This is not surprising as teachers have greater contact time with students. There is a challenge for school staff here in that dissonants feel less supported than non-dissonants in relating with Self and Others. SHALOM and FGLL can be used to identify dissonants who would benefit from increased support in 
these areas. Teachers were seen as providing similar levels of support for students' relationships with Nature and God, irrespective of dissonance.

Teachers and principals were the only sources, apart from God, that were described as giving students more help in relating with God, compared with Nature. Teachers in these schools, compared with those in state schools, have reported providing greater help for students in relating to God, as a reflection of their own beliefs and lived experience (Fisher, 2008b). It would be interesting to compare the results from students in these non-government schools, which have religious bases, with those of students in secular state schools.

It is really only themselves and God that provide reasonable levels of support for students in relating with Nature and God, although these levels are lower for students compared with their relationships with people, i.e., Self and Others. God is reported as providing the greatest support for relationship with Himself [sic], which is statistically higher than relationships with Self, Others and Nature for non-dissonants, and of a consistently reasonable level across the four areas for dissonants.

\section{Personal characteristics of dissonants}

The dissonants revealed lower levels of support, than did non-dissonants, from school staff, themselves and God in relating with Self and Others as well as from parents, female friends, themselves and God in relating with Nature and God. Their personality could have some bearing on these relationships. The dissonants scored higher on psychoticism as measured by a personality scale. Such people are described as being more aggressive, more impulsive and sensation-seeking (Eysenck \& Eysenck, 1985).

Dissonants also reported lower levels of happiness at secondary school level. The Oxford Happiness Inventory which was used to measure 'happiness' is actually the inverse of the Beck Depression Index with some added self-efficacy items. These results indicate a relationship between spiritual dissonance and psychological depression, which has been shown previously in studies with university students (Gomez \& Fisher, 2003).

Summary

Relationships with family, school and church are seen as protective factors related to resilience for young people at risk. The Quality of Life Influences Survey has shown itself to be useful in assessing levels of support from students themselves, other people (such as family and friends), school and God, which indicate key elements for resilience.

Spiritual well-being is reflected in the quality of relationships in four domains. The spiritual well-being measures SHALOM and Feeling Good, Living Life have been used to identify spiritual dissonants, who reported lower levels of support from parents, school teachers and principals, female friends and God, together with themselves, in building relationships in these four domains, namely with self, others, nature and/or God. The dissonants also showed higher levels of psychoticism and lower levels of happiness, the inverse of depression. 
In summary, how well students connect (especially with self and God) influences their spiritual well-being and resilience.

References

Argyle, M. \& P. Hills. 2000. Religious experiences and their relations with happiness and personality. The International Journal for the Psychology of Religion. 10, no.3: 157-172.

Aronson, R. 2000. Social pioneers: resilience among working-class achievers in American schools. PhD dissertation, University of Virginia.

Bell, C.C. 2001. Cultivating resiliency in youth. Journal of Adolescent Health. 29, no.5: 375-381.

BICE (2009) www.bicecei.org/ewb_pages/w/world-appeal-to-a-new-mobilization-forchildhood-geneva-june2009.(Accessed 10, December 2009)

Chan, C., Chan, T. \& Ng, S. 2006. The Strength-focused and Meaning-oriented Approach to resilience and Transformation (SMART): A body-mind-spirit approach to trauma management. Social Work in Health Care. 43, no.2/3: 9-36.

Crawford, M., Wright, M.O'D. \& Masten, A.S. 2006. Resilience and spirituality in youth. In Roehlkepartain, E.C. et al. (Eds) Handbook of spiritual development in childhood and adolescence (pp. 355-37). Thousand Oaks CA: Sage Pubs.

Eckersley, R. et al. 2006. Flashpoints \& signposts: Pathways to success \& wellbeing for Australia's young people. Project by Australia $21 \&$ Australian Youth Research Centre, supported by VicHealth.

Ellison, C. 1983. Spiritual well-being: Conceptualization and measurement. Journal of Psychology \& Theology. 11: 330-340.

Eysenck, H.J. \& M.W. Eysenck. 1985. Personality and individual differences: A natural science approach. New York: Plenum.

Fisher, J.W. 1998. Spiritual health: its nature and place in the school curriculum. PhD dissertation, University of Melbourne (http://eprints.unimelb.edu.au/ archive/00002994/) Published by Melbourne University Bookshop, 2010.

Fisher, J.W. 1999. Developing a spiritual health and life-orientation measure for secondary school students. Paper presented at University of Ballarat Annual Research Conference, 15 October, pp. 57-63, Ballarat, Australia.

Fisher, J.W. 2000. Being human, becoming whole: Understanding spiritual health and well-being. Journal of Christian Education. 43, no.3: 37-52.

Fisher, J.W. 2004. Feeling Good, Living Life: a spiritual health measure for young children. Journal of Beliefs \& Values. 25, no.3: 307-315. 
Fisher, J.W. 2006. Using secondary students' views about influences on their spiritual well-being to inform pastoral care. International Journal of Children's Spirituality. 11, no.3: 347-356.

Fisher, J.W. 2007. It's time to wake up and stem the decline in spiritual well-being in Victorian schools. International Journal of Children's Spirituality. 12, no.2: 165-177.

Fisher, J.W. 2008a. Nurturing students' spiritual well-being: Caring for the whole child. Journal of Christian Education. 51, no.1: 7-20.

Fisher, J.W. 2008b. Impacting teachers' and students' spiritual well-being. Journal of Beliefs \& Values. 29, no.3: 253-261.

Fisher, J. 2009. Reaching the heart: Assessing and nurturing spiritual well-being via education. EdD Dissertation, University of Ballarat. Available from http:// archimedes.ballarat.edu.au:8080/vital/access/HandleResolver/1959.17/13481

Fisher, J.W. \& Brumley, D.J. 2008. Nurses' and carers' spiritual well-being in the workplace. Australian Journal of Advanced Nursing. 25, no.4: 49-57.

Francis, L.J. 1996. The development of an Abbreviated form of the Revised Junior Eysenck Personality Questionnaire (JEPQR-A) among 13-15 year-olds. Personality and Individual Differences. 21, no.6: 835-844.

Frankl, V. 1969. Man's search for meaning. New York: Washington Square Press.

Gomez, R. \& Fisher, J.W. 2003. Domains of spiritual well-being and development and validation of the Spiritual Well-Being Questionnaire. Personality and Individual Differences 35, no.8: 1975-1991.

Haase, J. 2004. The Adolescent Resilience Model as a guide to interventions. Journal of Pediatric Oncology Nursing. 21, no.5: 289-299.

Hay, D. \& Nye, R. 1998. The spirit of the child. London: HarperCollins.

Koenig, H., McCullough, M. \& Larson, D. (Eds) 2001. Handbook of religion and health. Oxford: Oxford University Press.

Lee, T-Y., Kwong, W., Cheung, C., Ungar, M. \& Cheung, M. 2010. Children's resiliencerelated beliefs as a predictor of positive child development in the face of adversities: Implications for interventions to enhance children's quality of life. Social Indicators Research. 95, no.3: 437-453.

Masten, A., Best, K. \& Garmezy, N. 1990. Resilience and development: Contributions from the study of children who overcame adversity. Development and Psychopathology. 2: $425-444$.

National Interfaith Coalition on Aging 1975. Spiritual well-being: A definition. Athens, GA: NICA. 
Resnick, M. et al. 1993. The impact of caring and connectedness on adolescent health and well-being. Journal of Paediatrics \& Child Health. 29(Suppl.1): 433-442.

Richardson, G. 2002. The metatheory of resilience and resiliency. Journal of Clinical Psychology. 58, no.3: 307-321.

Richardson, G.E. \& Waite, P.J. 2002. Mental health promotion through resilience and resiliency education. International Journal of Emergency Mental Health. 4, no.1: 66-75.

Wallace, M. 2005. Is there separation of church and state in Australia and New Zealand? Australian Humanist, 77. http://www.hsnsw.au/MaxWallace.html

Yasui, M. 2009. Observed ethnic-racial socialization and early adolescent adjustment. $\mathrm{PhD}$ dissertation, University of Oregon.

\subsection{Publications relating to spirituality in Australian education}

\section{Background}

The spiritual development of students was first mentioned in official Australian curriculum documents in 1994 (Australian Education Council, 1994: Board of Studies (Victoria), 1994). This was followed by official support from the joint Ministers of Education in Australia, in which the spiritual development and well-being of students was listed as one of the core goals for schooling (MCEETYA, 1999, 2008). The Australian College of Educators, an august body of educators in universities and schools, commissioned a book 'to address this complex relationship between education and spirituality'. Due to the untimely death of the first author, this work was delayed. The book was eventually edited by Marian de Souza, who had previously edited two international handbooks related to spirituality, and also Julie Rimes. I was invited to write a chapter for this book. My chapter provided a comprehensive overview of research into spirituality and the spiritual dimension of education which had been carried out in Australia.

\section{Key points extracted from this publication}

- In 2010, the pertinent Curriculum frameworks of all Australian States and Territories, except for Victoria, mentioned spiritual development of students more than once.

- Divergence of opinion exists over the appropriate relationship between spirituality and religion in schools. Relationship with God is claimed as 'proper' spirituality. 
- A challenge is provided for teachers to reach the heart (spirit) of Australian students in order to help counter materialism and self-centredness, by focussing on connectedness, or building meaningful relationships, which enhance SWB.

- Schools are confounded by an overflowing curriculum, which is too often centred on academic performance to the detriment of character development and the wellbeing of the person and society.

- The spiritual standing of teaching staff has significant impact on students' spiritual well-being.

\section{Implications}

There is a need for educators to seek agreed meaning of 'spiritual development and wellbeing of students' to make sense of implementing the Ministers of Education's edicts referring to spiritual development and well-being of students as core educational goals.

There is a need for adequate training in and about spirituality for teachers and educational leaders.

The spiritual permeates across the curriculum and is not just pertinent to specific areas, such as Religious Education and Health. Who teachers are impacts on students' spiritual well-being more so than by what they say, i.e., lives speak louder than words.

\section{Paper:}

This paper was published as: Fisher, J.W. (2010) Reflections on publications relating to spirituality in Australian education. In M. de Souza \& J Rimes (Eds.), Meaning and connectedness: Australian perspectives on education and spirituality (pp.105-126). Mawson ACT: Australian College of Educators.

\section{REFLECTIONS ON PUBLICATIONS RELATING TO SPIRITUALITY IN AUSTRALIAN EDUCATION}

\footnotetext{
Abstract

This chapter begins with a brief overview of 'spiritual' in Australian curriculum documents. Following classic and contemporary definitions of spirituality, general comments are gleaned from publications on spirituality in Australia, and education in particular. Curriculum concerns and views on spirituality related to values education and school leadership are then canvassed.

Empirical research studies on spirituality reveal the variety and extent of work done in this area in Australia from early childhood to community education.
} 
Concluding comments challenge educators with regards the impact of their world-views on providing holistic, spiritually-inclusive education in Australia.

Author Dr John W Fisher,

Hon. Senior Research Fellow,

School of Education, University of Ballarat

Contact j.fisher@ballarat.edu.au mobile phone: 0438.395.915

\section{Brief biography}

John Fisher has taught and researched in state, Catholic, other Christian and independent schools in Australia, with 14 years as principal and 17 years in teacher education. For the last 17 years, John has been researching spiritual health and well-being among students and staff in primary and secondary schools and universities in Australia, Hong Kong and the UK, in health settings and the wider community (PhD 1998, University of Melbourne; EdD 2009, University of Ballarat).

\section{Introduction}

A search of curriculum frameworks on websites of 'Education Departments' in Australian States and Territories reveals that all but Victoria make multiple mention of spiritual development of students (see Table 1). These frameworks (other than Victoria) are in accord with the Adelaide Declaration on National Goals for Schooling in the TwentyFirst Century (MCEETYA, 1999), which was superseded by the Melbourne Declaration on Educational Goals for Young Australians (MCEETYA, 5 December, 2008). However, both these declarations of the joint Ministers of Education express a commitment to the 'spiritual development and... wellbeing of young Australians' as a vital role of schools (MCEETYA, 2008, p.4).

Table 1 'Spiritual' in Australian curriculum frameworks*

\begin{tabular}{|l|l|l|l|l|l|l|l|lll|}
\hline state & ACT & NT & SA & Tas & Qsld & Vic & WA & \multicolumn{3}{|c|}{ NSW } \\
\hline level & $\begin{array}{l}\text { Pre- } \\
10\end{array}$ & Up & $1-12$ & K-10 & $1-10$ & Prep- & K-10 & K-6 & $7-10$ & $11-12$ \\
& to 10 & & & & 10 & & & & \\
HPE & 4 & 1 & 7 & 20 & 2 & 0 & 2 & 2 & 0 & $2+4$ \\
SOSE & 1 & 0 & 3 & 0 & 5 & 1 & 2 & 16 & Ab1 & $11+19+1$ \\
Arts & 0 & 3 & 1 & 4 & 12 & 0 & - & 2 & Mu1 & $1+1+4+3$ \\
Eg & 0 & 0 & 0 & 0 & 0 & 0 & 0 & 0 & 0 & 1 \\
Ma & 0 & 0 & 0 & 0 & 2 & 0 & 1 & 0 & & 1 \\
Sc & 0 & 0 & 0 & 0 & 0 & 0 & 0 & 0 & 0 & 0 \\
Tech & 0 & 0 & 0 & 1 & 1 & 0 & 0 & 0 & 0 & 0 \\
LOTE & 0 & 1 & 0 & 0 & 0 & 0 & 0 & Ab4 & 0 & 0 \\
voc & & & & 3 & & & & & & \\
lng & & & & & & & & & & \\
\hline total & 5 & 5 & 11 & 28 & 22 & 1 & 5 & 24 & 2 & 48 \\
\hline
\end{tabular}

NB Ab=Aboriginal Studies, Mu=Music * Information extracted on 24 March 2010 from:

http://curriculum.edu.au/ccsite/cc_curriculum_frameworks_and_syllabuses,20029.html 
All but one of the curriculum frameworks contain one or two mentions of 'spiritual' in their general preamble. However, there is no obvious agreement between these Australian documents as to what 'spiritual' means.

\section{A recent historical perspective}

The Common and Agreed National Goals for Schooling in Australia (Australian Education Council, 1989) did not give recognition to spiritual aspects of human existence, as was done in the UK at that time. However, following reviews of curriculum for Australian schools in the early 1990s, the spiritual aspects of human development were included in A statement on health and physical education (HPE) for Australian schools (AEC, 1994). These references had been placed in the national documents by religious education staff from Queensland Department of Education, who were part of the HPE writing team. More references to spiritual development were likely to have been included in the culture strand of A statement on studies of society and environment for Australian schools (SOSE) (AEC, 1994) had work on this statement not been removed from the original writing team in Queensland due to political influence (Gilbert et al., 1992, p.25).

Rossiter (2006) contends that even when there was no formal requirement on schools to promote moral and spiritual development of students, it is likely that this purpose would have been implied in the way teachers cared for them. This could have applied to religious-based schools where religiosity was conflated with spirituality but cannot be assumed in other schools. Rossiter insists clarification is needed to distinguish between the spiritual/moral influence of the school community as a social organisation, and the curriculum, i.e., what happens in classroom practice.

Prior to formal inclusion of students' spiritual development in national curriculum documents, Metherell, (NSW Ministry of Education 1990, in Crawford \& Rossiter, 1992) declared:

The moral, ethical and spiritual development of students is a fundamental goal of education. It is clearly not confined to one area of the curriculum. All teachers, across all areas of the curriculum have a responsibility to inculcate in their students positive values and a capacity for moral and ethical judgement.

Following this lead, NSW curriculum documents contain most references to spirituality in Australia, especially at senior secondary level, across a range of subject areas.

The Victorian Curriculum and Standards Framework I (Board Of Studies, 1995) contained ten references to spiritual development of young people in the HPE component and five in the SOSE component, together with one in Mathematics (Fisher, 1998). When the crowded Victorian curriculum was pruned, the CSF II (BOS, 2000) was left with a solitary reference to 'spiritual' in the Rationale section to The Arts (Fisher, 2001a). The current Victorian Essential Learning Standards (VCAA, 2004) has a solitary reference in the History section, with none in the general preamble (Fisher, 2007).

In SA, an inquiry into spiritual wellbeing arose from feedback to the Wellbeing is Central to Learning Working Paper (Department of Education and Children's Services, 2005). A discussion paper was made available (DECS, 2006) which led to the Learner Wellbeing Framework for birth to year 12 (DECS, 2007) where 'spiritual' is described as including 'beliefs, values, morals and ethics; a sense of meaning and purpose; altruism; and a sense of connectedness to something larger than oneself' (DECS, 2007, p.5) 
(Burrows, 2006).

In spite of considerable input from Australian educators in the field, in a recent content and discourse analysis of learning syllabuses and support material in Queensland Studies Authority curriculum documents, Deagon (2009, p.iv) concluded, 'spiritual in educational and health contexts [still] needs considerable research to inform a latticed theoretical field.'

\section{Some views on the relation between religion and spirituality}

The Australian Catholic 'Green' Catechism that was used in primary schools in 1939 made it clear that 'being spiritual was equivalent to being religious' (Crawford \& Rossiter, 2005, p1). In the twenty-first century, 'a distinction has been drawn between the spiritual and the religious - and in some cases even a divergence between the two, which has consequences for what is understood as spirituality' (ibid.). Crawford and Rossiter warn, 'However, the broader and more generic the definition, the more that everything in life seems to become a part of spirituality' (ibid., p.2).

Blomberg, who was a curriculum consultant for Christian Parent-Controlled Schools, contends, 'what we most value sets the spiritual direction of our lives' (2009, p.113). He further argues that there are "two primordial "spiritualities"” at work in Western culture. The first of these, labelled 'rationalistic spirituality,' in which reason sets our life direction, is called idolatry by Blomberg because it puts faith in a source of order and meaning other than God. According to Blomberg's worldview, relation with God is the basis for the second, or 'proper,' spirituality (2006).

\section{Classic and contemporary descriptions of spirituality}

Fallding (1958, reprinted in 1999) provided a thought-provoking article on the meaning of 'spiritual', which in part he described as amounting to 'harmonious inclusion through trust within a fellowship which is given primacy over oneself' (p.27). He opposed selfcentredness, placing the individual in community as an expression of spirituality. In order for us to find inclusion in the whole of existence 'we need a leader with cosmic stature who nevertheless bears our humanity....Christ, the Redeemer' (p.33). Alternate approaches, such as 'the mystic's ecstasy' and 'the pantheist's immersion in nature' are 'substitute solutions to the human problem' (p.33). In summary, Fallding concluded, 'to attain spiritual good....we ought to partake of the society of Christ' (p.36).

The following composite description of spirituality encompasses the variety of views in vogue in contemporary literature:

Spirituality is concerned with a person's awareness of the existence and experience of inner feelings and beliefs, that give purpose, meaning and value to life. Spirituality helps individuals to live at peace with themselves, to love (God and)* their neighbour, and to live in harmony with the environment. For some, spirituality involves an encounter with God, or transcendent reality, which can occur in or out of the context of organised religion, whereas for others, it involves no experience or belief in the supernatural.

NB * These words were placed in parentheses as they will be meaningless to those people who have no concept of God (Fisher, 1998, p.190). 
This description highlights four sets of relationships seen to comprise spirituality and wellbeing.

\section{Theoretical position/understanding of spirituality in Australian education General comments on spirituality in Australia}

Tacey writes with an engaging style about spirituality in Australia (e.g. 2000, 2003). His views are based on wide reading and personal experience in Jungian psychology and lived experience among Indigenous Australians. Tacey states, 'The new outbreak of spirituality is a desperate attempt by youth culture to counter the advances of the profane and secular society, with its appalling materialism, disillusionment and absence of hope' (1999, p.28).

From analyses of data in the 2002-3 Wellbeing and Security Study, exploring the influence of religion and spirituality on wellbeing of individuals and Australian society in general, the authors concluded, 'that alternative spiritual journeying is better than a secular mindset, but may not provide the levels of satisfaction, internal or relational wellbeing that generally comes with a religious orientation' (Kaldor et al., 2004, p.15).

Paralleling these views, Eckersley (2008, p.12 ) contends that three features of Western culture - namely dominant chosen values; rate and complexity of change; and lack of shared vision of society and its future - prevent young people from establishing a sense of identity, values and beliefs in a sound social and spiritual context. In paraphrasing Eckersley, we need to reclaim the priority of community over individualism; responsibilities over rights; spiritual over the material; future over the present; and the enduring over the ephemeral. These ideas build on previous work in which, for Eckersley et al. (2006, p.37), 'Spirituality represents the broadest and deepest form of connectedness. It is the only form of meaning that transcends people's personal circumstances, social situation and the material world, and so has a powerful capacity to sustain them through adversity.'

\section{General comments on spirituality in Australian education}

Holistic education

Crittenden (2003) investigated the ethic of care in education coupled with the notion of spirituality. He claimed spiritual development is a distinctive part of each school's culture and that 'holistic functions of education are not only the preserve of independent and church schools' (p.9). In tune with this egalitarian approach, Webster (2003) used works of Kierkegaard, Nietzsche and Heidegger to develop an existential framework of spirituality that embraced both religious and secular contexts of education. The evaluative applicability of this framework was illustrated and tested through a critique of an educational project in Queensland.

The ACER research conference of 2004 focussed on 'Supporting Student Wellbeing.' In his opening address, Masters discussed mental, emotional, spiritual, physical and social wellbeing in providing a 'framework for thinking about students' growth and development as healthy, well-rounded individuals' (2004, p.2). Marshall presented wellbeing in terms of physical stamina, spiritual direction and intellectual disposition and discussed how it contributes to learning engagement (2004, p.66), whereas Hill noted the role of values in wellbeing, warning against the removal of the 
religious variable from the curriculum, especially in state schools, which would leave values education in free fall (2004, p.19).

In an exploration of the development and psychological function of meaning, identity and spirituality in the education of young people, Crawford and Rossiter (2006) provided useful discussions on the spiritual and moral dimension in general curriculum for state and independent schools; religious education in religious-based schools; and state-based religion studies courses. Their work situates the education of youth in contemporary Western culture.

Carrington (2006) presented a challenge to schools to provide inclusive, supportive environments as a foundation for young Australians' intellectual, physical, social, moral, spiritual and aesthetic development. On the other hand, Hill believes the challenge of education is to enlighten and skill students, while parents, friends and benevolent community most appropriately provide appropriate supportive relationships (2006). Hill further investigated the role of teacher in educating for well-being, recognising both human and spiritual aspects. He contends the liberating aspects of education help individuals to 'interrogate their cultural conditioning and critically evaluate the nature and significance of the various life activities commended to them in the curriculum' (ibid. p.7).

Interviews with 98 educators in 22 (state, Catholic, other Christian and independent) schools revealed a high level of interest in addressing student spiritual wellbeing across the curriculum (Fisher, 1998), in agreement with views espoused by Crawford and Rossiter (1992).

\section{Professional practice}

Teaching is a "knowing and caring" profession (OECD 1994, in Cumming 2000). In catering for the needs, interests and capacities of each student, teachers need to address many aspects of human development, including the spiritual (Brock, 1999 in Cumming 2000). Point 8.2 of Cumming's report indicates that 'accomplished teachers inspire their students to learn,' establishing teacher-student relationships built on trust, honesty, empathy and authenticity. Point 8.3 lists five pillars of learning: Learning to know; do; live together; be; and survive, which includes engagement with the spiritual in considering the profession of teaching in Australia.

\section{Focus on spirituality in Australian curriculum}

\section{Challenges for curriculum}

For a balanced curriculum, 'we need more than numeracy and literacy' (from Noddings, in Blomberg 2006, p. 91). 'In the current age, too many children are technical wizards and moral incompetents. Many people feel helpless in the face of moral and spiritual lethargy of our children' (Elly, in NASCC 1999, p.9). 'If the world view of our culture is in decline; if its cultural imagination has run dry, then what we most desperately need is a spiritually renewed imagination' (Lambert, in NASSC 1999, p.33).

\section{Values education and spirituality}

Hill made a substantial contribution to values education in Australia, which impacts on discussions of spirituality (1991, 2008). Wallace (2000) used a framework to interpret the 
place of values in spirituality education in WA, which applies equally well to other schools. Numerous other articles on this topic could make a chapter on its own. For example, de Souza argued that as spirituality is innate and relational in nature, it provides an ideal basis through which a values approach can be included in education, promoting a sense of 'self and place, meaning and purpose in learning' (2006a).

\section{Spirituality in school leadership and governance}

Through their governance, schools build intellectual, social, financial and spiritual capital and align them to achieve their goals (Caldwell et al., 2008). Here, 'spiritual capital' referred to strength of moral purpose and the degree of coherence among values, beliefs and attitudes about life and learning (for some schools, spiritual capital has a foundation in religion; in others it refers to ethics and values shared by members of the school and its community). In developing spiritual capital, Bulleen encouraged spiritual vision and growth among adolescents (1997). He examined belief systems and values, personal development, self concept, spirituality and how schools can foster such developments in their students.

Principals play a crucial role in setting the scene for spirituality in schools (Fisher, 1999a), where 'a fundamental leadership responsibility for principals is to nurture a spiritual base to their own leadership' (Bracken, 2004, p.iii). Bracken claims that support for newly appointed principals and aspiring principals should be a system priority in light of the multiple leadership roles principals employ in spiritual formation of teachers in Catholic schools (in the Parramatta Diocese). Jacob (1996, p.vii, reported in Belmonte (2007)) goes further, contending:

If lay principals are to lead their school communities to engage in Catholic educational purposing, they will need the philosophical, theological, and historical training that was part-and-parcel of the formation program for religious sisters and priests whose communities staffed Catholic schools... Without such a formative program, it is difficult to envision how, even with the best intentions, lay principals will ever engage in authentic Catholic educational purposing and foster their school's Catholic identity.

In a study of lay principals in Catholic schools in Victoria, Davison reinforced Jacob's views by concluding, 'the findings point to the need for further development of an authentic spirituality of educational and faith leadership, based in the reality of principals' lives as family and community members and educators in faith of their staff and wider community' (2006, p.iv).

In contrast to the Catholic schools' position, Heads of Anglican and Uniting Church independent schools 'respect deeply the foundational religious precepts of their schools. But they resist firmly any intrusion by the Church into their educational prerogative...They claim ultimately to be the spiritual leaders of their school' (Bednall, 2006, p.iii). In concert with this stance, Bell (2004) used Weberian constructs together with biblical theology to provide a definitive study of spiritual leadership in schools established in the Sydney Anglican Diocese.

In support of the trend for the creation of healthy school communities, LarewMicheletto (2002) argued that school leaders need to take on board more holistic notions of health which incorporate the spiritual with social, emotional and physical health. A 
practical example of what can be achieved when a school is committed to better meeting academic, social, emotional and spiritual needs of students from preparatory to year 12 was described by Gore (2003), who detailed the total restructure of a school to support students. In an age of restructure and change in schools, pastoral care is considered a key part of school's culture, reflecting on three important elements of emotional support; behaviour management; and spiritual development and service (Comius-Randall \& Boylan, 2003).

Spiritual intelligence (SQ) appears to have special significance for leadership in religious education (de Souza, 2006b). SQ can be used to empower and transform communities, by 'filtering out divisive elements and by creating communities that comprise individuals fired by care, compassion, vision, promise and passion' (p.152).

\section{Empirical research studies from early childhood to adult/community education} In early childhood

In a 12-month study with 3-7 year-olds, Giesenberg (2007) concluded that young children "live in" their spirituality, being very aware of their surroundings and able to express abstract concepts of love, beauty, wonder and compassion. Her view that young children's spirituality does not include relationship with a transcendent being is contrasted with Cupit's extensive work in this area. In developing a model of spiritual development in the public educative care of children, using narrative criticism of biblical descriptions of spirituality and childhood, within an evangelical framework, Cupit maintained, 'all children, without qualification of belief, community, rite or age, were identified as spirits who share a special relationship with God's Spirit both ontologically and experientially' (2001, p.i).

Nemme (2008) used case studies at early childhood, primary and junior secondary school levels to gain an understanding of spirituality across childhood. Observation, interviews, work samples and journal entries were used to investigate formal and informal interactions in addressing spiritual matters. Spiritual sensing categories were identified as awareness-sensing, mystery-sensing and values-sensing.

\section{At primary school}

Robertson (2001) constructed an understanding of spiritual health within the context of a primary school. This resulted in a working set of indicators of spiritual health, which provided assessment of the areas of the curriculum in which spiritual health is promoted and could be promoted. Fisher developed a unique quantitative measure of spiritual wellbeing for primary school students, balanced over the four domains of spiritual health (2004). He also reported on levels of spiritual wellbeing expressed by primary teachers in state, Catholic, other Christian and independent schools (2001b, 2007, 2008) and their influence on students' spiritual wellbeing (2009c).

In a qualitative study in Australian Catholic primary schools, Hyde (2005), identified four characteristics of children's spirituality - the felt sense, integrating awareness, weaving threads of meaning and spiritual questing. Two factors which inhibit children's spirituality were described as material pursuit and trivialising. As a means of interpreting young children's spirituality, Hyde also refers to four lifeworld existentials of lived body, lived time, lived space and lived human relation $(2003,2008)$. An alternative 
means of developing children's spirituality was proposed by Mountain (2007), who reported on the use of imagination.

Lyle (2007) offered a theology of spirituality, which emphasised the significance of relationships in the world, and with God, involving religious belief and practice. Analysis of a survey of people who work with children of primary school age indicated that their perceptions actually reflected a consciousness of imbalances in Christian ministry with these children, when considering the relational connections that comprise their holistic spiritual existence. Theological implications for spirituality and spiritual development suggest a broader context than that offered through programs that focus on teaching and learning about religious belief and practice.

Rymarz and Tuohy (2008), in accord with Mason et al. (2006), adopted a religious view of spirituality as the basis for investigating spiritual development of young people in Catholic upper primary to senior secondary schools. They found most students had a deistic conception of God, coupled with an expectation of lowering religiosity in transition from primary to secondary school.

\section{At secondary school}

students

A variety of assessments have been attempted of Australian students' spirituality/wellbeing:

Based on her study of 144 Australian adolescents in which some indicators of spiritual health were considered to be related to health-affecting behaviours, Gehrig (1998) proposed some areas, excluding relationship with God, in which schools might strengthen spiritual health in adolescents. Broader studies, based on Fisher's four domains model of spiritual health and well-being (1998), have been undertaken with thousands of Australian youth by Fisher (1999b, 2006, 2009b) and Hughes (2007) in which the quality of relationships of students with themselves, others, environment and/or God provided reflections of their spiritual well-being. Engebretson has also undertaken several studies on religiosity and spirituality among teenage boys $(2002,2007)$ which reinforce the importance of these four sets of relationships for spiritual development.

De Souza et al. (2004) reported implications for education based on a qualitative study on the perceptions of spiritual wellbeing held by young people who live in a regional city in Australia. In another qualitative study, Hodder (2009) found 'New Age' and 'evangelical' spiritual expressions among young people, which had implications for their wellbeing. This work built on Hodder's previous call for a spiritual foundation for Australian schooling (2007).

In a study on ethnicity and coping, D'Anastasi and Frydenberg (2005) found that a group of students labelled 'Australian minority group' (of Asian, African, Pacific Islanders and Middle Eastern students) used more spiritual support and resorted to social action more than did Anglo-Australian students.

The Spirit of Generation Y project was an Australian study that included some secondary school students. Three main (religious) strands by which spirituality of Generation Y can be described are Christian (43\%), Eclectic (17\%) and Humanist (31\%) (Mason et al., 2006). This study concluded that secularisation, the relativism of postmodernity, consumer capitalism and individualism are significant social forces 
shaping contemporary spirituality in Generation Y in Australia. Previously, people such as Eckersley, Rossiter and Tacey have spoken against these forces.

In developing a framework for 'spiritual sensitivity' and 'relational consciousness' through studying the 'limit' experience of students in four Catholic senior high schools, McQuillan (2001) discovered conflict between students' lived experiences and institutional religion. In contrast, investigation of the religious and spiritual development of 13-18 year-old Latter-day Saints revealed that both public and private forms of religious participation had major influence on spirituality (Carthew, 2008). Religiosity and spirituality also had some influence on these Latter-day Saints' moral reasoning and social attitudes.

teachers

According to Rowe (2003) research has shown, "what matters most" for students' cognitive, affective and behavioural outcomes of schooling is quality of teachers and teaching, supported by strategic teacher professional development. In line with this statement, Fisher's work with primary and secondary school teachers (2008) shows that teachers' own lived experience has greatest impact on how they perceive schools' influence on students' spiritual well-being.

Spiritual formation of teachers does not mean 'adding more water to an already overfull cup,' by asking teachers to do more. Rather, make space and provide opportunity for teachers to discover 'moments of grace' that providentially fill their day (at least in Catholic schools) (Downey, 2006). This is one way, individual educators can develop their inner selves by integration, awareness and human potential, thus promoting interconnectedness and spirituality in general (Griggs, 1996). In a particular instance, an auto-ethnographic study by a science teacher describes her attempts to reconcile science and soul in an effort to transform science teaching from an holistic view of education (Stack, 2006).

But the school setting makes a difference. Anglican schools studied in Adelaide placed greater emphasis on academic excellence compared with spiritual formation, so very little training in spirituality was provided for staff. In contrast, the Catholic and other-Christian schools saw spiritual formation as paramount, with relevant training being provided for staff (Zaplatynskj, 2005).

\section{Some snippets from the Tertiary/university sector}

Hill outlined how a form of tertiary study, 'theological study, undertaken rightly, can deepen and excite our spirituality' through which 'we can often deepen each other's spiritual depth by sharing some of the valuable analytic perspectives we have acquired through our studies' (2001, p.42).

Qualitative comments from a brief survey of teacher education students were categorised into five areas of self; religion; nature; relationships; and major life events by Rogers \& Hill (2002). These authors reported, 'trainee teachers were struggling with the notions of spirituality as much as the researchers were struggling to draw out and capture their understanding' (ibid., p.287) using qualitative methods. However, quantitative studies using SHALOM have successfully compared levels of spiritual wellbeing and attitudes to spirituality in education among pre-service teachers in Australian state, 
Catholic and Christian tertiary institutions (Fisher, 2000, 2002, 2009a) as well as some in the UK (Fisher et al., 2009).

Ayres (2006) declared that although 'universities always had as a primary goal the cultural and spiritual enrichment of all their students, they no longer have such a raison d'être' (p.24). He further contends, 'stress of the utilitarian is most pernicious in schools, which are subject to governmental policy' (ibid.). In the times of Plato and J.S. Mill the focus of education was on the person being taught, with the well-being of the state as an outcome. But today the emphasis in education is largely on the service of the state to enable successful competition in the international commercial arena. To redress the current imbalance, Ayres conjectured that what is needed now is a balance between the demands of society and the cultivation of the individual spirit.

Buchanan \& Hyde (2008) built on de Souza's work (2001, 2005), in exploring a model addressing the complementarity of cognitive, affective and spiritual dimensions of learning. Pre-service RE teachers in a Catholic university developed an understanding of holistic learning and planned appropriate learning and teaching strategies to effect this model.

\section{Community education/lifelong learning}

After reporting that spiritual values are largely ignored in adult education research and literature, Westrup (1998) discussed how adult learners' spiritual tradition influenced their motivation, participation and success. In similar vein, Sanders suggested that adult educators and educational approaches 'require a strong ethical and loving value base, and need to foster the 'spirit' wisdom of learners in order to counteract the despair and nihilism of the current age' (1999, p.iii)

Schmid (2006) examined the nexus between Arne Naess's ecological self, transpersonal psychology and three spiritual traditions, namely Aboriginal spiritualities, the Goddess movement and Tibetan Buddhism. These traditions were shown to encourage compassion, connectedness, interdependency as well as imparting ecological wisdom. This work was posited in the context of education for sustainability in lifelong learning.

Chung (2006) canvassed the influence of parent's worldviews and the role of cultural institutions in construction of identity that led to distinctive spirituality of young people in a Chinese evangelical church in Melbourne.

\section{Concluding comments}

When all is said and done, we have only just begun to tackle the issue of spirituality in education in Australia. Spiritual development and wellbeing of students are listed in key goals of schooling, reinforced by specific references in state and territory curriculum frameworks. In order to move beyond rhetoric to action, we could benefit from agreed meaning of 'spiritual development and well-being' of students. The publications reported in this chapter, and indeed in this book, provide food for thought in addressing meaning of these terms as well as appropriate staff and curriculum development.

Educators need to have a clear idea of their own worldview and the bias this presents in their understanding of the nature of spirituality and its place in education. Research has shown that teachers are the key to effectiveness in schools and that teachers' lived experience impacts greatly on their own and students' perceptions of spiritual 
wellbeing in schools. All teachers, across the curriculum, influence students' spiritual development by who they are and by what they say. When teachers are compassionate, humble, respectful, inspiring, sincere and trustworthy, they model positive aspects of spiritual wellbeing to students. For genuine education, teachers need not only to tolerate, but to accept, and even embrace, differences with other people, to relate spirit to spirit, for the benefit of schools and the wider community.

It is to be hoped that when/if a national Australian HPE curriculum statement is written, under the auspices of the Australian Curriculum, Assessment and Reporting Authority (Macdonald, 2010), that it will go beyond the physical, mental, emotional and social dimensions of health to reach the heart, i.e., the spiritual, which is foundational to health, for the (w)holistic wellbeing of Australians through education.

\section{$-.-.-\cdot$}

\section{Endnote}

Availability of publications on spirituality in Australian education

It would take at least two chapters in this book to address adequately the breadth and depth of all publications by Australians on spirituality in education. References to many papers can be found by searching the curriculum vitae of staff via university websites. Those who have been particularly prolific and only given selected presentation of their work here are de Souza, Hyde and Rossiter (Australian Catholic University), Tacey (La Trobe University) and Fisher (University of Ballarat). Relevant references to spiritual/ity are available in Australian Association for Research in Education conference abstracts, Australian Council for Educational Research conferences and publications, ACSA Curriculum Perspectives, Australasian Digital Theses, British Journal of Religious Education, Christian Research Association, Journal of Beliefs \& Values, Journal of Christian Education \& Belief, Pastoral Psychology, Personality And Individual Differences, Springerlink, Youth Studies Australia.

Special reference is made to the following:

A special edition of Health Education Australia on 'Spiritual health and wellbeing' (Guest editor Fisher, 2001) with papers exploring issues such as Buddhism, curriculum, Daoism, inner peace, meditation, Steiner approach and Yoga.

The Journal of Christian Education devoted a special issue to 'Children and Spirituality’ (May 2001) with contributions by four Australian authors, with relevant articles in other issues.

The International Journal of Children's Spirituality features numerous articles by Australians, with a special issue dedicated to research in spirituality in Australasia (Guest editors de Souza \& Hyde, 2007).

The Journal of Religious Education and Religious Education Journal of Australia feature many articles on spirituality in Australian education.

The International Handbook of the Religious, Moral and Spiritual Dimensions of Education (2006) and the International Handbook of Education for Spirituality, Care and Wellbeing (2009) (both edited by de Souza et al.) contain many relevant chapters by Australians. 


\section{References}

Australian Education Council (1994). A statement on health and physical education for Australian schools. Melbourne: Curriculum Corporation.

Australian Education Council (1994). A statement on studies of society and environment for Australian schools. Melbourne: Curriculum Corporation.

Ayres, P. (2006) Cheerless culture killers. Quadrant, (June): 20-24.

Bednall, J.M. (2006) Leading religiosity in Anglican and Uniting Church independent schools: A phenomenological exploration. PhD dissertation, University of Notre Dame, Fremantle Australia.

Bell, G.M. (2004) Pure charisma: A study of leadership in the Judaic Christian tradition in the light of Weberian thought. New Horizons in Education, 49:42-56.

Belmonte, A. (2007) Leadership challenges for Catholic lay principals in Australia. Perspectives on Educational Leadership. (March) 2 pages.

Blomberg, D. (2006) The formation of character: Spirituality seeking justice. Journal of Education \& Christian Belief, 10(2):91-110.

Blomberg, D. (2009) Whose spirituality? Which rationality? A narrational locus for learning. Journal of Education \& Christian Belief, 13(2):113-124.

Board of Studies (1995). Curriculum \& Standards Framework - Health and Physical Education. Carlton, Victoria: BOS.

BOS (2000) Curriculum \& Standards Framework II. Carlton, Victoria: BOS.

Bracken, A.J. (2004) The principal's leadership role in the formation of teachers in Catholic schools: A case study in one educational system. Ed dissertation, Australian Catholic University, Fitzroy Vic.

Buchanan, M. \& Hyde, B. (2008) Learning beyond the surface: Engaging the cognitive, affective and spiritual dimensions within the curriculum. International Journal of Children's Spirituality, 13(4):309-320.

Bulleen, A. (1997) Encouraging spiritual vision and growth among adolescents: 'The good life.' In The $6^{\text {th }}$ AHISA biennial conference: conference papers, 21-25 August, Hobart. Jolimont Vic: AHISA.

Burrows, L. (2006) Does spiritual well-being have a place in public education? In L. Jeffrey (Ed.) Conference of the Australian Association for Research in Education, 27-30 November 2006. Melbourne; AARE. 
Caldwell, B.J. \& Harris, J. (2008) Breakthrough in governance. London: Specialist Schools and Academies Trust.

Carrington, S. (2006) Developing an inclusive school culture. In M. Keeffe \& S. Carrington (Eds.) Schools and diversity, (pp.18-32). French's forest NSW: Pearson Education Australia.

Carthew, M.J. (2008) Spiritual, moral and social development as the outcomes of a program for youth. $\mathrm{PhD}$ dissertation, Flinders University of SA.

Comius-Randall, R. \& Boylan, G. (2003) Creating and managing a caring environment: Pastoral care in action. In C. Boylan \& B. Hemmings (Eds.) Global focus - local partnerships: Conference proceedings (pp.39-49). Darling Heights Qld: SPERA.

Chung, M.L. (2006) Chinese young people and spirituality: An Australian study. $\mathrm{PhD}$ dissertation, Australian Catholic University, Fitzroy Vic.

Crawford, M. \& Rossiter, G. (1992) Teaching wisdom: Religious education and the spiritual and moral development of young people. Journal of Christian Education, Papers 101:47-63.

Crawford, M. \& Rossiter, G. (2005) Spirituality and religious education (editorial). Journal of Religious Education, 53(1):1-2.

Crawford, M. \& Rossiter, G. (2006). Reasons for living: Education and young people's search for meaning, identity and spirituality. A handbook. Camberwell, Victoria: ACER Press.

Crittenden, A. H. (2003) Perceptions of spirituality through an ethic of care: Comparative responses to spiritual dimensions of education. Religious Education Journal of Australia, 19(2):9-19.

Cumming, J. (Ed.) (2000) Standards of professional practice for accomplished teaching in Australian classrooms: A national discussion paper. ACSA, ACE, AARE.

Cupit, G. (2001) Spiritual development and the public educative care of children: A critical evaluation of biblical and dynamic systems perspectives. $\mathrm{PhD}$ dissertation, Murdoch University WA.

D'Anastasi, T. \& Frydenberg, E. (2005) ethnicity and coping: What young people do and what young people learn. Australian Journal of Guidance and Counselling, 15(1):4359.

Davison, L. (2006) Lay principals under contract: 'Going down for the good turf': An exploration of the perceptions of selected secondary lay principals in relation to the 
religious and spiritual dimensions of their role. EdD dissertation, Australian Catholic University, Fitzroy, Vic.

Deagon, J.R. (2009) 'Spiritual' discourse models at work in Queensland Studies Authority curriculum documents. MEd dissertation, Griffith University, Gold Coast Campus.

Department of Education and Children's Services (DECS) (2005) Wellbeing is Central to Learning Working Paper. Adelaide: DECS.

DECS (2006) Does spiritual well-being belong in education? Spiritual well-being and education discussion paper. Adelaide: DECS.

DECS (2007) Learner wellbeing framework for birth to year 12. Adelaide: DECS. de Souza, M. (2001) Addressing the spiritual dimension in education : Teaching affectively to promote cognition. Journal of Religious Education, 49(3):31-41.

de Souza, M. (2005) Growing empathetic, compassionate, meaningful and hopefilled students: Re-discovering the spiritual dimension in education. New Horizons in Education, 113:41-52.

de Souza, M. (2006a) Rediscovering the spiritual dimension in education: Promoting a sense of self and place, meaning and purpose in learning. In M. de Souza et al. (Eds.) International handbook of the religious, moral and spiritual dimensions in education, (pp.1127-1139). Dordrecht: Springer.

de Souza, M. (2006b) Then role of spiritual intelligence in transforming Catholic religious education leadership. In R. Rymarz (Ed.), in Leadership in religious education, (pp.152-172). Strathfield NSW: St Paul's Publications.

de Souza, M., Cartwright, P. \& McGilp, E. (2004) The perceptions of young people who live in a regional city in Australia of their spiritual wellbeing : Implications for education. Journal of Youth Studies, 7(2):155-172.

Downey, M.J. (2006) Experiences of teachers' daily work which nourish and sustain the spirituality of lay teachers in Catholic high schools. EdD dissertation, Australian Catholic University, McAuley Campus Qld.

Eckersley, R. (2008) Values and visions: Youth and the failure of modern Western culture.Youth Studies Australia, 27(3):10-19.

Eckersley, R. Wierenga, A. \& Wyn, J. (2006) Flashpoints \& signposts: Pathways to success and wellbeing for Australia's young people. A project by Australia 21 and the Australian Youth Research Centre, supported by VicHealth. 
Engebretson, K. (2002) Expressions of religiosity and spirituality among Australian 14 year olds. International Journal of Children's Spirituality, 7(1):57-72.

Engebretson, K. (2007) Connecting: Teenage boys, spirituality and religious education. Strathfield NSW: St Paul's Publications.

Fallding, H. (1999) Towards a definition of the term "spiritual." Journal of Christian Education, 42(3):21-36.

Fisher, J.W. (1998). Spiritual health: Its nature and place in the school curriculum. $\mathrm{PhD}$ thesis, University of Melbourne (Published by Melbourne University Bookshop) Available from http://eprints.unimelb.edu.au/archive/00002994/

Fisher, J.W. (1999a). Helps to fostering students' spiritual health. International Journal of Children's Spirituality, 4(1):29-49.

Fisher, J.W. (1999b). Developing a Spiritual Health And Life-Orientation Measure for secondary school students. In J. Ryan, V. Wittwer \& P. Baird (Eds.), Research with a regional/rural focus: Proceedings of the University of Ballarat inaugural annual research conference, 15 October, 1999 (pp.57-63). Ballarat: University of Ballarat, Research and Graduate Studies Office.

Fisher, J.W. (2000). Being human, becoming whole: Understanding spiritual health \& well-being. Journal of Christian Education, 43(3):37-52.

Fisher, J.W. (2001a) Going beyond CSF II to nurture the head and heart of students in Victorian schools. Health Education Australia, 1(1): 6-9.

Fisher, J.W. (2001b). Comparing levels of spiritual well-being in state, Catholic and independent schools in Victoria, Australia. Journal of Beliefs and Values, 22(1), 99105.

Fisher, J.W. (2002) Enhancing university students' spiritual well-being. In J. Ryan \& P. Baird (Eds), Research for a better community: Proceedings of the University of Ballarat second annual research conference, 8 September 2000, (pp. 58-61). Ballarat: University of Ballarat, Research and Graduate Studies Office.

Fisher, J.W. (2004). Feeling Good, Living Life: A spiritual health measure for young children. Journal of Beliefs \& Values, 25(3):307-315.

Fisher, J.W. (2006). Using secondary students' views about influences on their spiritual well-being to inform pastoral care. International Journal of Children's Spirituality, 11(3):347-356.

Fisher, J.W. (2007). It's time to wake up and stem the decline in spiritual well-being in 
Victorian schools. International Journal of Children's Spirituality, 12(2): 165-177.

Fisher, J.W. (2008). Impacting teachers' and students' spiritual well-being. Journal of Beliefs

\& Values, 29(3):253-261.

Fisher, J.W. (2009a) Investigating Australian education students' views about spiritual well-being as compared with teachers in schools. International Journal of Children's Spirituality, 14(2):151-167.

Fisher, J.W. (2009b) Getting the balance: Assessing spirituality and well-being among children and youth. International Journal of Children's Spirituality, 14(3):273-288.

Fisher, J.W. (2009c) Reaching the heart: Assessing and nurturing spiritual well-being via education. EdD dissertation, University of Ballarat, Victoria, Australia. Available from http://archimedes.ballarat.edu.au:8080/vital/access/HandleResolver/1959.17/13481.

Fisher, J.W., Barnes, L.P. \& Marks, G. (2009) Pre-service teachers' spiritual well-being across time and faiths: Implications for religious education. Religious Education Journal of Australia, 25(2):10-16.

Gehrig, S. (1998) An investigation of the spiritual health status of young Australians aged 16 years. $\operatorname{MEd}($ Hons) dissertation, University of Sydney.

Giesenberg, A. (2007) The phenomenology of preschool children's spirituality. $\mathrm{PhD}$ dissertation, Queensland University of Technology.

Gilbert, R., Gordon, K., Hoepper, B., Land, R. (1992). Love's labours lost? - Writing a National Statement. Curriculum Perspectives - Newsletter edition, Nov. 25-7.

Gore, B. \& Lanyon, G. (2003) Restructuring schools to support students. In Conference papers: The Hutchins School, Sandy Bay, Tas., 22-25 April. Jolimont Vic: AHISA.

Griggs, D.E. (1996) Spirit of learning: An exploration into the role of personal/ spiritual development in the learning, teaching process. MSc(Hons) dissertation University of Western Sydney - Hawkesbury.

Hill, B.V. (1991) Values education in Australian schools. Hawthorn, Vic.: ACER

Hill, B.V. (2001) Do theological studies foster spirituality? Journal of Christian Education, 44(3):33-42.

Hill, B.V. (2004) Core values in balance. In Supporting student wellbeing: What does the research tell us about the social and emotional development of young people? (pp.17-19) 24-26 October 2004, Adelaide, SA. Melbourne: ACER. 
Hill, B.V. (2006) Am I a teacher or a nurse-maid? EQ Australia, 3, 6-7.

Hill, B.V. (2007) Is school chaplaincy being secularised? Journal of Christian Education, 50(1):49-59.

Hill, B.V. (2008) Values in free fall? RE and values in public schools. Journal of Christian Education, 51(3):43-55.

Hodder, J. (2007) Young people and spirituality: The need for a spiritual foundation for Australian schooling. International Journal of Children's Spirituality, 12(2):179-190.

Hodder, J. (2009) Spirituality and well-being: 'New Age' and 'evangelical' spiritual expressions among young people and their implications for well-being. International Journal of Children's Spirituality, 14(3):197-212.

Hughes, P. (2007). Putting Life Together: Findings from Australian Youth Spirituality Research. Melbourne: CRA/Fairfield Press.

Hyde, B. (2003) Lifeworld existentials: Guides to reflection on a child's spirituality. Journal of Religious Education, 51(3):27-33.

Hyde, B. (2005) Identifying some characteristic of children's spirituality in Australian Catholic primary schools: A study of hermeneutic phenomenology. $\mathrm{PhD}$ dissertation, Australian Catholic University.

Hyde, B. (2008). Children and spirituality: Searching for meaning and connection. London: Jessica Kingsley Publishers.

Kaldor, P., Hughes, P., Castle, K. \& Bellamy, J. (2004) Spirituality and wellbeing in Australia. NCLS Occasional Paper 6. Sydney: NCLS Research.

Larew-Micheletto, G. (2002) on school leadership, healthy school communities and passion. Health Education Australia, 2(1):19-23.

Lyle, D.A. (2007) Perceptions of the nature and development of children's spirituality and the implications for Christian ministry. DMin dissertation, Tabor College, Adelaide.

Macdonald, D. (2010) Health \& physical education presentation. At the National Curriculum Symposium, 25-27 February, University of Melbourne. Retrieved 20 April 2010 as http://www.education.unimelb.edu.au/news/National_Curriculum_Symposium/ 2010_National_Curriculum_Symposium.html

McQuillan, P. (2001) The 'limit' experience of senior high school students: A study across four Catholic high schools. PhD dissertation, Australian Catholic University, Fitzroy, Vic. 
Mason, M., Webber, R., Singleton, A. \& Hughes, P. (2006). The Spirit of Generation Y. Summary of the final report of a three year study. Retrieved 12 February, 2007, from: http://dlibrary.acu.edu.au/research/ccls/spir/sppub/sppub.htm Subsequently published as: Mason. M., Singleton, A. \& Webber, R. (2007). The Spirit of Generation Y. Melbourne: John Garratt.

Marshall, S. (2004) Strengthening learning through a focus on well-being. In, Supporting student wellbeing: What does the research tell us about the social and emotional development of young people? (pp.66-70) 24-26 October 2004, Adelaide, SA. Melbourne: ACER.

Masters, G.N. (2004) Conceptualising and researching student wellbeing. In Supporting student wellbeing: What does the research tell us about the social and emotional development of young people? (pp.2-6) 24-26 October 2004, Adelaide, SA. Melbourne: ACER.

Ministerial Council on Education, Employment, Training and Youth Affairs. (1999). The Adelaide Declaration on National Goals for Schooling in the Twenty-First Century. 2223 April. Adelaide: MCEETYA.

MCEETYA (2008). Melbourne Declaration on Educational Goals for Young Australians. 5 December. Melbourne: MCEETYA.

Mountain, V. Educational contexts for the development of children's spirituality: Exploring the use of imagination. International Journal of Children's Spirituality, 12(2):191-205.

Nemme, K. (2008) Nurturing the inner lives of children: An exploration of children's spirituality in three educational settings. PhD dissertation, University of Wollongong.

Robertson, J. (2001) Toward a constructed understanding of spiritual health. SMEC 691/692, Curtin University of Technology.

Rogers, G. \& Hill, D. (2002) Initial primary teacher education students and spirituality. International Journal of Children's Spirituality, 7(3):273-289.

Rossiter, G. (2006) The spiritual and moral dimension to the school curriculum: The evolution in personal development aims for Australian education. Journal of Catholic School Studies, 78(1):100-113.

Rowe, K. (2003) The importance of teacher quality as a key determinant of students' experiences and outcomes of schooling. ACER Research Conference, Carlton-Crest Hotel, Melbourne, 19-21 October. 
Rymarz, R. \& Tuohy, D. (2008) The religious participation and spiritual development of young people in Catholic schools: A longitudinal view. Journal of Religious Education, 56(4):40-52.

Sanders, M.R. (1999) Adult education for actualising human potential: Achieving consensus out of contested meanings. MEd dissertation, University of SA.

Schmid, E. (2006) An ecological sense of self as a necessary development for an ecologically sustainable future: The contributions of three spiritual or wisdom traditions to constructions of self and other in educational contexts. MEd dissertation, University of Canberra.

Stack, S. (2006) Integrating science and soul in education. PhD dissertation, Curtin University of Technology.

Tacey, D. (1999) Youth spirituality, religion and cosmic sacredness: Postmodernity, postChristianity, and the coming age. Interface: A Forum for Theology in the World, 2(2):2237.

Tacey, D. (2000) Re-Enchantment: The new Australian spirituality. Sydney: HarperCollins.

Tacey, D. (2003) The spirituality revolution: The emergence of contemporary spirituality. Sydney: HarperCollins.

Wallace, T. (2000) Values and spirituality: Enriching curriculum development and teaching/learning processes for a new millennium. Journal of Christian Education, 43(1):41-49.

Webster, R.S. (2003) An existential framework of spirituality for education. $\mathrm{PhD}$ dissertation, Griffith University.

Westrup, J. (1998) Invisibility? Spiritual values and adult education. Australian Journal of Adult and Community Education, 38(2):106-110.

Zaplatynskyj, E.N. (2005) "Spirituality and stuff like that": Formation of young people's spirituality and the role of secondary schools in Adelaide. Adelaide: Anglican Church, Diocese of Adelaide, Social Responsibilities Committee. 


\subsection{Spirituality and Religious Education in the National Curriculum}

\section{Background}

The almost exclusive use of overseas references to inform discussion on Religious Education (RE) in the (Australian) National Curriculum moved me to critique a paper published in the Religious Education Journal of Australia in 2011. This also provided an appropriate opportunity for me to add material relating to RE and spiritual education in Australia, which had been edited from the previously mentioned ACE book chapter (Chapter 4.2 herein), due to size constraints.

\section{Key points extracted from this paper}

- Humanists are attacking Christian Religious Education and chaplaincy in Australian schools despite the key Ministers of Education making statements that the spiritual development of students is a core goal for youth development for the $21^{\text {st }}$ Century.

- There has been gradual erosion over time of 'spirituality' in curriculum documents in the Australian state of Victoria.

- An Australian educator, Duncan Reid, displayed limited understanding of spirituality in education, especially in the Australian context.

- There is no legal separation of Church and State in Australia as there is, for example, in the USA.

- Emphasis on the importance of God for the spiritual well-being of young people varies by school type.

\section{Implications}

In light of the National Curriculum being developed, and the continuance of funding for chaplains in schools, there is a need to address religious and spirituality education for holistic education in Australian schools.

Religious Education and education in and for spiritual development should be included in Australian curricula, but the relationship between the two constructs needs to be clarified. 
This paper was published as: Fisher, J.W. (2012) Spirituality and Religious Education in the National Curriculum - A response to Duncan Reid. Religious Education Journal of Australia, 28(1): 3-8.

\title{
Spirituality and Religious Education in the National Curriculum - A Response to Duncan Reid.
}

\section{Dr John W. Fisher, Honorary Senior Research Fellow}

School of Education and Arts, University of Ballarat, Vic, Australia.

Email: j.fisher@ballarat.edu.au

\begin{abstract}
Duncan Reid's paper provided a springboard from which to launch into discussions about making space for Religious Education in the (Australian) National Curriculum (REJA, 27(2):10-15, 2011). Some brief comments are presented in this paper to expand thinking in the area of religious education with particular reference to spirituality. Due to size constraints and editorial direction, references of research in the area of spirituality related to religious education, that were edited out of the Australian College of Educators book on Australian perspectives on education and spirituality, have also been included here. It is hoped that this response will add to and help inform the debate about the place of Religious Education (and spirituality) in the evolving Australian National Curriculum.
\end{abstract}

\section{Key words}

Spirituality, RE, National Curriculum

\section{Introduction}

Duncan Reid's paper in the last issue of REJA (2011) presented cogent arguments for including Religious Education in the (Australian) National Curriculum. This paper comes at a time in which religious educators in the UK are fighting to prevent their area from being downgraded from its longstanding position in core curriculum by removal from public examinations at senior secondary school level. There are also political moves afoot in Australia at this time by secular humanists, who are intent on restricting, if not removing, Christian Religious Education from state schools and challenging the constitutional basis for funding of chaplains by the Australian Federal government. This political action is a blatant attempt by a minority to exert undue influence on the majority of Australians, who still claim religious affiliation of some sort, according to Census figures. Such actions highlight the necessity of addressing the role and function of religious as well as spirituality education for holistic, democratic education of young people in Australia.

Terence Lovat's concise overview of spirituality and religion in public schools 
(2010) concludes with the Adelaide and Melbourne Declarations in which spiritual development of young people is stated plainly as a goal of Australian schooling. Over the last two decades, we have seen the emergence followed by gradual erosion of spirituality in curriculum statements in Victoria, from Curriculum \& Standards Framework I through CSF II to the Victorian Essential Learning Standards (Fisher, 2007). Other states of Australia have had varying success in holding onto vestiges of holistic development for students within their curriculum statements (Fisher, 2010). With the advent of the National Curriculum, we have a slim opportunity of seeking a place for spirituality and religious education to be recognised as essential features of holistic education for Australian youth in line with the Declarations previously reported by the joint Ministers of Education in Australian states and territories.

\section{Reflections on Duncan Reid's paper}

Duncan's paper put the issue of Religious Education (RE) in context beginning with a summary of Barry McGaw's address to the Victorian Association for Religious Education AGM, which did not paint a rosy picture for RE gaining a guernsey for inclusion in the core of the National Curriculum, currently under construction. The perennial Australian educator Brian Hill was given appropriate mention as a proponent for RE as a core curriculum activity.

Duncan disclosed his Anglican perspective and his "single enduring idea for religious education" being "that the world is a holy place" (p.11). Following was an extension by Jenny Berglund, of the work by Gabriel Moran, in which three different ways of presenting religious education were described as education 'into', 'about' or 'from' religion. Problems were noted about each of these approaches to religious education. It was a pity that Duncan's two key sources, books from overseas, were not evenly balanced by work from Australia, as his paper pertained to Australia's National Curriculum.

Describing spirituality \& religion. A key concern with Duncan's paper is his truncated treatment of the issue of spirituality. His half a page certainly was only "a note about spirituality" (p.12); one that was too short to be meaningful, as well as presenting inaccurate and incomplete representations of Australian authors' work in this area. Duncan appears to accept problems associated with variations on teaching RE but has trouble doing the same for "spirituality in educational curricula" because of a stated lack of agreement of a definition for the term. There is wide variation in description of each term as well as opinions on how they relate to each other.

Whilst looking at only the ACE book for input from Australia, Duncan overlooked John Fisher's composite description of spirituality in vogue in contemporary literature:

Spirituality is concerned with a person's awareness of the existence and experience of inner feelings and beliefs that give purpose, meaning and value to life. Spirituality helps individuals to live at peace with themselves, to love (God and)* their neighbour, and to live in harmony with the environment. For some, spirituality involves an encounter with God, or transcendent reality, which can occur in or out of the context of organised religion, whereas for others, it involves no experience or belief in the supernatural. 
NB * These words were placed in parentheses as they will be meaningless to those people who have no concept of God (Fisher, p.108, 2010).

Duncan decided instead to attribute to John Fisher what was in fact a paraphrase of Richard Eckersley's comment on spirituality in Western culture (that of a dualist notion of "spiritual over the material") (ibid. p.109). He also gave a selected interpretation of Brendan Hyde's considerable work in the area (e.g., 2005, 2008, 2010), whilst totally refraining from comment on the work of Marian de Souza, who has personally published and edited major works with many contributions by Australians in the fields of both religious education and spirituality (e.g., International Handbook of the Religious, Moral and Spiritual Dimensions in Education (2006) and the International Handbook of Education for Spirituality, Care and Well-being (2009)).

Spirituality \& religious education. Duncan's contention that "spirituality may function as a watering down of religious education" by being "too "nice"" and "too acceptable to unquestioned cultural norms" shows a distinct lack of understanding of the extant literature in spirituality education. Although he states, "I do not in any way want to disparage the proponents of spirituality education" he warns of danger in following such pursuits because "spirituality thrives so well in our predominantly secular society" (p. 12, 2011). This not only exhibits his bias but also a lack of appreciation of spirituality providing impetus for close inspection of religious issues as it grabs attention. To imply that current spirituality education does not provide "spiritual resources with some prophetic and emancipatory backbone to them" (ibid.) totally undersells current pedagogy expounded in Australian studies in spirituality. Particular note should be made of de Souza's (2003) and Rossiter's (2010, 2011) work in this area. Spirituality education is not just about fluffy, feel good experiences. Rather, it involves serious study of meaning, purpose and values as it relates to world-views, whether religious or otherwise. As such, spirituality is broader than RE but never-the-less respectful and inclusive of it. Just as RE has a key role in spirituality education, so too do chaplains, whether or not they teach a subject entitled Religious Education.

Australian and overseas comments on RE in curriculum. The comments from overseas authors that dominated Duncan's paper make worthy contributions to debate on the topic of RE in curriculum, but as his paper focussed on Australian National Curriculum, it would have been considerate to use similar sentiments expressed by Australian authors to display our depth of scholarship. For example, Duncan's expansive treatment of the work by Terrence Copley with regards secularisation and indoctrination by omission can also be found in writing by Australian authors. Duncan also posits "support for personal identity formation" as a role of RE from his reading of papers out of a Scandinavian conference in 2005. Australian and other educators include this as a key element in spirituality, as well as religious, education.

\section{Australia - a backwater or bulwark of religious and spirituality education?}

Duncan's quote by Simon Anholt, a British branding expert, that Australia is a "dumb blonde" when it comes to education, "attractive but shallow and unintelligent" should be treated with the contempt it deserves. Duncan stretched this highly contestable quote for his own ends, by apparently assuming its veracity to attack "Australian education, at all 
levels" for the "omission of serious engagement with religious issues from the curriculum" (p.27, 2011). The "dumb blonde" comment displays ignorance on a number of levels. Considering the population of Australia and the major land mass we cover, educators from Australia (and New Zealand) punch above their weight when it comes to religious and spirituality education. Considerable financial and time commitments are made by Antipodean educators to play on the international stage in these areas. As well as the previously mentioned international handbooks, and the Australian College of Educators' book edited by Marian de Souza and others, Marian is the inaugural Chair of the International Association for Children's Spirituality. Brendan Hyde is one of the three editors with another four Australians on the editorial board of the International Journal of Children's Spirituality. The Australia-based Journal of Religious Education (editor Marian de Souza) and the Religious Education Journal of Australia (editor - Michael Buchanan) have international influence. Significant membership and participation in the International Seminar on Religious Education and Values comes from Australia and New Zealand, as well as occasional contributions to the Association of University Lecturers in Religious Education, based in the UK. Australian educators are also active honorary staff of the Centre for Religious and Spirituality Education in Hong Kong.

There are undoubtedly major gaps in curriculum offerings that would not be to the best liking of religious educators. However, they are not universally evident throughout the totality of Australian education. This is not the time, nor is there space here to expound on the variety and depth of RE curricula extant in Australian schools, but there is certainly much which encourages serious and vigorous engagement with religious issues.

\section{Additional references to spirituality in Australian education}

Examples of some work that has been done relating spirituality in religious settings in Australia were deleted from the book Meaning and connectedness: Australian perspectives on education and spirituality (de Souza \& Rimes (Eds.), 2010) in order to make John Fisher's chapter of similar size to others in that book. The editors exercised their judgement about what to delete based on the aim of that book being "about how spirituality is for ALL students and ALL schools and this can cloud the issue by dragging the religious dimension in" (Personal communication from editors, 3 June, 2010). It is more appropriate that the deleted material be presented in this religious education journal. Brief cameos on research by Australians that focuses on religion \& spirituality, chaplaincy, etc are given below:

In a national survey of 45,600 young Australians aged 11-24 years, about $14 \%$ valued spirituality/faith highly, with percentages ranging between states (Tasmania 9.2\%, SA $10.1 \%$, Victoria $10.6 \%$, ACT $10.9 \%$, NSW 14.4\%, NT $15.7 \%$, WA $18.4 \%$, Queensland, 20.0\%) (Mission Australia, 2008).

Buchanan (2008) maintains that teachers can encounter the spiritual dimension through involvement, commitment and connection to curriculum change. He proposed a five step plan for engaging teachers in promoting holistic engagement in this area of professional practice. 
Cultural and religious emphases. In the late 1800s each of the six Australian colonies promulgated similar Education Acts for free, compulsory and secular schooling. Many people mistakenly believe that secular means religion should be excluded from state/public schools. Unlike in the USA, "Australia does not have a legally entrenched principle or even vague set of conventions of the separation of church and state" (Wallace, 2005). Secular in this nation means freedom of, not freedom from, religion.

Researchers' worldviews influence the planning and interpretation of projects, especially with respect to religion. For example, Rowling and Gehrig contended "the future widespread acceptance of the concept of spiritual health is encumbered [italicised to emphasise bias] by its association with religiosity" (1998). They attempted to justify this position, by contrasting American research in youth resiliency (Resnick et al., 1993) with Australian research (Fuller et al., 1998), failing to recognise the flawed methodology of Fuller et al.'s study, in which religiosity was inadequately addressed as one protective factor for adolescents' well-being.

On the other hand, Bouma attested, "at the core of spirituality is the encounter with the other, some other, be it God, nature, a tree, the sea..." (2006, p.13), but in empirical studies reported in his book, Bouma referred solely to outdated religiosity data published from the National Church Life Survey. Singleton et al. reported using a "stipulated" definition of spiritual as "a conscious way of life based on a transcendent referent" (2006, p.247). In practice, almost all questions in these two reports reflected relation with God and religion. These are prime examples of conflating spirituality with religiosity.

In light of changing community attitudes to religious education, Hughes (2006) suggested that alternative forms of RE could be appropriate for schools, under the term 'spiritual literacy.' However, this could result in further conflation of the terms religious and spiritual. The nexus between RE and spirituality is explored further in the ACE book and other publications. For example, in work with pre-service teachers in a publiclyfunded Catholic university, Buchanan and Hyde (2008) proposed a model that shows how religious education is one curriculum area that can address the complementarity of the cognitive, affective and spiritual dimensions of learning, that is, a more holistic approach to learning in contrast to the dominant emphasis on cognitive learning outcomes so prevalent in contemporary secular society.

\section{Examples from specific types of school.}

Catholic schools. Informed by contemporary research on children's spirituality by educators in the USA and UK, Liddy (2002) presented a discussion on the work of RE in Catholic schools in Australia. About the same time, de Souza (2003) posited Catholic schools as nurturing frameworks for young people's spirituality. In practice, Hackett (2006) found that recently appointed RE teachers in Catholic schools in WA faced challenges to personal, spiritual and faith formation in the transition from a "crusade of delivery" to a "pilgrimage of formation" in teaching RE. A similar sentiment was expressed by White (2008), who argued that Catholic educators need to appreciate the importance of pedagogy in nurturing "spiritual pilgrims," by encountering the "mystery of the Divine," in contrast to simply teaching "educational tourists." Faculty leaders of RE in Catholic schools have a bi-partite responsibility of effecting curriculum change 
whilst maintaining ministerial oversight of staff. By providing opportunities to connect with self and other(s), key aspects of spiritual well-being, these faculty leaders of RE encouraged teachers to overcome resistance to curriculum change (Buchanan, 2010).

Anglican schools. Forty references to spirituality in education were presented in papers and proceedings of the $8^{\text {th }}$ Annual Conference of the National Anglican Schools Consultative Committee (NASCC, 2000). In a similar vein, Wallace produced a paper to stimulate debate and action concerning a "spirituality which is relevant in our contemporary context with the power to enliven and transform educational activities" from a basis of Anglican Christian spirituality (2006, p.43).

Indigenous issues. Tacey has written several generalist books on psychology and spirituality in Australia, with a clear understanding of Indigenous Australian spirituality in Edge of the Sacred (1995). In examining a series of strategic change indicators that address Indigenous concerns, McMahon et al. (2007) listed, among spiritual indicators, the notions of heritage, link between culture and spirituality, religious ceremonies and belief systems. In a study with young urban, Indigenous Australians, the role of cultural and spiritual expressions was investigated in affirming a sense of self, place, and purpose (de Souza \& Rymarz, 2007).

Christian schooling. Christian schooling at the end on the twentieth century developed in a "political, economic, cultural and educational context, shaped and driven by idolatrous, spiritual forces" (Wilson 1996), with "Enlightenment beliefs in the objective, rational, certainty of science crumbling under the weight of relativistic postmodernism." Taking a positive line for Christian teachers, Holm asserted, "teachers can be co-workers with God through the [spiritual] formation of students" (2007, p.45). He described a spiritual theology of teaching in which "conversations contribute to formation and to the creation of a mutual presence and grace ... so there is an exchange of words and feelings that resonates with the creative word of God working in the depths of identity of each person" (ibid.).

Other faith-based schools and alternate philosophies.

Baha'i beliefs. Pourshafie explored a Baha'i-inspired school in which education was seen as a vital instrument to stimulate development of innate wisdom through moral capabilities, promoting spiritual awareness (2007).

Islamic insight. In this secular, modern and liberal society, Ihram (2008) demonstrated how Muslim schools have similar problems to Catholic schools, struggling to instil faith in a spiritual, non-politicised religion.

Alternative spiritualities and Hinduism. Lovat (1998) reflected on implications for RE created by movements between mainstream and alternative spiritualities in Australia, as well as the contribution of Hinduism and Hindu-related spirituality to Australian religious and values education (2006). 
Montessori, etc. Ward (2002) investigated how narrative was used for meaningmaking in Montessori, Steiner, government and Catholic schools to enhance spiritual transformation of students.

Waldorf wisdom. Waldorf (Steiner) schools could be seen as centres for the possible social and spiritual renewal of the whole school community, and society as a whole, through promotion of lifelong learning (Stehlik, 2002).

At secondary school. Through exploring spirituality with 207 students in three senior secondary Catholic schools, Maroney (2008) also found strong evidence of individualism and moral self-reliance. The traditional 'Catholic God' was not wellaccepted for many students, a finding which reflects Fisher's (2006) study with students in independent and Catholic, but not in other-Christian, schools. Maroney's study highlights the importance placed on relationships with parents and friends for enhancing spirituality, in line with previous Australian studies by Engebretson (2004), Zaplatynskyj (2005), Fisher (2006), Hughes (2007), Mason et al. (2007), Mission Australia (2008).

Chaplains. Costley (1997) compared and contrasted personal experience as a chaplain, with an important spiritual role, in independent and state school systems. From interviews with 15-16 year-olds, Mellberg (1999), a state-school chaplain, found them eager to tell stories that illustrated their engagement in practices and transcendent life experiences of spirituality, that did not come from traditional Church or denominational faith perspective. In a study of spiritual wellbeing in schools, Fisher (2001) compared views expressed by state school chaplains with those of chaplains, RE and student welfare coordinators in Catholic and independent schools in Victoria. The Journal of Christian Education contains contributions by nine Australian authors in an issue devoted to "Chaplaincies in state schools" (May 2005).

The Australian National school chaplaincy program planned to assist schools and their communities "to support the spiritual wellbeing of their students" (DEST, 2007). An initial report of chaplaincy effectiveness (Hughes \& Sims, 2009) found "chaplains had provided support for students in exploring their spirituality and had provided guidance on religious, values and ethical matters" to varying extents in response to requests in schools. "In general, the spiritual aspect of chaplains' work was conducted in a low key way" (ibid., p.21) with only $2 \%$ of 688 principals and $1 \%$ of 1031 chaplains mentioning this among most important contributions to school life.

\section{Summary}

Duncan Reid's paper provided a springboard from which to launch into discussions about making space for Religious Education in the (Australian) National Curriculum. Some brief comments have been presented here to expand thinking in this area, vis-à-vis religious and spirituality education. Additional references of research in the area of spirituality related to religious education, that were edited out of the Australian College of Educators book on Australian perspectives on education and spirituality, have also been included. It is hoped that this response will add to and help inform the debate about the place of Religious Education (and spirituality) in the evolving Australian National Curriculum. 


\section{Notes on contributor}

Dr John Fisher has 48 years experience in teaching and research in science, education, religious studies, psychology and health. Over the last 18 years John has developed a passionate interest in spiritual health and well-being (PhD, 1998, Melbourne; EdD, 2009, Ballarat).

\section{References}

Bouma, G. (2006). Australian Soul: Religion and spirituality in the twenty-first century. Melbourne: Cambridge University Press.

Buchanan, M. T. (2008). Holistic engagement in curriculum innovation: Attending to the spiritual dimension. Religious Education Journal of Australia, 24(1), 3-7.

Buchanan, M. T. (2010). Attending to the spiritual dimension to enhance curriculum change. Journal of Beliefs \& Values, 31(2), 191-201.

Buchanan, M. T. \& Hyde, B. (2008). Learning beyond the surface: Engaging the cognitive, affective and spiritual dimensions within the curriculum. International Journal of Children's Spirituality, 13(4), 309-320.

Costley, H. (1997). A comparison of chaplaincy in the government and independent school system. I D. Johnstone et al. (Eds.). Managing the ministry: A handbook for school chaplains, (pp.89-94). Marion SA: Australian Association for Religious Education.

Department of Education, Science and Training (DEST) (2007). National School Chaplaincy Programme. Canberra: Australian Government. Retrieved 16 March, 2007, from: http://www.dest.gov.au/sectors/school_education/policy_initiatives reviews/key_issues/school_chaplaincy_programme/

de Souza, M. (2003). Catholic schools as nurturing frameworks for young people's spirituality. Journal of Religious Education, 51(1), 72-80.

de Souza, M., Durka, G., Engebretson, K., Jackson, R. \& McGrady, A. (Eds.) (2006). International Handbook of the Religious, Moral and Spiritual Dimensions in Education. Dordrecht: Springer.

de Souza, M. \& Rymarz, R. (2007). The role of cultural and spiritual expressions in affirming a sense of self, place, and purpose among young urban, Indigenous Australians. International Journal of Children's Spirituality, 12(3), 277-288.

de Souza, M., Francis, L.J., O’Higgins-Norman, J. \& Scott, D.G. (Eds.) (2009).International Handbook of Education for Spirituality, Care and WellbeingDordrecht: Springer.

de Souza, M. \& Rimes,J. (Eds.) (2010). Meaning and connectedness: Australian perspectives on education and spirituality. Mawson ACT: Australian College of Educators. 
Fisher, J.W. (2001). Comparing levels of spiritual well-being in state, Catholic and independent schools in Victoria, Australia. Journal of Beliefs \& Values, 22(1), 99-105.

Fisher, J.W. (2006). Using secondary school students' views about influences on their spiritual well-being to inform pastoral care. International Journal of Children's Spirituality, 11(3), 347-356.

Fisher, J. W. (2007). It's time to wake up and stem the decline in spiritual well-being in Victorian schools. International Journal of Children's Spirituality, 12(2), 165-177.

Fisher, J. (2010). Reflections on publications relating to spirituality in Australian education. In M.de Souza and J. Rimes (Eds.). Meaning and connectedness: Australian perspectives on education and spirituality (pp.105-118). Mawson ACT: Australian College of Educators.

Fuller, A., McGraw, K. \& Goodyear, M. (1998). The mind of youth. Melbourne: Vic Department of Education.

Hackett, C. (2006). A longitudinal study of the personal and professional responses of recently assigned secondary religious education teachers to curriculum demands. $\mathrm{PhD}$ dissertation, University of Notre Dame, Fremantle.

Holm, N. (2007). Identity formation through classroom conversations and collaboration with the spirit. Journal of Christian Education, 50(2), 45-54.

Hughes, P. (2006). The future of religious education in the context of postmodernity. In M. de Souza et al. (Eds.). International handbook of the religious, moral and spiritual dimensions in education, (pp.349-362). Dordrecht: Springer.

Hyde, B. (2005) Identifying some characteristic of children's spirituality in Australian Catholic primary schools: A study of hermeneutic phenomenology. $\mathrm{PhD}$ dissertation, Australian Catholic University.

Hyde, B. (2008). Children and spirituality: Searching for meaning and connection. London: Jessica Kingsley Publishers.

Hyde, B. (2010). Agency, play, and spiritual development in the early years' curriculum. In M.de Souza and J. Rimes (Eds.). Meaning and connectedness: Australian perspectives on education and spirituality (pp.92-104). Mawson ACT: Australian College of Educators.

Ihram, S. (2008). Islamic schools: Another faith perspective. In A. Benjamin \& D. Riley (Eds.). Catholic schools: Hope in uncertain times (pp. 149-161) Mulgrave Vic: John Garratt Publishing

Liddy, S. (2002). Children's spirituality. Journal of Religious Education, 50(1), 13-19.

Lovat, T.J. (1998). Movements between mainstream and alternative spiritualities in Australia: Implications for religious education. Religious Education Journal of Australia, 14(2), 10-13. 
Lovat, T. (2006). The contribution of Hinduism and Hindu-inspired spirituality to Australian religious and values education. In M. de Souza, K. Engebretson, R. Jackson \& G. Durka (Eds.). International handbook of the religious, spiritual and moral dimensions in education. (pp. 487-499) Dortrecht: Springer.

Lovat, T. (2010). Spirituality and the public school. In M.de Souza and J. Rimes (Eds.). Meaning and connectedness: Australian perspectives on education and spirituality (pp.19-30). Mawson ACT: Australian College of Educators.

McMahon, A., Reck, L. \& Walker, M. (2007). Defining well-being for Indigenous children in care. Children Australia, 32(2), 15-20.

Maroney, M. (2008). An exploration of a contemporary youth spirituality among senior students in three Catholic schools. PhD dissertation, Australian Catholic University, Fitzroy, Vic.

Mellberg, L. (1999). Searching for adolescent spirituality: A qualitative study of some Victorian state school students. MEd dissertation, University of SA.

Mission Australia. (2008). 2008 National Survey of Young Australians. Sydney: Author. National Anglican Schools Consultative Committee. (2000). $8^{\text {th }}$ annual conference 'The essence of Anglican Schooling? Our response for a post modern culture' and $3^{\text {rd }}$ annual seminar 'Future directions for chaplaincy, religious education and worship in Anglican schools.' All Saints' Anglican School, Merrimac, Qld, 27-30 May 1999. Brisbane: Anglican Schools Office.

Pourshafie, T. (2007). Essential features of wisdom education in Baha'i schooling. $\mathrm{PhD}$ dissertation, Flinders University of SA.

Reid, D. (2011). Making space for Religious Education in the National Curriculum. Religious Education Journal of Australia, 27(2): 10-15.

Resnick, M., Harris, L. \& Blum, R. (1993). The impact of caring and connectedness on adolescent health and well-being. Journal of Paediatrics and Child Health, 29(Suppl.1), 433-442.

Rossiter, G. (2010). Perspective on contemporary spirituality: implications for religious education in Catholic schools. International Studies in Catholic Education, 2(2), 129 147.

Rossiter, G. (2011). Reorienting the religion curriculum in Catholic schools to address the needs of contemporary youth spirituality. International Studies in Catholic Education, $3(1), 57-72$.

Rowling, L. \& Gehrig, S. (1998). Mental health of young people: Exploring the relationship between alienation from school, resilience, coping and spiritual health. AARE Conference paper. Retrieved 8 September 2005 as http://www.aare.edu.au/98pap/row98371.htm 
Singleton, A., Mason, M. \& Webber, R. (2004). Spirituality in adolescence and young adulthood: A method for a qualitative study. International Journal of Children's Spirituality, 9(3), 247-262.

Stehlik, T. (2002). Each parent carries the flame: Waldorf schools as sites for promoting lifelong learning, creating community, and educating for social renewal. Flaxton Qld: Post Pressed.

Tacey, D. (1995). Edge of the Sacred: Transformation in Australia. Sydney: HarperCollins.

Wallace, M. (2005). Is there a separation of church and state in Australia and New Zealand? Australian Humanist, 77. Retrieved 15 March 2010, from http://www.hsnsw.asn.au/MaxWallace.html

Wallace, T. (2006). Anglican spirituality and education. Journal of Christian Education, 49(3), 43-54.

Ward, G.C. (2002). Narrative, meaning making and personal development: Teachers' storied experience in Montessori, Steiner and other primary classrooms. $\mathrm{PhD}$ dissertation, University of Notre Dame, Fremantle, WA.

White, D. (2008). Catholic pedagogy: Nurturing pilgrims or educating tourists? Journal of Catholic School Studies, 80(1), 53-65.

Wilson, G. (1996). Christian school curriculum and the spirits of the age. In I. Lambert \& S. Mitchell (Eds.). Reclaiming the future: Australian perspectives on Christian schooling (pp.143-150). Sydney: CSAC.

\subsection{Importance of relating with God for school students' spiritual well-being}

\section{Background}

This paper is based on a debate that arose from previous conference presentations I had made relating to the importance of God in issues of spiritual well-being. In keeping with the emphasis in this thesis, data from primary and secondary schools in Australia were selectively interpreted with the key focus being on the importance of school students relating with God for the development of their spiritual well-being. This is not to say that other relationships with self, others and environment are not important for holistic wellbeing of students - they are.

\section{Key points extracted from this paper}

- My Four Domains Model of Spiritual Health/Well-Being underpinned the development of my Spiritual Health And Life-Orientation Measure (SHALOM) and my Feeling Good, Living Life (FGLL) instrument for use with primary school students. Both instruments were employed in this study. 
- It is becoming increasingly difficult to engage Australian State school staff in research on spirituality in education because of an assumed conflation of spirituality with Religious Education, which is only offered on a voluntary basis in these secular Australian State schools at primary level.

- The reported strength of students' relationship with God varied between nongovernment schools. The greatest strength of this relationship was found in Christian Community schools (CCS), followed by Catholic schools, with other independent schools reporting lowest levels of relationship with God at both primary and secondary levels.

- There was a significant decline in the levels of relationship with God reported by students from primary to upper secondary school levels in the Catholic and independent schools. This trend was not evident in the Christian Community Schools.

- There was negligible variation by gender. Only female students in Catholic secondary schools scored slightly higher $(\mathrm{p}<.05)$ than males on the SWB factors.

- In comparison with students from other schools, the CCS students reported receiving greater help than other students, with relating with God. They reported receiving this help from their mothers, female friends, selves, teachers, RE teachers and God. This help from RE teachers was particularly noticeable, being rated by students in the decreasing order from CCS to Catholic then independent schools.

- Regression analyses revealed that the importance of religion, not spirituality, together with help from God and themselves, explained greatest variance in the students' lived experience of relating with God.

\section{Implications}

More education is needed for school staff to help them appreciate the holistic nature of spirituality in education (which may or may not involve Religious Education).

Different types of non-government schools in Australia obviously have variations in school ethos with regard to relating with God. Religious Education staff in each type of school need to reflect on their modus operandi and their influence on the development of their students' spiritual well-being.

Students need opportunities to discuss the nexus between the importance of religion, direct help from God, and how they help themselves to relate with God for spiritual well-being. 


\title{
Paper:
}

This paper was published as: Fisher, J.W. (2010) Investigating the importance of relating with God for school students' spiritual well-being. Journal of Beliefs and Values, 31(3): 325-334.

\section{Investigating the importance of relating with God for school students' spiritual well- being}

Author John W Fisher PhD, EdD

\section{Affiliation}

Hon. Senior Research Fellow, School of Education, University of Ballarat, Victoria, Australia

\begin{abstract}
Fisher's spiritual well-being (SWB) questionnaires assessed students' levels of relationship in four domains, one of which is with God. Students also reported on the extent to which different entities helped them develop relationships in the four domains of SWB. Levels of perceived help for relating with God (from mothers, friends, themselves, teachers, RE teachers and God) varied significantly between schools, in line with students' self reports of relationship with God, i.e., Christian $>$ Catholic $>$ independent (>government) schools.

Contrary to the students' claims that teachers, especially RE teachers, provided major help for them in relating with God, other factors provided greater explanation of observed statistical variance. The 'importance of religion' and direct 'help from God' were the key factors, together with how well students 'help themselves.' It is not surprising, therefore, that school ethos, which is influenced by teachers and religious affiliation of students, plays a vital role in fostering students' relationship with God, for their spiritual wellbeing.
\end{abstract}

Keywords assessing spiritual wellbeing; teachers' role; relating with God

Correspondence detail $\quad$ Email: j.fisher@ballarat.edu.au

Investigating the importance of relating with God for school students' spiritual wellbeing

\section{Introduction}

The notions of 'spiritual development' and 'spiritual wellbeing' of young people are seen as vital in the role of schools in Australia. (Ministerial Council on Education, Employment, Training and Youth Affairs [MCEETYA] 2008). In support of this policy, Australian curriculum frameworks contain multiple mentions of spiritual development of students (http://curriculum.edu.au/ccsite/cc_curriculum_frameworks_and_syllabuses, 20029.html ). In addition, the federal Australian government took the initiative of funding more than 2700 extra chaplains (with 1915 in government schools), who have, as part of their mandate, the responsibility of nurturing the spiritual wellbeing of students 
(Department of Education, Science and Training [DEST] 2007).

However, no substantive definition of spirituality was given in any of the official Australian curriculum documents, leaving people confused about spirituality, and its relationship with religion. In discussing the nexus between spirituality and religion, current literature presents a broad spectrum of views ranging from spirituality as a subset of religion, through conflation of the two terms, to religion as a subset of spirituality, to the extreme of spirituality without religion. Rather simplistically, religion can refer to 'a set of core beliefs upon which people base their lives' (http://www.conservapedia.com/Religion), whereas spirituality can be described as 'that which lies at the heart of a person being human' (Fisher 1998). Religion and spirituality generally infer a relationship with a God, except in non-theistic religions such as Buddhism and in humanistic spirituality.

The application of spirituality to health and wellbeing yields the notion of spiritual well-being (SWB), which was described tentatively as 'the affirmation of life in a relationship with God, self, community and environment that nurtures and celebrates wholeness' (National Interfaith Coalition on Aging [NICA] 1975). Empirical research has supported the inclusion of these four sets of relationships in studies of spiritual well-being (Fisher, 1998; Hay and Nye 1998). An inspection of 172 available multi-dimensional spirituality and well-being measures revealed a dominant emphasis on relation with self (82\%), with lesser attention being paid to relation with others (53\%), God (52\%) and the environment (23\%) (Fisher 2009). In research over the last 17 years, the author found that relationships with environment and God have produced considerable debate in discussions about SWB. This paper focuses on the importance of relating with God for (transcendental) SWB.

\section{Method}

\section{Setting}

There are four types of schools described in this research. In Australia, 67\% of all students attend secular state schools, in which primary schools in most states can provide voluntary Christian religious education (RE) for one lesson a week. Reference to religion might occur infrequently in some classes, but there is no formal provision for religious studies in secondary state schools; $20 \%$ of Australian students attend Catholic schools, which have regular RE classes and masses; the remaining $13 \%$ attend independent schools, most with religious bases, religion classes and chaplains. A special subset, $40 \%$ of the independent schools ( $5 \%$ of the total student population), comprises low fee, other Christian schools, most of which have been established following the provision of funds from the federal, then state governments, since 1973.

\section{First studies}

The four domains model of spiritual well-being was used as the theoretical framework from which two quantitative measures of SWB were developed with secondary and primary school students in Australia. 


\section{Secondary students}

The 20-item Spiritual Health And Life-Orientation Measure (SHALOM) was developed with a convenience sample of 850 secondary school students (aged 12-18) in state, Catholic, independent and other Christian schools in Victoria (Fisher 1999). These schools were selected to include a range of ethnicities and religions. The transcendental domain of SWB in SHALOM, called the God-factor for simplicity, elicits responses about 'lived experiences' on a 5-point Likert scale (from 1=very low to 5=very high) for five items: 'developing personal relationship with the Divine/God; worship of the Creator; oneness with God, peace with God; prayer life.' Details of the other three domains of SWB can be found in the original report (Fisher 1999).

\section{Primary students}

The 16-item Feeling Good, Living Life (FGLL) instrument was developed with a purposive sample of 1080 primary school students (aged 5-12) in the four school types in Victoria and Western Australia (Fisher 2004). Responses are gathered on a 5-point Likert scale (YES, yes, ?, no, NO). Once again, the focus here is on the God-factor (transcendental SWB) comprising four items, namely 'do you know your God is a friend; talk with your God; know your God cares for you; think about your God?'

\section{Second studies}

It became increasingly difficult to gain support from staff for research in SWB in state schools because some principals and teachers assumed that spirituality equated with religion, which they believed did not fit with the secular humanistic philosophy prevalent in state schools (Fisher 2007). A number of the state school staff actively expressed the view that religion should be excluded from schools because of assumed separation of Church and State, although there is no such legal separation in Australia, as exists in the USA (Wallace 2005). Secular, in this instance means freedom of religion, not freedom from it. As these views oppose official government policy, it shows that greater education of school staff is needed about the nature of spirituality and its role in education in Australia.

The second round of studies were therefore undertaken with only students from Catholic, independent and other Christian schools, in Victoria. These studies were designed to relate students' responses on SWB measures with another instrument that was designed to gain insight into the level of help provided by 22 groups of 'people' for students' relations with self, Others, Nature and God. This instrument was called the Quality Of Life Influences Survey (QOLIS) (Fisher 2006). QOLIS sought four responses (on a four-point Likert scale, from $0=$ never to $3=$ always) indicating the extent to which 'people' at home, school, church and wider community influenced students' relationships with Self, Others, Nature and God.

\section{Primary students}

Three hundred and seventy-two primary school students (aged 10-12) completed FGLL in Victorian schools under the supervision of their teachers. They also completed QOLIS and an abbreviated form of the Junior Eysenck Personality Questionniare - revised 
(JEPQR-A) (Francis 1996), which used Yes/No responses in 48 items to gain insight into students' levels of extraversion, neuroticism and psychoticism, with an attendant 'lie' scale.

\section{Secondary students}

One thousand and two secondary school students (aged 12-18) completed SHALOM, together with QOLIS in Victorian schools under the supervision of their teachers. Additional instruments were used to gain greater understanding of participants. The Abbreviated form of the Junior Eysenck Personality Questionnaire - Revised (JEPQR-A) was employed together with questions on the importance of religion and spirituality, which were assessed on five-point Likert scales, (from 1=very low to $5=$ =very high). The Oxford Happiness Inventory (OHI) (Argyle \& Hills 2000), comprising 29 items with four alternative responses, was also completed by secondary school students.

\section{Limitation of studies.}

Due to sampling procedures, the results presented here are not necessarily representative of the four school types.

\section{Results}

Although the spiritual well-being measures sought information on four domains of spiritual well-being, the focus in this paper is on the transcendental domain of SWB, i.e., relation with God.

\section{First studies}

\section{Primary students}

The primary school students were aged 5-12, in grades prep-year 6 in Victoria and grades 1-7 in Western Australia. The mean value of scores on the four items in FGLL was taken as the score for the transcendental domain of SWB, i.e., their lived experience of relating with God.

ANOVA revealed significant variations between schools in students' lived experience of relating with God at primary level $(\mathrm{F}(3,1112)=91.1, \mathrm{p}<.001)$ (see Table 1). Students in the 'other' Christian schools reported stronger relationships with God compared with those in Catholic schools, which were in turn higher than both the independent and state schools.

Table 1. Primary students' lived experience of relating with God

\begin{tabular}{llcc}
\hline School type & $\mathrm{N}$ & mean & SD \\
\hline State & 357 & 3.35 & 1.41 \\
Independent & 130 & 3.51 & 1.20 \\
Catholic & 295 & 4.11 & .97 \\
other Christian & 334 & 4.62 & .58 \\
\hline
\end{tabular}




\section{Secondary students}

The junior secondary school students were aged 12-14 in years 7-9, with senior secondary students aged 15-18 in years 10-12 in Victoria. The mean value of scores on the five items in SHALOM was taken as the score for the transcendental domain of SWB, i.e., their lived experience of relating with God. ANOVA revealed significant variations between schools in students' lived experience of relating with God between schools at junior secondary $(\mathrm{F}(3,478)=65.3, \mathrm{p}<.001)$ and senior secondary $(\mathrm{F}(3,247)=21.2, \mathrm{p}<.001)$ levels (see Table 2).

Table 2. Secondary students' lived experience of relating with God

\begin{tabular}{lllllll}
\hline Level & \multicolumn{3}{l}{ Junior secondary } & \multicolumn{5}{l}{ Senior secondary } \\
\hline School type & $\mathrm{N}$ & mean & $\mathrm{SD}$ & $\mathrm{N}$ & mean & $\mathrm{SD}$ \\
\hline State & 124 & 2.53 & 1.04 & 13 & 2.94 & .48 \\
Independent & 20 & 2.79 & 1.30 & 81 & 2.61 & 1.00 \\
Catholic & 169 & 2.85 & 1.01 & 54 & 2.63 & 1.11 \\
Other Christian & 169 & 4.00 & .86 & 103 & 3.67 & 1.01 \\
\hline
\end{tabular}

Students in the 'other' Christian schools once again reported stronger relationships with God compared with those in Catholic schools, which were in turn higher than both the independent and state schools. There was a slight aberration in the results for senior secondary students in the state school, where the majority of this small group were members of a Bible-study group, which is not typical of state school students in Australia (indicated by italics in Table 2).

\section{Second studies}

\section{Primary students}

Similar results were found here compared with the first studies, with results from FGLL showing that Christian school students claim greater relationship with God than those in Catholic and independent schools (ANOVA - primary $\mathrm{F}(2,369)=79.7, \mathrm{p}<.001$ ) (see Table $3)$.

Table 3. Primary students' lived experience of relating with God (second study)

\begin{tabular}{lccc}
\hline School type & $\mathrm{N}$ & mean & SD \\
\hline Independent & 85 & 3.46 & 1.18 \\
Catholic & 59 & 3.42 & 1.12 \\
other Christian & 228 & 4.56 & .53 \\
\hline
\end{tabular}


Similar results were found here compared with the first studies, with results from SHALOM showing that Christian school students claim greater relationship with God than those in Catholic and independent schools at junior secondary $\mathrm{F}(2,556)=100.6$, $\mathrm{p}<.001$ ) and senior secondary levels $\mathrm{F}(2,440)=104.9$, $\mathrm{p}<.001$ ) (see Table 4).

Table 4. Secondary students' lived experience of relating with God (second study)

\begin{tabular}{lllllll}
\hline Level & \multicolumn{2}{l}{ Junior secondary } & \multicolumn{5}{l}{ Senior secondary } \\
\hline School type & $\mathrm{N}$ & mean & $\mathrm{SD}$ & $\mathrm{N}$ & mean & $\mathrm{SD}$ \\
\hline Independent & 110 & 2.46 & 1.06 & .59 & 1.99 & 1.03 \\
Catholic & 206 & 2.89 & 1.10 & 258 & 2.48 & 1.01 \\
Other Christian & 243 & 3.94 & .94 & 126 & 3.87 & .96 \\
\hline
\end{tabular}

\section{Level of schooling}

Rymarz and Tuohy (2008) found an expectation of lowering religiosity among Catholic school students in transition from primary to secondary school. Reported 'levels of relationship with God' were lower at the senior levels of Catholic $(\mathrm{t}(462)=4.07, \mathrm{p}<.001)$ as well as independent $(\mathrm{t}(167)=2.80, \mathrm{p}<.01)$ schools in studies reported here. However, a consistently high level of relation with God was evident between junior and senior secondary levels in the Christian schools $(\mathrm{t}(367)=.63, \mathrm{p}=.53 \mathrm{~ns})$.

\section{Gender}

No differences in the level of relationship with God were shown by gender across the total cohort studied, at primary $(\mathrm{t}(320)=1.23, \mathrm{p}=.22 \mathrm{~ns})$, junior secondary $(\mathrm{t}(568)=.57$, $\mathrm{p}=.57 \mathrm{~ns})$ or senior secondary $(\mathrm{t}(452)=.99, \mathrm{p}=.32 \mathrm{~ns})$ levels of schooling. In light of findings by Büssing et al.(2010), that a sample of senior females in west German Catholic and Protestant schools scored higher than males on a Prayer/trust in God (religious orientation) factor, data were subject to closer scrutiny. This revealed that, in the Catholic secondary schools only, in this study, females were found to score slightly higher than males $(\mathrm{t}(462)=2.08, \mathrm{p}<.05)$ on relationship with God.

\section{Helps}

Results for the primary, junior and senior secondary students in each of the three school types are discussed together because the same questions and scales were used in QOLIS. As well as the Christian school students claiming higher levels of relationship with God, they also indicated greater support for this relationship coming from mothers, female friends, themselves, teachers, RE teachers, and God (see Table 5). 
Table 5. Mean values of Help for students' relation with God (scale 0-3, last two* 1-5)

\begin{tabular}{llllllllll}
\hline School & \multicolumn{3}{l}{ Independent } & \multicolumn{3}{l}{ Catholic } & \multicolumn{3}{l}{ Christian } \\
\hline Help & p & js & ss & p & js & ss & p & js & ss \\
\hline Mother & 1.13 & .92 & .55 & 1.66 & 1.39 & 1.04 & 2.51 & 2.13 & 1.98 \\
Fem fr & 1.06 & .78 & .36 & 1.27 & 1.10 & .75 & 1.89 & 1.76 & 1.69 \\
Self & 1.35 & 1.02 & .54 & 1.61 & 1.36 & 1.08 & 2.21 & 2.16 & 1.97 \\
Tr & 1.58 & .99 & .47 & 2.17 & 1.77 & 1.37 & 2.50 & 2.46 & 2.20 \\
RE tr & 2.24 & 2.09 & 1.16 & 2.47 & 2.35 & 2.03 & 2.52 & 2.65 & 2.54 \\
God & 2.19 & 1.98 & 1.19 & 2.12 & 2.19 & 1.81 & 2.78 & 2.77 & 2.84 \\
\hline *Imp rel & & 2.29 & 2.07 & & 2.75 & 2.57 & & 3.77 & 3.88 \\
$*$ Imp spir & & 2.44 & 2.66 & & 3.03 & 3.12 & & 3.74 & 4.03 \\
\hline
\end{tabular}

Note: $\mathrm{p}=$ primary $\mathrm{j} s=$ junior secondary $\mathrm{ss}=$ senior secondary

Imp rel/spir= Importance of religion/spirituality

\section{Discussion}

In the first studies, students in the 'other' Christian schools reported higher lived experience of relating with God compared with those in Catholic schools, which were in turn higher than both the independent and state schools. When these initial findings were presented at a children's spirituality conference, it was suggested that the students in Christian schools were just repeating what they had been told without necessarily believing it. From more than 45 years of teaching and research, the author has observed marked differences in ethos in the four types of schools. The prevailing attitude within the predominately evangelical, Protestant Christian schools is one of expecting a vital presence of God within their community. The 'Lie' scale of JEPQ-R was used in the second studies to check for social-desirability of responses. The students in the Christian schools scored low (4.3/12), being lowest on this measure, nearly to a significant extent (at primary $\mathrm{F}(2,369)=2.71, \mathrm{p}=.068$; at secondary $\mathrm{F}(2,999)=2.19, \mathrm{p}=.113$ ). These students obviously believed what they were saying.

The major religious affiliations in Christian schools were $72 \%$ Protestant, $4 \%$ Catholic, 23\% none; in Catholic schools, 59\% Catholic, 9\% Protestant, 32\% none; in independent schools, $16 \%$ Anglican, 11\% Catholic, 73\% none. A similar trend was found in the second studies using FGLL and SHALOM among primary and secondary school students in three types of non-government schools, with regards to the levels of relationship with God, which could have been a reflection of the religious affiliation of students, or lack of it. If the Christian school students were unwittingly just reflecting the Christian ethos of their schools, it is difficult to see how this would also account for them 
reporting greater help in their relation with God from a broad base, at home (from mother, female friends, themselves), as well as school (teacher, RE teacher) and God.

Linear regression analyses (see Table 6) revealed that perceived 'help from God' was very important in explaining the level of personal relationship with God, among primary Catholic and independent school students. As $86 \%$ of the Christian primary school students had rated God's help at the highest level, little discrimination was shown in this area. A related question was not asked of the primary students, but the 'importance of religion' was shown to explain greatest variance on secondary school students' relation with God, with 'help from God' accounting for less variance among secondary students compared with those in primary schools. 'Importance of spirituality' accounted for small variance in secondary students' relationship with God, in contrast to the major part played by 'importance of religion.' How students 'helped themselves' relate to God was of second importance in contributing to the variance on their lived experience with God, among both primary and secondary school students in this study.

Other minor contributing factors were found. 'Mothers' were ascribed an overall influence on these primary students. There was a difference between schools, but not within schools, so significant variance was not revealed by individual school type. 'Mothers,' together with the 'importance of spirituality' and 'happiness' accounted for slight variance among secondary Christian school students.

The personality variable, 'psychoticism,' showed significant inverse relationship with lived experience of God, in the independent and Catholic primary schools. A 'person with low psychoticism is altruistic, socialized, empathic, and conventional' (Eysenck \& Eysenck 1985). None of the personality factors measured by the JEPQR-A contributed significant variance among the secondary school students, whereas 'teachers' and 'level of schooling' accounted for minor variance among Catholic secondary school students.

Overall, irrespective of school type, it was the 'importance of religion,' not spirituality, together with 'help from God' and how they 'help themselves' (self) that explained greatest variance in students' lived experience with God. These three highest factors reinforce the necessity of ensuring that students have opportunities to interrogate the nexus between the 'importance of religion' and direct 'help from God,' coupled with how they can 'help themselves' in personally relating with God, for spiritual well-being.

Students indicated that teachers, especially RE teachers, helped them a great deal in relating with God (see Table 5, mean values >>2.00 on a scale from 0-3 for RE teachers) except for the senior secondary independent school students. Although regression analyses did not reveal large variance being attributed to teachers in this area, teachers do contribute to the ethos of the schools. According to teachers, it is their lived experience which has greatest impact on their perceptions of help provided by schools for development of students' relation with God, for spiritual well-being (Fisher 2008). This perception ties in well with the students' rating of teachers' help, in line with students' reported relationship with God, with Christian school students higher than Catholic, then independent schools.

Other studies with Australian youth have indicated that family and friends provide major support for students' faith development (Hughes 2007; Mission Australia 2005; Maroney 2008). However, greater in-depth statistical analysis from other studies is needed, much more than percentage distribution, before a clear picture becomes available 
of comparative influences of school, home and wider community, on students' relationship with God.

Table 6. Linear regression analyses of helps for students' relation with God

\begin{tabular}{|c|c|c|c|c|c|c|c|c|}
\hline \multirow[t]{2}{*}{ school } & \multicolumn{4}{|c|}{ primary } & \multicolumn{4}{|c|}{ secondary } \\
\hline & all & Cath & Chr & Ind & all & Cath & Chr & Ind \\
\hline $\mathrm{R}^{2}$ & .57 & .68 & .26 & .71 & .68 & .59 & .51 & .64 \\
\hline $\mathrm{F}$ & 71.7 & 19.4 & 13.3 & 31.1 & 155.7 & 52.5 & 33.6 & 18.6 \\
\hline $\mathrm{df}$ & 6.321 & 5,51 & 5,195 & 5,64 & 10,733 & 9,327 & 9,293 & 9,94 \\
\hline \multirow[t]{2}{*}{$\mathrm{p}$} & $<.001$ & $<.001$ & $<.001$ & $<.001$ & $<.001$ & $<.001$ & $<.001$ & $<.001$ \\
\hline & \multicolumn{4}{|c|}{$\mathrm{B}^{\text {sig }}$ values } & \multicolumn{4}{|c|}{$\mathrm{B}^{\text {sig }}$ values } \\
\hline schltype & $.08 *$ & & & & $.04 *$ & & & \\
\hline PSY & $-.07 *$ & $-.29 * *$ & $-.04^{\mathrm{ns}}$ & $-.23 * *$ & & & & \\
\hline relaffil & & not & asked & & $.05^{*}$ & $.02^{\mathrm{ns}}$ & $-.02^{\mathrm{ns}}$ & $-.00^{\mathrm{ns}}$ \\
\hline level & & N/A & & & $-.06 * *$ & $-.12 * *$ & $-.04^{\mathrm{ns}}$ & $-.02^{\mathrm{ns}}$ \\
\hline imprel & & not & asked & & $.32 * * *$ & $.35 * * *$ & $.23 * * *$ & $.45 * * *$ \\
\hline impspir & & not & asked & & $.09 * *$ & $.06^{\mathrm{ns}}$ & $.14 * *$ & $-.02^{\mathrm{ns}}$ \\
\hline $\mathrm{OHI}$ & & not & asked & & $.05^{*}$ & $.04^{\mathrm{ns}}$ & $.10^{*}$ & $.09^{\mathrm{ns}}$ \\
\hline mother & $.24 * * *$ & $.08^{\mathrm{ns}}$ & $.11^{\mathrm{ns}}$ & $.15^{\mathrm{ns}}$ & $.12 * * *$ & $.07^{\mathrm{ns}}$ & $.20 * * *$ & $-.03^{\mathrm{ns}}$ \\
\hline self & $.28 * * *$ & $.21^{\mathrm{ns}}$ & $.37 * * *$ & $.42 * *$ & $.25 * * *$ & $.29 * * *$ & $.27 * * *$ & $.29 *$ \\
\hline teacher & $.07^{\mathrm{ns}}$ & $.05^{\mathrm{ns}}$ & $-.06^{\mathrm{ns}}$ & $.03^{\mathrm{ns}}$ & $.08 * * *$ & $.08^{*}$ & $-.03^{\mathrm{ns}}$ & $.13^{\mathrm{ns}}$ \\
\hline God & $.33 * * *$ & $.51 * * *$ & $.07^{\mathrm{ns}}$ & $.29 * *$ & $.12 * * *$ & $.09 *$ & $.13 * *$ & $.17 *$ \\
\hline
\end{tabular}

Note: $* \mathrm{p}<.05, * * \mathrm{p}<.01, * * * \mathrm{p}<.001 \quad$ Cath=Catholic, $\mathrm{Chr}=$ Christian, Ind= Independent

Further quantitative studies with a wider range of students, and appropriate interviews and/or focus groups with selected students, could help clarify the nature and extent of the contribution teachers make to the students' personal relation with God, in contrast to help from parents, friends and Church leaders. Such studies would also consider the ethos and purpose of different types of school, with respect to this aspect of students' lives.

\section{Conclusion}

Several studies with Australian primary and secondary school students in four types of schools have shown clear differences in the perceptions students have of their relationship 
with God, and origins of help in forming this relationship. Contrary to the students' claims that teachers, especially RE teachers, provided major help for them in this area, other factors provided greater explanation of observed statistical variance. The 'importance of religion' and direct 'help from God' were key factors, together with how well students 'help themselves.' It is not surprising, therefore, that the ethos of the school, influenced by teachers and differences in students' religious affiliation, plays a vital role in fostering students' relationship with God, for their spiritual wellbeing.

\section{References}

Argyle, M. \& P. Hills. 2000. Religious experiences and their relations with happiness and personality. The International Journal for the Psychology of Religion. 10, no.3: 157-172.

Büssing, A., A Föller-Mancini, J. Gidley \& P.Heusser. 2010. Aspects of spirituality in adolescents. International Journal of Children's Spirituality. 15, no.1: 25-44.

Department of Education, Science and Training (DEST). 2007. National School Chaplaincy Programme. Canberra: Australian Government.

http://www.dest.gov.au/sectors/school_education/policy_initiatives_reviews/keyissues/sc hool_chaplaincy_programme/

Eysenck, H.J. \& M.W. Eysenck. 1985. Personality and individual differences: A natural science approach. New York: Plenum.

Fisher, J.W. 1998. Spiritual health: its nature and place in the school curriculum. PhD diss., University of Melbourne (http://eprints.unimelb.edu.au/archive/00002994/)

Fisher, J.W. 1999. Developing a spiritual health and life-orientation measure forsecondary school students. Paper presented at University of Ballarat Annual Research Conference, 15 October, pp. 57-63, Ballarat, Australia.

Fisher, J.W. 2004. Feeling Good, Living Life: a spiritual health measure for young children. Journal of Beliefs \& Values. 25, no.3: 307-315.

Fisher, J.W. 2006. Using secondary students' views about influences on their spiritual well-being to inform pastoral care. International Journal of Children's Spirituality. 11, no. 3: 347-356.

Fisher, J.W. 2007. It's time to wake up and stem the decline in spiritual well-being in Victorian schools. International Journal of Children's Spirituality. 12, no.2: 165-177.

Fisher, J.W. 2008. Impacting teachers' and students' spiritual well-being. Journal of Beliefs \& Values. 29, no.3: 253-261.

Fisher, J.W. 2009. Getting the balance: Assessing spirituality and well-being amongchildren and youth. International Journal of Children's Spirituality. 14, no.3: 273288. 
Francis, L.J. 1996. The Development of an Abbreviated Form of the Revised Junior Eysenck Personality Questionnaire (JEPQR-A) among 13-15 year-olds. Personality and Individual Differences. 21, no.6: 835-844.

Hay, D. \& R. Nye. 1998. The spirit of the child. London: Fount.

Hughes, P. 2007. Putting Life Together: Findings from Australian Youth Spirituality Research. Melbourne: CRA/Fairfield Press.

Maroney 2008. An exploration of a contemporary youth spirituality among senior students in three Catholic schools. EdD diss., Australian Catholic University.

Ministerial Council on Education, Employment, Training and Youth Affairs. 2008. Melbourne Declaration on Educational Goals for Young Australians. 5 December. Melbourne: MCEETYA.

Mission Australia. 2005. 2005 National Survey of Young Australians. Sydney: Author.

National Interfaith Coalition on Aging (NICA). 1975. Spiritual well-being: A definition. Athens, Georgia: Author.

Rymarz, R., and D. Tuohy. 2008. The religious participation and spiritual development of young people in Catholic schools: A longitudinal view. Journal of Religious Education 56, no.4: 40-52.

Wallace, M. 2005. Is there separation of church and state in Australia and New Zealand? Australian Humanist, 77: http://www.hsnsw.au/MaxWallace.html

\subsection{New models of schooling - Community based Christian schools in Australia}

\section{Background}

The previous paper highlighted the distinctiveness of students in Christian Community schools (CCS). This paper provides information that shows how CCS differ from other non-government schools in Australia, especially in the area of their students'relationship with God.

\section{Key points extracted from this paper}

- Over the last 30 years, relatively low-fee, parent-controlled and community-based Christian schools have emerged on the Australian education landscape.

- These schools are distinctively Christian in name and nature. For example, prayer (communicating with God) is integral, not incidental, to the operation of Christian 
schools. Teachers are required to have a Christian worldview, as well as a reference from their church leader, to gain employment.

- Parents have a God-given responsibility to educate their children, which some share with Christian schools that are based on Biblical principles and practices.

- By loving God, and loving others as themselves, graduates of such schools might contribute to a reduction of materialism and self-centredness, and an increase in community values and emphasis on helping others.

\section{Implications}

In order to maintain stated standards in Christian schools, principals need to select committed Christians who see teaching as a vocation/calling, not just a preferred place or form of employment. Christian schools need to provide suitable induction programs for the development of a Christian worldview in staff and students. It is a challenge for staff to prepare and present an integral Christ-centred curriculum, which provides support for students developing relationships with God, without coercing students into a given belief system. Staff in Christian schools are the living curriculum, called to show lives that are honouring to Christ/God.

A genuine, holistic, Christ-centred education requires considerable effort to ensure it is not just 'icing on the cake', for example, as in only providing a regular RE lesson and chapel as the Christian component of the school. Staff devotions and morning prayers set the tone for each day amongst staff and students in Christian schools.

With the exception of Christian Parent Controlled Schools (now Christian Education National), other Christian schools encourage active involvement of churches in school governance and operation.

Paper:

This paper was presented as: Fisher, J.W. (2012) Leading the development of new models of schooling: Community-based Christian schools in Australia. Religious Education Journal of Australia, 28(2): 36-42.

\section{Leading the Development of New Models of Schooling: Community-based Christian schools in Australia}

John Fisher 


\begin{abstract}
Parent-controlled or community based Christian schools are a relatively new phenomenon in Australia. Nearly two-thirds of all students in Australia attend State, or public, schools. Around twenty percent attend Catholic schools, with the remainder attending other nongovernment or independent schools (Schools Australia, 2010). Most of the independent schools are tied to particular religious affiliations, such as Anglican, Baptist, Greek Orthodox, Islamic, Jewish, Lutheran, Presbyterian, Seventh Day Adventist. Approximately forty per cent of these independent schools, roughly five percent of the total Australian student population, comprise other new Christian schools. This paper explores leadership issues in new Christian schools that foster religious education as an integral part of the total formation of the individual.
\end{abstract}

Keywords: Christian schools, religious formation, Christian leadership

\title{
Introduction
}

Most of these new Christian schools have low-fees, having been established following the provision of funding from the Whitlam Labor government at Federal level in 1973.

Additional financial support from Australian State governments has been provided since that time. The schools referred to here as new Christian schools all have the word Christian clearly evident in their titles and at the very core of their operation. They were largely founded in the 1980s, stimulated by finances becoming available from Federal followed by State governments.

This chapter explores the roles that principals of these schools have played in establishing these relatively new Christian schools. The insights explored are drawn from the perspectives of eight principals of new Christian schools who agreed to participate in this study.

The study drew on the principles of grounded theory (Strauss \& Corbin, 1990) to analyze and conceptualize the key challenges that faced the principal of a new Christian school in offering effective leadership. Although these schools are relatively new, there were approximately 150 years of educational experience amongst the eight principals who provided in-depth responses to fifteen questions posed to each participant regarding aspects of leadership in Christian schools in Australia.

\section{Establishing the mission of the School}

The mission of these schools is generally established well before the organisation of the School itself. The mission of the school is evident from the very reason that the church or group of parents decides to establish the School. A few of these schools were begun by churches which provide physical and spiritual support. Many were begun by communities and are governed by a board consisting of committed Christians with a common concern for the holistic development of children.

Christian Parent-Controlled schools (CPC) are a particular group of schools, founded by members of the Reformed Churches of Australia, which were markedly influenced by the Dutch Reformed movement (Justins, 2002). A dominant view in these schools is that parents have the God-given responsibility, expressed in the Bible, for educating their children (Deuteronomy 6 and Ephesians 6). This principle is embraced by 
all types of new Christian school. Many of the principals interviewed quoted Ecclesiastes 4:12 "a cord of three strands is not easily broken" to indicate the strength of the home, church and school working together in the education of a child. However, churches have no official part in the structure or function of CPC schools, in order to separate the church from school politics.

The belief that the distinguishing characteristic of new Christian schools is that Christ is the Head (and Heart), not just in name only, is attested to vigorously by comments provided by the principals. This is in line with the Association of Christian Schools International (ACSI) which states its purpose as "assisting education of children and young people with the mind of Christ ... guiding them to reach their full potential in Christ" (ACSI webpage). The governing boards and principals are committed to seeking Christ's will for guidance in the principles and practices of the schools (Lowrie, 2004). There is a passionate belief of the Bible. The principals interviewed reflect this focus, which is to provide Christ-centered education, through which each student will achieve their God-given potential, growing in wisdom and knowledge of Christ, being educated for life and eternity. The students are encouraged to work together for God's pleasure and will, living daily as an act of worship, to glorify God. The role model in the schools is Christ. Other notions that feature prominently are love, service, nurture, empowerment and justice, through which students are exhorted to walk humbly (with their God), in cooperation, walking with, rather than competing against, others.

In response to the question, "How do your graduate students differ from those of other schools?" the principals were keen to illustrate how their students are prepared with a Christian world-view, reflecting attitudes and knowledge affected by a Christ-centred approach. This provides them with a foundation upon which to make decisions not to be conformed to the ways of the world. The following response from one principal was indicative of the responses of all the principals:

Through strong service and missions programs, graduate students are trained and equipped to see the world from God's perspective and to understand their place in serving the needs of others to bring glory to God and to build communities. The graduates have learnt to think critically, thus being equipped for lifelong learning, whilst exhibiting the delightful attributes of a lifestyle of kindness, compassion and a lack of selfishness. Most graduates speak very fondly of their time in the Christian schools and the special relationship built between them and the staff. These findings are consistent with those from Christian schools in the United Kingdom (Baker \& Freeman, 2005). Frequent comments were made about the level of commitment of staff in supporting and nurturing students, especially those with special needs, many of whom were failing in other schools. A good test of the level of satisfaction of students with the schools is the fact that many graduate students send their children to Christian schools. Some have also been employed as staff there. With Christ as the role model, many, but not all, of the students go on to live for Jesus, with an established and educated faith base. At least one principal is not yet satisfied with progress in this area, and he hopes to see better results in the years ahead. 


\section{The relation between the Principal and the Board}

The CPC schools hold the position that parents should govern the schools to have maximum influence on the education of their children. Other schools are equally firm that parents are invited to partner with the school in educating their children but that the responsibility for this in the school rests with the staff, without undue influence by parents, who could be deemed to have, according to some principals "a conflict of interest when it comes to making decisions that have the potential to disadvantage some individuals." Many new Christian schools, other than CPC schools, invite churches to nominate delegates or representatives to be members of the school Board. Churches are encouraged to have involvement in the school through engagement in student groups, staff devotions, school assemblies and chapel, as well as general relationships between the churches and the school.

No matter what Board structure operates in a school, the Board has the responsibility for setting principles (Lowrie, 2004). The principal is responsible for policies and practice to give effect to the principles that have been established by the Board. As mentioned earlier, a distinctive characteristic of new Christian schools is that Christ is the Head (and Heart). When politics replaces prayer as the modus operandi for decision-making in Christian schools, problems are likely to occur. Politics, expressed as power over people, are based on human, instead of heavenly wisdom. Politics, more often than not, produces factions, which stifle rather than stimulate growth. The principals perceived that "seeking and finding the will of God leads to harmony and progress."

When some Board members attempt to exert undue influence over the Board, or even directly on the principal, tension ensues. This sometimes results in fractured relationships that can only be resolved by changes of personnel, either at the Board or principal level. Such fractures, which are perceived by the school community as not glorifying God, can take time to heal.

One of the principals interviewed gave the example of a minister of a sponsoring church who was the chair of the school Board. This provided a protective mantle over the school, as it was presumed that the minister was listening to God. However, if the minister saw the school as an extension of the church over which she or he had control and attempted to act as pseudo-principal, the situation would have become intolerable for the incumbent principal. The principal would have been forced either to resist the inappropriate domination or to adopt the role of puppet-principal.

\section{The relation between the Principal and the Staff}

The hiring and professional development of staff present particular challenges for the principal of a new school. These challenges are magnified when the school is attempting to develop a new model of learning.

The principals involved in this study described what they looked for in teachers especially when employing them. One principal stated:

In all areas staff should be committed Christians with a calling in their life to serve in a Christian school. They must have character - serving as unto the Lord. They must be willing to go beyond the call of duty and serve because they love students. Must enjoy working with children! Not an entertainer but someone 
committed to seeing children develop by the transforming power of the Holy Spirit.

Although this is a job specification from one Christian school principal, all the others agreed that the key criterion for staff selection was Christian commitment: having "a walk with God," being "committed Christians," showing an "active Christian faith" in harmony with the theological foundations of the school. A person desiring to teach a new Christian school must be overtly a Christian-under-construction, not just a church-attender. As another principal stated:

Just as living in a garage does not make you a car, just attending church does not make a person Christian. Someone who thinks they have arrived, has not yet begun to understand humility, an essential element of being a Christian teacher, which enables God to continue the restoration work necessary in each of us. Added criteria for staff selection included being well-trained, with appropriate experience, professional, having competency to carry out the job, being an "out-of-the box thinker" (as one principal put it) and teachable, as well as a team player and a person of integrity. Professional and personal references are required to verify the claims made concerning each of these points. Some principals of new Christian schools required an existing staff member to personally vouch for a candidate.

The above criteria help potential staff to pass the first post in the race of staff selection. Principals not only take note of what other people say about a person, they also ask the person to speak about themselves, using instruments with sound psychometric properties, to complement the interview process. As Christian commitment is considered the prime selection criterion, there are two instruments that have been developed and used in Christian schools, churches and other settings over the last twenty years. The Fifteen Item Measure Of Religiosity (FIMOR) is based on five categories of religiosity described by religious sociologists Glock \& Stark, namely public practice, private practice, salience of belief, experience and belief (in Fisher, 1993). The Spiritual Health And LifeOrientation Measure (SHALOM) is a 20-item instrument that provides a measure of each person's ideals and lived experiences in each of four domains of spiritual well-being, which are reflected in the quality of relationships that a person has with themselves, other people, the environment and with God. SHALOM has been used extensively in nine different languages (Fisher, 2010). Spiritual dissonance, which is shown by marked variation between the ideals and lived experiences in the domains of SHALOM, reveals which teachers provide greatest help in nurturing students' spiritual well-being (Fisher, 2008). The revised and abbreviated Eysenck Personality Questionnaire (EPQR-A) is used to assess personality constructs of extraversion, neuroticism, psychoticism as well having an attendant Lie scale, which reveals social-desirability of responses (Francis et al., 1991).

As well as induction programs and personal development, existing staff are offered opportunities for Professional Development. Indeed, there is a requirement for staff to undertake ongoing professional development to maintain teacher registration (e.g., see Victorian Institute of Teaching). This takes many forms in Christian schools, from team learning, individual learning through reflection and integration of faith and teaching. Many staff undertake graduate studies through engaging in courses run by Christian higher education institutions such as Christian Heritage College, Brisbane; National 
Institute for Christian Education (for CPC staff); Southland College, Sydney; and Tabor College, Adelaide and Melbourne, as well as some theological colleges. Others are stepping outside the fold doing courses in the Australian Catholic University and public universities. Staff members in new Christian schools are sampling many fields, with the primary goal of reflecting on how best to foster their own relationship with God and see this inform their nurturing of young people in their schools to help them realise their Godgiven potential.

Teaching in new Christian schools requires a radically changed mindset from that of the secular perspective in which most teachers were trained. Occasional inputs though staff in-service sessions, retreats and conferences are considered insufficient. New staff members are put through induction programs in some schools, no matter how long they have taught elsewhere. In fact, the longer they have been teaching outside of new Christian schools, the more they are thought to be in need of it. One principal appointed a special staff member to establish a small group "of resident experts to work with teams of staff to develop a strong biblical world view in their courses."

Most new Christian schools start the day with staff prayer and devotions, followed by similar activities for students in Home Groups. They provide some subjects or units of work which are completely devoted to concepts of the Christian faith or related issues, e.g., Christian Living or Life Studies. A Certificate 3 course in theological studies is being undertaken by senior students and staff in one school. Service and mission programs have been established as core parts of Year 9 programs to focus students' thoughts and actions on the needs of others, as a practical expression of Christian faith. But Christian schooling is much more than "icing on the cake" (Mechielsen, 1982). There must be more than peripheral religious activities reaching to the heart of the school.

\section{Curriculum}

The principals who were interviewed played a key role in the development of the curriculum framework, The framework for the whole curriculum was "to reflect the values of Christ Jesus." A principal expressed it in the following statement:

The art work is acceptable to God, the music is specially selected to glorify God, the reading and writing texts are that which edifies and is pleasing to God. Students are constantly reminded of God's handiwork in science. History is interpreted in the light of God interfering in the agenda of man.

During the 1980s, when many new Christian schools were emerging in Australia, Accelerated Christian Education resource material was frequently used to provide for individualized student progress. This material, which emanated from Southern Baptist roots in the USA, was modified to be more suitable for Australian settings (ABC TV, 2008). Many home-schoolers still use this material, but only about twenty Christian schools continue with its use for limited student instruction. Staff members in most new Christian schools carefully select text books from those available for other Australian schools. Some choose resources from overseas - mainly from American, Christian publishers.

When government authorities inspect Christian schools in Australia to effect registration and review, they expect to see that the base curriculum is being offered in accord with guidelines provided by State and Federal Education authorities (ACARA). 
With the advent of the National Australian Curriculum, the lowest common denominators will be set for all schools across Australia. Although these frameworks set the basic requirements, schools are free to interpret them according to their world-view within limits, and more importantly they are free to add other areas which are omitted in official documents. For example, even though the joint Ministers of Education agreed on Educational Goals for Young Australians (MCEETYA, 2008) that expressed a commitment to the "spiritual development and ... well-being of young Australians" as a vital role of schools (MCEETYA, 2008, p. 4), no reference to this aspect of student development is evident in the National Curriculum currently under construction (Reid, 2011).

One principal commented that "curriculum cannot be distinctively Christian but rather the curriculum ... is taught from a Christian perspective," based on the admonition of Scripture in Philippians 4:8, "Whatever is true ... noble ... right ... pure ... lovely ... admirable, excellent or praiseworthy, think about such things." Other principals stated that the government frameworks are the starting documents "that are then infused with a biblical world view that encourages students to see that we are exploring God's world and we are looking for His presence in the topic being studied." As another principal stated:

Teachers develop curriculum materials from a Christian perspective by allowing God's truth as expressed in the Bible to permeate the formal curriculum we develop and from which we teach. However, it is our belief that the "hidden curriculum", by which we mean the basic assumptions, presuppositions and beliefs that we hold, based on God's revelation determine what we teach and the way in which we engage our students in the teaching/learning process.

A key outcome of curriculum in Christian schools is to raise responsible citizens who know what they believe and why they believe it in science, social, environmental and political issues, so as not to be conformed to inappropriate "ways of the world." Thorough questioning of issues helps develop independent learners, for whom academic excellence means that each student is achieving their God-given potential.

Although much effort is devoted to giving the curriculum a Christian perspective, many teachers find the daily task of presenting learning opportunities from a biblical and Christ-centered view challenging. Some teachers, for example in Mathematics, fail to see the relevance of a Christian world-view to their area. Other teachers find their areas raise controversy. For example, new Christian schools are often criticized for providing input on creation science alongside theories of evolution in studies of origin of the universe and life. Rather than inculcating one theory, students are encouraged to investigate a number of alternatives, that is, to study the evidence or lack thereof in support of evolution, from humanistic and deistic perspectives, through intelligent design to intentional design in six day Creation.

\section{Relation between Principal and Prospective Parents}

The Principals of the new Christian schools devote much of their attention to explaining the nature of their schools to prospective parents and students. They do this both through personal contact and by developing materials and events through which their mission is made plain. 
The Christian theological foundations and principles upon which the schools operate are clearly stated on websites and in enrolment information packs. The logos and key words are prominent in these materials. Most schools have open days and information evenings to display their school's operation and provide opportunity for questions of clarification. Videos of frequently asked questions (FAQs), with corresponding answers, are sometimes made available for families to increase their understanding of Christian schooling. By the time parents and their children come to an interview, there should be very few questions about the foundation and operation of the Christian school.

Some principals state that "God directs families to them." Most of the Christian schools expect that parents and children will accept and support the ethos of the school, even if they may not hold to the Christian faith themselves. Parents sign a contract acknowledging that their children will be influenced from a Christian perspective according to the doctrines set out in the theological foundations underpinning the school. Several principals perceived that many parents and children come to faith in Christ through children's involvement in Christian schools.

However, not all new Christian schools have an open enrolment policy. One principal likened this situation to an ardent footballer wanting to join a tennis club: "Yes, all are interested in sport, but the one might adversely influence the tenor of the club, especially if outspoken against tennis." The CPC schools are considered closed enrolment schools because their enrolment policy states "at least one parent must come from an active faith background" (Justins, 2002). Other schools require parents to be committed Christians with mature character and integrity so that they have a common basis from which to work in partnership with staff in nurturing their children in the ways of the Lord.

Once parents have seriously considered all available information on the school, if they decide to proceed with an application for enrolment, then an interview time is set with the principal or head of school. Several decisions need to be made to allow the effective integration of new families with students into the school community. From the principal's point of view many wondered "will the family be supportive of the culture of the school and form a productive and happy partnership to enhance the development of their child/ren?" A brief questionnaire called Nine Expectation Factors Of Schools (NEFOS) takes five to ten minutes for parent/s and student/s to complete while waiting for an interview. It only takes twenty seconds to 'score' to see if the respondents are consistent in their answers about the importance of the following for schooling. There is an inbuilt checker in NEFOS to see if the individual items are ranked the same as the summary terms. Marked differences create great opportunities for discussion during the interview. The nine factors considered are:
Prestige
Preparing students for employment
Students' personal expression
Moral standards
Academic standards
Religious nature
Teacher quality
Friends
Student behaviour
(Fisher, 1993)
Will the child/ren fit within the school ethos and environment? In order to help answer these questions, principals rely on student reports from previous schools and generally a character reference from a minister or other responsible community leader. 
Some difficulties are experienced taking on students who have been home-schooled, who do not have a report except the biased view of the parent.

Once students have been selected to join the Christian school community, it is essential that staff get to know who they are and what they can do, as quickly as possible. Orientation days provide ideal opportunities to gain insight into each student's abilities and capacities. As well as testing literacy and numeracy, a good understanding of secondary school students' religiosity can be found using FIMOR (mentioned above under staffing). The broader concept of spiritual well-being can be canvassed using SHALOM, with secondary school students, and Feeling Good, Living Life, with students in primary school (Fisher, 2004). An awareness of students' personality can also be made using a modified form of the Junior Eysenck Personality Questionnaire (Gomez et al., 2009). Decisions regarding who may continue to be enrolled in a school are at least as important, and may possibly be more important, than the decision of who to admit (McKinley, 1990).

\section{Ensuring Adequate Resources}

The new Christian schools founded in the 1980s began with little attention to good business principles. Formal feasibility studies were beyond the financial reach of most of the concerned groups. Commitment was the key word. Letter box drops, advertising in local churches and media, together with flyers in public places heralded the public meetings which revealed the level of interest in forming a Christian school in a given community. This work was accomplished by conscientious volunteers.

In the early days, many newly-appointed principals, or head teachers, were selected from a group of keen Christians who had various experiences in other educational institutions. A few had been principals or senior staff in State and other religious schools. Some had been in teacher education. Some had theological training, but the vast majority had no formal training in Christian world-view as it applied to education. Many good, Christian teachers were not prepared to take the plunge into untested waters by leaving the security of other schools to become foundational staff in the emerging Christian schools. In the face of challenges in curriculum, capital works, staffing and students, the life expectancy in the role of principal of Christian schools was often no more than three years.

With the advent of new Christian schools, business principles needed to be developed for the fairly novel field of low-cost, Christian schooling, outside the Catholic system. In the early days, the level of fees charged was similar to that in Catholic parochial schools, but many of the staff in those schools were originally in Religious Orders, with 'salaries' far lower than the stipulated salary for independent school teachers.

Recurrent funds for operating expenses are made available to Christian schools from government bodies, generally within twelve months of their initial operation, subject to satisfactory inspection by Registered Schools Boards. Roughly based on the SocioEconomic Status (SES) of families, each non-government school receives grants in the range from around ten to seventy percent of the average cost of educating a student in a State school (AISV, 2011). Schools in lower SES areas can therefore afford to set their fees at lower levels. 
Although the state assists with recurrent funding, the up-front funding of land acquisition and capital works posed enormous challenges in low-fee schools. Many churches made their halls and land available for use by Christian schools, until they were able to fund their independence. Capital grants from Government for building and large equipment acquisitions are made on a competitive basis and often have a lead time of several years. Many of the principals interviewed told tales of God's provision. Some bought large tracts of land slightly removed from the centre of current building activity, sub-divided off blocks on the periphery and used the capital gain to pay for the land and construct buildings. Others purchased transportable buildings that were renovated by parents, students and staff. Many received government grants at the eleventh hour, when all other avenues of funding were exhausted. Some schools have experienced the generosity of builders, who are actively involved in Mobile Mission Maintenance International, which exists to spread the gospel by building, renovating and maintaining properties and facilities used in Christian outreach (mmminternational.org).

An effective school administration must ensure that the school is financially viable. Although generous fee remissions are provided by many of the new Christian schools, debtors are still handled firmly. When parents are open about their financial circumstances, they are generally met with generosity. Failure to face responsibility is frowned upon because it sours relationships between families and the school, which creates tension and provides poor role modeling to students. Some schools negotiate voluntary service in the canteen, library, uniform and book store, or the school grounds for parents who receive fee remission for their child/ren. These arrangements mean that parents actively contribute to the school's operation without feeling as though they have been given a handout. One principal perceived this to be and example of "Christian community in action".

\section{Summary}

The principals of the new Christian schools of the 1980s faced (and continue to face) striking challenges in addition to those facing the principal of an established school of an established kind. The key feature of new Christian schools is the centrality of Christ. This begins at Board level. The members of the Board need to discern the will of God in establishing the vision for Christian schools. Principals must have the capacity to work in two teams. Firstly, with the Board, in establishing vision and principles upon which Christian schools are built. Secondly, in leading and inspiring staff in setting priorities and practices to meet the needs of students, within parameters established by the Board.

Knowledge about appropriate selection and ongoing development of staff is of paramount importance to ensure their actions match their words; that they aim to have their lives reflect the nature and character of Christ to students. As the living curriculum, staff members work creatively within guidelines set by education authorities to engage students in training for life, through development of a Christian world-view.

Inviting families and students, who will enhance and develop within the body of the school, is a perpetual challenge for principals. Students are advertisements for the schools, so the principal and staff members need to ensure that students' achievement, behaviour, character, demeanour, etc reflect the essence of Christian schooling. Effective retention policies are as important as enrolment. 
The foregoing challenges are coupled with the necessity for schools to be financially viable; that the service is exemplary and accessible; that facilities are adequate for the task and that staff members are suitably recompensed for their efforts and commitment. In Honouring Christ as Head, working according to biblical precepts and being inspired by God's living presence, the Holy Spirit, leaders of new Christian schools have an eternal source of wisdom, strength, love and grace to conquer whatever challenges come their way. It is not always easy, but it is possible, and it is rewarding.

\section{References}

ABC TV (2008). Compass: A Christian education. Retrieved February 27, 2012, from http://www.abc.net.au/compass/s2365157.htm

Association of Christian Schools International (ACSI). Retrieved March 1, 2012 from http://www.acsi.org

Association of Independent Schools Victoria (AISV) Education Funding - SWD and Special Needs. Retrieved February 27, 2012, from http://www.independentschools.vic.edu.au/parents/pubs/swdfunding.pdf

Association of Independent Schools Victoria (AISV) (2011). Funding for Independent Schools. Retrieved February 27, 2012, from Error! Hyperlink reference not valid.

Australian Curriculum, Assessment And Reporting Authority (ACARA). Retrieved February 27, 2012, from http://www.acara.edu.au/curriculum.html

Baker, S. \& Freeman, D. (2005). The love of God in the classroom: The story of the new Christian Schools. Fearn, Scotland: Christian Focus Publications.

Blomberg, D. (1997). Wisdom at play: In the world bot not of it. In I. Lambert \& S. Mitchell (Eds.) The crumbling walls of certainty: Towards a Christian critique of Postmodernity \& Education (pp. 120-135). Sydney: Centre for the Study of Australian Christianity.

Fisher, J.W. (1993). Background, Religiosity and Expectations of the Parents and Senior Students in a Christian School. Unpublished MEd Thesis, University of Melbourne.

Fisher, J. (2004). Feeling Good, Living Life: A spiritual health measure for young children. Journal of Beliefs \& Values, 25(3), 307-315.

Fisher, J.W. (2008). Impacting teachers' and students' spiritual well-being. Journal of Beliefs \& Values, 29(3), 252-261.

Fisher, J. (2010). Development and application of a spiritual well-being questionnaire called SHALOM. Religions, 1: 105-121. 
Fowler, S. (1998). Pathways to the future: The challenge of Christian Education at the end of the century. In D. Blomberg \& I. Lambert (Eds.) Reminding: Renewing the mind in learning (pp. 182-199). Sydney: Centre for the Study of Australian Christianity.

Francis, L.J., Philipchalk, R. \& Brown, L.B. (1991). The comparability of the short form EPQ-R with the EPQ among students in England, the U.S.A., Canada and Australia. Personality \& Individual Differences, 12, 1129-1132.

Gomez, R., Gomez, A. \& Fisher, J.W. (2009). Comparing the psychometric properties of the common items in the short and abbreviated versions of the Junior Eysenck Personality Questionnaires: A means and covariance structures analysis approach. In L. B. Palcroft \& M. V. Lopez (Eds.), Personality Assessment: New Research (pp. 171-186). New York: Nova Sciences Publishers, Inc.

Independent Schools Council of Australia. Retrieved February 27, 2012, from http://isca.edu.au/about-independent-schools/

Justins, C.F.R. (2002). Christian Parent Controlled Schools in Australia - A study of the relationship between foundational values and prevailing practices. EdD dissertation, Australian Catholic University, Fitzroy, Victoria. Available from: dlibrary.acu.edu.au/digital theses/public/adt-acuvp20.16082005/02whole.pdf

Lowrie, R.W. \& Lowrie, R.L. (2004). Serving God on the Christian School Board. Colorado Springs: Purposeful Design Publications.

McKinley, W.R. (1990). Maintaining Christian school distinctives. In S.E. Burris \& W.R. McKinley (Eds.). Critical issues facing Christian schools, (pp.153-179). Whittier, CA.: Association of Christian Schools International.

Mechielsen, J. (revised ed.). (1982). No icing on the cake: Christian foundations for education in Australasia. Melbourne: Brookes Hall.

Ministerial Council on Education, Employment, Training and Youth Affairs (MCEETYA) (2008). Melbourne Declaration on Educational Goals for Young Australians. 5 December. Melbourne: MCEETYA.

Owen, J. (2011). Muddy Spirituality: Bringing it all back down to earth. Dandenong: UNOH Publishers.

Reid, D. (2011). Making space for religious education in the national curriculum. Religious Education Journal of Australia, 27(2), 10-15.

Schools Australia (2010). Retrieved February 27, 2012, from http://www.abs.gov.au/ausstats/abs@.nsf/lookup/4221.0Main+Features42010?OpenDocu $\underline{\text { ment }}$ 
Victorian Institute of Teaching (VIT). Retrieved February 27, 2012, from http://www.vit.vic.edu.au/Pages/default.aspx

\subsection{Summary of chapter 4}

Emphasis on spiritual development and well-being of students entails fostering/nurturing relationships and connectedness. Relationship with God and selves influences spiritual well-being and resilience. Moving the focus of young people away from materialism of the world, to engage in higher pursuits of meaning, purpose, values, compassion and service for others, is not easy. Some schools focus on the role of religion/RE in achieving these goals, whereas others concentrate on spiritual development, which is integral to holistic education, based on a Christian worldview. Parent-Controlled, and Christian Community, schools provide a distinctive educational paradigm that has been shown to markedly influence their students' relationship with God, at the heart of developing their spiritual well-being. 


\section{Chapter 5 Spiritual Well-Being in Healthcare Settings}

\subsection{Introduction}

My $\mathrm{PhD}$ at the University of Melbourne investigated the nature of spiritual health and its place in the school curriculum. As publications in spiritualty and education were in their infancy in the early 1990s the majority of the references that informed that work came from health education, nursing and medical journals, in addition to readings in theology. Following completion of that work in 1998, I spent two years as Research Project Officer in the School of Nursing at the University of Ballarat (UB), where I developed my measures of spiritual health/well-being. After a three-year interlude as Principal of Ballarat Christian College, I spent ten years as Research Manager in Palliative Care in the Grampians Health Region in Victoria. In this decade, as well as completing my EdD at the University of Ballarat in 2009, I undertook ten projects in healthcare. Three of those projects which investigated aspects of spiritual well-being are reported here.

\subsection{Nurses' and carers' spiritual well-being in the workplace}

\section{Background}

SHALOM has been employed with school students and teachers, university students and staff to provide valuable insight into their spiritual health as well as the development and provision of help for clients in spiritual health/well-being. Whilst in the School of Nursing at UB, I worked with a Master of Nursing student on a project using SHALOM to study spiritual well-being among nurses in the Western region of Victoria (Lea, 2005). Whilst I was working in the Grampians Health Region, it seemed appropriate to test SHALOM's usefulness among nurses and carers in public and private hospitals in that region. A nurse educator from Adelaide, who had discovered my research work, put me in touch with three hospices with which she worked in Australian capital cities. As I initiated, planned, carried out the research and wrote the report, I claimed $90 \%$ contribution to this paper, with the palliative care physician, Dr David Brumley, agreeing that $10 \%$ was a fair allocation for his comment on the project.

Key points extracted from this paper

- Three aspects of SHALOM were employed to ascertain nurses' and carers' (i) ideals, (ii) lived experiences, and (iii) perceptions of help provided to clients, in each of four domains of spiritual health/well-being. 
- Similar to findings in my previous studies the beliefs and worldviews of the nurses and carers surveyed were shown to influence their ideals for spiritual well-being. Their ideals impacted on their lived experiences, which, in turn, were shown to have dominant influence on their perceptions of the help provided to support their clients' spiritual well-being in their workplace.

- A questionnaire can only indicate consequences of spiritual health, not the phenomenon itself. However, the $\alpha$-values for the 12 'scores' from SHALOM showed that it is a good measure of three aspects of spiritual health/well-being.

- Dissonants (previously defined in Chapter 4.1 herein) had lower expectations of the level of help being provided to support clients' spiritual well-being in their workplace.

\section{Implications}

The quality of a questionnaire is only as good as the theoretical base upon which it is built and the statistical procedures employed in collecting and analysing the data. With SHALOM, as each individual's ideals are compared with their own lived experiences on four statistically sound domains of $\mathrm{SH} / \mathrm{WB}$, there is no variation in meaning of the terms employed in the questionnaire, as there would be by comparing one person's responses with other people's.

Stepwise progression of the influence of nurses' and carers' ideals on their lived experiences, which in turn impacted on their perceptions of help for clients' spiritual well-being, suggest that nurses and carers need opportunities to consider the importance of the four sets of relationships with self, others, environment and/or God for their own SWB and for the holistic well-being of their clients. That is, they need appropriate preparation to provide holistic care for themselves and clients.

More study is needed to determine if nurses' and carers' perceptions of help provided for clients' SWB are realised in practice, and if dissonants actually do provide less care for clients' spiritual well-being compared with that provided by non-dissonants.

\section{Paper:}

This paper was published as: Fisher, J.W. \& Brumley, D.J. (2008) Nurses' and carers' spiritual well-being in the workplace. Australian Journal of Advanced Nursing, 25(4):4957. 


\section{AUTHORS}

John Fisher MSc, MEd, PhD,

Research Manager, Grampians Regional Palliative Care, Research Centre, Ballarat Health Services, Victoria, Australia; Senior Fellow, School of Rural Health, University of Melbourne, Victoria, Australia.

johnfi@bhs.org.au

David Brumley MBBS, FRACGP, FAChPM, MSc,

Clinical Director, Gandarra Palliative Care Unit, Ballarat Health Service and Ballarat Hospice Care Inc; Palliative Care Physician and Director, Grampians Regional Palliative Care Research Centre, Ballarat; Senior Lecturer Rural Medical School, University of Melbourne, Victoria, Australia.

\section{Key words:}

Assessing spiritual well-being; SHALOM; spiritual dissonance

\section{Acknowledgement}

The authors sincerely thank the William Buckland Foundation for the financial support provided for this and other research projects in palliative care in the Grampians Regional Palliative Care Service, Ballarat Health Services, Victoria, Australia.

\section{Abstract \\ Objective}

The aim of the study was to investigate nurses' and pastoral carers' spiritual wellbeing (SWB) and how it relates to their workplace.

\section{Design}

The study design was a survey of total populations in selected health care services.

\section{Setting}

The setting was a public and a private hospital in a regional setting, and three hospices in major cities which had a religious affiliation.

\section{Subjects}

Responses were obtained from 154 (11\%) nurses and 8 (6\%) carers in the public hospital, $40(7 \%)$ nurses in the private hospital and 16 nurses and 7 carers $(17 \%)$ in the three hospices.

\section{Main outcome measure}

The Spiritual Health and Life Orientation Measure (SHALOM) was used to provide insights into staff ideals for spiritual wellbeing, as well as their lived experiences in relating with self, others, the environment and/or God. The nurses' and carers' 
perceptions about how well clients are supported in these four domains of spiritual wellbeing in their workplace were also explored.

\section{Results}

The beliefs and worldview of health care staff influence their ideals for spiritual wellbeing (SWB) to a greater extent than age, gender, or workplace setting. These ideals markedly impact on their lived experiences which reflect their SWB. Ten percent of these staff showed spiritual dissonance in more than one of the four domains of SWB.

The major finding of this study is the influence that nurses' and carers' personal experience has on the level of help they thought clients received from the services offered in their workplace. Those who are more fulfilled in relationships, with themselves, others, the environment and/or God, believe that clients receive greater help in these areas from the services provided in their workplace.

\section{Conclusion}

SHALOM is a useful indicator of four domains of SWB of health care staff who project their own lived experience onto the way they see clients having their spiritual wellbeing nurtured. This has implications for health care staff in the workplace.

\section{INTRODUCTION}

There are many claims in the literature that 'spirituality' and 'wellbeing' are both multifaceted constructs that are elusive in nature (Sessanna et al 2007; Buck 2006; Swinton 2006; de Chavez 2005; McSherry et al 2004). An extensive review of the literature reveals common themes mentioned when discussing a combination of these two concepts in the form of spiritual wellbeing (SWB) (Como 2007; Sinclair et al 2006; Ross 2006; Delgado 2005; Chiu et al 2004; Moberg 2002; Govier 2000; Martsolf and Mickley 1998; Dyson et al 1997; Burkhardt 1989; Ellison 1983). Four main themes appeared in the framework definition proposed by the National Interfaith Coalition on Ageing, in Washington DC, USA, that SWB is 'the affirmation of life in a relationship with God, self, community and environment that nurtures and celebrates wholeness' (NICA 1975).

These themes and their components are included in the model of spiritual health (SH) developed by Fisher, where he describes spiritual health as a, if not the, fundamental dimension of people's overall health (ie physical, mental, emotional, social and vocational). Spiritual health is a dynamic state of being, shown by the extent to which people live in harmony within relationships in the following domains of spiritual wellbeing:

Personal domain - wherein one intra-relates with oneself with regards to meaning, purpose and values in life. The human spirit employs self awareness in its search for self worth and identity.

Communal domain - as expressed in the quality and depth of interpersonal relationships between self and others relating to morality, culture and religion. These are expressed in love, forgiveness, trust, hope and faith in humanity.

Environmental domain - moving beyond care and nurture for the physical and biological to a sense of awe and wonder; for some people it is the notion of unity with the environment. 
Transcendental domain - the relationship of self with something or some-One beyond the human level (ie ultimate concern, cosmic force, transcendent reality or God). This involves faith toward, adoration and worship of, the source of mystery of the universe (F In this model, spiritual wellbeing is reflected in the quality of relationships that people have in one or more of the four domains of spiritual health.

\section{Measuring spiritual well-being}

Many available religiosity/spirituality measures ask people for a single response about 'lived experience' on a series of questions (Ross 2006). In the best instruments, these questions are built on theoretical frameworks of relationships between spirituality and health that are considered important by the developers of the scales. The 'scores' thus obtained are arbitrary indicators of spiritual health or wellbeing, especially if they have only a small number items (Boero et al 2005). A questionnaire can never reveal the true nature of spirituality or wellbeing; it can only provide indicators that reflect or are 'consequences of spiritual health, not the phenomenon itself' (Moberg 2002).

The power of a questionnaire depends on its theoretical base and the rigour with which it is developed and tested (Gray 2006). Fisher developed SHALOM (1999) in the belief that an instrument based on input from 850 secondary school students with diverse cultural and religious backgrounds should have appropriate language and conceptual clarity for studies of SWB within general populations and individuals across all age groups. An initial selection of 60 items from Fisher's model of SH was reduced to the 20 item SHALOM using exploratory factor analysis - 5 items in each of the 4 domains.

Confirmatory factor analyses on SHALOM using data from 4462 people, including nurses and carers, showed good reliability as well as validity (Gomez and Fisher 2003). The acronym SHALOM reveals its two components - Spiritual Health measure And Life-Orientation Measure. The 'life orientation measure' elicits the 'ideals' people have for 'spiritual health' in the four domains of relationships with self, others, environment and/or God. The spiritual health measure asks people to reflect on 'lived experience; how they feel each item reflects their personal experience most of the time.'

With only 20 items, SHALOM cannot be considered an exhaustive measure of SWB. If the researcher/carer and respondents/clients had time, it would be possible to use suitable qualitative procedures to mine the depths of people's SWB. However rather than taking hours, in 5-10 minutes, plus 5 minutes scoring time, SHALOM provides an effective means of indicating key aspects of four domains of SWB.

Fisher (1998) proposed that each person's beliefs and world-view impact on their understanding and commitment to the importance of each of these four domains. Therefore it is important to gain some idea of a person's world-view before attempting to 'measure' their SWB. In SHALOM, each person is compared with themselves as their standard. No arbitrary group norms are employed to compare or rank people. The difference between their 'ideals' and how they feel ('lived experience') gives an indication of their SWB in each of the four domains. For example, if people do not think relating with the environment, or God, is important for SWB, when they score 'low' on the 'lived experience' category, it is in harmony with their 'ideals' in these domains of SWB.

Some people believe all that is necessary for SWB is a wholesome relationship 
with oneself (MacLaren 2004). Other people believe that you can only truly be yourself in relation with others (Thatcher 1993). With an impending global warming crises; people are beginning to see the importance of relating with the environment for sustenance and the wellbeing of humanity. Relating with a transcendent other/God is not restricted to religious practice. Some studies have introduced terms such as 'higher power' to replace 'God' in attempts to be more 'politically correct' and/or less offensive to non-theists (Hungelmann et al 1985). In the development of SHALOM, terms such as 'godlike force' and 'supernatural power' were trialled but found wanting as they were not meaningful to young people and therefore possibly a range of adults also. Whether theistic, or not, people have a concept of 'God.' As they compare their ideal of whatever, with their lived experience, it is up to each person to define their own meaning for each notion. For example, there are many different religions and denominations or branches of religions because of people's different views. A brief question about religion is asked in the demographic section of this survey, along with gender and age, but religion per se is not included in SHALOM.

The aim of this study was to investigate nurses' and pastoral carers' spiritual wellbeing and how it relates to their workplace.

\section{METHOD}

Following approval from ethics committees, staff in selected health services were invited to complete SHALOM. A Plain Language Statement and the survey in an envelope were attached to pay-slips of all staff in a public hospital (1365 nurses, 132 carers) and a private hospital (570 nurses) in a regional centre, as well as in three hospices (95 nurses, 40 carers) in separate states of Australia. The survey comprised demographic data and SHALOM.

SHALOM has 20 items, five for each of four domains of spiritual wellbeing, reflecting quality of relationships with self, others, the environment, and/or with God.

Table 1: Items in the four domains of SWB in SHALOM

\begin{tabular}{|l|l|l|l|}
\hline Personal & Communal & Environmental & Transcendental \\
\hline sense of identity & love of other people & $\begin{array}{l}\text { connection with } \\
\text { nature }\end{array}$ & $\begin{array}{l}\text { personal relationship } \\
\text { with the Divine/God }\end{array}$ \\
\hline self-awareness & $\begin{array}{l}\text { forgiveness toward } \\
\text { others }\end{array}$ & $\begin{array}{l}\text { awe at a breathtaking } \\
\text { view }\end{array}$ & $\begin{array}{l}\text { worship of the } \\
\text { Creator }\end{array}$ \\
\hline joy in life & $\begin{array}{l}\text { trust between } \\
\text { individuals }\end{array}$ & oneness with nature & oneness with God \\
\hline inner peace & respect for others & $\begin{array}{l}\text { harmony with the } \\
\text { environment }\end{array}$ & peace with God \\
\hline meaning in life & $\begin{array}{l}\text { kindness toward } \\
\text { other people }\end{array}$ & $\begin{array}{l}\text { sense of 'magic' in } \\
\text { the environment }\end{array}$ & prayer life \\
\hline
\end{tabular}


The respondents were asked to rate each of the 20 items using a 5-point Likert scale:

$1=$ very low $2=$ low $3=$ moderate $4=$ high $5=$ very high $\quad$ to show:

a) how important each area is for an ideal state of spiritual wellbeing, and

b) how they felt each item reflects their personal experience most of the time, and

c) how much help they think clients gain from their health care service to develop these aspects of life.

All statistical analyses (ie correlations (power $=0.95$ ), cross-tabulations (power $=0.95$ ), t-tests (power=0.94), ANOVA (power=0.89), multiple regression analyses (power=0.99)) were performed using SPSS for Windows Version 15.0. G*Power3 was used to compute the statistical power for tests (Faul et al 2007).

\section{RESULTS}

\section{Participants}

Responses were obtained from 154 nurses (11\% response rate) and 8 carers (6\% response rate) in the public hospital, 40 nurses (7\% response rate) in the private hospital, and 16 nurses and 7 carers $(17 \%)$ in the three hospices. The rate of responses reported here is commensurate with other recent surveys in the public hospital (personal communication, HR Department, February 2008). The results are therefore not necessarily representative of the institutions surveyed.

There were more female nurses $(87 \%)$ than males and all but one of the carers was female. Nurses in the hospices were older (average 49.4 years) than nurses in the hospitals $(39.1$ years $)(t(199)=4.48, p<0.001)$. Pastoral carers were even older: public hospital (51.3 years) and hospices (55.7 years).

The religious beliefs of staff responding to this study was similar in each of the health care settings, even though the private hospital and the hospices had a religious affiliation, $\mathrm{X}^{2}(8, \mathrm{n}=225=14.3, \mathrm{p}=0.075$, $\mathrm{phi}=0.252)$.

\section{Spiritual wellbeing}

Statistical tests showed very good results for the twelve factors relating to SHALOM (Personal, Communal, Environmental, Transcendental measures of 'ideal,' 'lived experience,' and 'help'). They had alpha values ranging from 0.81 to 0.91 , accounting for between 60 and $88 \%$ of the variance in each factor. The correlation values for all five items in each factor were greater than 0.68 , well above the minimum acceptable value of 0.4 .

ANOVA showed that setting was not significant for any of the SWB factors studied here (t-values ranged from 1.17 to 0.19 , with $p$ ranging from 0.24 to 0.85 ).

To check the relative impact on SWB, age, gender, position and religion were entered as predictor variables in linear regression analyses. The $R^{2}$-values (which give approximate percentages) and $\beta$-values (which indicate the size of effect of each predictor variable) are recorded in table 2 . 


\section{Ideals for SWB}

There are obviously factors other than gender, age and religion which contribute to the ideals or world view that nurses and carers hold and that impact on their relationships with self, others, the environment and God. However these are outside the scope of this study. Females often score higher than males on the ideals for Personal and Communal SWB (Gomez and Fisher 2005) but the Environmental impact here could relate to the older females working in the hospices who are also more religious. Staff who identified as 'Christian' scored higher than the other religions on the Transcendental (God) factor, with religions being higher than no religion.

Table 2: $\beta$-values and $\mathbf{R}^{2}$ values for regression analyses of influences on SWB

\begin{tabular}{|c|c|c|c|c|c|}
\hline \multirow{2}{*}{$\begin{array}{l}\text { Categories } \\
\text { of SWB }\end{array}$} & \multirow{2}{*}{$\begin{array}{l}\text { Predictor } \\
\text { variables }\end{array}$} & \multicolumn{4}{|c|}{ Domains of SWB } \\
\hline & & Per & Com & Env & Tra \\
\hline & $\mathrm{R}^{2}$ & 0.04 & 0.06 & 0.07 & 0.26 \\
\hline \multirow[t]{4}{*}{ Ideal } & gender & $* 0.19$ & $* * 0.20$ & $* 0.16$ & \\
\hline & religion & & $* 0.14$ & & $* * * 0.42$ \\
\hline & age & & & $* * 0.22$ & $* * * 0.22$ \\
\hline & $\mathrm{R}^{2}$ & 0.28 & 0.39 & 0.59 & 0.69 \\
\hline Lived & ideal & $* * * 0.50$ & $* * * 0.56$ & $* * * 0.75$ & $* * * 0.59$ \\
\hline \multirow[t]{4}{*}{ experience } & gender & & $* 0.12$ & & \\
\hline & age & & $*_{-0} 0.12$ & & \\
\hline & religion & & & & $* * * 0.36$ \\
\hline & $\mathrm{R}^{2}$ & 0.29 & .30 & 0.33 & 0.30 \\
\hline \multirow[t]{3}{*}{ Help } & lived experience & $* * * 0.51$ & $* * * 0.62$ & $* * * 0.55$ & $* * * 0.45$ \\
\hline & age & & & & $* 0.15$ \\
\hline & position & & & $* 0.12$ & \\
\hline
\end{tabular}

\section{Lived experiences of SWB}

These results read (with apologies to Descartes), 'What I think, I am,' in keeping with the idea expressed in Proverbs 23:7, 'As a man thinks in his heart, so is he.' It is clear that people's 'ideals' are the greatest single factor contributing to 'lived experience' 
in each of the four domains of SWB studied here. In other words, what people are in their heads and their hearts is worked out in their lives. There is a small influence of gender, with 40 year olds scoring lower than others on how well they relate to other people. Religious beliefs discriminated in staff's lived experience of relating with God, as they did for ideals.

\section{Perceived help for SWB}

The carers were slightly more concerned with their clients' environmental wellbeing than were the nurses. Older staff have a slighter higher perception of how well they nurture clients' relations with God. However the greatest impact is shown by these nurses' and carers' own lived experiences influencing the perceptions they have of the help provided in their workplace for nurturing the four domains of clients' SWB. These results support the theoretical views expressed by MacLaren (2004) that nurses' spirituality ' can become the unspoken element which underpins and may improve the quality of their care' and Pesut and Thorne (2007) that ' the identities which nurses bring to spiritual care encounters have far-reaching implications for patient experiences.' An exploratory study with 60 graduate nurses found a 'relationship of nurse's involvement and beliefs in spirituality and their attitudes toward providing spiritual care' (Willis 2000).

\section{DISCUSSION}

\section{Spiritual dissonance}

Numerical values of 'scores' on each scale of a SWB measure do not mean much unless they relate to something substantial. A key outcome of health service provision is holistic care for clients (McBrien 2006). In this study we were concerned with the health staff's perceptions of their own SWB as well as their perceptions of the help provided to clients in this area in their workplace.

Lived experience impacts markedly on perceived help for clients, but how? As most people admit they are not perfect, so it is not surprising to note some decline from 'ideals' to 'lived experiences.' Some variation is expected, but how much is unhealthy?

It has previously been proposed by Fisher (2006) that spiritual dissonance is indicated by a difference in mean value of greater than 1.0 between the 'ideal' and 'lived experience' in any domain of SWB, measured using SHALOM. For example, if a person's ideal rated as 'high' (mean value $=4.0$ across the 5 items), a 'lived experience' score below 3.0 (less than 'moderate') would indicate spiritual dissonance. Table 3 shows correlation values between the differences ( $d$ values) and help categories (c values) in the four domains of SWB (Personal, Communal, Environmental and Transcendental). The differences (d-scores) correlate moderately with each other indicating a pattern across domains. These d-scores would be expected to show a relation to ideals and lived experiences (because they are the difference between these two factors), and they do.

The interesting finding is the extent to which differences relate to perceived help (c values), especially in the Personal and Communal domains, to a lesser extent in the Environmental and almost non-existent in the Transcendental domains.

Using Fisher's definition above, spiritual dissonance was shown in the Personal 
domain ( $\mathrm{n}=26,11.6 \%)$, Communal domain $(\mathrm{n}=17,7.6 \%)$, Environmental domain $(\mathrm{n}=15$, $6.7 \%)$ and Transcendental domain $(n=38,16.9 \%)$. Greater dissonance was shown in the

Transcendental domain by the non-religious, $\mathrm{X}^{2}(1, \mathrm{n}=225=12.0, \mathrm{p}=.001$, phi=-.23).

Table 3: Pearson Correlation values of 'differences' with 'help' in domains of Spiritual Well-Being

\begin{tabular}{|l|l|l|l|l|l|l|l|}
\hline & d-com & d-env & d-tra & per-c & com-c & env-c & tra-c \\
\hline d-per & $* * * 0.587$ & $* * * 0.550$ & $* * * 0.310$ & $* * *-0.322$ & $* * *-0.351$ & $* * *-0.241$ & $* *-0.201$ \\
\hline d-com & & $* * * 0.497$ & $* * * 0.300$ & $* * *-0.316$ & $* * *-0.364$ & $* *-0.193$ & ${ }^{\text {ns }}-0.058$ \\
\hline d-env & & & $* * * 0.406$ & $* * * 0-.266$ & $* *-0.211$ & ${ }^{*}-0.133$ & ${ }^{\text {ns }}-0.114$ \\
\hline d-tra & & & & $*-0.162$ & ${ }^{*}-0.161$ & ${ }^{n s}-0.123$ & ${ }^{n-}-0.089$ \\
\hline
\end{tabular}

${ }^{*} \mathrm{p}<0.05 ; * * \mathrm{p}<0.01 ; * * * \mathrm{p}<0.001 ;{ }^{\mathrm{ns}}=$ not significant

Personal $=$ per $;$ Communal $=\mathrm{com} ;$ Environmental $=$ env $;$ Transcendental $=$ tra

This could perhaps indicate a remnant of religious influence lingering in the minds of the non-religious, positing a requirement of a god as an ideal for their own spiritual wellbeing $(\mathrm{M}=2.74, \mathrm{SD} 1.25)$, which they are rejecting in practice $(\mathrm{M}=2.06, \mathrm{SD}=.91)$, in contrast to the religious $\left(\mathrm{M}_{\text {ideal }}=3.85, \mathrm{SD}=1.15 ; \mathrm{M}_{\text {expce }}=3.60, \mathrm{SD}=1.09\right)$.

Only two staff $(0.9 \%)$ showed dissonance in all four domains, another $6(2.7 \%)$ in three domains, a further $15(6.7 \%)$ in two domains, with 40 (17.8\%) showing dissonance in only one domain of SWB.

Table 4: Cross-tabulations between spiritual dissonants and non-dissonants

\begin{tabular}{|l|l|l|l|l|l|}
\hline Variable & df & $\mathrm{N}$ & $\mathrm{X}^{2}$ value & $\mathrm{p}^{\text {sig }}$ & Phi \\
\hline Age & 4 & 216 & 3.070 & ${ }^{\mathrm{ns}} 0.546$ & 0.12 \\
\hline Gender & 1 & 219 & 0.012 & ${ }^{\mathrm{ns}} 0.912$ & -0.01 \\
\hline Setting & 2 & 225 & 0.589 & ${ }^{\mathrm{ns}} 0.745$ & 0.05 \\
\hline Position & 2 & 225 & 1.050 & ${ }^{\mathrm{ns}} 0.591$ & 0.07 \\
\hline Religion & 4 & 225 & 3.580 & ${ }^{\mathrm{ns}} 0.466$ & 0.13 \\
\hline
\end{tabular}

The health care staff who showed dissonance in more than one domain (i.e., in 4, 3 or $2=10.3 \%$ ) (hereafter called dissonants), were significantly different from the rest of the staff when it came to investigating the impact of dissonance on perceived help for clients' SWB. However these spiritual dissonants were not easily identifiable, being spread over a variety of work areas, with no distinct pattern by age, gender, setting, position or religion (See table 4 for cross-tabulation results).

The following graph shows mean values for each of the three factors: (A) ideal, 
(B) lived experience and (C) help, for each of the four domains of SWB (Personal, Communal), Environmental and Transcendental) compared by dissonance.

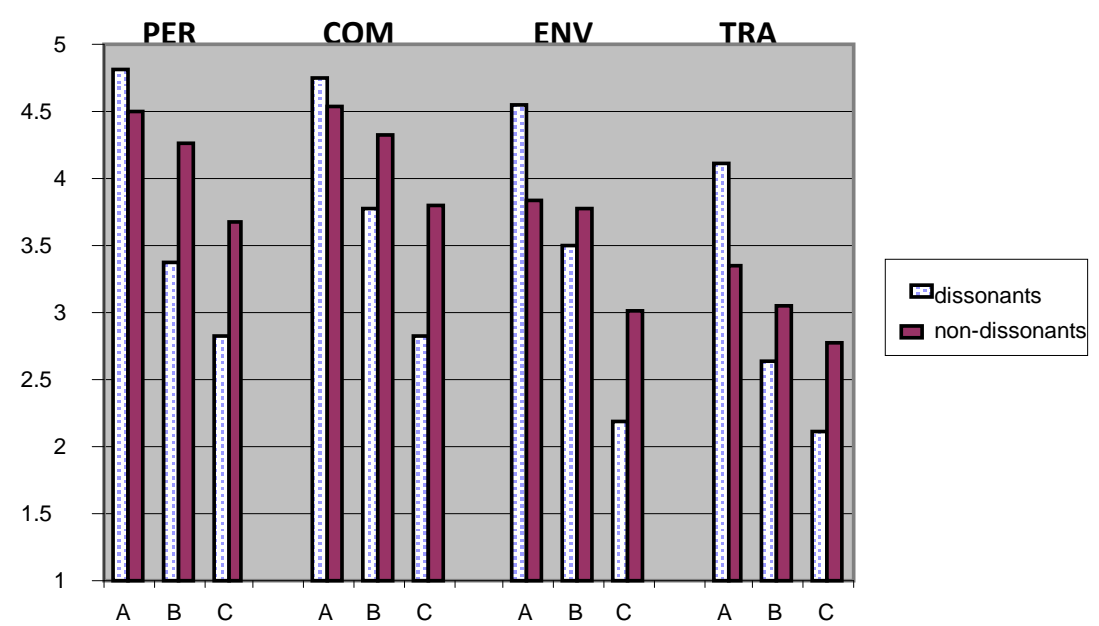

$\mathrm{PER}=$ Personal $; \mathrm{COM}=$ Communal ENV $=$ Environmental $; \mathrm{TRA}=$ Transcendental SWB

Mean values for SWB domains shown on graph above

\begin{tabular}{|c|c|c|c|c|c|c|c|}
\hline & & \multicolumn{3}{|c|}{ PER } & \multicolumn{3}{|c|}{ COM } \\
\hline & $\mathrm{n}$ & $\mathrm{A}$ & B & $\mathrm{C}$ & $\mathrm{A}$ & B & $\mathrm{C}$ \\
\hline dissonants & 23 & 4.81 & 3.38 & 2.83 & 4.75 & 3.78 & 2.83 \\
\hline \multirow[t]{3}{*}{ Non-dissonants } & 202 & 4.50 & 4.26 & 3.68 & 4.5 & 4.32 & 3.80 \\
\hline & & \multicolumn{3}{|c|}{ ENV } & \multicolumn{3}{|c|}{ TRA } \\
\hline & $\mathrm{n}$ & $\mathrm{A}$ & B & $\mathrm{C}$ & A & B & $\mathrm{C}$ \\
\hline dissonants & 23 & 4.55 & 3.50 & 2.18 & 4.10 & 2.68 & 2.06 \\
\hline Non-disssonants & 202 & 3.84 & 3.78 & 3.02 & 3.38 & 3.10 & 2.78 \\
\hline
\end{tabular}

The spiritual dissonants were more idealistic (higher As) however their lived experiences did not match their idealism (much lower Bs). As a consequence, in keeping with the above finding of the influence of lived experience on perceptions of help, dissonants thought less help was provided by the workplace for clients in nurturing these aspects of their care (low Cs).

It would be valuable to follow up this study with one on personality to see how strong a relationship personality has on ideals compared with lived experiences of SWB. A study on burnout would also reveal whether dissonance in the domains of SWB, measured by SHALOM, related to emotional exhaustion and/or depersonalisation (Maslach et al 1996) in comparison with a study using another SWB scale (Marsh 1998). 
It would also be desirable to observe people who tested high on dissonance in these SWB domains to see if they actually provided lower quality of care to clients, in line with their perceptions of the workplace. If it was found that the dissonants did provide lower care for the SWB of clients, the questions would need to be raised as to whether these people refer clients to others, or if professional support would be warranted to improve their skills in this area. Issues of competence and cost would need to be weighed against quality of client care in line with the stated mission and vision statements of the health care services. Recent research concluded that 'prevailing health care systems ... do not always lend themselves to holistic (including spiritual) approaches to care. This study identifies a need for nurse education to redress the clearly inadequate preparation nurses are given for this aspect of their role' (Lea 2005).

There is not space here to discuss the issue of whose responsibility it is to provide spiritual care for clients (Pesut 2006; Narayanasamy 2004; Kellehear 2002; Govier 2000). However this study has shown that SHALOM can be used to identify the potential of staff to provide such care. Identifying these people may go some way to helping overcome barriers to spiritual care (as expressed in Vance 2001).

\section{CONCLUSION}

Spiritual well-being is a complex construct. However, this study has shown that SHALOM is a useful indicator for four domains of spiritual health and wellbeing of health care staff, reflected in the quality of relationships they have with self, others, the environment and/or God. The beliefs and worldview of health care staff influence their ideals for SWB to a greater extent than age, gender, or workplace setting. These ideals markedly impact their lived experiences which reflect their SWB. In turn, their lived experiences have a major influence on their perceptions of help provided to clients in these areas in their workplaces.

Spiritual dissonance, resulting from distinct differences between ideals and lived experiences in four domains of $\mathrm{SH}$, was identified in a particular group (comprising ten percent) of these health care staff. They held high ideals they were not able to realise, resulting in lower perceptions of the workplace.

Using SHALOM to indicate levels of SWB of health care staff has implications for care of clients in the workplace.

\section{REFERENCES}

Boero, M., Caviglia, M., Monteverdi, R., Braida, V., Fabello, M. and Zorzella, L. 2005. Spirituality of health workers: a descriptive study. International Journal of Nursing Studies, 42(8):915-921.

Buck, H.G. 2006. Spirituality: concept analysis and model development. Holistic Nursing Practice, 20(6):288-292.

Burkhardt, M. 1989. Spirituality: an analysis of the concept. Holistic Nursing Practice, 3(3):69-77. 
Chiu, L., Emblen, J., Van Hofwegen, L., Sawatzky, R. and Meyerhoff, H. 2004. An integrative review of the concept of spirituality in the health sciences. Western Journal of Nursing Research, 26(4):405-428.

Como, J. 2007. A literature review related to spiritual health and health 0utcomes. Holistic Nursing Practice, 21(5):224-236.

de Chavez, A., Backett-Milburn, K., Parry, O. and Platt, S. 2005. Understanding and researching wellbeing: Its usage in different disciplines and potential for health research and health promotion. Health Education Journal, 64(1):70-87.

Delgado, C. 2005. A discussion of the concept of spirituality. Nursing Science Quarterly, $18(2): 157-162$.

Dyson, J., Cobb, M. and Forman, D. 1997. The meaning of spirituality: a literature review. Journal of Advanced Nursing, 26(6):1183-1188.

Ellison, C. 1983. Spiritual well-being: conceptualisation and measurement. Journal of Psychology and Theology, 11(4):330-340.

Faul, F., Erdfelder, E., Lang, A-G. and Buchner, A. 2007. G*Power 3: a flexible statistical power analysis program for the social, behavioral and biomedical sciences. Behavior Research Methods, 39(2):175-191.

Fisher, J. 1998. Spiritual health: its nature and place in the school curriculum. $\mathrm{PhD}$ thesis, University of Melbourne. Available from:

http://eprints.unimelb.edu.au/archive/00002994/ (accessed April 2008).

Fisher, J. 1999. Developing a spiritual health and life-orientation measure for secondary school students. In: Proceedings of University of Ballarat Annual Research Conference, 15 October, pp. 57-63.

Fisher, J. 2006. Using secondary students' views about influences on their spiritual wellbeing to inform pastoral care. International Journal of Children's Spirituality, 11(3):347-356.

Gomez, R. and Fisher, J. 2003. Domains of spiritual wellbeing and development and validation of the Spiritual Well-Being Questionnaire. Personality and Individual Differences, 35(8):1975-1991.

Gomez, R. and Fisher, J. 2005. The spiritual wellbeing questionnaire: testing for model applicability, measurement and structural equivalencies and latent mean differences across gender. Personality and Individual Differences, 39(8):1383-1393.

Govier, I. 2000. Spiritual care in nursing: a systematic approach. Nursing Standard, 14(17):32-36. 
Gray, J. 2006. Measuring spirituality: conceptual and methodological considerations. The Journal of Theory Construction and Testing, 10(2):58-64.

Hungelmann, J., Kenkel-Rossi, E., Klassen, L. and Stollenwerk, R. 1985. Spiritual wellbeing in older adults: harmonious inter-connectedness. Journal of Religion and Health, 24(2):147-153.

Kellehear, A. 2002. Spiritual care in palliative care: whose Job is It? In: B. Rumbold (ed), Spirituality and palliative care: social and pastoral perspectives. Oxford University Press: Melbourne, Victoria, Australia.

Lea, D. 2005. Spiritual awareness of professional nurses in the western region of Victoria: investigation of a significant component of holistic health care. M.Nursing thesis. University of Ballarat Available from: http://digthesis.ballarat.edu.au/adt/ public/adt-ADT20051027.121058/index.html (accessed April 2008).

McBrien, B. 2006. A concept analysis of spirituality. British Journal of Nursing, $15(1): 42-45$.

MacLaren, J. 2004. A kaleidoscope of understandings: spiritual nursing in a multi-faith society. Journal of Advanced Nursing, 45(5):457-464.

McSherry, W., Cash, K. and Ross, L. 2004. Meaning of spirituality: implications for nursing practice. Journal of Clinical Nursing, 13(8):934-941.

Marsh, V. 1998. Job stress and burnout among nurses: the mediational effect of spiritual wellbeing and hardiness. Dissertation Abstracts International, Section B: The Sciences and Engineering. Vol 58(8-B) p.4142. Texas Women's University, USA.

Martsolf, D. and Mickley, J. 1998. The concept of spirituality in nursing theories: differing world-views and extent of focus. Journal of Advanced Nursing, 27(2):294-303.

Maslach, C., Jackson, S. and Leiter, M. 1996. Maslach Burnout Inventory Manual. Consultant Psychologists Press: Palo Alto, California, USA.

Moberg, D. 2002. Assessing and measuring spirituality: confronting dilemmas of universal and particular evaluative criteria. Journal of Adult Development, 9(1):47-60.

Narayanasamy, A. 2004. The puzzle of spirituality for nursing: a guide to practical assessment. British Journal of Nursing, 13(19):1140-1144.

National Interfaith Coalition on Ageing. 1975. Spiritual well-being: a definition. Available from: http://www.ncoa.org/content.cfm?sectionID=383\&detail=394 (accessed April 2008). 
Pesut, B. 2006. Fundamental or foundational obligation? Problematising the ethical call to spiritual care in nursing. Advances in Nursing Science, 29(2):125-133.

Pesut, B. and Thorne, S. 2007. From private to public: negotiating professional and personal identities in spiritual care. Journal of Advanced Nursing, 58(4):396-403.

Ross, L. 2006. Spiritual care in nursing: an overview of the research to date. Journal of Clinical Nursing, 15(7): 852-862.

Sessanna, L., Finnell, D. and Jezewski, M. 2007. Spirituality in nursing and health related literature. Journal of Holistic Nursing, 25(4):252-262.

Sinclair, S., Pereira, J. and Raffin, S. 2006. A thematic review of the spirituality literature within palliative care. Journal of Palliative Medicine, 9(2):464-479.

Swinton, J. 2006. Identity and resistance: why spiritual care needs 'enemies'. Journal of Clinical Nursing, 15(7):918-928.

Thatcher, A. 1993. Spirituality without inwardness. Scottish Journal of Theology, 46:213228.

Vance, D. 2001. Nurses' attitudes toward spirituality and patient care. MEDSURG Nursing, 10(5):264-268.

Willis, W. 2000. The relationship of nurses' involvement and beliefs in spirituality and their attitudes toward providing spiritual care. M.Nursing thesis. University of South Florida, Tampa, Florida USA. Available from: http://handle.dtic.mil/100.2/ADA387304 (accessed April 2008). 


\subsection{Palliative care doctors need help with spiritual well-being}

\section{Background}

A similar survey instrument to that employed with nurses and carers in the previous study was used with Australian and New Zealand palliative care doctors to investigate their personal spiritual well-being and their perceptions of the amount of help provided to their clients. This study was part of a broader survey investigating burnout in palliative care doctors. I planned and coordinated this study, analysed the results and wrote the paper (90\% attribution), with comment being made by Dr David Brumley (10\% attribution).

\section{Key points extracted from this paper}

- The palliative care doctors who participated in this study reported ideals that were scored higher than their lived experiences. Similar to the nurses and carers in the previous paper (Chapter 5.1 herein), the palliative care doctors' lived experiences were scored more highly than their perceptions of help that they provide to clients for spiritual well-being.

- The full-time male palliative care doctors reported that they provide better holistic care than do their part-time female counterparts, who agree that they are spread too thinly across many areas of life. This perception of male doctors that they provide greater care than their female colleagues for clients' spiritual as well as more general well-being appears related to the greater contact they have with clients.

- These doctors report least support for the Transcendental domain of the four domains of spiritual well-being studied.

\section{Implications}

Because these palliative care doctors have a lower level of religious affiliation than the general population in Australia and New Zealand, their personal worldviews adversely influence the help that they report providing for their clients in the Transcendent domain of spiritual well-being. As many of these doctors lack time, training, expertise or interest in addressing the existential and religious concerns of clients, their clients would benefit from the doctors calling in help, e.g., from counsellors or chaplains, when a spiritual concern is identified.

Doctors cannot fake interest in patients' spiritual well-being because patients can tell. However, if they acknowledge the importance of assessing spiritual needs by being 
involved in the assessment process, they can then hand over responsibility to other members of a multi-disciplinary team to help ensure patients are cared for holistically.

There is no place for omission, or religious fanaticism, or patronising, psychointellectual bigotry on the part of palliative care doctors, or any other healthcare workers, in addressing the spiritual well-being of patients.

\section{Paper:}

This paper was published as: Fisher, J.W. \& Brumley, D.J. (2012) Palliative care doctors need help with spiritual well-being. Journal for the Study of Spirituality, 2(1): 49-60.

\section{Palliative care doctors need help with spiritual well-being}

John W. Fisher ${ }^{1}$ University of Melbourne, Australia

jwfisher@unimelb.edu.au

David Brumley ${ }^{2}$ University of Melbourne, Australia

chanterelle@mac.com

1. John W. Fisher is Senior Fellow, Rural Health Academic Centre, Faculty of Medicine, University of Melbourne, Victoria, Australia.

2. David Brumley is Senior Lecturer, Rural Health Academic Centre, Faculty of Medicine,

University of Melbourne, Victoria, Australia.

Abstract: Spirituality is widely recognized as a key component of holistic care for palliative care patients. Are palliative care doctors able to include this in their role or should it be done by others? A survey of 300 palliative care doctors in Australia and New Zealand yielded a 52 per cent response rate, providing insight into their ideals, lived experiences and perceptions of help for patients, in four domains of spiritual wellbeing, assessed using the Spiritual Health And Life-Orientation Measure (SHALOM).

Male palliative care doctors provided levels of help commensurate with their lived experience in two domains of spiritual wellbeing. Greater professional distancing of female palliative care doctors resulted in their perception of less holistic care being provided for patients. Palliative care doctors do not have adequate time, experience or training to provide all aspects of spiritual care, especially with regard to the relationship with God. Patients need holistic care provided by comprehensive, well-balanced teams. In brief, palliative care doctors need help personally and in providing spiritual care for patients.

Keywords: spiritual care; palliative care; assessment. 


\section{INTRODUCTION}

The World Health Organization includes spiritual care of palliative care patients in its definition of palliative care, but it does not say who should provide it (WHO). Some authors of journal articles intimate that all palliative care doctors and nurses should be able to attend to their patients' spiritual well-being, as part of the holistic care they are expected to provide (Astrow et al. 2001, Puchalski 2002) but this assumption is questioned by others (Walter 2002, Sheehan 2003, O'Connor and Fisher 2011). Palliative Care Australia's 'Standards for Providing Quality Palliative Care for all Australians' mention spiritual care, to be provided by an inter-disciplinary team, including a spiritual advisor (PCA 2005). A Consensus Conference on spiritual care recommended "interprofessional care that includes board-certified chaplains on the care team" (Puchalski et al. 2009). But, is such a person or position necessary? Or, are Palliative Care doctors and nurses able to provide spiritual care as part of their 'normal' care of patients? This paper focuses particularly on the capacity of palliative care doctors to address the spiritual needs of their patients.

With the shift in emphasis from biophysical to patient-centered care, the least discussed area involves spiritual/existential issues (Cartwright et al. 2007). Spirituality is important for patients, but many systems of care do not provide it (Puchalski et al. 2009). Staff often believe they have done their duty regarding the spiritual needs of each patient when they ask about religious affiliation (Puchalski et al. 2003). There is a wide range of views about the connection between religion and spirituality. The dominant religious view is that religion embraces spirituality, which is effectively seen as just one expression of religion. Some people equate the two words, interchanging them at will. Others have identified similarities, but also differences, between the two concepts. Increasing numbers of people present spirituality as an umbrella term, which embraces religiosity, whilst, at the humanistic extreme, there are those who claim a spirituality without religion (Fisher 2011).

Over the last three decades in particular, numerous publications have related spirituality and health. Spiritual health is described in this paper as a, if not the, fundamental state of health which permeates and integrates all other dimensions of health. In other words, it is the foundation yet also the glue that undergirds and binds the physical, mental, emotional, social, even the vocational dimensions of health together. Spiritual health is dynamic in nature, being expressed in each person's spiritual wellbeing. Spiritual well-being itself is reflected in the quality of relationships that each person has in up to four domains, namely with themselves (in terms of meaning, purpose and values in life); with other people (in terms of morality, culture and religion [for those for whom it is important]); with the environment; and/or with a Transcendent Other (commonly called God) (ibid.).

\section{METHOD}

\section{Study sample}

Following appropriate ethics approval, a total of 300 members of the Australian \& New Zealand Society of Palliative Medicine and Fellows of the Australasian Chapter of Palliative Medicine were posted a survey, together with a reply-paid envelope. These 
were sent from the executive offices of each association to ensure anonymity of responses.

\section{Measures}

The survey comprised four pages, one of which contained the Spiritual Health And LifeOrientation Measure (SHALOM) (author 12010 ) together with demographic data such as age, gender, religious affiliation, work time and skills, together with personality variables of extraversion, psychoticism and neuroticism, assessed using Eysenck's Revised Abbreviated Personality Questionnaire (Francis et al. 1992). The importance of religion and spirituality were each assessed on a five-point Likert scale from 1 (very low) to 5 (very high).

As each person embraces the four domains of spiritual health/well-being to varying extents, a balanced instrument with good psychometric properties was used to help assess each of them. This instrument, SHALOM, consists of 20 items, five for each of four domains of spiritual well-being (SWB) (Personal, Communal, Environmental and Transcendental SWB). Respondents were asked to show

- how important they think each area is for an ideal state of spiritual well-being,

- how they feel each item reflects their personal/lived experience most of the time, and

- what help they think they provide to patients to nurture their spiritual well-being. The items comprising Personal SWB are 'sense of identity', 'self-awareness', 'joy in life', ' inner peace', 'meaning in life'; Communal SWB canvases 'love of other people', 'forgiveness toward others', 'trust between individuals', 'respect for others', 'kindness'; Environmental SWB addresses 'connection with nature', 'awe at a breathtaking view', 'oneness with nature', 'harmony with the environment', 'a sense of 'magic' in the environment'; Transcendental SWB comprises 'personal relationship with the Divine/God', 'worship of the Creator', 'oneness with God', 'peace with God', 'prayer life' (Fisher 2010).

This spiritual well-being questionnaire has undergone rigorous psychometric testing (Gomez and Fisher 2003).

\section{Statistical analysis}

All statistical analyses reported here were performed using SPSS for Windows 19. Domain scores were calculated by taking the mean value of the five items in each of the four domains of spiritual well-being. Matched pairs t-tests were used to compare the three categories, of ideals, lived experience and perceived help for patients, in each of the four domains of spiritual well-being. Independent t-tests revealed variations by gender among palliative care doctors as well as differences between palliative care doctors and nurses' levels of spiritual well-being. Analysis of variance (ANOVA) indicated the impact of work time on palliative care doctors' perceptions of help they provide to patients. Linear regression analyses revealed which predictor variables made significant contribution to variance in the four domains of spiritual well-being. 


\section{RESULTS}

\section{Participants}

Completed surveys were received from 156 palliative care doctors from Australia and New Zealand. This is a $52 \%$ response rate to a single mailout. These palliative care doctors reported lower religious affiliation than the general populace (Australian doctors Christian $56 \%$ vs. $64 \%$, other religions $10 \%$ vs. $6 \%$, no religion $34 \%$ vs. $31 \%$; NZ doctors - Christian $44 \%$ vs. $56 \%$, other religions $12 \%$ vs. $7 \%$, no religion $44 \%$ vs. $35 \%$ ).

Levels of spiritual well-being

Matched pairs t-test results revealed the palliative care doctors' ideals were significantly higher than their lived experience. Their lived experience also outweighed their perceptions of help they provide to patients in the four domains of SWB studied here (Table 1).

\section{Help for patients}

Importance of religion and spirituality did not contribute significantly to explanation of variance for help in any of the four domains of SWB studied here. Previous studies have related palliative care doctors' lived experience with help provided for patients' SWB (Okon 2005, Seccareccia et al. 2009).

Table 1. Comparing three categories of Spiritual Well-Being domains among palliative care doctors

\begin{tabular}{|c|c|c|c|c|}
\hline \multirow[t]{2}{*}{ categories of SWB } & \multicolumn{4}{|c|}{ SWB Domains - mean values (SD) } \\
\hline & Personal & Communal & Environmental & Transcendental \\
\hline ideal & $4.52(.53)$ & $4.48(.55)$ & $3.67(.88)$ & $3.04(1.37)$ \\
\hline lived experience & $4.02(.51)$ & $4.05(.47)$ & $3.53(.82)$ & 2.61(1.27) \\
\hline help for patients & $3.31(.76)$ & $3.29(.78)$ & $2.47(.92)$ & $2.10(.96)$ \\
\hline \multicolumn{5}{|l|}{ Paired $\mathrm{t}^{\mathrm{sig}}$ values } \\
\hline ideal-lived exp & $11.2 * * *$ & $11.5 * * *$ & $3.2^{* * *}$ & $7.1^{* * *}$ \\
\hline lived exp-help & $11.0 * * *$ & $12.0 * * *$ & $13.7 * * *$ & $6.0 * * *$ \\
\hline \multicolumn{5}{|c|}{$* * \mathrm{p}<.01, * * * \mathrm{p}<.001 \exp =$ experience, help $=$ perceived help for patients } \\
\hline $\begin{array}{l}\text { Palliative ca } \\
\text { low levels of lived } \\
\text { levels of help provi } \\
\text { SWB and their pers } \\
\text { SWB were not refl } \\
\text { themselves (in term } \\
\text { love, trust, etc). }\end{array}$ & $\begin{array}{l}\text { doctors } 1 \\
\text { perience } \\
\text { ed to patie } \\
\text { nal/lived } \\
\text { ted highly } \\
\text { of meanin }\end{array}$ & $\begin{array}{l}\text { ed here foll } \\
\text { ating with } n \\
\text { these areas } \\
\text { ience in the } \\
\text { e help they } \\
\text { irpose, etc) }\end{array}$ & $\begin{array}{l}\text { this trend in the } \\
\text { and God (Table } \\
\text { le 2). However, } \\
\text { nal and Comm } \\
\text { de to patients in } \\
\text { ith others (in te }\end{array}$ & $\begin{array}{l}\text { heir moderate to } \\
\text { predicted the low } \\
\text { eir high ideals for } \\
\text { al domains of } \\
\text { lating with } \\
\text { s of forgiveness, }\end{array}$ \\
\hline
\end{tabular}


The level of 'holistic care' that the palliative care doctors indicated they provide to patients has considerable influence on their perceptions of help provided for patients' Personal SWB, and moderate influence on their Communal and Transcendental SWB, but is not significant for Environmental SWB (Table 2).

Table 2. Regression analyses results of palliative care doctors' perceived Help for patients' spiritual well-being

\begin{tabular}{lllll}
\hline Predictor & \multicolumn{2}{l}{ SWB Domains $(\beta$ values $)$} & \\
variables & Personal & Communal & Environmental & Transcendental \\
\hline gender & $-.23^{* *}$ & $-.21^{* *}$ & $-.20^{*}$ & $-.08^{\mathrm{ns}}$ \\
work time & $.16^{*}$ & $.16^{*}$ & $.04^{\mathrm{ns}}$ & $.19^{* *}$ \\
holistic care & $.28^{* * *}$ & $.18^{*}$ & $.13^{\mathrm{ns}}$ & $.16^{*}$ \\
lived experience & $.18^{*}$ & $.22^{* *}$ & $.40^{* * *}$ & $.58^{* * *}$ \\
\hline $\mathrm{F}^{\text {sig }}$ & $11.4^{* * *}$ & $9.3^{* * *}$ & $10.4^{* * *}$ & $27.2^{* * *}$ \\
$\mathrm{R}^{2}$ & .23 & .20 & .22 & .42 \\
\hline $\mathrm{F}_{\mathrm{p}<.05 ; * * \mathrm{p}<.01 ; * * * \mathrm{p}<.001}$ & & &
\end{tabular}

Gender is a key predictor variable for levels of help provided for palliative care patients' SWB in the Personal, Communal and, to a lesser extent, in the Environmental domains of SWB. T he male palliative care doctors in this study reported providing higher levels of help, especially for patients' relationships with self and others, compared with their female counterparts (see Table 3). In addition, a Chi-square test for independence indicated significant association between gender and work time, $\chi^{2}(3$, $\mathrm{n}=156)=14.6, \mathrm{p}=.002$, phi $=.306$, with more female palliative care doctors working parttime $(69 \%$, compared with males $44 \%)$.

Table 3. Independent T-test results by gender for palliative care doctors' perceptions of their provision of help for patients' spiritual well-being

\begin{tabular}{lcllll}
\hline $\begin{array}{l}\text { PC Drs' } \\
\text { gender }\end{array}$ & \multicolumn{5}{c}{ SWB Domains - mean values (SD) } \\
& $\mathrm{N}$ & Personal & Communal & Environmental & Transcendental \\
\hline male & 71 & $3.55(.55)$ & $3.53(.63)$ & $2.64(.91)$ & $2.26(.98)$ \\
female & 85 & $3.10(.85)$ & $3.10(.83)$ & $2.33(.91)$ & $1.97(.94)$ \\
\hline $\mathrm{t}^{\text {sig }}$ & & $3.9 * * *$ & $3.7 * * *$ & $2.10^{*}$ & $1.2^{\text {ns }}$ \\
\hline${ }^{*} \mathrm{p}<.05 ; * * * \mathrm{p}<.001$ & & & & \\
\hline
\end{tabular}


The general trend shown is that palliative care doctors who work longer hours (mainly the males) perceive that they provide greater help for patients' Personal, Communal \& Transcendental SWB (see Table 4).

In some palliative care settings, physical restrictions make it difficult to provide assistance for Environmental SWB, as assessed by SHALOM, especially in older and multi-storey facilities.

Table 4. ANOVA results by work time for palliative care doctors' perceptions of their provision of help for patients' spiritual well-being

\begin{tabular}{|c|c|c|c|c|c|}
\hline \multirow{2}{*}{$\begin{array}{l}\text { PC Drs' } \\
\text { work time }\end{array}$} & \multicolumn{4}{|c|}{ SWB Domains - mean values (SD) } & \multirow[b]{2}{*}{ Transcendenta } \\
\hline & $\mathrm{N}$ & Personal & Communal & Environmental & \\
\hline$<=30 \mathrm{hr} / \mathrm{wk}$ & 36 & $3.06(.78)$ & $3.11(.90)$ & $2.32(1.00)$ & $2.04(.97)$ \\
\hline $31-40$ & 54 & $3.27(.78)$ & $3.22(.81)$ & $2.40(.91)$ & $1.89(.86)$ \\
\hline $41-50$ & 44 & $3.41(.70)$ & $3.34(.68)$ & $2.74(.83)$ & $2.20(.88)$ \\
\hline$>50$ & 22 & $3.59(.61)$ & $3.68(.58)$ & 2.38(.99) & $2.54(1.22)$ \\
\hline $\mathrm{F}(3,152)^{\text {sig }}$ & & $2.7 *$ & $2.8^{*}$ & $1.8^{\mathrm{ns}}$ & $2.8^{*}$ \\
\hline
\end{tabular}

\section{Comparing palliative care doctors with nurses}

In comparing results from palliative care doctors in this study with previously reported work among nurses (Fisher and Brumley 2008) it is obvious that nurses rate themselves more highly than the palliative care doctors do in terms of their lived experiences, as well as help they perceive they provide to patients (see Table 5).

Table 5. Comparison of nurses \& palliative care doctors' levels of SWB

\begin{tabular}{|c|c|c|c|c|c|c|c|c|}
\hline SWB & Person & & Commur & & Envirc & mental & Transce & dental \\
\hline $\mathrm{N}$ & $\exp$ & help & $\exp$ & help & $\exp$ & help & $\exp$ & help \\
\hline Nurse 210 & 4.15 & 3.56 & 4.26 & 3.69 & 3.74 & 2.89 & 2.96 & 2.65 \\
\hline PCDr 156 & 4.02 & 3.31 & 4.05 & 3.29 & 3.53 & 2.47 & 2.61 & 2.10 \\
\hline $\mathrm{t}^{\mathrm{sig}}$ & $2.02 *$ & $2.75^{* *}$ & $4.01 * * *$ & $4.46^{* * *}$ & $2.30^{*}$ & $3.89 * * *$ & $2.59 * *$ & $4.91 * * *$ \\
\hline $\mathrm{Eta}^{2}$ & .11 & .15 & .21 & .23 & .12 & .20 & .14 & .25 \\
\hline
\end{tabular}


Even so, the levels of help are moderate to high for Personal and Communal SWB but low for Environmental and Transcendental SWB. These results indicate that both palliative care doctors and nurses could benefit from some assistance in developing their own SWB as well as in the provision of help for patients, especially for Environmental and Transcendental SWB.

\section{DISCUSSION}

Other work among caring professionals, using SHALOM, has shown high correlations of lived experience with help provided for clients (author 4 2008b). Male palliative care doctors partially followed this trend. However, the females reported providing less help for patients than that from males. The female palliative care doctors also perceived that they provide less help for clients than nurses do in each of the four domains of SWB. On this point, it is important to note that the reported levels of help for patients' spiritual well-being were self-reports from the palliative care doctors in this study, as they were in a previous study with nurses, the vast majority of whom were female (Fisher and Brumley 2008). Gender was not the only factor contributing to perceived help for patients' SWB. Contact time with patients plays a major role. Hence the nurses' reports of providing more help for patients in this area than that from palliative care doctors ties in with their greater contact with patients. So too with male PC doctors in this study, who are nearly all full-time, in contrast with the higher percentage of female PC doctors who are part-time.

The data revealed no significant differences among the female palliative care doctors by age, position, location or length of time in palliative care services. However, work-time (with full-time being > 40 hours per week) was shown to be the key factor influencing help provided for patients by female palliative care doctors. All help scores were rated less than moderate (i.e., a mean score of 3.0 on a scale from 1.0 to 5.0) for part-timers $(\mathrm{Per}=2.99$; Com $=2.98$; Env $=2.18$; Tra $=1.84)$. Full-time female palliative care doctors scored positively for help provided to patients on Personal SWB (3.37) and Communal SWB (3.38), but only moderate to low on Environmental SWB (2.70) and Transcendental SWB (2.31). These results reveal greater professional distancing of the part-time female palliative care doctors from their patients. In responses to preliminary findings from this study, several female palliative care doctors said that they feel isolated from patients, lacking continuity, because of their part-time status.

Although perceived levels of help for patients' Personal and Communal SWB were above 3.0, they were only moderate in size. More help could be forthcoming for patients to feel better connected with themselves, to be more at peace, and have stronger connections with others, e.g., sensing love and forgiveness as their lives draw to a close. Some palliative care facilities also take care to provide beautiful environments, with views of gardens, to provide nurture for patients through this means.

The area in which least spiritual support is seen to be provided is in connecting with the Transcendent. This goes far beyond a statement of religious affiliation, which may elicit positive responses from some but negative responses from others, depending on previous experiences with religious people and perceptions of religion (Hills et al. 2005). In SHALOM, the Transcendental domain of SWB focuses on the quality of a personal relationship with God, not just religious affiliation or activity. It is not surprising that the palliative care doctors felt least prepared to provide help in this domain of 
spiritual well-being because their own religious affiliations were noticeably lower than the general populace, as reported above. Not only that, but palliative care doctors are likely to lack training on how to do this. Some deeply religious providers may also feel it inappropriate to discuss religious themes, such as God, but would discuss broader spiritual themes, as in the Personal and Communal domains discussed above. Others have noted "discrepancies between physicians and patients pertaining to beliefs in God ... and feeling close to God. Doctors endorsed these beliefs or practices less often than patients" (Chochinov et al.2005). Many of the studies reporting patients' and physicians' wishes and actions have come from the USA (Cartwright et al. 2007, Maugans et al. 1991) where a considerably higher percentage of the population report belief in God and attendance at religious services, than in other Western countries, such as Australia, UK and New Zealand (Peach 2003).

It has been recommended that there should be "routine inquiry by physicians about the relevance of spirituality to the patient within the context of taking a medical history" (Post et al. 2000) in order to "honor patients as ... whole and integrated persons" (Cohen et al. 2001). However, palliative care doctors should delegate this responsibility to other staff if they are not comfortable with it, because patients can tell if a doctor is spiritually attuned to them (Gallup 1997) and some are reluctant to raise spiritual issues with 'busy' health professionals (Murray et al. 2004). Several suggestions for initial spiritual assessments include methods called FICA (Faith and belief, Importance, Community, Address in care) (Puchalski et al. 2000), SPIRIT (Spiritual belief system, Personal spirituality, Integration with a spiritual community, Ritualized practices and restrictions, Implications for medical care, Terminal events planning) (Maugans 1996), HOPE (sources of Hope, etc, Organized religion, Personal spirituality, End-of-life decisions) (Anandarajah et al. 2001), or FACT (Faith, Active, Coping, Treatment) (LaRocca-Pitts 2008).

Initial spiritual assessments are one thing; continuing spiritual care is another. Following initial assessment, greater understanding of each patient's level of spiritual harmony or dissonance can be achieved using SHALOM (author 1 2010). However, ethical questions could be raised if physicians want to act as pastoral caregivers as "it is a general mandate of modern developed societies to keep professional roles separate" (Peach 2003).

The question arises as to whether palliative care staff are adequately trained in spiritual matters. In the Netherlands, palliative care consultants coach professional caregivers on how to address spiritual issues (Kuin et al. 2006). In Australia, several staff development programs emanated from Federal Government funding for 'Local Palliative Care Grants - Pastoral Care, Counselling and Support' (Carey et al. 2009). These initiatives, however, only reach the committed palliative care staff who seek them out. Even so, spiritual care training has been shown to have "a positive influence on the spiritual well-being and the attitudes of the participating palliative care professionals which was preserved over a six-month period" (Wasner et al. 2005). Many US medical schools have recently included training in spiritual care in their curricula (Post et al. 2000).

A survey of palliative medicine fellowship directors in the United States found general agreement on content of training on spirituality, but a lack of "robust educational 
and evaluation methods to ensure ... desired attitudes, knowledge and skills" were met (Marr et al. 2007). This concern could be addressed by using a Competency Chart for Hospice palliative care spiritual care providers as a foundation to help clarify roles, responsibilities and tasks in providing spiritual care of patients in a variety of settings (Cooper et al. 2010). This Chart could also help clarify who is best qualified, with the best personal qualities, to provide the highest level of holistic care for patients, thus reducing role ambiguity and competition among clinical professionals who vie to include spiritual care in their scope of practice (Sinclair et al. 2006, Kellehear 2002).

It is important that whoever does the spiritual assessment and follow-up has appropriate skills to handle existential and religious issues and know to whom to make referrals when needed (Astrow et al. 2001). Patients should not be preached at nor subjected to any coercion (Hills et al. 2005). It is essential that those providing spiritual care understand and respect the patients' views at all times. Extreme views, such as religious fanaticism, by those who see spirituality as a treatment modality, or patronizing, pseudo-intellectual bigotry, by those who abhor the thought of the spiritual invading the realm of the clinical, should be avoided at all costs (Shehan 2003). Objective, competent, compassionate, patient-centered spiritual care is needed. Chaplains are trained to handle existential and religious issues in this manner.

\section{CONCLUSION}

With inadequate time and personal experience or training, palliative care doctors lack the capacity to help patients in all, especially the Transcendental, domains of SWB.

Therefore, a good case can be made for spiritual advisors, such as chaplains, to help 'assess' sensitively and provide spiritual care for patients. This would free palliative care doctors (and nurses) to concentrate on the biophysical-psychological aspects of care, as part of a comprehensive, well-balanced team providing holistic care for each patient. In short, palliative care doctors need help personally and in providing spiritual care for patients.

\section{REFERENCES}

Anandarajah, G. and Hight, E. 2001. 'Spirituality and medical practice: Using the HOPE questions as a practical tool for spiritual assessment"'. American Family Physician 63: 81-89.

Astrow, A.B., Puchalski, C.M. and Sulmasy, D,P. 2001. Religion, spirituality, and health care: Social, ethical, and practical considerations'. American Journal of Medicine 110: 283-287.

Carey, L.B. and Rumbold, B. 2009 Australian Local Palliative Care Projects Facilitating Pastoral and Spiritual Care. National Overview and Evaluation Program. La Trobe University, 2009. http://www.palliativecare.org.au/Portals/46/Together\%20conference/ B6\%20Lindsay \%20Carey.pdf [Accessed 07/09/2011]

Cartwright, C., Onwuteaka-Philipsen, B.D., Williams, G., Faisst, K., Mortier, F., Nilstun, T., Norup, M., van der Heide, A. and Miccinesi, G. 2007. 'Physician discussions with terminally ill patients: A cross-national comparison'. Palliative Medicine 21: 295-303. 
Chochinov, H.M. and Cann, B.J. 2005. Interventions to enhance the spiritual aspects of dying'. Journal of Palliative Medicine 8: S-103-115.

Cohen, C.B., Wheeler, S.E. and Scott, D.A. 2001. 'Anglican Working Group in Bioethics: Walking a fine line: Physician inquiries into patients' religious and spiritual beliefs'. Hastings Center Report 3: 29-39.

Cooper, D., Aherne M. and Pereira, J. 2010. 'The competencies required by professional hospice palliative care spiritual care providers'. Journal of Palliative Medicine 13: 869875.

Fisher, J.W. 2008. 'Impacting teachers' and students' spiritual well-being'. Journal of Beliefs \& Values 29:253-261. http://dx.doi.org/10.1080/13617670802465789

Fisher, J. 2010. 'Development an Application of a Spiritual Well-Being Questionnaire Called SHALOM'. Religions 1: 105-21. http://dx.doi.org/10.3390/rel1010105

Fisher, J. 2011. 'The Four Domains Model: Connecting Spirituality, Health and Wellbeing'. Religions 2: 17-28. http://dx.doi.org/10.3390/rel2010017

Fisher, J. W. and D. J. Brumley. 2008. 'Nurses' and carers' Spiritual Well-being in the Workplace'. Australian Journal of Advanced Nursing 25: 49-57.

Francis, L.J., Brown, L.B. and Philipchalk, R. 1992. 'The development of an abbreviated form of the revised Eysenck Personality Questionnaire (EPQR-A): Its use among students in England, Canada, the USA and Australia'. Personality \& Individual Differences 13: 443-449.

The George H Gallup International Institute. 1997. Spiritual beliefs and the dying process: A Report on a National Survey. Princeton: Gallup Institute.

Gomez, R. and J.W. Fisher. 2003. 'Domains of spiritual well-being and development and validation of the Spiritual Well-Being Questionnaire”. Personality \& Individual Differences 35: 1975-1991.

Hills, J., Paice, J.A., Cameron, J.R. and Shott, S. 2005. "Spirituality and distress in palliative care consultation". Journal of Palliative Medicine 8: 782-788.

Kellehear, A. 2002. "Spiritual care in palliative care: Whose job is it?" In Spirituality and Palliative Care (ed.) B. Rumbold, pp.166-177. Oxford: Oxford University Press.

Kuin, A., Deliens, L., van Zuylen, L., Courtens, A.M., Vernooij-Dassen, M.J. F.J., van der Linden, B. and van der Wal, G. 2006. "Spiritual issues in palliative care consultations in the Netherlands". Palliative Medicine 20: 585-592.

LaRocca-Pitts, M. 2008. "FACT: Taking a spiritual history in a clinical setting". Journal of Health Care Chaplaincy 15: 1-12.

Marr, L., Billings, J.A. and Weissman, D.E. 2007. "Spirituality training for palliative care fellows". Journal of Palliative Medicine 10: 169-177. 
Maugans, T.A. 1996. "The SPIRITual history”. Archives of Family Medicine 5, no.1: 1116.

Maugans, T.A. and Wadland, W.C. 1991. "Religion and family medicine: A survey of physicians and patients". Journal of Family Practice 32: 210-213.

Murray, S.A., Kendall, M., Boyd, K., Worth, A. and Benton, T.F. 2004. "Exploring the spiritual needs of people dying of lung cancer or heart failure: A prospective qualitative interview study of patients and their carers". Palliative Medicine 18: 39-45.

O’Connor, M. and Fisher, C. 2011. "Exploring the dynamics of interdisciplinary palliative care teams in providing psychosocial care: 'Everybody thinks that everybody can do it and they can't'”. Journal of Palliative Medicine 14: 191-196.

Okon, T.R. 2005. "Spiritual, religious, and existential aspects of palliative care". Journal of Palliative Medicine 8: 392-413.

Palliative Care Australia (PCA). 2005. Standards for providing quality palliative care for all Australians. Deakin West ACT: PCA.

Peach, H.G. 2003. "Religion, spirituality and health". Medical Journal of Australia 178: 415.

Post, S.G., Puchalski, C.M. and Larson, D.B. 2000. "Physicians and patient spirituality: Professional boundaries, competency, and ethics". Annals of Internal Medicine 132: 578583.

Puchalski, C.M. 2002. "Spirituality and end-of-life care: A time for listening and caring." Journal of Palliative Medicine 5: 289-294.

Puchalski, C.M. and Romer, A.L. 2000. "Taking a spiritual history allows clinicians to understand patients more fully”. Journal of Palliative Medicine 3: 129-137.

Puchalski, C,M., Kilpatrick, S.D., McCullough, M.E. and Larson, D.B. 2003. “A systematic review of spiritual and religious variables in Palliative Medicine, American Journal of Hospice and Palliative Care, Hospice Journal, Journal of Palliative Care, and Journal of Pain and Symptom Management”. Palliative \& Supportive Care 1: 7-13.

Puchalski, C., Ferrell, B., Virani, R., Otis-Green, S., Baird, P., Bull, J., Chochinov, H., Handzo, G., Nelson-Becker, H., Prince-Paul, M., Pugliese, K. and Sulmasy, D. 2009. "Improving the quality of spiritual care as a dimension of palliative care: The Report of the Consensus Conference". Journal of Palliative Medicine 12: 885-904.

Seccareccia, D. and Brown, J.B. 2009. "Impact of spirituality on palliative care physicians: Personally and professionally”. Journal of Palliative Medicine 12: 805-809.

Sheehan, M.N. 2003." Spirituality and medicine". Journal of Palliative Medicine 6: 429431.

Sinclair, S., Pereira, J. and Raffin, S. 2006. "A thematic review of the spirituality literature within palliative care". Journal of Palliative Medicine 9: 464-479. 
Walter, T. 2002. "Spirituality in palliative care: Opportunity or burden?" Palliative Medicine 16: 133-139.

Wasner, M., Longaker, C., Fegg, M.J. and Borasio, G.D. 2005. "Effects of spiritual care training for palliative care professionals". Palliative Medicine 19: 99-104.

World Health Organization. WHO Definition of Palliative Care. http://www.who.int/cancer/palliative/definition/en/ [Accessed 10/09/2011]

\subsection{Spiritual well-being of staff and family members in dementia care}

\section{Background}

SHALOM has been sought for use by researchers in a wide variety of healthcare settings in Australia and overseas. The opportunity arose for me to work with staff and family members who care for residents in a dementia care unit. As this unit was being reaccredited, staff needed to show how they addressed spiritual well-being of residents, as part of the competency requirements for holistic care. This enabled me to use SHALOM as part of preparation for this re-accreditation process, to extend the research I had done with doctors, nurses and carers in palliative care.

\section{Key points extracted from this paper}

- Staff and family members gave three responses to each of 20 items on SHALOM, indicating (i) their ideals for spiritual well-being, (ii) their lived experiences, and (iii) what help they thought residents in a dementia care unit need for their spiritual well-being, of relating with self, others, environment and/or with God.

- Staff reported significantly stronger, more vibrant relationships with self and others than did family members, who were significantly older than the staff. The family members were mainly spouses and siblings of elderly dementia patients.

- There was a consistency of responses on SHALOM from the Division 1 nurses (general qualified nurse), Division 2 nurses (enrolled nurse qualification), and domestic staff.

- There was very close agreement between the staff's and family members' perceptions of help needed by dementia patients for these patients' spiritual wellbeing in each of four domains. 


\title{
Implications
}

The processes used to select and train the staff in this dementia care unit should be carefully noted, because the staff employed there revealed consistently high levels of professionalism. They based their judgements about the spiritual needs of the dementia care patients on their professional ideals, supported by careful observation of residents in the dementia care unit. Previous studies with healthcare professionals had shown that they tend to base their perceptions of the level of help that clients need for SWB on their own lived experiences. This is what the family members did in this study.

\section{Paper:}

This paper was published as: Fisher, J.W. (2013) Staff's and family members' spiritual well-being in relation to help for residents with dementia. Journal of Nursing Education \& Practice, 2(4): 1-9.

\section{Type of article: Original Basic Research JNEP}

Title: Staff's and family members' spiritual well-being in relation to help for residents with dementia

Author: John W. Fisher

\begin{abstract}
Background: Spiritual well-being of providers and patients is paramount for holistic care in nursing. Spiritual well-being is reflected in relationships in four areas, namely with self, others, environment and/or Transcendent Other.

Method: Fisher's 20-item Spiritual Health And Life-Orientation Measure (SHALOM) was used to assess these four key components of spiritual health. A survey was completed by staff and family members of residents in a dementia care unit, to record three responses on SHALOM, namely their ideals for spiritual health, their lived experiences, and what they thought residents need for spiritual nurture in these four areas. Demographic variables were investigated, with respect to any impact on respondents' spiritual well-being.
\end{abstract}

Results: Variations were found in the staff's and family members' spiritual well-being based on age, religious group membership and activities, and whether or not the respondent was facing a spiritual challenge. However, regression analyses showed that these variables had no significant influence on the help that staff thought residents need to nurture their spiritual well-being. Regression analyses did show that staff's ideals contributed greatest explanation of variance in terms of help staff believe is needed for spiritual nurture of residents. On the other hand, it was the lived experiences of family members that showed greatest influence on what help they thought residents needed. This 
was especially true for family members who had difficulty living up to their own ideals. Even though they based their judgements on different rationale, staff and family members agreed on the priorities to be set in nurturing residents' spiritual well-being in a dementia care unit

Conclusion: Congruence was found between staff's and family members' perceptions of help needed to nurture residents' spiritual well-being. This study, using the spiritual wellbeing questionnaire called SHALOM, revealed that staff acted professionally basing their judgement on ideals, whereas family members reflected their own lived experience, when determining what they thought was needed to help nurture residents' spiritual well-being.

\section{Key words}

Spiritual well-being; Dementia; residential care; Nurses; Family

\section{Introduction}

Considerable interest is currently being shown in society about the spiritual well-being of people [1-2]. 'At least since Nightingale, spirituality has been central to the essence of modern nursing' [3]. Nurses have historically embraced a holistic approach to care for patients [4]. Increasing numbers of publications of holistic nursing journals, books and research and position papers focusing on the spiritual well-being (SWB) of patients show the growing interest and concern in this area [5-13].

There are nearly as many definitions of spirituality as there are people who attempt to describe it. The following description of spiritual health will be used in this paper.

Spiritual health is a fundamental dimension of people's overall health and wellbeing, permeating and integrating all the other dimensions of health (i.e. the physical, mental, emotional, social and vocational).

Spiritual health is a dynamic state of being, shown by the extent to which people live in harmony within relationships in up to four domains of spiritual well-being, namely with themselves, with others, with the environment and/or with a Transcendent other, commonly called God [14].

'Spiritual care is integral to quality nursing for nursing home residents' [15]. The process for accreditation of aged care services in Australia involves investigation of the 'Cultural and spiritual life' of residents [16]. Residents in a dementia care unit are often unable to express their own views cogently. This study was undertaken in order to check consistency of spiritual care expressed by family members, who had been caring for patients at home, with that of staff, who are now caring for them as residents, in a dementia care unit in regional Victoria, Australia.

Fisher's Spiritual Health And Life-Orientation Measure (SHALOM) was designed to identify respondents' perceptions of the importance of four key factors for spiritual health described above [17]. SHALOM was initially developed with secondary school students, in the belief that the language so employed would also make the instrument suitable for use with adults [18]. Extensive psychometric testing of this instrument with 
participants in educational and health services and the general community has shown its validity and reliability across various settings and age groups. Exploratory and confirmatory factor analyses, and item response theory analysis, have confirmed the distribution of the 20 items into four coherent factors in SHALOM, supporting the theoretical foundation upon which it was based [19-21].

\section{Aims of this study}

The basic instrument SHALOM sought two responses to indicate (1) staff's and family members' ideals for SWB as well as (2) their lived experience. Comparing these two provides a measure of spiritual harmony or dissonance in each of four domains of SWB. A third assessment was also made using SHALOM, in that participants were asked to indicate what (3) they think is needed to nurture spiritual well-being of residents in a dementia care unit.

It is the quality of relationships that people have with themselves, with others, nature and/or God that reflect their spiritual well-being. These four domains are investigated using SHALOM.

Previous studies using SHALOM have shown that carers' own spiritual wellbeing influenced their perceptions of the help they provide to clients for the clients' SWB [22]. So, staff's and family members' ideals and lived experiences of SWB were investigated to see how these influenced what they thought was needed to nurture residents' SWB. Demographic factors were also investigated for their potential impact on staff's and family members' SWB.

\section{Subjects and Method}

\section{Study design}

A questionnaire survey method was used to investigate spiritual well-being in a dementia care unit. Following ethics approvals at university and hospital level, the SHALOM questionnaire was administered to staff and family members of a 30-bed residential dementia care unit, in regional Victoria, Australia.

\section{Power analysis}

Even though the sample was small, post hoc power analysis using $\mathrm{G}^{*}$ Power 3 yielded a value of 0.51 [23]. As this value was less than 0.8 , the statistically significant differences, that were found between staff and family members, indicate real differences exist between the groups.

\section{Experimental method}

In order to provide as little disruption as possible to normal activities in the dementia care unit, whilst optimising opportunities for participation by staff and family members, questionnaires were given to respondents in small groups, at a staff meeting and a regular scheduled meeting of family members. Individuals were followed up by the coordinator of the unit if they were unable to be present when the groups met. Participation in the project was voluntary. All staff participated and $73 \%$ of the residents had one of their family members complete the survey. Some residents have no regular family contact and 
others were not available at the time of the study. However, everyone who was invited willingly participated.

\section{Research instrument}

A two-page printed questionnaire was given to staff and family members of patients. The front page sought demographic data, such as gender (F or M), age (assessed by decade, as previous studies have revealed reticence by some Australian respondents to give exact age), staff position (Division 1 or 2 Nurse, or Domestic carer). Although nature of relationship of family member to resident was not asked, observation revealed that it was mainly a spouse who completed the survey. As there is considerable discussion in the literature about the nexus between spirituality and religion, it is standard practice by this researcher to include questions which interrogate this connection. To this end, participation in religious activities was selected from 'not at all, less than once a month, once a month, once in 2-4 weeks, once a week.' Participants were asked if they had a religious group with which they were affiliated and whether or not they were experiencing a spiritual challenge, both answered using a Yes/No response. Spiritual challenge was not specified, but left to the participants for their interpretation.

Page two of the survey presented SHALOM, a 20-item instrument, with five items to assess each of four domains of spiritual well-being. The Personal domain comprises the items 'meaning, inner peace, identity, joy and self-awareness.' The Communal domain comprises 'love others, trust, kindness, respect others, forgiveness.' The Environmental domain comprises 'harmony with environment, connect with nature, "magic" in the environment, one with nature, awe at view.' The Transcendental/God domain comprises 'oneness with God, relation with Divine, worship Creator, prayer, peace with God.'

Participants were asked to provide three responses on each of these 20 items, using a five-point Likert scale from very high (5) to very low (1), to show:

'a. how important you think each area is for an ideal state of spiritual well-being, AND

b. how you feel each item reflects your personal experience most of the time, AND

c. what help you think dementia patients need to nurture their spiritual well-being' [24].

Scale scores were calculated by taking the mean value for each set of five items in the four domains of SWB.

\section{Statistical analyses}

SPSS for Windows version 19 was used to calculate means (SD) for ideals, lived experiences and helps for the 20 items and the four factors of SHALOM, whose validity was revealed using Principal Components Analysis. Matched pairs and independent ttests were also calculated to investigate relationships between the three categories of SHALOM (namely, ideals, lived experiences and helps). Linear regression analyses were employed to investigate influences on levels of help for residents' SWB.

\section{Results}

Participant details 
Table 1 shows participants in the study. Staff were identified by position and both groups were listed by age. As most family members were spouses, it is not surprising that they were older than staff (see Table 1).

Table 1 Details of participants

\begin{tabular}{|c|c|c|c|c|c|c|c|}
\hline & & & & & Age & & \\
\hline & & $\mathrm{N}$ & $20 \mathrm{~s}$ & $30 \mathrm{~s}$ & $40 \mathrm{~s}$ & $50 \mathrm{~s}$ & $60+$ \\
\hline Family & male & 10 & 1 & & 2 & 3 & 4 \\
\hline members & female & $13 *$ & & 1 & 2 & 3 & 6 \\
\hline & Total & 23 & $* 1 \mathrm{a}$ & not g & & & \\
\hline Staff & Div.1 & 7 & & 1 & 2 & 4 & \\
\hline & Div.2 & 10 & 2 & 4\# & 2 & 2 & \\
\hline & Domcare & 4 & & 1 & 2 & 1 & \\
\hline & Total & 21 & $\#=1$ & (1) & $20 a$ & emal & \\
\hline
\end{tabular}

NB Div 1 = Registered Nurse; Div 2 = Enrolled Nurse; Domcare = Domestic Care

Suitability of the SHALOM instrument

When assessing the suitability of data for factor analysis, the Kaiser-Meyer-Olkin (KMO) measure of sampling adequacy should yield a value of at least 0.6 (on a scale that ranges from 0 to 1) for a good factor analysis [25]. The 20-item SHALOM instrument was shown to comprise four unique factors, each with five items as described above. Principal components analysis extracted a single factor for each group of five items, testing ideals, lived experiences and helps for SWB. All KMO values in this study exceeded 0.6, with most of the variance explained exceeding $60 \%$, indicating the reliability of the scales (see Table 2)

Table 2 Principal component analysis for four domains of SHALOM, in three categories

\begin{tabular}{lccccccccc}
\hline & \multicolumn{8}{c}{ Domains of SWB in SHALOM } \\
\cline { 2 - 9 } & \multicolumn{2}{c}{ Per } & \multicolumn{2}{c}{ Com } & \multicolumn{2}{c}{ Env } & \multicolumn{2}{c}{ Tra } \\
\hline category & KMO & $\%$ & KMO & $\%$ & KMO & $\%$ & KMO & $\%$ \\
\hline ideal & .71 & 72.9 & .61 & 66.5 & .81 & 65.3 & .85 & 71.8 \\
exp & .83 & 69.6 & .62 & 53.9 & .73 & 62.1 & .88 & 80.4 \\
help & .86 & 68.9 & .83 & 66.3 & .81 & 69.9 & .85 & 79.7 \\
\hline
\end{tabular}

NB Per $=$ Personal, Com $=$ Communal, Env $=$ Environmental, Tra $=$ Transcendental domains of SWB. Exp = lived experience, help = perceived help for dementia patients 
Levels of spiritual well-being for staff and family members.

The staff and family members gave positive responses, in that their stated ideals, lived experiences and help needed for residents' SWB were reported to be above the middle value in the range of possible scores (i.e., score of 3 on the scale from 1-5) in each of the four domains of spiritual well-being (see Table 3). These results indicate good levels of SWB among staff and family, with satisfying relationships with self, with others, nature and God.

They also expressed consistently high expectations for care of the residents' SWB.

Table 3 Mean (SD) values for four Domains of SWB in three categories using SHALOM

\begin{tabular}{lccc|ccc}
\hline \multicolumn{3}{c|}{ Staff -category } & \multicolumn{3}{c}{ Family members - category } \\
\hline Domain of SWB & ideal & lived exp & $\begin{array}{c}\text { help } \\
\text { needed }\end{array}$ & ideal & lived exp & $\begin{array}{c}\text { help } \\
\text { needed }\end{array}$ \\
(in SHALOM) & & & & & & \\
\hline Personal & $4.39(.55)$ & $4.51(.60)$ & $4.12(.60)$ & $4.27(.75)$ & $3.69(.77)$ & $3.76(.82)$ \\
Communal & $4.55(.50)$ & $4.60(.52)$ & $4.18(.56)$ & $4.47(.72)$ & $4.25(.66)$ & $3.85(.87)$ \\
Environmental & $3.86(.85)$ & $4.01(.86)$ & $3.69(.83)$ & $3.80(1.10$ & $3.64(.95)$ & $3.46(1.14$ \\
& & & & ) & & ) \\
Transcendental & $3.82(1.14$ & $3.44(1.21)$ & $3.85(.90)$ & $3.96(.72)$ & $3.62(.89)$ & $3.55(.85)$ \\
& ) & & & & & \\
\hline
\end{tabular}

With the staff's very positive scores it was not surprising to find that their lived experiences scored significantly higher than the corresponding family members' for the Personal $(\mathrm{t}(42)=-3.96, \mathrm{p}<.001)$ and Communal $(\mathrm{t}(42)=-2.36, \mathrm{p}<.05)$ domains. Staff were coming from a very positive position of spiritual health in these areas, which has previously been shown to relate to quality of help provided to patients for their spiritual well-being [22].

Factors affecting participants' spiritual well-being and their influence on help for residents.

\section{Staff position.}

No significant differences were found between the occupational groups comprising the staff, namely Division One (with general nursing qualification) and Division Two (with enrolled nursing qualification) nurses and Domestic Care staff.

As there was only one male staff member, testing by gender was inappropriate. 
Age.

The age of 50 years was chosen to divide the staff and family members into two groups of reasonably equal size to enable adequate statistical testing in this small sample.

* Staff - The under 50s scored significantly higher than the over 50s on the lived experience item inner peace $(\mathrm{t}(19)=2.39, \mathrm{p}<.05)$, expressing greater well-being in the Personal domain. The over 50s were more idealistic in the Personal domain with higher scores than the under 50s for identity $(\mathrm{t}(19)=-3.83, \mathrm{p}<.05)$ and self-awareness $(\mathrm{t}(19)=-$ $2.17, \mathrm{p}<.05)$. They also had more idealistic expectations regarding harmony with the environment $(\mathrm{t}(19)=-2.76, \mathrm{p}<.05)$. The over 50s showed considerably higher ideals and lived experience on the Transcendental domain/God factor. These results suggest that reflection and contemplation could be significant means by which older staff enhance their spiritual well-being. The most important finding is that no differences by age were observed for staff's expression of help-needed-for-residents with dementia despite the personal variations amongst staff.

* Family members - As previously stated, the family members were significantly older than the staff. The over 50s had higher scores than the under 50s in the Personal $(\mathrm{t}(20)=2.29, \mathrm{p}<.05)$ and Environmental $(\mathrm{t}(20)=3.19, \mathrm{p}<.01)$ domains

Family members did not show the same variation by age on the Transcendental domain/God factor as was shown amongst staff, nor did the under 50s reflect similar positive personal attitudes that were shown among staff. Once again, age of family members did not significantly influence levels of help needed for residents' SWB.

\section{Religious group.}

Amongst staff, 13 were affiliated with religious groups, eight were not. Amongst family members 20 were affiliated with religious groups, two were not. The very small number of non-affiliates could skew comparisons, so the staff and family members were considered together, as a single entity

As would be expected, expressions of lived experience in relation to God were significantly higher for those members who were affiliated with a religious group $(\mathrm{t}(41)=2.34, \mathrm{p}<.05)$. However, there was no difference in expectations of help for residents' SWB, based on participants' religious affiliation $\left(\mathrm{t}(41)=-.42, \mathrm{p}=.68^{\mathrm{ns}}\right)$

\section{$\underline{\text { Religious activities }}$}

It was not surprising to find that the regular church-attenders had higher expectations and experience of worship enhancing their spiritual well-being (ideal $\mathrm{t}(29)=2.45, \mathrm{p}<.05$, experience $t(29)=2.12, p<.05)$. They also experienced the positive effect of prayer on their spiritual well-being $(\mathrm{t}(29)=2.23, \mathrm{p}<.05)$. The less frequent church-attenders had a more idealistic expectation that being one with nature would nurture their spiritual wellbeing $(\mathrm{t}(27)=-2.12, \mathrm{p}<.05)$. However, no significant variation was found on help for residents' $S W B$, based on religious activities of staff and family members. 


\section{Spiritual challenge.}

The six staff and five family members who acknowledged facing a spiritual challenge were more idealistic than the others in the Personal, Environmental and Transcendental/ God-factors. These people were sensitive to spiritual challenges but did not display significantly different results in their lived experiences nor in perceptions of help needed for residents' $S W B$.

\section{Discussion}

Determining residents' needs for spiritual well-being.

All staff and family members perceived residents' need for support for SWB similarly. There was no differentiation by age, gender, etc according to demographic data collected in this study.

A previous study using SHALOM with nurses showed that they projected their lived experience onto the way they saw clients having their spiritual well-being nurtured [22]. Therefore linear regression analyses, using ideals and lived experiences as predictor variables, were performed on perceived needs for residents' SWB by both staff and family members in this study (see Table 4).

Table 4 Linear regression analyses of perceived help for residents' SWB

\begin{tabular}{|c|c|c|c|c|c|c|c|c|}
\hline \multirow[b]{3}{*}{ RA } & \multicolumn{8}{|c|}{ Domains of SWB in SHALOM } \\
\hline & \multicolumn{4}{|c|}{ Staff } & \multicolumn{4}{|c|}{ Family members } \\
\hline & Per & Com & Env & Tra & Per & Com & Env & Tra \\
\hline $\mathrm{F}$ & $9.5 * *$ & $10.3 * *$ & $10.8 * *$ & $8.0 * *$ & 2.6 & $3.9 *$ & $6.6 * *$ & 1.9 \\
\hline $\mathrm{R}^{2}$ & .51 & .53 & .55 & .47 & .21 & .28 & .40 & .16 \\
\hline Bideal & .71 & .94 & .65 & .79 & .24 & -.07 & .30 & .06 \\
\hline$\beta \exp$ & -.05 & -.41 & .16 & -.16 & .36 & .57 & .39 & .36 \\
\hline
\end{tabular}

NB $* \mathrm{p}<.05 ; * * \mathrm{p}<.01$ exp $=$ lived experience

These results reveal that the staff's ideals provided greater explanation of variance in their perceptions of help for residents' SWB, much more than staff's lived experiences did. This finding contrasted with the level of help perceived to be provided for clients by nursing staff, which showed the reverse order, in the previous study reported above [22]. The staff in this residential care unit acted in a very professional manner, by putting aside their own lived experience, relying on ideals for determining perceived needs for help with residents' SWB. In contrast, the results show that family members projected their lived experiences onto their perception of residents' need for help with SWB. 
Priorities for developing spiritual well-being.

Although they used different rationale to determine what help they thought residents need for nurturing their SWB, staff and family members in this study showed remarkably similar rank order of priorities. An inspection of the top ten items reveals that nine are the same, although the order differs slightly (see Table 5).

Table 5 Top ten items perceived to be important for help with residents' SWB

\begin{tabular}{cll}
\hline Rank order & Staff's perceptions & Family members' perceptions \\
\hline 1 & love others & love others \\
2 & trust & Trust \\
3 & joy\# & Identity \\
4 & identity & respect others* \\
5 & inner peace & inner peace \\
6 & kindness $*$ & peace with God \\
7 & peace with God & joy\# \\
8 & self-awareness & self-awareness \\
9 & oneness with God & oneness with God \\
10 & meaning in life & meaning in life
\end{tabular}

$\mathrm{NB} *=$ not in the other group's top items. $\#=$ different order

Developing relationships in the Communal domain of spiritual well-being were of greatest concern to the staff and family members, closely followed by those in the Personal domain. However, both the staff and family members perceived that the Transcendental/God factor was of greater importance than the Environmental factor for the residents to develop spiritual well-being.

\section{Implication for nursing practice}

Further study is warranted to clarify the relationship between nurses' perceptions of patients' needs for help, and nurses' perceived level of help they provide. These could also be compared with patients' reports on level of help they receive for spiritual wellbeing, if they were competent to make such an assessment (i.e., not dementia patients).

It is proposed that SHALOM could be beneficial to aged care services seeking a tool to help staff reflect on their own spiritual well-being as well as the spiritual life of their residents. This would be in keeping with accreditation requirements, which require spiritual needs of patients to be considered as part of holistic care [15]. 


\section{Strengths and weaknesses of this study}

This study provided positive outcomes related to nursing practice in an exploration of patients' spiritual needs in a residential dementia care unit. The sample was small in size, yet it comprised all the staff and vast majority of families representing residents in this unit. Despite the size, significant results were obtained providing further evidence for the sensitivity of SHALOM as an investigative instrument.

\section{Conclusion}

This study has shown that SHALOM can be a useful tool to help nursing staff and others reflect on their own spiritual well-being and see how well their own views match with others', as well as patients' needs for help. Responses on three categories of SHALOM provided assessments for the Personal, Communal, Environmental, and Transcendental/God domains of spiritual well-being in terms of staff's and family's (1) ideals; (2) lived experience; and (3) what help they thought residents with dementia need to nurture their SWB.

Although variations were found in the staff's and family members' own spiritual well-being based on age, religious group membership and activities, and whether or not the participant was facing a spiritual challenge, these variables had no significant impact on what staff and family members thought was needed to help nurture residents' spiritual well-being.

The staff in this study were able to differentiate between their ideals and lived experiences when it came to deciding what they thought would be best for nurturing residents' spiritual well-being. The staff's ideals contributed greatest variance in explaining what help they thought residents needed to nurture their SWB. The family members, on the other hand, used their lived experience as a basis for selecting what they considered most appropriate for nurturing the spiritual well-being of residents with dementia. Even though they used different rationale, the staff and family members agreed on the priorities they thought should be set in meeting the residents' needs for nurturance of their spiritual well-being.

\section{Acknowledgements}

Sincere thanks are expressed for the generous manner in which the staff and family members associated with this residential care unit participated in the study. Because of their support, it is hoped that these results will enable and encourage others to share mutual concerns for the spiritual well-being of similar residents with dementia.

\section{References}

[1] Harding SR, Flannelly KJ, Galek K, Tannenbaum HP. Spiritual care, pastoral care, and chaplains: Trends in the health care literature. J Health Care Chapl, 2008;14:99117.

[2] Gilbert P. Seeking inspiration: The rediscovery of the spiritual dimension in health \& social care in England. Ment Health, Relig \& Cult, 2010;13:533-546 
[3] Wright KB. Professional, ethical, and legal implications for spiritual care in nursing. Image: J Nurs Schol, 1998;30:81-83.

[4] Ronaldson S(ed.). Spirituality: The heart of nursing. Melbourne: Ausmed Pub., 1997.

[5] McSherry W. Nurses' perceptions of spirituality and spiritual care. Nurs Standard, 1998;13:36-40.

[6] Sherwood GD. The power of the nurse-client encounter: Interpreting spiritual themes. J Holist Nurs, 2000;18:159-175.

[7] MacKinlay E. Spiritual care: Recognising spiritual needs of older adults. J Relig, Spir \& Aging, 2006;18:59-71.

[8] Moberg DO. Disabilities, spirituality \& well-being in late life: Research foundations for study \& practice. J Relig, Spir \& Aging, 2008;20:313-340.

[9] Goodall MA.The evaluation of spiritual care in a dementia care setting. Dementia, 2009;8:167-183

[10] Bursell J, Mayers CA. Spirituality within dementia care: perceptions of health professionals. Br J Occup Ther, 2009;73:144-151

[11] Jolley D, Benbow SM, Grizzell M, Willmott S, Bawn S, Kingston P. Spirituality and faith in dementia. Dementia, 2010;9:311-325.

[12] Keast K, Leskovar C, Brohm R. A systematic review of spirituality and dementia in LTC. Ann Long Term Care, 2010:18:41-47.

[13] MacKinlay E, Trevitt C. Living in Aged Care: Using spiritual reminiscence to enhance meaning in life for those with dementia. Int J Ment Health Nurs, 2010;19:394-401.

[14] Fisher JW. Helps to fostering students' spiritual health. Int J Children's Spir 1999;4:29-49.

[15] Hicks TJ. Spirituality and the elderly: nursing implications with nursing home residents. Geriat Nurs 1999;20:144-146.

[16] Department of Health \& Family Services. Standards \& Guidelines Manual. Kingston, ACT: CanPrint Communications P/L, 1998.

[17] Fisher JW. Developing a spiritual health and life-orientation measure for secondary school students. In Proceedings of the University of Ballarat Annual Research Conference, 15 October, 1999; Ballarat. Edited by Wittwer V, Baird P. Ballarat: UB Research \& Graduate Studies Office, 1999: 57-63.

[18] Fisher J. Development and application of a spiritual well-being questionnaire called SHALOM. Religions, 2010;1:105-121. 
[19] Gomez R, Fisher JW. Domains of spiritual well-being and development and validation of the Spiritual Well-Being Questionnaire. Pers and Indiv Diff, 2003;35:1975-1991.

[20] Gomez R, Fisher JW. Item Response Theory analysis of the Spiritual Well-Being Questionnaire. Pers and Indiv Diff, 2005;38:1107-1121.

[21] Gomez R, Fisher JW. The Spiritual Well-Being Questionnaire: Testing for model applicability, measurement and structural equivalencies and latent mean differences across gender. Pers and Indiv Diff, 2005;39:1383-1393.

[22] Fisher JW, Brumley DJ. Nurses' and carers' spiritual well-being in the workplace. Australian J Adv Nurs, 2008;25:49-57.

[23] Faul F, Erdfelder E, Buchner A, Lang A-G. G*Power 3: A flexible statistical power analysis program for the social, behavioural, and biomedical sciences. Behav Res Methods, 2007;39:175-191.

[24] Fisher JW. Reaching the Heart: Assessing and nurturing spiritual well-being via education. EdD dissertation, University of Ballarat, Australia, 2009. Available at:http://archimedes.ballarat.edu.au:8080/vital/access/HandleResolver/1959.17/13481

[25] Tabachnick BG, Fidell LS. Using multivariate statistics $\left(5^{\text {th }}\right.$ Ed.). Boston: Pearson Education, 2007.

\subsection{Summary of Chapter 5}

The way carers live often influences the type of spiritual care they believe they give to clients. Although much healthcare literature equates spirituality and well-being with religiosity and religious affiliation, the Transcendental domain (relationship with God) was generally less well catered for than the Personal and Communal aspects of SWB by the Australian and New Zealand nurses and medical staff who participated in the three studies reported here.

These results suggest that more appropriate training is needed in the education programs of Australian and New Zealand nurses and medical practitioners in line with that being reported in universities and hospitals in the USA and UK. Better training would ensure that the spiritual well-being of clients was adequately included in their holistic care. 


\section{Chapter 6 Relating with God and Spiritual Well-Being in Community Settings}

\subsection{Introduction}

Following specific discussions of university and school students and healthcare in previous chapters, this chapter provides reports of research on aspects of spirituality/wellbeing and relationship with God within the general populace in Australia.

\subsection{Quality of life in the workplace: Spirituality, meaning and purpose.}

\section{Background}

This paper is not placed in chronological order of my research. It was actually one of the earliest projects I undertook using SHALOM while I was Research Project Officer in the School of Nursing (SON) at the University of Ballarat in 2000. When the conference on Spirituality, Leadership and Management was mooted to be held at the University of Ballarat in 2000, I was invited onto the organising committee by the Vice Chancellor. In keeping with the theme of the conference, I was motivated to work with one of my colleagues in SON, Associate Professor Eileen Sellers, on a project assessing quality of life among the university's staff. As spiritual well-being can be considered a key aspect of quality of life, use of SHALOM was appropriate for this project. Allocation of credit for this paper is shared between the two authors.

\section{Key findings extracted from this paper}

- Of the four domains of spiritual well-being assessed using SHALOM, staff at the University of Ballarat reported feeling good about themselves and their relationship with other people, and with the environment.

- However, in keeping with the highly secular composition of this staff cohort, relationship with God was scored much lower, indicating the majority of staff who participated in the survey placed less importance on this element for their spiritual well-being. For those for whom relationship with God is important, their religious activity significantly enhanced their relationship with God.

- Staff at the university did not expect the workplace to play a major role in enhancing their spiritual well-being. Such support was seen as more likely to come from family and friends. 


\section{Implications}

Negative workplace feelings, which according to the research reported below can arise from administrative practices, warrant further investigation in order to discover how to improve the quality of life (including spiritual well-being) of the university's employees. Such improvement of their quality of life could be expected to also improve the university's organisational effectiveness.

The research indicates that positive feelings that come from colleagues, family and friends help sustain employees' well-being. These positive feelings need to be enhanced for the university staff's continued well-being.

Other studies have shown that carers' lived experience has a major influence on the quality of spiritual well-being they provide for their clients. It is therefore not surprising to note some lower scores on spiritual well-being reported by students at this university, which has been reported Chapter 3 in this thesis.

\section{Paper:}

This paper was published as: Fisher, J.W. \& Sellers, E.T. (2000) Quality of life in the workplace: Spirituality, meaning and purpose. Refereed paper in the Proceedings of the $3^{\text {rd }}$ Annual Conference on Spirituality, Leadership and Management, University of Ballarat, 1-4 December, pp.14-19.

Conference: Redefining Success and Reinvigorating the Workplace $3^{\text {rd }}$ Annual Conference on Spirituality, Leadership and Management to be held at the University of Ballarat, 1-4 December, 2000.

Paper title: Quality of Life in the workplace: spirituality, meaning and purpose.

Theme: $\quad$ Spiritual and management practices that enable business and community sustainability.

Authors: Dr John W. Fisher, Research Project Officer, School of Nursing, University of Ballarat Dr Eileen T. Sellers, Associate Professor, School of Nursing, University of Ballarat.

Contact details:

phone: 0438.395.915 fax: (03) 5327.9719

e-mail: j.fisher@ballarat.edu.au 


\begin{abstract}
This paper reports on research which aimed to investigate relationships between meaning and purpose in life and workplace expectations. It provides an overview of the methodology and outcomes of a survey conducted at a regional university. Survey methods included the distribution of two valid and reliable instruments to all employees of that university with data analysed using SPSS procedures.

Analysis of the Spiritual Health and Life-Orientation Measure (SHALOM), developed by the principal researcher, and a purpose-designed questionnaire pertaining to meaning and purpose in the workplace, provided interesting findings. Overall, participants classified as administrators, professionals, service workers or labourers reported that they feel good about themselves and their relationships with others and the environment. The relationship with a god-type figure was of lesser importance for the spiritual well-being of the majority of participants. The participants do not expect the workplace to provide a major role in their spiritual well-being. They also reported significantly high levels of feelings of turbulence at work, and trends toward high anxiety and discomfort with autocratic managerial practices characterised by a focus on profits over people. The female staff described the workplace as more friendly, warm and caring than the males. The females also reported greater work satisfaction and were less depressed in doing their job than the males.

Interpretation of these results indicates that a somewhat anxious and turbulent work place environment prevails. The personal impact of this unrest appears to be mediated by the support of families and friends of employees. The notion that workplace feelings which are negative (e.g., anxiety) emanate from administrative practices, while those which are positive are a function of collegial behaviours, merits further exploration.
\end{abstract}

\title{
Introduction
}

In the distant past, the workplace was depicted as a place distinct from the home where the goals of task accomplishment were paramount. Over time, the concept of workplace has expanded to encompass various geographical and psychological milieux. Due perhaps to an upsurge of competitive forces, increased demands for accountability, an increase in working responsibilities, and the perceived economic value of a multi-skilled workforce, in recent years the workplace represents to many a venue through which self actualisation may be effected. More recently, in accordance with such employee expectations, the role of spirituality at work has been emphasised, especially the obligations of leaders and managers to view spiritual matters as integral components of their holistic duty of care to employees.

While workplace considerations of spirituality are increasingly addressed in the organisational management literature (Bennis, 1999; Bolman \& Deal, 1995; Drucker, 1992; Kernberg, 1998; Mitroff \& Denton, 1999), investigations of spirituality and 'soul' are also emerging in the literature specifically related to higher education (Gaff \& Simpson, 1994; Green, 1998; Hoff, 1999; Ling \& Ling, 1994).

In order to provide workplace leadership effectively in the new millennium, regard for the spiritual well-being of employees would appear to be an essential component of the managerial repertoire (Lobel, Googins, \& Bankert, 1999; Morgan, 
1997; Nyhan, 2000). It therefore follows that the present state of spiritual well-being in the workplace must be investigated and documented (Adams, 1998; Briskin, 1996; Coady, 2000). This paper reports on such an investigation in an academic setting in Victoria.

\section{Background and Method}

As an outcome of his research of spirituality, Fisher (1999a) derived the following description of spiritual health and well-being.

a. Spiritual health is a fundamental dimension of people's overall health and well-being, permeating and integrating all the other dimensions of health (i.e. the physical, mental, emotional, social and vocational).

b. Spiritual health is a dynamic state of being, shown by the extent to which people live in harmony within relationships in the following domains of spiritual well-being:

- Personal domain (wherein one intra-relates with oneself with regards to meaning, purpose and values in life. The human spirit creates self-awareness, relating to self-esteem and identity)

- Communal domain (as expressed in the quality and depth of inter-personal relationships, between self and others, relating to morality, culture and religion. This includes love, justice, hope \& faith in humanity)

- Environmental domain (past care and nurture for the physical and biological, to a sense of awe and wonder; for some, the notion of unity with the environment)

- Transcendental domain (Relationship of self with some-thing or some-One beyond the human level, i.e. ultimate concern, cosmic force, transcendent reality, or God. This involves faith toward, adoration and worship of, the source of Mystery of the universe).

Part a. of this definition outlines the inter-connective nature of spiritual health, and reflects that it is a dynamic entity (Swift 1994). Part b. highlights the dynamic nature of spiritual health, in which internal harmony depends on intentional self-development, coming from congruence between expressed and experienced meaning, purpose and values in life. This often is the result of personal challenges which go far beyond contemplative meditation leading to a state of bliss, perceived by some as internal harmony (Fisher, 2000). The quality, or rightness of relationship, in each of the four domains constitutes a person's spiritual well-being in that domain. An individual's spiritual health is indicated by the combined effect of spiritual well-being in each of the domains embraced by the individual. Depending on people's world-views and beliefs, they are likely to embrace these four sets of relationships to varying extents.

The four sets of relationships shown to be important for spiritual well-being have been operationalised in the Spiritual Health And Life-Orientation Measure (SHALOM) developed by Fisher (1999b, Gomez \& Fisher (in press)). SHALOM has been employed 
with secondary school students and staff, nurses, family members and university students, and, in the case of the study with which this paper is concerned, with university staff. Accordingly, SHALOM has proven reliability and validity and is the instrument of choice when spiritual well-being is under investigation.

Two instruments were employed to examine the spiritual well-being of the employees in a regional multi-sectoral university in Victoria: SHALOM (Fisher, 1999b) and modified sections from a purpose-designed questionnaire suggested by current literature (Mitroff \& Denton, 1999). It was hypothesised that participants would report an expectation that the workplace would enhance relationships with self and others, and to some extent with the environment. On the other hand, since the survey took place in a secular institution, it was not anticipated that respondents would report an expectation that the workplace should enhance relationships with God or a higher being.

The entire population of the university, nearly 800 employees, was sent a confidential survey form and a return envelope by internal mail. Completed forms were returned to the principal researcher within a two week time period. Demographic data pertaining to gender, educational background, age and self-defined job classification were also obtained.

Results

\section{$\underline{\text { Sample }}$}

A response rate of $21 \%(n=165)$ was achieved, with $23 \%$ of the female $(n=108)$ and $15 \%$ of the male staff $(n=57)$ responding. This rate equates with that of a separate survey on equity which was distributed to this university's staff in the fortnight prior to this investigation, implying that the interest and/or availability of staff was typical of this particular time period.

\section{SHALOM}

The SHALOM instrument asks participants to give three responses to each of 20 items to show: a. how important they think each is for an ideal state of spiritual health, AND

b. how they feel each item reflects their personal experience most of the time,

AND c. how much they expect their workplace to help develop the stated aspect of their lives.

The 20 items were assigned to four factors representing the four domains of spiritual well-being:

Personal

sense of identity

self-awareness

joy in life

inner peace

meaning in life

\section{Communal}

love of other people

forgiveness toward others

trust between individuals

respect for others

kindness toward other people 


\section{Environmental}

connection with nature

awe at breathtaking view

harmony with environment

oneness with nature

sense of 'magic' in environment

\section{Transcendental}

personal relationship with

Divine/God

worship of the Creator

oneness with God

peace with God

prayer life

Factor analysis showed that the four factors of SHALOM were valid for this sample with alpha values ranging from .763 to .904 and item-total correlation values being $>0.58$ for all items in each factor (Hair et al., 1984).

Results in Table 1 show that the scores for the perceived ideals for spiritual wellbeing in each of the four domains were significantly higher than that for the lived experience, which exceeded that for perceptions of help needed from the workplace.

Table 1 Mean values for three categories of the four domains of spiritual well-being

domains of spiritual well-being

\begin{tabular}{l|llll}
\hline category & personal & communal & environmental & transcendental \\
\hline ideals & 4.56 & 4.54 & 4.07 & 2.95 \\
lived experience & 3.92 & 4.02 & 3.76 & 2.53 \\
help needed & 3.26 & 3.32 & 2.44 & 1.54 \\
\hline
\end{tabular}

These findings were consistent across each of the four job classifications, namely management/ administration, professional/associate, clerical/sales/service, labourer. Female staff were more idealistic than the males in communal well-being $(\underline{t}(140)=3.29$, $\mathrm{p}=.001)$ and they scored higher than their male counterparts for the lived experience for the communal $(\underline{\mathrm{t}}(142)=2.13, \mathrm{p}=.036)$ and transcendental $(\mathrm{t}(141)=1.99, \mathrm{p}=.049)$ wellbeing. Studies using other spiritual health measures have found no significant difference by gender (Baider et al., 1999; Holland et al., 1998). An advantage of SHALOM over other spiritual health measures is that it can be used to compare people's stated ideals with their lived experience to assess the spiritual harmony <-> distress in each of four domains. For example, ANOVA results showed that the administrators showed less spiritual harmony than other staff in personal well-being $(\mathrm{F}(3,138)=2.72, \mathrm{p}=.047)$.

The hypothesis was confirmed in that moderate-high levels of well-being were experienced in the personal, communal and environmental domains but lower levels in 
the transcendental domain of spiritual well-being. The staff expect a reasonable level of help in nurturing relationships in the personal and communal domains but not the environmental, except for the labourers for whom it is important. In general, the staff in this secular university does not expect help from the workplace for nurturing the transcendent domain of spiritual well-being. About $13 \%$ of the staff reported attending church at least once a month, presumably to enhance this aspect of their quality of life. This figure is lower than the $20 \%$ national average reported by Hughes (2000).

The staff showed that spirituality was much more important than religion in their lives $(\mathrm{t}(160)=13.37, \mathrm{p}=.000)$ supporting the argument that spirituality does not equate with religion, but can include it (eg, Tloczynski et al., 1997).

\section{$\underline{\text { Spiritual helps }}$}

Of the 16 activities listed on the questionnaire, the following were perceived by the staff to build up their spiritual well-being (see Table 2). The scores ranged from 1 to 5 on a Likert scale.

Table 2 Activities enhancing spiritual well-being, by gender

\begin{tabular}{llll}
\hline & Female & & Male \\
\hline mean & activity & 3.82 & family \\
\hline 4.17 & family & 3.76 & being happy \\
4.14 & being happy & 3.69 & nature \\
3.95 & nature & 3.59 & time-out \\
3.92 & time-out & 3.59 & walks \\
3.92 & friends & 3.50 & helping others \\
3.83 & walks & 3.45 & friends \\
3.72 & helping others & 3.31 & music \\
3.68 & self-improvement & 3.18 & self-improvement \\
3.63 & music & & \\
\hline
\end{tabular}

Results of the correlations displayed in Table 3 show that nature and music were seen to enhance the respondents' environmental well-being. Helping others correlates with relating to others for communal well-being naturally enough. Relating to friends is seen to build up personal well-being. The Bible enhances personal and transcendental well-being whereas the pastor was seen to enhance communal and transcendental wellbeing. Prayer positively influences personal and transcendental well-being, but meditation was only shown to enhance transcendental well-being. The Church is also seen to build up transcendental well-being. The importance of religion in life is seen to 
correlate with personal, communal and transcendental well-being whereas the importance of spirituality in life correlates with environmental well-being in addition to the other three.

Table 3 Pearson correlation values of spiritual helps with domains of spiritual well-being

lived experience domain of spiritual well-being

\begin{tabular}{|c|c|c|c|c|}
\hline spiritual help & Personal & Communal & Environmental & Transcendental \\
\hline nature & & & $.404 * *$ & \\
\hline music & & & $.210 *$ & \\
\hline help others & & $.171 *$ & & \\
\hline friends & $.181 *$ & & & \\
\hline Bible & $.226 * *$ & & & $.503 * * *$ \\
\hline pastor & & $.199 *$ & & $.492 * * *$ \\
\hline prayer & $.179 *$ & & & $.747 * * *$ \\
\hline meditation & & & & $.249 * *$ \\
\hline Church & & & & $.577 * * *$ \\
\hline importance of religion & $.224 * *$ & $.257 * *$ & & $.742 * * *$ \\
\hline importance of spirituality & $.186^{*}$ & $.155^{*}$ & $.292 * * *$ & $.361 * * *$ \\
\hline
\end{tabular}

The female staff, especially the professionals, considered friends and selfimprovement enhanced their spiritual well-being to a greater extent than the males. Being happy was considered of greater importance to female administration/managers than to their male colleagues for spiritual well-being. Although religious factors were considered of low importance for the enhancement of spiritual well-being of staff in this secular university, the professional and clerical staff rated these factors (prayer, meditation and church) more highly than the administration for their spiritual well-being.

\section{Meaning and purpose in the workplace}

When asked to indicate the three reasons that provide most meaning and purpose in their jobs, the staff indicated that reaching their potential (54\%), giving service to others (42\%), doing interesting work (39\%), working for an ethical organisation (32\%) and having good co-workers (31\%) were most important. At 13\%, making money and doing new things were rated lowest.

Work contributes to general meaning for most of the university staff (3.57 on a scale from 1-5) but the male administrators were not as positive about this as the females. Work providing general meaning correlates with personal and communal well-being (see 
Table 4). The male administrators also expressed higher level of depression in the job than their female colleagues. Depression correlates negatively with personal, communal and transcendental well-being. The female staff, especially the professionals, expressed greater work satisfaction than the males and opportunity to express soul and spiritual satisfaction at work. These three characteristics of the workplace correlate with personal, communal and transcendental well-being. As would be expected, expressing self at work correlates with personal well-being as do prayer and meditation with transcendental wellbeing. Being able to express your total feelings at work correlates with personal and communal well-being (see Table 4).

Table 4 Pearson correlation values of meaning at work with domains of spiritual wellbeing

\begin{tabular}{llll}
\hline & \multicolumn{3}{l}{ lived experience domain of spiritual well-being } \\
\cline { 2 - 3 } meaning at work & Personal & Communal & Transcendental \\
\hline general meaning & $.272^{* *}$ & $.165^{*}$ & \\
work satisfaction & $.336^{* * *}$ & $.207 * *$ & $.170^{*}$ \\
express total self & $.251^{* *}$ & & \\
express total feelings & $.231^{* *}$ & $.215^{* *}$ & \\
express complete soul & $.298^{* * *}$ & $.287^{* * *}$ & $.256^{* *}$ \\
depression in job & $-.313 * * *$ & $-.173^{*}$ & $-.255^{* *}$ \\
pray/meditate & & & $.333^{* * *}$ \\
spiritual satisfaction & $.286^{* * *}$ & $.166^{*}$ & $.215^{* *}$ \\
\hline$* * * \mathrm{p}<.001 * * \mathrm{p}<.01$ & $* \mathrm{p}<.05$ & &
\end{tabular}

\section{Describing the workplace}

In describing their workplace on scales from 1-5, the employees perceived the workplace to be worldly (3.94) as opposed to spiritual, profit first (3.60) as opposed to people first, turbulent (3.58), high anxiety (3.55, with the professionals scoring significantly higher than the administration and clerical staff), friendly (3.53, higher for females than males), tolerant of minorities (3.37) and autocratic (3.36). The female staff were more positive than the males about the workplace being happy, warm and friendly, and slightly more caring. These characteristics correlated with personal and communal well-being (see Table 5). 
Table 5 Pearson correlation values of description of workplace with domains of spiritual well-being

\begin{tabular}{lll}
\hline \multicolumn{3}{c}{ lived experience domain of spiritual well-being } \\
\hline description of work place & Personal & Communal \\
\hline happy & $.215^{* *}$ & $.200^{* *}$ \\
warm & $.158^{*}$ & \\
ethical & $.221^{* *}$ & $.198^{*}$ \\
friendly & $.214^{* *}$ & $.216^{* *}$ \\
caring & & \\
\hline$* * \mathrm{p}<.01 * \mathrm{p}<.05$ &
\end{tabular}

\section{Discussion and conclusion}

It is clear that employees in this study of an academic organisation do expect that personal meaning and purpose in life will be supported and/or enhanced by their daily experiences at work. At the same time, consistent with current literature, they report feelings of turbulence in the workplace. Trends toward high anxiety and discomfort with autocratic managerial practices characterised by a focus on profits over people were also evident.

The researchers postulate that these trends may be even more pronounced than demonstrated as the relatively low response rate could be interpreted as indication of long term disillusionment. That is, it is believed that the perception of some employees that participation in such surveys is not likely to make a difference in the workplace culture is likely to have affected the participation rate. In fact Coady (2000) claims that many in academia have a feeling of dread that their jobs will be lost and that the traditional academic culture of interaction, discourse, and collegiality is at peril. Similarly, Wolverton, Gmmelch, Wolverton, \& Sarros $(1999,179)$ maintain that 'excessive stress remains a disease endemic to higher education.'

The findings related to gender differences also warrant deliberation. The female staff described the workplace as more friendly, warm and happy than their male colleagues and reported greater work satisfaction and less depression. Although there is insufficient information in this small study to generalise to the total population, it is interesting in that it disaffirms the conclusion of a study by Gardiner and Tiggeman $(1999,313)$ that 'women and men in male dominated industries did not differ in interpersonal orientation.' This finding could also be viewed as contradictory to much of the literature which describes the obstructive 'glass ceiling' in the workplace which precludes the advancement of women in a culture dominated by male values (Ward, 1998; Wicks, 1999). On the other hand, the findings could be seen as confirmation of gender stereotypes which label women as more openly communicative and interrelational than men (Abrams \& Hogg, 1999).

In agreement with the work of Mitroff \& Denton $(1999,31)$, this report is considered to be a 'systematic beginning, not a final, definitive product.' At the least, 
however, study results demonstrate that a somewhat anxious and turbulent workplace environment prevails within the study context. While the personal impact of this unrest appears to be mediated by the support of families and friends of employees, other notions appear to merit further investigation. These include the premise that negative workplace feelings emanate from administrative practices while positive feelings are a function of collegial behaviours and factors external to the workplace.

Academic leaders would be wise to heed the advice of Nixon, Beattie, Challis, \& Walker $(1998,5)$ who suggest that they should 'forge mutually supportive relationships against the horizontal grain of institutional hierarchies.' Genuine transformational leaders, according to Bass (cited in Bass \& Steidlmeier, 1999), must support the needs of employees for achievement and self-actualisation. At the very least, further examination of the issues raised by this study has the potential to improve organisational effectiveness through enhancement of the knowledge available to $21^{\text {st }}$ century university managers.

\section{References}

Abrams, D., \& Hogg, M. A. E. (1999). Social identity and social cognition. Malden, MA: Blackwell.

Adams, D. (1998). Examining the fabric of academic life: an analysis of three decades of research on the perceptions of Australian academics abut their roles. Higher Education, 36, 421-435.

Bass, B. M., \& Steidlmeier. (1999). Ethics, character, and authentic transformational leadership behavior. Leadership Quarterly, 10(2), 181-217.

Baider, L. et al. (1999). The role of religious and spiritual beliefs in coping with malignant melanoma: An Israeli sample. Psycho-Oncology, 8(1), 227-35.

Bennis, W. (1999) The end of leadership: exemplary leadership is impossible without full inclusion, initiatives, and cooperation of followers. Organizational Dynamics 28(1), 71-80.

Bolman, L. G., \& Deal, T. E. (1995). Leading with soul: an uncommon journey of spirit. San Francisco: Jossey-Bass.

Briskin, A. (1996). The stirring of soul in the workplace. San Francisco: Jossey-Bass.

Coady, T. E. (2000). Why universities matter: a conversation about values, means and directions. St. Leonards, NSW: Allen \& Unwin.

Drucker, P. F. (1992). Managing for the future: the 1990s and beyond. New York: Truman-Talley.

Fisher, J. W. (1999a). Helps to fostering students' spiritual health. International Journal of Children's Spirituality, 4(1), 29-49.

Fisher, J. W. (1999b). Developing a spiritual health and life-orientation measure for secondary school students. Proceedings of the University of Ballarat annual research conference, 15 October, 57-63. Ballarat: SEDS, University of Ballarat. 
Fisher, J. W. (2000). Being human, becoming whole: Understanding spiritual health and well-being. Journal of Christian Education, 43(3), 133-145.

Gaff, J. G., \& Simpson, R. D. (1994). Faculty development in the United States. Innovative Higher Education, 18(3), 167-177.

Gardiner, M., \& Tiggemann, k. M. (1999). Gender differences in leadership style, job stress and mental health in male and female dominated industries. Journal of Occupational and organizational psychology, 72(3), 301-315.

Gomez, R. \& Fisher, J. W. (in press). Domains of Spiritual Well-Being and development and validation of the Spiritual Well-Being Questionnaire. Personality and Individual Differences (accepted 30 December 2002).

Green, M. F. E. (1998). Transforming higher education: views from leadership around the world. Phoenix, AZ: American Council on Education, Oryx press.

Hair, J. F. et al (1984). Multivariate Data Analysis. New Jersey: Prentice-Hall.

Hoff, K. S. (1999). Leaders and mangers: essential skills required within higher education. Higher Education, 38(3), 311-331.

Holland, J. et al. (1998). A brief spiritual beliefs inventory for use in quality of life research in life-threatening illness. Psycho-Oncology, 7, 460-9.

Hughes, P. (2000). Spirituality. Pointers - Bulletin of the Christian Research Association, $10(1), 1$.

Kernberg, O. (1998). Ideology, conflict and leadership in groups and organization. London: Yale University Press.

Ling, L., \& Ling, P. (1994). Administration for innovation in higher education. Innovative Higher Education, 18(3), 221-236.

Lobel, S. A., Googins, B. K., \& Bankert, E. (1999). The future of work and family: critical trends for policy, practice, and research. Human Resource Management, $38(3), 243-254$.

Mitroff, I. I., \& Denton, E. A. (1999). A spiritual audit of corporate America: a hard look at spirituality, religion, and values in the workplace. San Francisco: Jossey-Bass.

Morgan, G. (1997). Images of Organization (2nd ed ed.). Thousand Oaks, CA: Sage.

Nixon, J., Beattie, M., Challis, M., \& Walker, M. (1998). What does it mean to be an academic? A colloquium. Teaching in Higher Education, 3(3), 227-249.

Nyhan, R. C. (2000). Changing the paradigm - trust and its role in public sector organizations. American Review of Public Administration, 30(1), 78-103.

Swift, G. (1994). A contextual model for holistic nursing practice. Journal of Holistic Nursing, 12(3), 265-281. 
Tloczynski, J., Knoll, C. \& Fitch, A. (1997). The relationship among spirituality, religious ideology and personality. Journal of Psychology and Theology,2592), 208-213.

Ward, K. (1998). Addressing academic culture: service learning, organizations, and faculty work. New Directions for Teaching and Learning, 73, 73-80.

Wicks, D. (1999). Nurses and doctors at work: rethinking professional boundaries. St.Leonard's, NSW: Allen \& Unwin.

Wolverton, M., Gmmelch, W. H., Wolverton, M. L., \& Sarros, J. C. (1999). Stress in academic leadership: US and Australian department chairs/heads. Review of Higher Education, 22(2), 165+.

\subsection{Relating with God, happiness, personality and age}

\section{Background}

Inconsistent results have been reported in the literature with regard to investigations of relationships between religion and happiness. Inconsistent results have also been reported in the literature concerning relationship between age and happiness, or life satisfaction. The Transcendental domain of SHALOM assesses a person's relationship with God, not just their religious activities such as church attendance, or their religious affiliation, which have been used by researchers in previous studies. Personality factors of extraversion (positive impact) and neuroticism (negative impact) have been described by previous researchers as dominant predictors of subjective well-being, which is a feature of happiness (Saraglou, 2002: Furnham, 2007; Henningsgaard, 2008).

This paper reflects on several studies I conducted among secondary school and university students, and church attendees. The particular focus of the research was on how relating with God influences one's happiness over and above personality and age.

\section{Key points extracted from this paper}

- The Oxford Happiness Inventory (OHI) is an instrument which is commonly used to assess happiness. Confirmatory Factor Analyses of results from three studies led to a reduction of the original 29-item Oxford Happiness Inventory to a more precise 19-item measure with three factors which I labelled as (i) contentment, (ii) expressions of happiness, and (iii) quality of life.

- In line with previous studies reported in the literature, personality constructs of extraversion (positive impact) and neuroticism (negative impact) were found to be 
major contributors to explanations of variance in people's happiness, as measured by the modified 19-item version of the $\mathrm{OHI}$ and the three subscales therein.

- However, after controlling for personality and age, multiple regression analyses revealed small, yet significant, additional explanation of variance in happiness (subjective well-being) according to the nature of the participants' relationship with God.

\title{
Implications
}

SHALOM is a sensitive instrument which provides a direct measure of the extent of people's relationship with God. This contrasts with previous studies reported in the literature which have employed church attendance and religious affiliation, which do not necessarily assess one's relationship with God.

As the four domains of spiritual well-being assessed using SHALOM are related to happiness, and because they are expressions of who a person is at their very core of being, this research continues the discussion as to whether spirituality can be considered an expression of personality. Relating with God can change people's lives. Further work is needed to clarify the relationship between personality and spirituality.

\section{Paper:}

This paper was published as: Fisher, J.W. (2013) Relating with God contributes to variance in happiness, over that from personality and age. Religions, 4: 313-324.

\section{Relating with God Contributes to Variance in Happiness, over that from Personality and Age}

John Fisher

School of Education \& Arts, University of Ballarat, Victoria, 3350, Australia; e-mail: j.fisher@ballarat.edu.au; Tel.: +61.438.395.915

\begin{abstract}
A previous study on university students reported that personal, communal, and environmental spiritual well-being contributed to happiness over and above personality but that relating with God did not. In this study, happiness was assessed using a modified Oxford Happiness Inventory. Personality scores were obtained using forms of Eysenck's Personality Questionnaire. Four domains of spiritual well-being were determined using Fisher's Spiritual Well-Being Questionnaire. Relationship with God was reflected by the Transcendental domain of spiritual well-being in this instrument. Studies with 466 university students from Australia, Northern Ireland, and England, 494 people attending churches in Ballarat, and 1002 secondary school students in Victoria showed that relating with God accounts for variance on happiness, over and above personality, and age.
\end{abstract}


Keywords: happiness; personality; age; relation with God

\section{Introduction}

Quality of relationship with God provides a measure of one of four domains of spiritual well-being, the other three being relationship with self (in terms of meaning, purpose, and values in life); relationship with others (in terms of morality, culture, and religion [for those for whom it is important]); and relationship with the environment (beyond care, nurture, and stewardship to a real connection with nature) [1]. These four domains of spiritual well-being have been assessed using the Spiritual Health And Life-Orientation Measure (SHALOM), which was developed with secondary school students, with the intention that language and conceptual clarity suitable for 12-18 year-olds should make the instrument appropriate for use with adults as well [2].

The focus of spiritual 'well-being' fits with contemporary studies in the emerging field of positive psychology, which is dedicated to understanding the process of human happiness [3]. Happiness is a multi-faceted concept often used synonymously with the notion of subjective well-being. Diener described three components of happiness as 'frequency and degree of positive affect or joy; absence of negative feelings, such as depression or anxiety; and average level of satisfaction over a period' [4]. The Oxford Happiness Inventory (OHI), which is largely based on the inverse of the Beck Depression Index [5], is one of the most frequently used instruments for assessing happiness $[3,6,7]$.

Consistent findings have been made in a number of studies relating happiness with personality traits, to the extent that happiness has been described as 'a thing called stable extraversion' [8]. Extraversion $(+)$ and Neuroticism $(-)$ appeared to be the strongest predictors of happiness levels in several studies $[3,9,10]$. Personality has been reported as a greater determinant of happiness than social class, money, social relationships, work, religion, or other external variables $[3,11]$.

Questions have been raised concerning any relationship between age and happiness, or life satisfaction. Fukuda contended there is an age effect for happiness with downward movement for 18-55 (and 80-89), and with upward movement for 56-69 [12]. Although previous support for such a U-shaped relationship between life satisfaction and age had been presented [13], others conclude there is only a weak U-shaped pattern in happiness for the 20-60 age range [14]. Keeping age in mind, no age differences were found across a study of religious denominations, although conceptualizations of God varied dependent on religious affiliation [15]. Relationship with God, which would be built on people's conceptualizations of God, has also been found to be more strongly associated with happiness than is social cohesion, which was indicated by religious attendance in a study by Childs [16].

Other studies with adults variously report positive correlations between church attendance and life satisfaction [17], and participation in religious activities and well-being [18], whereas, religious practice and happiness were positively associated among students in Germany [19], but not in Estonia [20]. Among young adults in Qatar, a relationship was found between health, well-being, and religiosity [21], but church attendance did not predict life satisfaction among adolescents [22], or well-being of graduate students [23]. The conclusions that perceived control acts as mediator between religiosity/spirituality and well-being in adults [24], and that intrinsic religiosity leads to improved spiritual 
well-being among seminary students [25], point to internal motivation being a key to positive outcomes in well-being. Therefore, variations in findings by church attendance and religious affiliation are not surprising, particularly among the young, because many children are forced to attend by parents [26] so they would not be likely to relate kindly to religion or God. The main motivation for some adolescents' and adults' participation in religious activities is obviously for human companionship, more than to celebrate and build relationships with God. In addition, religious affiliation appears to be a historical legacy for many, which is useful at times of census, weddings, and funerals, evidenced by marked variations, at least in Australia, between approximately $70 \%$ who claim religious affiliation on the census and about 5\% who regularly attend religious activities [27].

Previous studies have shown inconsistent results in the relationship between religion and happiness, depending on measures used [28]. Five studies by Francis and others suggest a consistent relationship between happiness (measured using the $\mathrm{OHI}$ ) with religiosity (assessed using the Francis Attitude to Christianity Scale (FACS)) [29]. Although Francis et al. claimed that the OHI was an appropriate measure of happiness, based on an adequate theoretical discussion of this construct, Kashdan later raised concerns about conceptual issues related to the $\mathrm{OHI}$ and the subsequent Oxford Happiness Questionnaire [30]. The authors of the OHI acknowledged that a loose array of constructs was assessed by this instrument [31]. The composition of the FACS is, as its name suggests, decidedly Christian, with five of its 24 items relating to Jesus, two items mention the bible and three items, the church. The other 14 items are more religious, not specifically Christian, with eight mentioning God, five prayer and one, both of these.

A more compact, general measure of relationship with God will be reported in this paper, as will a modified OHI. Studies in this paper will bypass the uncertainties of trying to assess the relationship with God through religious activities and affiliation, by directly addressing it through responses to the five items comprising the Transcendental domain of the Spiritual Health And Life-Orientation Measure (SHALOM) [2].

In a study with university students, Gomez and Fisher [32] reported that personal, communal, and environmental spiritual well-being provided additional variance to the prediction of happiness over personality dimensions assessed using Eysenck Personality Questionnaires [33]. As transcendental spiritual well-being (relationship with God) did not provide similar influence in that sample, it was predicted that relationship with God could possibly be a critical factor in particular groups, such as those who are religious. In order to test this hypothesis, and any relationship with age of respondents, the emergent questions for this research became, 'In what circumstances does connecting with God relate to happiness, over and above personality?' and, 'Does age enter this equation?'

\section{Materials and Methods}

Following approvals from the University of Ballarat Human Research Ethics Committee, several studies were conducted using SHALOM, and the OHI, together with Eysenck Personality Questionnaires (EPQs) to investigate how happiness relates to personality, age, and relationship

with God. 


\subsection{Materials}

\subsubsection{Assessing Relationship with God}

SHALOM is a 20-item measure, with five items for each of four domains of spiritual well-being, all assessed using a five-point Likert scale (from $1=$ very low to $5=$ very high), to elicit two responses, showing each person's ideals for spiritual well-being, as well as their lived experiences in each of the four domains. The quality of relationship with God (TRAB) is reflected in the importance of developing 'personal relationship with the Divine/God', 'worship of the Creator', 'oneness with God', 'peace with God', and 'prayer life'. A domain score is calculated by taking the mean value of responses to the five items. Only the lived experience scores will be used in this paper [2].

\subsubsection{Assessing Happiness}

The OHI comprises 29 items, each scored from 0 to 3 . The respondent chooses one of four sentences constructed to reflect incremental steps defined as unhappy or mildly depressed, a low level of happiness, a high level of happiness, and mania. For example, item 1 of the OHI:

$0 \quad$ I do not feel happy.

1 I feel fairly happy.

2 I am very happy.

3 I am incredibly happy [34].

A summary happiness score is obtained by calculating the mean value of the items assessed in the factor. Factor analysis will be used to report a modified 19-item version of the $\mathrm{OHI}$ in this paper.

\subsubsection{Assessing Personality}

Various forms of Eysenck's Personality Questionnaires (EPQ) [33] were also used in these studies. The Junior and Adult versions of the Revised and abbreviated EPQs (JEPQR-A and EPQR-A) each comprise 48 questions with Yes/No responses, which yield factor scores for the personality variables Extraversion, Neuroticism, and Psychoticism, with an attendant Lie scale, which indicates social-desirability of responses $[35,36]$.

\subsection{Participants}

\subsubsection{Study 1. University Students}

The cohort in this study comprised 302 students from an Australian public university, 133 pre-service teachers from a religious university in Northern Ireland, and 31 pre-service teachers from an English public university. At the end of lectures, the university students were invited to participate in the survey comprising SHALOM, OHI, and EPQR-A, and some demographic details. The task took 10 to 15 minutes, with 80 to $90 \%$ of students participating. 


\subsubsection{Study 2. Church-Attenders}

People who attended church services in six denominations in Ballarat, Victoria were invited to complete the survey comprising SHALOM, EPQR-A, and OHI together with some demographic details. There was an 80\%-90\% participation rate with 494 respondents taking 10 to 20 minutes to complete the survey.

\subsubsection{Study 3. Secondary School Students}

Following approvals from principals, parents, and students, secondary students in three Catholic schools, six Christian Community schools, and one other non-government school in Victoria completed a survey comprising SHALOM, OHI, Junior EPQR, and some demographic variables in class, under the supervision of teachers, who followed instructions from the author. The survey took approximately 20 minutes of class time. Participation rates varied from $45 \%$ in the non-government school to $95 \%$ in the Christian Community schools, with a total of 1002, 12-18 year-olds participating.

As no significant differences were found by gender for happiness $(\mathrm{OHI})$ and relationship with God (TRAB), in any of these three studies, gender details of participants will not be shown here.

\subsection{Limitations}

The participants in each study reported here do not necessarily represent the total population from which they were drawn. The majority of participants in these studies came from Ballarat, a regional centre, 100km west of Melbourne. Ballarat has a population of 95,000, of whom 95\% are Caucasian. In Study 1- Universities, University of Ballarat supplied $65 \%$ of university students in this study. In Study 2 - Church-attenders, only Christian churches in Ballarat are represented in this study. Although Buddhist, Jewish, and Islamic groups in Melbourne were invited, circumstances did not permit their participation. In Study 3 - Secondary schools, several Jewish schools in the Melbourne area declined participation with apologies that they felt a little over-researched. Several denominational Christian church schools gave a similar reply. No response came from any of the Islamic schools in Melbourne that were invited to participate.

\section{Results and Discussion}

\subsection{Measures}

\subsubsection{Relationship with God (Transcendental Spiritual Well-Being via SHALOM)}

The five items used to assess transcendental spiritual well-being cohered strongly to yield a discreet factor which indicated levels of relationship with God among the university students, church-attenders, and secondary school students (see Table 1 for values).

\subsubsection{Personality (via Eysenck Personality Questionnaires)}

Factor analyses of the 48-item Eysenck Personality Questionnaires yielded four factors for Extraversion (sociable, sensation-seeking, carefree, and optimistic traits), Neuroticism 
(anxious, worrying, and moody traits), Psychoticism (solitary, troublesome, cruel, inhumane traits) and a Lie scale (indicating social desirability of responses) for each of the three groups reported here (see Table 1 for values).

The low alpha coefficient reported for the Psychoticism scale indicates problems associated with measuring this dimension of personality, especially among religious groups [35].

Table 1. Mean (SD) and $\alpha$ coefficients for factors on happiness, personality, and relating with God.

\begin{tabular}{l|l|llllll}
\hline & Total & \multicolumn{3}{|c}{ University students } & \multicolumn{2}{c}{ Church attendees } & \multicolumn{2}{c}{ Secondary students } \\
\hline $\mathrm{N}$ & 1952 & \multicolumn{2}{|c}{456} & \multicolumn{2}{c}{494} & \multicolumn{2}{c}{1002} \\
\hline factor & $\mathrm{M}(\mathrm{SD})$ & $\mathrm{M}(\mathrm{SD})$ & $\alpha$ & $\mathrm{M}(\mathrm{SD})$ & $\alpha$ & $\mathrm{M}(\mathrm{SD})$ & $\alpha$ \\
\hline OHI-19 & $1.54(.49)$ & $1.42(.43)$ & .89 & $1.45(.49)$ & .91 & $1.63(.50)$ & .90 \\
contentment & $1.61(.57)$ & $1.54(.51)$ & .85 & $1.65(.56)$ & .88 & $1.62(.59)$ & .86 \\
express happiness & $1.85(.52)$ & $1.79(.47)$ & .77 & $4.62(.49)$ & .82 & $1.99(.50)$ & .75 \\
quality of life & $1.15(.68)$ & $.94(.61)$ & .77 & $1.99(.50)$ & .80 & $1.29(.68)$ & .78 \\
\hline Extraversion & $8.63(3.20)$ & $8.55(3.11)$ & .84 & $6.75(3.59)$ & .84 & $9.60(2.55)$ & .78 \\
Neuroticism & $6.16(3.26)$ & $5.92(3.23)$ & .80 & $4.79(3.40)$ & .82 & $6.95(2.95)$ & .76 \\
Psychoticism & $2.69(2.17)$ & $2.56(1.87)$ & .56 & $2.19(1.57)$ & .33 & $2.99(2.48)$ & .74 \\
Lie scale & $4.09(2.53)$ & $3.80(2.32)$ & .65 & $4.95(2.90)$ & .70 & $3.79(2.33)$ & .64 \\
\hline Relate with God & $3.21(1.24)$ & $2.70(1.29)$ & .96 & $3.99(.81)$ & .90 & $3.06(1.22)$ & .94 \\
\hline
\end{tabular}

\subsubsection{Happiness (Oxford Happiness Inventory (OHI))}

The original Oxford Happiness Inventory (OHI) comprised 29 items, for which Hills and Argyle proposed a seven factor structure [31], in which some items cross-loaded onto more than one factor. In response to Kashdan's criticism of the construct of the OHI [30], factor analyses were performed here to check for consistency in structure of a happiness measure between groups of different status and age. Principal components analyses (PCA) with Varimax rotation of the OHI data for the three groups reported here showed that 19 of the items loaded consistently onto three discreet factors. These explained $42 \%$ to $47 \%$ of the variance, with the other ten items explaining another $8 \%$ to $12 \%$ of variance, but distributed inconsistently across one to three additional factors among the three groups.

The first of the three consistent factors can be called 'contentment' (comprising feel happy, optimistic, satisfied, in control, life is rewarding, pleased, life is good, find beauty, meaning and purpose), as each of these items fits well into the definition of contentment as 'an internal satisfaction that does not demand changes in external circumstances' [37]. The second set of items is self-explanatory, being called 'expressions of happiness' (comprising joy/elation, fun with others, cheerful effect, laugh, amused). The third set of items clearly reflects 'quality of life' (comprising effort, rested, energetic, mentally alert, healthy). These three factors display aspects of Diener's multi-faceted description of happiness [4], but do not match any of the original factors in the structure of $\mathrm{OHI}$ 
proposed by Hills and Argyle [31]. When these three factors were themselves subjected to PCA, they were found to cohere into a single higher-order factor, which can be called 'happiness', constituting a modified 19-item OHI (OHI-19). Confirmatory factor analysis was performed using AMOS(Analysis of Moment Structures) to investigate the construct validity of the resultant three-factor OHI-19. Values of fit indices displayed acceptability for the OHI-19, for the relative Chi-square (with $\times^{2} / \mathrm{df}=3.08$, which is $<5$ ), Normed Fit Index $=.93(>.90)$, Comparative Fit Index $=.95$ (>.93) and Root Mean Square Error Approximation $=.046(<.05)[38]$. The resultant Cronbach's alpha values for the OHI-19 were strong at $.89, .91$, and .90 for the university student, church-attenders, and secondary school samples, respectively (see Table 1 for details).

\subsubsection{Age}

Results from the three studies were combined to facilitate comparison by age, because of consistency in the instruments used to collect respondents' views.

\subsection{Identifying Variations in Happiness}

SPSS(Statistical Product \& Service Solutions) for Windows 19 was used to perform three-step hierarchical regression analyses on happiness as the dependent variable, with personality scores for Extraversion, Neuroticism, Psychoticism, and Lie scale entered in step 1, and age in step 2, and relationship with God (TRAB from SHALOM) in step 3.

Table 2. Results of hierarchical regression analyses of happiness among university and religious secondary school students and church-attenders, by personality (step 1), age (step 2), relationship with God (step 3 ) (standardized beta and $R^{2}$ values shown)

\begin{tabular}{|c|c|c|c|c|}
\hline & $\begin{array}{l}\text { Modified Oxford } \\
\text { Happiness } \\
\text { Inventory } \\
\text { OHI-19 }\end{array}$ & Contentment & $\begin{array}{l}\text { Expressions } \\
\text { of happiness }\end{array}$ & $\begin{array}{l}\text { Quality } \\
\text { of life }\end{array}$ \\
\hline Stepl $\left(R^{2}\right)$ & $(.29 * * *)$ & $(.26 * * *)$ & $(.32 * * *)$ & $(.16 * *)$ \\
\hline Extraversion & $.36 * * *$ & $.26 * * *$ & $.48 * * *$ & $.20 * * *$ \\
\hline Neuroticism & $-.31 * * *$ & $-.37 * *$ & $-.13 * * *$ & $-.25 * * *$ \\
\hline Psychoticsm & -.00 & $-.06 * *$ & -.03 & $.06 * *$ \\
\hline Lie & $.16 * * *$ & $.12 * * *$ & $.05 *$ & $.20 * * *$ \\
\hline Step $2\left(\Delta R^{2}\right)$ & $(.03 * * *)$ & $(.00 *)$ & $(.03 * * *)$ & $(.03 * * *)$ \\
\hline Age & $-.22 * * *$ & $-.08 * * *$ & $-.22 * * *$ & $-.24 * * *$ \\
\hline Step3 $\left(R^{2}\right)$ & $(.02 * * *)$ & $(.02 * * *)$ & $(.01 * * *)$ & $(.02 * * *)$ \\
\hline God (TRAB) & $.17 * * *$ & $.18 * * *$ & $.10 * * *$ & $.16 * * *$ \\
\hline
\end{tabular}

\subsubsection{Happiness and Personality}

In line with previous studies [39], the two personality constructs of Extraversion (+) and Neuroticism (-) were found to be major contributors in explaining the variance in happiness, as assessed using the modified OHI-19 (see Table 2). 
Closer inspection of the three component subscales of OHI-19 (in Table 2) revealed a comparable contribution to explanation of variance in 'contentment' and 'quality of life' by Extraversion and Neuroticism. However, it was not surprising to note the strong relationship between Extraversion and 'expressions of happiness', as both relate to positive affect.

\subsubsection{Happiness and Age}

Combination of the three projects reported here enabled investigation of happiness by age, at step 2 in the regression analysis. These studies did not support a U-shaped relationship of happiness with age. However, higher values were reported by younger respondents, with greater consistency among those aged 20 upwards (see Table 3).

Table 3. Mean (SD) values \& ANOVA (Analysis of Variance) of happiness scales by age.

\begin{tabular}{l|l|l|llr}
\hline Age & $\mathrm{N}$ & OHI-19 & Contentment & $\begin{array}{l}\text { Expressions of } \\
\text { happiness }\end{array}$ & $\begin{array}{l}\text { Quality of } \\
\text { life }\end{array}$ \\
\hline $12-17$ & 1002 & $1.63(.50)$ & $1.62(.59)$ & $1.99(.50)$ & $1.29(.68)$ \\
$18-19$ & 224 & $1.53(.44)$ & $1.61(.51)$ & $1.95(.48)$ & $1.04(.63)$ \\
$20 \mathrm{~s}$ & 275 & $1.43(.45)$ & $1.57(.53)$ & $1.74(.44)$ & $.98(.64)$ \\
$30 \mathrm{~s}$ & 124 & $1.42(.49)$ & $1.59(.61)$ & $1.62(.49)$ & $1.06(.65)$ \\
$40 \mathrm{~s}$ & 114 & $1.39(.48)$ & $1.59(.57)$ & $1.50(.47)$ & $1.09(.66)$ \\
$50 \mathrm{~s}$ & 104 & $1.38(.48)$ & $1.62(.57)$ & $1.53(.49)$ & $.98(.64)$ \\
$60+$ & 109 & $1.38(.44)$ & $1.64(.52)$ & $1.58(.44)$ & $.91(.64)$ \\
\hline total & 1952 & $1.54(.49)$ & $1.61(.57)$ & $1.85(.52)$ & $1.15(.68)$ \\
\hline ANOVA & $\mathrm{F}(6,1910)$ & 15.7 & .38 & 45.5 & 15.5 \\
& $\mathrm{p}$ & $<.001$ & $.90^{\mathrm{ns}}$ & $<.001$ & $<.001$ \\
\hline
\end{tabular}

In particular, teenagers reported greater 'expressions of happiness' and 'quality of life' than older respondents, with consistent measures of 'contentment' being reported across the age span.

\subsubsection{Happiness, Personality, Age, and Relation with God}

After controlling for personality and age, step 3 of the multiple regression analysis revealed that relationship with God explained small, yet significant, additional variance in happiness among the populations studied here. In other words, it appears that people who have positive relationship with God also have greater contentment and higher quality of life. They show greater expressions of happiness as well (see Table 2). These findings complement the formative work by Francis and others [29], and extend it by considering the additional effect of age. Further studies are warranted with more diverse populations to check the consistency of these findings, using the modified Oxford Happiness Inventory, Eysenck's Personality Questionnaires together with the spiritual well-being questionnaire called SHALOM. 


\section{Conclusions}

In light of diversity in findings from previous studies of religiosity and church attendance with happiness and well-being, a direct measure of relationship with God was used here, instead of potentially flawed methods of assuming that religious activities, such as church attendance and religious affiliation, necessarily imply relationship with God. To this end, the importance of relating with God was assessed by the transcendental domain of the Spiritual Well-Being Questionnaire, called SHALOM. Happiness is a multi-faceted construct, often referred to as subjective well-being, assessed here using a modified 19item Oxford Happiness Inventory (OHI-19), in which Factor Analysis revealed three components, called 'contentment', 'expressions of happiness', and 'quality of life'. The happiness scales (OHI-19 and its three subsets) all related positively with Extraversion and negatively with Neuroticism, as measured by Eysenck's Personality Questionnaires. The younger secondary school students reported greater happiness than the other participants in these studies. This work has shown that relating with God provided additional, small yet significant, explanation of variance in happiness, over and above that by personality and age.

Given the relatively small size of groups reported on here, additional replication studies are needed, with the instruments employed here, to check if a significant positive relationship between happiness and relationship with God is consistently shown among other people in other places.

\section{Postscript}

One of the reviewers raised the question as to how this paper relates to Piedmont's claim that spirituality represents an additional factor of personality [40]. As that question is tangential to the key focus of this paper, comments will be made in this postscript. An opposing view to Piedmont's is presented by Unterrainer et al. who claim 'religiosity could be understood as a personality trait..., whereas spirituality or the amount of Spiritual Well-Being might be better conceived as a distinctive indicator of subjective well-being' ([41], p. 124). Subjective well-being is often equated with happiness. In my work, spirituality is based on Fisher's definition:

Spirituality is concerned with a person's awareness of the existence and experience of inner feelings and beliefs, that give purpose, meaning and value to life. Spirituality helps individuals to live at peace with themselves, to love (God and)* their neighbour, and to live in harmony with the environment. For some, spirituality involves an encounter with God, or transcendent reality, which can occur in or out of the context of organised religion, whereas for others, it involves no experience or belief in the supernatural (NB $*$ These words are placed in parentheses as they will be meaningless to those people who do not relate with [or believe in] God ([1], p. 190).

This definition underpinned the development of the Spiritual Well-Being Questionnaire (called SHALOM) used in this study. Previous research has shown that the Personal, Communal, and Environmental domains of spiritual well-being explain variance in happiness over and above personality [32]. This study showed that the fourth domain of spiritual well-being, relating with God, does likewise. So, spiritual well-being is definitely related to happiness, or subjective well-being. The four domains of spiritual 
well-being are expressions of who a person is at their very core, or heart level. Therefore these features could fit with a definition of personality, described as 'a dynamic and organized set of characteristics possessed by a person who uniquely influences his or her cognitions, emotions, motivations, and behaviors in various situations' [42]. If personality is an enduring feature of a person, and relating with God has been shown to lead to change in people's lives, would this indicate that relating with God (one aspect of spirituality) leads to change in personality? Or, that spirituality/spiritual well-being per se is an aspect of personality? Further work is needed to clarify the relationship between personality and spiritual well-being.

Conflict of Interest The author declares no conflict of interest.

\section{References}

1. John W. Fisher. "Spiritual health: Its nature and place in the school curriculum." $\mathrm{PhD}$ Thesis, University of Melbourne, 1998. Available online: http://eprints.unimelb.edu.au/archive/00002994/ (accessed on 2 December 1999).

2. John Fisher. "Development and application of a spiritual well-being questionnaire called SHALOM.” Religions 1 (2010): 105-21.

3. Adrian Furnham, and Irene Christoforou. "Personality traits, emotional intelligence, and multiple happiness." North American Journal of Psychology 9 (2007): 439-62.

4. Ed Diener. "Subjective well-being." Psychological Bulletin 95 (1984): 542-75.

5. Michael Argyle, Maryanne Martin, and Jill Crossland. "Happiness as a function of personality and social encounters." In Recent Advances in Social Psychology: An International Perspective. Edited by Joseph P. Forgas, J. Michael Innes. Amsterdam: Elsevier Science, 1989, 189-203.

6. Leslie J. Francis, Laurence B. Brown, David Lester, and Ronald Philipchalk. "Happiness as stable extraversion: A cross-cultural examination of the reliability and validity of the Oxford Happiness Inventory among students in the U.K., U.S.A., Australia and Canada." Personality \& Individual Differences 24 (1998): 167-71.

7. Leslie J. Francis, and Yaacov J. Katz. "Internal consistency, reliability and validity of the Hebrew translation of the Oxford Happiness Inventory." Psychological Reports 87 (2000): 193-96.

8. Leslie J. Francis. "Happiness is a thing called stable extraversion.” Personality \& Individual Differences 24 (1999): 5-11.

9. Vassilis Saroglou, V. "Religion and the five factors of personality: A meta-analytic review." Personality \& Individual Differences 32 (2002): 15-25.

10. Jude M. Henningsgaard, and Randolph C. Arnau. "Relationships between religiosity, spirituality, and personality: A multivariate analysis." Personality \& Individual Differences 45 (2008): 703-08.

11. Ed Diener, Eunkook M. Suh, Richard E. Lucas, and Heidi, L. Smith. "Subjective well-being: Three decades of progress." Psychological Bulletin 125 (1999): 276302.

12. Kosei Fukuda. "A happiness study using age-period-cohort framework." Journal of Happiness Studies 14 (2013): 135-153. 
13. Joppe de Ree, and Rob Alessie. "Life satisfaction and age: Dealing with underidentification in age-period-cohort models." Social Science \& Medicine 73 (2011): 177-82.

14. Paul Fritjers, and Tony Beatton. "The mystery of the U-shaped relationship between happiness and age." Journal of Economic Behavior \& Organization 82 (2012): 52542.

15. Jacqueline L. Noffke, and Susan H. McFadden. "Denominational and age comparisons of God concepts." Journal for the Scientific Study of Religion 40 (2001): 747-56.

16. Ellen Childs. "Religious attendance and happiness: Examining gaps in the current literature - A research note." Journal for the Scientific Study of Religion 49 (2010): 550-60.

17. Christopher G. Ellison, Jason D. Boardman, David R. Williams, and James S. Jackson. "Religious involvement, stress, and mental health: Findings from the 1995 Detroit area study." Social Forces 80 (2001): 215-49.

18. Joanna Maselko, and Laura D. Kubzansky. "Gender differences in religious practices, spiritual experiences and health: Results from the US General Social Survey." Social Science \& Medicine 62 (2006): 2848-60.

19. Leslie J. Francis, Hans-Georg Ziebertz, and Christopher A. Lewis. "The relationship between religion and happiness among German students." Pastoral Psychology 51 (2003): 273-81.

20. Leslie J. Francis, Ahto Elken, and Mandy Robbins. "The affective dimension of religion and personal happiness among students in Estonia." Journal of Research on Christian Education 21 (2012): 84-90.

21. Ahmed M. Abdel-Khalek. "The relationships between subjective well-being, health, and religiosity among young adults from Qatar." Mental Health, Religion \& Culture 16 (2013): 306-18.

22. Lisa Miller, and Brien S. Kelley. "Relationships of religiosity and spirituality with mental health and psychopathology." In Handbook of the Psychology of Religion and Spirituality. Edited by Raymond F. Paloutzian, and Crystal L. Park. New York: Guilford, 2005, 460-78.

23. Joseph W. Ciarrochi, and Erin Deneke. "Hope, optimism, pessimism, and spirituality as predictors of subjective well-being controlling for personality." Research in the Social Scientific Study of Religion 16 (2005): 160-83.

24. Brenda R. Jackson, and Cindy S. Bergeman. How does religiosity enhance wellbeing? The role of perceived control." Psychology of Religion \& Spirituality 3 (2011): 149-61.

25. Ian T. Williamson, and Steven J. Sandage. "Longitudinal analyses of religious and spiritual development among seminary students." Mental Health, Religion \& Culture 12 (2009): 787-801.

26. Mark D. Holder, Ben Coleman, and Judi M. Wallace. "Spirituality, religiousness and happiness in children aged 8-12years.” Journal of Happiness Studies 11 (2010): 131-50.

27. Commonwealth of Australia. Australian Census data. Available online: http:www.abs.gov.au/AUSSTATS (accessed on 30 May 2013). 
28. Christopher A. Lewis, and Sharon M. Cruise. "Religion and happiness: Consensus, contradictions, comments and concerns." Mental Health, Religion \& Culture 9 (2006): 213-25.

29. Leslie J. Francis, Susan H. Jones, and Carolyn Wilcox. "Religiosity and happiness: During adolescence, young adulthood, and later life." Journal of Psychology \& Christianity 19 (2000): 245-57.

30. Todd B. Kashdan. "The assessment of subjective well-being (issues raised by the Oxford Happiness Questionnaire).” Personality \& Individual Differences 36 (2004): 1225-32.

31. Peter Hills, and Michael Argyle. "Positive moods derived from leisure and their relationship to happiness and personality." Personality \& Individual Differences 25 (1998): 523-35.

32. Rapson Gomez, and John W. Fisher. "Domains of spiritual well-being and development and validation of the Spiritual Well-Being Questionnaire." Personality \& Individual Differences 35 (2003): 1975-91.

33. Hans J. Eysenck, and Michael W. Eysenck. Personality and Individual Differences: A natural science approach. New York: Plenum Press, 1985.

34. Michael Argyle, and Peter Hills. "Religious experiences and their relations with happiness and personality." International Journal for the Psychology of Religion 10 (2000): 157-72.

35. Leslie J. Francis, Ronald Philipchalk, and Laurence B. Brown. "The comparability of the short form EPQ-R with the EPQ among students in England, the U.S.A., Canada and Australia." Personality \& Individual Differences 12 (1991): 1129-32.

36. Leslie J. Francis. "The development of an abbreviated form of the Revised Junior Eysenck Personality Questionnaire (JEPQR-A) among 13-15 year-olds.” Personality \& Individual Differences 21 (1996): 835-44.

37. Chad O. Brand, Charles W. Draper, Trent C. Butler, and Archie W. England, (Eds). Holman Illustrated Bible Dictionary. Nashville, TN: Holman Bible Publishers, 2003.

38. Lawrence S. Meyers, Glenn Gamst, and Anthony J. Guarino. Applied Multivariate Research: Design and Interpretation, 2nd ed. Thousand Oaks, CA: Sage Publications, 2013.

39. Helen Cheng, and Adrian Furnham. "Personality, self-esteem, and demographic predictions of happiness and depression." Personality \& Individual Differences 34 (2003): 921-42.

40. Ralph L. Piedmont. "Does spirituality represent the sixth factor of personality? Spiritual transcendence and the Five-Factor Model.” Journal of Personality 67 (1999): 985-1013.

41. Human-Friedrich Unterrainer, Karl H. Ladenhauf, K.H., Sandra J. Waller-Liebman, and Andreas Fink. "Different types of religious/spiritual well-being in relation to personality and subjective well-being." International Journal for the Psychology of Religion 21 (2011): 115-26.

42. Wikipedia. "Personality psychology." Available online: http://en.wikipedia.org/wiki/Personality_psychology (accessed on 30 May 2013). 


\subsection{Summary of chapter 6}

The papers presented in this chapter show that SHALOM is a sensitive instrument for investigating the influence of spiritual well-being on other aspects of life such as satisfaction in the workplace and happiness. The Transcendental domain of SHALOM (relating with God) is particularly useful for explaining additional variance in happiness over and above that explained by personality and age. 


\section{Chapter 7. Synthesis of Studies}

\subsection{Introduction}

In Chapters 3 to 6, findings were presented from several of my studies in spiritual wellbeing, especially into the relationship with God of university students and school education, of healthcare workers and in a broader section of the community. In each of these studies I used the SHALOM research instrument. This chapter provides an overview of the further development and application of SHALOM in Australia and overseas. It also details the double-response technique which I propose is a better method of assessing the quality of relationships that comprise spiritual well-being. A new spiritual well-being questionnaire presented here will also be compared with the SHALOM instrument.

\subsection{Development and application of SHALOM}

\section{Background}

Following publication of my Four Domains Model of Spiritual Health/Well-Being in 1998, which is presented and discussed in Chapter 2 herein, I worked on developing suitable quantitative measures to assess spiritual well-being. This work led to the emergence of SHALOM in 1999. My publications using SHALOM and my articles on the psychometric properties of its lived experience components, reported as the Spiritual Well-Being Questionnaire (SWBQ) (Gomez \& Fisher, 2003, 2005 a \& b), have resulted in more than 400 requests from researchers who have wanted to use it in studies in Australia and overseas, in 23 languages. Researchers requesting a copy of SHALOM are sent the instrument, together with an information sheet which I regularly update (copy in Appendix C). Further email communication often ensues and I usually provide help to plan projects. Some researchers are also given assistance with analysis of data, others with interpreting findings. The 'cost' to these researchers of using SHALOM is an agreement that they will provide me with feedback on its usefulness.

\section{Key points extracted from this paper}

- Only a fraction of all the requests that I have received to use SHALOM have so far resulted in completed studies and publications based on SHALOM. Requests I have made for feedback, always at least 12 months after the researcher received SHALOM, have resulted in nearly a third of recipients either not being available or not replying to me. A further quarter has explained that, for various reasons, 
they did not use SHALOM. A few replied that they used the theoretical base to develop their own measures, and the remainder either provided a report of the work they did or are still working on their research.

- The Personal and Communal domains of spiritual well-being are well embraced by most people, which is shown by the relatively high scores most people ascribe to these domains when using SHALOM.

- People seem to be responding favourably to expressing the quality of their relationships with the Environment for spiritual well-being.

- A marked divergence of views is apparent in participants' responses to items related to the Transcendental domain of spiritual well-being (relating with God).

- A few researchers either added or changed items in SHALOM without reporting appropriate statistical tests upon the new measures thus created.

\section{Implications}

Many researchers, who may well have the best of intentions, do not always complete their projects or obtain usable results.

The SWBQ/SHALOM instrument is a useful indicator, not an exhaustive measure, of spiritual well-being. It should be employed without adjustment in order to enhance comparison of results of new studies with those currently available, and to compile a valuable bank of results to aid wider understanding of spiritual well-being. If researchers wish to add to the 20-item SHALOM instrument, they can do so. However, they should test and report the psychometric properties and change the instrument's name, because any change to, or addition of, items yields a new instrument and the results cannot be compared with existing studies using SHALOM.

Because quite a number of researchers requesting SHALOM did not provide feedback on their results, which was a condition of its provision, I have considered charging for its use. However, that would penalise researchers from poor countries, many of whom have sought the use of SHALOM. Just as God's peace and blessing (shalom) is provided freely, so too is SHALOM. Whether recipients appropriate either or both for their well-being is up to them.

\section{Paper:}

This paper was first published as: Fisher, J. (2010) Development and application of a spiritual well-being questionnaire called SHALOM. Religions, 1: 105-121. 
However, the copy presented here is an expanded and updated version, submitted for publication as a book chapter: Fisher, J. (2014?) Engaging with a Spiritual Well-Being Questionnaire called SHALOM, in Büssing, A. (ed.) Spirituality and health (e-book under construction).

\title{
Engaging with a Spiritual Well-being Questionnaire Called SHALOM
}

\section{John Fisher ${ }^{1,2}$}

${ }^{1}$ Faculty of Education \& Arts, Federation University Australia, Victoria, Australia; email: j.fisher@federation.edu.au; Tel.: +61-4-3839-5915; Fax: +61-3-5320-3763

${ }^{2}$ Rural Health Academic Centre, Faculty of Medicine, University of Melbourne; e-mail: jwfisher@unimelb.edu.au

\begin{abstract}
The Four Domains Model of Spiritual Health and Well-Being was used as the theoretical base for the development of several spiritual well-being questionnaires, which culminated in the Spiritual Health And Life-Orientation Measure (SHALOM). SHALOM comprises 20 items with five items reflecting the quality of relationships of each person with themselves, with other people, with the environment, and/or with God, in the Personal, Communal, Environmental and Transcendental domains of spiritual well-being, respectively. SHALOM has undergone rigorous statistical testing in several languages. This instrument has been used in education, healthcare and wider community settings, having been sought for 400 studies in 22 languages. SHALOM provides a unique way of assessing spiritual well-being as it compares each person's ideals with their lived experiences, providing a measure of spiritual harmony or dissonance in each of the four domains. A generic form of SHALOM has recently been developed, in which reference to God has been expanded to include other Transcendents.
\end{abstract}

Keywords: spiritual well-being; assessment; SHALOM; spiritual harmony/ dissonance ; Transcendent

\section{Introduction}

It is not easy working out how to assess spiritual well-being (SWB). Some researchers have attempted to employ a single question to capture the essence of this complex construct $[1,2]$. One such study defined spirituality as 'personal beliefs in God or a higher power' [3]. These authors criticized their own single-item measure and their 'theistic conceptualization' of spirituality, concluding, 'The scientific community must seek to produce indicators to accurately reflect how youth experience spirituality in their own lives, rather than trying to categorize them according to outdated indicators of "religiosity".'

Many attempts at assessing spirituality and spiritual health/well-being (SH/WB) reported in the literature range from single item measures to one with 156 items [4-11]. It 
is difficult to make sense of this diversity of research because the conceptual bases upon which the research is founded vary markedly between studies [12].

Much of the research confounds spirituality and religion. Although there are commonalities between these two constructs, many authors agree they are not synonymous [6-8, 13-18]. Researchers must attempt to remain aloof from their personal world-views as far as they possibly can so as not to allow their ideologies to constrain research projects associated with SWB, e.g., privilege religion or deny its relevance to some people. All measurement devices are built on a values base (generally the researcher's), and most instruments present norms for populations studied. Norms vary so much between groups so that what appears to be positive for SWB in one group might have negative implications in another. Furthermore, each group believes that its own criteria for 'true' spirituality is better than everyone else's and should possibly be the normative base for all humanity. Investigating spirituality is complicated because any measure cannot be perfect, and it only reflects the phenomenon or its consequences, because it cannot be measured directly [7].

Most measures are self-reports, but they might not reflect reality, because "feeling well is not necessarily being well". It is essential to check the validity of any instrument used. Does it "genuinely measure spirituality or its components?"[7]. The power of a questionnaire depends on its theoretical base and the rigour with which it is developed and tested [18].

Nearly all available religiosity/spirituality measures ask people for a single response about 'lived experience' on a series of questions [19]. In the best instruments, these questions are built on theoretical frameworks of relationships between spirituality and health that are considered important by the developers of the scales. The 'scores' thus obtained are limited indicators of spiritual health or well-being, especially if they only have a handful of items [20]. As mentioned above, the notion of a group norm of spiritual health is also problematic. People's spiritual health depends on their world-view and beliefs as well as lived experience [14, 21], so development of a single measure, which purports to be an objective standard by which to compare people, challenges the multifaceted nature of spiritual health.

A clear conceptual foundation is needed upon which to develop a sound measure of SWB. The Spiritual Well-Being Scale is a commonly used instrument in the US, comprising two 10-item measures, one for Existential Well-Being, the other for Religious Well-Being [22]. This scale was considered too God-oriented for use with increasingly secular Australians, although it was used to validate SHALOM during its development. Some factor analyses on the SWBS have questioned the validity of the proposed factor structure for differing populations [23, 24] and ceiling effects have been noted, especially for the RWB factor among highly religious groups [25]. Nevertheless the SWBS had been used in 182 studies by 2007 [26].

\section{Four Domains Model of Spiritual Health and Well-Being (4D model of SH/WB)}

Ellison suggested that spiritual well-being "arises from an underlying state of spiritual health and is an expression of it, much like the color of one's complexion and pulse rate are expressions of good [physical] health"[22]. Fehring, Miller and Shaw supported this 
view by adding, "spiritual well-being is an indication of individuals' quality of life in the spiritual dimension or simply an indication of their spiritual health" [27].

Although Ellison only used two facets of SWB in the SWBS, four main themes appear in the framework definition of spiritual well-being proposed by the National Interfaith Coalition on Aging (NICA), in Washington DC: "the affirmation of life in a relationship with God, self, community and environment that nurtures and celebrates wholeness" [28]. An extensive review of literature revealed that these four sets of relationships are the key features mentioned when discussing spiritual well-being over the last three decades [15, 19, 22, 29-31]. Detailed descriptions of these four domains of spiritual health were developed from interviews with 98 educators from 22 secondary schools (State, Catholic and Independent) in Victoria, Australia, together with surveys from 23 Australian experts [21]. The following definition was derived, in which spiritual health is described as:

a, if not the, fundamental dimension of people's overall health and well-being, permeating and integrating all the other dimensions of health (i.e., physical, mental, emotional, social and vocational). Spiritual health is a dynamic state of being, shown by the extent to which people live in harmony within relationships in the following domains of spiritual well-being:

Personal domain - wherein one intra-relates with oneself with regards to meaning, purpose and values in life. Self-awareness is the driving force or transcendent aspect of the human spirit in its search for identity and self-worth.

Communal domain - as shown in the quality and depth of interpersonal relationships, between self and others, relating to morality, culture and religion. These are expressed in love, forgiveness, trust, hope and faith in humanity.

Environmental domain - beyond care and nurture for the physical and biological, to a sense of awe and wonder; for some, the notion of unity with the environment.

Transcendental domain - relationship of self with some-thing or some-One beyond the human level (ie, ultimate concern, cosmic force, transcendent reality or God). This involves faith towards, adoration and worship of, the source of Mystery of the universe [21].

This definition outlines the inter-connective and dynamic nature of spiritual health, in which internal harmony depends on intentional self-development, coming from congruence between expressed and experienced meaning, purpose and values in life at the Personal level. This intentional self-development often eventuates from personal challenges, which go beyond contemplative meditation, leading to a state of bliss, perceived by some as internal harmony.

Morality, culture and religion are included in the Communal domain of spiritual health, in accord with Tillich's view that the three interpenetrate, constituting a unity of the spirit, but "while each element is distinguishable, they are not separable" [32]. In the work presented here, religion (with small ' $r$ ') is construed as essentially a human, social activity with a focus on ideology and rules (of faith and belief systems), as distinct from a 
relationship with a Transcendent Other such as that envisioned in the Transcendental domain of spiritual health. Whilst it is acknowledged that the ideals of most religions would embrace relationships with both horizontal and vertical aspects, the two are separated for emphasis in this model.

\section{Development of Measures}

A search in 2009 revealed nearly 190 quantitative measures of spirituality and/or Spiritual Health/Well-Being (SH/WB) in available literature published since 1967 [33]. These have been critiqued in light of the four domains model of spiritual health and well-being. Many more religiosity measures have also been reported [4, 5]. Four measures based directly upon the 4D model of SH/WB are:

\subsection{Spiritual Health in Four Domains Index (SH4DI)}

The Spiritual Health in Four Domains Index (SH4DI) was developed by overlaying the 4D model of SH/WB on a selection from 150 items used to study spirituality among 311 primary teachers in the UK [34]. Exploratory factor analyses were used to establish four factors in the SH4DI, each comprised of 6 items, with response sets on a 5-point Likert scale. Another study of mainly pastoral carers (in 1998) in a variety of Victorian schools led to a refinement of the SH4DI, by introducing two levels of response for each item [35]. This study contained 8 items representing each of the four domains with 5-point Likert scales (ranging from 'very high' to 'very low').

\subsection{Spiritual Health And Life-Orientation Measure (SHALOM)}

The title SHALOM was chosen to represent the very essence of SWB. The Hebrew word Shalom means "completeness, wholeness, health, peace, welfare, safety, soundness, tranquility, prosperity, fullness, rest, harmony, the absence of agitation or discord.' (Strong's Concordance - Ref. 7965, 1979). The acronym SHALOM reveals its two components - Spiritual Health measure (SHM) And Life-Orientation Measure (LOM). The LOM elicits the 'ideals' people have for SH in four sets of relationships with self, others, environment and/or God. The SHM asks people to reflect on 'lived experience/how they feel each item reflects their personal experience most of the time.'

SHALOM was developed in the belief that an instrument based on input from 850 secondary school students with diverse cultural and religious backgrounds should have appropriate language and conceptual clarity for studies of SWB within general populations and individuals, from teens to the twilight years [36]. An initial selection of 60 items derived from the 4D model of spiritual health was reduced to the 20-item SHALOM using exploratory factor analysis (Table 1). The 5 items in each of four domains of SH were scored using Likert scale responses from $1=$ very low to $5=$ very high.

The 'lived experience' component of SHALOM has been extensively tested and reported as the Spiritual Well-Being Questionnaire (SWBQ) [37-39]. In hindsight, it would have been better to have referred to this part of SHALOM as the Spiritual Health Measure to avoid any potential confusion with Moberg's instrument called SWBQ, which has 42-items distributed across 7-factors [40]. Some confusion could also possibly occur 
with Ellison's Spiritual Well-Being Survey (SWBS) [22], which shares three quarters of its name with the SWBQs.

Table 1. Items comprising four domains of spiritual well-being in SHALOM.

\begin{tabular}{|l|l|}
\hline Personal & Communal \\
\hline sense of identity & love of other people \\
\hline self-awareness & forgiveness toward others \\
\hline joy in life & trust between individuals \\
\hline inner peace & respect for others \\
\hline meaning in life & kindness toward other people \\
\hline Environmental & Transcendental \\
\hline connection with nature & personal relationship with the Divine/God \\
\hline awe at a breathtaking view & worship of the Creator \\
\hline oneness with nature & oneness with God \\
\hline harmony with the environment & peace with God \\
\hline sense of 'magic' in the environment & prayer life \\
\hline
\end{tabular}

Confirmatory factor analyses were performed on the SWBQ using data from 4462 nurses and carers, university students and staff, school students and teachers, employees in a manufacturing plant and church-attendees. The SWBQ showed good reliability (Cronbach's alpha, composite reliability and variance extracted) as well as (construct, concurrent, discriminant, predictive) validity [37]. Factorial independence from personality shown by the SWBQ indicates that it does more than just 'religify' existing personality constructs [Van Wicklin, cited in 41]. Some researchers have tried to equate spiritual well-being with mental well-being [42, 43]. However, Rowold has recently provided evidence that the German version of the SWBQ/SHALOM scales are independent of mental, as well as physical and emotional well-being, adding to our 'knowledge about the validity of the construct of spiritual well-being' [44]. The stringent process applied to the development of SWBQ/SHALOM yielded salient features of each of the domains to make the overall instrument a balanced, sensitive, flexible tool for assessing spiritual health and well-being, tapping into features beyond mental, emotional and physical well-being.

With only 20 items, SWBQ/SHALOM cannot be considered an exhaustive measure of SH/WB. If carers and clients have time, as well as confidential relationships, it is possible to use suitable qualitative procedures to mine the depths of people's SH/WB [45]. Rather than taking considerable time for an in-depth qualitative assessment, 
possibly hours, in 5-10 minutes plus 5 minutes scoring time the SWBQ/SHALOM provides an effective means of indicating key aspects of these four domains of SH/WB.

Some people believe that a wholesome relationship with oneself is all that is necessary for SH/WB [46]. Other people believe that you can only truly be yourself in relation with others [47]. Increasing numbers of Westerners are beginning to note what has been recognised by Indigenous peoples and many Easterners for some time, in that it is important to relate with the environment not only for sustenance but also for the wellbeing of humanity. Relating with a Transcendent Other/God is considered part of, but not restricted to, religious practice. Some studies have introduced terms such as 'higher power' to replace 'God' in attempts to be more inclusive and/or less offensive to nontheists [48]. In the development of SHALOM, terms such as 'godlike force' and 'supernatural power' were trialed but found wanting as they were not meaningful to teenagers (and therefore a range of adults?). Whether theistic, or not, nearly all people have a concept of 'God.' As they compare their ideals with their lived experience, it is up to each person to define their own meaning for each notion under investigation. For example, many different religions and denominations exist because of people's differing views. A brief question about religion is asked in the demographic section of the author's surveys, along with gender and age, but religion per se is not included in the SWBQ/SHALOM.

In a recent review of 'ten questionnaires that address spirituality as a universal human experience', the SWBQ was judged to be the only instrument that had proven validity and reliability and was promising for easy administration in clinical nursing investigations [49].

3.3 Feeling Good, Living Life is a 16-item measure designed for use with children aged 4 to 12 years [50]. It uses more concrete language to express concepts than that employed in SHALOM.

3.4 Francis et al. used the theoretical basis of the 4D model of SH/SWB to develop a 28-item questionnaire that they employed in studies of youth spirituality in the UK [51,52].

\section{Applications of the Spiritual Well-Being Questionnaires}

All people requesting information about the SH4DI or the SWBQ/SHALOM are sent a copy of SHALOM, with references to the theoretical model underpinning it, and papers describing its application, together with a scoring key. The 'cost' of receiving this material from the author is agreement to provide comments on the instrument's usefulness. Over 400 requests have so far been received for copies of SHALOM in 23 languages. However, less than half of all requests translate into completed projects. With follow-up e-mails being sent to recipients of SHALOM over 12 months after the original communication, about 20 per cent were no longer at the stated e-mail address and 15 per cent did not reply to e-mails, even though their addresses still seemed to be 'active.'

Various reasons were provided for non-completion of projects - some because the projects changed and a few because they were cancelled; a small number used the information for reference only; five people used the material as a basis for developing their own research procedures and/or instruments; one person withdrew due to ill health; 
two could not use it because of 'separation of church and state' issues in public schools in the USA; two could not see any way of changing current practice in their health services; one thought it was not suitable for use with old people in Scotland (although SHALOM has been successfully used elsewhere with people aged into their 80s); one reported undefined difficulties by 11-13 year-olds in the USA (in spite of successful use in Australia with this age group [53,54] and even with 8-12 year-olds in Canada [55]); a Thai person wanted to use a specifically Thai instrument and two studies with Indigenous people (New Zealand and Canada) wanted more culturally-specific content.

Table 2. SWB levels among school students and staff using the SWBQ.

\begin{tabular}{|c|c|c|c|c|c|c|c|c|c|c|c|}
\hline \multirow{2}{*}{\multicolumn{2}{|c|}{ SCHOOLS }} & & & \multicolumn{8}{|c|}{ Four Domains of SWB } \\
\hline & & & & \multicolumn{2}{|c|}{ PER } & \multicolumn{2}{|c|}{$\mathrm{COM}$} & \multicolumn{2}{|c|}{ ENV } & \multicolumn{2}{|c|}{ TRA } \\
\hline ref & sample & country & $\mathrm{n}$ & mean & SD & mean & SD & mean & SD & mean & SD \\
\hline \multicolumn{12}{|c|}{ students } \\
\hline \multirow[t]{4}{*}{53} & Sec-State & Aus & 141 & 3.58 & .78 & 3.77 & .70 & 3.24 & .89 & 2.57 & 1.01 \\
\hline & Catholic & & 225 & 3.83 & .79 & 3.92 & .66 & 3.29 & .93 & 2.79 & 1.03 \\
\hline & CCS & & 380 & 3.67 & .68 & 3.79 & .72 & 2.94 & .99 & 3.88 & .93 \\
\hline & Independent & & 103 & 3.80 & .84 & 3.96 & .70 & 3.25 & .77 & 2.65 & 1.06 \\
\hline \multirow[t]{3}{*}{54} & Sec Catholic & Aus & 464 & 3.88 & .77 & 4.05 & .73 & 3.24 & .88 & 2.66 & 1.07 \\
\hline & CCS & & 369 & 3.76 & .69 & 4.00 & .63 & 2.77 & .96 & 3.92 & .95 \\
\hline & Independent & & 169 & 3.74 & .71 & 3.95 & .75 & 3.07 & .85 & 2.30 & 1.07 \\
\hline \multirow[t]{4}{*}{55} & Primary prF & Canada & ) & 3.79 & .54 & 3.71 & .70 & 3.79 & .81 & 3.69 & .85 \\
\hline & prM & & ) 320 & 3.90 & .65 & 3.71 & .75 & 3.14 & .85 & 3.90 & .60 \\
\hline & $\mathrm{puF}$ & & ） & 3.90 & .70 & 4.00 & .59 & 3.65 & .78 & 3.31 & 1.01 \\
\hline & puM & & ) & 3.76 & .66 & 3.76 & .59 & 3.23 & .87 & 2.99 & 1.10 \\
\hline 56 & Sec Anglican & UK & 796 & 3.40 & .76 & 3.67 & .68 & 2.48 & .96 & 1.82 & 1.05 \\
\hline 57 & Sec Angl F & UK & 228 & 4.00 & .86 & 4.24 & .72 & 3.19 & .97 & 2.73 & 1.26 \\
\hline 58 & Secondary & Spain & 114 & 3.75 & .80 & 3.82 & .69 & 3.18 & .92 & 2.65 & 1.17 \\
\hline \multirow[t]{3}{*}{59} & Sec nonrelig & Hong & 305 & 3.53 & .80 & 3.59 & .78 & 3.00 & .85 & 2.51 & 1.05 \\
\hline & Relig schl1 & Kong & 341 & 3.73 & .65 & 3.75 & .63 & 3.25 & .75 & 3.09 & 1.01 \\
\hline & Relig schl2 & & 409 & 3.57 & .71 & 3.66 & .67 & 3.18 & .71 & 2.72 & 1.06 \\
\hline 60 & Secondary & HK & 14828 & 3.54 & .78 & 3.64 & .76 & 3.10 & .85 & 2.71 & 1.03 \\
\hline 61 & Secondary & Aus & 114 & 3.86 & .68 & 4.12 & .56 & 3.54 & .85 & 3.14 & .97 \\
\hline \multicolumn{12}{|c|}{ staff } \\
\hline 62 & Pre-schl trs & HK & 146 & 3.92 & .62 & 3.97 & .57 & 3.68 & .63 & 3.30 & .97 \\
\hline \multirow[t]{3}{*}{35} & Tr State & Aus & 41 & 3.87 & .58 & 4.09 & .67 & 3.10 & .83 & 2.54 & 1.08 \\
\hline & Independent & & 53 & 4.06 & .62 & 4.21 & .59 & 3.29 & .77 & 3.58 & 1.07 \\
\hline & Catholic & & 49 & 4.34 & .52 & 4.41 & .47 & 3.72 & .67 & 3.89 & .75 \\
\hline \multirow[t]{4}{*}{63} & Tr State & Aus & 68 & 4.18 & .64 & 4.36 & .59 & 3.81 & .91 & 2.32 & 1.28 \\
\hline & Independent & & 253 & 4.07 & .64 & 4.24 & .60 & 3.64 & .85 & 3.40 & 1.19 \\
\hline & Catholic & & 163 & 4.17 & .59 & 4.33 & .53 & 4.02 & .70 & 3.59 & .92 \\
\hline & CCS & & 335 & 4.01 & .57 & 4.15 & .54 & 3.21 & .88 & 4.21 & .63 \\
\hline
\end{tabular}

NB CCS $=$ Christian Community Schools $\mathrm{F}=$ Female, $\mathrm{M}=$ Male Aus=Australia $\mathrm{pr}=$ private, $\mathrm{pu}=$ public $\mathrm{stu}=$ students $\mathrm{tr}=$ teacher prim $=$ primary $\mathrm{PER}=$ Personal $\mathrm{COM}=\mathrm{Com} \mathrm{ENV}=$ Environmental $\mathrm{TRA}=$ Transcendental

The main problem with using a particular measure is that the results cannot be compared with other research or groups. Moberg has emphasized the need to 'combine particularistic and universal strategies for clinical assessments and scientific research' in SWB [7]. The SWBQ/SHALOM provides a valuable base for the universal study of SH/WB. Points of particular concern are easily employed in auxiliary questions, e.g., in questioning ways in which SWB is enhanced, items can include ancestor worship, importance of place, totem, sacred writings, symbols or rituals, etc. The item scores can 
then be correlated with the four SH/WB domain scores, and gender, personality, happiness, etc and for comparison between groups.

Work is still in progress, with no reports yet from many of the recent studies, including 55 requests from 21 countries in 2013.

Reports have been received from 51 studies, in five of which researchers only reported $\alpha$-values for the four domains of SH/WB and/or correlation values with other personal characteristics, but not mean values for domain scores. As many researchers seem constrained by the notion of norms, mean values for the four domains of SWB (plus SD where available) from the above studies are listed in the following tables. Care should be taken in interpreting these data as they do not claim to be representative of the populations studied and some sub-groups are small in size.

Although SHALOM was developed for use with secondary school students and adults, a Canadian study reports its effective use in a study of SWB and happiness with primary school children aged 8 to 12 years [55]. The papers referenced in Table 2 provide a basis for discussion of the variations between groups of students and staff. Many instruments are developed using university student populations, especially psychology students, because they are often given course credit for participation in research projects. Selection of these students provides a particular bias to research, as does use of other convenience samples.

Table 3. SWB levels among university students using the SWBQ.

\begin{tabular}{|c|c|c|c|c|c|c|c|c|c|c|c|}
\hline \multirow{2}{*}{\multicolumn{4}{|c|}{ UNIVERSITY }} & \multicolumn{8}{|c|}{ Four Domains of SWB } \\
\hline & & & & \multicolumn{2}{|c|}{ PER } & \multicolumn{2}{|c|}{ COM } & \multicolumn{2}{|c|}{ ENV } & \multicolumn{2}{|c|}{ TRA } \\
\hline & & country & $\mathrm{n}$ & mean & SD & mean & SD & mean & SD & mean & SD \\
\hline 44 & Uni stu & Ger & 49 & 3.60 & .63 & 3.89 & .39 & 2.69 & .69 & 1.98 & 1.14 \\
\hline \multirow[t]{9}{*}{64} & Uni- Tr ed & Aus & 163 & 4.02 & .69 & 4.12 & .66 & 3.31 & .87 & 3.43 & 1.23 \\
\hline & Nursed & & 121 & 4.20 & .65 & 4.44 & .47 & 3.51 & .86 & 2.71 & 1.23 \\
\hline & Midwifery & & 68 & 4.07 & .74 & 4.39 & 1.52 & 3.37 & .81 & 2.65 & 1.13 \\
\hline & InfoTech & & 12 & 3.75 & .80 & 3.65 & .78 & 3.30 & .83 & 1.66 & 1.07 \\
\hline & Science & & 58 & 3.84 & .70 & 4.08 & .58 & 3.21 & 1.02 & 2.17 & 1.08 \\
\hline & Engineering & & 22 & 3.65 & .71 & 3.93 & .72 & 3.23 & .90 & 2.35 & 1.27 \\
\hline & Humanities & & 61 & 3.95 & .68 & 4.15 & .67 & 3.40 & .95 & 2.25 & 1.06 \\
\hline & Bus-Manage & & 37 & 3.64 & .71 & 3.82 & .89 & 2.93 & 1.09 & 2.04 & 1.12 \\
\hline & Bus -acct & & 41 & 3.71 & .94 & 3.88 & .74 & 3.19 & .77 & 2.38 & 1.14 \\
\hline 65 & Hlth ed stu trs & Aus & 20 & 3.70 & & 4.06 & & 2.76 & & 2.08 & \\
\hline 62 & Pre serv trs & HK & 574 & 3.95 & .64 & 4.05 & .60 & 3.46 & .71 & 2.95 & 1.11 \\
\hline \multirow[t]{4}{*}{66} & Tred - State & Aus & 637 & 4.09 & .67 & 4.29 & .60 & 3.26 & .84 & 2.57 & 1.12 \\
\hline & Christian & & 119 & 3.89 & .68 & 4.08 & .54 & 2.90 & .68 & 3.94 & .67 \\
\hline & Catholic & & 472 & 4.11 & .67 & 4.34 & .57 & 3.52 & .80 & 3.27 & .95 \\
\hline & NIreland & NIre & 133 & 4.00 & .72 & 4.11 & .70 & 3.25 & .85 & 3.70 & 1.05 \\
\hline 67 & AOG Lib Arts & USA & 375 & 3.94 & .54 & 4.08 & .66 & 3.06 & .91 & 3.82 & .91 \\
\hline 68 & Nurse ed & Indo & 105 & 4.09 & .67 & 4.04 & .73 & 3.92 & .78 & 4.20 & .73 \\
\hline \multirow[t]{2}{*}{69} & RE stu & Turkey & 137 & 4.22 & .77 & 4.31 & .62 & 4.07 & .81 & 4.43 & .75 \\
\hline & Divinity stu & & 122 & 4.03 & .79 & 4.05 & .72 & 3.88 & .76 & 4.22 & .77 \\
\hline 58 & Ed Psych stu & Spain & 151 & 4.29 & .61 & 4.21 & .56 & 3.51 & .89 & 2.26 & 1.15 \\
\hline 70 & Psych stu & Aus & 122 & 3.63 & .65 & 3.84 & .58 & 3.10 & .90 & 2.03 & 1.07 \\
\hline 44 & Psych stu & Ger & 164 & 3.35 & .68 & 3.79 & .54 & 2.72 & .88 & 1.67 & .89 \\
\hline
\end{tabular}

NB (Some studies did not provide SD data) Tred $=$ Teacher education/pre-service trs Aus $=$ Australia Ger $=$ Germany $\mathrm{HK}=$ Hong Kong Ind $=$ Indonesia NIre $=\mathrm{N}$ IrelandPER $=$ Personal domain of SWB COM $=$ Communal domain of SWB $\mathrm{ENV}=$ Environmental domain of SWB TRA = Transcendental domain of SWB 
Results from health and community projects are shown in Table 4.

Table 4. SWB levels in health care, Churches, business and community using the SWBQ.

\begin{tabular}{|c|c|c|c|c|c|c|c|c|c|c|c|}
\hline \multirow[b]{3}{*}{ ref } & \multirow[b]{3}{*}{ sample } & \multirow[b]{3}{*}{ country } & \multirow[b]{3}{*}{$\mathrm{n}$} & \multicolumn{8}{|c|}{ Four Domains of SWB } \\
\hline & & & & \multicolumn{2}{|c|}{ PER } & \multicolumn{2}{|c|}{ COM } & \multicolumn{2}{|c|}{ ENV } & \multicolumn{2}{|c|}{ TRA } \\
\hline & & & & mean & SD & mean & SD & mean & SD & mean & $\mathrm{SD}$ \\
\hline & \multicolumn{11}{|l|}{ HEALTH } \\
\hline 71 & Nurses & Aus & 246 & 4.17 & .60 & 4.29 & .52 & 3.67 & .86 & 2.94 & 1.21 \\
\hline \multirow[t]{2}{*}{72} & Nurse & Aus & 210 & 4.15 & .66 & 4.26 & .56 & 3.74 & .85 & 2.96 & 1.25 \\
\hline & carer & & 15 & 4.41 & .44 & 4.31 & .40 & 3.93 & .55 & 3.76 & 1.35 \\
\hline \multirow[t]{2}{*}{73} & Nurse dem pts & Aus & 21 & 4.51 & .60 & 4.60 & .52 & 4.01 & .86 & 3.44 & 1.21 \\
\hline & family & & 23 & 3.69 & .77 & 4.25 & .66 & 3.64 & .95 & 3.62 & .89 \\
\hline 74 & Nurses & USA & 33 & 3.98 & & 3.95 & & 3.15 & & 4.03 & \\
\hline 75 & PalCare Drs & ANZ & 156 & 4.02 & .51 & 4.05 & .44 & 3.53 & .83 & 2.61 & 1.27 \\
\hline 76 & Alcoholics & Canada & 85 & 3.81 & .66 & 3.91 & .60 & 3.56 & .74 & 3.61 & .86 \\
\hline 77 & Cancer pts & Port & 169 & 3.10 & .84 & 3.47 & .57 & 3.25 & .97 & 3.66 & .92 \\
\hline 78 & Renal pts & UK & 72 & 2.43 & 1.16 & 2.37 & 1.08 & 2.39 & 1.10 & 2.40 & 1.18 \\
\hline \multicolumn{12}{|c|}{ CHURCH } \\
\hline 79 & Church & Aus & 494 & 3.87 & .72 & 4.05 & .61 & 3.34 & .95 & 3.99 & .81 \\
\hline 80 & Church & UK & 34 & 3.61 & & 3.85 & & 3.35 & & 3.49 & \\
\hline 81 & Cathedral visit & UK & 2695 & $3.59 *$ & & $3.79 *$ & & $3.51 *$ & & $2.72 *$ & \\
\hline 82 & BudChap & USA & 48 & 3.16 & .82 & 3.66 & .65 & 3.41 & .91 & 2.58 & 1.27 \\
\hline \multicolumn{12}{|c|}{ BUSINESS } \\
\hline 83 & Employees & Aus & 316 & 2.03 & .64 & 1.95 & .57 & 2.28 & .82 & 2.88 & 1.11 \\
\hline \multirow[t]{2}{*}{84} & Uni staff & Aus & 162 & 3.92 & .70 & 4.02 & .64 & 3.76 & .76 & 2.52 & 1.23 \\
\hline & Manuf ind & & 53 & 3.62 & .69 & 3.73 & .60 & 3.17 & .75 & 2.40 & 1.00 \\
\hline 85 & Home eco & I'nat & 66 & 4.03 & .85 & 4.05 & .75 & 3.50 & 1.04 & 2.93 & 1.25 \\
\hline 86 & Bus/ed stu & Aus & 125 & 4.15 & .64 & 4.28 & .61 & 3.69 & .95 & 2.28 & 1.34 \\
\hline \multirow[t]{2}{*}{87} & Business & Aus & 1179 & 3.82 & .68 & 3.85 & .61 & 3.27 & .78 & 2.62 & 1.16 \\
\hline & executives $\mathrm{M}$ & & 731 & 3.50 & .75 & 3.57 & .70 & 3.05 & .81 & 2.61 & 1.13 \\
\hline 88 & Public Corp & PRico & 265 & 4.58 & .66 & 4.36 & .74 & 3.92 & .95 & 4.33 & .96 \\
\hline \multicolumn{12}{|c|}{ COMMUNITY } \\
\hline 89 & Dom violence & SAfr & 563 & 4.30 & .72 & 4.32 & .67 & 4.22 & .73 & 4.38 & .68 \\
\hline 90 & Community & Port & 237 & 3.81 & .57 & 3.70 & .55 & 3.59 & .76 & 2.88 & .95 \\
\hline 44 & Community & Ger & 207 & 3.69 & .61 & 3.83 & .44 & 3.56 & .66 & 3.02 & 1.09 \\
\hline 91 & Consumers & Aus & 1011 & 3.54 & .79 & 3.64 & .73 & 3.15 & .87 & 2.65 & 1.26 \\
\hline 92 & Public & UK & 43 & 3.53 & & 3.83 & & 3.17 & & 1.61 & \\
\hline
\end{tabular}

NB (Some studies did not provide SD data) $*=$ estimated values extracted from results $\mathrm{PER}=$ Personal $\mathrm{COM}=$ Communal $\quad \mathrm{ENV}=$ Environmental $\mathrm{TRA}=$ Transcendental domain of SWB

Several studies only reported total scores for SWB, not the individual four factor scores. Included is a report from Chile, where a PhD student in Social Psychology used SHALOM to show that Personal SWB correlated well with happiness and life satisfaction and Communal SWB did likewise with life satisfaction among 126 university students [93]. A Portuguese study with 710 peri- and post-menopausal women revealed that spirituality [total SWB score from SHALOM] was a negative, significant predictor for the majority of menopausal symptoms' severity, independent of socio-demographic factors, health and menopausal status [94, 95]. Students in a liberal arts college in the USA indicated a significant negative correlation of SWB with frequency and quantity of alcohol consumption as well as frequency of inebriation [96]. 
replaced by fascination. Although the intent of the inverted commas around magic (in the original) was to imply fascination, or wonder, an advantage of using 'magic' is that it helps to identify fundamentalists, who ignore the inverted commas to express a literal view on magic. The change of Item 15 from 'prayer life' to 'prayer enriches my life' changes the meaning of the item substantially to one that is ego-centric away from a more balanced approach to prayer including adoration, confession, thanksgiving and supplication, in relationship with a Transcendent Other.

A 20-item instrument cannot hope to be a perfect measure of SWB for all people. However, the SWBQ/SHALOM has shown it is a valid, reliable 'spiritual thermometer' which provides an indication of SWB among a wide range of people. Changing any feature of the original instrument effectively produces a new one, the results from which cannot be compared directly with those from studies employing the original. If anyone wants to improve on the SWBQ/SHALOM, it is recommended that the original 20 items be used, to allow direct comparison with previous research findings, such as those reported in Tables 1-3 above. Additional items can be investigated, using the same 5point Likert scale, to enrich study in this field.

\section{General Comments on SWBQ studies}

The studies reported above show that nearly all people are prepared to accept that relationships with themselves and others influence spiritual well-being. These relationships can be positive or negative and quite often it is in dark times that people are thrown onto their inner strength to find answers to meaning, purpose, etc in life, i.e., personal and communal spiritual pursuits (often referred to as existential [22], humanistic (Spilka cited in [7]), or non-theistic [102]).

Fewer people think about how relating with the environment can enhance spiritual well-being. To some, even suggesting this sounds 'New Age', and some practices are. But, many have 'peak experiences' in special places or events that transcend emotional enjoyment, and enhance spiritual well-being.

The above results show marked divergence of views when relating with a Transcendent [Other], often referred to as God, for spiritual well-being. Some people blame God for the hurt they experience from other people, many of whom are religious. So, in an attempt to minimise this hurt by removing the cause, they deny God's existence even though attributing blame to that source. Others believe that humans have the power to understand and solve all challenges by exercising power of the mind, so eliminating the necessity to introduce the notion of a Transcendent [Other]. We are still waiting to clearly define what the 'mind' is, as well as 'transcendent realities.'

The 1990s were labelled the 'Decade of the Brain' by US Congress. Some hypotheses, conjecture and cautious interpretations of empirical studies suggest that regions of the brain might hold keys to understanding how our spirits relate with selftranscendence and how the brain might have evolved to locate a god-factor. None of this work is definitive and it is all highly influenced by the researchers' world-views. But, it is fascinating reading $[103,104]$.

\section{Spiritual Harmony/Dissonance}

Each person's beliefs and world-view impact their understanding and commitment to the importance of each of the four domains for spiritual health. It is, therefore, important to gain some idea of a person's world-view before attempting to 'measure' their SH/WB. In SHALOM, each person is compared with themselves as their standard. No arbitrary group norms are employed to compare or rank people. The difference between their 'ideals' and how they feel/'lived experience' gives an indication of their SH/WB in each of the four domains. For example, if people do not think relating with the environment is 
important for SH/WB, when they score 'low' on the 'lived experience' category, this is in harmony with their 'ideals' in this domain of SH/WB, thus not an immediate cause for concern. In a similar vein, those who do not consider 'God' to be important for spiritual well-being score very low on ideals and nearly all score very low on lived experience as well. Somewhat surprisingly, many indicate some, albeit a small, relationship with a God, they do not consider to be important. Scoring low on ideals and lived experience yields low dissonance, or put positively, shows harmony between these two measures, so does not reflect a low score on spiritual well-being as does a single-response on lived experience using other measures.

Spiritual dissonance was initially described in the author's work as a marked difference between the ideal and lived experiences in any of the four domains of spiritual well-being, indicated by a difference in mean values of more than 1.0 on a scale from 1 to 5. This value is approximately one to two standard deviations in each of the mean values for the four domains of SH/WB. In reported studies, the level of dissonance for secondary school students is close to eight percent in the Personal, Communal and Environmental domains and over 20 percent in the Transcendental domain, with significant variation between school types [54]. Of at least equal, or maybe, greater concern is the finding that similar percentages of teachers show dissonance between their ideals and lived experiences (12\% Personal, 10\% Communal, 5\% Environmental, 17\% Transcendental) [105].

As teachers' lived experiences are major predictors of how much help they provide to students in schools for SWB [105] this finding has implications for the workplace. Similar findings have been made with nurses [72] and palliative care doctors [75]. These results indicate that how people live influences how much help they give to nurture the SWB of others.

Subsequent analyses have shown that using dissonance scores for each of the 20 items in SHALOM (that is, the difference between ideal and lived experience scores) actually provides a statistically stronger instrument than using just the lived experience scores, as is done in other spirituality measures [106]. The dissonance technique thus provides a better measure of quality of relationships in the four domains, which reflect spiritual well-being. An application of this technique, in a recent study using SHALOM, has revealed, 'spiritual harmony shared the strongest relationship with mental health when compared to any other variable used in this study' [98, p.84]. This finding applied equally well to the religious and secular participants in that study.

\section{Generic version of SHALOM}

A small number of researchers have complained that SHALOM was too God-oriented, even though the word was only mentioned in three of the twenty items in SHALOM, in contrast to the ten times in the 20 items in SWBS [22]. It appears that what they were really saying is that they would only be happy with no reference to God, according to their world-view. This limited view of the world does not fit with most Western civilisations, where census data show that a majority of the populace claim adherence to God-based religions [107]. Traditional Western views of spirituality arose from religious studies, especially in the Catholic Church [108].

Many authors concur with Seaward's view, 'Although spirituality and religion are separate but related concepts that often overlap, it is inconceivable to separate the concept of spirituality from the divine aspect of the universe.' [109, p.77]. That notwithstanding, in light of the claim of theistic bias leveled at the existing SHALOM, four of the five original Transcendental factor items had the words 'God,' 'Divine' and 'Creator' replaced by the word 'Transcendent.' In the revised version, respondents were presented with the statement, 'When people believe their lives are influenced by SomeOne or SomeThing beyond the human and natural worlds, they use different words. [To effect the instruction 
for participants to] Please choose one of the following to show what best describes the supernatural influence in your life, ' eighteen alternatives were provided, namely Allah, Angel/s, Buddha, Deceased person, Deity/deities, Divine, Fate, Father God, Gaia, God, Heaven, Higher power, Higher self, Mystery, Otherness, Presence, Something there, Universe/universal spirit,' or respondents could indicate 'Not an area in which I believe.' The 'Tao' was inadvertently omitted from the list, although no respondents in that study indicated Taoism as their preferred religion/world-view from 26 alternatives provided.

Confirmatory factor analyses revealed that the modified, generic form of SHALOM showed acceptable model fit, comprising four clearly delineated domains of spiritual well-being. Of particular interest was the finding that the modified Transcendental domain of spiritual well-being holds together well statistically and provides the greatest explanation of variance in spiritual well-being overall [101, 110], as had been shown with the original version $[106,111,112]$. This modified SHALOM can be employed in future studies as a generic measure of spiritual well-being across a variety of worldviews. However, the nature of the cohort under investigation should determine which version of SHALOM is used, not the world-view of the investigators.

\section{Conclusion}

Few people consider themselves to be spiritually self-sufficient. Most need help to guide them in their search for meaning, purpose and values in life from a personal perspective. And, from a communal perspective, their continuing quest for in-depth relationships with others will build on their personal search, by clarifying and embracing aspects of morality, culture (and religion, among those for whom it is important). This human journey is set in an environment that is teetering on the brink of regression, facing major physical challenges, in terms of energy, finance, global warming, pollution and water shortage, apart from the threat of terrorism and tension between religious groups assailing World peace in hot spots around the globe. How much time they take to embrace the mystical aspects of environmental well-being may well be a moot point. On top of all this, is the perennial question about the existence, or otherwise, of a Divine Creator/ Transcendent Other/God, higher power or Ultimate Concern who/that has the potential for an over-arching influence on the quality of relationships and development in the other three (Personal, Communal and Environmental) domains of spiritual health and wellbeing.

Although no 20-item instrument can hope to capture perfectly the multidimensional nature of spiritual well-being, the SWBQ/SHALOM has shown itself to be a valid and reliable instrument for assessing key aspects of the SWB in several languages, across a variety of settings, with different age groups. SHALOM provides a novel means of attaining insight into the quality of relationships in four domains which reflect spiritual well-being by comparing each person's ideals with their lived experience, yielding a measure of spiritual harmony or dissonance in each of the four domains.

It is recommended that future researchers use the SWBQ/SHALOM as it is, either in the original 'God' version or the modified generic version, depending on people being surveyed. Additional questions, which may be added, can be correlated with the four domain scores and/or compared with results from existing studies, such as those reported in this paper. In this way, other research currently in progress and new studies will provide a growing bank of results to help our understanding of spiritual well-being in different cultures and settings. 


\section{References}

1. Johnson, M.E.; Piderman, K.M.; Sloan, J.A.; Huschka, M. et al. Measuring Spiritual Quality of Life in Cancer Patients. J Support Oncol. 2007, 5, 437-442.

2. Cummins, R.A. Australian Unity Wellbeing Index Survey 19. 2008 Retrieved 16 October, 2008, from:

http://www.deakin.edu.au/research/acqol/index_wellbeing/index.htm

3. Good, M.; Willoughby, T. The role of spirituality versus religiosity in adolescent psychosocial adjustment. J Youth Adolesc. 2006, 35, 41-55.

4. Hill, P.C.; Hood, R.W.; Eds. Measures of Religiosity. Religious Education Press: Birmingham, Alabama, USA, 1999.

5. Koenig, H.G.; McCullough, M.E.; Larson, D.B. Handbook of Religion and Health. Oxford University Press: Oxford, UK, 2001.

6. MacDonald, D.A.; Friedman, H.L. Assessment of Humanistic, Transpersonal, and Spiritual Constructs: State of the Science. J Human Psychol. 2002, 42, 102-125.

7. Moberg, D.O. Assessing and Measuring Spirituality: Confronting Dilemmas of Universal and Particular Evaluative Criteria. J Adult Dev. 2002, 9, 47-60.

8. Hill, P.C.; Pargament, K.I. Advances in the Conceptualization and Measurement of Religion and Spirituality. Am Psychol. 2003, 58, 64-74.

9. Egbert, N.; Mickley, J.; Coeling, H. A Review and Application of Social Scientific Measures of Religiosity and Spirituality: Assessing a Missing Component in Health Communication Research. Health Commun. 2004, 16, 7-27.

10. King, J.E.; Crowther, M.R. The measurement of religiosity and spirituality. J Org Change. 2004, 17, 83-101.

11. Roehlkepartain, E.C.; Benson, P.L.; Scales, P.C.; Kimball, L.; King, P.E. With Their Own Voices: A global exploration of how today's young people experience and think about spiritual development. Search Institute: Minneapolis, Minnesota, USA, 2008 .

12. Berry, D. Methodological Pitfalls in the Study of Religiosity and Spirituality. West J Nurs Res. 2005, 27, 628-647.

13. Zinnbauer, B.J.; Pargament, K.I.; Scott, A.B. The Emerging Meanings of Religiousness and Spirituality: Problems and Prospects. J Personal. 1999, 67, 889919.

14. Hill, P.C.; Pargament, K.I.; Hood, R.W.; McCullough, J.P.; Swyers, D.B.; Larson, D.B.; Zinnbauer, B.J. Conceptualizing Religion and Spirituality: Points of Commonality, Points of Departure. J Theory Soc Behav. 2000, 30, 51-77.

15. Benson, P.L. Emerging Themes in Research on Adolescent Spiritual and Religious Development. Appl Dev Sci. 2004, 8, 47-50.

16. McCarroll, P.; O’Connor, T.StJ.; Meakes, E. Assessing Plurality in Spirituality Definitions. In Spirituality and Health: Multidisciplinary Explorations; Meier, A., 
O’Connor, T. StJ., Van Katwyk, P.L., Eds.; Wilfrid Laurier University Press: Waterloo, ON, Can., 2005; pp. 43-61.

17. Buck, H.G. Spirituality: Concept Analysis and Model Development. Holist Nurs Pract. 2006, 20, 288-292.

18. Gray, J. Measuring Spirituality: Conceptual and Methodological Considerations. $J$ Theory Construct Test. 2006, 10, 58-64.

19. Ross, L. Spiritual care in nursing: an overview of the research to date. J Clin Nurs. $2006,15,852-862$.

20. Boero, M.; Caviglia, M.; Monteverdi, R.; Braida, V. et al. Spirituality of health workers: a descriptive study. Int J Nurs Stud. 2005, 42, 915-921.

21. Fisher, J.W. Spiritual health: its nature and place in the school curriculum. $\mathrm{PhD}$ thesis, University of Melbourne, 1998. Available from http://eprints.unimelb.edu.au/archive/00002994/

22. Ellison, C. Spiritual well-being: Conceptualization and measurement. J Psychol Theol. 1983, 11, 330-340.

23. Ledbetter, M.F.; Smith, L.A.; Fischer, J.D.; Vosler-Hunter, W.L.; Chew, G.P. An evaluation of the construct validity of the Spiritual Well-Being Scale: A confirmatory factor analytic approach. J Psychol Theol. 1991, 19, 94-102.

24. Gow, A.J.; Watson, R.; Whiteman, M.; Deary, I.J. A stairway to heaven? Structure of the Religious Involvement Inventory and Spiritual Well-Being Scale. J Relig Health. 2010, published online 08 July, DOI 10.1007/s10943-010-9375-2 Springer.

25. Scott, E.L.; Agresi, A.A.; Fitchett, A. Factor analysis of the 'Spiritual Well-Being Scale' and its clinical utility with psychiatric inpatients. J Sci Stud Relig. 1998, 37, 314-321.

26. Koenig, H.G. Concerns about measuring "spirituality" in research. J Nerv Ment Dis. 2008, 196, 349-355.

27. Fehring, R.; Miller, J.; Shaw, C. Spiritual well-being, religiosity, hope, depression, and other mood states in elderly people coping with cancer. Oncol Nurs Forum. 1997, 24, 663-671.

28. National Interfaith Coalition on Aging. Spiritual well-being: a definition. Author: Athens, Ga., USA, 1975.

29. Burkhardt, M.A. Spirituality: An analysis of the concept. Holist Nurs Pract. 1989, 3, 69-77.

30. Como, J.M. A Literature Review Related to Spiritual Health and Health Outcomes. Holist Nurs Pract. 2007, 21, 224-236.

31. Martsolf, D.S.; Mickley, J.R. The concept of spirituality in nursing theories: Differing world-views and extent of focus. J Adv Nurs. 1998, 27, 294-303.

32. Tillich, P. Systematic Theology, Volume III: Life and the Spirit History and the Kingdom of God. University of Chicago Press: Chicago, USA, 1967. 
33. Fisher, J.W. Reaching the heart: Assessing and nurturing spiritual well-being via education. EdD dissertation, University of Ballarat, Victoria, Australia, 2009.

Available from

http://archimedes.ballarat.edu.au:8080/vital/access/HandleResolver/1959.17/13481

34. Fisher, J.W.; Francis, L.J.; Johnson, P. Assessing spiritual health via four domains of well-being: The SH4DI. Pastoral Psychol. 2000, 49, 133-145.

35. Fisher, J.W. Comparing levels of spiritual well-being in State, Catholic and Independent schools in Victoria, Australia. J Beliefs Values. 2001, 22, 113-119.

36. Fisher, J.W. Helps to fostering students' spiritual health. Int J Children's Spirituality. 1999, 4, 29-49.

37. Gomez, R.; Fisher, J.W. Domains of spiritual well-being and development and validation of the Spiritual Well-Being Questionnaire. Pers Indiv Differences. 2003, $35,1975-1991$.

38. Gomez, R.; Fisher, J.W. Item Response Theory analysis of the Spiritual Well-Being Questionnaire. Pers Indiv Differences. 2005, 38, 1107-1121.

39. Gomez, R; Fisher, J.W. The Spiritual Well-Being Questionnaire: Testing for model applicability, measurement and structural equivalencies and latent mean differences across gender. Pers Indiv Differences. 2005, 39, 1383-1393

40. Moberg, D.O. Subjective measures of spiritual well-being. Rev Relig Res. 1984, 25, 351-364.

41. Piedmont, R.L. Spiritual Transcendence and the Scientific Study of Spirituality. $J$ Rehabil. 2001, 67, 4-14.

42. Salandar, P. Who needs the concept of 'spirituality'? Psychooncol. 2006, 15, 647649.

43. Tsuang, M.T.; Simpson, J.C.; Koenen, K.C.; Kremen, W.S.; Lyons, M.J. Spiritual well-being and health. J Nerv Ment Dis. 2007, 195, 673-680.

44. Rowold, J. Effects of spiritual well-being on subsequent happiness, psychological well-being, and stress. J Relig Health. 2011, 50(4), 950-963. DOI 10.1007/s10943009-9316-0 Springer.

45. Burkhardt, M.A.; Nagai-Jacobson, M.G. Reawakening spirit in clinical practice. $J$ Holist Nurs. 1994, 12, 9-21.

46. MacLaren, J. A kaleidoscope of understandings: Spiritual nursing in a multi-faith society. J Adv Nurs. 2004, 45, 457-464.

47. Thatcher, A. A critique of inwardness in Religious Education. Br J Relig Educ. 1991, 14, 22-27.

48. Hungelmann, J.; Kenkel-Rossi, E.; Klassen, L.; Stollenwerk, R. Spiritual well-being in older adults: harmonious inter-connectedness. J Relig Health. 1985, 24, 147-153.

49. de Jager Meezenbroek, E.; Garssen, B.; van den Berg, M; van Dierendonck, D. et al. Measuring spirituality as a universal human experience: A review of spirituality 
questionnaires. J Relig Health. 2012, 51, 336-354. DOI 10.1007/s10943-010-9376-1 Springer.

50. Fisher, J. Feeling Good, Living Life: A spiritual health measure for young children. $J$ Beliefs \& Values, 2004, 25, 307-315.

51. Francis, L.J.; Robbins, M. Urban hope and spiritual health: The adolescent voice. Epworth: Peterborough, UK, 2005.

52. Francis, L.J.; Penny, G.; Baker, S. Defining and assessing spiritual health: A comparative study among 13- to 15-year-old pupils attending secular schools, Anglican schools and private Christian schools in England and Wales. Peabody J Educ. 2012, 87, 351-367.

53. Fisher, J.W. Developing a Spiritual Health And Life-Orientation Measure for secondary school students. In Research with a regional/rural focus: Proceedings of the University of Ballarat inaugural annual research conference; In Ryan, J., Wittwer V., Baird, P, Eds.; University of Ballarat, Research and Graduate Studies Office: Ballarat, Australia, 1999; pp. 57-63.

54. Fisher, J.W. Using secondary students' views about influences on their spiritual wellbeing to inform pastoral care. Int J Children's Spirituality. 2006, 11, 347-356.

55. Holder, M.D.; Coleman, B.; Wallace, J.M. Spirituality, religiousness, and happiness in children aged 8-12 years. J Happiness Stud. 2010, 11, 131-150.

56. Leaver, L. Spiritual development in adolescence; Can it be measured? Can it be increased? Accessed 17 August 2010 from: www.farmington.ac.uk/documents/new_reports/PS59.pdf

57. Hostler, M. Anglican Girls' School spiritual survey. Personal communication 7 June 2013.

58. Muñoz-García, A.; Aviles-Herrera, M.J. Effects of academic dishonesty on dimensions of spiritual well-being and satisfaction: A comparative study of secondary school and university students. Assess Eval Higher Educ. 2013, Published online 10 Sep. DOI:10.1080/02602938.2013.832729.

59. Mok, I. A study of the spiritual health of adolescents in three Hong Kong Secondary Schools. EdD dissertation, Hong Kong Institute of Education, 2013.

60. Fisher, J.W.; Wong, P.H. Comparing levels of spiritual well-being and support among pre-service teachers in Hong Kong and Australia. Relig Educ J Aust, 2013, $29,34-40$.

60. Yuen, Y.M. Celeste Yuen Private communication May 2014, ymyuen@ied.edu.hk.

61. Norwood, R. Adolescent spiritual well-being as a determinant of physical health and well-being. $4^{\text {th }}$ Year Psychology project, University of Wollongong, NSW, Australia.

63. Fisher, J.W. It's time to wake up and stem the decline in spiritual well-being in Victorian schools. Int J Children's Spirituality. 2007, 12, 165-177.

64. Fisher, J.W. Tertiary students' career choice and SHALOM. Paper presented at the International Seminar on Religious Education and Values (ISREV XII), Israel, 23-28 July, 2000. 
65. Deagon, J.R. Pre-service teachers' attitudes and beliefs about spiritual health and wellbeing and their university experience. MEd, Survey research report, Griffith University, Mt Gravatt, Queensland, Australia, 2009.

66. Fisher, J.W.; Barnes, L.P.; Marks, G. Pre-service teachers's spiritual well-being across time and faiths: Implications for religious education. Relig Educ J Aust. 2009, $25,10-16$.

67. Malaret, P. Spiritual well-being of students in a liberal arts college. Personal communication, 27 Mar 2013.

68. Sugianto, A. Factors correlated with the provision of spiritual care by nursing students. BSc Nurs research project, Faculty of Nursing \& Heath Sciences, Universitas Pelita Harapan Tangerang, Indonesia, 2013.

69. Fisher, J.W.; Coskun, M.K. (2013) Investigating spiritual well-being among Divinity and Religious Education students in Turkey. Relig Educ J Aust. 2013, 29, 21-28.

70. Stott, A. The relationship of spiritual well-being to other measures of subjective well-being. Post-grad. Dip Psych. dissertation, Department of Psychology, University of Ballarat, Australia, 2002.

71. Lea, D.M. Spiritual awareness of professional nurses in the Western region of Victoria: Investigation of a significant component of holistic health care. MNurs. dissertation, School of Nursing, University of Ballarat, Australia, 2005.

72. Fisher, J.W.; Brumley, D.J. Nurses' and carers' spiritual well-being in the workplace. Aust J Adv Nurs. 2008, 25, 49-57.

73. Fisher, J.W. Staff's and family members' spiritual well-being in relation to help for residents with dementia. J Nurs Educ Prac. 2012, 2, 1-9.

74. Sykes, C. Spiritual health in nurses practising in end-of-life care. Union University, TN, USA (under review)

75. Fisher, J.W.; Brumley, D. Palliative care doctors need help with spiritual well-being. J Study Spirituality, 2012, 2, 49-60.

76. Streukens, J.P. Alcoholism: Spirituality and personality dynamics. PhD dissertation, Faculty of Graduate Studies, University of Calgary, Alberta, Canada, 2009.

77. Caldeira, S. Relation between spiritual well-being and nursing diagnostic spiritual distress in cancer patients undergoing chemotherapy. PhD Nursing project, Institute of health Sciences, The Catholic University of Portugal. Personal communication 2013.

78. Ashraifeen, A. PhD, University of Stirling, Scotland (work in progress).

79. Fisher, J.W. An investigation of spiritual well-being among people who attend Christian churches in Ballarat, Work in progress.

80. Doores, P. G. Modelling spirituality: A critical examination of the value of models of spirituality as a basis for encouraging spiritual growth in a Christian church community. M.A thesis, Oxford Brookes University, Oxford, UK, 2004. 
81. Brice-Annis, J. The soul of St David's: Mapping the spiritual quest of visitors to St David's Cathedral. PhD thesis, Institute of Education, University of Warwick, 2010.

82. Monteiro, L.M. Burnout and spiritual incongruence: An evidence-based counselling model for Buddhist chaplains. Thesis for Upaya Buddhist Chaplaincy Program, Upaya Zen Institute, Santa Fe, NM, USA, 2011.

83. Becker, P.L. Spirituality in Australian organizations employee attitudes and impact on well being. D Psychol. Dissertation, Swinburne University of technology, Victoria, Australia, 2002.

84. Fisher, J.W.; Sellers, E.T. Quality of life in the workplace: Spirituality, meaning and purpose. Refereed paper in the Proceedings of the 3rd Annual Conference on Spirituality, Leadership and Management, University of Ballarat, Australia, 2000; pp. 14-19.

85. Deagon, J.R. Cross-cultural views and perceptions of spiritual health and well-being in home economics sites: Public expressions and social enactments. $\mathrm{PhD}$ Thesis, Griffith University, Qsld, Australia, submitted Nov 2013.

86. Hall, H. How the domains of spiritual well-being predict current quality of life and general well-being. Post-grad. Dip Psych. dissertation, Department of Psychology, University of Ballarat, Australia, 2005.

87. Fernando, M.; Chowdhury, R.M. The relationship between spiritual well-being and ethical orientations in decision making: An empirical study with business executives in Australia. J Bus Ethics. 2010, published online: 19 January, DOI 10.1007/s10551009-0355-y Springer.

88. Sanchez, B.I. The perception of the SWB and its relationship with optimism, autoefficacy and organizational citizenship behavior in a workplace sample from a public corporation of Puerto Rico. PhD dissertation (in progress).

89. Vogt, T. The impact of an Interim Protection Order (Domestic Violence Act 116 of 1998) on the victims of domestic violence. D Pyschol. Dissertation, University of Stellenbosch, South Africa, 2007.

90. Gouveia, M.J.; Pais Ribeiro, J.; Marques, M. Adaptação Portguesa do Questionário de Bem Espiritual : resultados psicométricos preliminares. In Actas do $7^{\circ}$ congresso nacional de psicologia da saúde; Leal, I., Pais-Ribeiro, J., Silva, I., Marques, S., Eds.; ISPOA : Lisboa, 2008 ; pp. 423-426.

91. Chowdhury, R.M.M.I.; Fernando, M. The role of spiritual well-being and materialism in determining consumers' ethical beliefs: An empirical study with Australian consumers. J Bus Ethics. 2012, published online: 3 April, DOI 10.1007/s10551-0121282-x Springer.

92. Mulligan, E. Assessing the concurrent validity of the WHOQOL-SPRB Bref: A new measure of spiritual quality of life. Personal communication 9 May, 2012.

93. Perez, F.A. Correlation between spiritual well-being, subjective happiness and life satisfaction. Social Psychology thesis student, University of Talca, Chile. Personal communication 22 Jan, 2011. 
94. Pimenta, F.; Leal, I.; Maroco, J.; Ramos, C. Menopause symptoms: Does spirituality predict the severity of the symptoms? Submitted to J Pschosom Obs Gyn. Extract from PhD dissertation, ISPA, University Institute, Lisbon, Portugal, 2011.

95. Pimenta, F.; Leal, I.; Maroco, J.; Ramos, C. What predicts well-being in midlife women? The influence of socio-demographic, health and menopause-related factors, lifestyle, life events, menopausal symptoms, body shape concerns, stress and spirituality. Submitted to Psychotherapy Psychosomatics. Extract from $\mathrm{PhD}$ dissertation, ISPA, University Institute, Lisbon, Portugal, 2011.

96. Kathol, N. Alcohol use in college: The relationship with religion, spirituality and proscriptive attitudes. Hons Psych Sc thesis, university of San Diego, USA, 2011.

97. Dehshiri, G.R. Using the SWBQ to investigate community in Iran. Work in progress.

98. Moore, J.T. Dogmatism, coping, and spirituality: Predicting mental health among the religious and the secular. PhD dissertation, University of Louisville, USA, 2013.

99. Moodley, T. The relationship between coping and spiritual well-being during adolescence. PhD dissertation, Department of Psychology, University of the Free State, Bloemfontein, South Africa, 2008.

100. Van Rooyen, B.M. Spiritual well-being in a group of South African adolescents. $\mathrm{PhD}$ dissertation, Department of Psychology, University of the Free State, Bloemfontein, South Africa, 2007.

101. Fisher, J.W. (2014) Religious Education Journal of Australia (Accepted for publication, July)

102. Haber, J.R.; Jacob, T.; Spangler, D.J.C. Dimensions of Religion/Spirituality and Relevance to Health Research. Int J Psychol Relig. 2007, 17, 265-288.

103. Hamer, D. The God Gene: How Faith is Hardwired into Our Genes. Doubleday: New York, 2004.

104. Beauregard, M.; O'Leary, D. The Spiritual Brain: A Neuroscientist's Case for the Existence of Soul. Harper Collins: New York, USA, 2007.

105. Fisher, J.W. Impacting teachers' and students' spiritual well-being. J Beliefs Values. 2008, 29, 252-261.

106. Fisher, J.W. Assessing spiritual well-being: Relating with God explains greatest variance in spiritual well-being among Australian youth. Int J Children's Spirituality. 2013, 18, 306-317.

107. CIA, World Fact Book - Religions, 2010. Downloaded from https://www.cia.gov/library/ publications/the-world-fact-book/religions, 26 Jan, 2014.

108. Schmidt, R.H. God seekers: Twenty centuries of Christian spiritualities. Eerdmans Publ: Michigan, 2008.

109. Seaward, B.L. Health of the human spirit: Spiritual dimensions for personal health. Allyn \& Bacon: Boston, MA, USA, 2001. 
110. Fisher, J.W. (2013) You can't beat relating with God for spiritual well-being: Comparing a generic version with the original spiritual well-being questionnaire called SHALOM. Religions. 2013, 4, 325-335.

111. Fisher, J.W. Investigating the importance of relating with God for school students' spiritual well-being. J Beliefs Values. 2010, 31, 325-334.

112. Fisher, J.W. The importance of relating with God for spiritual well-being. In M. Weiss \& M. Fowler (Eds.), Spirituality: New reflections on theory, praxis \& pedagogy (pp.147-161). Oxford, UK: InterDisciplinary Press, 2012. Available from http://www.inter-disciplinary.net/wp-content/uploads/2012/02/ fishersp paper.pdf

\subsection{Importance of relating with God for spiritual well-being}

$$
\text { Background }
$$

When trying to find a way of comparing the relative importance of each of four domains of spiritual well-being on the whole, it became clear to me that one cannot just compare the mean values in each domain. Inspiration struck on my drive home from university one day in November 2011. That evening was one of intense statistical analyses, which had very heart-warming results.

\section{Key points extracted from this paper}

- Thirty-two studies which I had conducted with approximately 15000 people by late 2008 had shown that the 20 items of SHALOM cohered into four factors of spiritual well-being comprising that instrument. Moreover, these four factors cohered into a single higher-order factor that I called spiritual well-being.

- Linear Regression Analyses of data sets collected using SHALOM revealed that, of the four sets of relationships assessed by SHALOM, relationship with God (Transcendental Domain) explained the greatest variance in overall spiritual wellbeing, for all but the very religious groups. Participants in the very religious groups nearly all scored this factor highly, thus showing very little variance.

- Using a double response method, comparing each person's lived experience with their stated ideals, provides a better assessment of the quality of relationships in the four domains that reflect their spiritual well-being. Regression Analyses of the dissonance scores thus obtained indicated that, of the four sets of relationship assessed using SHALOM, relating with God is most important for a person's spiritual well-being. 


\title{
Implications
}

Consideration of relationship with God needs to be included in any study of spiritual well-being. If not, the most important factor is omitted.

The double response method ensures that people's levels of spiritual well-being are not misrepresented if they do not consider relating with God to be important for their spiritual well-being. If they rate this factor lowly for both their ideals for SWB and their lived experiences, there is no spiritual dissonance evident. On the other hand, traditional psychological procedures, which report ratings of lived experiences only, could misrepresent such people as they would 'score' lower than religious people on a total spirituality scale. SHALOM is a fairer way of assessing each person's spiritual well-being in that it allows each person to indicate how well they live up to their ideals in up to four domains of spiritual well-being.

\section{Paper:}

This paper was published as: Fisher, J.W. (2012) The importance of relating with God for spiritual well-being. In M. Weiss \& M. Fowler (Eds.), Spirituality: New reflections on theory, praxis \& pedagogy (pp.147-161). Oxford, UK: InterDisciplinary Press. http://www.inter-disciplinary.net/wp-content/uploads/2012/02/ fishersppaper.pdf

\section{The importance of relating with God for spiritual well-being John W Fisher}

\begin{abstract}
Motivation to inquire into the nature of spirituality and its relationship to health, especially in education, came from the 1994 Australian curriculum statements at national and state level. The emergent model of spiritual health and well-being posits four domains in which the quality of relationships reflects the underlying spiritual health and well-being of an individual. These relationships are with oneself, with others, with the environment and/or with God.

On presentation of this research, people do not question relationships with self, others and nature as having a genuine place in studies of spiritual health and well-being. It is always the God-factor which provokes discussion.

There has been considerable debate in the literature over the nexus between spirituality and religion. It is assumed that religions offer some avenue for developing relationships with a Transcendent Other, most often called God, at least at a theoretical level. In practice, human agencies can block formation of such a relationship or usurp adherents' energy by focussing on interpersonal relationships, to the detriment of that with the Transcendent. My research focuses on relationships, which release people to reach their potential, rather than religions, which are human constructs that can restrict people's full development.

The most contentious issue in discussions over spiritual well-being relates to the question of a Transcendent Other (God) having influence over humans. World-views and opinions are many, but empirical studies are few. Research needs to focus clearly on this
\end{abstract}


point. My Spiritual Health And Life-Orientation Measure (SHALOM) has been used extensively to assess four domains of spiritual well-being in education, health and community, including religious, settings. This presentation will provide evidence from a variety of sources to answer the question, 'How important is relating with God for spiritual well-being?'

Key words God, spiritual well-being, SHALOM, assessment, dissonance, spiritual harmony

\section{Introduction}

There are many, varied descriptions of spirituality. However, common threads within most descriptions acknowledge that spirituality 'appears to denote approaches to discovering, experiencing, and living out the implications of an authentic human life' [1]. 'For some, spirituality involves an encounter with God, or transcendent reality, which can occur in or out of the context of organised religion, whereas for others, it need involve no experience or belief in the supernatural' [2]. Much discussion has related to the connection or otherwise between spirituality and religion [3,4].Western traditionalists view religion as the overarching umbrella under which spirituality is a subset [5]. Others see some similarities, yet distinct differences between the two concepts [6]. Some even attempt to divorce the Transcendent from spirituality [7], which leaves a question as to how their notion of spirituality differs from other aspects of psychology [8].

In connecting spirituality with positive aspects of health in psychology, the first recorded use of the term 'spiritual well-being' seems to have been by the National Interfaith Coalition on Aging, in Washington DC, who described it as 'the affirmation of life in relationship with God, self, community and environment that nurtures and celebrates wholeness' [9]. As this was an Interfaith group it is not surprising to note that they placed God at the head of the list of four relationships. Although this was a tentative suggestion of a description, it has been supported with empirical qualitative evidence [1012]. A full description of the four domains model of spiritual health and well-being is readily available in an open access journal [13].

A plethora of instruments have been spawned in attempts to capture the essential elements of spirituality and its relation with health and well-being. Building on the work of Hill \& Hood, MacDonald \& others [14-18], I critiqued nearly 200 spirituality and wellbeing and related measures according to their contribution to the four domains of spiritual health/well-being. I found that $82 \%$ of the spirituality and well-being instruments had three or more items reflecting Personal SWB, 54\% with items for Communal, 26\% for Environment, and $63 \%$ with Transcendental SWB [16].

Of the 16 instruments that contained three or more items for each of the four factors of SWB, there were only four which provided an equal number of items, thus not privileging one area over others. I was involved in the development of these four instruments. In a recent review of 24 commonly used measures, and another of ten popular spirituality questionnaires [17], the instrument that was viewed most favourably was the Spirituality Well-Being Questionnaire (SWBQ) [18]. The SWBQ is actually the lived experience half of the Spiritual Health And Life-Orientation Measure (SHALOM), which was developed using the four domains model of spiritual health/well-being as its theoretical base [19]. 
When SHALOM and findings from associated research have been presented at conferences, people do not question whether relationships with oneself and other people are relevant for spiritual well-being. Even those with the environment are accepted. It is always the Transcendental/God factor which stimulates discussion. In Western nations, many of the minority, who profess no belief in a God or Transcendent Other, feel they have the right to query whether such an area is valid for research. On the other hand, there are some religious folk who cannot conceive of spiritual well-being devoid of relationship with God; the very thought of not asking about this area is complete anathema to them. In the face of such diverse views, researchers need to ensure that prevailing views are canvassed and included to prevent bias in the planning and study of sensitive areas such as spiritual well-being.

In light of the level of interest the topic stimulates, this paper focuses on the importance of relating with God for spiritual well-being. It interrogates empirical evidence to compare the influence of relating with God, with that of self, others and environment, for spiritual well-being.

\section{Method}

Sample

All available research that used a precursor to SHALOM, SHALOM itself and the SWBQ, among 9956 people, are reported. Due to space limitations, only summary results will be given here for studies in which I was actively involved. A study with 146 secondary school staff used a precursor to SHALOM [20]. Five studies with 3873 secondary school students, and two studies with 966 teachers in Australia and Hong Kong are reported [18, 19, 21]. Six studies with 2963 university students in Australia, Hong Kong, UK, Northern Ireland and Turkey are also included [19, 22, 28]. Five studies report on 975 healthcare workers and patients from Australia, Canada and Scotland [24-26]. Two community studies report on 539 workers from Australia and Iran [27, 28], together with 494 church-attendees from Australia [29].

Ten additional studies using the SWBQ/SHALOM, among an extra 4687 people in schools, universities, businesses and community in Australia, Canada, Germany, Portugal, South Africa and UK, have been reported in an open access journal [19]. See references 45 (3 studies), 53, 55, 70, 72, 73, 74, 75 in that paper.

Instrument

SHALOM comprises 20 items distributed in four domains of SWB, with 'sense of identity, self-awareness, joy in life, inner peace, meaning in life' reflecting Personal SWB; 'love of other people, forgiveness toward others, trust between individuals, respect for others, kindness toward other people' reflecting Communal SWB; 'connection with nature, awe at a breathtaking view, oneness with nature, harmony in the environment, sense of 'magic' in the environment' reflecting Environmental SWB; 'personal relation with the Divine/God, worship of the Creator, oneness with God, peace with God, prayer life' reflecting Transcendental SWB. Two responses were sought to each item, both using a 5-point Likert scale, to indicate 'a. how important you think each area is for an ideal state of spiritual well-being, AND b. how you feel each item reflects your personal experience most of the time [19]. 


\section{Procedure}

Data in each of the studies were subjected to Principal Components Analysis (PCA) to show that the 20 items cohered in the four factors as described for SHALOM. As a previous investigation revealed that the lived experience scores for these four factors cohered in a single higher-order factor, called spiritual well-being [18], the 22 full studies reported here were tested to show that this held true for all of them. Linear regression analyses were then performed to examine how well the four contributing factors explained total variance in the aggregate spiritual well-being.

Findings from the initial analyses led to the difference between ideals and lived experience scores (spiritual dissonance) being subjected to the same procedure (i.e., PCA and subsequent regression analysis) in 18 of the 22 studies, where full information was available.

All analyses employed SPSS for Windows 19.

\section{Limitations}

Although SHALOM has been sought for use in over 150 studies in 12 different languages, many are still work in progress, so only those with completed results were reported here. Three studies with small sample sizes, less than 50, were not included. As convenience sampling was used to obtain participants, the results are not necessarily representative of the whole populations from which they were drawn.

\section{Results}

The mean (SD) values for the lived experience components of SHALOM are shown in Table 1.

Table 1. Mean (SD) values \& Principal Components Analyses and Regression Analyses of lived experience in four domains of Spiritual Well-Being

\begin{tabular}{|c|c|c|c|c|c|c|c|}
\hline & & & sample & & & & \\
\hline & $1^{\mathrm{st}} \operatorname{tr}$ & stu & $\operatorname{tr}$ & uni & hlth & cty & chu \\
\hline $\mathrm{n}$ & 146 & 3873 & 966 & 2963 & 975 & 539 & 494 \\
\hline SWB & & & & $\mathrm{M}(\mathrm{SD})$ & & & \\
\hline Per & $4.36(.54)$ & $3.67(.72)$ & $4.05(.60)$ & $4.05(.66)$ & $4.07(.66)$ & $4.20(.85)$ & $3.87(.72)$ \\
\hline Com & $4.38(.53)$ & $3.76(.70)$ & $4.19(.56)$ & $4.21(.62)$ & $3.93(.57)$ & $4.25(.76)$ & $4.05(.61)$ \\
\hline Env & $3.60(.77)$ & $3.15(.87)$ & $3.57(.86)$ & $3.43(.81)$ & $3.66(.85)$ & $3.99(.94)$ & $3.34(.95)$ \\
\hline Tra & $3.67(1.01)$ & $3.14(1.07)$ & $3.62(1.07)$ & $2.97(1.13)$ & $2.98(1.28)$ & $3.88(1.05)$ & $3.99(.81)$ \\
\hline KMO & .76 & .70 & .66 & .65 & .66 & .75 & .74 \\
\hline $\mathrm{RA}$ & & & $\beta$-values & & SWB & & \\
\hline Per & .23 & .30 & .29 & .29 & .27 & .31 & .30 \\
\hline Com & .23 & .29 & .27 & .27 & .24 & .23 & .26 \\
\hline Env & .33 & .34 & .40 & .36 & .36 & .34 & .40 \\
\hline Tra & .43 & .41 & .50 & .50 & .54 & .39 & .34 \\
\hline
\end{tabular}

Per=Personal, Com=Communal, Env=Environmental, Tra=Transcendental lived experience domains of SWB. RA=Regression analysis. tr=teacher, stu=student, hlth=health studies, cty=community studies, chu=church-attendees.

The Kaiser-Meyer-Olkin (KMO) values produced using Principal Components Analysis all exceed 0.6 indicating reliable measures, with good internal consistency, 
showing the factors cohered to give an overall measure for SWB [30]. As only these four factors make up SHALOM, Linear Regression Analyses were performed by entering the four domains of SWB as contributing factors, with the $\beta$-values indicating the relative contribution of each factor to SWB as a whole.

\section{Discussion}

Analysis of SWB - lived experience

In the 22 studies with available data, 18 showed that relating with God (Transcendental SWB) provided greatest explanation for the variance in SWB overall. As SWB comprises Personal, Communal, Environmental and Transcendental domains of SWB, it is obvious that the contributing factor with the largest variation (i.e., Standard Deviation) will have greatest effect on SWB (i.e., highest $\beta$ value). In the ten additional studies, it would therefore be expected that similar results would prevail if regression analyses were performed on these data, because the Transcendental SWB scores display the highest standard deviation among the four domains of SWB in all but one of those projects [31].

These results appear to present good evidence for claiming that relating with God is the most important factor for spiritual well-being (from the four factors studied). However, the results are not without concern. It is interesting to note that it was among four religious groups (Christian Community secondary school students, pre-service teachers in Christian and Islamic universities and church-attenders) that relating with God did not appear to be most important for SWB. This finding can be explained in that, in the religious groups, the reported level of relationship with God was higher than in other groups, which, together with strong cohesion, i.e., less diversity, within the religious groups, was displayed by the lower SD. As mentioned above, it is the factor with the greatest diversity (i.e., largest SD) that provides greatest explanation of variance in the overall SWB. So, even though the religious groups had the highest score on relating with God, this statistical quirk appeared to indicate that this relationship was not the most important contributor for spiritual well-being for them.

A more serious flaw exists in this method of investigation. Even though SWB is shown statistically to comprise four domains using SHALOM, it is unreasonable to compare people with religious convictions with those without such views, on a total score of the four components. Those without a faith will obviously score lower on relationship with God (Transcendental SWB) thus providing greater variance (SD) in this factor. This would skew the results to give a false finding.

Nearly all spirituality/well-being measures do exactly what has been described here. That is, they compare all people on the basis of their lived experience on the same factors, whether or not each participant's worldview includes that factor.

\section{Dissonance - Spiritual Harmony}

Even though the SWBQ/SHALOM is psychometrically sound [32,33], with its four domains, a 20-item instrument cannot provide an exhaustive measure of spiritual health/well-being. Different items would most likely yield different values, besides which each person interprets the meaning of the items differently, and people embrace the four domains of SWB to varying extents, depending on their worldview [34]. Therefore, a fairer method of assessing SWB would involve comparing each person with themselves, i.e., their ideals compared with their lived experience. My description of SWB contends 
that it is the quality of relationships that reflects SWB in each of the four domains [2]. Quality is more equitably assessed by looking at the relative level of harmony or dissonance between ideal and lived experiences, rather than by using only lived experience scores.

SHALOM enables comparison of people's ideals with their lived experience as the means of assessing each person's SWB. So, if a person does not believe in God, for example, their score on the ideal will be low: when they also score low on lived experience, there is no dissonance shown by this person in that domain of SWB, i.e., they appear to be living in harmony with their stated ideal. It was interesting to note that, in the 18 studies with full data, the percentage of people who expressed very low or no relationship with God for their ideals of SWB, ranged from zero among Christian and Islamic university students to 23 per cent among manufacturing and university staff. Rigorous factor analyses of the 20-items in SHALOM have been done in many studies. However, no such analysis has been reported on the dissonance between the ideals and lived experience. This major oversight is about to be corrected.

Scores for participants' ideals as well as lived experiences were available in 18 of the 22 studies reported above, for a total of 9166 people. Factor analyses (PCA) of dissonance scores on the four factors yielded KMO values greater than 0.6, showing that the dissonance factors cohered into a single higher-order factor, called spiritual harmony, as it reflects the quality of relationships in four domains of SWB (see Table 2).

Table 2. Factor analyses of dissonance scores in four domains of SWB \& Regression Analyses of resultant Spiritual Harmony

\begin{tabular}{lllllll}
\hline & stu & tr & $\begin{array}{l}\text { sample } \\
\text { uni }\end{array}$ & hlth & cty & chu \\
\hline $\mathrm{n}$ & 3854 & 966 & 2863 & 887 & 213 & 494 \\
\hline SWB & \multicolumn{5}{c}{$\mathrm{M}(\mathrm{SD})$} \\
$\mathrm{dPer}$ & $.26(.66)$ & $.35(.56)$ & $.29(.59)$ & $.37(.63)$ & $.64(.65)$ & $.46(.66)$ \\
$\mathrm{dCom}$ & $.17(.50)$ & $.38(.50)$ & $.19(.51)$ & $.32(.53)$ & $.52(.54)$ & $.51(.57)$ \\
$\mathrm{dEnv}$ & $.36(.73)$ & $.10(.57)$ & $.16(.55)$ & $.13(.60)$ & $.31(.59)$ & $.09(.57)$ \\
$\mathrm{dTra}$ & $.51(.90)$ & $.46(.62)$ & $.41(.77)$ & $.46(.83)$ & $.39(.68)$ & $.72(.77)$ \\
\hline KMO & .69 & .76 & .69 & .72 & .72 & .73 \\
\hline RA & & & $\beta$-values & spiritual & harmony & \\
\hline $\mathrm{dPer}$ & .32 & .32 & .33 & .32 & .35 & .33 \\
$\mathrm{dCom}$ & .31 & .29 & .28 & .27 & .28 & .28 \\
$\mathrm{dEnv}$ & .35 & .33 & .30 & .31 & .31 & .28 \\
$\mathrm{dTra}$ & .43 & .36 & .43 & .43 & .36 & .38 \\
\hline
\end{tabular}

$\mathrm{dPer}=$ Personal, $\mathrm{dCom}=$ Communal, $\mathrm{dEnv}=$ Environmental, $\mathrm{dTra}=$ Transcendental differences between ideals \& lived experience in domains of SWB.

It is perfectly acceptable to aggregate people with different worldviews to analyse their levels of spiritual harmony. As each person is their own standard, against which they are measured, their worldview will not be judged. It is simply their level of adherence to the worldview that is. Several provisos should be noted, however. Low scores on ideals (and consequently lived experience) in the Personal and, to a lesser extent, the Communal domains of SWB, as measured by SHALOM, correlate significantly with depression. This 
should be considered when interpreting results for potential counselling or pastoral care. Genuine environmentalists, e.g., Indigenous people, look askance at the materialistic manner in which many Westerners mistreat the environment, through a lack of comprehension of its importance to life. Also, people who have a living relationship with God wonder how anyone could not even desire the same.

A close inspection of the $\beta$-values in Table 2 , obtained by linear regression analyses of spiritual harmony, revealed that the Transcendental/God-factor provided the greatest explanation of variance on spiritual harmony. These results provide empirical evidence that relating with God is the most important factor for $S W B$, at least among the people studied here.

Implication of this study

In light of the consistent findings, using difference between ideals and lived experience as a sound method of assessing SWB, it is recommended that researchers select SHALOM as at least one of the instruments for use in future studies of SWB, to obtain equitable results irrespective of participants' worldview. Over time, aggregate data will throw more light on the importance of relating with God for spiritual well-being.

\section{Conclusion}

Spiritual well-being is reflected in the quality of relationships in up to four areas, namely with self, others, environment and/or God. People are generally content to accept self, others and environment as legitimate contributors to SWB, but the God-factor is controversial. Nearly all measures of spirituality/well-being only ask for a single response on surveys, to indicate level of lived experience. Ideals are also sought by SHALOM, which provides a balanced selection of items across four domains of SWB. Analysis of 32 studies provided reasonable support for the notion that relationship with God has greatest importance for SWB. However, potential objections and limitations to just using lived experience have been discussed. A more equitable method of comparing each person's ideals with their lived experience has shown unequivocally that relating with God is most important for spiritual well-being, among people with a variety of worldviews.

\section{References}

1. Muldoon, Maureen \& King, Norman. 'Spirituality, Health care, and Bioethics', Journal of Religion \& Health 34 (1995): 329-349.

2. Fisher, John. 'Spiritual Health: Its Nature and Place in the School Curriculum' PhD diss., University of Melbourne, 1998. Available from:

http://eprints.unimelb.edu.au/archive/00002994/

3. Buck, Harleah. 'Spirituality: Concept Analysis and Model Development', Holistic Nursing Practice 20 (2006): 288-292.

4. McCarroll, Pam, Thomas O'Connor and Elizabeth Meakes. 'Assessing Plurality in Spirituality Definitions'. In Spirituality and Health: Multidisciplinary Explorations, edited by A. Meier, T.J. O’Connor and P.L. Van Katwyk, 43-61. Waterloo, Canada: Wilfrid Laurier University Press, 2005.

5. Piedmont, Ralph. 'Spiritual Transcendence and the Scientific Study of Spirituality', Journal of Rehabilitation 67 (2001): 4-14. 
6. Hill, Peter, Kenneth Pargament, Michael McCullough, James Swyers, David Larsen \& Brian Zinnbauer. 'Conceptualizing Religion and Spirituality: Points of Commonality, Points of Departure', Journal for the Theory of Social Behaviour 30 (2000): 51-77.

7. Daaleman, Timothy \& Frey, Bruce. The Spirituality Index of Well-Being: A New Instrument for Health-related Quality of Life Research,' Annals of Family Medicine 2 (2004): 499-503.

8. Kapuscinski, Afton \& Kevin Masters. 'The Current Status of Measures of Spirituality: A Critical Review of Scale Development', Psychology of Religion \& Spirituality 4 (2010): 191-205.

9. National Interfaith Coalition on Aging (NICA), Spiritual Well-being: A Definition. Athens, GA: NICA, 1975.

10. Hay, David \& Rebecca Nye. The Spirit of the Child. London: Fount, 1998.

11. Elton-Chalcraft, Sally. 'Empty Wells: How Well are we Doing at Spiritual Wellbeing?' International Journal of Children's Spirituality 7 (2002): 309-328.

12. de Souza, Marian, Patricia Cartwright and Jacqueline McGilp. 'The Perceptions of Young People who Live in a Regional City in Australia of their Spiritual Well-being: Implications for Education', Journal of Youth Studies 7 (2004): 155-172.

13. Fisher, John. 'The Four Domains Model: Connecting Spirituality, Health and Wellbeing', Religions 2 (2011): 17-28; doi:10.3390/rel2010017

14. Hill, Peter \& Ralph Hood, eds. Measures of Religiosity. Birmingham, AL: Religious Education Press, 1999.

15. Vivat, Bella. 'Measures of Spiritual Issues for Palliative Care Patients: A Literature Review', Palliative Medicine 22 (2008): 859-868.

16. Fisher, John. 'Reaching the Heart: Assessing and Nurturing Spiritual Well-being via Education' EdD diss., University of Ballarat, 2009. Available from: $<\mathrm{http}$ :// archimedes.ballarat.edu.au:8080/vital/access/HandleResolver/1959.17/13481>

17. Meezenbroek, Eltica de J., Bert Garssen, Machteld van den Berg, Dirk von Dierendonck, Adriaan Visser \& Wilmar Scaufeli. 'Measuring Spirituality as a Universal Human Experience: A Review of Spirituality Questionnaires', Journal of Religion \& Health doi 10.1007/s10943-010-9376-1, published online: 20 July 2010.

18. Gomez, Rapson \& John Fisher. 'Domains of Spiritual Well-being and Development and Validation of the Spiritual Well-Being Questionnaire', Personality \& Individual Differences 35 (2003): 1975-1991.

19. Fisher, John. 'Development and Application of a Spiritual Well-being Questionnaire called SHALOM', Religions 1 (2010): 105-121. doi:10.3390/rel1010105.

20. Fisher, John. 'Comparing Levels of Spiritual Well-being in State, Catholic and Independent Schools in Victoria, Australia', Journal of Beliefs \& Values 22 (2001): 113 119.

21. Fisher, John. 'Developing a Spiritual Health And Life-Orientation Measure for Secondary School Students'. In Research with a Regional/Rural Focus: Proceedings of the University of Ballarat Inaugural Annual Research Conference, edited by J. Ryan, V. 
Wittwer \& P. Baird, 57-63. Ballarat: University of Ballarat, Research and Graduate Studies Office, 1999.

22. Fisher, John. 'Tertiary Students' Career Choice and SHALOM'. Paper presented at the International Seminar on Religious Education and Values (ISREV XII), Israel, 23-28 July, 2000.

23. Fisher, John, L. Philip Barnes and Genee Marks. 'Pre-service Teachers' Spiritual Well-being Across Time and Faiths: Implications for Religious Education', Religious Education Journal of Australia 25 (2009): 10-16.

24. Lea, Dorothy. 'Spiritual Awareness of professional Nurses in the Western Region of Victoria: Investigation of a Significant Component of Holistic Health Care' MNurs. diss., School of Nursing, University of Ballarat, Australia, 2005.

25. Fisher, John \& David Brumley. 'Nurses' and Carers' Spiritual Well-being in the Workplace', Australian Journal of Advanced Nursing 25 (2008): 49-57.

26. Fisher, John \& David Brumley. 'When it comes to Spiritual Well-being, Palliative Care Doctors are Different'. At Australian \& New Zealand Society for Palliative Medicine Conference, Darwin, Australia, 23-6 September, 2008.

27. Fisher, John \& Eileen Sellers. 'Quality of Life in the Workplace: Spirituality, Meaning and Purpose', Refereed paper in the Proceedings of the 3rd Annual Conference on Spirituality, Leadership and Management, University of Ballarat, Australia, 2000, 14 19.

28. Dehshiri, G. Rehsif. Using the SWBQ to investigate community in Iran. Work in Progress.

29. Fisher, John. An investigation of spiritual well-being among people who attend churches in Ballarat. Work in progress.

30. Tabachnik, Barbara \& Linda Fidell. Using Multivariate Statistics $\left(5^{\text {th }}\right.$ ed.). Chicago: University of Chicago Press, 2007.

31. Vogt, Tertia. 'The Impact of an Interim Protection Order (Domestic Violence Act 116 of 1998) on the Victims of Domestic Violence. DPysch diss., University of Stellenbosch, South Africa, 2007.

32. Gomez Rapson \& John Fisher. 'Item Response Theory Analysis of the Spiritual WellBeing Questionnaire', Personality \& Individual Differences 38 (2005): 1107-1121.

33. Gomez, Rapson \& John Fisher. 'The Spiritual Well-Being Questionnaire: Testing for Model Applicability, measurement and Structural Equivalencies and Latent Mean Differences across Gender', Personality \& Individual Differences 39 (2005): 1383-1393.

34. Sire, James. The Universe Next Door: A Basic Worldview Catalog ( $\left.5^{\text {th }} \mathrm{ed}\right)$. USA: Intervarsity Press, 2009.

John Fisher is an Honorary Senior Research Fellow in the School of Education and Arts, University of Ballarat, Victoria Australia.

Email: j.fisher@ballarat.edu.au 


\subsection{Assessing spiritual well-being among Australian youth}

\section{Background}

The paper, which I presented in Prague in 2012 (reported in Chapter 7.2) made the obvious point, 'Different items would most likely yield different values [on spiritual wellbeing measures] besides which, each person interprets meaning of the items differently'. In trying to think of a way to investigate this proposition, I was prompted to revisit the data from which SHALOM was extracted to see if another spiritual well-being questionnaire could be developed, and compared with SHALOM. If so, I would be able to use the same participants, who would effectively respond on both 'measures' at the same time. That is, it would comprise a well-controlled experiment.

\section{Key findings extracted from this paper}

- A second spiritual well-being questionnaire (which I called SWBQ2) was developed from residual data left after selecting the 'best' five items for each of four domains of SWB for incorporation into the SHALOM instrument.

- Variations were found between reported lived experience scores on the two measures for items related to the Personal, Communal and Environmental domains, but not the Transcendental domain. However, this lack of apparent significant difference between the two measures on the Transcendental domain masked the fact that State, Catholic and Independent school students scored higher on the SWBS2 instrument than the Christian Community school (CCS) students in this area. The CCS students scored 'godlike force' lowest of all Transcendental SWB items. This finding indicated how important relating with 'God', and not some substitute, is for these students.

- Dissonance scores (difference between lived experience and ideals) were computed. Greater consistency was observed between the dissonance scores on the two instruments, contrasted with variations found using lived experience scores only.

- Confirmatory Factor Analyses of lived experience and dissonance scores provided a range of fit indices. Scrutiny of these fit indices revealed that the dissonance factors yielded stronger instruments than those using only lived experience.

- Exploratory Factor Analyses revealed that the dissonance scores for the four domains of spiritual well-being in SHALOM and SWBQ2 cohered into single 
higher-order factors. I called this higher-order factor 'spiritual harmony', because a lack of dissonance indicates harmony.

- Regression Analyses of the dissonance factors on each instrument showed that the dissonance scores related to the Transcendental domain explained greatest variance in spiritual harmony, in similar manner to which lived experience scores for the Transcendental domain have explained greatest variance in overall spiritual well-being.

\section{Implications}

As the developmental study was built on my four domains model of spiritual health/wellbeing, all 12 items that were developed for each domain were considered likely candidates for inclusion in the final measure. So it is not surprising that a second set of five items, in addition to the first five extracted for each domain comprising SHALOM, could be extracted to form a psychometrically sound alternative measure of spiritual wellbeing.

With different scores being found using different measures with the same population at the same time, the question was raised, 'Is there no absolute measure for spiritual well-being?'

Regression Analyses of lived experiences scores showed that the Transcendental domain of SWB explained greatest variance overall for spiritual well-being, on both instruments. However, the dissonance method provides fairer/better assessment of quality of relationships in the four domains of SWB. Moreover, Regression Analyses of dissonances also showed that the Transcendental domain (relating with God) was most important for spiritual well-being/harmony.

Dissonance scores generated by using SHALOM with school students can provide their teachers with insights into the students' spiritual well-being in the four domains measured. Such insights can be valuable to teachers in their work of nurturing their students' spiritual well-being. However, teachers need appropriate training and experience in this area to adequately help students, as my previous studies have shown that teachers' lived experience influences how well they care for students' spiritual wellbeing (Fisher, 2008, 2009).

\section{Paper:}

This paper was published as: Fisher, J.W. (2013) Assessing spiritual well-being: Relating with God explains greatest variance in spiritual well-being among Australian youth. International Journal of Children's Spirituality 18(4): 306-317. 
Author: John W. Fisher, School of Education \& Arts, University of Ballarat, Victoria, Australia

Email: j.fisher@ballarat.edu.au

John Fisher is an Honorary Senior Research Fellow in the School of Education \& Arts, University of Ballarat, Victoria, Australia. He has extensive experience in teaching and research in science, education, psychology, sociology, health and religious education in schools, tertiary institutions and the wider community. John is currently completing his third doctorate in the area of spiritual health and well-being.

\begin{abstract}
How do we set standards in assessing spiritual well-being (SWB)? Most measures only provide scores on arbitrary scales. Therefore, if the questions differ, the scores are likely to as well. This paper reports on two scales developed with 460 Australian secondary school students, with diverse cultural and religious backgrounds, from state, Catholic, Christian Community and independent schools.

The four domains model of spiritual health/well-being was the theoretical base from which 12 items were developed to reflect quality of relationships with each of self, others, environment and God/the Divine. The instrument with the five top-scoring items in each domain, known as SHALOM, has been sought for use in over 200 studies in 20 languages. The second-highest sets of five items were extracted and found to form statistically valid factors, for a new instrument called SWBQ2.

As would be expected, the mean values for the factor scores varied between SHALOM and SWBQ2, overall and by school type. However, regression analyses of the lived experience scores showed that relating with God provided greatest explanation of variance in SWB, on both measures. A double-response method introduced for SHALOM was also used with SWBQ2 to compare each person's lived experience with their ideals, better reflecting quality of relationships, rather than just the arbitrary scores. There was negligible difference in dissonance scores on the four factors in both measures, that is, in comparing the difference between ideals and lived experiences. This method showed consistency in the quality of relationships reflecting SWB, contrasted with variance shown using only lived experience, as mentioned above. Relating with God was again most influential on SWB.

These findings have implications for methods used in assessing SWB as well as outcomes.
\end{abstract}

Key words: measures; spiritual well-being; youth; God; SHALOM

\title{
Introduction
}

At the Second Global Conference on Spirituality, held in Prague in March 2012, empirical evidence was presented to show that relating with God was the most important of four domains of spiritual well-being, in that it explained the greatest variance therein (Fisher 2012). A number of researchers have presented this position theoretically, based on their worldviews, but empirical evidence had previously been lacking to support this position. It was also postulated in Fisher's Prague presentation that different items would 
yield differing scores on the spiritual well-being factors. This paper aims to present data which will validate or deny that contention and discuss implications of the findings for assessment of spiritual well-being. This paper also provides further analyses of the importance of relating with God for spiritual well-being among Australian youth.

When considering spiritual well-being, the most controversial discussion focusses on the issue of Transcendent Other. For some, this is the central, imperative component of spiritual well-being (Pargament 1999, Koenig 2009, Casas et al. 2009), whereas others believe there is no evidence for the existence of a god (Gidley 2005) or any other form of Transcendent beyond the human and natural world. This meta-physical reality cannot be observed directly using scientific equipment, but the effects can be. For example, a recent, randomized, blinded study with cancer patients showed significantly greater improvements in their spiritual well-being over time, when they were prayed for by an external intercessory prayer group (without their knowledge), as compared to a control group, who were not prayed for (Olver \& Dutney 2012).

No qualitative or quantitative instrument can be an exhaustive measure of spiritual well-being because of its complex nature. Quality of life studies really stretch credibility when they purport to assess spiritual well-being by asking for a response to a single-item, such as, 'How would you describe your overall spiritual well-being?' on a scale from $0=$ 'as bad as it can be' to $10=$ 'as good as it can be' (Johnson et al. 2007). At the other end of the scale, one spirituality instrument comprised 156 items (Roehlkepartain et al. 2008). Comprising 20 items, with five in each of four domains of spiritual well-being, SHALOM can be considered a good indicator of spiritual health and well-being, something like a spiritual thermometer. In a recent review of commonly used measures, the spiritual wellbeing questionnaire (called SHALOM) was described as the most promising (Meezenbroek et al. 2012).

SHALOM has been validated and used in numerous studies of spiritual well-being (Fisher 2010). This instrument provides a novel method of determining the quality of relationships in four domains of spiritual well-being. Instead of simply asking for a response indicating lived experience on each item, SHALOM asks for this, after eliciting each person's ideals for spiritual health/well-being, using the same items. In this way, each person becomes the standard against which they are measured. The lived experience scores can, however, still be used to compare between groups. But, as this study will show, that standard method, used by psychologists universally, is not without its concerns.

\section{Method}

\section{Participants}

The total sample comprised 460 students from four different types of secondary schools (State, Catholic, Christian Community and other independent schools) in Victoria Australia. There were 51\% males and 49\% females, aged 12 to 18 years, in Years 7 to 12 .

\section{Procedure and measures}

Following appropriate ethics approval, all participants joined in a survey comprising 48 items chosen to reflect four sets of relationships considered to be pertinent to spiritual 
well-being. These items were selected from Fisher's four domains model of spiritual health/well-being (1998), in comparison with items in existing spirituality measures, and subjected to scrutiny by three researchers experienced in personality and spirituality/religiosity. The surveys were completed in school time, by the students in groups under the supervision of school staff. All responses by students were anonymous. Students were asked to give two responses to each item, indicating the importance of these items on (1) their ideals for spiritual well-being and (2) their lived experience most of the time, using a 5-point Likert scale, ranging from very low (rated 1) to very high (rated 5).

SHALOM was built on a theoretical framework that provided 12 items for each of four domains of spiritual well-being. The 'best' five items for each factor (indicated by highest item-total correlation in exploratory factor analyses) were selected to constitute SHALOM (Fisher 2010) (see Table 1). However, the next best five items for each of the factors were extracted here to form another instrument, called SWBQ2 (see Table 2). Having these two instruments enabled the checking of the proposition that different items would yield different values, i.e., 'measures', of spiritual well-being in the same participants. The two least suitable items were discarded from the formative list of 12 in each domain.

\section{Results and discussion}

The two 20-item sets for assessing spiritual well-being (SHALOM and SWBQ2) were subject to principal components analysis (PCA) using SPSS Version 19. Prior to performing the PCA, the suitability of data for factor analysis was assessed. Inspection of the correlation matrices revealed that all coefficients were .4 and above. The KaiserMeyer-Olkin values were both .91, exceeding the recommended minimum value of .6 (Kaiser, 1974) and Bartlett's Test of Sphericity (Bartlett, 1954) reached statistical significance, supporting the factorability of the correlation matrices.

Principal components analyses revealed the presence of four components with eigenvalues exceeding 1, explaining $34.8 \%, 15.5 \%, 9.3 \%$ and $5.2 \%$ of the variance respectively in SHALOM (total variance explained was 64.8\%), and 34.2\%, 11.7\%, 7.1\% and $5.4 \%$ respectively in SWBQ2 (total variance explained was 58.4\%). All the variables loaded onto the appropriate scales revealing sound measures for Personal, Communal, Environmental and Transcendental domains of spiritual well-being for SHALOM and SWBQ2. Reliability analyses of the scales revealed stronger Cronbach's $\alpha$ coefficient values for the four factors on SHALOM compared with SWBQ2, but all are within acceptable limits for research purposes ( $\alpha$, mean and SD values shown on Tables 1 and 2$)$ (Meyers et al., 2013, p. 722).

Results on the last row in Table 2 show there are strong correlations between the four spiritual well-being domain scores measured using SHALOM and SWBQ2. However, matched pairs t-tests comparing domains in SHALOM with those in SWBQ2 reveal higher scores for Personal $(\mathrm{t}(459)=3.0, \mathrm{p}=.003)$ and Communal spiritual well-being $(\mathrm{t}(459)=13.7, \mathrm{p}<.001)$, with lower scores on Environmental spiritual well-being $(\mathrm{t}(459)=-$ $6.5, \mathrm{p}<.001)$ on SHALOM, but no significant difference on Transcendental spiritual wellbeing $\left(\mathrm{t}(459)=-.9, \mathrm{p}=.334^{\mathrm{ns}}\right)$ between the two instruments. Closer inspection, by school type, reveals some interesting findings (see Table 3 ). 
The Catholic and Independent school students gained similar factor scores on the Personal domain for each measure. The State school students scored 'contentment' lowest on SWBQ2, but did not show significant differences between the Personal domain scores on the two measures.

Table 1. Pattern matrix for PCA with Oblimin Rotation of 4-factor solution of SHALOM items, together with Cronbach's alpha coefficient for reliability analyses of scales

\begin{tabular}{|l|l|l|l|l|}
\hline Item & Per swb & Tra swb & Env swb & Com swb \\
\hline meaning & .83 & & & \\
\hline inner peace & .54 & & & \\
\hline identity & .76 & & & \\
\hline joy & .76 & & & \\
\hline self-awareness & .73 & & & \\
\hline love others & & & & .73 \\
\hline trust & & & & .69 \\
\hline kindness & & & & .87 \\
\hline respect others & & & & .62 \\
\hline forgiveness & & & & .44 \\
\hline environmental harmony & & & .77 & \\
\hline connect with nature & & & .85 & \\
\hline 'magic' in environment & & & .91 & \\
\hline one with nature & & & .86 & \\
\hline awe at view & & & .57 & \\
\hline oneness with God & & .86 & & \\
\hline relation with divine & & .90 & & \\
\hline worship Creator & & .85 & & \\
\hline prayer & & .87 & & \\
\hline peace with God & & .83 & & \\
\hline Eigenvalue & 6.96 & 3.10 & & \\
\hline Alpha value & .83 & .92 & & \\
\hline Mean(SD) & $3.75(.79)$ & $3.93(.69)$ & $3.18(.95)$ & \\
\hline NB. Per swb Persona & & & \\
\hline
\end{tabular}

NB. Per swb = Personal spiritual well-being, Com $=$ Communal, Env $=$ Environmental, Tra $=$ Transcendental domains of spiritual well-being

However, students in the Christian Community Schools (CCS) scored lower on the SWBQ2 compared with SHALOM, because of their lower rating of 'self-esteem' and 'freedom.'

Students in each of the four types of school scored lower on Communal spiritual well-being on SWBQ2. Catholic and Independent school students scored higher on Environmental spiritual well-being, measured using SWBQ2 compared with SHALOM, with a trend in this direction being shown by State school students.

The lack of apparent significant difference in scores on Transcendental spiritual well-being between the two instruments masked the fact that the State, Catholic and other Independent school students scored higher on SWBQ2, whereas the CCS students scored lower. State school students reated 'faith in higher power' highest of all Transcendent 
items; Catholic and Independent school students did likewise with 'eternal life.' However, CCS students scored highest on all the Transcendent items in each measure, but they favoured 'relate with a godlike force' least of any.

Table 2. Pattern matrix for PCA with Oblimin Rotation of 4-factor solution of SWBQ2 items, together with Cronbach's alpha coefficient for reliability analyses of scales

\begin{tabular}{|c|c|c|c|c|}
\hline Item & Com swb & Tra swb & Env swb & Per swb \\
\hline self-esteem & & & & .84 \\
\hline purpose for life & & & & .60 \\
\hline contentment & & & & .60 \\
\hline freedom & & & & .38 \\
\hline values & & & & .19 \\
\hline empathy & .40 & & & \\
\hline faith in people & .46 & & & \\
\hline ethics & .56 & & & \\
\hline hope & .56 & & & \\
\hline justice & .73 & & & \\
\hline +ve attitude to environ & & & .83 & \\
\hline unity with environ & & & .78 & \\
\hline awe in nature & & & .65 & \\
\hline scenic beauty & & & .54 & \\
\hline environ concern & & & .80 & \\
\hline relate godlike force & & .75 & & \\
\hline adoration & & .70 & & \\
\hline Faith in higher power & & .79 & & \\
\hline intune with God & & .85 & & \\
\hline eternal life & & .75 & & \\
\hline Eigenvalue & 6.85 & 2.33 & 1.42 & 1.07 \\
\hline Alpha value & .72 & .85 & .82 & .79 \\
\hline Mean(SD) & $3.67(.75)$ & $3.59(.67)$ & $3.36(.79)$ & $3.20(.98)$ \\
\hline Correlation with SHALOM & .76 & .69 & .76 & .84 \\
\hline
\end{tabular}

Table 3. Matched pairs t-test results for spiritual well-being by school type

\begin{tabular}{|c|c|c|c|c|c|c|c|c|}
\hline \multirow{2}{*}{$\begin{array}{l}\text { School } \\
\text { swb }\end{array}$} & \multicolumn{2}{|l|}{ State (89) } & \multicolumn{2}{|c|}{ Catholic (116) } & \multicolumn{2}{|l|}{ CCS (199) } & \multicolumn{2}{|c|}{ Independent (56) } \\
\hline & SHALOM & SWBQ2 & SHALOM & SWBQ2 & SHALOM & SWBQ2 & SHALOM & SWBQ2 \\
\hline Per & $3.60(.79)$ & $3.56(.80)$ & $3.79(.84)$ & $3.79(.66)$ & $3.77(.74)$ & $3.69(.76)$ & $3.83(.85)$ & $3.88(.72)$ \\
\hline $\mathrm{t}^{\mathrm{sig}}$ & \multicolumn{2}{|l|}{$.70^{\mathrm{ns}}$} & \multicolumn{2}{|l|}{$-.07^{\mathrm{nS}}$} & \multicolumn{2}{|l|}{$5.4^{.000}$} & \multicolumn{2}{|l|}{$-.6^{\mathrm{ns}}$} \\
\hline Com & $3.82(.73)$ & $3.49(.70)$ & $3.88(.65)$ & $3.56(.69)$ & $3.98(.66)$ & $3.61(.65)$ & $4.02(.68)$ & $3.71(.63)$ \\
\hline $\mathrm{t}^{\mathrm{sig}}$ & \multicolumn{2}{|l|}{$5.0^{.000}$} & \multicolumn{2}{|l|}{$7.3^{.000}$} & \multicolumn{2}{|l|}{$9.8^{.000}$} & \multicolumn{2}{|l|}{$4.3^{.000}$} \\
\hline Env & $3.29(.95)$ & $3.39(.72)$ & $3.31(.93)$ & $3.50(.79)$ & $3.01(.99)$ & $3.23(.80)$ & $3.29(.77)$ & $3.48(.75)$ \\
\hline $\mathrm{t}^{\mathrm{sig}}$ & \multicolumn{2}{|l|}{$-1.7^{\mathrm{ns}}$} & \multicolumn{2}{|l|}{$-3.2^{.001}$} & \multicolumn{2}{|l|}{$-4.8^{.000}$} & \multicolumn{2}{|l|}{$-2.7^{.010}$} \\
\hline Tra & $2.53(.99)$ & $2.84(.92)$ & $2.78(1.02)$ & $2.97(.94)$ & $3.84(1.00)$ & $3.61(.90)$ & $2.64(1.00)$ & $2.79(.89)$ \\
\hline $\mathrm{t}^{\mathrm{sig}}$ & \multicolumn{2}{|l|}{$-4.2^{.000}$} & \multicolumn{2}{|l|}{$-3.6^{.000}$} & \multicolumn{2}{|l|}{$5.4^{.000}$} & \multicolumn{2}{|l|}{$-2.4^{.022}$} \\
\hline
\end{tabular}




\section{Relative importance of relating with God}

The four domain scores for spiritual well-being from SHALOM and SWBQ2 were subjected to principal components analysis, which revealed that both sets cohered into a single higher-order factor, called Spiritual Well-Being (SWB) (SHALOM - KMO = .72, $56.2 \%$ variance explained; $\mathrm{SWBQ} 2-\mathrm{KMO}=.75,62.8 \%$ variance explained). As these four domains comprised SWB, linear regression analyses were performed on each of the spiritual well-being questionnaires to ascertain the relative contribution made to each, by the four contributing factors (see Table 4 for details).

Table 4. $\beta$-values from linear Regression Analyses of the lived experience values on four domains of spiritual well-being in SHALOM and SWBQ2

\begin{tabular}{|l|l|l|l|l|l|}
\hline swb/School & All (460) & State & Catholic & CCS & Independent \\
\hline SHALOM & & & & & \\
\hline Per & .30 & .32 & .31 & .29 & .35 \\
\hline Com & .26 & .29 & .24 & .27 & .28 \\
\hline Env & .36 & .38 & .34 & .385 & .32 \\
\hline Tra & .44 & .39 & .37 & .390 & .41 \\
\hline max diff. & $8 / 36=22 \%$ & $1 / 38=3 \%$ & $3 / 34=9 \%$ & $4 / 385=1 \%$ & $6 / 35=17 \%$ \\
\hline SWBQ2 & & & & & \\
\hline Per & .30 & .32 & .26 & .31 & .31 \\
\hline Com & .27 & .28 & .27 & .28 & .27 \\
\hline Env & .32 & .30 & .31 & .32 & .32 \\
\hline Tra & .39 & .37 & .37 & .38 & .39 \\
\hline max diff. & $7 / 32=22 \%$ & $7 / 32=22 \%$ & $6 / 31=19 \%$ & $6 / 32=19 \%$ & $7 / 32=22 \%$ \\
\hline
\end{tabular}

Overall, the $\beta$-values for Transcendental spiritual well-being were greater by $22 \%$ than those for Personal, Communal and Environmental spiritual well-being on SHALOM and SWBQ2, indicating that Transcendental spiritual well-being explained greatest variance in spiritual well-being overall. In this sense, relating with God is shown to be most important for spiritual well-being. Investigation by school type showed that Transcendental spiritual well-being outscored the other domains by $1 \%$ to $17 \%$ on SHALOM and $13 \%$ to $22 \%$ on SWBQ2.

\section{Interim summary}

The findings reported here, comparing spiritual well-being domain scores using SHALOM and SWBQ2, support the prediction that different items were likely to yield different scores or measures of spiritual well-being. This raises a question as to how much trust can be put in values obtained using single responses on an arbitrary choice of items, purported to represent each given domain of spiritual well-being, or any other entity for that matter. Because terms such as purpose for life, love, unity with the environment have differing meanings for different people, comparing two people's scores as measures of spiritual well-being, could be like comparing chalk with cheese. Each person's concept of God is likely to provide even more divergent opinions.

Comparing summed scores over a range of variables, which is what most spiritual well-being surveys do, is not fair. Apart from the potential of bias due to the developer's 
worldview, each respondent's worldview will determine the importance of each item to the respondent. For example, if a person does not believe in a god, and therefore scores low on lived experience of a relationship with such an entity, that person's overall cumulative score of all the domains is likely to be lowered in comparison with that of a believer in God. In contrast, each person's lived experience can be compared with their own ideals. For example, no belief in a god will yield a low score for ideals for spiritual well-being as well as a low score for lived experience, therefore no dissonance in this domain of spiritual well-being on instruments reported here. Using this double-response, or dissonance, method provides a fairer assessment of the relationships which reflect spiritual well-being.

Even though the items in the two measures used here were built from the same theoretical foundation, with relevant domain scores highly correlated, significant variations were still evident, showing there is no apparent absolute measure/value for spiritual well-being, or is there?

\section{Alternative ways of assessing SWB}

Using scores of an arbitrary set of items for each factor of SWB, have been shown here to yield varying results with different items. So, how can we assess the level of spiritual well-being? Fisher's spiritual well-being questionnaires provide a novel means of measuring SWB. All other measures ask for a single response to each item, for example, 'How does this item reflect your spiritual well-being?' Fisher's instruments ask for two responses, namely, 'What is your ideal for spiritual well-being?' and 'How does it reflect your lived experience?' By taking the difference between the two responses, a measure of the quality of relationship is obtained in each of four domains of spiritual well-being. In other words, each person is assessed against themselves as their standard, rather than against some group norm. This is the theory. How well does it work in practice?

Exploratory factor analyses (PCA) were performed on the differences between the ideal scores and lived experience scores for the 20 items in four domains of spiritual wellbeing, hereafter called dissonances in order to distinguish them from the notion of significant differences in calculations. PCA revealed the presence of four components with eigenvalues exceeding 1, explaining total variance of $56.7 \%$ with $\mathrm{KMO}$ value $=.93$ for dSHALOM and 52.1\% variance and KMO =.91 for dSWBQ2. Just as the four domain scores cohered into a single higher order factor called Spiritual Well-Being, the dissonances also did. This combined factor will be called Spiritual Harmony, as less dissonance provides greater harmony.

AMOS was used to perform confirmatory factor analyses to investigate the relative construct validity of the spiritual well-being measures SHALOM, SWBQ2, dSHALOM, dSWBQ2 with their four component factors. A range of fit indices was selected to test the CFA models to see which best represents the data sets and which instrument fits best. Absolute fit indices were the relative Chi-square $\left(\mathrm{X}^{2} / \mathrm{df}\right)$, Akaike's Information Criterion (AIC), and the Expected Cross-Validation Index (ECVI). Relative Fit Indices were the Incremental Fit Index (IFI), Normed Fit Index (NFI) and TuckerLewis Index (TLI). The Parsimonious Normed Fit Index (PNFI) was used. Noncentralitybased Indices were the Root Mean Square Error Approximation (RMSEA) and the Comparative Fit Index (CFI). The target values to indicate good fit indices are listed in 
the bottom row of Table 5 (Moss 2009, Meyers et al. 2013).

SHALOM and dSHALOM display acceptable to good values on fit indices, whereas SWBQ2 and dSWBQ2 show lower values with only borderline acceptability on NFI and CFI. On most fit indices the two dissonance measures performed better than the lived experience only measures, providing more support for the technique of comparing ideals with lived experience to assess the quality of relationships in four domains that reflect spiritual well-being. From these results it can be clearly seen that dSHALOM is the preferred measure of spiritual well-being (see Table 5 for details).

Table 5 Summary results for confirmatory factor analyses of SWB measures.

\begin{tabular}{|l|l|l|l|l|l|l|l|l|l|}
\hline SWBQ & $\mathrm{X}^{2} / \mathrm{df}$ & AIC & ECVI & IFI & NFI & TLI & PNFI & RMSEA & CFI \\
\hline SHALOM & 2.70 & 575 & 1.25 & .941 & .909 & .931 & .79 & .061 & .940 \\
\hline SWBQ2 & 2.80 & 591 & 1.29 & .915 & .874 & .901 & .76 & .063 & .915 \\
\hline dSHALOM & $\mathbf{2 . 1 3}$ & $\mathbf{4 8 2}$ & $\mathbf{1 . 0 5}$ & $\mathbf{. 9 4 5}$ & .901 & $\mathbf{. 9 3 6}$ & .78 & $\mathbf{. 0 5 0}$ & $\mathbf{. 9 4 4}$ \\
\hline dSWBQ2 & 2.42 & 529 & 1.15 & .916 & .866 & .902 & .75 & .056 & .916 \\
\hline good range & $<2-3$ & lowest & lowest & $>.90$ & $>.90$ & $>.90$ & $>.50$ & $<.05-.08$ & $>.93$ \\
\hline
\end{tabular}

\section{The relative importance of relating with God for spiritual well-being/harmony}

Regression analyses of Spiritual Harmony by school type once again showed that the dissonance in Transcendental spiritual well-being explained greatest variance in Spiritual Harmony, ranging from $13 \%$ to $25 \%$ above other spiritual well-being factors on SHALOM and $6 \%$ to $33 \%$ in SWBQ2 (see Table 6 for details).

Table 6. $\beta$-values from linear Regression Analyses of the dissonances between ideals and lived experience values on four domains of spiritual well-being in SHALOM and SWBQ2

\begin{tabular}{|l|l|l|l|l|l|}
\hline swb/School & All & State & Catholic & CCS & Independent \\
\hline SHALOM & & & & & \\
\hline dPer & .29 & .25 & .29 & .30 & .28 \\
\hline dCom & .28 & .29 & .23 & .29 & .27 \\
\hline dEnv & .29 & .31 & .33 & .29 & .27 \\
\hline dTra & .37 & .43 & .41 & .32 & .38 \\
\hline max diff. & $8 / 29=28 \%$ & $12 / 31=39 \%$ & $8 / 33=24 \%$ & $2 / 30=7 \%$ & $10 / 38=26 \%$ \\
\hline SWBQ2 & & & & & \\
\hline dPer & .30 & .28 & .28 & .31 & .32 \\
\hline dCom & .26 & .25 & .26 & .27 & .24 \\
\hline dEnv & .30 & .29 & .36 & .28 & .26 \\
\hline dTra & .35 & .41 & .38 & .31 & .38 \\
\hline max diff. & $5 / 30=17 \%$ & $12 / 29=41 \%$ & $2 / 36=6 \%$ & $=$ top & $6 / 32=19 \%$ \\
\hline
\end{tabular}


Much greater consistency was shown within and between students in the schools studied here using the dissonance method compared with lived experiences only. Matched pairs t-tests revealed that the only significant difference, with $\mathrm{p}<.01$, on values for dissonances was shown in Transcendental spiritual well-being in CCS (see Table 7). This finding contrasts with the eleven scores with $\mathrm{p}<.01$ shown in Table 3.

Table 7. Matched pairs t-test results for Spiritual Harmony by school type

\begin{tabular}{|c|c|c|c|c|c|c|c|c|}
\hline swb/Schl & \multicolumn{2}{|l|}{ State (89) } & \multicolumn{2}{|c|}{ Catholic (116) } & \multicolumn{2}{|l|}{ CCS (199) } & \multicolumn{2}{|c|}{ Independent (56) } \\
\hline & SHALOM & SWBQ2 & SHALOM & SWBQ2 & SHALOM & SWBQ2 & SHALOM & SWBQ2 \\
\hline dPer & $.24(.57)$ & $.25(.60)$ & $.35(.58)$ & $.28(.54)$ & .47(.75) & .50(.77) & $.56(.76)$ & $.48(.81)$ \\
\hline $\mathrm{t}^{\mathrm{sig}}$ & \multicolumn{2}{|l|}{$-.24^{\mathrm{ns}}$} & \multicolumn{2}{|l|}{$1.4^{\mathrm{ns}}$} & \multicolumn{2}{|l|}{$-.9^{\mathrm{ns}}$} & \multicolumn{2}{|l|}{$1.2^{\mathrm{ns}}$} \\
\hline dCom & $.17(.68)$ & $.31(.53)$ & $.38(.46)$ & $.36(.51)$ & $.51(.74)$ & $.45(.67)$ & $.43(.74)$ & $.50(.60)$ \\
\hline $\mathrm{t}^{\mathrm{sig}}$ & \multicolumn{2}{|l|}{$-2.5^{.015}$} & \multicolumn{2}{|l|}{$.63^{\mathrm{ns}}$} & \multicolumn{2}{|l|}{$2.2^{.032}$} & \multicolumn{2}{|l|}{$-1.1^{\mathrm{ns}}$} \\
\hline dEnv & $.30(.71)$ & $.22(.61)$ & $.30(.66)$ & $.23(.70)$ & $.32(.71)$ & $.41(.70)$ & $.39(.74)$ & $.44(.66)$ \\
\hline $\mathrm{t}^{\mathrm{sig}}$ & \multicolumn{2}{|l|}{$1.1^{\mathrm{ns}}$} & \multicolumn{2}{|l|}{$1.2^{\mathrm{ns}}$} & \multicolumn{2}{|l|}{$-2.3^{.024}$} & \multicolumn{2}{|l|}{$.6^{\mathrm{ns}}$} \\
\hline dTra & $.57(1.01)$ & $.50(.87)$ & $.54(.81)$ & .46(.74) & $.65(.82)$ & $.53(.76)$ & $.87(1.03)$ & $.74(.96)$ \\
\hline $\mathrm{t}^{\mathrm{sig}}$ & \multicolumn{2}{|l|}{$1.0^{\mathrm{ns}}$} & \multicolumn{2}{|l|}{$1.9^{\mathrm{ns}}$} & \multicolumn{2}{|l|}{$3.8^{000}$} & \multicolumn{2}{|l|}{$2.4^{.019}$} \\
\hline
\end{tabular}

Once again, it was the God-factor that revealed the greatest difference in the spiritual well-being scores among students studied here, similar to findings reported above and in other studies using SHALOM (Fisher 2012).

\section{Conclusion}

A survey based on the four domains model of spiritual health/well-being (Fisher 1998), among a diverse group of Australian secondary school students, yielded data that were used to develop a second spiritual well-being questionnaire, called SWBQ2, in addition to the tried and tested Spiritual Health And Life-Orientation Measure (SHALOM). As predicted, using lived experiences, for matched pairs t-tests on SHALOM and SWBQ2, revealed significant differences in scores on these four domains of spiritual well-being, by school type. As investigating lived experience is the standard technique for assessing spiritual well-being in other instruments, these findings raise questions about the meaning of scores based on single responses (e.g., lived experience) to a group of items, which may or may not have been developed from a sound theoretical foundation.

Using a double-response method, that is, comparing each respondent's ideals with lived experiences and comparing dissonance between these, showed great consistency between dissonance scores on the two measures of spiritual well-being employed here, namely SHALOM and SWBQ2. dSHALOM also yielded the strongest values from confirmatory factor analyses on SHALOM, SWBQ2 and dissonance in both these instruments. This double-response technique using SHALOM can be recommended as the best method for assessing the quality of relationships that reflect spiritual well-being in the four domains studied here. This is important because a constructivist approach to learning asks teachers to lead students from where they are at into a broader understanding of themselves, their capacities and the world around them (Packer \& Goicoecha 2000). Teachers therefore need to know their students' current levels of understanding, to provide appropriate experiences for their ongoing development. Given 
enough time, each teacher could come to a detailed understanding of each student in her/his care, through interpersonal dialogue and interaction (Lipscomb \& Gersch 2012). Realistically, this is difficult, given the complexities of [time-starved] classrooms in which most teachers operate. Therefore, teachers can benefit from help in assessing students' capacities and disposition. As well as language and mathematics skills, useful information can be obtained on temperament, personality and spiritual well-being using well-constructed, valid measures. Teachers could gain from having a profile of every student, not just for those with behavioural or learning difficulties. Such profiles can help teachers ensure that the silent majority are not taken for granted in their classrooms. To this end, SHALOM can be used as a suitable instrument to indicate the quality of relationships in four domains of spiritual well-being. Students' ideals are influenced by home, school and religious groups, for some (Fisher 2008a). Having this insight available to teachers should help ensure they do not inadvertently diminish the worldview held by any student in their class, many of whom would hold this very privately. SHALOM can also reach the heart of students, to reveal any potential dissonance between ideals and lived experiences, without causing emotional distress (Fisher 2009 Chap.15).

Overall, using the two spiritual well-being questionnaires called SHALOM and SWBQ2, with lived experiences as well as dissonance between these and ideals, the domain scores for relating with God explained the greatest variance in spiritual wellbeing and spiritual harmony, in comparison with the other three domains. So, concentrating effort on this domain will provide greatest influence on students' spiritual well-being. However, teachers must have appropriate experience in this area, because their lived experience influences how well they nurture students' spiritual well-being (Fisher 2008).

\section{References}

Bartlett, M.S. 1954. A note on the multiplying factors for various chi square approximations. Journal of the Royal Statistical Society 16, Series B: 296-8.

Casas, F., Gonzalez, M., Figuer, C. \& Malo, S. 2009. Satisfaction with spirituality, satisfaction with religion and personal well-being among Spanish adolescents and young university students. Applied Research Quality of Life 4: 23-45.

Fisher, J.W. 1998. Spiritual health: Its nature and place in the school curriculum. $\mathrm{PhD}$ thesis, University of Melbourne. Available from http://eprints.unimelb.edu.au/archive/00002994/

Fisher, J.W. 2008. Impacting teachers' and students' spiritual well-being. Journal of Beliefs \& Values 29, no. 3: 253-261.

Fisher, J.W. 2009. Reaching the heart: Assessing and nurturing spiritual well-being via education. EdD dissertation, University of Ballarat, Victoria, Australia. Available from http://archimedes.ballarat.edu.au:8080/vital/access/HandleResolver/1959.17/13481 
Fisher, J. 2010. Development and application of a spiritual well-being questionnaire called SHALOM. Religions 1: 105-121.

Fisher, J.W. 2012. The importance of relating with God for spiritual well-being. In Spirituality: New reflections on theory, praxis \& pedagogy. Eds M.C. Fowler, M. Weiss \& J.L. Hochheimer, 147-161. Oxford, UK: InterDisciplinary Press.

Gidley, J. 2005. Giving hope back to our young people: Creating a new spiritual mythology for western culture. Journal of Futures Studies: Epistemology, Methods, Applied and Alternative Futures 9: 17-30.

Johnson, M.E. et al. 2007. Measuring spiritual quality of life in cancer patients. The Journal of Supportive Oncology 5, no. 9: 437-42.

Kaiser, H. 1974. An index of factorial simplicity. Psychometrika 39: 31-6.

Koenig, H.G. 2009. Research on religion, spirituality and mental health: A review. Canadian Journal of Psychiatry 54, no. 5: 283-91.

Lipscomb, A. \& Gersch, I. 2012. Using a 'spiritual listening tool' to investigate how children describe spiritual and philosophical meaning in their lives. International Journal of Children's Spirituality 17, no. 1: 5-23.

Meezenbroek, E deJ. et al. 2012. Measuring spirituality as a universal human experience: A review of spirituality questionnaires. Journal of Religion \& Health 51, no. 2: 336-54.

Meyers, L.S., Gamst, G. \& Guarino, A.J. (2013) Applied multivariate research: Design and interpretation. $2^{\text {nd }}$ ed. Sage Pubs: Thousand Oaks, CA.

Moss, S. 2009. Fit indices for structural equation modeling. http://www.psychit.com.au/Psychlopedia/article.asp?id=277 (accessed 3 April 2013).

Olver, I.N. \& Dutney, A. 2012. A randomized, blinded study of the impact of intercessory prayer on spiritual well-being in patients with cancer. Alternative Therapies in Health \& Medicine 18, no. 5: 18-27.

Packer, M.J. \& Goicoecha, J. 2000. Sociocultural and constructivist theories of learning: Ontology, not just epistemology. Educational Psychologist 35, no. 4: 227-241.

Pargament, K.I. 1999. The Psychology of Religion and Spirituality? Yes and No. The International Journal for the Psychology of Religion 9, no. 1: 3-16.

Roehlkepartain, E.C. et al. 2008. With their own voices: A global exploration of how today's young people experience and think about spiritual development. Minneapolis, Minnesota, USA: Search Institute. 


\subsection{Summary of Chapter 7}

A synthesis of many studies that have used SHALOM showed there are great similarities across cultures in people's responses to questions on their Personal and Communal spiritual well-being. Varying emphases are reported on relationship with the environment. However, the greatest divergence of views across the range of studies was apparent in terms of people's relationship with God.

A double response/dissonance method of comparing each person's ideals for spiritual well-being with their lived experiences provides a fairer and better assessment of the quality of their relationships, which reflect their spiritual well-being in each of four domains. This view holds from a theoretical perspective. Since expressions used in the 20 items of the SWB instruments (e.g., love, trust, peace with God) will have different meanings for different people, it is better to compare each person with themselves than with an arbitrary group norm based on other people's diversity of meanings for each item. The dissonance method also provides stronger psychometric properties as is revealed by Confirmatory Factor Analyses reported here.

Two sets of Regression Analyses, using (i) lived experience scores and (ii) dissonance scores, revealed that people's relationship with God explains greatest variance in their overall spiritual well-being. This can be interpreted as indicating that, of the four sets of relationships studied, relationship with God is the most important for spiritual well-being among the variety of people surveyed. 


\section{Chapter 8 God, other Transcendents and spiritual well-being}

\subsection{Introduction}

Previous chapters in this thesis have reported many studies using SHALOM to assess four domains of spiritual well-being. The cumulative results of these studies are two-fold. Firstly, it is clear that my double-response method of comparing each person's lived experience with their stated ideals for spiritual well-being is a fairer and better method of assessing the quality of relationships which reflects their spiritual well-being, rather than simply investigating their lived experience only, which is what other researchers' spirituality/well-being measures do.

Secondly, the results have shown that one's relationship with God (Transcendental SWB) explains the greatest variance in one's spiritual well-being overall (using both (i) lived experience scores only, and (ii) dissonance scores). In this regard, relating with God is shown to be the most important of the four domains studied for people's spiritual wellbeing.

\subsection{You can't beat God for spiritual well-being - with a generic SHALOM Background}

Some people, admittedly only a vocal minority, have objected to the use of the word (and thus the concept of) 'God' being used in SHALOM, mainly because it does not fit their worldview. Quantitative researchers should not use their own worldview as the lens through which they try to discern meaning of reality. I live in the Western world in which census data reveal that the majority of people claim some form religious affiliation, most of which are God-based. An increasing number of Westerners appears to be loosening ties with organised religions, but this does not mean that their relationship with God is necessarily waning. An increasing number of people claim to believe in God without belonging to an organised religious group (Davie, 2004). In Eastern sectors of the world, many religions are not God-based.

Therefore, in order to be as fair as possible to all, and in order to make SHALOM as universally applicable as possible, I tried to determine if a generic version of this SWB measure could be constructed. Such a version would need to maintain similarly strong psychometric properties as the original (or even improve on them). To this end, the theistic words 'God', 'Divine' and 'Creator' were replaced by the word 'Transcendent' in four of the five items in the Transcendental domain of SWB in SHALOM. Eighteen alternative Transcendents were presented to survey respondents to choose from to 
represent 'someOne or someThing beyond the human and natural worlds that influences your life'. A nineteenth alternative was provided, 'not an area in which I believe'.

Invitations to participate in a web survey were sent to 600 people whom I knew to be involved with spirituality and religious education, as well as some I knew to be directly opposed to religion of all kinds (members of the Australian Atheist Forum), on the grounds that they should have a clear idea, or at least a strong opinion, as to what spiritual well-being entails.

\section{Key findings extracted from this paper}

- Completed responses were received from 453 people in 13 geographic regions across the world, $58 \%$ of whom indicated they had a relationship with a theistic Transcendent; $19 \%$ chose other religious forms of Transcendent; $15 \%$ selected a nontheistic Transcendent; and 8\% denied belief in any form of Transcendent influence on their lives.

- Principal Components Analyses of the revised SHALOM instrument revealed four components which mirrored the original instrument. These four components also loaded onto a single higher-order factor called spiritual well-being. Regression Analysis of this four-domains-in-one measure showed that Transcendental spiritual well-being explained the greatest variance in SWB overall, just as the God-factor had shown the greatest variance in previous studies with the original version of SHALOM.

- The original and generic SHALOM instruments were compared using Confirmatory Factor Analyses. The modified form yielded acceptable fit indices, but they were not quite as good as the original, which had used 'God' terms. Separation of the sample showed that respondents who chose nontheistic Transcendents gained acceptable fit indices, but those embracing theistic Transcendents did not. This finding applied to the lived experiences alone, as well as to dissonance between ideals and lived experiences. In other words, 'God' was more acceptable than 'Transcendent' for the majority of people in this study.

\section{Implications}

In early studies, survey respondents used their own interpretation of the word 'God' in SHALOM, just as they did for every other term. This worked well. With increasing secularisation, and for political reasons (e.g., separation of Church and State in the US preventing researchers using the 'God' word in surveys in schools), the word 'Transcendent' may be used in some circumstances. However, this generic term does not 
produce as good a spiritual well-being instrument as the original. The nature of the cohort being investigated should determine which version of SHALOM is used, not the worldview of the researchers.

The generic form of SHALOM can be used with well-educated people who claim the influence of a nontheistic Transcendent on their lives. The original SHALOM, which used 'God' words, is preferable for people who have a personal/theistic Transcendent in whom they believe.

More research is needed with a wide range of people to test the general applicability of these findings.

\section{Paper:}

This paper was published as: Fisher, J.W. (2013) You can't beat relating with God for spiritual well-being: Comparing a generic version with the original Spiritual Well-Being Questionnaire called SHALOM. Religions, 4: 325-335.

\section{John Fisher}

School of Education \& Arts, University of Ballarat, Victoria 3350 Australia Email: j.fisher@ballarat.edu.au

\section{Abstract}

The Spiritual Health And Life-Orientation Measure (SHALOM) is a 20-item instrument that measures the quality of relationships of the respondent with self, others, the environment and/or a Transcendent Other. In the Transcendental domain, four of the five items had the words 'God, 'Divine' and 'Creator' replaced by the word 'Transcendent' to make the survey more generic by removing any implied reference to any god or religion. Invitations to complete a web survey were sent to people who had published papers in spirituality, or belonged to associations for spirituality or religious studies, as well as the Australian Atheist Forum. 409 respondents from 14 geographic regions, completed the survey. Confirmatory factor analysis revealed that the modified, generic form of SHALOM showed acceptable model fit, comprising four clearly delineated domains of spiritual well-being. The paper analyses the results derived from using the modified, generic version and, in comparison with results of applications of the original survey instrument, concludes with discussion of the comparative utility of each of the versions of SHALOM. Further studies with more people are warranted, but, from evidence presented here, it looks like you can't beat relating with God for spiritual well-being.

Keywords: spiritual well-being; measures; God; SHALOM

\section{Background}

It is not surprising that the concept God is pre-eminent in National Interfaith Coalition on Aging's [italics for emphasis] description of spiritual well-being as 'the affirmation of life in relationship with God, self, community and environment that nurtures and celebrates wholeness' [1]. By 1983, a broad understanding of spirituality had been unleashed from its roots in Roman Catholic monastic moorings [2], which provided a traditional bi-polar view of spirituality as (i) the individual on a quest (ii) to find her/his truest self in the 
context of reality [3]. This reality, or cosmic totality, may be God or some other Transcendent, a generic, secular term that had replaced God for some people by the end on the twentieth century [4]. A more recent shift in the understanding of spirituality was not instigated by the further inclusion of secular ideas into definitions of spirituality, but by a move from the dual structure (of personal quest, for an external reality) to an inward focus. The notion of the Self became paramount, with individual freedom and search for meaning becoming the whole focus of spirituality for many (ibid.). This focus is evident in the structure of numerous instruments designed to measure spirituality and spiritual health/well-being investigated by Fisher [5]. The most significant focus of these measures was on relationship with self, exceeding that of relationship with God, followed by relationship with others, with least emphasis on the environment.

Very few instruments contain equal numbers of items by which to assess these four domains of spirituality or spiritual health/well-being, namely relationships with self, others, environment and Transcendent Other (commonly called God). The Spiritual Health And Life-Orientation Measure (SHALOM), which was first reported in 1999 [6], is one such instrument. It has been sought for use in over 200 studies in 20 languages [7]. SHALOM has been thoroughly tested for its statistical validity [8-10]. Its 20 items are distributed evenly over four domains of spiritual well-being, and measures quality of relationships with oneself, with others, with the environment and/or with a Transcendent Other [7]. Simple language was selected to enable respondents to understand and probe complex constructs, as SHALOM was developed for use with secondary school students, in the belief that an instrument suitable for them would also be useful for adults.

Consequently, the words 'God', 'Divine' and 'Creator' appeared in four of the five items used to assess the Transcendental domain of spiritual well-being, because notions such as 'higher power' and 'godlike force' were less comprehensible to the students [11].

Participants in studies using SHALOM have made negligible comment about the composition of the Transcendental factor, using 'God' and related terms. It is mainly academics who have voiced concern that the current form of SHALOM favours people with theistic beliefs, because it includes the word 'God'. However, this criticism is not valid, because SHALOM employs a double-response method of comparing each person's ideals with their lived experience. So, if a person does not embrace a belief in any god, then there will be no dissonance when they score 'very low' (equivalent to negligible or none) on lived experience in this domain, as it will match their presumably 'very low' scores for their ideals relating to spiritual well-being. This function separates SHALOM from other instruments which can underrate people's spiritual well-being if they score low on lived experience in this area, in comparison with other people's scores.

The most contentious issue in discussions of spiritual well-being relates to the question of a Transcendent Other (that is, some-One or some-Thing that exists beyond the human and natural worlds) having influence over humans. Worldviews and opinions are many, but empirical studies of them are few. Research needs to focus clearly on discussions of the Transcendent. To this end, the project being reported in this paper investigated whether replacing the words 'God,' 'Divine' and 'Creator' with the word 'Transcendent' would lead to as valid a spiritual well-being questionnaire as the original SHALOM has proven to be. If so, the modified SHALOM could be a more generic 
instrument, suitable for use with people embracing worldviews ranging from belief in God to disbelief in any Transcendent.

\section{Procedure}

With increasing interest in spirituality and well-being, especially over the last 30 years, numerous quantitative surveys have been developed [5, 12-15]. Of these many instruments, recent evidence has been presented to show that the spiritual well-being questionnaire, called SHALOM, is considered the best [16], or most promising [17], of all available spiritual well-being measures. That notwithstanding, in light of the claim of theistic bias levelled at the existing SHALOM, four of the five original Transcendental factor items had the words 'God,' 'Divine' and 'Creator' replaced by the word 'Transcendent.' In the revised version, respondents were presented with the statement, 'When people believe their lives are influenced by SomeOne or SomeThing beyond the human and natural worlds, they use different words. Please choose one of the following to show what best describes the supernatural influence in your life. 'Eighteen alternatives were provided, namely Allah, Angel/s, Buddha, Deceased person, Deity/deities, Divine, Fate, Father God, Gaia, God, Heaven, Higher power, Higher self, Mystery, Otherness, Presence, Something there, Universe/universal spirit' or 'Not an area in which I believe.'

The following comments were also placed on the survey, 'What you have chosen can be called the Transcendent influence on your life. Please keep this interpretation in mind when you see the term Transcendent in the questions that follow.' Respondents were asked for two responses on each of the 20 items on SHALOM, to indicate the importance of each item for (i) their ideals for spiritual well-being, and (ii) their lived experiences, using a 5-point Likert scale with a continuum from 'very low' (scored as 1) to 'very high' (scored as 5).

Six hundred people, who had published papers on spirituality that had been accessed by the author, were sent an email invitation to complete an online survey, comprising the revised 20-item SHALOM, together with questions on demographics and background beliefs. The survey was also advertised among members of the International Association for Children's Spirituality, the International Seminar on Religious Education and Values, the Parliament of the World's Religions and was promoted by the Director of the Centre for Religious and Spirituality Education in Hong Kong, as well as amongst people who are not likely to believe in the supernatural/Transcendent, namely in the Atheist Foundation of Australia, via their web Forum. It was anticipated that the survey would take 10 to 15 minutes to complete. Potential participants were also asked to let others know about the survey, in an effort to extend the sample size using a snow-ball technique.

Data, collected using the LimeSurvey technique, were subjected to basic statistical and maximum likelihood confirmatory factor analyses (using SPSS and AMOS). These results, and those from previous studies employing similar statistical techniques, were used to compare the usefulness of the revised and original versions of SHALOM in measuring and explaining relationships in each of four domains of spiritual well-being, with particular emphasis on the Transcendental domain of spiritual well-being. 


\section{Results and discussion}

\subsection{Participants}

A total of 409 completed web-surveys were received from 14 people in geographic regions (Australia/New Zealand 62, Pacific OECD 3, Central Asia/China 24, Southern Asia 37, Middle East/North Africa 9, Saharan Africa 8, Southern Europe 5, Central Europe 31, Western Europe 46, former Soviet Union 51, UK 56, North America 69, Central America 1, South America 7). Fifty six percent of these were in direct response to a written invitation from the author, $40 \%$ by referred invitation, and $4 \%$ by direct access to the survey on the web. Females comprised 59\% of the cohort (mean age 38.8 years, SD $=15.1$ ), with $41 \%$ males (mean age 45.7 years, $\mathrm{SD}=17.1$ ). English was not the primary language spoken for $52.3 \%$ of the respondents. Sixty-five percent were either married $(58 \%)$ or had been married (6\% divorced/separated, $1 \%$ widowed).

The education level of the respondents exceeded that of the general population with $64 \%$ claiming a post-graduate degree, $8 \%$ a post-graduate diploma and $16 \%$ an undergraduate degree. The majority were professionals working with people (78\%) and technology $(9 \%)$ or were managers $(8 \%)$. A wide range of worldviews was held by participants (agnostic 21, atheist 26, Baha'i 1, Buddhism 28, Catholic/Orthodox Christianity 110, Protestant Christianity 137, Christian Science 10, environmentalism 6, existentialism 5, Hari Krishna 1, Hindu 5, humanism 9, Islam 24, Judaism 10, Jehovah's Witness 1 , native spirituality 4 , Shinto 2 , Tao 5, Wicca 2, Zoroastrianism 1). In short $18 \%$ claimed no religious affiliation, $27 \%$ Catholic, 33\% Protestant, $22 \%$ other religions. A broad range of views was also shown on the description of a Transcendent influencing the participants (Allah 23, Angel/s 11, Buddha 6, Deceased person 2, Deity/deities 5, the Divine 11, Fate 21, Father God 58, Gaia 1, God 150, Higher power 23, Higher Self 9, Mystery 10, Otherness 5, Presence 13, Something there 6, Universe/universal spirit 16; Not an area believed in 39).

\subsection{Comparison groups}

As the respondents to the web-survey were more educated than the general population, a similarly-sized sample of university students and staff was selected from respondents to previous studies, which used the original SHALOM $[18,19]$. This sample was made up of 378 older students and staff in an Australian public university, $72 \%$ of whom were female; $53 \%$ were aged in their 20 s, $15 \%$ in their 30 s, $18 \%$ in their $40 \mathrm{~s}$, and $13 \%$ aged over 50. Forty percent had no religious affiliation, $27 \%$ were Catholic, 30\% Protestant and $3 \%$ followed other religions. Another sample, comprising 460 secondary school students among whom SHALOM was originally developed, comprised $49 \%$ females and $51 \%$ males, aged 12 to 18 years, in Years 7 to 12 in State, Catholic, Christian Community and other independent schools in Victoria, Australia; 22\% of these claimed no religion, $26 \%$ Catholic, $50 \%$ Protestant and $2 \%$ other religion [11].

\subsection{Psychometric properties of the revised, generic SHALOM, and comparison with the original}

Principal component analysis of responses from the web survey of the revised SHALOM revealed the presence of four components, which explained $72.5 \%$ of total variance. All 
the variables loaded onto the appropriate scales revealing sound measures for Personal, Communal, Environmental and (modified) Transcendental domains of spiritual wellbeing. Reliability analyses of the scales yielded good Cronbach's $\alpha$-coefficients, with the Transcendental domain yielding a very good value of .95 (for details see Table 1).

Table 1. Pattern matrix for PCA with Oblimin Rotation of 4-factor solution of generic SHALOM items, together with Cronbach's alpha coefficient for reliability analyses of scales

\begin{tabular}{|c|c|c|c|c|}
\hline Item & Com SWB & Tra SWB & Env SWB & Per SWB \\
\hline Identity & & & & .88 \\
\hline Self-awareness & & & & .82 \\
\hline Joy & & & & .40 \\
\hline Inner peace & & & & .41 \\
\hline Meaning & & & & .40 \\
\hline Love others & .77 & & & \\
\hline Forgive others & .79 & & & \\
\hline Trust & .68 & & & \\
\hline Respect others & .79 & & & \\
\hline Kindness & .83 & & & \\
\hline Connect with nature & & & .79 & \\
\hline Awe at view & & & .62 & \\
\hline One with nature & & & .92 & \\
\hline Harmony with & & & .79 & \\
\hline environment & & & & \\
\hline 'magic' in environment & & & .80 & \\
\hline Relation with & & .92 & & \\
\hline Transcendent & & & & \\
\hline Worship Transcendent & & .90 & & \\
\hline One with Transcendent & & .86 & & \\
\hline Peace with Transcendent & & .89 & & \\
\hline Prayer life & & .88 & & \\
\hline Eigenvalue (\% variance) & $8.93(44.7 \%)$ & $2.78(13.9 \%)$ & $1.87(9.3 \%)$ & $1.00(4.6 \%)$ \\
\hline alpha value & .88 & .95 & .87 & .86 \\
\hline mean(SD) & $4.02(.74)$ & $3.33(1.25)$ & $3.32(.98)$ & $3.98(.78)$ \\
\hline
\end{tabular}

NB. Per SWB = Personal spiritual well-being, Com = Communal, Env = Environmental, Tra $=$ Transcendental. Only values .40 and above are recorded.

When subjected to principal components analysis, these four domains cohered into a single higher-order factor, called spiritual well-being (SWB) (Kaiser-Meyer-Olkin value $=.74,63.8 \%$ total variance explained). As spiritual well-being is made up of these four domains, linear regression analysis was performed to determine the relative contribution made by each of them to the whole. At .42, the $\beta$-value for Transcendental SWB far exceeded the others (Personal SWB .27, Communal SWB .25, Environmental SWB .33), indicating that Transcendental spiritual well-being explained greatest variance in spiritual well-being overall. This finding parallels those of the original SHALOM, which 
concluded that relating with God is shown to be most important for spiritual well-being $[11,20]$.

Confirmatory factor analyses (CFA) were performed using AMOS to investigate the relative construct validity of the original and modified versions of SHALOM, with their four component factors. As there is not a sole appropriate test, a range of fit indices was selected to test the CFA models to see which best represents the data sets. Absolute fit indices were the relative Chi-square $\left(\mathrm{X}^{2} / \mathrm{df}\right)$, Akaike's Information Criterion (AIC), and the Expected Cross-Validation Index (ECVI). Relative Fit Indices were the Incremental Fit Index (IFI), Normed Fit Index (NFI) and Tucker-Lewis Index (TLI). The Parsimonious Normed Fit Index (PNFI) was used. Noncentrality-based Indices were the Root Mean Square Error Approximation (RMSEA) and the Comparative Fit Index (CFI). The target values to indicate good fit indices are listed in the bottom row of Table 2 [20, 21].

Values of fit indices for the modified version of SHALOM displayed borderline acceptability, for relative Chi-square (with $\mathrm{X}^{2} / \mathrm{df}>3.5$, where values below 2 are good, those between 2 and 3 are generally considered acceptable, with some people accepting up to 5) and RMSEA (value of .078, which is just below the normally accepted upper limit of .08). The two cohorts that were tested using the original version of SHALOM, employing the term God, displayed acceptable to good values on the fit indices investigated. Despite considerable differences in age and world-views, especially religious aspects, between the secondary school and university cohorts studied, their fit indices for the original SHALOM were markedly similar, indicating the consistency of this instrument as a measure of spiritual well-being. Although the modified, more generic form of SHALOM, using the term Transcendent, is an acceptable measure of spiritual well-being, it is not as good as the original, which employs the term God in the measure of Transcendental SWB (see Table 2).

Table 2. Summary results for confirmatory factor analyses of versions of SHALOM

\begin{tabular}{|l|l|l|l|l|l|l|l|l|l|}
\hline $\begin{array}{l}\text { Version of } \\
\text { SHALOM }\end{array}$ & $\mathrm{X}^{2} / \mathrm{df}$ & AIC & ECVI & IFI & NFI & TLI & PNFI & RMSEA & CFI \\
\hline Uni. sample & 2.70 & 574 & 1.51 & .944 & .914 & .935 & .79 & .067 & .944 \\
\hline Sec. students & 2.70 & 575 & 1.25 & .941 & .909 & .931 & .79 & .061 & .940 \\
\hline Generic & 3.51 & 668 & 1.64 & .931 & .906 & .920 & .78 & .078 & .931 \\
\hline good range & $<2-3$ & lowest & lowest & $>.90$ & $>.90$ & $>.90$ & $>.50$ & $<.05-.08$ & $>.93$ \\
\hline
\end{tabular}

\section{Conclusion}

Four of the five items in the Transcendental domain of the original Spiritual Health And Life-Orientation Measure (SHALOM) were adjusted by replacing the words 'God, 'Divine' and 'Creator' with the word 'Transcendent.' Before completing the 20-items on the revised SHALOM in a web survey, respondents who had previously expressed 
interest in spirituality, or a likely aversion to it, were asked to indicate their description of any Transcendent influence on their lives, or if they did not believe in such an entity. Confirmatory factor analysis revealed that the modified, generic form of SHALOM showed acceptable model fit, comprising four clearly delineated domains of spiritual well-being. Of particular interest was the finding that the modified Transcendental domain of spiritual well-being holds together well statistically and provides the greatest explanation of variance in spiritual well-being overall. This modified SHALOM can be employed in future studies as a generic measure of spiritual well-being across a variety of worldviews. However, the nature of the cohort under investigation should determine which version of SHALOM is used, not the worldview of the investigators.

It should also be kept in mind that the model fit for the more generic version of SHALOM was not as good as that for the original, when it was compared with a select sample of university students and staff, and a cohort of secondary school students. Further studies with more people are warranted, but, from evidence presented here, it looks like you can't beat relating with God for spiritual well-being.

\section{References}

1. National Interfaith Coalition on Aging. Spiritual well-being: A definition. Athens, GA.: Author, 1975.

2. Principe, W. Toward defining spirituality. Stud. Relig., 12 (1983): 127-141.

3. Van Ness, P.H. Spirituality and the secular quest. NY: Crossroad Publishing Co., 1996.

4. Bregman L. Spirituality definitions: A moving target, In Spirituality: Theory, praxis and pedagogy, Edited by M. Fowler, J.D. Martin III, J.L. Hochheimer. Oxford, UK: InterDisciplinary Press, 2012, pp. 4-10.

5. Fisher, J.W. Reaching the heart: Assessing and nurturing spiritual well-being via education. EdD dissertation, University of Ballarat, Victoria, Australia, 2009. Available from http://archimedes.ballarat.edu.au:8080/vital/access/HandleResolver/1959.17/13481

6. Fisher, J. W. Developing a Spiritual Health And Life-Orientation Measure for secondary school students. In Research with a regional/rural focus: Proceedings of the University of Ballarat inaugural annual research conference, Edited by J. Ryan, V. Wittwer, P. Baird. Ballarat, Australia: University of Ballarat, Research and Graduate Studies Office, 1999, pp. 57-63.

7. Fisher, J. Development and application of a spiritual well-being questionnaire called SHALOM. Religions, 1 (2010): 105-121.

8. Gomez, R., and Fisher, J.W. Domains of spiritual well-being and development and validation of the Spiritual Well-Being Questionnaire. Pers. Indiv. Differ., 35 (2003): 1975-1991. 
9. Gomez, R., and Fisher, J.W. Item Response Theory analysis of the Spiritual WellBeing Questionnaire. Pers. Indiv. Differ., 38 (2005): 1107-1121.

10. Gomez, R., and Fisher, J.W. The Spiritual Well-Being Questionnaire: Testing for model applicability, measurement and structural equivalencies and latent mean differences across gender. Pers. Indiv. Differ., 39 (2005): 1383-1393.

11. Fisher, J.W. Assessing spiritual well-being: Relating with God explains greatest variance in spiritual well-being among Australian youth. Int. J. Children's Spiritual. 18, (2013): 306-317.

12. Hill, P.C., and Hood, R.W. Measures of Religiosity. Birmingham, AL, USA,: Religious Education Press, 1999.

13. MacDonald, D.A., Kuentzel, J.G., and Friedman, H.L. A survey of measures of transpersonal constructs. Part II - Additional instruments. J. Transpers. Psychol., 31 (1999): 155-177.

14. Koenig, H.G., McCullough, M.E., and Larson, D.B. Handbook of Religion and Health. Oxford, UK: Oxford University Press, 2001.

15. Vivat, B. Measures of spiritual issues for palliative care patients: A literature review. Palliat. Med., 22 (2008): 859-868.

16. Moodley, $\mathrm{T}$. The relationship between coping and spiritual well-being during adolescence. PhD dissertation, Department of Psychology, University of the Free State, Bloemfontein, South Africa, 2008.

17. Meezenbroek, E deJ., Garssen, B., van den Berg, M., van Dierendonck, D. et al. Measuring spirituality as a universal human experience: A review of spirituality questionnaires. J. Relig. Health., 51 (2012): 336-54.

18. Fisher, J.W., and Sellers, E.T. Quality of life in the workplace: spirituality, meaning and purpose. Refereed paper in the Proceedings of the $3^{\text {rd }}$ Annual Conference on Spirituality, Leadership and Management, University of Ballarat, Australia, 2000, pp. 14-19.

19. Fisher, J.W. Investigating Australian education students' views about spiritual wellbeing as compared with teachers in schools. Int. J. Children's Spiritual., 14 (2009): 151-167.

20. Fisher, J.W. The importance of relating with God for spiritual well-being. In Spirituality: New reflections on theory, praxis \& pedagogy. Edited by M.C. Fowler, M. Weiss, J.L. Hochheimer. Oxford, UK: Inter Disciplinary Press, 2012; pp. 147161. 
21. Moss, S. Fit indices for structural equation modelling. 2009. http://www.psychit.com.au/ Psychlopedia/article.asp?id=277 (accessed on 3 April 2013).

22. Meyers, L.S., Gamst, G., and Guarino, A.J. Applied multivariate research: Design and interpretation, $2^{\text {nd }}$ ed. Thousand Oaks, CA: Sage Publications, 2013.

\subsection{Comparing the influence of God and other Transcendents on spiritual well-being.}

\section{Background}

Although the psychometric properties of the generic form of SHALOM are not quite as strong as those of the original instrument, the generic form is still an acceptable measure of spiritual well-being. The generic form of SHALOM has the advantage that it identifies various forms of Transcendent, that can be used to answer the second research question posed in this thesis, 'How does relating with a Transcendent influence other domains of spiritual well-being?'

\section{Key findings extracted from this paper}

- Of the 453 highly educated survey respondents, 59\% reported they were Christian, $23 \%$ stated they embraced other religions and $18 \%$ expressed no religious affiliation.

- Significant correlations were found on lived experience scores between Transcendental SWB and the other three domains of SWB, for all but the respondents who did not believe in a Transcendent.

- However, the strongest correlations were found on dissonance scores between Transcendental SWB and Personal and Communal SWB for those embracing Theistic Transcendents (i.e., relating with (Father) God and Allah).

- Morever, Regression Analyses showed that only relating with theistic Transcendents (such as God) contributed significantly to variance in both lived experience and dissonance for Personal and Communal SWB.

- Further research is needed to ascertain the exact nature of the relationship between Transcendental and Environmental SWB. 


\section{Implications}

Relating with God (theistic Transcendent) facilitates relationship with self and other people to a significant extent, which relating with other Transcendents fails to do. These results indicate that, although everyone has the right to express their views as to what seems important to them, not all views are of equal value in practice.

These studies show that relating with God must be included in studies of spiritual well-being, otherwise the key component thereof is excluded. Furthermore, Australian schools need to ensure that they provide opportunities for students to critically evaluate the impact of the four sets of relationships that nurture spiritual well-being, especially the most important one - relating with God. Failure to do this would mean that these schools would continue to fall short of the joint Australian Ministers of Education's edicts that spiritual development and well-being of young people is a core curriculum goal in the twenty-first century.

Paper:

This paper has been published as Fisher, J.W. (2014). Comparing the influence of God and other Transcendents on spiritual well-being. Religious Education Journal of Australia, 30(2): 9-15.

\section{Comparing the influence of God and other Transcendents on spiritual well-being Dr John W Fisher}

Adjunct Associate Professor, Faculty of Education \& Arts, Federation University Australia.

Email: j.fisher@federation.edu.au

\footnotetext{
Abstract

The Spiritual Health And Life-Orientation Measure (SHALOM) comprises 20 items, spread evenly over four domains, assessing the quality of relationships people have with themselves, others, the environment, and/or with a Transcendent. The Transcendent domain of the original version of SHALOM was heavily God-oriented, as students with whom it was developed did not understand terms such as 'higher power.' Over the years SHALOM has been used, a few people have questioned its general applicability, because of the word 'God.' Therefore a generic form of SHALOM was recently developed which replaced the God-words with the word 'Transcendent', providing nineteen alternatives from which respondents could choose, including an option, "not an area in which I believe."
} 
An invitation to complete a web-survey using this generic SHALOM instrument was sent to 600 people most of who were involved in spirituality and religious studies; some were atheists. 453 complete returns have been analysed to show that the generic form of SHALOM yields acceptable psychometric properties.

This presentation compares two methods of interpreting data from the survey. Using lived experience only, some variation was shown on Personal and Environmental spiritual wellbeing (SWB), with relationship with God dominating Transcendental SWB. The alternative dissonance method, comparing lived experience with ideals, shows greater sensitivity, with people who relate with God expressing least dissonance between ideals and lived experience over the four domains of spiritual well-being. Those who claim nontheistic Transcendents, such as fate, higher self and higher power, as their motivating forces in life show greatest dissonance, therefore less spiritual well-being. Relating with God helps people relate better with self and others compared with other Transcendents studied here. This finding has clear implications for Religious Education as a starting point by which to enhance students' spiritual well-being in line with the Australian Ministers of Education's edicts.

Key words: God; Transcendents; spiritual well-being

\section{Introduction}

Some people believe that spirituality must reflect relationship with the sacred, however defined (Pargament, 2007; Koenig, 2011). Moberg contends, "Theology is implicated in every aspect of studying spirituality, even if that is not recognized by most nontheologians" (Moberg, 2011, p.13). A broader description of spirituality sees it as "all attempts to find meaning, purpose, and hope in relation to the sacred or significant (which may have a secular, religious, philosophical, humanist, or personal dimension)" (Büssing et al., 2014). Recent research has investigated the effect or impact of spirituality on health and well-being (e.g., Park, 2007; Ellsworth, 2010; Rosmarin et al., 2011; Büssing et al., 2014). Over the last three decades, a plethora of instruments has been developed to assess aspects of spirituality, spiritual development and spiritual well-being (Hill \& Hood, 1999; Fisher, 2009; Koenig et al., 2012). The key focus of each of these instruments appears to reflect the worldview held by its developer/s (Moberg, 2002), some of whom deny a Transcendental influence on life.

Spirituality affects each person's relationship with themselves, and others, as well as the environment in which we live and move, and have our being. Spiritual health is reflected in the quality of relationships that people have in those three domains, as well as in a possible fourth domain, that provides a focus on a Transcendent, for those for whom it is important (Fisher, 1998). The Spiritual Health And Life Orientation Measure (SHALOM) was built on the four domains model of spiritual health and well-being (Fisher, 1998; 2011), which provides for a range of worldviews from atheistic/humanistic to religious.

SHALOM has been sought for use in over 400 studies in 23 languages, increasingly in medical environments, as well as counselling, education, pastoral care and vocational settings. The original Spiritual Health Measure that was developed comprised 30 items to investigate relationships with self, others, environment and God as well as rationalistic 
ideas (Fisher, 1998). This was refined, leading to SHALOM which comprises 20 items, with five in each of four domains of spiritual well-being (SWB) that reflect quality of relations with self, with others, with the environment and/or with a Transcendent (Fisher, 1999; 2010). As this instrument was developed with secondary school students, the fourth domain uses God-words, since these students did not comprehend more esoteric terms, such as "higher power" (Fisher, 2013a).

Over the years SHALOM has been presented at conferences, several people who did not believe in metaphysical realities criticised SHALOM for being too God-oriented, even though the word 'God' only features twice in the 20 items. Non-theism is definitely a very minor worldview as presented in the list of world religions (CIA, 2010) comprising an estimated $2.0 \%$ atheist, $9.7 \%$ non-religious in contrast to $33.4 \%$ Christian, $22.7 \%$ Muslim, 13.8\% Hindu, 6.8\% Buddhist, 0.4\% Sikh, 0.2\% Jewish, 0.1\% Baha’̌, 11.0\% other religions. With the vast majority of the world's population reflecting some form of religious belief, related with a god, these few comments by non-theists could easily have been dismissed as inconsequential. However, as it is most desirable to allow each person equal opportunity of presenting her/his view, a generic version of SHALOM was recently developed, in which each person can choose from a list of alternative Transcendents, or claim no such influence in her/his life (Fisher, 2013b).

Previous research using SHALOM has shown that the Transcendental domain of spiritual well-being provides greatest explanation for variance in spiritual well-being overall (Fisher, 2012; 2013a). The question that followed from that finding is the key focus of this presentation, namely: "How does relationship with God, or other Transcendents, influence other aspects of spiritual well-being, namely relationship with self, others and environment?"

\section{Method}

\section{Research instrument}

SHALOM is a spiritual well-being questionnaire that comprises four factors, each of which has five questions in which each question elicits a response on a five-point Likert scale, yielding a range of raw scores from 5 to 25 , or mean values from 1.00 to 5.00 , for each factor. Cronbach's $\alpha$-values for Personal SWB (.85), Communal SWB (.87), Environmental SWB (.86) and Transcendental SWB (.94) show that the five-item sets cohere strongly as the designated factors of spiritual well-being in the SHALOM instrument used in this study. SHALOM has been rigorously tested by Confirmatory Statistical Analyses in several languages (Fisher, 2010). It is one of only two spirituality measures subjected to Item Response Theory analysis (Hall, Reise \& Haviland, 2007). This spiritual well-being questionnaire has been described as the most promising available measure of spiritual well-being (Meezenbroek et al., 2012). 


\section{Procedure}

Invitations were sent by email to 600 people who had published papers or given conference presentations on spiritual issues, together with general invitations on the websites of the Australian Atheist Forum, International Association for Children's Spirituality, International Seminar on Religious Education and Values, and the Parliament of the World's Religions. The Director of the Centre for Religious and Spirituality Education in Hong Kong also promoted the survey among his Asian colleagues and students. The invitation was to complete a web survey entitled 'Background, beliefs and spiritual well-being' using the LimeSurvey technique. The survey contained 8 demographic questions, 11 questions about beliefs and religion, and sought two responses (indicating ideals and lived experiences) on each of the 20 items comprising SHALOM (Fisher, 2013b).

The survey questions were asked, following:

"When people believe their lives are influenced by SomeOne or SomeThing beyond the human and natural worlds, they use different words. Please choose one of the following to show what best describes the supernatural influence in your life." Nineteen alternatives were provided, namely “Allah, Angel/s, Buddha, Deceased person, Deity/deities, Divine, Fate, Father God, Gaia, God, Heaven, Higher power, Higher self, Mystery, Otherness, Presence, Something there, Universe/universal spirit" or "Not an area in which I believe." "What you have chosen can be called the Transcendent influence on your life. Please keep this interpretation in mind when you see the term Transcendent in the questions that follow."

Personal SWB was assessed by responses to five items - developing 'identity', 'self-awareness', 'joy', 'inner peace', and 'meaning'. Communal SWB was assessed using the five items - developing 'love of others', 'forgiveness toward others', 'trust', 'respect' and 'kindness'. Environmental SWB employed 'connecting with nature', 'awe at a view', 'one with nature', 'harmony with environment', and 'magic' in the environment' as its five items. Transcendental SWB queried 'relation with Transcendent', 'worship of Transcendent', 'one with Transcendent', 'peace with Transcendent' and 'prayer life'.

Data underwent Analysis of variance (ANOVA), correlation and regression analyses, using SPSS for Windows Version 21.

\section{Results and Discussion}

\section{Participants}

Completed web surveys were received from 453 respondents who came from 13 geographical regions (Australia/NZ 64, Pacific 5, Central Asia/China 28, Southern Asia 54, Middle East/ North Africa 12, Saharan Africa 7, Southern Europe 7, Central Europe 30, Western Europe 46, former Soviet Union 51, UK 60, North America 79, Central \& Southern America 10). Fifty-five per cent of responses came directly from the invitation. Thirty-nine per cent of responses were referred, with a further $5 \%$ via direct access to the website. The cohort comprised $60 \%$ female (mean age 38.4 years, SD $=14.9$ ) and $40 \%$ 
male (mean age 45.7 years, $\mathrm{SD}=16.7$ ). Thirty-seven per cent were single, $56 \%$ married, $6 \%$ separated/divorced, and $1 \%$ widowed. English was a second language for $53 \%$ of the cohort.

The respondents reported levels of education that exceeded that of the general population, with $17 \%$ undergraduate degrees, $8 \%$ a post-graduate diploma, and $66 \%$ with a postgraduate degree. Most of the respondents were professionals working with people $(79 \%)$ and technology $(9 \%)$ or were managers $(8 \%)$. A wide range of worldviews were represented - 18\% claimed no religious affiliation, 26\% Catholic/Orthodox, 33\% Protestant, $23 \%$ other religions. Many views were also expressed regarding Transcendental influences on respondents' lives. As the number of respondents selecting some of the 19 alternatives for Transcendent was small, responses have been grouped as follows:

Theistic $(n=262)-$ Allah 33, Father God 64, God 165.

Other religious ( $\mathrm{n}=84)-$ Buddha 7, Angels 11, Deity 5, Divine 13,

Higher power 26, Universal spirit 22.

Non-religious ( $\mathrm{n}=70)$ - Deceased 2, Fate 22, Gaia 1, Higher Self 8, Mystery 11, Otherness 6, Presence 14, Something there 6.

Not believe $(n=37)$

Mean values on four domains of spiritual well-being

\section{lived experience}

Analysis of variance did not reveal any significant differences by Transcendents on Communal SWB (Table 1). Those who did not believe in a Transcendent reported significantly lower levels of Personal SWB and Environmental SWB, as well as Transcendental SWB naturally, where it is interesting to note that they scored above the minimum of 1.00. People who claimed influence by fate reported lowest lived experience in Personal SWB (mean = 3.59). Those who related with a Theistic Transcendent (Allah or God) scored significantly higher than those who related to other Transcendents.

Table 1. Comparing mean values for lived experience in 4D SWD by Transcendent

\begin{tabular}{l|l|llll}
\hline \multicolumn{2}{l|}{} & \multicolumn{4}{l}{ lived experience in 4D SWB } \\
\hline No. & Transcendent & Per & Com & Env & Tra \\
\hline 262 & Theistic & 4.08 & 4.08 & 3.36 & $\mathbf{3 . 9 3}$ \\
84 & Other religious & 4.06 & 4.03 & 3.62 & 3.15 \\
70 & Non-religious & 3.88 & 3.91 & 3.45 & 2.79 \\
37 & Not believe & $\mathbf{3 . 7 5}$ & 4.05 & $\mathbf{2 . 8 3}$ & $\mathbf{1 . 4 5}$ \\
\hline 453 & total & 4.02 & 4.04 & 3.38 & 3.41 \\
\hline \multicolumn{7}{|l|}{ ANOVA $\left(\mathrm{F}^{\text {sig }}\right)$} & $3.24 *$ & $1.02^{\text {ns }}$ & $6.31^{* * *}$ & $\mathbf{9 0 . 5} * * *$ \\
\hline$* 0.05, * * \mathrm{p}<.01, * * * \mathrm{p}<.001$.
\end{tabular}


As each person makes meaning of each term in a survey according to her/his worldview, comparing scores on lived experiences between people can be somewhat spurious. A fairer way of comparing each person's quality of relationships, in the four domains of SWB, is to compare dissonance scores, found by subtracting each person's lived experience scores from those for her/his stated ideals. Not only does this appear fairer, by comparing each person with themselves, but these dissonance (or put positively, spiritual harmony) scores using SHALOM have been shown to provide statistically stronger scales for SWB, than that provided by lived experience scores alone (Fisher, 2013a \& b; Moore, 2013), which is what other spirituality measures generally use.

Analysis of variance reveals a consistency in dissonance scores, being higher in each of the four domains of SWB for people who profess influence by Other religious and Nonreligious Transcendents, with the exception of Communal SWB for Other religious (see Table 2). This means that those with higher dissonance do not live up to their ideals in relating with themselves and other people, as well as with the Environment and their Transcendent.

Table 2. Comparing mean values for dissonance in 4D SWD by Transcendent

\begin{tabular}{l|l|llll}
\hline \multicolumn{2}{l|}{} & \multicolumn{4}{|c}{ dissonance in 4D SWB } \\
\hline No. & Transcendent & Per & Com & Env & Tra \\
\hline 262 & Theistic & .25 & .38 & .08 & .27 \\
84 & Other religious & .41 & .41 & .38 & .58 \\
70 & Non-religious & .56 & .54 & .39 & .56 \\
37 & Not believe & .25 & .23 & .25 & .17 \\
\hline 453 & total & .32 & .40 & .20 & .37 \\
\hline \multicolumn{7}{|l|}{ ANOVA $\left(\mathrm{F}^{\text {sig }}\right)$} & $2.44 * *$ & $2.11 *$ & $3.11 * *$ & $5.02 * * *$ \\
\hline$* 05, * * \mathrm{p}<.01, * * * \mathrm{p}<.001$.
\end{tabular}

ANOVA of dissonance for Environmental SWB revealed that reliance on higher power and higher-self related to greater dissonance (i.e., less spiritual harmony), whereas relating with Allah, God and Father God led to greater spiritual harmony (i.e., significantly lower dissonance).

Those who embrace a Theistic Transcendent showed very little dissonance, or high degree of harmony, between ideals and lived experience, in each of the four domains of spiritual well-being. It is not surprising that those who do Not believe in a Transcendent revealed small dissonance between their lower lived experiences and equally low ideals.

Correlation of Transcendental SWB with other SWB factors

There was moderate correlation between the lived experience scores for Transcendental SWB and each of the other three SWB factors, namely Personal SWB ( $\mathrm{r}=.47)$, Communal SWB ( $r=.38)$ and Environmental SWB ( $r=.37)$. However, stronger relationships were shown by the correlations $(\mathrm{r}>\mathrm{50})$ revealed by comparing dissonance scores for 
Transcendental SWB with Personal SWB (r=.54), Communal SWB (r=.50) and Environmental SWB ( $\mathrm{r}=.58)$.

Significant correlations were revealed between lived experience scores for Transcendental SWB and Personal, Communal and Environmental SWB for most of the listed Transcendents (see Table 3).

Table 3. Correlation of Transcendental SWB with other SWB factors

\begin{tabular}{|c|c|c|c|c|c|c|c|}
\hline \multirow{2}{*}{ No. } & \multirow[b]{2}{*}{ Transcendent } & \multicolumn{3}{|c|}{ lived experience } & \multicolumn{3}{|c|}{ dissonance } \\
\hline & & Per & Com & Env & Per & Com & Env \\
\hline 262 & Theistic & $.63 * * *$ & $.58 * * *$ & $.41 * * *$ & $.60 * * *$ & $.57 * * *$ & $.53 * * *$ \\
\hline 84 & Other religious & $.43 * * *$ & $.37 * *$ & $.40 * * *$ & $.43 * * *$ & $.43 * * *$ & $.59 * * *$ \\
\hline 70 & Non-religious & $.39 * *$ & $.29 * *$ & $.46 * * *$ & $.53 * * *$ & $.49 * * *$ & $.58 * * *$ \\
\hline 37 & Not believe & .10 & .16 & $.36^{*}$ & .27 & $.34 *$ & $.81 * * *$ \\
\hline 453 & total & $.47 * * *$ & $.38 * * *$ & $.37 * * *$ & $.54 * * *$ & $.50 * * *$ & $.58 * * *$ \\
\hline
\end{tabular}

$* \mathrm{p}<.05, * * \mathrm{p}<.01, * * * \mathrm{p}<.001$

Only Universal spirit and fate failed to show significant correlations here. It was not surprising to find that those who did not believe in a Transcendent also showed no correlation of Transcendental SWB scores with those of Personal and Communal SWB. The small correlation between Environmental and Transcendental SWB for this group most likely arose as a statistical artefact brought about by the low scores for each of the two factors.

Strongest correlations $(r>.50)$ were found between dissonance scores for Transcendental with Personal and Communal SWB factors among those embracing Theistic Transcendents. Those who do 'Not believe' showed only weak or no significant correlation between their Transcendental SWB and Communal and Personal SWB.

Correlations revealed consistency in scores reflecting the strength of relationship between Transcendental SWB and the other three SWB factors, except for those who do Not believe. However, these scores did not show cause and effect because correlations do not reveal direction of influence. Further analyses are needed to help clarify this. Since the correlations did not exceed 0.7, for all factors except Environmental SWB for Nonbelievers, they can be considered sufficiently independent of each other to perform standard multiple regression analyses (Pallant, 2007).

\section{Regression analyses with Transcendental SWB as predictor variable for other SWB factors}

In order to determine the influence of Transcendental SWB on the other three factors of spiritual well-being, standard multiple regression analyses were performed for lived experience, as well as for dissonance scores, for each of the three factors of SWB in turn, as dependent variables. The Transcendental and the two other relevant SWB factor scores were entered together, as predictor variables. Standardised regression coefficients $(\beta$ values) were used to determine how greatly Transcendental SWB contributed to variance in the other three spiritual well-being domains, in turn, for each of the listed 
Transcendents (except for Environmental SWB for Non-believers, due to the exclusion stated above).

The regression analyses showed that only Theistic Transcendents contributed significantly to variance in lived experience for Personal and Communal SWB. That is, people who related with God found that this relationship helped them relate better with themselves as well as other people, compared with any help provided by other Transcendents. People who lack belief in a Transcendental influence in life actually indicated this had a small negative influence on their relationship with themselves.

Table 4. Regression analyses with Transcendental SWB as predictor variable (with the other two relevant SWB factors) ( $\beta$-values shown)

\begin{tabular}{|c|c|c|c|c|c|c|c|}
\hline & & lived ex & erience & & dissona & & \\
\hline No. & Transcendent & Per & Com & Env & Per & Com & Env \\
\hline 262 & Theistic & $.29 * * *$ & $.15 * *$ & $.15^{*}$ & $.33 * * *$ & $.32 * * *$ & $.28 * * *$ \\
\hline 84 & Other religious & .11 & .00 & .20 & -.03 & .11 & $.33 * * *$ \\
\hline 70 & Non-religious & .13 & -.05 & $.30 * *$ & .17 & .13 & $.31 * *$ \\
\hline 37 & Not believe & -.13 & .04 & $.28 *$ & -.11 & -.02 & \\
\hline 453 & total & $.19 * * *$ & .01 & $.16^{*}$ & $.18 * * *$ & $.19 * * *$ & $\begin{array}{l}\mathbf{. 3 1} * * * \\
(\mathrm{n}=416)\end{array}$ \\
\hline
\end{tabular}

Nearly all the nominated Transcendents appeared to nurture relationships with the environment. Further research is needed to see if this is a genuine relationship, or merely a statistical outcome of similarly moderate to low scores.

Similarly, regression analyses with the dissonance scores revealed that being in harmony with God contributes to harmony with self and others. However, not believing in a Transcendent once again indicated a negative influence relating with self. Religious Education is an ideal means of helping people build a relationship with God. In so doing, they are more likely to love self and others, at heart (spiritual) level. This process reflects perfectly the scriptural commandment to "love God and [obviously provides support to] love your neighbour as yourself” (Deut 6:5; Matt 22:37; Lk 10:27). Many religions/ philosophies embrace the second part of this Commandment (i.e., to love 'others') as the Golden Rule (Seaward, 2001), yet, some of these belief systems are similar to positive psychology, in having people rely on their own efforts to build relationships with self and others. In this way, they miss out on the potential benefit of a strong 'vertical' relationship with the source of love, the Creator of the universe, who is often referred to as God.

Religious Education at the core of curriculum in schools, supported by chaplaincy, provides a firm foundation for holistic education that nurtures students' (and hopefully staff's) spiritual well-being. This foundation contrasts with the philosophy and positive psychology thrusts, that are akin to building on shifting sand, buffeted by waves of fluctuating humanistic opinion, that are currently being trialled in some schools in Australia, at the insistence of a vocal minority. Having Religious Education included in the Australian national curriculum (Reid, 2011) would make a start to adding substance to 
the Ministers of Education's statements that spiritual development and well-being of young people is a core goal of education for the $\mathrm{C} 21^{\text {st }}$ (MCEETYA, 2008).

Spiritual education is considered an aspect of Religious Education in many Australian non-government schools and as an integral component of the curriculum in a minority of them. Wright contends that spiritual education goes beyond spiritual nurture to include critical spiritual pedagogy which is a "process of critical empowerment rooted in a search for truth and the recognition that spirituality is a vital yet fundamentally controversial issue" (2000, p.139). Hill sees RE as open-ended exploration of systems of belief with students as "informed choosers" (2004, p.87). However, students need alternative views to be presented in a meaningful manner so they have a genuine basis for choice. Teaching cannot be values-free, besides which Cooling maintains that sustained neutrality in the classroom amounts to practical atheism (2010). Therefore, teachers need to be objective, or to at least reveal their personal bias, when discussing a subject, so that indoctrination, whether deliberate or inadvertent, will be minimised. Crawford and Rossiter provide a thought-provoking comparison of educational goals for state-based Religion Studies with generalised aims of denominational religious education in religious (church-related) schools (2006, pp.473-4). A key point of difference between these two approaches is shown in their potential "for catalysing change in young people" (ibid.).

In summary, Mohr's claim, (2006, p.175) “Agnostics and atheists can have a rich spiritual life despite the lack of a deity in their belief systems" gains slim support from this study. Results presented here show that non-believers in any Transcendent score lowest, indicating low SWB, on Personal and Environmental SWB factors, as well as negligibly on Transcendental SWB. This study also found that relationship with a personal, theistic Transcendent (such as God) enhances one's relationship with oneself and others to a greater extent than that done by alternative religious Transcendents (such as angels, deity, higher power, universal spirit), non-religious Transcendents (such as fate, higher self, otherness, presence) or lack of belief in any form of Transcendent (i.e., someOne or someThing beyond the human and natural worlds), as is done by nearly all atheists. In fact, non-belief in a Transcendent impacted negatively on relationship with oneself and other people for those in that category in this study. In brief, although everyone is entitled to express their view, not all views are of equal value when it comes to relating with Transcendents for spiritual well-being.

Ensuing discussion indicated that education should lay a solid foundation upon which young people can build their lives. Without being given the chance to critically evaluate the four sets of relationships that nurture spiritual well-being, especially the most important one of relating with God (through religious education or equivalent) our young people are being "systematically indoctrinated in a secular, modernist, rationalistic worldview which excludes or privatises religion by omission" (Copley, 2005). Australian schools which fail to provide these opportunities for holistic education are falling short of the joint Ministers of Education's edicts regarding spiritual development and well-being of students. 


\section{Limitations}

In some people's views assessing spiritual well-being via quantitative measures only could be considered a limitation. Qualitative studies can add depth to investigations, so it would be interesting to see what qualitative questions could be asked and what recruitment techniques and methods of analysis could be applied in a qualitative study such that it would add equal or greater meaning, or more accurate results, to the comprehensive quantitative study reported here. With only twenty items, SHALOM cannot be considered an exhaustive measure of spiritual well-being. It is, however, an excellent 'spiritual thermometer', having been used in scores of studies in many languages (Fisher, 2010).

There are many variables which influence spiritual well-being but not all of them can be assessed in a single study. SHALOM has been used to show relationships of SWB with personality and happiness and other aspects of healthcare, in education, and studies in business, church and community settings (Fisher, 2010). This current paper is not a general exposition on spiritual well-being. It has a specific focus which is clearly stated as, "How does relating with God or other Transcendents influence other aspects of spiritual well-being?"

Although participants in this study reflected quite well the religious affiliations of the World populations (CIA, 2010), they were highly educated. Extended studies are needed to show if similar results would be forthcoming from the general population. However, the respondents in this study were deeply engaged with spirituality, or diametrically opposed to it (e.g., atheists), so their range of views is important to note. I welcome further relevant, quantitative and/or qualitative studies with a wider group of people, which will reinforce, refine or refute the findings presented herein. If, and until, such studies are undertaken, the findings presented here stand as valid and reliable results.

\section{Conclusion}

Firstly, using dissonance scores (i.e., difference between ideals and lived experience) provides greater sensitivity in revealing relationships between Transcendental and other spiritual well-being factors, compared with using lived experience scores only.

Secondly, it has been shown that Theistic Transcendents, that can be perceived of as personal relationship with God, influence Personal and Communal spiritual well-being more so than other Transcendents, or lack of belief in any Transcendental influence on life.

Thirdly, most Transcendents appear to influence relationship with the environment, but no clear pattern emerged from this study. Further investigation is warranted on the nature of the relationships with environment held by adherents to varying Transcendents.

Fourthly, although some Transcendents (such as fate, higher self and higher power) may appear to be cognitively sound bases upon which to found ideals for spiritual well-being (i.e., they may appear to be philosophically useful), they are of meagre practical benefit for spiritual well-being, especially in relating with self and others. 
In summary of the second to fourth points, it warrants re-stating that, although everyone is entitled to express their opinions, not all are of equal worth. Empirical evidence presented here has shown that, of the four sets of relationships studied, the relationship with God is the most important, but not the only one which counts, for spiritual wellbeing. Therefore, those who say that relating with the sacred is THE focus for SWB are partially right. However, those who claim that God does not count for spiritual well-being have a minority view that does not hold among most other people, at least those in the West.

Finally, putting this research into practice in Religious Education, should lead to nurturing a relationship with God which is likely to benefit people much more than humanistic efforts of individuals to enhance life, by themselves. Through love of God, people are more likely to love self and others. These three relationships coalesce with environment to foster holistic spiritual well-being, with God playing a pivotal, but not exclusive, role in this process. For holistic education of students, schools need to go beyond the $3 \mathrm{Rs}$ to include a fourth $\mathrm{R}$, relationships.

\section{Acknowledgements}

Help from Grant Meredith was greatly appreciated in the setting up the LimeSurvey used in this study and extracting data therefrom. Comments on a draft of this paper were gratefully received from Assoc. Professor Brad Mitchell (Federation University Australia) and the Rev'd Canon Professor Leslie J. Francis (University of Warwick),

\section{Notes on Contributor}

Dr John Fisher has completed three doctorates in spiritual health and well-being. He has expertise in teaching and research in science, education, sociology, psychology, religious studies and health education. John has extensive experience in schools and universities, as well as with youth and adults in churches. John holds honorary positions as Visiting Professor in the University of Glyndŵr, Wales and Senior Fellowships in the University of Melbourne and Hong Kong Institute of Education.

\section{References}

Büssing, A., Baumann, K., Hvidt, N.C., Koenig, H.G., Puchalski, C.M. \& Swinton, J. (2014). Editorial: Spirituality and health. Evidence-Based Complementary \& Alternative Medicine, published 30 January. http://dx.doi.org/10.1155/2014/682817

CIA (2010). World Fact Book - Religions. Retrieved from https://www.cia.gov/library/ publications/the-world-fact-book/religions, 26 January, 2014.

Cooling, T. (2010). Called to teach: Teaching as a mission vocation. UK: Grove Books. Copley, T. (2005). Indoctrination, Education and God. UK: SPCK.

Crawford, M. \& Rossiter, G. (2006). Reasons for Living. Victoria: ACER press. 
Ellsworth, R.B. \& Ellsworth, J.B. (2010). Editorial: Special issue on spirituality, mental health and well-being. International Journal of Applied Psychoanalytical Studies, 7(2), 99-101.

Fisher, J.W. (1998). Spiritual health: its nature and place in the school curriculum. $\mathrm{PhD}$ dissertation, University of Melbourne. Available from http://eprints.unimelb.edu.au/ archive/00002994/

Fisher, J.W. (1999). Developing a Spiritual Health And Life-Orientation Measure for secondary school students. In J. Ryan, V. Wittwer \& P. Baird (Eds.), Research with a regional/rural focus: Proceedings of the University of Ballarat inaugural annual research conference (pp. 57-63). Ballarat, Australia: University of Ballarat, Research and Graduate Studies Office: Ballarat, Australia.

Fisher, J.W. (2009). Reaching the heart: Assessing and nurturing spiritual well-being via education. EdD dissertation, University of Ballarat, Victoria, Australia. Available from http://archimedes.ballarat.edu.au:8080/vital/access/HandleResolver/1959.17/13481

Fisher, J. (2010). Development and application of a spiritual well-being questionnaire called SHALOM. Religions, 1, 105-121.

Fisher, J. (2011). The Four Domains Model: Connecting spirituality, health and wellbeing. Religions, 2, 17-28.

Fisher, J.W. (2012). The importance of relating with God for spiritual well-being. In M. Weiss \& M. Fowler (Eds.), Spirituality: New reflections on theory, praxis \& pedagogy (pp.147-161). Oxford, UK: InterDisciplinary Press.

Fisher, J.W. (2013a). Assessing spiritual well-being: Relating with God explains greatest variance in spiritual well-being among Australian youth. International Journal of Children's Spirituality, 18, 306-317.

Fisher, J.W. (2013b). You can't beat relating with God for spiritual well-being: Comparing a generic version with the original spiritual well-being questionnaire called SHALOM. Religions, 4, 325-335.

Hall, T.W., Reise, S.P. \& Haviland, M.G. (2007). An Item Response Theory Analysis of the Spiritual Assessment inventory. International Journal for the Psychology of Religion, 17(2), 157-178.

Hill, B.V. (2004). Exploring religion in schools: A national priority. Adelaide: Open Book Publishers.

Hill, P.C. \& Hood, R.W. (Eds.) (1999). Measures of religiosity. Birmingham, Alabama: Religious Education Press.

Koenig, H.G. (2011). Spirituality \& health research: Methods, measurement, statistics \& resources. West Conshohocken, PA, USA: Templeton Press. 
Koenig, H.G., King, D.A. \& Carson, V.B. (2012). Handbook of religion \& health. $2^{\text {nd }} e d$. New York: Oxford University Press.

MCEETYA (2008). Melbourne Declaration on Educational Goals for Young Australians. 5 December. Melbourne: MCEETYA.

Meezenbroek, E deJ., Garssen, B., van den Berg, M., van Dierendonck, D. et al. (2012). Measuring spirituality as a universal human experience: A review of spirituality questionnaires. Journal of Religion \& Health., 51, 336-354.

Moberg, D.O. (2011). Expanding horizons for spirituality research. Retrieved from http://hirr.hartsem.edu/sociology/spirituality-research.html, 15 October, 2013.

Mohr, W.K. (2006). Spiritual issues in psychiatric care. Perspectives in Psychiatric Care, 42(3), 174-183.

Moore, J.T. (2013). Dogmatism, coping \& spirituality: Predicting mental health among the religious and the secular. $\mathrm{PhD}$ dissertation, University of Louisville, KY, USA.

Pallant, J. (2007). SPSS survival manual. $3^{\text {rd }}$ Ed. Sydney: Ligare Book Printer.

Pargament, K.I. (2007). Spiritually integrated psychotherapy: Understanding and addressing the sacred. New York: Guilford Press.

Park, C.L. (2007). Religiousness/Spirituality and health: A meaning systems perspective. Journal of Behavioral Medicine, 30(4), 319-328.

Reid, D. (2011). Making space for Religious Education in the National Curriculum. Religious Education Journal of Australia, 27(2), 10-15.

Rosmarin, D.H., Wachholtz, A. \& Ai, A. (2011). Beyond descriptive research: Advancing the study of spirituality and health. Journal of Behavioral Medicine, 34(6), 409-413.

Seaward, B.L. (2001). Health of the human spirit: Spiritual dimensions for personal health. Boston, MA, USA: Allyn \& Bacon.

Wright, A. (2000). Spirituality and education. London: RoutledgeFalmer. 


\section{Chapter 9 Conclusion}

Although some people will not acknowledge it, at our very core we human beings are spirit, who have a soul and live in a body (Moberg, 2011). Within humanity there are very many divergent beliefs. My model of spiritual health/well-being posits that whatever worldview we hold filters our understanding of, and approach to, life, particularly in four areas: how well we relate with ourselves in terms of meaning, purpose and values; how well we relate with other people with regards to morality, culture and religion (for those for whom religion is important); how well we connect with the environment (for quality of life as well as a sustainable future); and whether or not we relate with someOne or someThing beyond the human and natural worlds - a Transcendent (commonly known as God). The National Interfaith Coalition on Aging (NICA, 1975), Fisher (1998) and others posit these four sets of relationships as the basis of spiritual well-being. Our worldview will help or hinder our relationship in each, and all, of these areas, the last of which is the most controversial.

Apart from the quantity of written material added by this project, it contributes to the overall study of spiritual well-being through its breadth as well as its depth in terms of the expansive use of my 20-item spiritual well-being questionnaire, SHALOM, which is based on the four domains model of spiritual well-being (Fisher, 1998). The answer to the first research question, 'How important is relating with God (or Transcendent) for spiritual well-being?' appears to have a definitive answer. The prime finding of this research is that, despite a contemporary drift toward secularisation in the West, the evidence makes it clear that the traditional, Western view of spirituality still holds sway. That is, the research confirms that relating with God provides the greatest explanation for variance in the spiritual well-being of people; as such it is most important area of personal relationship, compared with relationships with self, others and the environment for spiritual well-being.

A generic form of the SHALOM questionnaire was developed to address the second research question, 'How does relating with God and other Transcendents influence the other domains of spiritual well-being?' Use of this generic form of SHALOM revealed that relating with God (theistic Transcendent) facilitates one's relationship with self (Personal SWB) and other people (Communal SWB), which relationships with other Transcendents (based on other religious, and non-theistic views, or even disbelief in any form of Transcendent) fail to do. This finding contrasts with Mohr's claim, 'Agnostics and atheists can have a rich [italics added] spiritual life despite 
the lack of deity in their belief systems' (2006). Agnostics and atheists can have a form of spiritual life, but it is questionable how rich it is. Additionally, more work is needed to clarify how people's relationships with a variety of Transcendents influence their relationship with the Environment.

As well as the principal finding of the importance of relating with God for spiritual well-being, this project presents a challenge to mainstream psychology in which other spiritual well-being measures except mine simply ask for a single-response that relates to lived experience on each of the items comprising each measure. This thesis scrutinizes a novel means of investigating the quality of relationships which reflect spiritual well-being. Two responses are sought for each item comprising the measures, namely each person's stated ideals as well as their lived experience. Taking the difference between these two responses, indicates how well each person lives up to their stated ideals. This technique provides a better, psychometrically more sound and more consistent, means of assessing spiritual well-being, compared with lived experiences alone. My spiritual well-being questionnaires, including the SHALOM instrument, are the only reported spirituality measures to use such a double-response technique to date. No matter what age, background, culture, gender, health, occupation, race, religion or worldview pertains to any individual, by using SHALOM s/he is compared with her/himself. Each person is the most relevant standard for comparison rather than some arbitrary group norm, which is based on a multitude of meanings, coming from many people's interpretations of each item. This double response technique makes SHALOM useful for the study of the spiritual well-being of individuals, as well as of small and large groups.

It would be too audacious to claim that SHALOM is universally useful, because this thesis only reports on 52 studies, with 41686 people in 27 countries. However, my hope is that SHALOM will continue to prove helpful to many people in assessing spiritual well-being as an adjunct to providing appropriate spiritual care.

In light of the findings of the research reported and discussed in this thesis, there is an obvious need to reverse the trend revealed in the analysis presented of the composition of recent spirituality/well-being questionnaires (in Chapter 2). There it was reported that the percentage of items assessing relationship with God in spirituality/wellbeing measures has declined over recent time. Kapuscinski \& Masters (2010) had made an earlier call for all spirituality scales to include a transcendent component to help differentiate spirituality from other constructs (p.201). However, my research has shown that relationship with self, others and environment are valid components of spiritual well- 
being, but just not as important as relating with a transcendent, especially God. In conclusion, it is important to ensure that relating with God is considered in any future study of spirituality/wellbeing, because, of the four sets of relationships investigated with SHALOM, relating with God is more important than relating with self, others or the environment in assessment of, and enhancement of, one's spiritual well-being. 


\section{REFERENCES - for Chapters 1, 2, and 9}

\section{(Note: Specific references for Chapters 3 to 8 are included after each publication)}

Adams, F. (1939). The Genuine Works of Hippocrates, trans. from the Greek (Aphorisms, I.1). London, UK: Bailliere, Tindall \& Cox, p. 299.

Annenberg Learner

Argyle, M. \& Hills, P. (2000) Religious experiences and their relations with happiness and personality. The International Journal for the Psychology of Religion, 10(3), 157172.

Australian Education Council (AEC) (1994). A statement on studies of health and physical education for Australian schools. Melbourne: Curriculum Corporation.

Bartholomew, B. (2014). The Spiritual Genome. North Hollywood, CA.: Timeline Publishing Inc.

Bauman, P.J. (1995). Correlations among marital intimacy, object relations, mental representations of God and spiritual well-being. Dissertation Abstracts International, Section B: Science Eng. Vol55 (11-B), p. 5058.

Benson, P.L. (2004) Emerging themes in research on adolescent spiritual and religious development. Applied Developmental Science, 8, 47-50.

Benzein, E., Norberg, A. \& Saveman, B-I. (1998). Hope: future imagined reality. The meaning of hope as described by a group of healthy Pentecostalists. Journal of Advanced Nursing, 28, 1063- 1070.

Berryman, J.W. (1990). Teaching as presence and the existential curriculum. Religious Education, 85(4), 509-534.

Board of Studies (1994). Curriculum \& Standards Framework - Draft for Consultation 15 June, 1994. Carlton, Victoria: BOS.

Bontempo, A. M. (2004). Making meaning out of mayhem: A grounded theory of resiliency, relationship, and women coping with breast cancer. Dissertation Abstracts International, Section B: Science Eng. Vol 64 (12-B), p.6321.

Bregman, L. (2012). Spirituality definitions: A moving target. In Spirituality: Theory Praxis and Pedagogy. Edited by Martin Fowler, John D. Martin III, and John L. Hochheimer. Oxford, UK: Inter-Disciplinary Press, pp. 4-10.

Brown, I. (1978). Exploring the spiritual dimension of school health education. Eta Sigma Gamman, 10, 12-16.

Chan, C., Ho, Petula S.Y. \& Chow, E. (2001). A Body-Mind-Spirit Model in health: An eastern approach. Social Work Health and Mental Health, 34(3 /4), 261-282. 
Chiu, L. Emblen, J.D., Van Hofwegen, L., Sawatzky, R. \& Meyerhoff, H. (2004). An integrative review of the concept of spirituality in the health sciences. Western Journal of Nursing Research, 26, 405-428.

Chown, M. (2012). In the beginning. New Scientist 216, Issue 2893, 02624079, $12 / 1 / 2012$.

Cohen, M.Z., Holley, L.M., Wengel, S.P. \& Katzman. M. (2012). A platform for nursing research on spirituality and religiosity: Definitions and measures. Western Journal of Nursing Research, 34(6), 795-817.

Copeland, K. (undated). Kenneth Copeland Ministries. Understanding the Soul. Retrieved on 15 April 2014 from http://www.kcm.org/print/real-help/article/understanding-soul

Cotton, S. et al. (2010). Measurement of religiosity/spirituality in adolescent health outcomes: Trends and recommendations. Journal of Religion \& Health, 49, 414-444.

Dawkins, R. (2006). The God Delusion. New York: Houghton Mifflin.

Dehshiri, G.R. Using the SWBQ to investigate community in Iran, Work in progress.

Dericquebourg, R. (2007). The healing regions. A specific sub-group within the global field of religion. Australian Religion Studies Review, 20, 139-157.

Diaz, D.P. (1993). Foundations for spirituality: Establishing the viability of spirituality within the health disciplines. Journal of Health Education, 24, 324-326.

Dossey, L. (2014). Spirituality and nonlocal mind: A necessary dyad. Spirituality in Clinical Practice, 1(1), 29-42.

Encyclopaedia Britannica. (2013). Retrieved on 10 June 2014 from http://www.britannica.com/EBcheckedtopic/124443/cogito-ergo-sum

Fahlberg, L.L., \& Fahlberg, L.A. (1991). Exploring spirituality and consciousness with an expanded science: Beyond the ego with empiricism, phenomenology, and contemplation. American Journal of Health Promotion, 5(4), 273-281.

Fisher, J.W. (1998). Spiritual health: Its nature and place in the school curriculum. PhD thesis, University of Melbourne (http://eprints.unimelb.edu.au/archive/00002994/)

Fisher, John (1999). Developing a Spiritual Health And Life-Orientation Measure for secondary school students. In Proceedings of University of Ballarat Annual Research Conference, 15 October, pp. 57-63

Fisher, J. (2004). Feeling Good, Living Life: A spiritual health measure for young children. Journal of Beliefs \& Values, 25(3), 307-315.

Fisher, J.W. (2006). Using secondary students' views about influences on their spiritual well-being to inform pastoral care. International Journal of Children's Spirituality, 11(3), 347-356. 
Fisher, J.W. (2009). Reaching the heart: Assessing and nurturing spiritual well-being via education. EdD dissertation, University of Ballarat, Victoria, Australia. Available online: http://archimedes.ballarat.edu.au:8080/vital/access/HandleResolver/1959.17/13481

Fisher, J. (2010). Development and application of a Spiritual Well-being Questionnaire called SHALOM. Religions, 1, 105-121.

Fisher, J. (2011). The Four Domains Model: Connecting spirituality, health and wellbeing. Religions, 2, 17-28.

Fisher, J.W. \& Wong, P.H. (2013). Comparing levels of spiritual well-being and support among pre-service teachers in Hong Kong and Australia. Religious Education Journal of Australia, 29(1), 34-40.

Fisher, J.W. \& Coskun, M.K. (2013). Investigating spiritual well-being among Divinity and Religious Education students in Turkey. Religious Education Journal of Australia, 29(2), 21-28.

Francis, L.J., Brown, L.B. \& Philipchalk, R. (1992). The development of an abbreviated form of the revised Eysenck personality questionnaire (EPQR-A): Its use among students in England, Canada, the USA and Australia. Personality \& Individual Differences, 13, 443-449.

Francis, L.J. \& Robbins, M. (2005). Urban Hope and Spiritual Health: The Adolescent Voice. Peterborough, UK: Epworth.

Francis, L.J., Penny, G. \& Baker, S. (2012). Defining and assessing spiritual health: A comparative study among 13- to 15-year old pupils attending secular schools, Anglican schools, and private Christian schools in England and Wales. Peabody Journal of Education, 87(3), 351-367.

Geisler, N. \& Turek, F. (2004). I Don't Have Enough Faith to be an Atheist. Wheaton, IL: Crossway Books.

Gibson, C., Yomarken, A. \& Breitbart, W. (2006). Meaning-centered group psychotherapy for cancer patients. In C.M. Puchalski, (Ed.), A time for listening and caring: Spirituality and the care of the chronically ill and dying (pp.269-282). New York: Oxford University Press.

Gomez, R. \& Fisher, J.W. (2003). Domains of spiritual well-being and development and validation of the Spiritual Well-Being Questionnaire. Personality and Individual Differences, 35(8), 1975-1991.

Gomez, R \& Fisher, J.W. (2005a) Item Response Theory analysis of the Spiritual WellBeing Questionnaire. Personality and Individual Differences, 38(5),1107-1121.

Gomez, R \& Fisher, J.W. (2005b) The Spiritual Well-Being Questionnaire: Testing for model applicability, measurement and structural equivalencies and latent mean differences across gender. Personality and Individual Differences, 39(8), 1383-1393.

Goodloe, R. \& Arreola, P. (1992). Spiritual health: Out of the closet. Health Education, 23, 221-226. 
Gough, H.R., Wilks, S.E. \& Prattini, R.J. (2010). Spirituality among Alzheimer's caregivers: Psychometric reevaluation of the Intrinsic Spirituality Scale. Journal of Social Science Research, 36, 278-288.

Gouveia, M.J., Pais Ribeiro, J. \& Marques, M. (2008). Adaptação Portguesa do Questionário de Bem Espiritual : resultados psicométricos preliminares. In Actas do $7^{\circ}$ congresso nacional de psicologia da saúde; Leal, I., Pais-Ribeiro, J., Silva, I., Marques, S., Eds.; ISPOA : Lisboa, pp. 423-426.

Graves, D. (undated). John Wesley's heart strangely warmed. Retrieved on 7 May 2014 from http://christianity.com/church/church-history/timeline/1701-1800/john-wesleysheart-strangely-warmed

Gray, S. (2001). Spiritual well-being and reasons for living: Assessing the connections. Dissertation Abstracts International, Section B: Science Eng. Vol 61(8-B), p.4405.

Guy, J.C. (2009). The relationship between young adults' spiritual well-being and attachment to God and their recollections of parental and faith-group spiritual influences. Ph.D. dissertation, Capella University, Minnesota.

Hagin, K.W. (undated). The dividing of soul and spirit. Retrieved on 15 April 2014 from http://www.rhema.org/index.php? option_content\&view=article\&id=274:the-dividing-ofsoul-and-spirit

Hall, T.W., Reise, S.P. \& Haviland, M.G. (2007). An Item response Theory Analysis of the Spiritual Assessment Inventory. International Journal for the Psychology of Religion, 17(2), 157-178.

Hanfstingl, B. (2013). Ego and Spiritual Transcendence: Relevance to psychological resilience and the role of age. Evidence-Based Complementary and Alternative Medicine 2013, article ID 949838. http://dx.doi.org/10.1155/2013/949838

Harvey, C.L. (1996). The role of the soul. A paper presented at 'Whose Values?', the Third Annual Conference on "Education, Spirituality and the Whole Child", Roehampton Institute, London, June.

Hawking, S. \& Mlodinow, L. (2010). The Grand Design. London: Bantam Press.

Hay, D., Reich, K.H. \& Utsch, M. (2006). Spiritual development: Intersections and divergence with religious development. In E.C. Roehlkepartain, P.E. King, L.M. Wagener \& P.L. Benson, (Eds.) The Handbook of Spiritual Development in Childhood and Adolescence (pp.46-59). Thousand Oaks, CA, USA: Sage Publications.

Heelas,P. \& Woodhead, L. (2005). The Spiritual Revolution: Why religion is giving way to spirituality. Oxford, UK: Blackwell.

Helminiak, D. (1996). The Human Core of Spirituality: Mind as Psyche and Spirit. Albany, NY: State University of New York Press.

Helminiak, D.A. (2008). Confounding the Divine and the Spiritual: Challenges to a Psychology of Spirituality. Pastoral Psychology, 57, 161-182. 
Hill, P.C. \& Hood, R.W. (Eds.) (1999). Measures of Religiosity. Birmingham, Alabama: Religious Education Press.

Hill, P.C., Pargament, K.I., Hood, R.W., McCullough, J.P., Swyers, D.B., Larson, D.B. \& Zinnbauer, B.J. (2000). Conceptualizing religion and spirituality: Points of commonality, points of departure. Journal for the Theory of Social Behavior, 30(1), 51-77.

Horsburgh, M. (1997). Towards an inclusive spirituality: Wholeness, interdependence and waiting. Disability and Rehabilitation, 19(10), 398-406.

Hughes, P. (2007). Putting Life Together: Findings from Australian Youth Spirituality Research. Melbourne: CRA/Fairfield Press.

Hyland, M.E., Wheeler, P., Kamble, S. \& Masters K.S. (2010). A sense of 'Special Connection', self-transcendent values and a common factor for religious and nonreligious spirituality. Archive for the Psychology of Religion, 32, 293-326

Hyman, C. \& Handal, P.J. (2006). Definitions and evaluation of religion and spirituality by religious professionals: A pilot study. Journal of Religion and Health, 45(2), 264-282.

Jewish Encyclopedia. (2002). Book of Adam. Retrieved on 30 May 2014 from http://www.jewishencyclopedia.com/articles/759-adam-book-of

Jo, K. (2005). A threefold relational approach to spiritual maturity: An exploratory study of Korean evangelical spirituality. Dissertation Abstracts International, Section B: Hum. Soc Sci Vol 66(3-A), p.1042.

Jose, N., \& Taylor, E. (1986). Spiritual health: A look at barriers to its inclusion in the health education curriculum. The Eta Sigma Gamman, 18(2), 16-19.

Joules, S. (2007). The mediating role of God attachment between religiosity and psychological adjustment in young adults. Dissertation Abstracts International Section B: Science Eng Vol 68(6-B), p. 4133.

Kapuscinski, A.N. \& Masters, K.S. (2010). The current status of measures of spirituality: A critical review of scale development. Psychology of Religion \& Spirituality, 2(4), 191205.

Koenig, H.G. (2008). Concerns about measuring "Spirituality" in research. The Journal of Nervous and Mental Disease, 196(5), 349-355.

Koenig, H.G. (2011). Spirituality \& Health Research: Methods, measurement, statistics and resources. West Conshohocken, PA, USA: Templeton Press.

Koenig, H.G., McCullough, M.E. \& Larson, D.B. (Eds.) (2001). Handbook of Religion and Health. Oxford: Oxford University Press.

Koenig, H.G., King, D.A. \& Carson, V.B. (2012). Handbook of Religion and Health. $2^{\text {nd }}$ ed. New York: Oxford University Press. 
Larson, D.B., Swyers, J.P. \& McCullough, M.E. (Eds). (1998). Scientific research on spirituality and health: A consensus report. Rockville, MD: National Institute for Healthcare Research.

Lennox, J.C. (2009). God's Undertaker: Has science buried God? rev. ed. Oxford, UK: Lion Books.

Lennox, J.C. (2011). God and Stephen Hawking: Whose design is it anyway? Oxford, UK: Lion Books.

Lukoff, D., Lu, F., Turner, R. (1992). Toward a more culturally sensitive DSM-IV. Psychoreligious and psychospiritual problems. The Journal of Nervous and Mental Disease, 180(11), 673-682.

MacDonald, D.A, Kuentzel, J.G. \& Friedman, H.L. (1999). A survey of measures of transpersonal constructs. Part II-Additional instruments. Journal of Transpersonal Psychology, 31(2), 155-177.

McFadden, D.M. (2006). An investigation of the lived experience of spirituality and religion in the lives of those diagnosed with a severe or chronic mental illness. $\mathrm{PhD}$ Dissertation, St Mary's University, Texas.

Mack, M.L. (2003). The relationships between images of God, self-esteem, and spiritual well-being: A case study of Roman Catholic women. Dissertation Abstracts International, Section B: Science Eng. Vol64 (3-B), p.1498.

McGrath, A. (2007). The Dawkins Delusion? London: SPCK Publishing.

Mahlungulu, S.N. \& Uys, L.R.(2004). Spirituality in nursing: an analysis of the concept. Curationis, 27, 15-26.

Martsolf, D.S. \& Mickley, J.R. (1998). The concept of spirituality in nursing theories: Differing world-views and extent of focus. Journal of Advanced Nursing, 27, 294-303.

Marty, M. (1997). Designed to be imprecise. Aging and Spirituality, 9(1), 3.

Maton, K.I. (1989). The stress-buffering role of spiritual support: Cross-sectional and prospective investigations. Journal for the Scientific Study of Religion, 28, 310-323.

Meezenbroek, E de J. et al. (2010). Measuring spirituality as a universal human experience: A review of spirituality questionnaires. Journal of Religion \& Health, doi 10.1007/s10943-010-9376-1, published online: 20 July 2010. REFERENCE IN FULL

Miller, G., Fleming, W. \& Brown-Anderson, F. (1998). Spiritual Well-Being Scale ethnic differences between Caucasians and African-Americans. Journal of Psychology \& Theology, 26, 358-364.

Ministerial Council on Education, Employment, Training and Youth Affairs. (1999). The Adelaide Declaration on National Goals for Schooling in the Twenty-First Century. 2223 April. Adelaide: MCEETYA.

MCEETYA (2008). Melbourne Declaration on Educational Goals for Young Australians. 
5 December. Melbourne: MCEETYA.

Mirman, M.C. (2012). An atheist's guide to the divine: Throwing out the bathwater but keeping the baby. Research in the Social Scientific Study of Religion, 23, 171-189.

Moberg, D.O. (2002). Assessing and measuring spirituality: Confronting dilemmas of universal and particular evaluative criteria. Journal of Adult Development, 9(1), 47-60.

Moberg, D.O. (2005). Research in spirituality, religion, and aging. Journal of Gerontological Social Work, 45(1-2), 11-40.

Moberg, D.O. (2010). Spirituality research: Measuring the immeasurable? Perspectives on Science and Christian Faith, 62(2), 99-114.

Moberg, D.O. (2011). Expanding horizons for spirituality research. Retrieved on 15 October 2013 from http://hirr.hartsem.edu/sociology/spirituality-research.html

Mohr, W.K. (2006). Spiritual issues in Psychiatric Care. Perspectives in Psychiatric Care, 42(3), 174-183.

Mok, I. (2013). A study of the spiritual health of adolescents in three Hong Kong Secondary Schools. EdD dissertation, Hong Kong Institute of Education.

Moodley, T. (2008). The relationship between coping and spiritual well-being during adolescence. PhD disertation, Department of Psychology, University of the Free State, Bloemfontein, South Africa.

Morris H.M. (1984). The Genesis Record: A scientific and devotional commentary on the book of beginnings. Grand Rapids, MI: Baker House Books.

National Interfaith Coalition on Aging (NICA) (1975). Spiritual well-being: A definition. Athens, Georgia: Author.

Neto, F.; Ferreira, A.V. \& Pinto, M. da C. (2006). Perdão aos outros, perdão de Deus e religiosidade em adolescentes. Forgiveness of others, forgiveness by God, and religiosity among adolescents. Psicologia Educação Cultura, 10, 387-406.

Newberg, A.B., d'Aquili, E. \& Rause, V. (2001). Why God won't go away: Brain Science and the Biology of Belief. New York: Ballantine Books.

Newby, M. (1996). Towards a secular concept of spiritual maturity. In R. Best (Ed.) Education, spirituality and the whole child. (pp.99-107). London: Cassell.

Nielsen, B.H. (2001). An investigation into the relationship between self-esteem and patriarchal and feminist attitudes of Protestant women seminarians and lay women regarding selected biblical passages and Christian theological constructs. Dissertation Abstracts International, Section B: Science Eng. Vol61 (7-B), p. 3904.

Niuatoa, M.J. Fa'a-Samoa (2007). The epistemology of Samoan spirituality. A theological and psychological exploration for religious education of spiritual formation. Dissertation Abstracts International, Section A: Hum \& Soc Sci. Vol 68(5-A) p.2004. 
Nolan, P. \& Crawford. P. (1997). Towards a rhetoric of spirituality in mental health care. Journal of Advanced Nursing, 26, 289-294.

Oneha, M.F. (2001). Ka mauli o ka 'oina a he mauli kanaka: An ethnographic study from a Hawaiian sense of place. Pac Health Dialog, 8, 299-311.

Pandya, S.K. (2011). Understanding brain, mind and soul: Contributions from neurology and neurosurgery. Mens Sana Monographs 9(1) 129-149. Retrieved on 15 April 2014 from http://www.ncbi.nlm.nih.gov/pmc/articles/PMC3115284/

Park, N.S. et al. (2011). Typologies of religiousness/spirituality: Implications for health and well-being. Journal of Religion \& Health, doi: 10.1007/s10943-011-9520-6.

Principe, W. (1983). Toward defining spirituality. Studies in Religion, 12, 127-41.

Reid, D. (2011). Making space for Religious Education in the National Curriculum. Religious Education Journal of Australia, 27(2), 10-15.

Resnick, M., Harris, L. \& Blum, R. (1993). The impact of caring and connectedness on adolescent health and well-being. Journal of Paediatrics and Child Health, 29(Suppl.1), S3-S9.

Ribeiro, V. (1989). Loneliness in the institutionalized elderly: A descriptivelexploratory study. DNSc dissertation, Boston University.

Rovers, M. \& Kocum, L. (2010). Development of a Holistic Model of Spirituality. Journal of Spirituality in Mental Health, 12(1), 2-24.

Rowold, J. (2011). Effects of spiritual well-being on subsequent happiness, psychological well-being, and stress. Journal of Religion \& Health, 50(4), 950-963.

Saucier, G. \& Skrzypińska, K. (2006). Spiritual but not religious? Evidence for two independent dispositions. Journal of Personality, 74. DOI: 10.1111/j.14676494.2006.0049.x. PAGES???

Schaeffer, F. (1972). Genesis in Space and Time: The flow of Biblical History. Downers Grove, IL: InterVarsity Press.

Schneiders, S.M. (2003). Religion vs. Spirituality: A contemporary conundrum. Spiritus, 3, 163-185.

Seaward, B.L. (2001). Health of the Human Spirit: Spiritual Dimensions for Personal Health. Boston: Allyn and Bacon.

Seligman, M. (2014). God comes at the end. Spirituality in Clinical Practice, 1(1), 67-70.

Seybold, K.S. (2005). God and the brain: Neuroscience looks at religion. Journal of Psychology and Religion, 24(2), 122-129.

Shelton, S. (2010). Spirituality, mental health and the new physics. International Journal of Applied Psychoanalytic Studies, 7(2), 161-171. 
Sinott, J.D. (2001). Introduction: Special Issue on Spirituality and Adult Development, Part 1. Journal of Adult Development, 8(4), 199-200.

Sire, J.W. (2009). The universe next door: A basic worldview catalog $5^{\text {th }}$ ed. Downers Grove, IL, USA: InterVarsity Press.

Slife, B.D., Reber, J.S. \& Lefevor, G.T. (2012). When God truly matters: A theistic approach to psychology. Research in the Social Scientific Study of Religion 23, 213-236.

Sloan, J.A., Aaronson, N., Cappelleri, J.C., Fairclough, D.L., Varrichio, C. et al. (2002). Assessing the clinical significance of single items relative to summated scores. Mayo Clinic Proceedings, 77, 479-487.

Smith, D. (2000). Secularism, religion and spiritual development. Journal of Beliefs \& Values, 21(1), 27-38.

Smith, L.L. (2004). Object relations in the dynamics of spiritual and psychological wellbeing. Dissertation Abstracts International, Section B: Science Eng. Vol 65 (6-B), p.3211.

Spilka, B. (1993). Spirituality: Problems and directions in operationalizing a fuzzy concept. Paper presented at the meeting of the American Psychological Association, Toronto, August.

States, J.A. (2002). Self-efficacy and spirituality in the recovery process from alcohol dependence: A paradox. Dissertation Abstracts International. Section B: Science Eng. Vol 64(3-B), p.3390.

Sulmasy, D.P. (2002). A Biopsychosocial-Spiritual Model for the care of patients at the end of life. The Gerontologist, 42(special issue III), 24-33.

Tanyi, R. \& Werner, J. (2007). Spirituality in African-American and Caucasian Women in End-Stage renal Disease on Hemodialysis Treatment. Health Care for Women International, 28, 141-154.

Tatsumura, Y.; Maskarinec, G.; Shumay, D.M. \& Kakai, H. (2003). Religious and spiritual resources, CAM, and conventional treatment in the lives of cancer patients. Alternative Therapies in Health \& Medicine, 9, 64-71.

Tramontana, Z.M.(2009). The connection between spirituality and recovery from bulimia nervosa. Dissertation Abstracts International, Section B: Science Eng. Vol 69(12-B), p 7839.

Turner, R.P., Lukoff, D., Barnhouse, R.T. \& Lu, F.G. (1995). Religious or spiritual problem: A culturally sensitive diagnostic category in the DSM-IV. Journal of Nervous and Mental Disease, 183, 435-444.

Urgesi, C., Aglioti, S.M., Skrap, M. \& Fabbro, F. (2010). The spiritual brain: Selective cortical lesions modulate human self-transcendence. Neuron 65, 309-319.

Van Rooyen, B.M. (2007). Spiritual well-being in a group of South African adolescents. $\mathrm{PhD}$ dissertation, University of the Free State, Bloemfontein. 
Vela, D.G.W. (1997). The role of religion/spirituality in building strong families: Respondents' perceptions. A qualitative, grounded theory. Dissertation Abstracts International, Section B: Hum Soc Sci. Vol 57(9-A), p. 4151.

Vivat, B. (2008). Measures of spiritual issues for palliative care patients: A literature review. Palliative Medicine, 22, 859-868.

Vogt, T. (2007). The impact of an Interim Protection Order (Domestic Violence Act 116 of 1998) on the victims of domestic violence. D Pyschol. Dissertation, University of Stellenbosch, South Africa.

Waaijman, K. (2006). What is spirituality? Acta Theologica Supplementum, 8, 1-18.

Waaijman, K. (2007). Spirituality - A multifaceted phenomenon. Studies in Spirituality, 17, 1-113. doi:10.2143/SIS17.0.2024643

Warren, E.M. (1998). Spiritual maturity within an attachment framework. Dissertation Abstracts International, Section B: Science Eng. Vol 59 (6-B), p.3078.

Whitfield, C.L. (1984). Stress management and spirituality during recovery. Alcoholism Treatment Quarterly, 1(1), 3-54.

Wikipedia. Timeline of psychiatry. Retrieved on 12 May 2014 from http://en.wikipedia. org/wiki/Timeline_of_psychiatry

Wikipedia. Transhumanism. Retrieved on 12 May 2014 from http://en.wikipedia.org/ wiki/Transhumanism

Wilson, C. (1999). Predictors of depression among cancer patients as a function of social support, spiritual well-being, and god representation. Dissertation Abstracts International, Section B: Science Eng. Vol 60 (3-B), p.1320.

Wright, A. (2000). Spirituality \& Education. Florence, KY, USA: Taylor \& Francis.

York R.H. (2012). The concepts of the indwelling spirit and the self-critic in theistic theory and research. Research in the Social Scientific Study of Religion 23, 151-170.

Zinnbauer, B.J., Pargament, K.I. \& Scott, A.B. (1999). The emerging meanings of religiousness and spirituality: Problems and prospects. Journal of Personality, 67(6), 889919.

Zinnbauer, B.J., Pargament, K.I. (2002). Capturing the meanings of religiousness and spirituality: One way down from a definitional Tower of Babel. Research in the Social Scientific Study of Religion, 13, 23-54. 


\section{Appendix A Attribution of papers to authors \& Final Project Report}

PhD by Publication

Joint application form for claiming authorship Research Services
University of Ballarat

Learn lo succest

\begin{tabular}{|l|l|}
\hline Publication title: & Nurses' and carers' spiritual well-being in the workplace \\
\hline Publication details: & Australian Journal of Advanced Nursing, 25(4), 49-57(2008) \\
\hline
\end{tabular}

Declaration of authors:

In accordance with the University's Code of Good Practice for the Conduct of Research and the Australian Code for the Responsible Conduct of Research, each signatory certifies that:

(a) they meet the criteria for authorship through having substantial participation in

- conception and design, or analysis and interpretation of data;

- drafting the article or revising it critically for important intellectual content and

- final approval of the version to be published

(b) they take public responsibility for their part of the publication

(c) there is no other author who meets the criteria for authorship (unless such a person(s) is excluded through their written consent)

(d) the person identified below is the principal author

The principal author is:

\begin{tabular}{|l|l|c|c|}
\hline Full name (printed) & School & Signature & Date \\
\hline John Wayne Fisher & Education \& Arts & 2 & $10 / 10 / 11$ \\
\hline
\end{tabular}

Signatories (all authors including the principal author, in agreed order of author listing):

\begin{tabular}{|c|c|c|c|}
\hline \multicolumn{1}{|c|}{ Full name } & $\begin{array}{c}\text { Share of } \\
\text { contribution (\%) }\end{array}$ & Signature & Date \\
\hline John Wayne Fisher & $90 \%$ & & $10 / 10 / 1$ \\
\hline David James Brumley & $10 \%$ & 1 & $10 / 1 / 1$ \\
\hline & & & \\
\hline & & & \\
\hline & & & \\
\hline
\end{tabular}

If more than six authors please attach additional details. 
PhD by Publication

Joint application form for claiming authorship

University of Ballarat Research Services

\begin{tabular}{|l|l|}
\hline Publication title: & $\begin{array}{l}\text { Pre-service teachers' spiritual well-being across time and faiths: } \\
\text { Implications for Religious Education }\end{array}$ \\
\hline Publication details: & Religious Education Journal of Australia, 25(2), 10-16 (2009) \\
\hline
\end{tabular}

\section{Declaration of authors:}

In accordance with the University's Code of Good Practice for the Conduct of Research and the Australian Code for the Responsible Conduct of Research, each signatory certifies that:

(a) they meet the criteria for authorship through having substantial participation in

- conception and design, or analysis and interpretation of data;

- drafting the article or revising it critically for important intellectual content and

- final approval of the version to be published

(b) they take public responsibility for their part of the publication

(c) there is no other author who meets the criteria for authorship (unless such a person(s) is excluded through their written consent

(d) the person identified below is the primcipal author

The principal author is:

Full name (printed)

School

John Wayne Fisher

Education \& Arts

\begin{tabular}{|l|l|}
\hline Signature & Date \\
\hline$y+2$ & $29 / 7 / 12$ \\
\hline
\end{tabular}

Signatories (all authors including the principal author, in agreed order of author listing):

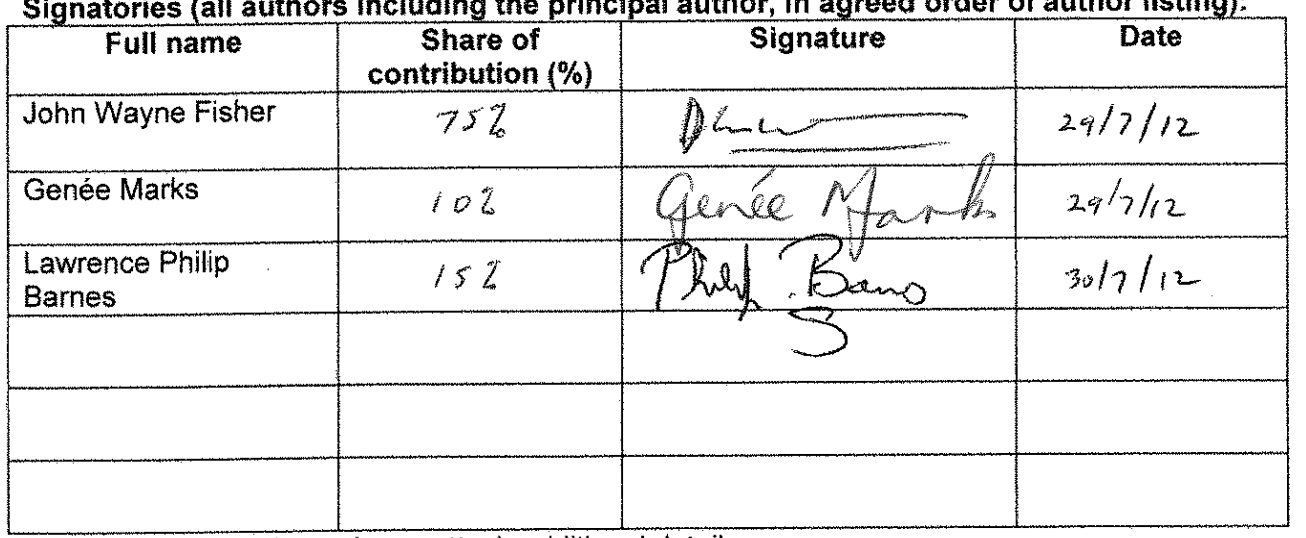

If more than six authors please attach additional details. 


\section{Final Project Report Federation

1) Project Details:

\begin{tabular}{|l|l|}
\hline Project No: & B12-016 \\
\hline Project Name? & Background, beliefs and spiritual well-being \\
\hline
\end{tabular}

2) Principal Researcher Details:

\begin{tabular}{|l|l|}
\hline Full Name: & Lawrence Angus \\
\hline Schoollsection: & Faculty of Education \& Arts \\
\hline Phone: & \\
\hline Fax: & 0438279740 \\
\hline Emaill & l.angus @federation.edu.au \\
\hline
\end{tabular}

3) Project Status:

\begin{tabular}{l}
\hline Please indicate the current status of the project: \\
$\begin{array}{l}\text { X Data collection complete } \\
\text { Completion date: } \quad 11 / 12 / 13\end{array}$ \\
\hline
\end{tabular}

4) Special Conditions:

If this project was approved subject to conditions, were these met?

\begin{tabular}{|l|l|l|}
\hline$X N / A$ & $\square$ Yes & $\square$ No \\
\hline
\end{tabular}

5) Changes to project:

\begin{tabular}{|l|}
\hline Were any amendments made to the originally approved project? \\
\hline $\mathrm{XNO}$ \\
\hline
\end{tabular}

6) Storage of Data:

Please indicate where the data collected during the course of this project is stored:

On the researcher's computer in a password protected file at FedUni.

7) Research Participants:

Were there any events that had an adverse effect on the research participants? $\mathrm{X}$ No 


\section{Final Project Report \\ Human Research Ethics Committee

8) Summary of Results:

8.1. Please provide a short summary of the results of the project (no attachments please): 453 completed surveys were received online. One paper has been published (Fisher, J.W. (2013) You can't beat relating with God for spiritual well-being: Comparing a generic version with the original spiritual well-being questionnaire called SHALOM. Religions, 4(3):325-335). Another paper will be published following a collegial presentation at the International Seminar on Religious Education \& Values, York St John University, York, UK 27 July - 1 August, 2014: 'God, other Transcendents and spiritual well-being.' Both these papers will form part of John Fisher's current PhD dissertation, being finalised in 2014.

8.2. Were the aims of the project (as stated in the application for approval) achleved? Please provide details.

Participants' beliefs were tied to ideals and lived experiences in 4 domains of spiritual well-being Replacing the God-words with choices of Transcendent provided a statistically valid, generic form of SHALOM.

The web-based survey yielded 453 responses, most directly, some indirectly and a few via direct web access, from 600 invitations sent by email to people who had published in the area of spirituality.

9) Feedback:

The HREC welcomes any feedback on:

- difficulties experienced with carrying out the research project; or

- appropriate suggestions which might lead to improvements in ethical clearance and monitoring of research.

It would have been good to gain more responses, but the number obtained was none-the-less pleasing.

10) Signature/s:

\begin{tabular}{|c|c|c|c|}
\hline $\begin{array}{l}\text { Principal } \\
\text { Researcher: }\end{array}$ & Print name: Lawrence Angus & Date: & $29 / 1 / 14$ \\
\hline $\begin{array}{l}\text { Other/Student } \\
\text { Researchers: }\end{array}$ & Print name: John W Fisher & Date: & $29 / 1 / 14$ \\
\hline
\end{tabular}

Please return to the Ethics Officer, Mt. Melen campus, as soon as possible. 


\section{Appendix B Composition of Spirituality/Well-Being Measures}

\section{Multiple-item measures}

It is not possible for single or even the available two to four item measures to adequately cover the four domains of spiritual health \& well-being. In accord with comments by Sloan (2002), it seems reasonable to suggest that multifaceted constructs would be best measured with multidimensional, multi-item measures of SWB.

A summary of available multi-item spirituality measures follows. The Table lists the three types of spirituality measures in this thesis within four sections:

- General (measures that have been used with adults, some university students and in health-related studies),

- University only (with most studies being performed with psychology students),

- Schools (for studies with students and teachers), and

- Health-only studies related to spirituality and well-being.

Rather than identify abbreviations as footnotes to this Table, the organisational detail is presented here in the hope that it will help readers negotiate the considerable detail contained therein.

- Please remember that the items in each of the study/instruments have been classified on the basis of my four domains model of SH/WB, in which:

$\mathrm{P}=$ Personal SWB C=Communal SWB E=Environmental SWB

$\mathrm{T}=$ Transcendental $\mathrm{SWB}$ (including God) $\mathrm{R}=$ Religious variables $\mathrm{O}=$ Other variable

Some items cross-load over two factors so $0.5 \mathrm{~s}$ are used to represent this.

- The first, that is left-hand, column shows the Year in which the study or instrument was reported.

A minimum of 3 items per factor is considered necessary to produce a sturdy measure for a given factor.

- The second column lists the study/instruments in alphabetical order in each section.

- Columns 3 to 8 show the allocation of items to each of the domains of SWB (P, C, E,

$\mathrm{T})$, plus $\mathrm{R}$ and $\mathrm{O}$ :

As SWB is seen as being relational, it is important to distinguish between religious belief statements (R) and expressions of religious faith, in practice, in relationship with God (T). Religious faith might also be expressed through relationship with other people, in which case it would be classified as R/C.

- Column 9 labelled FA, indicates the status of the instrument with respect to Factor Analysis (e.g., Y2 indicates that, Yes, the data generated by the study/instrument have been subjected to factor analysis with 2 discrete resultant factors. $\mathrm{N}$ indicates that No factor analysis was reported for the study/instrument. The symbol '?' indicates doubt about the validity of claims made relating to the factor analysis. For example, items crossloading on factors but factors being treated as discrete entities, or, item-to-total correlations being too low to be considered (e.g. value < 0.3 ).

- Columns 10 to 12 show the Number of people in each study, the type of respondent and place (country) in which the study was performed.

- Column 13 lists the name of the first author.

- Column 14 lists the Source of a copy of the actual instrument:

$\mathrm{C}=$ Contact with author, $\mathrm{H}=$ Hill \& Hood 1999, $\mathrm{P}=$ Publication, $\mathrm{T}=$ Thesis,

$\mathrm{W}=\mathrm{Web}$, Underlined $=20$ source

Abbreviations: Afr-Am $=$ African-American, alc $=$ alcoholics,

Qol=Quality of Life; F=Female; stu = students; $10=$ primary; $20=$ secondary. 

Composition of Original SH/WB, Spirituality and Related/partial measures

Listed chronologically in each section

\begin{tabular}{|c|c|c|c|c|c|c|c|c|c|c|c|c|c|}
\hline \multicolumn{14}{|c|}{ GENERAL (including some uni) } \\
\hline \multicolumn{2}{|c|}{ SH/WB measures } & \multicolumn{4}{|c|}{ SWB } & \multirow[b]{2}{*}{7} & \multirow[b]{2}{*}{8} & \multirow[b]{2}{*}{9} & \multirow[b]{2}{*}{10} & \multirow[b]{2}{*}{11} & \multirow[b]{2}{*}{12} & \multirow[b]{2}{*}{13} & \multirow[b]{2}{*}{14} \\
\hline Col.1 & 2 & 3 & 4 & 5 & 6 & & & & & & & & \\
\hline Yr & Study/instrument & $\mathbf{P}$ & $\mathbf{C}$ & $\mathbf{E}$ & $\mathbf{T}$ & $\mathbf{R}$ & $\mathbf{O}$ & FA & $\mathbf{N}$ & type & place & $1^{\text {st }}$ author & $\mathbf{S}$ \\
\hline 83 & Spiritual Well-Being Scale(SWBS) & 10 & & & 10 & & & Y2+ & 206 & stu/adults & USA & Ellison & $\mathrm{P}$ \\
\hline 84 & Spiritual Well-Being Questionnaire (SWBQ) & 10 & 6 & & 4 & 18 & 4 & Y7 & 981 & adults? & US/Swed & Moberg & $\mathrm{P}$ \\
\hline 94 & Revised Spiritual Well-being Scale & 10.5 & 4 & 1 & 5.5 & & & Y3? & 393 & Cath srs & USA & Kelly & $\mathrm{T}$ \\
\hline 95 & Mental Physical Spiritual Well-being Scale & 5.5 & 2 & 1 & 0.5 & 1 & 20 & Y3? & 358 & uni/adult & Aus & Vella-Brodrick & $\mathrm{P}$ \\
\hline 95 & Spiritual Wellness Inventory (SWI) & 24 & 9.5 & 4.5 & 5 & 3 & 9 & Y10 & 515 & adults & USA & Ingersoll & $\mathrm{W}$ \\
\hline 96 & JAREL SWB Scale & 11.5 & 4.5 & & 3 & 2 & & Y3 & $?$ & adults & USA & Hungelmann & $\mathrm{P}$ \\
\hline 97 & New Spiritual Well-Being Scale & 10.5 & 1 & & 2 & 2.5 & & $\mathrm{~N}$ & 119 & adults & Aus & Fraid & $\mathrm{T}$ \\
\hline 98 & Spirituality and Well-Being & 3.5 & & & 3 & 3.5 & 7 & $\mathrm{~N}$ & 70 & adult $\mathrm{F}$ & USA & Kennedy & $\mathrm{P}$ \\
\hline 98 & Spiritual Wellness tool & 10 & 5 & & 0.5 & 1.5 & 1 & $?$ & $?$ & church & USA & Hart & $\mathrm{T}$ \\
\hline 99 & Revised Spiritual Well-being Scale & 15.5 & 1.5 & & 11 & 2 & & Y2/5? & 150 & adults & USA & Endyke & $\mathrm{T}$ \\
\hline 04 & Spiritual Health Inventory (SHI) & 15 & 2.5 & 3 & 5 & 2.5 & & Y3 & 243 & jail/alc & USA & Korinek & $\mathrm{P}$ \\
\hline 04 & Spirituality Index of Well-Being (SIWB) & 12 & & & & & & Y2 & 523 & out-pts & USA & Daaleman & $\mathrm{P}$ \\
\hline 07 & Adapted Spiritual Well-Being Scale & 17.5 & 0.5 & & & & & $\mathrm{~N}$ & 10 & hospice pts & USA & Wlodarczyk & $\mathrm{P}$ \\
\hline 07 & Spiritual Health Locus of Control Scale & 5 & & & 7.5 & & 0.5 & Y4 & 108 & Afr-Am F & USA & Holt & $\mathrm{P}$ \\
\hline 08 & Geriatric Spiritual Wellbeing Scale & 4 & 8 & 1 & 2.5 & 0.5 & & Y4? & 138 & elderly & USA & Dunn & $\mathrm{P}$ \\
\hline 14 & Clergy Spiritual Well-Being Scale & & 1.5 & & 7.5 & 1.5 & 1.5 & Y2 & 1513 & clergy & USA & $\begin{array}{l}\text { Proeschold- } \\
\text { Bell }\end{array}$ & $\mathrm{P}$ \\
\hline \multicolumn{2}{|c|}{ Spirituality measures } & \multicolumn{4}{|c|}{ SWB } & & & & & & & & \\
\hline Yr & $\begin{array}{r}\text { Study/instrument } \\
\end{array}$ & $\mathbf{P}$ & $\mathbf{C}$ & $\mathbf{E}$ & $\mathbf{T}$ & $\mathbf{R}$ & $\mathbf{O}$ & FA & $\mathbf{N}$ & type & place & $\mathbf{1}^{\text {st }}$ author & $\mathbf{S}$ \\
\hline 84 & Spiritual Maturity Index & 8 & 3 & & 17 & 2 & & Y1? & & & USA & Ellison & $\mathrm{H}$ \\
\hline 88 & Spiritual Orientation Inventory (SOI) & 35.5 & 19.5 & 4.5 & 17.5 & 8 & & $\mathrm{~N}$ & 120 & uni/adult & USA & Elkins & $\mathrm{P}$ \\
\hline 90 & Index of Spiritual Orientation & 3 & & 1 & 4 & 4 & 7 & Y3 & 313 & pts/adult & USA & Glik & $\mathrm{P}$ \\
\hline 91 & Human Spirituality Scale (HSS) & 6.5 & 8.5 & 5 & & & & Y3 & 285 & adults & USA & Wheat & $\mathrm{T}$ \\
\hline
\end{tabular}




\begin{tabular}{|c|c|c|c|c|c|c|c|c|c|c|c|c|c|}
\hline Yr & Study/instrument & $\mathbf{P}$ & $\mathbf{C}$ & $\mathbf{E}$ & $\mathbf{T}$ & $\mathbf{R}$ & $\mathbf{O}$ & FA & $\mathbf{N}$ & type & place & 1st author & $\mathbf{S}$ \\
\hline 91 & $\begin{array}{l}\text { Index of Core Spiritual Experience } \\
\text { (INSPIRIT) }\end{array}$ & 5 & 3 & 1 & 7 & 3 & & Y4 & 83 & outpts & USA & Kass & $\mathrm{P}$ \\
\hline 93 & Spirituality Assessment Scale (SAS) & 18 & 5.5 & 3.5 & 1 & & & Y4 & 189 & adults & USA & Howden & $\mathrm{T}$ \\
\hline 93 & $\begin{array}{l}\text { Temperament \& Character Inventory Self- } \\
\text { transcendence (TCIS) }\end{array}$ & 4.5 & 3.5 & 4 & 3 & & & $\begin{array}{l}\mathrm{Y} 7 ? \\
\mathrm{~N}\end{array}$ & $\begin{array}{l}300 \\
2738\end{array}$ & $>50$ twins & $\begin{array}{l}\text { USA } \\
\text { Aus }\end{array}$ & $\begin{array}{l}\text { Cloninger } \\
\text { Kirk } 99\end{array}$ & $\begin{array}{l}\mathrm{P} \\
\mathrm{P}\end{array}$ \\
\hline 96 & Orientation Toward R\&S Index & 5.5 & 3 & & 1.5 & 2 & 6 & Y3? & 220 & uni/pts & USA & Goldfarb & $\mathrm{P}$ \\
\hline 96 & Spiritual Assessment Inventory (2) & 11.5 & 16.5 & & 20 & 8 & 16 & $\mathrm{~N}$ & 56 & church & USA & Cunyus & $\mathrm{T}$ \\
\hline 96 & Spiritual Beliefs Scale & 3.5 & 1 & & 3.5 & & & Y2 & 295 & alcohol & USA & Schaler & $\mathrm{P}$ \\
\hline 97 & Psychomatrix Spirituality Inventory (PSI) & 23 & 12.5 & 3.5 & 9.5 & 13 & 18.5 & Y7? & 714 & adults & USA & Wolman & $\mathrm{P}$ \\
\hline 97 & Spiritual Experience Index-Revised & 6 & 3 & 1 & 3 & 10 & & $\mathrm{Y} 2$ & 286 & uni/adult & USA & Genia & $\mathrm{P}$ \\
\hline 98 & Spiritual Beliefs Inventory (SBI-15R) & 2 & 2.5 & & 6 & 4.5 & & Y2 & 301 & adults & USA & Holland & $\mathrm{P}$ \\
\hline 98 & $\begin{array}{l}\text { Spiritual Involvement and Beliefs Scale } \\
\text { (SIBS) }\end{array}$ & 14.5 & 4 & & 4 & 2.5 & 1 & Y4? & 83 & adults & USA & Hatch & $\mathrm{P}$ \\
\hline 99 & $\begin{array}{l}\text { Brief Multidimensional Measure of } \\
\text { Religiousness/Spirituality }\end{array}$ & 5.5 & 6.5 & 1 & 9.5 & 10.5 & & Y9 & 1445 & adults & USA & $\begin{array}{l}\text { Fetzer } \\
\text { Idler 03/04 }\end{array}$ & $\begin{array}{l}\mathrm{W} \\
\mathrm{P}\end{array}$ \\
\hline 99 & Daily Spiritual Experiences Scale - 6 & 1.5 & & 1 & 3 & 0.5 & & $?$ & & uni/adults & USA & Fetzer & $\mathrm{W}$ \\
\hline 99 & Personal Experiences Scale (PES) & 18.5 & 11 & 20 & 8 & 12.5 & 20 & Y8 & 246 & uni & USA & Perez & $\mathrm{T}$ \\
\hline 99 & Spiritual Practices scale & 14.5 & 8.5 & & 9 & 27 & 3 & $\mathrm{~N}$ & 88 & uni & USA & $\begin{array}{l}\text { Endyke } \\
\text { Janzen }\end{array}$ & $\mathrm{T}$ \\
\hline 01 & $\begin{array}{l}\text { Royal Free Interview for R/S Beliefs } \\
\text { RFIRSB -self-report version }\end{array}$ & 0.5 & 0.5 & 0.5 & 4.5 & 4 & & $\mathrm{~N}$ & 297 & adults & UK & King, $M$ & $\mathrm{P}$ \\
\hline 01 & $\begin{array}{l}\text { Spiritual History Scale in Four Dimensions } \\
\text { (SHS-4) }\end{array}$ & 1 & 4 & & 6.5 & 11.5 & & Y4 & 228 & elderly & USA & Hays & $\mathrm{P}$ \\
\hline 01 & Spiritual Needs (parent's perceptions) & 8 & 12.5 & 2 & 10 & 9.5 & 1 & Y2? & 523 & parents & USA & Smith JM & $\mathrm{T}$ \\
\hline 01 & Spirituality/Religiosity Scale & 0.5 & 0.5 & & 5 & 3 & & Y1 & 41 & black F & USA & Lukwago & $\mathrm{T}$ \\
\hline 02 & Daily Spiritual Experiences Scale & 2 & 2 & 1 & 9 & 2 & & Y2? & 355 & uni/adult & USA & Underwood & $\mathrm{P}$ \\
\hline 02 & Independent Spirituality Assessment Scale & 29 & 9 & & 1 & & & Y10 & 508 & adults & USA & Rojas & $\mathrm{T}$ \\
\hline 02 & Spiritual Transcendence Index (STI) & 4 & & & 4 & & & $\mathrm{Y} 2$ & 226 & adults & USA & Seidlitz & $\mathrm{P}$ \\
\hline 03 & CRRUCS/Gallup Spiritual Index & 2 & 1 & & 1 & 5 & & $2 ?$ & 1509 & adults & USA & Gallup & $\mathrm{W}$ \\
\hline
\end{tabular}




\begin{tabular}{|c|c|c|c|c|c|c|c|c|c|c|c|c|c|}
\hline Yr & Study/instrument & $\mathbf{P}$ & $\mathbf{C}$ & $\mathbf{E}$ & $\mathbf{T}$ & $\mathbf{R}$ & $\mathbf{O}$ & FA & $\mathbf{N}$ & type & place & 1st author & $\mathbf{S}$ \\
\hline 03 & Older Adult Spirituality Scale & 6.5 & 1 & & 2.5 & 1 & & $\mathrm{~N}$ & 320 & elderly & USA & Eggers & $\mathrm{P}$ \\
\hline 03 & Spiritual Beliefs Scale (2) & & & & & 4 & & $\mathrm{~N}$ & 165 & patients & USA & Kimmel & $\mathrm{P}$ \\
\hline 03 & Spiritual Focus Questionnaire (SFQ) & 7.5 & 3 & 3.5 & 4 & 2 & & Y5 & 456 & $\mathrm{~F} / \mathrm{pts}$ & USA & Wikoff & $\mathrm{T}$ \\
\hline 04 & $\begin{array}{l}\text { ASPIRES- Spiritual Transcendence Scale- } \\
\text { revised Short Form }\end{array}$ & 1.5 & 5 & & & 1.5 & 1 & Y3? & 322 & uni? & USA & $\begin{array}{l}\text { Piedmont } \\
\text { Smith, DJ06 }\end{array}$ & $\begin{array}{l}\mathrm{P} \\
\mathrm{P}\end{array}$ \\
\hline 04 & $\begin{array}{l}\text { Christian Spiritual Participation Profile } \\
\text { (CSPP) }\end{array}$ & 8 & 14 & 2 & 13.5 & 12.5 & & Y4 & 1687 & church & USA & Thayer & $\mathrm{P}$ \\
\hline 04 & State-Trait Spirituality Inventory & 6 & & 1 & 4 & 1 & 1 & $\mathrm{Y} 2$ & 141 & church & USA & Harvey & $\mathrm{T}$ \\
\hline 05 & $\begin{array}{l}\text { Body-Mind-Spirit Well-Being - Spirituality } \\
\text { scale }\end{array}$ & 10.5 & 1 & 1 & 0.5 & & & Y3 & 674 & adults & $\begin{array}{l}\text { Hong } \\
\text { Kong }\end{array}$ & $\mathrm{Ng}$ & $\mathrm{P}$ \\
\hline 05 & Embodied Spirituality Scale & 0.5 & 1.5 & & 5 & & 2 & $\mathrm{~N}$ & 267 & church & USA & Horn & $\mathrm{P}$ \\
\hline 05 & Expressions of Spirituality Index - Revised & 12.5 & & 7 & 5.5 & 4 & 1 & Y4? & 309 & adults & USA & Clarke & $\mathrm{T}$ \\
\hline 05 & Korean Spiritual Maturity Assessment & 20 & 8.5 & & 7 & 3.5 & 9 & $?$ & 180 & Christians & SKorea & Jo & $\mathrm{T}$ \\
\hline 05 & Religious \& Spiritual variables & 2 & 2 & & 1.5 & 2.5 & & $\mathrm{~N}$ & 453 & 21-26уо & USA & Horosewski & $\mathrm{T}$ \\
\hline 05 & Spiritual \& Religious Dimension Scale & 11 & & 2.5 & 2 & 19.5 & & Y5 & 180 & uni/adults & Aus & Nasel & $\mathrm{P}$ \\
\hline 05 & Spiritual Leadership \& Transformation (SLT) & 15.5 & 13.5 & & & & 4 & Y7 & 370 & army & USA & Fry & $\mathrm{P}$ \\
\hline 05 & Spiritual Personality Questionnaire & 17.5 & 11.5 & 2.5 & 0.5 & & & $?$ & $?$ & adults & $\mathrm{UK}$ & MySkillsProf & $\mathrm{W}$ \\
\hline 05 & $\begin{array}{l}\text { Spirituelle Bedürfnisse krebskranker Menschen-- } \\
\text { Einstellung und Praxis (SpREUK-P1.1) }\end{array}$ & 7 & 6 & 3 & 1 & 8 & & Y5 & 354 & well/sick & Germany & Büssing & $\mathrm{P}$ \\
\hline 06 & Exceptional Experiences Questionnaire & 10 & 2 & 5 & 7 & 1 & & Y4 & 705 & adults & Europe & Kohls & $\mathrm{P}$ \\
\hline 06 & $\begin{array}{l}\text { Integrating Spirituality in the Workplace } \\
\text { Survey }\end{array}$ & 15.5 & 1.5 & & 2 & & 2 & Y3? & 569 & soc wkrs & USA & $\begin{array}{l}\text { Chamiec- } \\
\text { Case }\end{array}$ & $\mathrm{T}$ \\
\hline 06 & Spirit at Work Scale (SAWS) & 13 & 3 & & 2 & & & Y4 & 335 & adults & Canada & Kinjerski & $\mathrm{P}$ \\
\hline 07 & $\begin{array}{l}\text { ASP Questionnaire (Expressions of } \\
\text { spirituality) }\end{array}$ & 21 & 6.5 & 1.5 & 6.5 & 4.5 & & Y7 & 488 & adults & Europe & Büssing & $\mathrm{P}$ \\
\hline 07 & $\begin{array}{l}\text { Health Intelligence Questionnaire - } \\
\text { Spirituality subscale }\end{array}$ & 3 & 0.5 & & 5 & 0.5 & & Y2 & 140 & adults & USA & Rachelle & $\mathrm{T}$ \\
\hline 08 & Spiritual Competencies Scale & 3 & 2 & & 1.5 & 9.5 & 12 & Y6 & 602 & uni & USA & Robertson & $\mathrm{T}$ \\
\hline 08 & Spiritual Connection Questionnaire(SCQ14) & 6.5 & 2.5 & 2 & 3 & & & Y1? & 420 & uni/adults & UK & Wheeler & $\mathrm{P}$ \\
\hline 08 & Spiritual Screening Tool for Older Adults & 8.5 & 3.5 & 1 & 3.5 & 3.5 & & $\mathrm{~N}$ & 49 & elderly & USA & Stranahan & $\mathrm{P}$ \\
\hline
\end{tabular}




\begin{tabular}{|c|c|c|c|c|c|c|c|c|c|c|c|c|c|}
\hline Yr & Study/instrument & $\mathbf{P}$ & $\mathbf{C}$ & $\mathbf{E}$ & $\mathbf{T}$ & $\mathbf{R}$ & $\mathbf{O}$ & FA & $\mathbf{N}$ & type & place & 1st author & $\mathbf{S}$ \\
\hline 11 & Spirituality in the Workplace & 1.5 & 6.5 & 4 & 4 & & & Y3 & 2230 & adults & USA & Liu & $\mathrm{P}$ \\
\hline 11 & Women's Spirituality Instrument & 1 & 2.5 & 1 & & 8.5 & 2 & Y1 & 366 & women & USA & Yakushko & $\mathrm{P}$ \\
\hline 12 & Spiritual Attitude \& Involvement List (SAIL) & 16 & 3.5 & 4 & 2.5 & 2 & 2 & Y7 & 1035 & uni/adults & N'lands & Meezenbroek & $\mathrm{P}$ \\
\hline 12 & Spiritual Care Questionnaire & 9 & 9 & & & 15 & & Y4 & 200 & nurse stu & Iran & Iranmanesh & $\mathrm{P}$ \\
\hline 12 & Spirituality Scale & 1.5 & & 2 & 1.5 & & 3 & $\mathrm{~N}$ & 1931 & adults & Finland & Lindeman & $\mathrm{P}$ \\
\hline \multicolumn{2}{|c|}{ Related/partial spirituality measures } & \multicolumn{4}{|c|}{ SWB } & & & & & & & & \\
\hline Yr & $\begin{array}{r}\text { Study/instrument } \\
\end{array}$ & $\mathbf{P}$ & $\mathbf{C}$ & $\mathbf{E}$ & $\mathbf{T}$ & $\mathbf{R}$ & $\mathbf{O}$ & FA & $\mathbf{N}$ & type & place & $\mathbf{1}^{\text {st }}$ author & $\mathbf{S}$ \\
\hline 64 & Purpose in Life Test (PIL) & 13 & & 2 & & & 5 & $?$ & & & USA & $\begin{array}{l}\text { Crumbaugh } \\
\text { Leath } 99\end{array}$ & $\begin{array}{l}\mathrm{P} \\
\mathrm{W}\end{array}$ \\
\hline 67.a & Religious Orientation Scale & 4 & 3 & & 2 & 11 & & $\mathrm{~N}$ & 309 & church & USA & $\begin{array}{l}\text { Allport } \\
\text { Valentine } 07\end{array}$ & $\begin{array}{l}\mathrm{P} \\
\mathrm{T}\end{array}$ \\
\hline 73 & Life Regard Index (LRI) & 26.5 & & 0.5 & & & 1 & $?$ & & & USA & Battista/Leath & $\mathrm{W}$ \\
\hline 79 & East-West Questionnaire & 11 & 4.5 & 7 & 1 & 2 & 8.5 & $\mathrm{~N}$ & 329 & uni/adult & USA & Gilgen & $\mathrm{P}$ \\
\hline 87 & Health-Promoting Lifestyle profile (HPLP) & 15.5 & 6.5 & 1 & 0.5 & 0.5 & 24 & Y6 & 952 & adults & USA & Walker, $\mathrm{S}$ & $\mathrm{P}$ \\
\hline 92 & Quality of Life Index (QLI) & 15 & 11 & 1 & 1 & & 5 & Y4 & 349 & pts & USA & Ferrans & $\mathrm{P}$ \\
\hline 97 & Scale of Resilience (SCOPE) & 19 & 12.5 & 0.5 & & & & Y5? & 283 & parents & USA & Vestal & $\mathrm{T}$ \\
\hline 98 & Brief RCOPE & 4.5 & 4 & 1 & 10.5 & 1 & & $\mathrm{Y} 2$ & 1387 & uni/adult & USA & Pargament & $\mathrm{P}$ \\
\hline 98 & Personal Meaning Profile & 29.5 & 17.5 & 1.5 & 5.5 & & 2 & Y7 & $?$ & $?$ & USA? & $\begin{array}{l}\text { Wong } \\
\text { Leung } 03\end{array}$ & $\begin{array}{l}\mathrm{P} \\
\mathrm{T}\end{array}$ \\
\hline 99 & Pargament's Meaning Scale & 14 & & 0.5 & 4.5 & 1 & & $?$ & & adults? & USA & Pargament & $\mathrm{P}$ \\
\hline 00 & Africultural Coping Systems Inventory & 3 & 7 & & 2 & 7 & 11 & Y4 & 220 & Afr-Am & USA & Utsey & $\mathrm{P}$ \\
\hline 00 & $\begin{array}{l}\text { Francis-Louden Mystical Orientation Scale } \\
\text { (FLMOS) }\end{array}$ & 7 & & 4.5 & 9.5 & & & Y1? & $?$ & priests & UK & $\begin{array}{l}\text { Francis } \\
\text { Edwards } 08\end{array}$ & $\begin{array}{l}\mathrm{P} \\
\mathrm{P}\end{array}$ \\
\hline 01 & Life-Regard Index-Revised & 28 & & & & & & Y2? & 91 & adults & USA & Harris, A & $\mathrm{P}$ \\
\hline 03 & Adult Strengths & 1 & & & 2 & 4 & 45 & $9 ?$ & 369 & adults & USA & Isaacowitz & $\mathrm{P}$ \\
\hline 03 & Life Attitude Scale & 17.5 & 6 & 1 & 3.5 & 1 & 3 & Y5 & 183 & adults & Canada & Leung & $\mathrm{T}$ \\
\hline 03 & Salient Beliefs Review (SBR) & 4.5 & 2.5 & & & & & $\mathrm{~N}$ & 79 & adults & USA & Bloch & $\mathrm{P}$ \\
\hline 04 & Short Index of Mystical Orientation & 0.5 & & 5 & 3.5 & & & $\mathrm{~N}$ & 1468 & priests & UK & Francis & $\mathrm{P}$ \\
\hline 05 & Existential Meaning Scale & 10 & & & & & & $\mathrm{Y} 1$ & 150 & adults & USA & Lyon & $\mathrm{T}$ \\
\hline
\end{tabular}




\begin{tabular}{|c|c|c|c|c|c|c|c|c|c|c|c|c|c|}
\hline Yr & Study/instrument & $\mathbf{P}$ & $\mathbf{C}$ & $\mathbf{E}$ & $\mathbf{T}$ & $\mathbf{R}$ & $\mathbf{O}$ & FA & $\mathbf{N}$ & type & place & 1st author & $\mathbf{S}$ \\
\hline 06 & Beliefs and Values Scale & 5 & & 1 & 3 & 11 & & Y2 & 656 & adult/pts & UK & King & $\mathrm{P}$ \\
\hline 06 & $\begin{array}{l}\text { Sources of Meaning \& Meaningfulness } \\
\text { Questionnaire (SoMe) }\end{array}$ & 13.5 & 5.5 & 1 & 1 & 1 & 4 & Y4 & 202 & $19-68$ уо & Germany & Schnell & $\mathrm{P}$ \\
\hline 08 & Attitudes to Mysticism Scale & 3 & 1 & & 4 & 14 & 2 & $\mathrm{~N}$ & 90 & uni/adult & UK & Edwards & $\mathrm{P}$ \\
\hline 09 & Meaningful Life Measure & 23 & & & & & & Y5 & 200 & uni/adult & UK & Morgan, J & $\mathrm{P}$ \\
\hline 09 & Thai Healthy Aging Scale - sp hlth subscale & 6.5 & 2.5 & & 2 & 4 & 1 & Y1/16 & 350 & aged & Thailand & Thiamwong & $\mathrm{P}$ \\
\hline 09 & Worldview Analysis Scale & 5.5 & 9.5 & 5 & 2.5 & 8.5 & 14 & Y7 & 816 & uni & USA & Obasi & $\mathrm{P}$ \\
\hline
\end{tabular}

\begin{tabular}{|c|c|c|c|c|c|c|c|c|c|c|c|c|c|}
\hline \multicolumn{14}{|c|}{ UNIVERSITY only } \\
\hline \multicolumn{2}{|c|}{ SH/WB measures } & \multicolumn{4}{|c|}{ SWB } & & & & & & & & \\
\hline Yr & $\begin{array}{r}\text { Study/instrument } \\
\end{array}$ & $\mathbf{P}$ & $\mathbf{C}$ & $\mathbf{E}$ & $\mathbf{T}$ & $\mathbf{R}$ & $\mathbf{O}$ & $\mathbf{F A}$ & $\mathbf{N}$ & type & place & $1^{\text {st }}$ author & $\mathbf{S}$ \\
\hline 06 & Spiritual Wellness Survey & 10 & 4 & & 1 & & & $\mathrm{~N}$ & 303 & uni & USA & Patneaude & $\mathrm{T}$ \\
\hline 07 & Brief Spiritual Well-being Scale & 3 & & & 3 & & & $\mathrm{~N}$ & 150 & grad stu & USA & Kroft & $\mathrm{T}$ \\
\hline 12 & $\begin{array}{l}\text { Multidimensional Inventory for Religious/ } \\
\text { Spiritual Well-Being (MI-RSWB-E) }\end{array}$ & 14.5 & 11 & 1 & 6.5 & 6 & 9 & Y6 & 400 & uni & UK & Unterrainer & $\mathrm{P}$ \\
\hline \multicolumn{2}{|c|}{ Spirituality measures } & \multicolumn{4}{|c|}{ SWB } & & & & & & & & \\
\hline Yr & $\begin{array}{r}\text { Study/instrument } \\
\end{array}$ & $\mathbf{P}$ & $\mathbf{C}$ & $\mathbf{E}$ & $\mathbf{T}$ & $\mathbf{R}$ & $\mathbf{O}$ & $\mathbf{F A}$ & $\mathbf{N}$ & type & place & $1^{\text {st }}$ author & $\mathbf{S}$ \\
\hline 85 & Spirituality Scale & 3.5 & 2 & 6.5 & 0.5 & 5 & 2.5 & $?$ & $?$ & Afr-Am & USA & Jagers & $\mathrm{T}$ \\
\hline 86 & Spiritual Perspective Scale & 5 & 2.5 & & 2.5 & & & $?$ & $?$ & $?$ & USA & $\begin{array}{l}\text { Reed } \\
\text { Jesse } 99\end{array}$ & $\mathrm{~T}$ \\
\hline 96 & Spiritual Assessment Inventory (SAI) & 3.5 & 2 & & 37 & 0.5 & & Y5 & 449 & uni & USA & Hall & $\mathrm{P}$ \\
\hline 96 & Spiritual Maturity Index & 3 & 1 & & 8.5 & 0.5 & 2 & $\mathrm{~N}$ & 100 & uni & USA & Ashdown & $\mathrm{T}$ \\
\hline 97 & Expressions of Spirituality Inventory(ESI) & 43 & 5.5 & 18.5 & 10.5 & 12.5 & 8 & Y5 & 938 & uni & Canada & MacDonald & $\mathrm{T}$ \\
\hline 97 & Spirituality Assessment Scale(2) & 8.5 & 7 & & 6.5 & 2 & 6 & Y4? & 332 & grad stu & USA & Beazley & $\mathrm{T}$ \\
\hline 99 & Cognitive-Behavioral Spirituality Scale & 6 & & & 9 & & & Y3? & 103 & uni & USA & Niederman & $\mathrm{W}$ \\
\hline 99 & $\begin{array}{l}\text { Multidimensional Spiritual Orientation } \\
\text { Inventory (MSOI) }\end{array}$ & 35 & 6 & & 8 & 14 & & Y6 & 444 & uni & USA & Morgan, D & $\mathrm{T}$ \\
\hline 99 & Spiritual Transcendence Scale & 9 & 10 & 2 & 1.5 & 1.5 & & Y3 & 735 & uni & USA & Piedmont & $\mathrm{P}$ \\
\hline 00 & Spirituality Questionnaire & 21 & 3 & 1 & 13.5 & 9.5 & 2 & $\mathrm{~N}$ & 674 & uni & Canada & $\begin{array}{l}\text { Fazakas- } \\
\text { deHoog }\end{array}$ & $\mathrm{T}$ \\
\hline 02 & Spiritual beliefs \& religious participation & 1.5 & 2.5 & & 4 & 8 & & Y2 & 192 & uni & USA & Walker, K & $\mathrm{P}$ \\
\hline
\end{tabular}




\begin{tabular}{|c|c|c|c|c|c|c|c|c|c|c|c|c|c|}
\hline Yr & Study/instrument & $\mathbf{P}$ & $\mathbf{C}$ & $\mathbf{E}$ & $\mathbf{T}$ & $\mathbf{R}$ & $\mathbf{O}$ & $\mathbf{F A}$ & $\mathbf{N}$ & type & place & 1st author & $\mathbf{S}$ \\
\hline 02 & Spiritual Involvement Scale (SIS) & 7 & 5 & & 4.5 & 0.5 & 1 & Y2 & 136 & uni & USA & Fenzel & $\mathrm{C}$ \\
\hline 02 & Spirituality Rating Scale & $15 ?$ & & & & & & Y5 & 385 & uni & Japan & Hayato & $\mathrm{P}$ \\
\hline 03 & Intrinsic Spirituality Scale & $6 ?$ & & & & & & $\mathrm{Y}$ & 172 & uni & USA & Hodge & $\mathrm{P}$ \\
\hline 03 & Means-Ends Spirituality Questionnaire & 17.5 & 8 & 1 & 10 & 5.5 & & Y2 & 405 & uni & USA & Ryan & $\mathrm{P}$ \\
\hline 04 & Miller Measure of Spirituality (MMS) & 12 & 4.5 & 2.5 & 7 & 1.5 & 3.5 & Y2? & 781 & uni & USA & Miller & $\mathrm{P}$ \\
\hline 04 & Spiritual Meaning Scale & 10.5 & 1 & & 2 & 0.5 & & Y1 & 465 & uni & USA & Mascaro & $\mathrm{P}$ \\
\hline 04 & Spiritual Transformation Inventory & 8.5 & 13 & & 20 & 2.5 & & Y19? & 371 & uni & USA & Hall & $\mathrm{W}$ \\
\hline 05 & Inclusive Spirituality Index & 24 & 13.5 & 7 & 0.5 & 1 & 1 & Y6 & 251 & uni & USA & Muse-Burke & $\mathrm{T}$ \\
\hline 05 & $\begin{array}{l}\text { Ryff's Scales of Psychological \&spiritual } \\
\text { wellbeing }\end{array}$ & 8.5 & & & 1.5 & & & Y2? & 233 & uni & $\begin{array}{l}\text { Nether } \\
\text { lands }\end{array}$ & $\begin{array}{l}\text { van } \\
\text { Dierendonck }\end{array}$ & $\mathrm{P}$ \\
\hline 05 & Spiritual growth Survey & 3.5 & 1 & & 14.5 & 1 & & Y1 & 176 & uni & USA & Hancock & $\mathrm{P}$ \\
\hline 05 & Spiritual Support Scale (SSS) & 4.5 & & & 4.5 & 3 & & Y1 & 453 & uni & USA & $\mathrm{Ai}$ & $\mathrm{P}$ \\
\hline 05 & Theistic Spiritual Outcome Survey & 7.5 & 4.5 & 1 & 4 & & & Y3 & 344 & uni & USA & Richards & $\mathrm{P}$ \\
\hline 06 & Spirituality, Religion \& Life Satisfaction & 2 & & & 1 & 2 & 2 & $\mathrm{~N}$ & 522 & uni & USA & Zullig & $\mathrm{P}$ \\
\hline 07 & $\begin{array}{l}\text { College Students Beliefs \& Values (CSBV) } \\
\text { Spirituality Factor Scale } \\
\text { Spiritual Quest } \\
\text { Ethic of caring, compassionate self-concept } \\
\text { Global citizenship, personal God }\end{array}$ & $\begin{array}{l}9 \\
7 \\
0.5 \\
\end{array}$ & \begin{tabular}{|l|l}
1 \\
11 \\
6 \\
\end{tabular} & $\begin{array}{l}3 \\
1\end{array}$ & $\begin{array}{l}1 \\
5.5 \\
\end{array}$ & & 1 & Y12 & 14527 & uni & USA & $\begin{array}{l}\text { HERI, } \\
\text { UCLA }\end{array}$ & $\mathrm{W}$ \\
\hline 07 & Fundamental Spiritual Profile (FSP) & 21.5 & 14 & 4 & 6.5 & & 7 & Y10 & 1080 & uni & USA & Del Rio & $\mathrm{T}$ \\
\hline 07 & Spiritual Fitness Assessment & 12 & 4.5 & & 11.5 & 10 & & Y5? & 196 & Cath uni & USA & $\begin{array}{l}\text { Fletcher } \\
\text { Kassab } 11\end{array}$ & $\begin{array}{l}\mathrm{W} \\
\mathrm{P}\end{array}$ \\
\hline 07 & Spirituality Scale (4) & 9 & 1 & & 2 & 1 & & $\mathrm{~N}$ & 221 & uni & USA & Nelms & $\mathrm{P}$ \\
\hline 08 & $\begin{array}{l}\text { Spiritual Intelligence Self-Report Inventory } \\
\text { SISRI- } 24\end{array}$ & 15 & 2.5 & 3.5 & 1 & & 2 & Y4 & 619 & uni & Canada & King, D & $\begin{array}{l}\mathrm{T} \\
\mathrm{W}\end{array}$ \\
\hline 08 & Wilderness Spirituality Scale & 3.5 & 0.5 & 15 & 1 & & 8 & Y2? & 608 & uni & USA & Bloom & $\mathrm{T}$ \\
\hline 09 & Similarity of Offender's Spirituality Scale & 8 & & & & 1 & & Y2 & 200 & uni & USA & Davis & $\mathrm{P}$ \\
\hline 10 & Community Spirituality Scale & 0.5 & 3.5 & & 1.5 & 1.5 & & Y1 & 198 & theol stu & USA & Rovers & $\mathrm{P}$ \\
\hline 11 & Spiritual Maturity Scale & 5.5 & 1.5 & & 2.5 & 10.5 & & Y2 & 541 & uni & USA & Watson & $\mathrm{T}$ \\
\hline
\end{tabular}




\begin{tabular}{|c|c|c|c|c|c|c|c|c|c|c|c|c|c|}
\hline \multicolumn{2}{|c|}{ Related/partial spirituality measures } & \multicolumn{4}{|c|}{ SWB } & \multirow[b]{2}{*}{$\mathbf{R}$} & \multirow[b]{2}{*}{$\mathbf{O}$} & \multirow[b]{2}{*}{ FA } & \multirow[b]{2}{*}{$\mathbf{N}$} & \multirow[b]{2}{*}{ type } & \multirow[b]{2}{*}{ place } & \multirow[b]{2}{*}{$1^{\text {st }}$ author } & \multirow[b]{2}{*}{$\mathbf{S}$} \\
\hline Yr & \begin{tabular}{|r|} 
Study/instrument \\
\end{tabular} & $\mathbf{P}$ & $\mathbf{C}$ & $\mathbf{E}$ & $\mathbf{T}$ & & & & & & & & \\
\hline 75 & Mysticism Scale & 2 & & 17 & 9 & & 4 & Y3 & 300 & uni & USA & Hood & $\mathrm{H}$ \\
\hline 81 & Life Attitude Profile & 44 & & & & & & Y7 & 219 & uni & USA & Reker & $\mathrm{P}$ \\
\hline 87 & Word-Spirit Orientation Scale & 4.5 & 1 & & 1 & 9.5 & & $?$ & $?$ & Uni? & USA & Hsieh & $\mathrm{P}$ \\
\hline 89 & Intrinsic/Extrinsic Measurement & 3 & 3 & & 2 & 6 & & Y3? & 771 & uni & USA & Gorsuch & $\mathrm{P}$ \\
\hline 91 & Quest Scale & 1.5 & & 0.5 & 0.5 & 9.5 & & $\mathrm{~N}$ & 214 & uni & USA & Batson & $\mathrm{P}$ \\
\hline 97 & $\begin{array}{l}\text { Santa Clara Strength of Religious Faith } \\
\text { Questionnaire (SCORF) }\end{array}$ & 2.5 & 1 & & 2 & 4.5 & & Y1 & 102 & uni & USA & $\begin{array}{l}\text { Plante/ } \\
\text { Freiheit } 06\end{array}$ & $\begin{array}{l}\mathrm{P} \\
\mathrm{P}\end{array}$ \\
\hline 00 & Religious Coping (RCOPE) & 33.5 & 14.5 & & 46.5 & 10.5 & & Y17 & 540 & uni & USA & Pargament & $\mathrm{P}$ \\
\hline 01 & Adolescent Lifestyle Profile & 13 & 10 & & 2 & 2 & 17 & $?$ & 168 & Afr-Am uni & USA & $\begin{array}{l}\text { Hendricks } \\
\text { Hendricks04 }\end{array}$ & $\mathrm{T}$ \\
\hline 03 & Affective Neuroscience Personality Scales & 5 & 2 & 3 & & 2 & 98 & Y7 & 171 & uni stu & USA & Davis, $\mathrm{K}$ & $\mathrm{P}$ \\
\hline 03 & Personal Meanings of Spirituality & 7.5 & 0.5 & 0.5 & 3.5 & 3.5 & 4.5 & Y2 & 254 & uni & USA & Graci & $\mathrm{P}$ \\
\hline 04 & Life Attitude Profile-Revised (LAP-R) & 48 & & & & & & Y6 & 524 & uni & USA & Dennis & $\mathrm{P}$ \\
\hline 06 & $\begin{array}{l}\text { Body-Mind-Spirit Wellness Behavior \& } \\
\text { Characteristic Inventory (BMS-WBCI) }\end{array}$ & 13.5 & 0.5 & & & 1 & 29 & Y3 & 41 & uni & USA & Hey & $\mathrm{P}$ \\
\hline 06 & Meaning in Life Questionnaire (MLQ) & 10 & & & & & & Y2 & 154 & uni & USA & Steger & $\mathrm{P}$ \\
\hline 07 & Mystical Experience Scale(MES) & 7.5 & 4 & 3.5 & 4 & & & Y1? & 778 & uni & Aus/UK & Lange & $\mathrm{P}$ \\
\hline
\end{tabular}

\begin{tabular}{|c|c|c|c|c|c|c|c|c|c|c|c|c|c|}
\hline \multicolumn{14}{|c|}{ SCHOOL } \\
\hline \multicolumn{2}{|c|}{ SH/WB measures } & \multicolumn{4}{|c|}{ SWB } & \multirow[b]{2}{*}{$\mathbf{R}$} & \multirow[b]{2}{*}{$\mathbf{O}$} & \multirow[b]{2}{*}{ FA } & \multirow[b]{2}{*}{$\mathbf{N}$} & \multirow[b]{2}{*}{ type } & \multirow[b]{2}{*}{ place } & \multirow[b]{2}{*}{$1^{\text {st }}$ author } & \multirow[b]{2}{*}{$\mathbf{S}$} \\
\hline Yr & Study/instrument & $\mathbf{P}$ & $\mathbf{C}$ & $\mathbf{E}$ & $\mathbf{T}$ & & & & & & & & \\
\hline 88 & Spirituality Inventory & 6.5 & 6 & & 15 & 12.5 & & $\mathrm{~N}$ & 591 & SDA adol & USA & Youlden & $\mathrm{T}$ \\
\hline 99 & 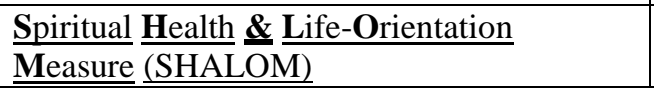 & 5 & 5 & 5 & 5 & & (5) & Y4 & 850 & $2^{0} \mathrm{stu}$ & Aus & Fisher & $\mathrm{P}$ \\
\hline 00 & $\begin{array}{l}\text { Spiritual Health in } 4 \text { Domains Index } \\
\text { (SH4DI) }\end{array}$ & 7 & 5.5 & 5 & 4 & 1.5 & 1 & Y4 & 311 & $1^{0}$ teachrs & UK & Fisher & $\mathrm{P}$ \\
\hline 01 & Level of $\underline{\text { SWB }}$ in schools & 8 & 8 & 8 & 8 & & & Y4 & 144 & teachers & Aus & Fisher & $\mathrm{P}$ \\
\hline 03 & Modified Spiritual Well-Being Scale & 11.5 & & & 8.5 & & & $\mathrm{~N}$ & 71 & $11-12$ yo & USA & Patrick & $\mathrm{T}$ \\
\hline 03 & Spiritual Well-Being Questionnaire SWBQ(2) & 5 & 5 & 5 & 5 & & & Y4 & 2071 & $2^{0}$,uni,tr & Aus & Gomez/Fisher & $\mathrm{P}$ \\
\hline
\end{tabular}




\begin{tabular}{|c|c|c|c|c|c|c|c|c|c|c|c|c|c|}
\hline Yr & Study/instrument & $\mathbf{P}$ & $\mathbf{C}$ & $\mathbf{E}$ & $\mathbf{T}$ & $\mathbf{R}$ & $\mathbf{O}$ & FA & $\mathbf{N}$ & type & place & 1st author & $\mathbf{S}$ \\
\hline 04 & Feeling Good/Living Life(FGLL) & 4 & 4 & 4 & 4 & & & Y4 & 1080 & $1^{0}$ student & Aus & Fisher & $\mathrm{P}$ \\
\hline 05 & Urban Hope \& Spiritual Health & 6 & 9.5 & 4.5 & 2 & 3 & 3 & $\mathrm{~N}$ & 23418 & 13-15уо & UK & Francis & $\mathrm{P}$ \\
\hline 07 & SWBQ(2) modified & 4 & 5 & 7 & 5 & & & $\mathrm{~N}$ & 1184 & $13-20$ yo & S Africa & Van Rooyen & $\mathrm{T}$ \\
\hline 07 & $\begin{array}{l}\text { Young People Putting Life Together } \\
\text { Australian Youth Spirituality }\end{array}$ & 36 & 54 & 5.5 & 6.5 & 31 & & $\mathrm{~N}$ & 4000 & $13-24$ yo & Aus & Hughes & $\mathrm{P}$ \\
\hline 13 & SWBQ2 & 5 & 5 & 5 & 5 & & & Y4 & 460 & $13-20$ yo & Aus & Fisher & $\mathrm{P}$ \\
\hline \multicolumn{2}{|c|}{ Spirituality measures } & \multicolumn{4}{|c|}{ SWB } & & & & & & & & \\
\hline Yr & Study/instrument & $\mathbf{P}$ & $\mathbf{C}$ & $\mathbf{E}$ & $\mathbf{T}$ & $\mathbf{R}$ & $\mathbf{O}$ & FA & $\mathbf{N}$ & type & place & $\mathbf{1}^{\text {st }}$ author & $\mathbf{S}$ \\
\hline 00 & Adolescent Spirituality & 4 & 18.5 & & 5.5 & 19 & & $\mathrm{~N}$ & 141 & $11-25$ yo & USA & Holder & $\mathrm{P}$ \\
\hline 00 & $\begin{array}{l}\text { Smithline Spirituality Inventory for Teens } \\
\text { (SSIT) }\end{array}$ & 3 & 4.5 & & 3.5 & 3 & 1 & Y2? & 196 & hi schl & USA & Smithline & $\mathrm{T}$ \\
\hline 00 & $\begin{array}{l}\text { TestWell: Wellness Inventory- Spirituality } \\
\text { \& Values Section }\end{array}$ & 2.5 & 2.5 & & & & 45 & $?$ & $?$ & $\begin{array}{l}\text { high } \\
\text { school }\end{array}$ & USA & $\begin{array}{l}\text { National } \\
\text { Wellness } \\
\text { Institute }\end{array}$ & $\mathrm{W}$ \\
\hline 01 & Religion/Spirituality Survey & 7.5 & 4 & & 3.5 & 8 & & $\mathrm{~N}$ & 100 & $\begin{array}{l}\text { 12-19yo } \\
\text { Afr-Am }\end{array}$ & USA & Chase & $\mathrm{T}$ \\
\hline 02 & $\begin{array}{l}\text { WHOQOL-Spiritual, Religion \& Personal } \\
\text { Beliefs (SRPB) - Field test Instrument }\end{array}$ & 22 & 1 & 3 & 2 & 4 & & Y6/8? & 3636 & 16-90yo & world & $\begin{array}{l}\text { WHOQOL } \\
\text { SRPB gp }\end{array}$ & $\mathrm{P}$ \\
\hline 03 & Sifers Childrens Spirituality Scale (SCSS) & 6 & 5.5 & & 7.5 & & 1 & $\mathrm{~N}$ & 175 & 7-14yo & USA & Sifers & $\mathrm{C}$ \\
\hline 04 & Spirituality scale(3) & 2 & 0.5 & & 3 & 0.5 & 2 & $\mathrm{~N}$ & 642 & $2^{0} \mathrm{stu}$ & USA & Ritt-Olson & $\mathrm{P}$ \\
\hline 05 & Prague Spirituality Questionnaire & 8.5 & 6.5 & 8 & 4 & 7 & 2 & Y6 & 1088 & hi schl & Czech & Rican10 & $\mathrm{P}$ \\
\hline 06 & Generation Y study & 2 & 1 & & 10.5 & 11.5 & & $\mathrm{~N}$ & 1216 & 13-29уо & Aus & Mason & $\mathrm{W}$ \\
\hline 06 & Spiritual Sensitivity Scale (SSS) & 7 & 3 & 1 & & & & Y4? & 496 & stu/adults & Finland & Tirri & $\mathrm{P}$ \\
\hline 08 & $\begin{array}{l}\text { Search Institute Inventory of Youth Spiritual } \\
\text { Development (SIIYSD) }\end{array}$ & 59 & 32.5 & 12.5 & 17.5 & 27.5 & 7 & $\mathrm{~N}$ & 6853 & $12-25$ уо & $\begin{array}{l}8 \\
\text { countries } \\
\end{array}$ & $\begin{array}{l}\text { Center for } \\
\text { Sp Devt }\end{array}$ & $\mathrm{C}$ \\
\hline 10 & Aspects of spirituality (ASP-S) & 10 & 3.5 & 2 & 3 & 6.5 & & Y4 & 254 & Adol. & $\mathrm{W}$ & Büssing & $\mathrm{P}$ \\
\hline 10 & Christian Inventory of Spirituality & 17 & 10.5 & & 15.5 & 4 & 1 & Y5 & 954 & adults & drug/alc & Shorkey & $\mathrm{P}$ \\
\hline
\end{tabular}




\begin{tabular}{|c|c|c|c|c|c|c|c|c|c|c|c|c|c|}
\hline \multicolumn{2}{|c|}{ Related/partial spirituality measures } & \multicolumn{4}{|c|}{ SWB } & \multirow[b]{2}{*}{$\mathbf{R}$} & \multirow[b]{2}{*}{$\mathbf{O}$} & \multirow[b]{2}{*}{ FA } & \multirow[b]{2}{*}{$\mathbf{N}$} & \multirow[b]{2}{*}{ type } & \multirow[b]{2}{*}{ place } & \multirow[b]{2}{*}{$1^{\text {st }}$ author } & \multirow[b]{2}{*}{$\mathbf{S}$} \\
\hline Yr & Study/instrument & $\mathbf{P}$ & $\mathbf{C}$ & $\mathbf{E}$ & $\mathbf{T}$ & & & & & & & & \\
\hline nd & Child Health Questionnaire & 7 & 3 & & & & 77 & & & 10-18уо & USA & HealthAct & $\mathrm{W}$ \\
\hline 93 & Faith Maturity Scale(FMS) & 7.5 & 10 & 3 & 8.5 & 8 & 1 & $\mathrm{~N}$ & 3986 & yth/adult & USA & Benson & $\underline{\mathrm{H}}$ \\
\hline 94 & $\begin{array}{l}\text { Multidimensional Life Satisfaction Scale for } \\
\text { Children }\end{array}$ & 7.5 & 13.5 & 3 & & & 16 & Y5 & 725 & $1^{0}$ school & USA & Huebner & $\mathrm{P}$ \\
\hline 94 & Scale of Racial Socialisation for Adolescents & 3 & 1 & & 1.5 & 1.5 & 30 & Y4 & 200 & Af-Am yth & USA & Stevenson & $\mathrm{P}$ \\
\hline 98 & Frameworks for Life Questionnaire & 4 & 1 & & 1 & 3.5 & 75.5 & $\mathrm{~N}$ & 144 & 15-16уо & Aus & Gehrig & $\mathrm{T}$ \\
\hline 98 & $\begin{array}{l}\text { Personal Inventory of Kid's Optimal } \\
\text { Capacities (PIKOC) }\end{array}$ & 8 & 14 & & & & 70 & Y3/4? & 174 & grade $3-5$ & USA & Ziegler & $\mathrm{T}$ \\
\hline 00 & Children's Quality of life (C-QOL) Thai & 3 & 7 & 4 & & 3 & 45 & $\mathrm{~N}$ & 35 & $5-8$ уо & Thailand & Jirojanakul & $\mathrm{P}$ \\
\hline 00 & $\begin{array}{l}{ }^{2} \text { Vécu et Santé Perçue de l'Adolescent } \\
\text { (VSP-A) }\end{array}$ & 15 & 12 & 2 & & & 11 & Y6 & 2941 & $11-17$ yo & France & Simeoni & $\mathrm{P}$ \\
\hline 02 & Quality Of Life Profile -Adolescent Version & 8 & 8 & 3 & & 1 & 17 & Y8 & 899 & 12-16yo & UK & Bradford & $\mathrm{P}$ \\
\hline 04 & S/R \& Thriving in Adolescence & 1 & 9.5 & & & 9.5 & 27 & Y16 & 1000 & $9-15$ уо & USA & Dowling & $\mathrm{P}$ \\
\hline 07 & $\begin{array}{l}\text { Alcohol-related God Locus of Control Scale } \\
\text { for Adolescents (AGLOC-A) }\end{array}$ & & & & 12 & & & Y1 & 356 & $\begin{array}{l}\text { Afr-Am. } \\
\text { youth }\end{array}$ & USA & Goggin & $\mathrm{P}$ \\
\hline 07 & Benefit Finding Scale for Children (BFSC) & 5 & 5 & & & & & Y1 & 199 & 7-18уо & USA & Phipps & $\mathrm{P}$ \\
\hline 07 & Chinese Positive Youth Development Scale & 6.5 & & 0.5 & & & 83 & Y15 & 322 & adol & Hong & Shek & $\mathrm{P}$ \\
\hline \multicolumn{14}{|c|}{ HEALTH } \\
\hline \multicolumn{2}{|c|}{ SH/WB measures } & \multicolumn{4}{|c|}{ SWB } & & & & & & & & \\
\hline Yr & Study/instrument & $\mathbf{P}$ & $\mathbf{C}$ & $\mathbf{E}$ & $\mathbf{T}$ & $\mathbf{R}$ & $\mathbf{O}$ & FA & $\mathbf{N}$ & type & place & $1^{\text {st }}$ author & $\mathbf{S}$ \\
\hline 92 & Spiritual Health Inventory & 14 & 5.5 & & 3 & 1.5 & 7 & $?$ & 23 & ca pts & USA & Highfield & $\mathrm{P}$ \\
\hline 92 & Spiritual Health Inventory & 10 & 10 & & 5 & 1 & 5 & $?$ & 27 & nurses & USA & Highfield & $\mathrm{P}$ \\
\hline 99 & Spirit Core Scale & 25 & 4 & & 1 & 2 & & Y5 & 668 & adolescent & USA & Johnson & $\mathrm{T}$ \\
\hline 03 & $\begin{array}{l}\text { End-Stage Renal Disease Spiritual Beliefs } \\
\text { Scale }\end{array}$ & & 8 & & & 4 & & $\mathrm{~N}$ & 165 & pts & USA & Kimmel & $\mathrm{P}$ \\
\hline 06 & Spirituality Transcendence Measure & 11 & 4.5 & & & 4.5 & 2 & $\mathrm{Y} 3$ & 37 & ca pts & Taiwan & Leung & $\mathrm{T}$ \\
\hline 09 & Brief Serenity Scale & 19 & 1 & & & & & Y3 & 86 & org t'plant & USA & Kreitzer & $\mathrm{P}$ \\
\hline 10 & Spiritual Distress Scale & 14.5 & 6 & & 2 & 3.5 & 4 & Y4 & 85 & ca pts & Taiwan & $\mathrm{Ku}$ & $\mathrm{P}$ \\
\hline 11 & Physician's spiritual well-being scale & 10 & 4 & & & 1 & 5 & Y4 & 177 & physician & Taiwan & Fang & $\mathrm{P}$ \\
\hline 12 & EORTC QLQ-SWB36 & 8.5 & 6 & & 4 & 5.5 & 12 & $?$ & 113 & PC ca pts & world & Vivat & $\mathrm{P}$ \\
\hline 12 & Spirit 8 & 7 & & 1 & & & & Y1 & 285 & pallcare & Africa & Selman & $\mathrm{P}$ \\
\hline
\end{tabular}




\begin{tabular}{|c|c|c|c|c|c|c|c|c|c|c|c|c|c|}
\hline \multicolumn{2}{|c|}{ Spirituality measures } & \multicolumn{4}{|c|}{ SWB } & \multirow[b]{2}{*}{$\mathbf{R}$} & \multirow[b]{2}{*}{$\mathbf{O}$} & \multirow[b]{2}{*}{ FA } & \multirow[b]{2}{*}{$\mathbf{N}$} & \multirow[b]{2}{*}{ type } & \multirow[b]{2}{*}{ place } & \multirow[b]{2}{*}{$1^{\text {st }}$ author } & \multirow[b]{2}{*}{$\mathbf{S}$} \\
\hline Yr & Study/instrument & $\mathbf{P}$ & $\mathbf{C}$ & $\mathbf{E}$ & $\mathbf{T}$ & & & & & & & & \\
\hline 84 & Spirituality Self-Assessment Scale & 20.5 & 9 & 0.5 & 3 & & 1 & $\mathrm{~N}$ & $?$ & alcs & USA & Whitfield & $\mathrm{P}$ \\
\hline 92 & Spiritual Injury Scale & 6 & & & 2 & & & $?$ & $?$ & adults & USA & Berg & $\mathrm{W}$ \\
\hline 94 & Nurses Spiritual Care Perspective Scale & & 1.5 & & 3 & 5.5 & 2 & $\mathrm{~N}$ & 244 & pts/carers & USA & Taylor & $\mathrm{P}$ \\
\hline 95 & Spiritual Beliefs Questionnaire & 1.5 & & & 2 & 1.5 & 2 & $\mathrm{~N}$ & 101 & drug users & UK & Christo & $\mathrm{P}$ \\
\hline 97 & Spiritual Needs Inventory & 4.5 & 7.5 & 1 & 1 & 3 & & Y5 & 100 & pts & USA & Hermann & $\mathrm{P}$ \\
\hline 00 & Spirituality \& Religion Survey & 1.5 & 1.5 & & 4.5 & 12 & 1.5 & $\mathrm{~N}$ & 275 & HIV pts & USA & Somlai & $\mathrm{P}$ \\
\hline 00 & Spirituality at Work & 20.5 & 7.5 & & 2 & & 3 & Y7 & 696 & hosp staff & USA & Ashmos & $\mathrm{P}$ \\
\hline 01 & $\begin{array}{l}\text { Spiritual Support for terminally ill - nurse } \\
\text { assessment }\end{array}$ & 3.5 & 2 & 1 & 3 & 7.5 & 4 & $\mathrm{~N}$ & 328 & nurses & Finland & $\begin{array}{l}\text { Kuuppelo- } \\
\text { mäki }\end{array}$ & $\mathrm{P}$ \\
\hline 02 & $\begin{array}{l}\text { Functional Assessment of Chronic Illness } \\
\text { Therapy - SWBS (FACIT-Sp-12) }\end{array}$ & 10.5 & & & & 1.5 & & Y2? & 1617 & ca pts & USA & $\begin{array}{l}\text { Peterman } \\
\text { Canada } 08 \\
\end{array}$ & $\begin{array}{l}\mathrm{P} \\
\underline{\mathrm{P}}\end{array}$ \\
\hline 02 & $\begin{array}{l}\text { Ironson-Woods Spirituality/Religiousness } \\
\text { Index }\end{array}$ & 7.5 & 6 & & 5 & 6.5 & & Y4 & 279 & HIV pts & USA & Ironson & $\mathrm{P}$ \\
\hline 02 & Physicians' Spiritual Assessment Survey & 3 & 2 & & 2 & 1 & 18 & $\mathrm{~N}$ & 38 & psychol & USA & Milne & $\mathrm{T}$ \\
\hline 02 & Spirituality \& Spiritual Care Rating Scale & 7 & 5.5 & 0.5 & 1 & 3 & & Y4? & 549 & nurses & UK & McSherry & $\mathrm{P}$ \\
\hline 03 & Spirituality Scale (SS) (2) & 10 & 3 & 6 & 2.5 & 1.5 & & Y3 & 240 & chronic pt & USA & Delaney & $\mathrm{T}$ \\
\hline 05 & Spiritual Strategies Scale (SSS) & 5 & 5.5 & & 1.5 & 5 & 1 & Y6 & 79 & elderly & USA & Nelson-Becker & $\mathrm{P}$ \\
\hline 06 & Higher Power Relationship Scale & 8 & & & 8 & 1 & & Y1 & 350 & subs use & USA & Rowan & $\mathrm{P}$ \\
\hline 06 & $\begin{array}{l}\text { Multidimensional Measurement of } \\
\text { religiosity/Spirituality Instrument }\end{array}$ & 24 & 4 & 2.5 & 15 & 13.5 & & Y5 & 515 & Uni/alc & USA & Stewart & $\mathrm{P}$ \\
\hline 06 & $\begin{array}{l}\text { Spiritual Interests Related to Illness Tool } \\
\text { (SpIRIT) }\end{array}$ & 18.5 & 10.5 & & 7.5 & 5.5 & & Y8 & 244 & pts/carers & USA & Taylor & $\mathrm{P}$ \\
\hline 06 & Spiritual Needs Assessment Scale (SNAS) & 11 & 4.5 & 3.5 & 1.5 & 2.5 & & Y6? & 683 & pts & USA & Flannelly & $\mathrm{P}$ \\
\hline 07 & Spirituality in hospice & 17.5 & 0.5 & & & & & $\mathrm{~N}$ & 10 & pts & USA & Wlodarczyk & $\mathrm{P}$ \\
\hline 07 & Spirituality Self-Rating Scale & 1.5 & 1 & & 1.5 & 2 & & $\mathrm{~N}$ & 791 & uni, drugs & USA & Galanter & $\mathrm{P}$ \\
\hline 08 & $\begin{array}{l}\text { Multidimensional Measure of Spirituality- } \\
\text { Religiosity }\end{array}$ & 6.5 & 12 & & 16 & 5.5 & & Y4 & 237 & subs use & USA & Neff & $\mathrm{P}$ \\
\hline 08 & Spiritual Needs Scale & 10.5 & 4 & & 2 & 5 & 4.5 & Y5 & 257 & ca pts & Korea & Yong & $\mathrm{P}$ \\
\hline 08 & Spiritual Transformation Scale & 23.5 & 8.5 & 1 & 4 & 3 & & Y2 & 253 & ca pts & USA & Cole & $\mathrm{P}$ \\
\hline 08 & Treatment Spirituality/Religiosity Scale & & & & 2 & 8 & & Y1 & 3347 & pts/staff & USA & Lillis & $\mathrm{P}$ \\
\hline 09 & Sexual-Spiritual Integration Scale & 8.5 & & & 3 & 3.5 & 9 & Y3 & 383 & adults & USA & Wittstock & $\mathrm{T}$ \\
\hline
\end{tabular}




\begin{tabular}{|c|c|c|c|c|c|c|c|c|c|c|c|c|c|}
\hline Yr & Study/instrument & $\mathbf{P}$ & $\mathbf{C}$ & $\mathbf{E}$ & $\mathbf{T}$ & $\mathbf{R}$ & $\mathbf{O}$ & FA & $\mathbf{N}$ & type & place & $1^{\text {st }}$ author & $\mathbf{S}$ \\
\hline 09 & Spiritual Connection Scale & & 1.5 & & 3 & 1.5 & & $\mathrm{~N}$ & 163 & aged & USA & $\begin{array}{l}\text { Leppert } \\
\text { Krause } 02\end{array}$ & $\mathrm{P}$ \\
\hline 09 & 10 Spiritual Emergency Subscales & 29.5 & 3 & 13.5 & 11 & 8 & 19 & Y1 & 109 & adults & Aust & Goretzki & $\mathrm{P}$ \\
\hline 10 & Spiritual Needs Questionnaire & 7 & 4.5 & 2 & 2.5 & 3 & & Y4 & 210 & pain, ca pts & Europe & Büssing & $\mathrm{P}$ \\
\hline 11 & Spiritual Care Inventory & 11 & 4.5 & & 0.5 & 1 & & Y3? & 298 & carers & USA & Burkhart & $\mathrm{P}$ \\
\hline 12 & $\begin{array}{l}\text { Spiritual Needs Assessment for Patients } \\
\text { (SNAP) }\end{array}$ & 9 & 6.5 & & 1 & 6.5 & & $3 ?$ & 47 & outpts & USA & Sharma & $\mathrm{P}$ \\
\hline 12 & Spirituality in coping & 7 & 16 & & 8 & & 1 & Y8? & 100 & AfAm ca & USA & Holt & $\mathrm{P}$ \\
\hline 14 & GES questionnaire & 4.5 & 2.5 & & 1 & & & Y3 & 108 & pallcare & Spain & Benito & $\mathrm{P}$ \\
\hline 14 & Quality of Spiritual Care Scale & 7 & 2 & & 1 & & & Y2 & 165 & fam carer & USA & Daaleman & $\mathrm{P}$ \\
\hline
\end{tabular}

\begin{tabular}{|c|c|c|c|c|c|c|c|c|c|c|c|c|c|}
\hline \multicolumn{2}{|c|}{ Related/partial spirituality measures } & \multicolumn{4}{|c|}{ SWB } & \multirow[b]{2}{*}{$\mathbf{R}$} & \multirow[b]{2}{*}{$\mathbf{O}$} & \multirow[b]{2}{*}{ FA } & \multirow[b]{2}{*}{$\mathbf{N}$} & \multirow[b]{2}{*}{ type } & \multirow[b]{2}{*}{ place } & \multirow[b]{2}{*}{$\mathbf{1}^{\text {st }}$ author } & \multirow[b]{2}{*}{$\mathbf{S}$} \\
\hline $\mathbf{Y r}$ & Study/instrument & $\mathbf{P}$ & $\mathbf{C}$ & $\mathbf{E}$ & $\mathbf{T}$ & & & & & & & & \\
\hline 86 & Nowotny's Hope Scale & 22 & 4 & & 1 & 2 & & $\mathrm{~N} ?$ & 306 & adults+ca & USA & Nowotny & $\mathrm{W}$ \\
\hline 86 & Self-Transcendence Scale & 8 & 4 & & & 1 & 2 & $\mathrm{~N}$ & 55 & aged & USA & Reed & $\mathrm{C}$ \\
\hline 87 & Meaning in Life Scale (1) & 8 & 4 & & 2 & 1 & & $\mathrm{~N}$ & 257 & LT care & Canada & Warner & $\mathrm{P}$ \\
\hline 91 & Brown-Peterson Recovery Progress Inventory & 19 & 16 & & 7 & 1 & 10 & & 58 & alcs & USA & Brown & $\mathrm{P}$ \\
\hline 95 & Quality Of Life - Cancer Survivors & 6 & & & & 1 & 34 & Y4 & 686 & ca pts & USA & Ferrell & $\mathrm{P}$ \\
\hline 96 & Life Evaluation Questionnaire (LEQ) & 15 & 8 & & & 1 & 20 & Y5 & 200 & ca pts & UK & Salmon & $\mathrm{P}$ \\
\hline 96 & Long-Term Quality of Life Instrument & 4 & 2 & 1 & 1 & & 26 & Y4 & 188 & F ca pts & USA & Wyatt & $\mathrm{P}$ \\
\hline 97 & $\begin{array}{l}\text { McGill Quality of Life Questionnaire } \\
\text { MQOL }\end{array}$ & 8 & 1 & 1 & & & 6 & Y4? & 120 & ca pts & Canada & Cohen & $\mathrm{P}$ \\
\hline 98 & Missoula-VITAS qol index & 11 & 5 & & 1 & & 8 & Y6? & 257 & PC pts & USA & Byock & $\mathrm{P}$ \\
\hline 98 & $\begin{array}{l}\text { Revised Hospice Quality of Life Index - } \\
\text { Social/Sniritual Well-being }\end{array}$ & 1.5 & 3.5 & 1 & 1 & & 11 & $\mathrm{Y} 1 / 3$ & 255 & $\begin{array}{l}\text { hospice } \\
\text { Dts }\end{array}$ & USA & McMillan & $\mathrm{P}$ \\
\hline 98 & $\begin{array}{l}\text { Skalen zur Erfassung von Lebensqualität bei } \\
\text { Tumorkranken (SELT-M) + spiritual QL }\end{array}$ & 8 & & & & & 16 & $\mathrm{~N}$ & 89 & ca pts & Swiss & $\begin{array}{l}\text { van } \\
\text { Wegberg }\end{array}$ & $\mathrm{P}$ \\
\hline 99 & Perceived meanings of cancer pain inventory & 5 & & & & & 22 & Y6 & 200 & ca pts & Taiwan & Chen & $\mathrm{P}$ \\
\hline 01 & Quality Of Life -Cancer Survivors (2) & 11 & 1 & & & 1 & 24 & Y5/6? & 177 & adults & USA & Zebrack & $\mathrm{P}$ \\
\hline 01 & Valuation of Life - swb subscale & 7 & & & & 1 & & $\mathrm{~N}$ & 319 & aged & USA & $\begin{array}{l}\text { Lawton } 01 \\
\text { Dennis } 05\end{array}$ & $\begin{array}{l}\mathrm{P} \\
\mathrm{W}\end{array}$ \\
\hline
\end{tabular}




\begin{tabular}{|c|c|c|c|c|c|c|c|c|c|c|c|c|c|}
\hline Yr & Study/instrument & $\mathbf{P}$ & $\mathbf{C}$ & $\mathbf{E}$ & $\mathbf{T}$ & $\mathbf{R}$ & $\mathbf{O}$ & FA & $\mathbf{N}$ & type & place & 1st author & $\mathbf{S}$ \\
\hline 02 & Existential Loneliness Questionnaire & 9.5 & 11.5 & 1 & & & & $\mathrm{~N}$ & 47 & HIV F & USA & Mayers & $\mathrm{P}$ \\
\hline 04 & Benefit Finding Scale & 10 & 8 & & & & 2 & Y3? & 364 & F ca pts & USA & Tomich & $\mathrm{P}$ \\
\hline 04 & City of Hope QOL-Ostomy Questionnaire & 5 & & & & 5 & 13 & Y4? & 1513 & pts & USA & Grant & $\mathrm{P}$ \\
\hline 04 & $\begin{array}{l}\text { Problems \& Needs in Palliative Care (PNPC) } \\
\text { questionnaire (sp subset) }\end{array}$ & 2 & 1 & & 1 & 1 & & $\mathrm{~N}$ & 64 & ca pts & N'lands & Osse & $\mathrm{P}$ \\
\hline 04 & $\begin{array}{l}\text { Self-Perception \& Relationships Tool (S- } \\
\text { PRT) }\end{array}$ & 7 & 14 & & 14 & & & Y5 & 136 & patients & Canada & Atkinson & $\mathrm{P}$ \\
\hline 05 & $\begin{array}{l}\text { Missoula-VITAS Quality of Life Index - } \\
\text { Revised (MVQOLI-R) }\end{array}$ & 8.5 & 5.5 & 1 & & & 10 & Y5 & 175 & pts & USA & Schwartz & $\mathrm{P}$ \\
\hline 05 & Palliative care Outcome Scale (POS) & 2 & & & & & 8 & $\mathrm{~N}$ & 471 & pts & N'lands & Büssing & $\mathrm{P}$ \\
\hline 06 & ALSSQOL & 17.5 & 19 & 2 & 1 & 2.5 & 17 & Y6 & 342 & ALS pts & USA & Simmons & $\mathrm{P}$ \\
\hline 06 & Meaning in Life Scale (2) & 19.5 & & & & 1.5 & & Y4 & 167 & ca pts & USA & Jim & $\mathrm{P}$ \\
\hline 07 & Chinese Cancer Coherence Scale & 9 & 1 & & 1 & & & $\mathrm{Y} 2$ & 390 & F ca pts & $\mathrm{HK}$ & Chan & $\mathrm{P}$ \\
\hline 07 & QE Health Scale & 12 & 1.5 & 1.5 & 3 & & 10 & Y5-6? & 205 & disabled & $\mathrm{NZ}$ & Faull & $\begin{array}{l}\mathrm{T} \\
\mathrm{P}\end{array}$ \\
\hline 07 & Heart Failure Caregiver Quality of Life scale & 6 & 2 & & & 1 & 7 & Y1 & 100 & carers & USA & Nauser & $\mathrm{T}$ \\
\hline 07 & Personal Meaning Profile & 23 & 9 & & 4 & 3 & & Y5 & 294 & ca pts & N'lands & Jaarsma & $\mathrm{P}$ \\
\hline 07 & $\begin{array}{l}\text { Systemic Lupus Erythematosus Needs } \\
\text { Questionnaire (SLENQ) }\end{array}$ & 14.5 & 1.5 & & & 1 & 66 & Y7 & 386 & $\begin{array}{l}\text { SLE } \\
\text { support }\end{array}$ & Aust & Moses & $\mathrm{P}$ \\
\hline 09 & Cancer \& Deity Questionnaire & & & & 12 & & & Y2 & 52 & ca pts & USA & Bowman & $\mathrm{P}$ \\
\hline 10 & $\begin{array}{l}\text { Health-Related Quality of Life in Stroke } \\
\text { Patients HRQOLISP-40 sp subscale }\end{array}$ & 1.5 & 0.5 & & 5 & 4 & & Y2 & 353 & pts & $\begin{array}{l}\text { Nigeria } \\
\text { Germany }\end{array}$ & Owolabi & $\mathrm{P}$ \\
\hline 11 & $\begin{array}{l}\text { Culturally appropriate Positive Mental Health } \\
\text { Measure }\end{array}$ & & & & 5 & 2 & 41 & Y6 & 404 & adults & S'pore & Vaingankar & $\begin{array}{l}\mathrm{P} \\
\mathrm{W}\end{array}$ \\
\hline 11 & View of God Inventory & 1 & & & 3 & 8 & & $\mathrm{Y} 2$ & 101 & HIV pts & USA & Ironson & $\mathrm{P}$ \\
\hline
\end{tabular}




\section{REFERENCES - for SH/WB, Spirituality \& Partial/related measures}

Ai, A.L., Tice, T.N., Peterson, C. \& Huang, B. (2005). Prayers, spiritual support, and positive coping with the September 11 National Crisis. Journal of Personality, 73(3), 763-792. doi:10.111/j.1467-6494.2005.00328.x

Allport, G.W. \& Ross, J.M. (1967). Personal religious orientation and prejudice. Journal of Personality and Social Psychology, 5, 423-443.

Ashdown, F.S. (1996). Spiritual Maturity Index: A revision. D Clin Psych dissertation, George Fox University, Newberg, Oregon.

Ashmos, D.P. \& Duchon, D. (2000). Spirituality at work: A conceptualization and measure. Journal of Management Inquiry, 9(2), 134-145.

Atkinson, M.J., Wishart, P.M., Wasil, B.I. \& Robinson, J.W. (2004). The Self-Perception and Relationships Tool (S-PRT): A novel approach to the measurement of subjective health-related quality of life. Health and Quality of Life Outcomes, 2, 36.15 pages. doi:10.1186/1477-7525-2-36.

Batson, C.D. \& Schoenrade, P.A. (1991). Measuring religion as Quest: 2) reliability concerns. Journal for the Scientific Study of Religion, 30(4), 430-447.

Battista, J. \& Almond, R. (1973). The development of meaning in life. Psychiatry, 36, 409-427.

Beazley, H. (1997). Meaning and measurement in organizational settings: Development of a Spirituality Assessment Scale. PhD dissertation, George Washington University, D.C.

Benito, E., Oliver, A., Galiana, L., Barreto, P., Pascual, A., Gomis, C. \& Barbero, J. (2014). Development and validation of a new tool for the assessment and spiritual care of palliative care patients. Journal of Pain and Symptom Management, 47 (6), 1008-1018.e1. doi: 10.1016/j.jpainsymman.2013.06.018

Benson, P.L., Donahue, M.J. \& Erickson, J.A. (1993). The Faith Maturity Scale: Conceptualization, measurement, and empirical validation. In M. Lynn \& D.O. Moberg (Eds.), Research in the Social Scientific Study of Religion (Vol. 5, pp.1-26). Greenwich: JAI Press.

Berg, G.E. Living Water Computer Assessment Program. Accessed 14 March 2014 from http://www.spiritualassessment.com/Manual.html

Bloch, D.P. (2003). Salient Beliefs Review: Administrator's Guide. Indianapolis, IN: JIST Publishing Inc.

Bowman, E.S., Beitman. J.A., Palesh, O., Pérez, J.E. \& Koopman, C. (2009). The Cancer and Deity Questionnaire: A new religion and cancer measure. Journal of Psychosocial Oncology, 27, 435-453. 
Bradford, R., Rutherford, D.L. \& John, A. (2002). Quality of life in young people: Ratings and factor structure of the Quality of Life Profile - Adolescent version. Journal of Adolescence, 25, 261-274.

Brown, H.P. \& Peterson, J.H. (2008). Assessing spirituality in addiction treatment and follow-up. Alcoholism Treatment Quarterly, 8(2), 21-50.

Burkhart, L. Schmidt, L. \& Hogan, N. (2011). Development and psychometric testing of the Spiritual Care Inventory instrument. Journal of Advanced Nursing, 67(11), 24632472.

Büssing, A., Balzat, H.-J., Heusser, P. (2010). Spiritual needs of patients with chronic pain disease and cancer - validation of the Spiritual Needs Questionnaire. European Journal of Medical Research, 15, 266-273.

Büssing, A., Föller-Mancini, A., Gidley, J. \& Heusser, P. (2010). Aspects of spirituality in adolescents. International Journal of Children's Spirituality, 15(1), 25-44.

Büssing, A., Matthiessen, P.F. \& Ostermann, T. (2005).Engagement of patients in religious and spiritual practices: Confirmatory results with the SpREUK-P 1.1 questionnaire as a tool of quality of life research. Health and Quality of Life Outcomes, 3, 53. 11 pages,

Büssing, A., Ostermann, T. \& Matthiessen, P. (2007). Distinct expressions of vital spirituality: The ASP Questionnaire as an exploratory research tool. Journal of Religion and Health, 46(2), 267-286.

Byock, I.R. \& Merriman, M.P. (1998). Measuring quality of life for patients with terminal illness: The Missoula-VITAS ${ }^{\circ}$ quality of life index. Palliative Medicine, 12, 231-244.

Canada, A.L., Murphy, P.E., Fitchett, G., Peterman, A.H. \& Shrover, L.R. (2008). A 3factor model for the FACIT-Sp. Psycho-Oncology, 17, 908-916.

Center for Spiritual Development in Childhood \& Adolescence) (2008). Search Institute Inventory of Youth Spiritual Development. This survey tool was used for the report With Their Own Voices Roehlkepartain et al. (Eds.) (2008), listed below.

Chamiec-Case, R.R. (2006). Developing a tool to measure social workers' perceptions regarding the extent to which they integrate their spirituality in the workplace. Doctor of Social Work dissertation, Fordham University Graduate School of Social Science.

Chan, T.H.Y., Ho, R.T.H. \& Chan, C.L.W. (2007). Developing an outcome measurement for meaning-making intervention with Chinese cancer patients. Psycho-Oncology, 16(9), 843-850.

Chase, M.W. (2001). Spirituality as a salutogenic factor in African American adolescents: Understanding the relationships among religion, health, and well-being. $\mathrm{PhD}$ dissertation, California School of Professional Psychology - Berkeley/Alameda. ProQuest doc ID: 729036591. 
Chen, M.-L. (1999). Validation of the structure of the perceived meanings of cancer pain inventory. Journal of Advanced Nursing, 30(2), 344-351.

Christo, G. \& Franey, C. (1995). Drug users' spiritual beliefs, locus of control and the disease concept in relation to Narcotics Anonymous attendance and six0month outcomes. Drug \& Alcohol Dependence, 38, 51-56.

Clarke, S. (2005). Religiosity and spirituality in younger and older adults. $\mathrm{PhD}$ dissertation, University of North Texas.

Cohen, S.R., Mount, B.M., Bruera, E., Provost, M., Rowe, J. \& Tong, K. (1997). Validity of the McGill Quality of Life Questionnaire in the palliative care setting: a multi-centre Canadian study demonstrating the importance of the existential domain. Palliative Medicine, 11, 3-20.

Cole, B.S., Hopkins, C.M., Tisak, J., Steel, J.L. \& Carr, B.I. (2008). Assessing spiritual growth and spiritual decline following a diagnosis of cancer: reliability and validity of the Spiritual Transformation Scale. Psycho-Oncology, 17, 112-121.

Crumbaugh, J.L. \& Maholick, L.T. (1964). An experimental study in existentialism: The psychometric approach to Frankl's concept of noogenic neurosis. Journal of Clinical Psychology, 20, 200-207.

Cunyus, J.G. (1996). A Spiritual Assessment Inventory: An objective standard for an elusive reality. Doctoral dissertation, Pacific Western University.

Daaleman, T.P. \& Frey, B.B. (2004). The Spirituality Index of Well-Being: A new instrument for health-related quality of life research. Annals of Family Medicine, 2(5), 499-503.

Daaleman, T.P., Reed, D., Cohen, L.W. \& Zimmerman, S. (2014). Development and preliminary testing of the Quality of Spiritual Care Scale. Journal of Pain and Symptom Management, 47(4), 793-800. doi: 10.1016/j.jpainsymman.2013.06.004

Davis, D.E., Worthington, E.L., Hook, J.N., Van Tongenen, D.R., Green, J.D. \& Jennings, D.J.II. (2009). Relational spirituality and the development of the Similarity of the Offender's Spirituality Scale. Psychology of Religion and Spirituality, 1(4), 249-262.

Davis, K.D., Panksepp, J \& Normansell, L. (2003). The Affective Neuroscience Personality Scales: Normative data and implications. Neuro-Psychoanalysis, 5(1), 57-69.

Delaney, C. (2003). The spirituality scale: Development, refinement and psychometric testing of an instrument to assess the human spiritual dimension. $\mathrm{PhD}$ dissertation, University of Connecticut. ProQuest doc ID: 765281331.

Del Rio, C.M. (2007). Psychometric properties of the Spiritual Typology Inventory. PhD dissertation, Southern Illinois University at Carbondale. ProQuest doc ID: 1456390391. 
Dennis, D., Muller, S.M., Miller, K. \& Banerjee, P. (2004). Spirituality among a college student cohort: A quantitative assessment. American Journal of Health Education, 35(4), 220-227.

Dennis, M.P., Gitlin, L.N., Winter, L. \& Chee, Y.K. (2005). The role of spiritual wellbeing in moderating frail elders' affective response to functional difficulty. Center for Applied Research on Aging and Health Research Papers. Paper 7. http://jdc.jefferson.edu/carah_papers/7

Dowling, E.M., Gestsdottir, S., Anderson, P.M., von Eye, A., Almerigi, J. \& Lerner, R.M. (2004). Structural relations among spirituality, religiosity, and thriving in adolescence. Applied Developmental Science, 8(1), 7-16.

Dunn, K.S. (2008). Development and psychometric testing of a new geriatric spiritual well-being scale. International Journal of Older People Nursing, 3, 161-169.

Edwards, A.C. \& Lowis, M.J. (2008). Construction and validation of a scale to assess attitudes to mysticism: The need for a new scale for research in the psychology of religion. Spirituality and Health International, 9(1), 16-31.

Eggers, S.J. (2003). Older adult spirituality: What is it? A factor analysis of three related instruments. Journal of Religious Gerontology, 14(4), 3-11.

Elkins, D., Hedstrom, L., Hughes, L., Leaf, J. \& Saunders, C. (1988). Toward a humanistic-phenomenological spirituality. Journal of Humanistic Psychology, 28(4), 518. Retrieved Spiritual Orientation Inventory 11 October, 2007, from: http://cla.calpoly.edu/ bfiorito/soi.html.

Ellison, C. (1983). Spiritual well-being: Conceptualization and measurement. Journal of Psychology and Theology, 11(4), 330-340.

Ellison, C.W. (1984). Personality, religious orientation, and spiritual well-being. Unpublished manuscript, Alliance Theological Seminary, Nyack, NY. In P.C. Hill, \& R.W. Hood, (Eds.) (1999). Measures of Religiosity (pp.210-204). Birmingham, Alabama: Religious Education Press.

Endyke, P.D. (1999). A revision of the Spiritual Well-Being Scale. (ceiling effects). $\mathrm{PhD}$ dissertation, George Fox University, USA.

Endyke, P., Bufford, R., Gathercoal, K . \& Koch, C. (1999). Spiritual well-being: A proposed scale revision. Paper presented at the Meeting of the Christian Association for Psychological Studies, Western Regional Meeting, Newberg, Oregon. (see Janzen, D.M)

Fang, C.K., Li, P.Y., Lai, M.L., Lin, M.H., Bridge, D.T. \& Chen, H.W. (2011). Establishing a 'physician's spiritual well-being scale' and testing its reliability and validity. Journal of Medical Ethics, 37, 6-12.

Faull, K. (2006). Health and the spiritual self: Development and application of a theory and measure of the process of healthy change. $\mathrm{PhD}$ thesis, University of Waikato. 
Faull, K. \& Hills, M.D. (2007). The QE Health Scale (QEHS): Assessment of the clinical reliability and validity of a spiritually based holistic health measure. Disability \& Rehabilitation, 29(9), 701-716. (Also see 29(13), 999-1010).

Fazakas-deHoog, L.L. (2000). The development of a multidimensional spirituality questionnaire and its relationship with quality of life. MA dissertation, University of Western Ontario (Canada). ProQuest doc ID: 729262121.

Fenzel, L.M. (2002). The development of the Spiritual Involvement Scale: Examining the spiritual lives of late adolescents. Poster presented at the Biennial Conference of the Society for Research on Adolescence, New Orleans, April, 2002. Accessed 29 October, 2008, from: 1fenzel@1oyola.edu.

Ferrans, C.E. \& Powers, M.J. (1992). Psychometric testing of the Quality of Life Index. Research in Nursing and Health, 15(1), 29-38. doi 10.1002/nur.4770150106.

Ferrell, B.R., Hassey Dow, K. \& Grant, M. (1995). Measurement of the Quality Of Life in Cancer Survivors (QOL-CS). Quality of Life Research, 4, 523-531.

Fetzer Institute (1999). Brief Multidimensional Measure of Religiousness/Spirituality. Retrieved 21 May, 2007, from http://www.fetzer.org/PDF/Total_Fetzer_Book.pdf.

Fetzer Institute (1999). Daily Spiritual Experiences Scale (6 items). Retrieved 21 May, 2007, from: http://www.fetzer.org/PDF/Total_Fetzer_Book.pdf.

Fisher, John (1999). Developing a Spiritual Health And Life-Orientation Measure for secondary school students. In Proceedings of University of Ballarat Annual Research Conference, 15 October, pp. 57-63.

Fisher, J.W. (2001). Comparing levels of spiritual well-being in state, Catholic and independent schools in Victoria, Australia. Journal of Beliefs and Values, 22(1), 99-105.

Fisher, John (2004). Feeling Good, Living Life: A spiritual health measure for young children. Journal of Beliefs \& Values, 25(3), 307-315.

Fisher, J.W. (2013). Assessing spiritual well-being: Relating with God explains greatest variance in spiritual well-being among Australian youth. International Journal of Children's Spirituality, 18(4), 306-317.

Fisher, J.W., Francis, L.J. \& Johnson, P. (2000). Assessing spiritual health via four domains of well-being: The SH4DI. Pastoral Psychology, 49(2), 133-145.

Flannelly, K.J., Galek, K. \& Flannelly, L.T. (2006). A test of the factor structure of the Patient Spiritual Needs Assessment Scale. Holistic Nursing Practice, 20(4), 187-190.

Fletcher, D. (2007). Spiritual Fitness Assessment. http://www.faithandhealthConnection. org/wp-content/uploads/2007/11/spiritual_fitness-assessment_4_8_071.pdf (see Kassab \& MacDonald, 2011)

Fraid, R. (1997). The impact of obesity on subjective quality of life. Master of Clinical Psychology dissertation, Deakin University (Burwood) Victoria, Australia. 
Francis, L.J. \& Louden, S.H. (2000). The Francis-Louden Mystical Orientation Scale: A study among male Anglican priests. Research in the Social Scientific Study of Religion, $11,99-116$.

Francis, L.J. \& Louden, S.H. (2004). A Short Index of Mystical Orientation (SIMO): A study among Roman Catholic priests. Pastoral Psychology, 53(1), 49-51.

Francis, L.J. \& Robbins, M. (2005). Urban Hope and Spiritual Health: The Adolescent Voice. Peterborough, UK: Epworth.

Freiheit, S.R., Sonstegard, K., Schmitt, A. \& Vye, C. (2006). Religiosity and spirituality: A psychometric evaluation of the Santa Clara Strength of Religious Faith Questionnaire. Pastoral Psychology, 55, 27-33. doi: 10.1007/s11089-006-0029-y.

Fry, L.W., Vitucci, S. \& Cedillo, M. (2005). Spiritual leadership and army transformation: Theory, measurement, and establishing a baseline. The Leadership Quarterly, 16, 835-862.

Galanter, M., Dermatis, H., Bunt, G., Williams, C., Trujillo, M. \& Steinke, P. (2007). Assessment of spirituality and its relevance to addiction treatment. Journal of Substance Abuse Treatment, 33(3), 257-264.

Gallup, G.H. \& Johnson, B.R. (2003). New index tracks "Spiritual State of the Union." The Gallup Organization, Gallup Poll Tuesday briefing 28 January. http://www.gallup.com

Gehrig, S. (1998). The spiritual health of sixteen year old Australians: A study of spiritual health and its relationship with health behaviours. MEd thesis, University of Sydney.

Genia, V. (1997). The Spiritual Experience Index: Revision and reformulation. Review of Religious Research, 38(4), 344-361.

Gilgen, A.R. \& Cho, J.H. (1979). Questionnaire to measure Eastern and Western thought. Psychological Reports, 44, 835-841.

Glik, D.C. (1990). Participation in spiritual healing, religiosity, and mental health. Sociological Inquiry, 60(2), 158-176.

Goggin, K., Murray, T.S., Malcarne, V.L., Brown, S.A. \& Wallston, K.A. (2007). Do religious and control cognitions predict risky behavior? I. Development and validation of the Alcohol-related God Locus of Control Scale for Adolescents (AGLOC-A). Cognitive Therapy Research, 31, 111-122.

Goldfarb, L.M., Galanter, M., McDowell, D., Lifshutz. \& Dermatis, H. (1996). American Journal of Drug \& Alcohol Abuse, 22(4), 549-561.

Gomez, R. \& Fisher, J.W. (2003). Domains of spiritual well-being and development and validation of the Spiritual Well-Being Questionnaire. Personality and Individual Differences, 35(8), 1975-1991. 
Goretzki. M., Thalbourne, M.A. \& Storm, L. (2009). The questionnaire measurement of spiritual emergency. The Journal of Transpersonal Psychology, 41(1), 81-97.

Graci, G.M., O'Rourke, N. \& Mahoney, M.J. (2003). Personal meanings of spirituality. Constructivism in the Human Sciences, 8(1), 47-56.

Grant, M., Ferrell, B., Dean, G., Uman, D., Chu, D. \& Krouse, R. (2004). Revision and psychometric testing of the City of Hope Quality of Life-Ostomy Questionnaire. Quality of Life Research, 13, 1445-1457.

Hall. T.W. (2004). Spiritual Transformation Inventory ${ }^{\mathrm{TM}}$, web-based inventory, available through Concentus Assessment Solutions.

Hancock, T.E., Bufford, R.K., Lau, B. \& Ninteman, N. (2005). Attempting valid assessment of Spiritual Growth: A survey of Christ-centered living. Christian Education Journal, Series 3, vol 2(1), 130-153.

Harris, A.H.S. (2001). Psychometric properties of the Life-Regard Index-Revised: A validation study of a measure of personal meaning. Psychological Reports, 89(3), 759773.

Hart, M. (1998). Utilizing a spiritual wellness tool to assist the pastoral caregiver in the dialogue of spirituality. D Min. dissertation, Brite Divinity School, Texas Christian University.

Harvey, M. B. (2004). Development and psychometric properties of the State-Trait Spirituality Inventory. PhD dissertation, University of North Texas. ProQuest doc ID: 790293881.

Hatch, R.L., Burg, M.A., Naberhaus, D.S. \& Hellmich, L.K. (1998). The Spiritual Involvement and Beliefs Scale: Development and testing of a new instrument. Journal of Family Practice, 46(6), 476-486.

Haugan, G et al. (2012). The Self-Transcendence Scale. Journal of Holistic Nursing, $30(3), 147-159$.

Hayato, H. (2002). Development of Spirituality Rating Scale and study of its reliability and validity. Journal of Japan Academy of Nursing Science, 22(3), 29-38.

Hays, J.C., Meador, K.G., Branch, P.S. \& George, L.K. (2001). The Spiritual History Scale in Four Dimensions (SHS-4): Validity and reliability. The Gerontologist, 41(2), 239-249.

Healthactchq (n.d.) CHQ: Child Health Questionnaire. Retrieved 14 December, 2007 from http://healthactchq.com/chq.html.

Hendricks, C., Pender, N. \& Hendricks, D. (2001). The Adolescent Lifestyle Profile, copyrighted by the National Library of Congress (see Hendricks, D.L. below) 
Hendricks, D.L. (2004). The relationship of hope and self-efficacy to health-promoting behaviors among student-athletes attending historically black colleges and universities. EdD dissertation, Auburn University, Alabama.

Hermann, C.P. (1997). Spiritual needs of dying patients: A methodological study. $\mathrm{PhD}$ dissertation, University of Kentucky, Lexington, Kentucky.

Hey, W.T., Calderon, K.S. \& Carroll, H. (2006). Use of body-mind-spirit dimensions for the development of a Wellness Behaviour and Characteristic Inventory for college students. Health Promotion Practice, 7, 125-132.

Higher Education Research Institute (HERI) (2007) 2007 College Students' Beliefs and Values (CSBV) Factor Scales Table. Retrieved 20 May, 2008, from: Spirituality in Higher Education, UCLA, http://www.spirituality.ucla.edu.

Highfield, M.F. (1992). Spiritual health of oncology patients: Nurse and patient perspectives. Cancer Nursing, 15(1), 1-8.

Hodge, D.R. (2003). The Intrinsic Spirituality Scale: A new six-item instrument for assessing the salience of spirituality as a motivational construct. Journal of Social Science Research, 30(1), 41-61.

Holder, D.W., Durant, R.H., Harris, T.L., Daniel, J.H., Obeidallah, D. \& Goodman, E. (2000). The association between adolescent spirituality and voluntary sexual activity. Society for Adolescent Medicine, 26, 295-302.

Holland, J.C., Kash, K.M., Passik,S., Gronert, M.K., Sison, A., Lederberg, M., Russak, S.M., Bader, L. \& Fox, B. (1998). A brief Spiritual Beliefs Inventory for use in quality of life research in life-threatening illness. Psycho-Oncology, 7, 460-469.

Holt, C.L., Clark, E. \& Klem, P.R. (2007). Expansion and validation of the Spiritual Health Locus of Control Scale: Factorial analysis and predictive ability. Journal of Health Psychology, 12, 597-612.

Holt, C.L., Schultz, E., Caplan, L., Blake, V., Southward, V.L. \& Buckner, A.V. (2012). Assessing the role of spirituality in coping among African Americans diagnosed with cancer. Journal of Religion and Health, 51(2), 507-521.

Hood, R.W. Jr (1975). The construction and preliminary validation of a measure of reported mystical experience. Journal for the Scientific Study of Religion, 14, 29-41.

Horn, M.J., Piedmont, R.L., Fialkowski, G.M., Wicks, R.J. \& Hunt, M.E. (2005). Sexuality and spirituality. Theology \& Sexuality, 12(1), 81-102.

Horosewski, M.L. (2005). A synthesis of spirituality, mutuality, and sexuality: Toward an understanding of religious and spiritual variables in sexual health communication research. $\mathrm{PhD}$ dissertation, University of Kentucky, Lexington.

Howden, J.W. (1993). Development and psychometric characteristics of the Spirituality Assessment Scale. PhD dissertation, Texas Women's University. 
Hsieh, T.T. (1987). Heavenly-minded and earthly good: A study of social interest, ethical style, and Word-Spirit orientation among Christians. Journal of Psychology \& Theology, 15(2), 141-147.

Huebner, E.S. (1994). Preliminary development and validation of a multidimensional Life Satisfaction Scale for Children. Psychological Assessment, 6(2), 149-158.

Hughes, P. (2007). Putting Life Together: Findings from Australian Youth Spirituality Research. Melbourne: CRA/Fairfield Press.

Hungelmann, J., Kenkel-Rossi, E., Klassen, L. \& Stollenwerk, R. (1996). Focus on spiritual well-being: Harmonious interconnectedness of mind-body-spirit - Use of the JAREL Spiritual Well-Being Scale. Geriatric Nursing, 17(6), 262-266.

Idler, E.L., Musick, M.A., Ellison, C.G., George, L.K., Krause, N., Ory, M.G., Pargament, K.I., Powell, L.H., Underwood, L.G. \& Williams, D.R. (2003). Measuring multiple dimensions of religion and spirituality for health research: Conceptual background and findings from the 1998 General Social Survey. Research on Aging, 25(4), 327-365. (erratum, 26(2), 284, March, 2004).

Ingersoll, R.E. (1995). Construction and initial validation of the Spiritual Wellness Inventory. Unpublished $\mathrm{PhD}$ dissertation, Kent State University. Retrieved 21 October 2008 from http://elloittingersoll.com/Spiritual_Wellness_Test.html.

Iranmanesh, S., Tirgari, B. \& Cheraghi, M.A. (2012). Developing and testing a Spiritual Care Questionnaire in the Iranian context. Journal of Religion \& Health, 51, 1104-1116.

Ironson, G., Solomon, G.F., Balbin, E.G., O’Cleirigh, C., George, A., Kumar, M., Larson, D. \& Woods, T.E. (2002). The Ironson-Woods Spirituality/Religiousness Index is associated with long survival, health behaviors, less distress, and low cortisol in people with HIV/AIDS. Annals of Behavioral Medicine, 24(1), 34-48.

Ironson, G., Stuetzle, R., Ironson, D., Balbin, E., Kramer, H., George, A., Schneiderman, N. \& Fletcher, M.A. (2011). View of God as benevolent and forgiving or punishing and judgmental predicts HIV disease progression. Journal of Behavioural Medicine, 34, 414425.

Isaacowitz, D.M., Vaillant, G.E. \& Seligman, M.E.P. (2003). Strengths and satisfaction across the adult lifespan. International Journal of Aging and Human Development, 57(2), 181-201.

Jaarsma, T.A., Pool, G., Ranchor, A.V. \& Sanderman, R. (2007). The concept and measurement of meaning in life in Dutch cancer patients. Psycho-Oncology, 16, 241-248.

Jagers, R.J. (1985). Spirituality: Towards an understanding of Afro-American religious expression. Unpublished Master's thesis, Howard University, Washington, D.C.

Janzen, D.M. (2005). A correlational study of anxiety level, spiritual practices, and spiritual well-being. DPsy, dissertation, George Fox University, Oregon. 
Jesse, D.E. (1999). Holistic Obstetrical Problem Evaluation (HOPE): Testing a midwifery theory to predict maternal and perinatal health outcomes. $\mathrm{PhD}$ dissertation, University of Tennessee.

Jim, H.S., Purnell, J.Q., Richardson, S.A., Golden-Kreutz, D. \& Andersen, B.L. (2006). Measuring meaning in life following cancer. Quality of Life Research, 15, 1355-1371.

Jirojanakul, P. \& Skevington, S. (2000). Developing a quality of life measure for children aged 5-8 years. British Journal of Health Psychology, 5, 299-321.

Jo, K. (2005). A three-fold relational approach to spiritual maturity: An exploratory study of Korean evangelical spirituality. PhD dissertation, School of Theology, Fuller Theological Seminary, Pasadena, CA.

Johnson, K.L. (1999). Measuring the spirit and spiritual attributes of resiliency. U Utah. Dissertation Abstracts International: Section B: The Sciences \& Engineering, Vol 59(11B), May, 1999.pp.6113.

Kass, J.D., Friedman, R., Leserman, J., Zuttermeister, P.C. \& Benson, H. (1991). Health outcomes and a new index of spiritual experience. Journal for the Scientific Study of Religion, 30(2), 203-211.

Kassab, V.A. \& MacDonald, D.A. (2011). Examination of the psychometric properties of the Spiritual Fitness Assessment. Journal of Religion \& Health, 50, 975-985.

Kelly, M.K. (1994). A revision of the Spiritual Well-Being Scale. PhD dissertation, University of Nebraska, Lincoln.

Kennedy, J.E., Davis, R.C. \& Taylor, B.G. (1998). Changes in spirituality and well-being among victims of sexual assault. Journal for the Scientific Study of Religion, 37(2), 322328.

Kimmel, P.L., Emont, S.L., Newmann, J.M., Danko, H. \& Moss, A.H. (2003). ESRD Patient quality of life: Symptoms, spiritual beliefs, psychosocial factors, and ethnicity. American Journal of Kidney Diseases, 42(4), 713-721.

King, D.B. (2008). Rethinking claims of spiritual intelligence: A definition, model, and measure. Unpublished Master's thesis, Trent University, Peterborough, Ontario, Canada. Retrieved 21 October, 2008, from: http://dbking.net/spiritualintelligence/model/htm.

King, M., Jones, L., Barnes, K., Low, J., Walker, C., Wilkinson, S., Mason, C, Sutherland, J. \& Tookman, A. (2006). Measuring spiritual belief: Development and standardization of a Beliefs and Values Scale. Psychological Medicine, 36, 417-425.

King, M., Speck, P. \& Thomas, A. (2001). The Royal Free Interview for Spiritual and Religious Beliefs: Development and validation of a self-report version. Psychological Medicine, 31, 1015-1023. 
Kinjerski, V. \& Skrypnek, B.J. (2006). Measuring the intangible: Development of the Spirit at Work Scale. Paper presented at the Sixty-fifth Annual Meeting of the Academy of Management, Atlanta, GA, 16 pages.

Kirk, K.M., Eaves, L.J. \& Martin, N.G. (1999). Self-transcendence as a measure of spirituality in a sample of older Australian twins. Twin Research, 2, 81-87.

Kohls, N. \& Walach, H. (2006). Exceptional experiences and spiritual practice: A new measurement approach. Spirituality and Health International, 7, 125-150.

Korinek, A.W. \& Arredondo, R. (2004). The Spiritual Health Inventory (SHI):

Assessment of an instrument for measuring spiritual health in a substance abusing population. Alcoholism Treatment Quarterly, 22(2), 55-66.

Krause, N. Church-based social support and health in old age: Exploring variations by age. Journal of Gerontology: Social Sciences, 57B(6), S332-S347.

Kreitzer, M.J. \& Gross, C.R. (2009). The Brief Serenity Scale: A psychometric analysis of a measure of spirituality and well-being. Journal of Holistic Nursing, 27(1), 7-16.

Kroft, R. (2007). A Brief Spiritual Well-Being Scale with Degree Completion Students. Doctor of Education dissertation, George Fox University, Newberg, Oregon.

Ku, Y.-L., Kuo, S.-M., Yao, C.-Y. (2010). Establishing the validity of a spiritual distress scale for cancer patients hospitalized in southern Taiwan. International Journal of Palliative Nursing, 16(3), 133-137.

Kuuppelomäki, M. (2001). Spiritual support for terminally ill patients: Nursing staff assessments. Journal of Clinical Nursing, 10, 660-670.

Lange, R. \& Thalbourne, M.A. (2007). The Rasch Scaling of mystical experiences: Construct validity and correlates of the Mystical Experience Scale (MES). The International Journal for the Psychology of Religion, 17(2), 121-140.

Lawton, M.P., Moss, M., Hoffman, C., Kleban, M.H., Ruckdeschel, K. \& Winter, L. (2001). Valuation of life: A concept and scale. Journal of Aging \& Health, 13(1), 3-31.

Leath, C. (1999). The experience of meaning in life from a psychological perspective. Psychology Honors Paper, U of W. Retrieved 21 October, 2008, from: http://ea.freehostia.com/cleath/docs/meaning.htm.

Leung, K.-K., Chiu, T.-Y. \& Chen, C.-Y. (2006). The influence of awareness of terminal condition on spiritual well-being in terminal cancer patients. Journal of Pain \& Symptom Management, 31(5), 449-456.

Leung, M., Steinfort,T. \& Vroon, E.J. (2003). Life Attitudes Scale: development and validation of a measurement of the construct of tragic optimism. MA dissertation, Trinity Western University. 
Lillis, J., Gifford, E., Humphreys, K. \& Moos, R. (2008). Assessing spirituality/religiosity in the treatment environment: The Treatment Spirituality/Religiosity Scale. Journal of Substance Abuse Treatment, 35, 427-433.

Lindeman, M., Blomqvist, S. \& Takada, M. (2012). Distinguishing spirituality from other constructs. The Journal of Nervous \& Mental Disease, 200(2), 167-173.

Liu, C.H. \& Robertson, P.J. (2011). Spirituality in the workplace: Theory and measurement. Journal of Management Inquiry, 20(1), 35-50.

Lukwago, S.N. (2001). Measurement and health-related correlates of collectivism, spirituality, racial pride and time orientation in urban black women. $\mathrm{PhD}$ dissertation, Saint Louis University.

Lyon, D.E. \& Younger, J. (2005). Development and preliminary evaluation of the Existential Meaning Scale. Journal of Holistic Nursing, 23(1), 54-65.

MacDonald, D.A. (1997). The Development of a comprehensive factor analytically derived measure of spirituality and its relationship to psychological functioning. $\mathrm{PhD}$ dissertation, University of Windsor, Ontario, Canada.

McMillan, S.C. \& Weitzner, M. (1998). Quality of life in cancer patients: Use of a Revised Hospice Index. Cancer Practice, 6(5), 282-288.

McSherry, W., Draper, P. \& Kendrick, D. (2002). The construct validity of a rating scale designed to assess spirituality and spiritual care. International Journal of Nursing Studies, 39, 723-734.

Mascaro, N., Rosen, D.H. \& Morey, L.C. (2004). The development and construct validity, and clinical utility of the Spiritual Meaning Scale. Personality and Individual Differences, 37(4), 845-860.

Mason, M., Webber, R., Singleton, A. \& Hughes, P. (2006). The Spirit of Generation $Y$. Summary of the final report of a three year study. Retrieved 12 February, 2007, from: http://dlibrary.acu.edu.au/research/ccls/spir/sppub/sppub.htm Subsequently published as: Mason. M., Singleton, A. \& Webber, R. (2007). The Spirit of Generation Y. Melbourne: John Garratt. [AND Hughes, P. (2007) Putting Life Together (see above)].

Mayers, A.M., Khoo, S-T. \& Svartberg, M. (2002). The Existential Loneliness Questionnaire: Background, development, and preliminary findings. Journal of Clinical Psychology, 58(9), 1183-1193.

Meezenbroek, E. deJ., Garssen, B., van den Berg, M., Tuytel, G. et al. (2012). Measuring spirituality as a universal human experience: Development of the Spiritual Attitude and Involvement List (SAIL). Journal of Psychosocial Oncology, 30(2), 141-167.

Miller, E.D. (2004). The development and validation of a new measure of spirituality. North American Journal of Psychology, 6(3), 423-430. 
Milne, J.M. (2002). The spiritual well-being of health psychologists: Spiritual-care attitudes and practices. $\mathrm{PhD}$ dissertation, Capella University

Moberg, D.O. (1984). Subjective measures of spiritual well-being. Review of Religious Research, 25(4), 351-364.

Morgan, D.T. (1999). The initial development of the Multidimensional Spiritual Orientation Inventory. PhD dissertation, Brigham Young University, Utah.

Morgan, J. \& Farsides, T. (2009). Measuring Meaning in Life. Journal of Happiness Studies, 10(2), 197-214. doi: 10.1007/s10902-007-9075-0.

Moses, N., Wiggers, J., Nicholas, C. \& Cockburn. J. (2007). Development and psychometric analysis of the systemic lupus erythematosus needs questionnaire (SLENQ). Quality of Life Research, 16, 461-466.

Muse-Burke, J.L. (2005). Development and validation of the Inclusive Spirituality Index. $\mathrm{PhD}$ dissertation, Lehigh University.

MySkillsProfile (2005). Spiritual Personality Questionnaire. Retrieved 20 March, 2014, from: MySkillsProfile.com

Nasel, D.D. \& Haynes, W.D.G. (2005). Spiritual and Religious Dimensions Scale:

Development and psychometric analysis. Australian Journal of Psychology, 57(1), 61-71.

National Wellness Institute (2000). TestWell: Wellness Inventory, High School Edition. Retrieved 27 October, 2008, from:

http://www.nationalwellness.org/freepdf/assessments/QsetTeen10.pdf.

Nauser, J.A. (2007). Heart failure family caregivers: Psychometrics of a new quality of life scale and variables associated with caregiver outcomes. $\mathrm{PhD}$ dissertation, Indiana University.

Neff, J.A. (2008). A new multidimensional measure of spirituality-religiosity for use in diverse substance abuse treatment populations. Journal for the Scientific Study of Religion, 47(3), 393-409.

Nelms, L.W., Hutchins, E., Hutchins, D. \& Pursley, R.J. (2007). Spirituality and the health of college students. Journal of Religion and Health, 46(2), 249-265.

Nelson-Becker, H. (2005). Development of a Spiritual Support Scale for use with older adults. Journal of Human Behavior in the Social Environment, 11(3/4), 195-212.

Ng, S.M., Yau, J.K.Y., Chan, C.L.W., Chan, C.H.Y. \& Ho, D.Y.F. (2005). The Measurement of body-mind-spirit well-being: Toward multidimensionality and transcultural applicability. Social Work in Health Care, 41(1), 33-52.

Niederman, R. (1999). The Cognitive-Behavioral Spirituality Scale. Retrieved 12 October, 2008, from: http://www.geocities.com/randynied/CBSSinfo.htm?200712. In, The conceptualization of a model of spirituality, unpublished doctoral dissertation, University of Georgia, Athens (Social Work). 
Nowotny, M.L. (1989). Assessment of hope in patients with cancer: development of an instrument. Oncology Nursing Forum, 16(1), 57-61. Instrument downloaded on 30 January, 2014, from: http://www.outcomesdatabase.org/print/670

Obasi, E.M., Flores, L.Y. \& James-Myers, L. (2009). Construction and initial validation of the Worldview Analysis Scale (WAS). Journal of Black Studies 39(6), 937-961. doi:10.1177/0021934707305411

Osse, B.H.P., Vernooij, M.J.F. \& Schadé, E. (2004). Towards a new clinical tool for needs assessment in the palliative care of cancer patients The PCNC instrument. Journal of Pain and Symptom Management, 28(4), 329-341.

Owolabi, M.O. (2010). Psychometric properties of the HRQOLISP-40: A novel, shortened multiculturally valid holistic stroke measure. Neurorehabilitation and Neural Repair, 24(9), 814-825.

Pargament, K.I. (1999). Pargament's Meaning Scale and factor loadings, In, Fetzer Institute/National Institute on Aging Working Group, Multidimensional Measurements of Religiousness/Spirituality for Use in Health Research, (pp.21-22). Kalamazoo, MI: Fetzer Institute.

Pargament, K.I., Koenig, H.G. \& Perez, L.M. (2000). The many methods of religious coping: Development and initial validation of the RCOPE. Journal of Clinical Psychology, 56(4), 519-543.

Pargament, K.I., Smith, B.W., Koenig, H.G. \& Perez, L. (1998). Patterns of positive and negative religious coping with major life stressors. Journal for the Scientific Study of Religion, 37(4), 710-724.

Patneaude, A.B. (2006). Spiritual wellness among undergraduate college students. $\mathrm{PhD}$ dissertation, Colorado State University, Fort Collins, Colorado.

Patrick, S.K. (2003). Children and spirituality: Exploring the relationships among spiritual well-being, religious participation, competence and behavior in 11 and 12 yearolds. PhD dissertation, University of Northern Colorado, Greeley, Colorado.

Perez, S. Religious and non-religious aspects of spirituality and their relation to MyerBriggs Personality Typology. Dissertation Abstracts International: Section B: The Sciences \& Engineering. Vol. 59(9-B), Mar 1999, pp.5104. Downloaded on 7 February, 2007, from: http://gateway.ut.ovid.com/gw1/ovidweb.cgi

Peterman, A.H., Fitchett, G., Brady, M.J., Hernandez, L. \& Cella, D. (2002). Measuring spiritual well-being in people with cancer: The Functional Assessment of Chronic Illness Therapy - Spiritual Well-Being Scale (FACIT-Sp). Annals of Behavioral Medicine, 24(1), 49-58.

Phipps, S., Long, A.M. \& Ogden, J. (2007). Benefit Finding Scale for children: Preliminary findings from a childhood cancer population. Journal of Pediatric Psychology, 32(10), 1264-1271. 
Piedmont, R.L. (1999). Does spirituality represent the sixth factor in personality? Spiritual transcendence and the Five Factor Model. Journal of Personality, 67(6), 9851013.

Piedmont, R.L. (2004). Assessment of Spirituality and Religious Sentiments (ASPIRES) Technical Manual. In, D.J. Smith (2006). Rehabilitation counsellor willingness to integrate spirituality into client counselling sessions. Journal of Rehabilitation, 72(3), p.6.

Plante, T.G. \& Boccaccini, M.T. (1997). The Santa Clara Strength of Religious Faith Questionnaire (SCORF). Pastoral Psychology, 45(5), 375-387.

Proeschold-Bell, R.J., Yang, C., Toth, M., Rivers, M.C. \& Carder, K. (2014). Closeness to God among those doing God's work: A spiritual well-being measure for clergy. Journal of Religion \& Health 53(3), 878-894. doi: 10.1007/s10943-013-9682-5

Rachelle, A. (2007). Health Intelligence: Theory, model, validity of questionnaire and path to stress, spirituality, personality, psychological well being and health status. $\mathrm{PhD}$ dissertation, Yeshiva University, New York.

Reed, P.G. (1986) Spiritual Perspective Scale. Unpublished instrument, Arizona State University.

Reed, P.G. (1991). Self-Transcendence and mental health in oldest-old adults. Nursing Research, 40(1), 5-11. Copy received on 19 May, 2014, from: preed@arizona.edu.

Reker, G.T. \& Peacock, E.J. (1981). The Life Attitude Profile (LAP): A multidimensional instrument for assessing attitudes toward life. Canadian Journal of Behavioral Science, 13(3), 264-273.

Rican, P. \& Janosova, P. (2010). Spirituality as a basic aspect of personality: A crosscultural verification of Piedmont's model. International Journal for the Psychology of Religion, 20(1), 2-13.

Rich, Y. \& Cinamon, R.G. (2007). Journal of Humanistic Psychology,47(1), 7-29.

Richards, P.S., Smith, T.B., Schowalter, M., Richard, M., Berrett, M.E. \& Hardman, R.K. (2005). Development and validation of the Theistic Spiritual Outcome Survey.

Psychotherapy Research, 15(4), 457-469.

Ritt-Olson, A., Milam, J., Unger, J.B., Trinidad, D., Teran, L., Dent, C.W. \& Sussman, S. (2004). The protective influence of spirituality and "Health-as-a-Value" against monthly substance use among adolescents varying at risk. Journal of Adolescent Health, 34, 192199.

Robertson, L.A. (2008). The Spiritual Competency Scale: A comparison to the Aservic Spiritual Competencies. PhD dissertation, College of Education, University of Central Florida, Orlando, Florida. 
Roehlkepartain, E.C., Benson, P.L., Scales, P.C., Kimball, L. \& King, P.E. (2008). With Their Own Voices: A global exploration of how today's young people experience and think about spiritual development. Minneapolis, Minnesota, USA: Search Institute.

Rojas, R.R. (2002). Management theory and spirituality: A framework and validation of the Independent Spirituality Assessment Scale. Doctor of Business Administration dissertation, Argosy University, Sarasota.

Rovers, M. \& Kocum, L. (2010). Development of a holistic model of spirituality. Journal of Spirituality in Mental Health, 12, 2-24.

Rowan, N.L., Faul, A.C., Cloud, R.N. \& Huber, R. (2006). The Higher Power Relationship Scale: A validation. Journal of Social Work Practice in the Addictions, 6(3), 81-95.

Ryan, K. \& Fiorito, B. (2003). Means-Ends Spirituality Questionnaire: Reliability, validity and relationship to psychological well-being. Review of Religious Research, 45(2), 130-154.

Salmon, P., Manzi, F. \& Valori, R.M. (1996). Measuring the meaning of life for patients with incurable cancer: The Life Evaluation Questionnaire (LEQ). European Journal of Cancer, 32A(5), 755-760.

Schaler, J.A. (1996). Spiritual thinking in addiction-treatment providers: The Spiritual Belief Scale (SBS). Alcoholism Treatment Quarterly, 14(3), 7-33.

Schnell, T. \& Becker, P. (2006). Personality and meaning in life. Personality and Individual Differences, 41, 117-129.

Schwartz, L.M. (2005). Spiritual struggles and student development. Spirituality in Higher Education Newsletter, IV(4). Retrieved 27 October, 2008 from: spiritualitynewsletter@gseis.ucla.edu.

Seidlitz, L., Abernethy, A.A., Duberstein, P.R., Evinger, J.S., Chang, T.H. \& Lewis, B.L. (2002). Development of the Spiritual Transcendence Index. Journal for the Scientific Study of Religion, 41(3), 439-453.

Selman, L., Siegert, R.J., Higginson, I.J., Agupio, G., et al. (2012). The 'Spirit 8' successfully captured spiritual well-being in African palliative care: factor and Rasch analysis. Journal of Clinical Epidemiology, 65, 434-443.

Sharma, R.K., Astrow, A.B., Texeira, K. \& Sulmasy, D.P. (2012). The Spiritual Needs Assessment for Patients (SNAP): Development and validation of a comprehensive instrument to assess unmet spiritual needs. Journal of Pain and Symptom Management, 44(1), 44-51.

Shek, D.T.L., Siu, A.M.H. \& Lee, T.K. (2007). The Chinese Positive Youth Development Scale: A validation study. Research on Social Work Practice, 17, 380-391. 
Shorkey, C.T. \& Windsor, L.C. (2010). Inventory of spirituality in alcohol/other drug research: Psychometric dimensions. Alcoholism Treatment Quarterly, 28, 17-37.

Sifers, S.K. \& Warren, J.S. (2003). Measuring Spirituality in Children. Unpublished manuscript, retrieved 12 October, 2008, from: sarah.sifers@ mnsu.edu.

Simeoni, M.C., Auquier, P., Antoniotti, S., Sapin, C. \& San Marco, J.L. (2000).

Validation of a French health-related quality of life instrument for adolescents: The VSP-

A. Quality of Life Research, 9(4), 393-403.

Simmons, Z., Felgoise, S.H., Bremer, B.A., Walsh, S.M., et al. (2006). The ALSSQOL : Balancing physical and not physical factors in assessing quality of life in ALS.

Neurology, 67(1), 1659-1664.

Sloan, J.A., Aaronson, N., Cappelleri, J.C., Fairclough, D.L., Varrichio, C. et al. (2002). Assessing the clinical significance of single items relative to summated scores. Mayo Clinic Proceedings, 77, 479-487.

Smith, D.J. (2006). Rehabilitation counselor willingness to integrate spirituality into client counseling sessions. Journal of Rehabilitation, 72(3), 4-11.

Smith, J.M.W. (2001). Parents' perceptions of the spiritual needs of their adult son or daughter with developmental disabilities. D.N.Sc. dissertation, Rush University, College of Nursing.

Smithline, C.W. (2000). Spirituality as a protective factor against adolescent substance abuse. PhD dissertation, California School of Professional Psychology,

Berkeley/Alameda.

Somlai, A.M. \& Heckman, T.G. (2000). Correlates of spirituality and well-being in a community sample of people living with HIV disease. Mental Health, Religion \& Culture, 3(1), 57-70.

Steger, M.F., Frazier, P., Oishi, S. \& Kaler, M. (2006). The Meaning in Life Questionnaire: Assessing the presence of and search for meaning in life. Journal of Counseling Psychology, 53(1), 80-93.

Stevenson, H.C. (1994). Validation of the Scale of Racial Socialization for African American Adolescents: Steps towards multidimensionality. Journal of Black Psychology, 20, 445-468.

Stewart, C. \& Koeske, G.F. (2006). A preliminary construct validation of the Multidimensional Measurement of Religiousness/Spirituality Instrument: A study of Southern USA samples. International Journal for the Psychology of Religion, 16(3), 181196.

Stranahan, S. (2008). A spiritual screening tool for older adults. Journal of Religion and Health, 47(4), 491-503. 
Taylor, E.J. (2006). Prevalence and associated factors of spiritual needs among patients with cancer and family caregivers. Oncology Nursing Forum, 33(4): 729-735.

Taylor, E., Highfield, M. \& Amenta, M. (1994). Attitudes and beliefs regarding spiritual care. Cancer Nursing, 17(6), 479-487.

Thayer, O.J. (2004). Constructing a spirituality measure based on learning theory: The Christian Spiritual Participation Profile. Journal of Psychology and Christianity, 23(3), 195-207.

Thiamwong, L. Stewart, A.L. \& Warahut, J. (2009). Development, reliability and validity of the Thai Healthy Aging Survey. Walailak Journal of Science \& Technology, 6(2), 167 188.

Tirri, K., Nokelainen, P. \& Ubani, M. (2006). Conceptual definition and empirical validation of the Spiritual Sensitivity Scale. Journal of Empirical Theology, 19(1), 37-62.

Tomich, P.L. \& Helgeson, V.S. (2004). Is finding something good in the bad always good? Benefit finding among women with breast cancer. Health Psychology, 23(1), 1623.

Underwood, L.G. \& Teresi, J.A. (2002). The Daily Spiritual Experience Scale: Development, theoretical description, reliability, exploratory factor analysis, and preliminary construct validity using health-related data. Annals of Behavioral Medicine, 24(1), 22-33.

Unterrainer, H-F., Nelson, O., Collicutt, J. \& Fink, A. (2012). The English version of the Multidimensional Inventory for Religious/Spiritual Well-Being (MI-RSWB-E): First results from British college students. Religions, 3, 588-599.

Utsey, S.O., Adams, E.P. \& Bolden, M. (2000). Development and initial validation of the Africultural Coping Systems Inventory. Journal of Black Psychology, 26, 194-215.

Vaingankar, J.A.et al. (2011). The positive mental health instrument: Development and validation of a culturally relevant scale in a multi-ethnic Asian population. Health and Quality of Life Outcomes, 9, 92-109. From: http://www.hqlo.com/content/9/1/92

Valentine, S.L. (2007). Measuring religiosity in non-biblical spiritual practices: A new perspective on I/E and Quest orientations. MA thesis, University of Houston Clear Lake.

van Dierendonck, D. (2005). The construct validity of Ryff's Scales of psychological well-being and its extension to spiritual well-being. Personality and Individual Differences, 36, 629-643.

Van Rooyen, B.M. (2007). Spiritual well-being in a group of South African adolescents. $\mathrm{PhD}$ dissertation, University of the Free State, Bloemfontein.

van Wegberg, B., Bacchi, M., Heusser, P., Helwig, S. Schaad, R., von Rohr, E., Bernhard, J., Hürny, C., Castiglione, M. \& Cerny, Th. (1998). The cognitive-spiritual dimension - 
an important addition to the assessment of quality of life: Validation of a questionnaire (SELT-M) in patients with advanced cancer. Annals of Oncology, 9, 1091-1096.

Vella-Brodrick, D.A. \& Allen, F.C.L. (1995). Development and psychometric validation of the Mental, Physical, and Spiritual Well-Being Scale. Psychological Reports, 77, 659674.

Vestal, J.E.C. (1997). Development of the Scale of Resilience (SCORE). PhD dissertation, Texas Women's University, Denton, Texas.

Vivat, B., Young, T., Efficace, F. et al. (2012). Cross-cultural development of the EORTC QLQ-SWB36: A stand-alone measure of spiritual well-being for palliative care patients with cancer. Palliative Medicine, 27(5), 457-469.

Walker, K.L. \& Dixon, V. (2002). Spirituality and academic performance among African American college students. Journal of Black Psychology, 28(2), 107-121.

Walker, S.N., Sechrist, K.R. \& Pender, N.J. (1987). The Health-Promoting Lifestyle Profile: Development and psychometric characteristics. Nursing Research, 36(2), 76-81.

Warner, S.C. \& Williams, J.I. (1987). The Meaning In Life Scale: Determining the reliability and validity of a measure. Journal of Chronic Disease, 40(6), 503-512.

Watson, A. (2011). A developmental approach to measuring spiritual maturity from a Christian perspective. $\mathrm{PhD}$ dissertation, Oklahoma State University.

Wheat, L.W. (1991). Development of a scale for the measurement of human spirituality. $\mathrm{PhD}$ dissertation, University of Maryland College Park.

Wheeler, P. \& Hyland, M.E. (2008). The development of a scale to measure the experience of spiritual connection and the correlation between this experience and values. Spirituality and Health International, 9(4), 193-217. doi: 10.1002/shi.348.

Whitfield, C.L. (1984). Stress management and spirituality during recovery. Alcoholism Treatment Quarterly, 1(1), 3-54.

Wittstock, J.S. (2009). Further validation of the Sexual_Spiritual Integration Scale: Factor structure and relations to spirituality and psychological integration. $\mathrm{PhD}$ dissertation, Department of Pastoral Counseling, Loyola College, Maryland.

Wlodarczyk, N. (2007). The effect of music therapy on the spirituality of persons in an inpatient hospice unit as measured by self-report. Journal of Music Therapy, 44(2), 113122.

WHOQOL SRPB Group (2002). WHOQOL Spirituality, Religiousness and Personal Beliefs (SRPB) Field test Instrument. Geneva, Switzerland: WHO.

Wikoff, K.L. (2003). Development and psychometric evaluation of the Wikoff Spiritual Focus Questionnaire. PhD dissertation, University of San Diego. 
Wolman, R. (1997). Spirituality: What does it mean to you? New Age Journal, Sep/Oct pp.78-81.

Wong, P.T.P. (1998) Meaning centered counseling. In P.T.P. Wong \& P.S. Taylor (Eds.), The Human Quest for Meaning: A handbook of psychological research and clinical application (pp. 395-435). Mahwah, NJ: Erlbaum.

Wyatt, G., Kurtz, M.E., Friedman, L.L., Given, B. \& Given, C.W. (1996). Preliminary testing of the Long-Term Quality of Life (LTQL) Instrument for female cancer survivors. Journal of Nursing Measurement, 4(2), 153-170.

Yakushko, O. (2011). Preliminary validation of the Women's Spirituality Instrument: Development of a measure to assess feminist religious and spiritual attitudes. Psychology of Religion \& Spirituality, 3(3), 194-200.

Yong, J., Kim, J., Han, S-S. \& Puchalski, C.M. (2008). Development and validation of a scale assessing spiritual needs for Korean patients with cancer. Journal of Palliative Care, 24(4), 240-246.

Youlden, B.R. (1988). A study for educational administrators concerning the relationships between selected dimensions of Christian Education and student spirituality in Seventh-Day Adventist day academies in the United States of America. $\mathrm{PhD}$ dissertation, School of Education, Andrews University.

Zebrack, B.J. \& Chesler, M.A. (2001). A psychometric analysis of the Quality-Of-LifeCancer Survivors (QOL-CS) in survivors of childhood cancer. Quality of Life Research, 10, 319-329.

Ziegler, D.L. (1998). The validity and reliability of a self-report measure of health integrity, the Personal Inventory of Kid's Optimal Characteristics - The PIKOC. PhD dissertation, University of Oregon.

Zullig, K.J., Ward, R.M. \& Horn T. (2006). The association between perceived spirituality, religiosity, and life satisfaction: The mediating role of self-rated health. Social Indicators Research, 79, 255-274. 


\section{Appendix C Information letter for SHALOM}

Dear

Thank you for expressing an interest in SHALOM which I developed, half of which has been reported in Personality and Individual Differences as SWBQ:

Gomez, R \& Fisher, J.W. (2005) The Spiritual Well-Being Questionnaire: Testing for model applicability, measurement and structural equivalencies, and latent mean differences across gender. Personality and Individual Differences 39(8): 1383-1393.

Gomez, R \& Fisher, J.W. (2005) Item Response Theory analysis of the Spiritual Well-Being Questionnaire. Personality and Individual Differences, 38(5):1107-1121.

Gomez, R. \& Fisher, J.W. (2003) Domains of spiritual well-being and development and validation of the Spiritual Well-Being Questionnaire. Personality and Individual Differences 35(8): 19751991.

The SWBQ is half of an instrument called the Spiritual Health And Life-Orientation Measure (SHALOM) which asks for two responses from people for each of 20 -items - 5 in each of four domains of spiritual well-being proposed in my model of swb reported:

Fisher, J.W. (1998) Spiritual health: Its nature and place in the school curriculum. $\mathrm{PhD}$ thesis, University of Melbourne. (http://eprints.unimelb.edu.au/archive/00002994/)

Fisher, J.W. (1999) Helps to fostering students' spiritual health. International Journal of Children's Spirituality, 4(1), 29-49.

Fisher, J. (2011) The Four Domains Model: Connecting spirituality, health and well-being. Religions, 2: 17-28.

My model was used to develop an earlier SWBQ with Rev Professor Leslie J. Francis:

Fisher, J.W., Francis, L.J. \& Johnson, P. (2000) Assessing spiritual health via four domains of well-being: the SH4DI. Pastoral Psychology, 49(2), 133-145.

If you are interested in reading them and have any difficulty accessing these references, please let me know and I will send a copy.

\section{I have attached a copy of SHALOM3. The third column is completely optional. You can change the heading to suit your project, or you can delete it altogether.}

Some people just use the central column, which comprises the SWBQ reported in PAID. However, recent work that I have done shows that the double-response method (comparing lived experience with ideals) gives a better measure of quality of relationships in the four domains, thus swb, than the somewhat arbitrary lived experience scores on their own:

Fisher, J.W. (2012) The importance of relating with God for spiritual well-being. E-book chapter from presentation at $2^{\text {nd }}$ Global Conference on Spirituality, 21-24 March 2012, Prague. http://www.inter-disciplinary.net/wp-content/uploads/2012/02/fishersppaper.pdf

I like to gain the ideal (Life-Orientation Measure) as well as the reported lived experience (Spiritual Health Measure) as I believe it is important to compare each person with themselves to test the congruence/level of harmony, or spiritual well-being, in each of the four domains:

Personal swb - items 5, 9, 14, 16, 18

Communal swb - items 1, 3, 8, 17, 19

Environmental swb - items 4, 7, 10, 12, 20

Transcendental swb - items 2, 6, 11, 13, 15. 
You can either use the mean value of the 5 items in each group, or the sum of the items. If you have any missing values, I have found that you can use the mean of four items per factor quite satisfactorily, which you cannot do with the summation method if you have missing values.

I have developed the notion of spiritual dissonance to reflect a significant difference between the ideals and lived experience. A difference in the mean values of greater than 1.00 (>1 SD) in two or more of the four domains has recently identified distinct groups of people who have very high ideals, which they do not live up to. As people's own lived experience has been shown to have a major impact on the help they think they provide to others in developing SWB, it is no surprise to find that these spiritual dissonants perceive themselves as providing less help than others in this area of well-being. These findings have implications for their own well-being and that of the workplace. For references, see:

Fisher, J.W. (2009) Investigating Australian education students' views about spiritual well-being as compared with teachers in schools. International Journal of Children's Spirituality, 14(2):151167.

Fisher, J.W. (2008) Impacting teachers' and students' spiritual well-being. Journal of Beliefs \& Values, 29(3):252-261.

Fisher, J.W. \& Brumley, D.J. (2008) Nurses' and Carers' Spiritual Well-Being in the Workplace. Australian Journal of Advanced Nursing, 25(4):49-57.

Fisher, J.W. (2007) It's time to wake up and stem the decline in spiritual well-being in Victorian schools. International Journal of Children's Spirituality, 12(2):165-177.

Fisher, J.W. (2009) Reaching the heart: Assessing and nurturing spiritual well-being via education. EdD dissertation, University of Ballarat, Victoria, Australia. Available from http://archimedes.ballarat.edu.au:8080/vital/access/HandleResolver/1959.17/13481

Fisher, J.W. \& Brumley, D. (2012) Palliative care doctors need help with spiritual well-being. Journal for the Study of Spirituality, 2(1): 49-60.

Fisher, J.W. (2012) Staff's and family members' spiritual well-being in relation to help for residents with dementia. Journal of Nursing Education \& Practice, 2(4):1-9.

The 'cost' for using my instrument SHALOM is to let me know how well it works with your cohort under investigation, so I can keep an eye on its usefulness.

The third column can be added to gauge what help people expect from their church/ or group /or workplace in developing each of the areas of swb (SHALOM3). I have used this with nurses relating to patients' needs, with teachers and students relating to students' needs and with church attendees relating to their own needs.

What size group do you expect to study? I have used SHALOM with staff from the university and a manufacturing industry. It has also been used by DPsych students, Masters students in nursing and humanities, psychologists, educators and research students and with employees in a range of businesses. SHALOM has been translated into 22 different languages and has been or is being used in over 300 studies in Australia and overseas.

You might be interested in reading about the use of SHALOM in an open access journal: Fisher, J. (2010) Development and application of a spiritual well-being questionnaire called SHALOM. Religions, 1: 105-121.

A review of instruments has called my SWBQ-SHALOM the most promising:

E.de J. Meezenbroek et al (2010) Measuring spirituality as a universal human experience: A review of spirituality questionnaires. Journal of Religion and Health doi 10.1007/s10943-0109376-1, published online 20 July 2010.

Further recent work has focussed on spiritual dissonance and the importance of relating with God or other Transcendents for spiritual well-being: 
Fisher, J.W. (2013) Assessing spiritual well-being: Relating with God explains greatest variance in spiritual well-being among Australian youth. International Journal of Children's Spirituality, 18(4):306-317.

Fisher, J.W. \& Coskun, M.K. (2013) Investigating spiritual well-being among Divinity and Religious Education students in Turkey. Religious Education Journal of Australia, 29(2):21-28.

Fisher, J.W. (2013) Relating with God contributes to variance in happiness, over that from personality and age. Religions, 4(3):313-324.

Fisher, J.W. \& Wong, P.H. (2013) Comparing levels of spiritual well-being and support among pre-service teachers in Hong Kong and Australia. Religious Education Journal of Australia, 29(1):34-40.

In light of minor criticism of SHALOM as being too God-oriented (mainly by academics of a nonreligious persuasion, often atheists) (even though God is only mentioned twice in 20 items) I developed a generic version of SHALOM, in which the theistic words were replaced by the word 'Transcendent' with 19 choices provided for respondents, including one 'not an area in which I believe.'

Fisher, J.W. (2013) You can't beat relating with God for spiritual well-being: Comparing a generic version with the original spiritual well-being questionnaire called SHALOM. Religions, 4(3):325335.

This project also shows that God contributes to variance in Personal and Communal swb much better than any other religious or non-religious Transcendents.

Fisher, J.W. (2014) Comparing the influence of God and other Transcendents on spiritual wellbeing. Religious Education Journal of Australia, 30(2):9-15.

If this generic version of SHALOM (which provided acceptable psychometric properties - see the Religions 2013 paper above) would be more appropriate for the people with whom you will work, please let me know and I will send a copy.

I look forward to hearing your response as to the suitability of SHALOM for your project.

Best wishes and shalom,

John

John W. Fisher MSc, MEd, PhD, EdD, PhD

Adjunct Associate Professor

Hon. Senior Research Fellow

Faculty of Education \& Arts

Centre for Religious \& Spirituality Education

Federation University Australia

Hong Kong Institute of Education

PO Box 663 Ballarat Vic 3353 Australia

e-mail j.fisher@federation.edu.au

Hon. Senior Fellow

Rural Health Academic Centre,

Faculty of Medicine

University of Melbourne

e-mail jwfisher@unimelb.edu.au

mob +61.438.395.915
Visiting Professor

Institute of Health, Medical Sciences \& Society

University of Glyndwr

Wales, UK 